\title{
Synthese und Selbstorganisation von Perylendiimid-Oligonucleotid-Konjugaten
}

\section{Dissertation}

\author{
Zur Erlangung des Grades \\ „Doktor der Naturwissenschaften“ \\ am Fachbereich Chemie und Pharmazie \\ der Johannes Gutenberg-Universität Mainz
}

\author{
vorgelegt von \\ Moustafa A. Abdalla \\ geboren in Bani-Suef/Ägypten
}

Mainz 2004 
Tag der mündlichen Prüfung: 15.06.2005 
Dieser Arbeit wurde in der Zeit von Januar 2001 bis Januar 2004 am Max-Planck-Institut für Polymerforschung im Arbeitskreis von Prof. Dr. Klaus Müllen durchgeführt.

Herrn Prof. Dr. Müllen möchte ich ganz herzlich dafür danken, dass er mir dieses faszinierende Thema gestellt hat. Nicht nur seine stets motivierenden Worte haben mich immer ermutigt, sondern auch seine Anregungen, Ideen, und persönliche Unterstützung. Für die vielen fruchtbaren fachlichen Diskussionen bin ich ihm sehr dankbar, denn die haben mich immer vorangebracht. 
Dieser Arbeit ist meinem Vater, meiner leider verstorbenen Mutter und meiner Lamiaa gewidmet 
„Wenn Du im Leben glücklich sein willst, musst Du Dir vor Augen halten, dass es Menschen gibt, die ärmer sind als Du und solche, die mehr Wissen als Du haben“

Ein alter arabischer Weiser 


\section{Inhaltsverzeichnis}

1 Einleitung................................................................................................................1

1.1 Nukleinsäure, Struktur und Eigenschaften.............................................................

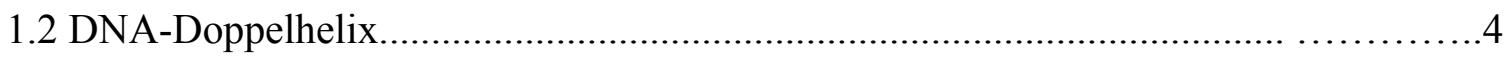

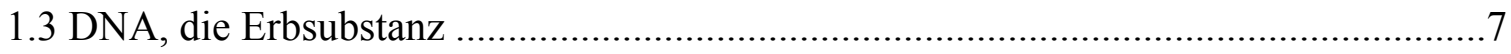

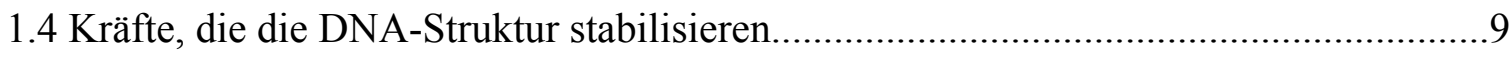

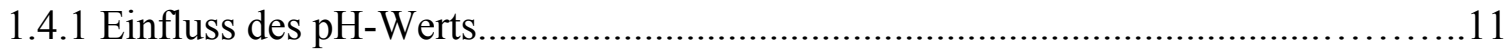

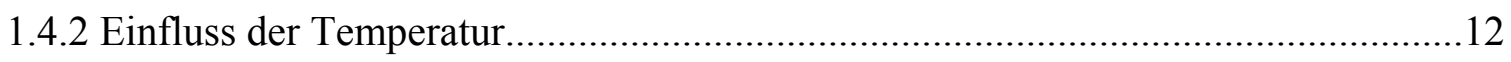

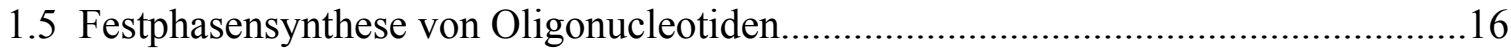

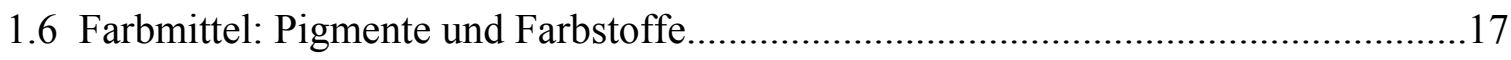

1.7 Rylenfarbmittel, Struktur und Eigenschaften....................................................... 19

1.8 Synthese von Perylentetracarbonsäurederivativen................................................20

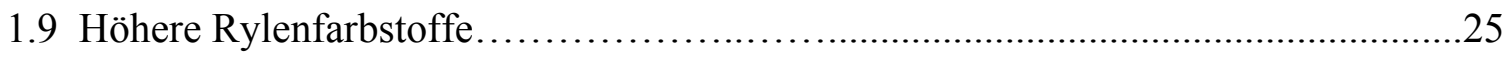

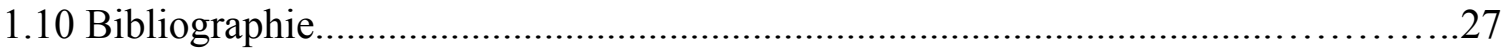

2 Motivation und Aufgabenstellung...................................... 31

\section{Perylendiimid-Oligonucleotid-Konjugate, Synthese und}

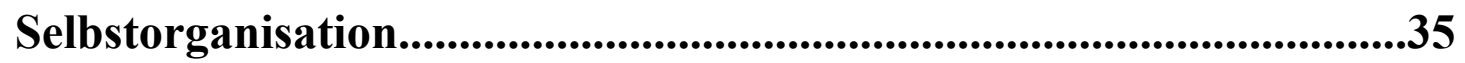

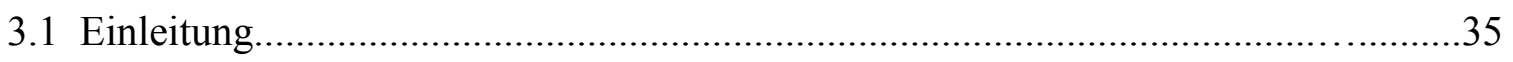

3.2 Grundlagen der automatisierten Oligonucleotidsynthese .........................................

3.2.1 Trägerauswahl für die DNA-Festphasensynthese............................................ 41

3.2.2 Die Monomere in der Festphasen-DNA-Synthese..............................................44

3.2.2.1 Exozyklische Aminschutzgruppen : Benzoyl- und Isobutyryl-Gruppe...........45

3.2.2.2 Einführung der $\mathrm{OH}^{`}$-Schutzgruppe (DMTr-).....................................................46

3.2.2.3 Einführung der Phosphoamiditgruppe....................................47 
3.3 Synthese von Perylendiimid-bis(oligonucleotid)-konjugaten...................48

3.3.1 Synthese des Perylendiimid-dicarboxyderivats..............................49

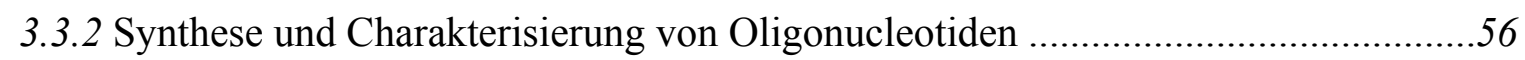

3.3.3 Synthese und Charakterisierung von Perylendiimid-

Oligonucleotid-Konjugaten.........................................67

3.4 Selbstorganisation der Perylendiimid-bis(oligonucleotid)-konjugate...............101

3.4.1 Fluoreszenz-Korrelations-Spektroskopie (FCS).......................... 101

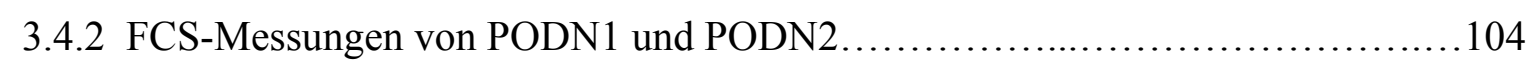

3.4.3 Überführung von PODN in organische Lösungsmittel......................... 105

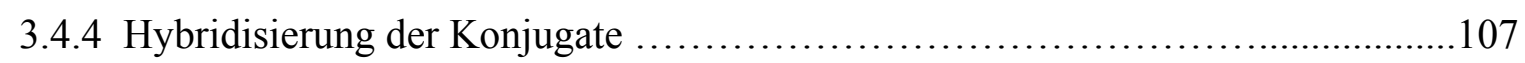

3.5 Synthese und Selbstorganisation eines Perylendiimid-DNA-Sandwichs............113

3.6 Synthese eines asymmetrischen Perylendiimid-bis(oligonucleotid)-konjugats.....120

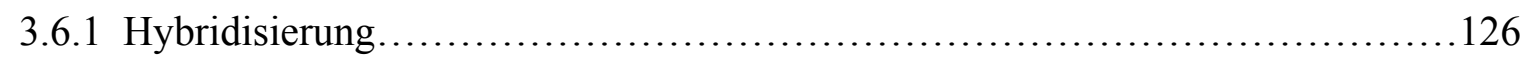

3.6.2 Einbau des Perylendiimids in die DNA-Sequenz............................. 129

3.7 Synthese von hoch fluoreszierenden Perylendiimid-oligonucleotid-konjugaten...134

3.8 Synthese und Hybridisierung von Trisoligonucleotiden.......................... 147

3.8.1 Synthese und Charakterisierung............................................ 148

3.8.2 Hybridisierung ................................................... 152

3.9. Bis(biotin) funktionalisiertes Perylendiimid als Baustein für Nanostrukturen an

Oberflächen........................................................ 156

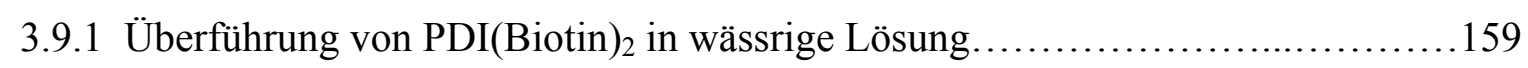

3.9.2 Bindung zwischen dem PDI(Biotin $)_{2}$ und Streptavidin...................... 160

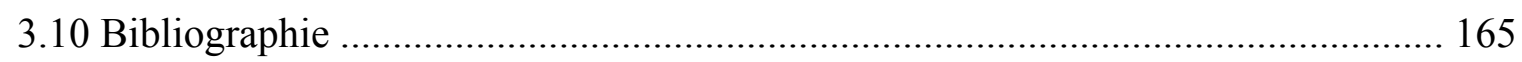

\section{Wasserlösliche Rylenfarbstoffe für die Anwendung in biologischen}

Systemen..................................................................174

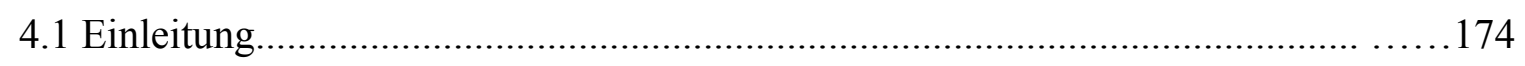

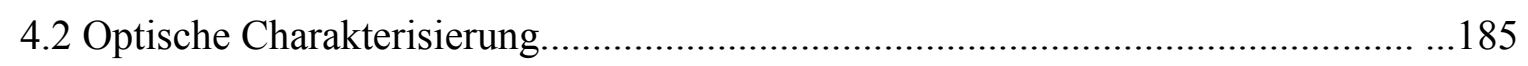

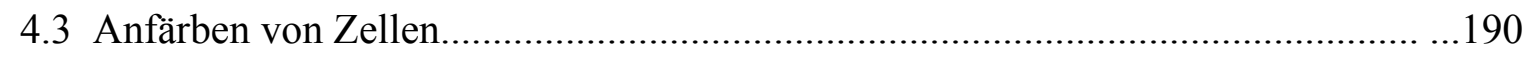


5 Zusammenfassung................................................196

6 EXPERIMENTELLER TEIL_................................................................. 205

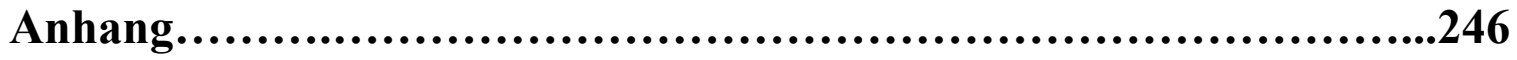




\section{Einleitung}

Die Synthese von funktionellen Strukturen im Nanometermaßstab ist ein hoch aktives Forschungsgebiet, das in den letzten zwei Jahrzehnten großes Interesse bei vielen Forschern erweckte ${ }^{1-2}$. Als vorrangige Anwendungsmöglichkeiten für solche Nanostrukturen werden molekulare Elektronik und Biosensoren genannt ${ }^{3}$. Mit Hilfe der supramolekularen Chemie konnte man vielversprechende makromolekulare Architekturen bilden. Alle Biomakromoleküle sind in ihrer Form und Funktion sehr stark auf die supramolekularen Kräfte (Wasserstoffbrücken, $\pi$-Wechselwirkung, elektrostatische Wechselwirkung und van der Waals-Wechselwirkung) angewiesen. Weiterhin besitzen sie molekulare Erkennungseigenschaften, die vielen Biomolekülen ermöglichen, ein anderes Molekül zu erkennen und mit ihm eine nicht-kovalente Bindung einzugehen. Diese einzigartige Eigenschaft der biologischen Systeme ermöglicht es, Makromoleküle mit mehreren Strukturabschnitten, die unterschiedliche und spezifische Funktionen oder Eigenschaften besitzen, zu bilden. Diese Abschnitte sind miteinander so verknüpft, dass supramolekulare Strukturen mit neuen Eigenschaften und Applikationen ${ }^{4}$ über das Selbstorganisationsprinzip machbar sind. Der Zusammenbau von molekularen Bausteinen über nicht kovalente Wechselwirkungen bietet quasi eine biologische Lösung für ein chemisches Problem ${ }^{5}$. Die Programmierbarkeit von Biomolekülen, wie z.B. Desoxyribonukleinsäuren DNA und Proteinen, stellt einen anspruchsvollen und bedeutenden $\mathrm{Weg}^{3,6-7}$ dar, organische und anorganische Verbindungen in definierte Positionen zueinander zu organisieren. Im folgenden Abschnitt werden die Struktur und die Eigenschaften der DNA erläutert.

\subsection{Nukleinsäure, Struktur und Eigenschaften}

DNA ist der Träger der genetischen Informationen. In seiner Struktur sind alle Gene enthalten. Die DNA tritt deshalb in allen Zellen des Tier- und Pflanzenreiches auf. Sie 
regelt den Aufbau der Proteine, die für die Funktion und somit das Leben jeder Zelle unentbehrlich sind. Die DNA ist ein Polymer aus DesoxyriboNucleotid-Einheiten, deren Wiederholungseinheiten als Nucleotide bezeichnet werden. Nucleotide bestehen aus drei Komponenten:

- einem stickstoffhaltigen Heterocyclus (Pyrimidin oder Purin)

- einer Desoxyribose,

- einem Phosphorsäurerest.

Eine Desoxyribose und Base bilden zusammen ein Nukleosid. Die Basen sind Nglykosidisch mit dem $1^{`}$-C-Atom des Zuckers (2`-Desoxyribose) verknüpft (s. Abb. 1) und bilden $\beta$-Nukleoside. In den $\beta$-Nukleosiden liegt die Base oberhalb des Riboserings, in den $\alpha$-Nukleosiden, die nicht in der Natur vorkommen, liegt sie unterhalb des Zuckerrings.

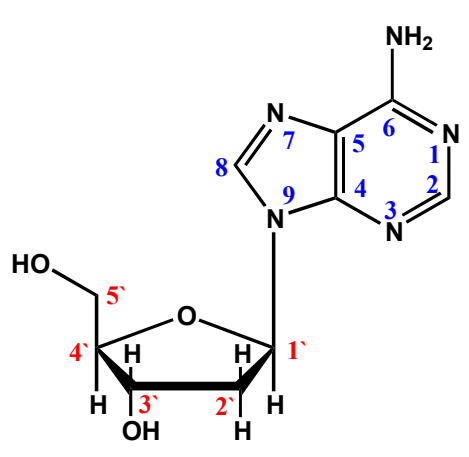

A

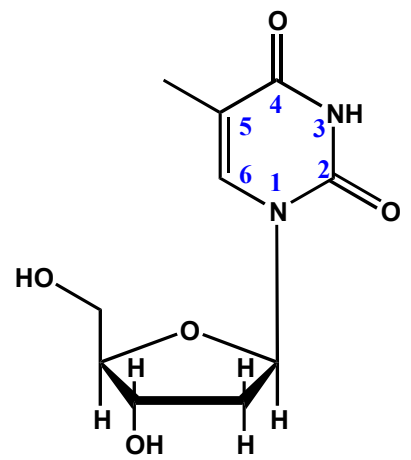

T

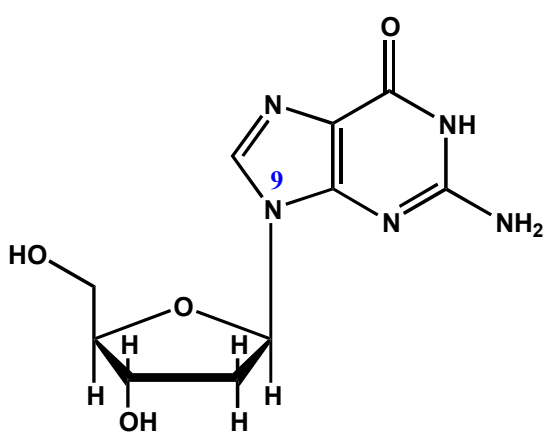

G

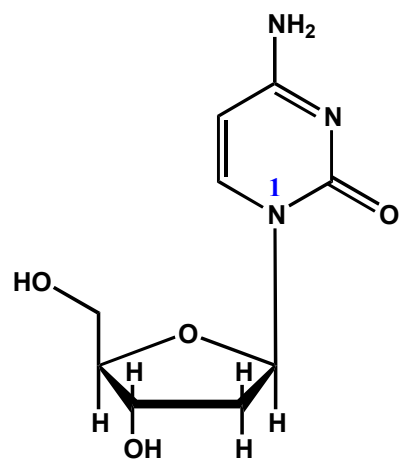

C

Abbildung 1: Die DNA-Nukleoside, Adenosin (A), Guanosin (G), Thymidin (T) und Cytidin (C), zur Unterscheidung von den Ringziffern im Heterocyclus bezeichnet man die C-Atome des Zuckers in Nukleosiden und Nucleotiden mit $1^{`}$ bis $5^{`}$ 
Ist die 5 '-OH-Gruppe der Desoxyribose in den Nukleosiden mit Phosphorsäure verstert, so entsteht das Nukleosid-5 '-phosphat (Nucleotid). Die einzelnen Nucleotide werden über eine Diesterbindung zu langen Ketten (Oligonucleotiden) verknüpft. Nucleotide sind von daher die Bausteine der Nukleinsäure. Damit besteht das Rückgrat der DNA aus einem Polyester, in dem jeweils ein Zuckerrest (Desoxyribose) mit einem Phosphorsäurerest abwechselt. Die Phosphorsäure ist dabei mit der 5`-OH-Gruppe im Zuckerrest des einen und mit der 3`-OH-Gruppe im Zuckerrest des anderen Nucleotids verestert (s. Abb. 2). Nukleinsäuren können sehr lang sein und eine beliebige Sequenz haben.

Zur Vereinfachung wird die Abkürzung der DNA-Sequenzen auf die Symbole der Basen reduziert, deren Abfolge die Sequenz der Nucleotide in einem Nukleinsäuremolekül darstellt. Adenosin $=\mathrm{A}$, Cytidin $=\mathrm{C}$, Guanosin $=\mathrm{G}$ und Thymidin $=\mathrm{T}$. DNA Sequenzen werden grundsätzlich von der $5^{`}$ - in die $3^{`}$-Richtung notiert.
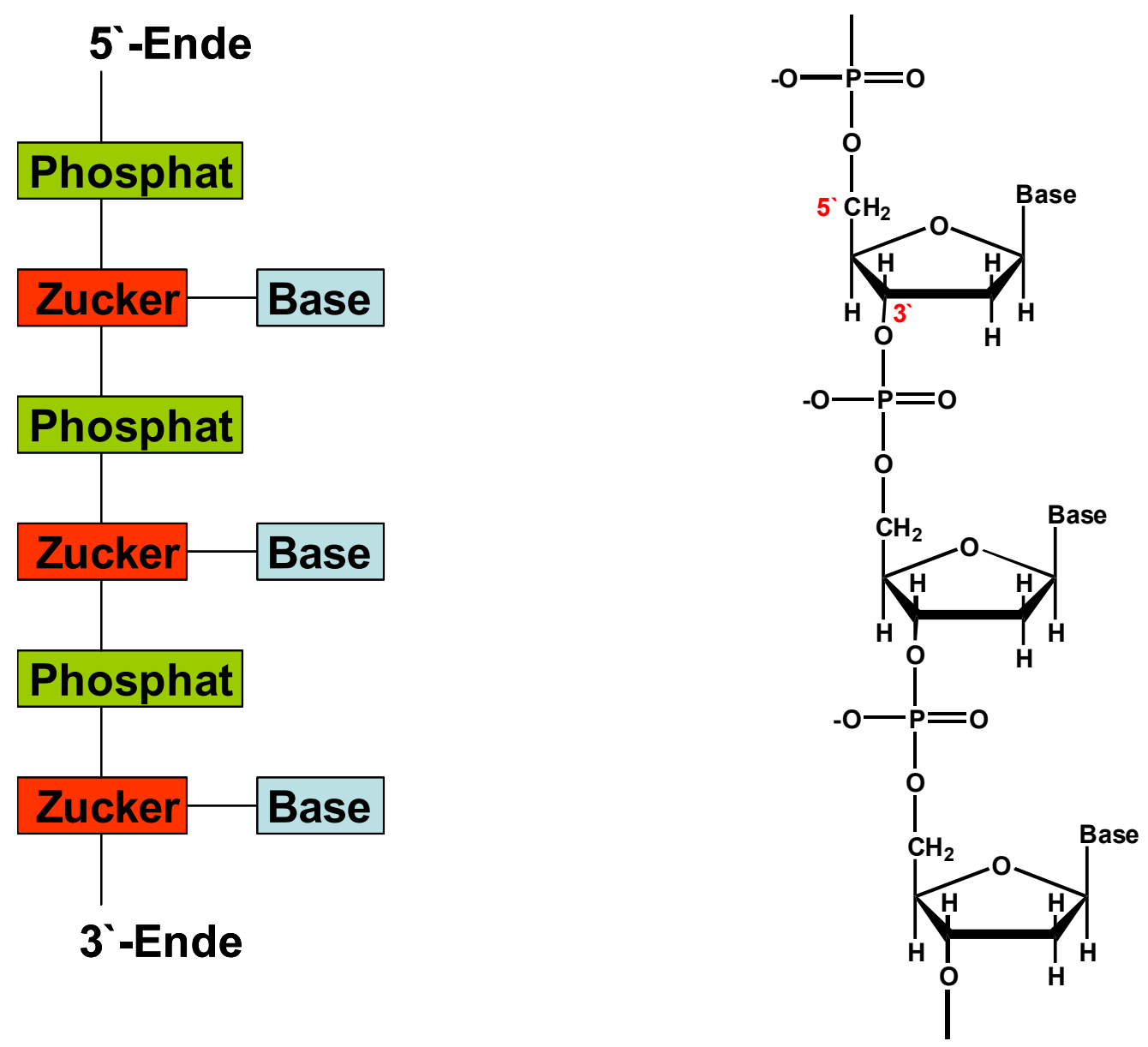

Abbildung 2: Die allgemeine Struktur eines kurzen Abschnittes der DNA. 


\subsection{DNA-Doppelhelix}

Im Jahre 1953 stellten James Watson und Francis Crick ihr Modell für die Struktur der DNA vor ${ }^{10}$. Laut diesem Strukturmodell liegt die DNA als Doppelhelix vor. Zur Bildung einer DNA-Doppelhelix lagern sich zwei Oligonucleotidstränge in antiparalleler Richtung zusammen (Abb. 3 und 4). Sie sind um eine gemeinsame Achse gewunden. Diese läuft im idealen Fall genau durch die Mitte der DNA-Doppelhelix. Die Purin- und Pyrimidinbasen sind zum inneren der Helix gerichtet, während sich die Phosphat- und Desoxyribosereste außen befinden. Die beiden Sequenzen der DNA-Doppelhelix werden durch die Wasserstoffbrücken zwischen den Basenpaaren zusammengehalten. Während Adenin zwei Wasserstoffbrücken mit Thymin bildet, ist Guanin mit Cytosin durch drei Wasserstoffbrücken gepaart.

Der Durchmesser der DNA-Doppelhelix beträgt $2 \mathrm{~nm}$. Die benachbarten Basen entlang der Helixachse sind $0.34 \mathrm{~nm}$ voneinander entfernt und um $36^{\circ}$ gegeneinander verdreht. Deshalb wiederholt sich die Struktur nach zehn Basen auf jedem Strang, d. h. in Abständen von $3.4 \mathrm{~nm}^{8}$. Die Doppelhelix kommt in mehreren Formen vor:

-A-Form: hat ca. 11 Basenpaare (bp) pro Windung. Der Durchmesser beträgt 2,3 nm, d.h. kompakter als die B-Form. Entsteht aus der B-Form bei drastischer Abnahme des Wassergehalts ${ }^{8}$.

- B-Form: die von Watson und Crick vorhergesagte Struktur. Sie ist die Struktur, die die DNA in der Zelle einnimmt.

- Z-Form: Im Gegensatz zu der B-Form ist die Z-Form linksgängig. Sie bildet sich in einer DNA-Doppelhelix aus, die abwechselnd aus Purin- und Pyrimidin-Nucleotiden aufgebaut ist. Die Ursache ist eine Umorientierung der glykosidischen Bindung zwischen Guanin und der Desoxyribose. 
Die verschiedenen Formen der Doppelhelix bilden sich bei unterschiedlichem Wassergehalt sowie in Abhängigkeit der vorhandenen Gegenionen aus. In Tabelle 1 sind die Parameter der unterschiedlichen Doppelhelixformen zusammengestellt.

\begin{tabular}{|c|c|c|c|c|}
\hline Form & $\begin{array}{c}\text { Drehrichtug } \\
\text { der Helix }\end{array}$ & $\begin{array}{c}\text { Basenpaarug } \\
\text { pro Windung }\end{array}$ & $\begin{array}{c}\text { Abstand zwischen } \\
\text { den Basenpaaren } \\
\text { (nm) }\end{array}$ & $\begin{array}{c}\text { Durchmesser der } \\
\text { Doppelhelix } \\
\text { (nm) }\end{array}$ \\
\hline A & rechtsgängig & 11 & 0.26 & 2.3 \\
\hline B & rechtsgängig & 10.4 & 0.34 & 1.9 \\
\hline Z & linksgängig & 12 & 0.37 & 1.8 \\
\hline
\end{tabular}

Tabelle 1: Eigenschaften der verschiedenen Formen der DNA-Doppelhelix

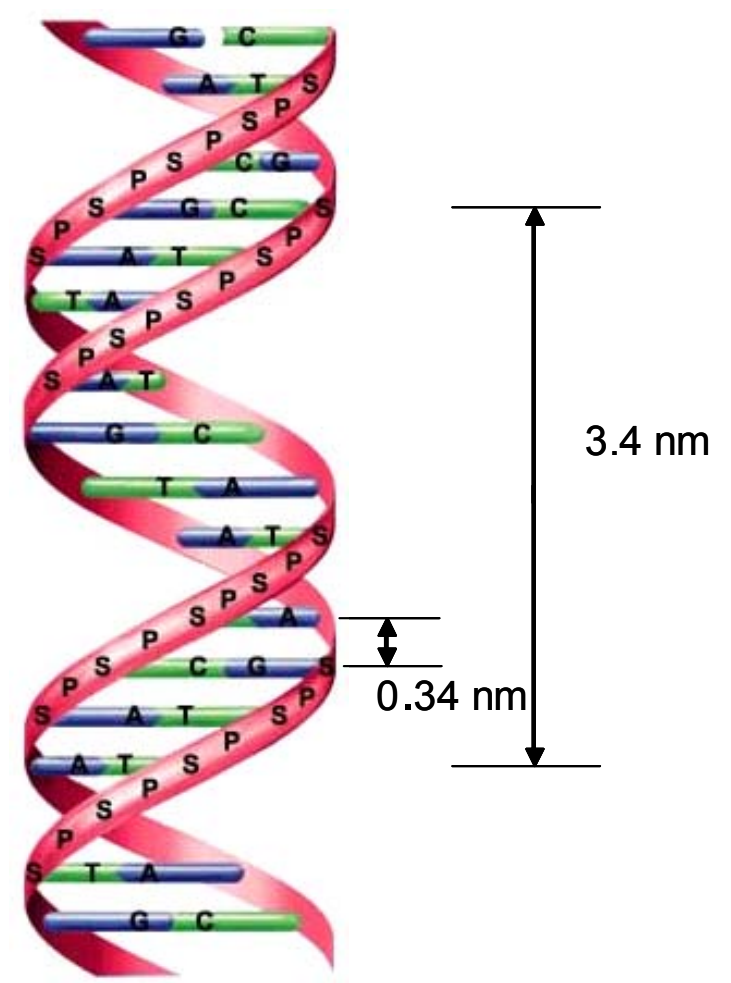

Abbildung 3: Die DNA-Doppelhelix, Darstellung der Watson-Crick-Bindung

Entsprechend dem Strukturmodell von Watson und Crick muss aus sterischen Gründen und wegen der Möglichkeiten zur Bildung von Wasserstoffbrücken Guanin mit Cytosin und Adenin mit Thymin paaren. Diese sterische Beschränkung ist auf die regelmäßige Helixstruktur des Zucker-Phosphat-Rückgrats von jeder Oligonucleotidkette 
zurückzuführen. Die zwei glykosidischen Bindungen an einem Basenpaar sind fast genau $1.08 \mathrm{~nm}$ voneinander entfernt. Ein Purin-Pyrimidin-Basenpaar passt perfekt in diesen Raum, dagegen reicht der Platz für zwei Purine nicht aus, während zwei Pyrimidine zu weit auseinander liegen, um Wasserstoffbrücken bilden zu können. Deshalb muss aus sterischen Gründen ein Partner eines Basenpaares in der DNA-Helix immer ein Purin und der andere ein Pyrimidin sein. Adenin kann nur mit Thymin und nicht mit Cytosin paaren, weil dann zwei Wasserstoffatome in die Nähe der einen Bindungsstelle kämen und keines in die Nähe des anderen. Ebenso kann Guanin nur mit Cytosin und nicht mit Thymin paaren. Diese Einschränkung bei der Basenpaarungen in der DNA führt dazu, dass die Anteile an $\mathrm{A}$ und $\mathrm{T}$ bzw. an $\mathrm{G}$ und $\mathrm{C}$ in der DNA immer gleich sind ${ }^{9}$. Daraus gilt folgende Gleichung:

Anzahl der Purin-Bausteine $=$ Anzahl der Pyrimidin-Bausteine

$$
(\mathrm{A}+\mathrm{G}) \quad=\quad(\mathrm{T}+\mathrm{C})
$$

Durch die freie Kombinierbarkeit der einzelnen Basenpaare kann eine fast unendlich große Zahl spezifischer DNA-Moleküle aufgebaut werden.

Die Doppelhelix hat zwei verschiedenen Furchen, eine kleine und eine große Furche. Da sich die Zucker-Base-Bindungen der komplementären Basenpaare nicht direkt gegenüber einander liegen, d.h. nicht diametral zueinander stehen (ihr Abstand ist kleiner als der Durchmesser der Doppelhelix), sind die vertikalen Abstände zwischen den beiden Einzelsträngen der DNA nicht immer gleich groß. Sie bilden dann entweder eine kleine oder große Furche. Diese Furchen in der DNA-Doppelhelix sind von großer Bedeutung, wenn die DNA mit Proteinen in Wechselwirkungen tritt, die an der Weitergabe der genetischen Informationen beteiligt sind. 


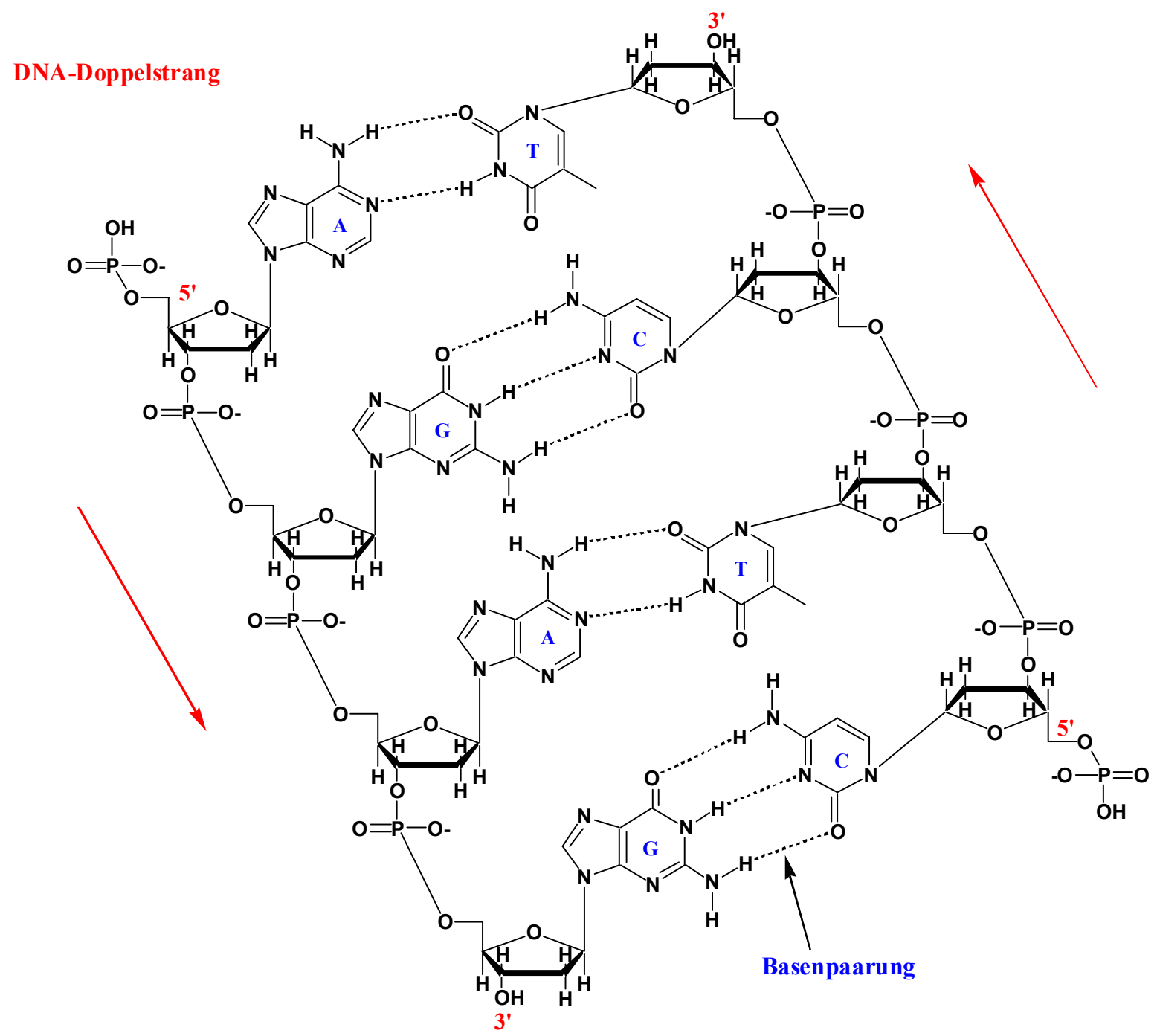

Abbildung 4: DNA-Doppelstrang und die Basenpaarung in der DNA, die zwei Stränge liegen antiparallel zueinander.

\subsection{DNA, die Erbsubstanz}

In der Basensequenz der DNA sind die Informationen der Erbsubstanz (Gene) gespeichert. Die Gene bestimmen, welche Arten von Proteinen eine Zelle herstellt. Drei aufeinander folgende Basen stellen einen Kode einer bestimmten Aminosäure dar. Damit ist durch die Basensequenz eines Gens die Aminosäuresequenz eines Proteins festgelegt. Die DNASequenz wird nicht direkt in die entsprechende Aminosäuresequenz übersetzt. Stattdessen 
wird zuerst die RNA gebildet (Transkription). Sie sind Hilfsstrukturen bei der Übermittlung dieser Information (Abb. 5).

\section{DNA $\stackrel{\text { Transkniption }}{\longrightarrow}$ mRNA $\stackrel{\text { Translation }}{\longrightarrow}$ Proteine}

\section{Replikation}

Abbildung 5: Darstellung der Weitergabe der Geninformationen

Die RNA ist wie die DNA ein langes Polymer aus Nucleotiden, die durch Phosphatdiesterbindungen miteinander verknüpft sind. Die chemische Struktur der RNA unterscheidet sich von der DNA in doppelter Hinsicht. In der Ribonukleinsäure, wie der Name zeigt, bestehen die Zuckereinheiten aus Ribose und nicht aus Desoxyribose wie bei der DNA. Ribose enthält in der 2'-Position eine Hydroxylgruppe, die in der 2`Desoxyribose nicht vorhanden ist (Abb. 5). Der andere Unterschied liegt in den vier Basen. In der RNA wird Thymin (T) durch Uracil (U) ersetzt. Die anderen drei Basen (A, C, und G) sind die gleichen wie in der DNA. Obwohl im Uracil die Methylgruppe des Thymins fehlt, kann Uracil genauso Wasserstoffbrücken mit Adenin bilden.

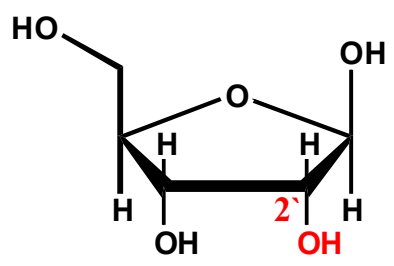

Ribose

RNA<smiles>O=c1cc[nH]c(=O)[nH]1</smiles>

Uracil (U)

RNA

Abbildung 6: Die strukturellen Unterschiede zwischen DNA und RNA

Zellen enthalten RNA mit unterschiedlichen Funktionen.. Die sogenannte messenger$R N A$ (mRNA) ist der Informationsträger für die Proteinsynthese. Die mRNA wird von RNA-Polymerasen hergestellt und übersetzt die DNA-Sequenz in die entsprechende 
RNA-Sequenz. Diesen Prozess nennt man Transkription, er erfolgt nach der DNAReplikation, in der die DNA sich verdoppelt, um die genetischen Informationen weiterzugeben. Nach der Transkription muss die mRNA in die entsprechende Aminosäuresequenz übersetzt werden, ein Prozess, der als Translation bezeichnet wird. Hierbei repräsentieren immer drei DNA-Basen (Codon) eine Aminosäure im Protein. Die Codons in einem mRNA-Molekül werden in ihrer Rheinfolge von Transfer-RNAMolekülen (tRNA) abgelesen. Die tRNAs transportieren Aminosäuren in einer aktivierten Form zum Ribosom, wo laut einer durch die mRNA festgelegten Reihenfolge die Peptidbindungen geknüpft werden. Die ribosomale RNA (rRNA) ist der Hauptbestandteil der Ribosomen und spielt sowohl eine strukturelle als auch katalytische Rolle bei der Proteinsynthese.

\subsection{Kräfte, die die DNA-Struktur stabilisieren}

Vorraussetzung für die molekulare Erkennung der Nukleinsäure ist die Bildung von Wasserstoffbrücken zwischen den Nukleobasen. Eine wichtige Konsequenz dieser molekularen Erkennung liegt darin, dass in der DNA eine Sequenz die andere bestimmt. RNA liegt meist als Einzelstrang vor, aber sie enthält auch doppelsträngige Regionen. Sie faltet zusammen, um die sogenannte Hairpin-Strukturen $\mathrm{zu}$ bilden, in denen Basenpaarungen zwischen komplementären Regionen im gleichen Strang stattfinden.

Von allen Merkmalen der DNA ist die spezifische Basenpaarbildung eine der bedeutungsvollsten. Zusätzlich zu den normalen Watson/Crick-Basenpaarungen (Abb. 7) können sich zwischen einem A- und einem T-Nucleotid sowie zwischen einem G- und CNucleotid weitere Wechselwirkungen ausbilden, die als Hoogsteen-Basenpaarungen bezeichnet werden (Abb. 7). Hierbei paart das Adenin via N-6 und N-7 mit dem Thymin. Das Guanin kann nur nach Protonierung mit dem Cytosin $\left(\mathrm{C}^{+}\right)$ein Hoogsteen-Basenpaar bilden. 

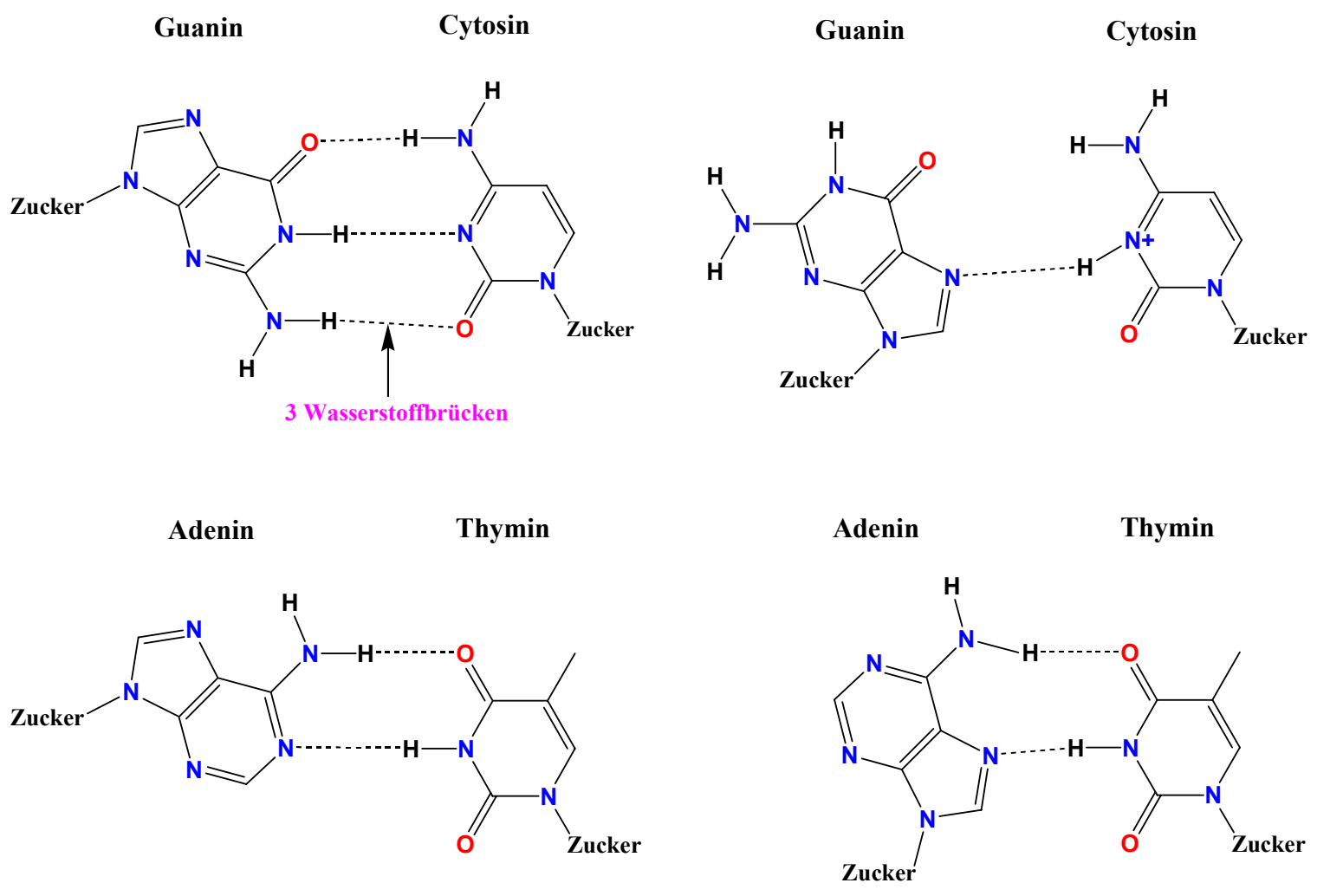

Zucker $=2^{\prime}$-Deoxyribose

\section{Watson-Crick-Basenpaarung}

GC $^{+}$Hoogsteen-Basenpaarung

Abbildung 7: Darstellung der Watson-Crick- und Hoogsteen-Basenpaarungen

Diese Hoogsteen-Basenpaarungen finden sich bei DNA-Abschnitten mit 30 oder mehr Purin-Nucleotiden in einem Strang und dem komplementären Strang, der die entsprechenden Pyrimidin-Nucleotiden enthält. Z. B. bei der Folge:

GAGAGAGAGA........

СТСТстстСт.........

\section{(Purine)}

\section{(Pyrimidine)}

Abbildung 8: Bespiel für Purin- und Pyrimidin-Nucleotiden

Bei niedrigem pH-Wert können sich die Basenpaarungen entwinden, und beim Rückfalten entstehen die Hoogsteen-Basenpaarungen. Dadurch bildet sich eine intermolekulare Triplex-Struktur, die sich als ein spitzer Knick in der Doppelhelix zeigt. 
Wie bereits erwähnt wurde, sind die Nucleotide in der DNA oder der RNA miteinander über 3',5'-Phosphordiesterbindung verknüpft. Dieses Phosphordiester-Bindeglied trägt eine negative Ladung. DNA sowie RNA sind von daher Polyanionen. Wenn sich zwei dieser Stränge zu einem Doppelstrang zusammenlagern, wird die Abstoßung durch die negativen Ladungen sehr groß sein. Deshalb sind Metallionen, die positiv geladen sind, notwendig, um die negativen Ladungen der DNA oder RNA zu kompensieren. Hierfür werden Salze (als Puffer-Lösung) für die Durchführung von Experimenten mit DNA oder RNA benötigt. In der Regel setzt man einen Puffer bei $p H=7$ ein. Mehr Salz kann zu stabileren Doppelsträngen führen, weniger Salz destabilisiert sie. Proteine, die sich an DNA binden, nutzen diese negativen Ladungen als Bindungsstellen aus, da sie selbst viele positive Ladungen an ihrer Oberfläche besitzen.

Die nicht kovalenten Wechselwirkungen, die die DNA-Doppelhelix zusammenhalten, können leicht gelöst werden. Die Trennung der Stränge in einer DNA-Doppelhelix oder der komplementären Abschnitte in einem Einzelstrang, die zusammen Wasserstoffbrücken bilden, wird als Denaturierung bezeichnet. Vollständige Denaturierung der DNA-Doppelhelix findet in vivo nicht statt. Dagegen kommen bei der DNA-Replikation und -Transkription lokale Denaturierungen vor. In vitro können Lösungen von einer DNA-Doppelhelix so manipuliert werden, dass die Stabilität der Doppelhelix beeinflusst und die Auftrennung in Einzelstränge ermöglicht wird.

\subsubsection{Einfluss des pH-Werts}

Die Änderung des pH-Werts einer DNA-Lösung kann den Ionisationszustand der Base, des Zuckers und des Phosphates beeinflussen. Bei pH-Wert oberhalb 11-12 kann die Abstößung zwischen den negativen Ladungen der beiden Stränge in der DNADoppelhelix zu einer Trennung der Stränge führen. Aus diesem Grund kann man die DNA mit Alkali denaturieren. Die Alkalibehandlung von RNA kann auch zur Entfaltung der RNA führen. Diese Behandlung muss unter milden Bedingungen durchgeführt werden, weil die Zuckerphosphat-Bindung im Rückgrat der RNA hydrolysiert werden 
kann. In Lösungen mit niedrigem $\mathrm{pH}-\mathrm{Wert}(\mathrm{pH} \leq 3)$ dissoziieren die DNA-Stränge. Unter diesen Bedingungen wird die N-glykosidische Bindung zwischen der Purinbase und dem Zucker gebrochen. Dieser Vorgang bezeichnet man als Depurination. Die PyrimidinZucker-Bindung ist dagegen bei diesem $\mathrm{pH}-$ Wert stabiler als die Purin-Zucker-Bindung. Deshalb wird die Säurebehandlung für die Denaturierung der DNA-Doppelhelix nicht verwendet.

\subsubsection{Einfluss der Temperatur}

Der einfachste Weg zur Denaturierung von DNA-Doppelhelix ist die Erhöhung der Temperatur, bis alle Wasserstoffbrücken gelöst sind. In diesem Fall dissoziieren oder schmelzen die Stränge. DNA-Einzelstränge absorbieren UV-Licht stärker als die DNADoppelstränge. Aus diesem Grund nimmt die Absorption des UV-Lichtes von diesen geschmolzenen Abschnitten zu. Die Zunahme des Absorptionsmaximums ist proportional zu der Größe der Denaturierung. So kann man den Denaturierungsprozess der Nukleinsäure durch die Erhöhung der Temperatur und die gleichzeitige Kontrolle des Absorptionsmaximums verfolgen (Abb. 9). Wenn man eine DNA-Lösung aufheizt, nimmt die Absorption langsam zu. Darauf folgt eine plötzliche Zunahme der Absorption über einen kleinen Temperaturbereich, und danach beobachtet man keine Veränderung in der Absorption mehr. In der ersten Phase liegt die DNA unverändert als Doppelstrang vor, in der zweiten Phase werden die Wasserstoffbrücken gelöst, bis schließlich in der dritten Phase die dissozierten Einzelstränge vorliegen. Der Wendepunkt der Kurve wird als Schmelzteperatur $\left(\mathrm{T}_{\mathrm{m}}\right)$ bezeichnet. Dabei sind bei der $\mathrm{T}_{\mathrm{m}} 50 \%$ der DNA geschmolzen, d.h. die Wasserstoffbrücken zwischen $50 \%$ der Basenpaare werden bei dieser Temperatur gebrochen. 


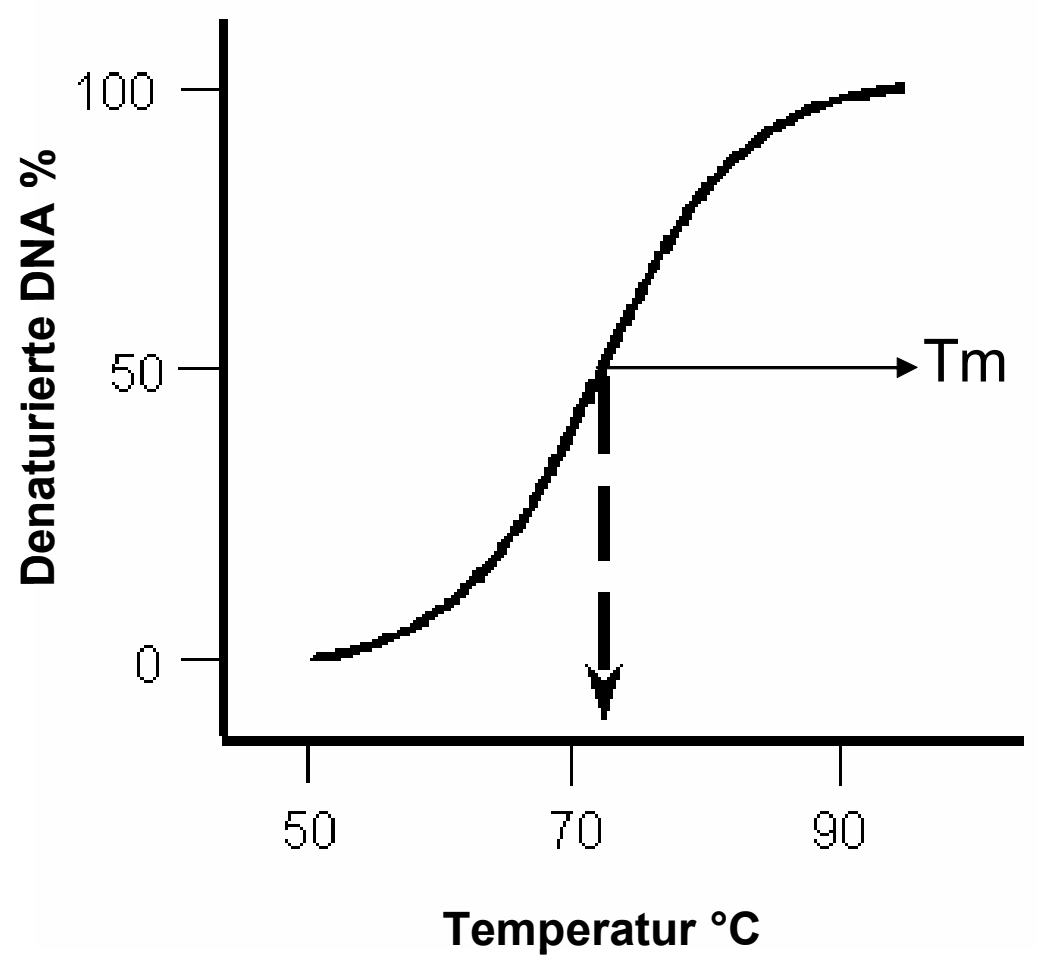

Abbildung 9: Schmelzkurve für die DNA. Durch die Erhöhung der Temperatur werden die Wasserstoffbrücken, die die DNA zusammenhalten, gebrochen. Die Absorption nimmt mit dem Schmelzen von DNA-Abschnitten zu. Diese Zunahme in der Absorption ist proportional zu dem Umfang der Denaturierung. Bei $\mathrm{T}_{\mathrm{m}}$ beträgt die Veränderung im Absorptionsmaximum die Hälfte der gesamten Veränderung

Die $T_{m}$-Temperatur von Nukleinsäuren ist ein Maßstab für ihre Stabilität. Je stabiler eine Nukleinsäure ist, desto höher ist die Temperatur, die für das Spalten der Doppelstränge in Einzelstränge notwendig ist. $\mathrm{T}_{\mathrm{m}}$ hängt von der Basenzusammensetzung ab. Eine GCreiche DNA schmilzt bei einer viel höhen Temperatur als eine AT-reiche DNA. Das hängt damit zusammen, dass bei einer GC-Basenpaarung drei Wasserstoffbrücken zu brechen sind, während bei einer AT-Basenpaarung lediglich zwei gelöst werden müssen. Es wird mehr Wärmenergie benötigt, um eine GC-reiche DNA-Doppelhelix in Einzelstränge zu trennen. Die Abhängigkeit der $\mathrm{T}_{\mathrm{m}}$ vom GC-Inhalt der DNA ist linear und nimmt bei etwa $0.4{ }^{\circ} \mathrm{C}$ bei jeder Zunahme an GC-Basenpaarungen von einem Prozent zu. So kann man durch die Bestimmung von der $\mathrm{T}_{\mathrm{m}}$ für eine unbekannte Probe den GC- 
Inhalt der Probe im Vergleich zu einer bekannten Probe ermitteln. Die $T_{m}$ wird durch die Ionenstärke in der DNA-Lösung beeinflusst. Bei einer niedrigen Ionenkonzentration stoßen sich die negativen Ladungen der Phosphatgruppen ab und destabilisieren somit die DNA-Doppelhelix, während bei hoher Ionenkonzentration das Salz die Doppelhelix vor der Abstoßung der negativen Ladungen schützt und damit die Helix stabilisiert. Deshalb wird bei niedriger Salzkonzentration weniger Wärmenergie (kleiner $\mathrm{T}_{\mathrm{m}}$-Wert) gebraucht, um die Strangauftrennung auszuführen.

Der Differenz zwischen dem $\mathrm{T}_{\mathrm{m}}$-Wert von langen DNA-Doppelhelices und Hybriden aus Oligonucleotiden ist ziemlich groß. Der $\mathrm{T}_{\mathrm{m}}$-Wert bei Oligonucleotidhybriden ist viel niedriger als im Falle einer langen DNA. Das liegt darin, dass Oligonucleotide sehr kurz sind, um gleichzeitig Abschnitte mit Doppelsträngen und Einzelsträngen zu haben. Ihre $\mathrm{T}_{\mathrm{m}}$ ist die Temperatur, bei der $50 \%$ der Moleküle in Einzelstränge dissoziieren und somit im Gleichgewicht zwischen Einzelsträngen und Hybriden halten (Abb. 10). Lange Inkubationszeit von DNA bei hoher Temperatur kann das Zucker-Phosphat-Rückgrat brechen. Deshalb muss bei hohen Temperaturen die Inkubationszeit verkürzt werden.

Substanzen wie Harnstoff, Dimethylsulfoxid (DMSO) und Formamid brechen die Wasserstoffbrücken der DNA-Basenpaarungen auf und vermindern dadurch die $\mathrm{T}_{\mathrm{m}}$-Werte der DNA. Das Ausmaß der $\mathrm{T}_{\mathrm{m}}$-Verminderung hängt von ihrer Konzentration ab. Diese Eigenschaft ist sehr vorteilhaft, da man durch die Zugabe eines dieser Reagenzien den $\mathrm{T}_{\mathrm{m}}$-Wert vermindern und dadurch thermisch labile Nukleinsäuren dissoziieren kann. 
a)
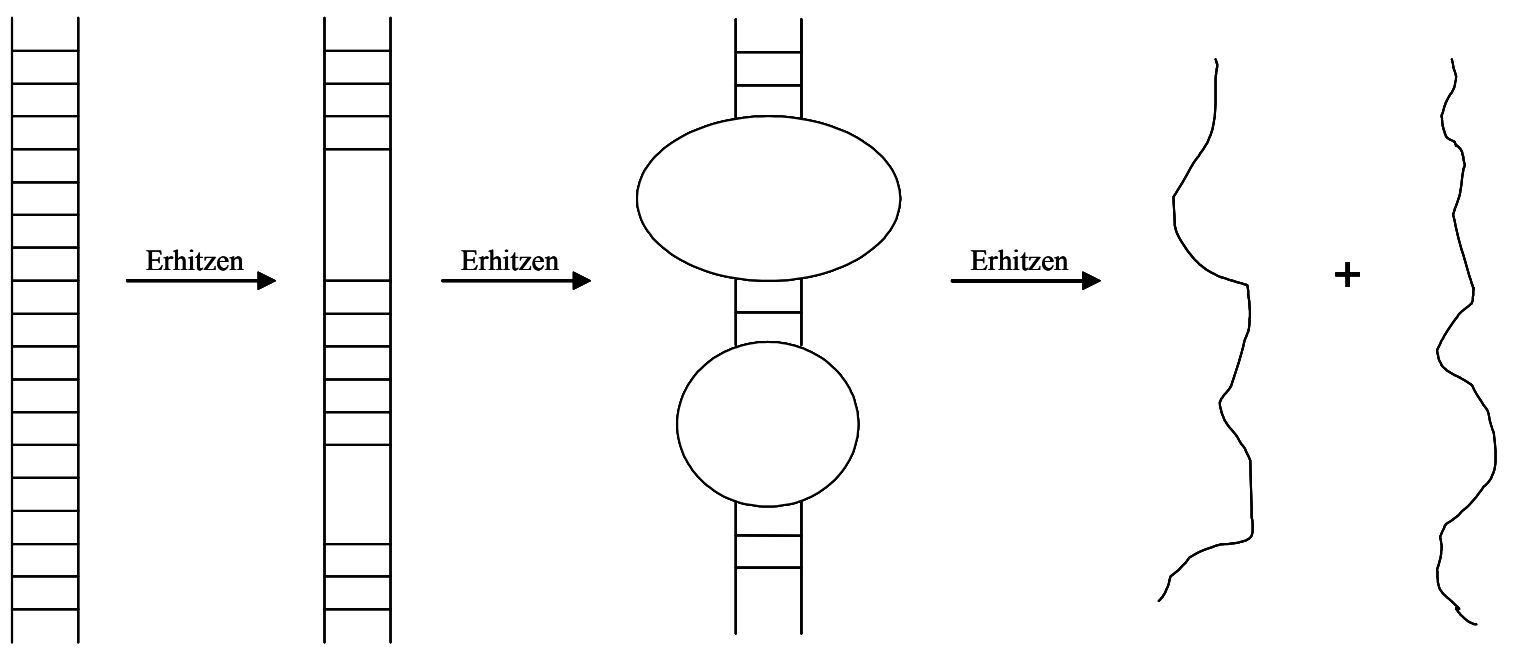

DNA-Doppelhelix

AT-reiche Abschnitte

Bei $\mathrm{T}_{\mathrm{m}}$ sind $50 \%$ der schmelzen zuerst

b)

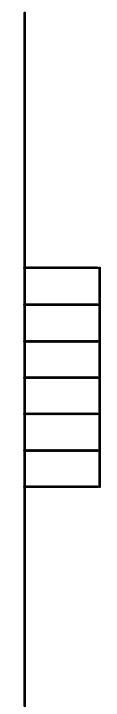

Hybrid
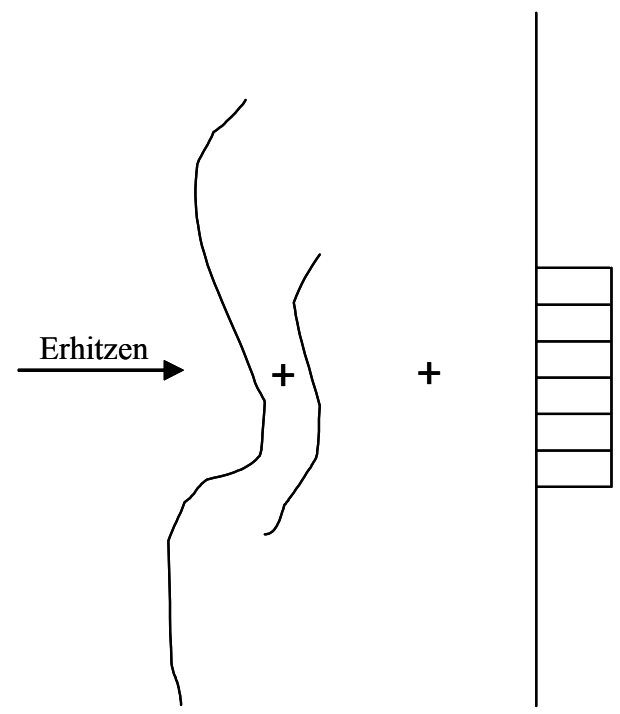

Erhitzen

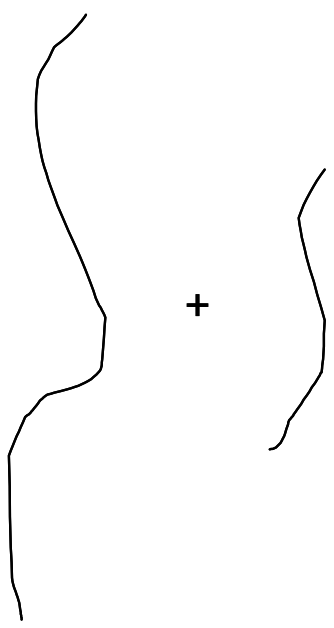

Bei $\mathbf{T}_{\mathrm{m}}$ sind $50 \%$ der

Denaturiert Hybride denaturiert

Abbildung 10: a) Denaturierung einer langen DNA, AT-reiche Abschnitte schmelzen zuerst. Bei $\mathrm{T}_{\mathrm{m}}$ ist die Hälfte der Wasserstoffbrücken aufgebrochen. b) Denaturierung von Hybriden aus Oligonucleotiden 


\subsection{Festphasensynthese von Oligonucleotiden}

Ein Oligonucleotid ist im strengen Sinne eine kurze Nukleinsäure, deren Länge 50 Basen nicht überschreit. ist. In den letzten Jahren wurde diese Definition erweitert und schließt zur Zeit unabhängig von ihrer Länge chemisch hergestellte Nukleinsäuren ein. Als Watson und Crick die Doppelhelixstruktur der DNA vorstellten, wurde die Verbindung zwischen der DNA-Struktur und ihrer biologischen Bedeutung enthüllt. Daraus entstand die Wissenschaft der Molekularbiologie, die die Grenzfläche zwischen Chemie und Biologie erforscht. Es war eine Selbstverständlichkeit, dass diese Entdeckung bei den Chemikern ein großes Interesse an der Synthese der neu entdeckten Biomakromoleküle, Nukleinsäuren und Proteine, erwecken würde. Die Synthese von Peptiden (kleine Proteine) wurde schneller entwickelt als die von Oligonucleotiden, da die Chemie besser zugänglich war. Als Folge waren Peptidsynthesizer die ersten verfügbaren automatisierten Systeme. Erst später ermöglichte die Festphasensynthese die Herstellung jeder gewünschten DNA-Sequenz. Eine sehr wichtige Anwendung dieses Syntheseverfahren ist die Herstellung von neuen Genen. Durch die Expression solcher im Labor hergestellten Gene können neue Proteine mit neuartigen Eigenschaften in beliebiger Menge synthetisiert werden. Eine weitere sehr wichtige Anwendung solcher synthetischer Oligonucleotide ist die Markierung mit radioaktiven Markern (wie ${ }^{32} \mathrm{P}$ ) oder Fluoreszenzfarbstoffen. Diese markierten Oligonucleotide nennt man DNA-Sonden. So kann man eine DNA-Sonde, die mit einer bekannten und komplementären Sequenz in einem Chromosom hybridisiert, als Ausgangspunkt für die Analyse noch unbekannter DNA einsetzen. Dabei werden die Fluoreszenzeigenschaften bzw. die Radioaktivität des Markers nach der Hybridisierung untersucht. Ist der Marker noch vorhanden, deutet das darauf hin, dass die komplementäre Sequenz zu der markierten DNA-Sonde im Chromosom vorhanden ist. In diesem Zusammenhang ist es wünschenswert, neue Fluoreszenzmarker zu entwickeln und kovalent an DNA anzubinden, um die Gefahren der Handhabung von radioaktiven Markern zu vermeiden. Perylenfarbstoffe könnten wegen ihrer starken Fluoreszenz, Photostabilität und chemischen Beständigkeit ${ }^{11,23}$ als Fluoreszenzmarker für DNA-Sonden angewendet werden. Voraussetzung ist dabei die 
kovalente Anknüpfung von Perylenen an Oligonucleotide unter Erhalt ihrer Fluoreszenzeigenschaften.

\subsection{Farbmittel: Pigmente und Farbstoffe}

Farbmittel sind durch ihre Fähigkeit, Licht im sichtbaren Bereich des elektromagnetischen Spektrums (400- $700 \mathrm{~nm}$ ) zu absorbieren oder zu emittieren, gekennzeichnet. Natürliche Farbmittel wurden seit dem prähistorischen Zeitalter eingesetzt, wie Höhlenmalereien in Europa (Altamira, Spanien), im alten Ägypten und in China. Die ältesten synthetischen Pigmente wurden im alten Ägypten und in China entdeckt, nämlich Egyptian Blue $\left(\mathrm{CaCuSi}_{4} \mathrm{O}_{10}\right)$, Han Blue $\left(\mathrm{BaCuSi}_{4} \mathrm{O}_{10}\right)$ und Han Purple $\left(\mathrm{BaCuSi}_{2} \mathrm{O}_{4}\right)$.

Farbmittel können in zwei Klassen eingeteilt werden, Farbstoffe und Pigmente. Die Löslichkeit ist der entscheidende Parameter für diese Einteilung. Farbstoffe sind im Applikationsmedium lösliche organische Farbmittel. Farbstoffen müssen eine Affinität zu den Substraten (z.B. Textilien, Leder, Papier, Haare usw.), die gefärbt werden sollten, aufweisen. Dagegen sind Pigmente im Anwendungsmedium praktisch unlösliche, anorganische oder organische, bunte oder unbunte Farbmittel und gewinnen durch die Einführung von Zusatzstoffen (wie z.B. Polymere beim Einsatz von Lackpigmenten und zum Färben von Kunststoffen) eine Affinität zum Substrat. Im Hinblick auf die optischen Eigenschaften der beiden Klassen existiert ein weiterer Unterschied. Bei Farbstoffen bestimmt das einzelne Molekül die Lichtabsorption und somit auch die Farbe, während bei Pigmenten die Kristallstruktur $\mathrm{zu}$ den optischen Eigenschaften beiträgt. Die chemische Grundstruktur der Farbstoffe und Pigmente ist in vielen Fällen gleich. Die für die Applikation von Pigmenten benötigte Unlöslichkeit wird durch den Ausschluss von Gruppen, die solche Pigmente löslich machen könnten, durch die Bildung unlöslicher Salze, durch die Bildung von Metallkomplexen bei Verbindungen ohne Löslichkeitfördernde Gruppen oder durch die Einführung von Löslichkeit herabsetzenden Gruppierungen (z.B. Carbonamidgruppen) erreicht. In den 70er Jahren des vergangen Jahrhundertes zeichnete sich als Folge der Entwicklung neuer Technologien und 
Einsatzgebiete, wie in der Molekularbiologie, Medizin, Elektronik und Lasertechnik, eine Trendwende in der Farbstoffindustrie ab. Bis dahin wurden Farbmittel für das Färben von Textilien und Leder, für Druckverfahren und in der Kosmetik eingesetzt. Bei den neuen Einsatzgebieten werden die Farbmittel nicht für die ästhetische und äußere Erscheinung verwendet, sondern für physikalische und chemische Funktionen, die das Farbmittel erfüllen muss. Derartige Farbmittel werden als funktionelle Farbstoffe bezeichnet ${ }^{12}$. Zu den funktionellen Farbstoffen gehören nicht nur chemische Verbindungen, die aus dem sichtbaren Bereich des Spektrums einen bestimmten Wellenlängenbereich absorbieren, sondern auch Verbindungen, die im ultravioletten bzw. im nahen Infrarotbereich absorbieren. Unter den verschiedenen Arten der funktionellen Farbstoffe sind die Fluoreszenzfarbstoffe in der vorliegenden Arbeit von besonderem Interesse. Fluoreszenzfarbstoffe sind Farbstoffe, die Licht absorbieren und Energie aufnehmen und danach wieder in verschiedenen Formen (wie z.B. Fluoreszenz) freisetzen.

Viele chemische Verbindungen haben aromatische Ringstrukturen, die delokalisierte Elektronen in den $\pi$-Orbitalen besitzen. Die Elektronen dieser Orbitale treten leicht in Wechselwirkung mit der Umgebung und erreichen bei der Absorption eines Anregungsphotons ein höheres Orbital $\left(\pi^{*}\right)$. Die Absorption eines Anregungsphotons (hv) hebt ein Elektron aus dem Grundzustand $\mathrm{S}_{0}$ in einen der angeregten Zustände $\mathrm{S}_{1}$ oder $\mathrm{S}_{2}$.

Dieser Vorgang ist extrem schnell (innerhalb von $10^{-15} \mathrm{~s}$ ). Aus dem oberen angeregten Zustand $\mathrm{S}_{2}$ ist ein Übergang nach $\mathrm{S}_{1}$ möglich, ohne dass ein Photon emittiert wird. Aber beim Übergang in den Grundzustand wird die freiwerdende Energie als Fluoreszenzphoton emittiert. Die Energie des emittierten Photons ist immer geringer als die des absorbierten Photons. Damit ist die Wellenlänge des Fluoreszenzlichts größer als die des Anregungslichts.

Bei manchen Verbindungen kann es zu einem Übergang aus einem angeregten SingulettZustand in einen Triplett-Zustand $\left(\mathrm{T}_{1}\right)$ kommen. Bei diesem Vorgang erfolgt eine Spinumkehr des angeregten Elektrons. Auch der Sprung in den Grundzustand erfordert eine Spinumkehr. Diese Vorgänge sind jedoch sehr unwahrscheinlich, und die Emissionsraten sind sehr gering, was der Grund für das langsame Abklingen der Phosphoreszenz bei Spielzeug und Leuchtziffern ist, welche im Dunkeln leuchten. Der 
Einsatz von optischen Aufhellern basiert auf diesem Effekt. Optische Aufheller sind farblose chemische Verbindungen, deren Absorptionsmaxima im nahen Ultraviolettbereich liegt und im blauen oder violetten Spektralbereich emittieren.

Fluoreszenzfarbstoffe werden als Sicherheitsmarker auf Textilien und Warnschildern eingesetzt. Ein weiterer Anwendungsbereich für Fluoreszenzfarbstoffe ist ihr Einsatz in der analytischen Chemie, Biochemie und im medizinischen Bereich als Fluoreszenzmarker ${ }^{13-14}$, der in letzter Zeit sehr großes Interesse weckte. Maßgeblich dabei ist die Entwicklung neuer Technologien, die heute die Messung der Fluoreszenz eines einzelnen Moleküls ermöglichen.

\subsection{Rylenfarbmittel, Struktur und Eigenschaften}

Als Rylenfarbmittel bezeichnet man alle Farbmittel, deren chromogenes System aus Naphthalin als Wiederholungseinheit aufgebaut ist. Dabei sind die Naphthalineinheiten in den verschiedenen Rylenfarbmitteln über die peri-Positionen verknüpft.

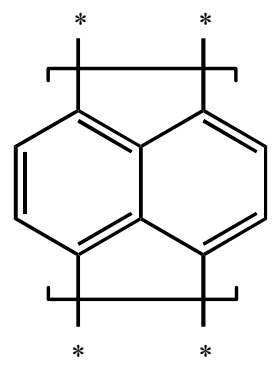

1-1

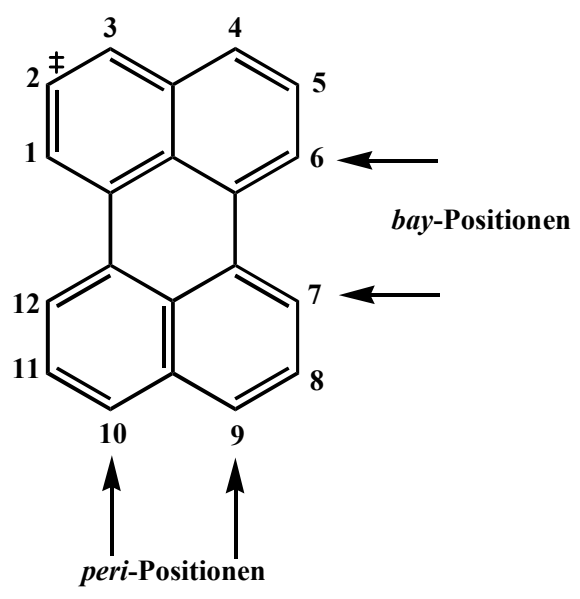

1-2

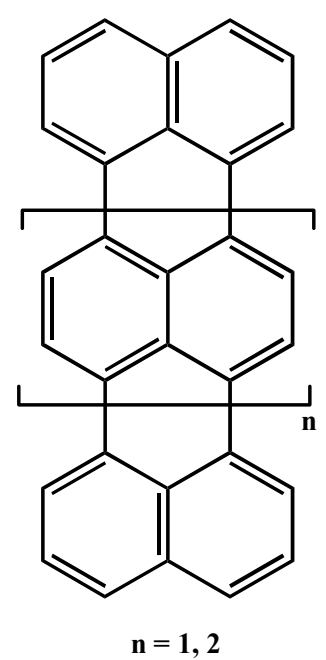

1-3

Abbildung 11: Allgemeine Struktur des Naphthalins 1-1, der Rylenfarbstoffe und die Nomenklatur des Perylens 1-2 
Bei Perylenfarbstoffen, die in dieser Arbeit eine zentrale Rolle spielen, handelt es sich chemisch um Perylentetracarbonsäuredianhydride, Perylentetracarbonsäurediimide und dessen Derivate, die Naphthalintetracarbonsäure als Basisverbindung enthalten. Perylenderivate zählen zu den Pigmenten mit guter bis sehr guter Lichtechtheit und sind bekannt für ihre chemische und thermische Stabilität ${ }^{11}$. Die wesentlichen Einsatzgebiete der Perylenpigmente sind hochwertige Industrielacke, wie Automobillacke sowie Spezialdruckfarben, bzw. Blech- und Plakatdruckfarben. Abbildung 11 zeigt die allgemeine Struktur und die Nomenklatur der Positionen des niedrigsten Homologe der Rylenfarbstoffe, das Perylen 1-2. Die zwei höheren Glieder der Rylenfarbstoffe werden als Terrylen bzw. Quaterrylen bezeichnet.

\subsection{Synthese von Perylentetracarbonsäurederivativen}

Die Synthese von Perylenpigmenten und -farbstoffen wurde auf die Grundlage der 1913 von M. Kardos ${ }^{15-17}$ entwickelten Verfahren vorangetrieben. Dabei wird in der ersten Stufe Acenaphthen 1-4 zum 1,8-Naphthalindicarbonsäureanhydrid 1-5 oxidiert. Die Oxidation erfolgt entweder mit Salpetersäure oder mit Luftsauerstoff an einem Vanadiumoxidkatalysator. Durch die Kondensation von 1-5 mit Ammoniaklösung erhält man 1,8-Naphthalindicarbonsäureimid 1-7. Bringt man dieses Produkt mit einer Alkalimischung, z. B. eine Mischung aus Natriumacetat, Natriumhydroxid und Kaliumhydroxid, bei $200^{\circ} \mathrm{C}$ zum Schmelzen, kann durch eine anschließende Oxidation mit Luftsauerstoff Perylen-3,4,9,10-tetracarbonsäurediimid 1-8 hergestellt werden.

Durch die Verseifung des Perylendiimides 1-8 mit Schwefelsäure entsteht das Perylen3,4,9,10-tetracarbonsäuredianhydrid 1-9. Durch Kondensation von 1-9 mit primären aliphatischen und aromatischen Aminen sind N,N`-dialkyl- und N,N`-diarylsubstituierte Perylentetracarbonsäurediimide 1-10 leicht erreichbar ${ }^{18-20}$. Man kann auch einfache alkylsubstituierte Perylentetracarbonsäurediimide wie das N,N`-Dimethylderivat durch den Einsatz von N-alkylsubstituierten Naphthalindicarboximiden 1-6 oder durch Alkylierung von 1-8 herstellen ${ }^{21-22}$. 
Perylentetracarbonsäurederivate zählen wegen ihrer exzellenten Eigenschaften zu den Hochleistungsfarbmitteln. $\mathrm{Zu}$ diesen Eigenschaften gehören eine sehr gute Wetter- und Lichtechtheit (photochemische Stabilität), hohe Farbstärke und auch sehr gute chemische Beständigkeit $^{11,23}$. Besonderes wichtig $\mathrm{zu}$ erwähnen ist die gute bis sehr gute Migrationsechtheit der Perylentetracarbonsäurederivate in Kunststoffen wie Vinylpolymeren und Polyethylen und die hervorragende thermische Stabilität $t^{16,20,24}$.

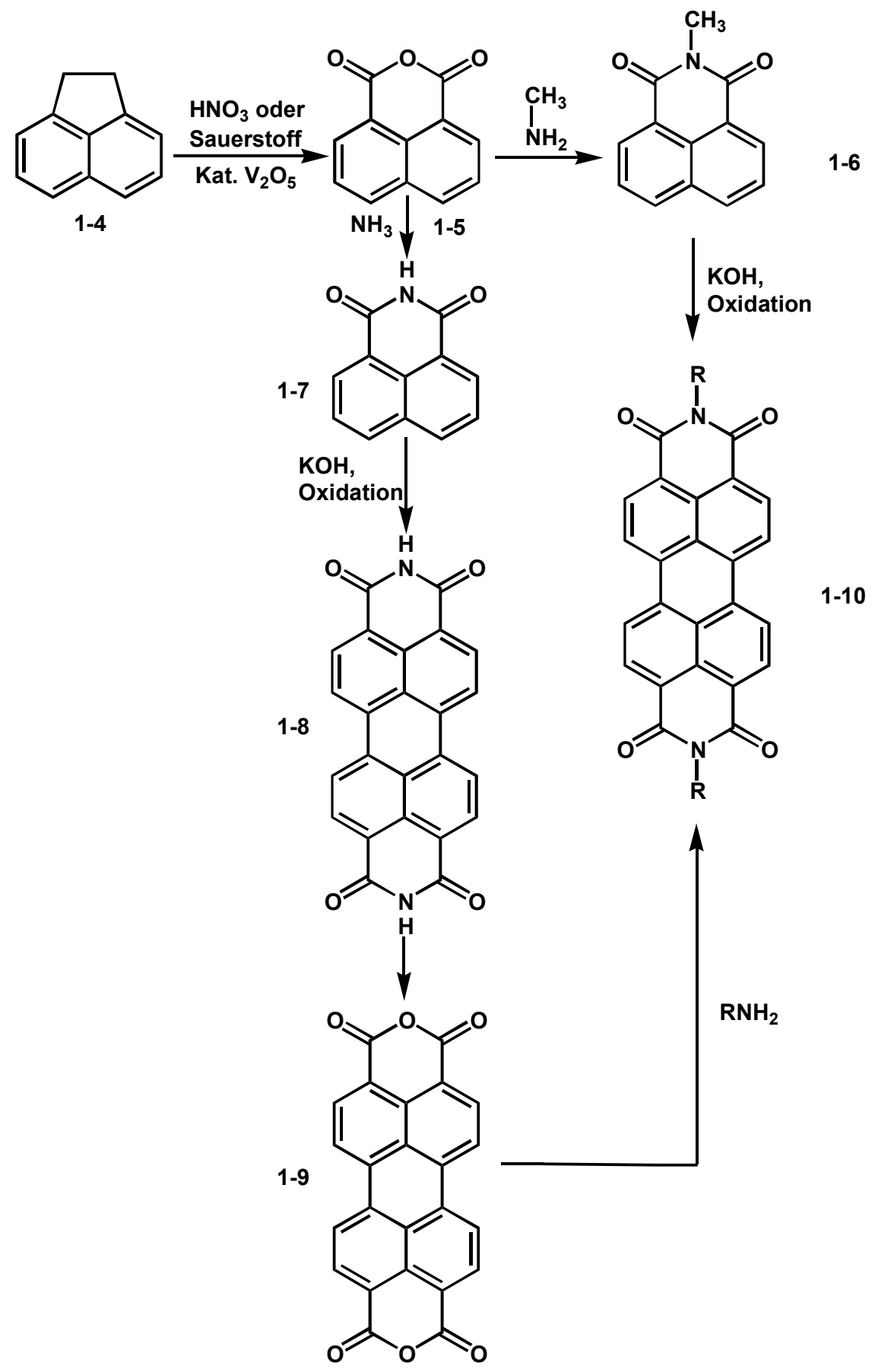

Abbildung 12: Synthese von Perylenpigmenten und Farbstoffen 
Das Färben von Polymeren wird entweder während ihrer Herstellung oder im Laufe ihrer Verarbeitung durchgeführt. In beiden Fällen erfolgt der Färbeprozess meistens bei hohen Temperaturen zwischen 100 und $350^{\circ} \mathrm{C}$. Die Tatsache, dass die Perylentetracarbonsäurederivate eine relativ hohe chemische Beständigkeit gegenüber Säuren und Basen besitzen, was für säure- und basenkatalysierte Polymerisationsreaktionen unverzichtbar ist, ermöglicht deren Einsatz als säure- bzw. basenresistente Farbmittel.

Perylenpigmente eigenen sich zur Verwendung in hochwertigen Dispersionsfarben und Autolacken ${ }^{16}$. Besonderes hervorzuheben ist, dass Perylenpigmente eine breite Farbplatte abdecken. In Abhängigkeit vom Substituenten an der Imidstruktur werden rote, bordeauxrote, violette, braune und sogar schwarze Farbtöne erreicht ${ }^{16,25}$.

Diese Änderungen in den Farbtönen der Perylendiimide sind auf die Anordnung der Moleküle in der Kristallstruktur zurückzuführen. So kann die Änderung des Imidsubstituenten $\mathrm{zu}$ einer anderen Kristallstruktur und damit $\mathrm{zu}$ anderen optischen Eigenschaften führen. Die Analyse der Kristallstruktur beweist, dass z.B. bei den schwarzen Perylenpigmenten eine stärkere Überlagerung der einzelnen aromatischen $\pi$ Systeme als bei den roten Pigmenten vorhanden ist ${ }^{26-28}$.

In der Kristallstruktur neigen alle Perylenimide zur parallelen Stapelung der aromatischen $\pi$-Systeme. Die Struktur des Imidsubstituenten ist hier besonderes wichtig. Raumbeanspruchende Imidsubstituente verhindert die parallele Stapelung der einzelnen Moleküle im Kristall. Einige Beispiele für solche Substituenten sind in Tabelle 2 eingetragen. Substituenten wie 2,6-Diisopropylanilin (letzter Eintrag in Tabelle 2) und 2,5-Di-tert.-butylanilin sind sterisch anspruchsvoll. Sie sind bezüglich der Ebene des Perylengerüsts um $90^{\circ} \mathrm{C}$ gedreht ${ }^{29-31}$. Eine weitere und ganz wichtige Konsequenz dieser Imidsubstituenten ist die Verbesserung der Löslichkeit der Perylenderivate. Die Imidsubstituenten verhindern die parallele Stapelung und verringern dabei die Gitterenergie im Festkörper, was zu einer deutlichen Erhöhung der Löslichkeit in organischen Lösungsmitteln führt ${ }^{19,32}$. Als Folge dieser Verbesserung in der Löslichkeit weisen die löslichen Perylentetracarbonsäurediimide eine verstärkte Fluoreszenz auf (Fluoreszenzquantenausbeute nahe $100 \%$ ). 


\begin{tabular}{|c|c|}
\hline $\mathrm{C}$ & Farbton \\
\hline & bordeauxrot \\
\hline
\end{tabular}

Tabelle 2: Die Struktur und der Farbton einiger Perylenpigmente mit verschiedenen Imidsubstituenten<smiles>[Y]C(=O)c1ccc2c3c(ccc4c5ccc(C([X])=O)c6ccc2c4c65)-c13</smiles>

Abbildung 13: Struktur von Perylendiimid mit verschiedenen Imidsubstituenten

Eine beachtliche weitere Steigerung der Löslichkeit von Perylendiimiden wird durch die Einführung von Phenoxyresten in die bay-Positionen ${ }^{33}$ erreicht. Solche Phenoxyreste 
tragen oft Alkylreste wie tert.-Butyl oder tert.-Octyl, was sich positiv auf die Löslichkeit auswirkt.

Die Synthese von Perylenderivaten mit Phenoxyresten erfolgt durch die Chlorierung von Perylendiimiden 1-10 mit Thionylchlorid in Nitrobenzol zu 1-11. Anschließend wird über nucleophilen Austausch das Chlor durch Phenolat substituiert, wie in Abb. 14 gezeigt.<smiles>[R]N1C(=O)c2ccc3c4ccc5c6c(ccc(c7ccc(c2c37)C1=O)c64)C(=O)N([R])C5=O</smiles>

$1-10$

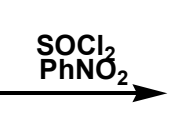<smiles>[R]N1C(=O)c2cc(Cl)c3c4c(Cl)cc5c6c(cc(Cl)c(c7c(Cl)cc(c2c37)C1=O)c64)C(=O)N([R])C5=O</smiles>

$1-11$

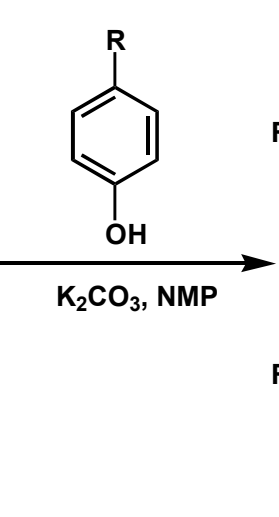

(N)<smiles></smiles>

1-12

Abbildung 14: Chlorierung und Phenoxylierung von Perylentetracarboxdiimid, R = Alkyl or Aryl, $\mathrm{R}^{\prime}=\mathrm{Alkyl}$

Mit der Phenoxylierung wird auch eine bathochrome Verschiebung des Absorptionsmaximums von ca. $520 \mathrm{~nm}$ in 1-10 auf ca. $580 \mathrm{~nm}$ in 1-12 verursacht. Der Grund für diese bathochrome Verschiebung der Absorptionsbanden ist die Erweiterung des konjugierten $\pi$-Systems des Perylenmoleküls.

Einen Zugang zu Perylenderivaten, die noch langwelliger absorbieren, stellt die Umsetzung von Perylentetracarbonsäuredianhydrid mit ortho-Phenylendiaminen dar ${ }^{25,34}$. Abb. 15 zeigt die Umsetzung von Perylentetracarbonsäuredianhydrid mit orthoPhenylendiamin zur Synthese von Bisimidazolderivat des Perylens. Obwohl man auf diesem Weg ein Gemisch aus syn- und anti-Isomeren, 1-13 und 1-14, erhält, beträgt die bathochrome Verschiebung des Absorptionsmaximums bis zu $100 \mathrm{~nm}$. 
<smiles>O=C1OC(=O)c2ccc3c4ccc5c6c(ccc(c7ccc1c2c73)c64)C(=O)OC5=O</smiles><smiles>Nc1ccccc1N</smiles>

$1-9$

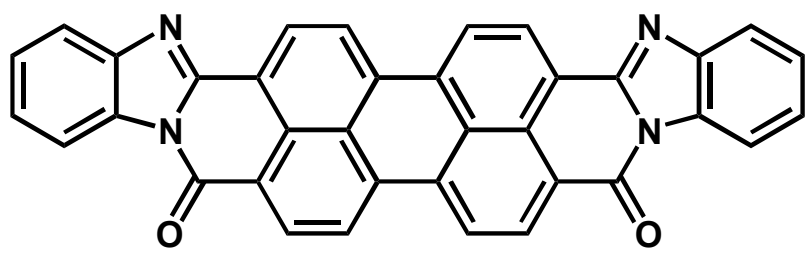

$1-13$

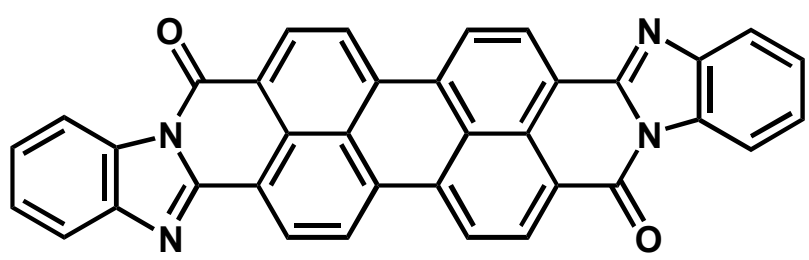

$1-14$

Abbildung 15: Synthese von Perylenbisimidazolderivaten

Lösliche Perylenderivate sind nicht nur wegen ihrer thermischen, chemischen, und photochemischen Stabilität als funktionelle Farbstoffe sehr reizvoll. Sie werden auf Grund ihrer starken Fluoreszenzintensität (Fluoreszenzquantenausbeute nahe $100 \%$ ) nicht nur als leuchtende Signalfarben in Lacken, Druckfarben und Polymeren eingesetzt, sondern auch z. B. in Fluoreszenzsolarkollektoren ${ }^{35-36}$, als Laserfarbstoffe ${ }^{37-38}$ und für analytische Nachweisverfahren ${ }^{39-40}$. Eine weitere interessante Anwendung ist das Färben von Gewächshausfolien mit Tetraphenoxyperylentetracarboxdiimiden. Dabei führt die Wellenlänge des Fluoreszenzlichts zur Steigerung des Ertrags bestimmter Nutzpflanzen ${ }^{41-}$ 42. Auch in der Xerographie finden Perylentetracarboxdiimide eine Anwendung ${ }^{43-45}$, wo man photoelektrisch aktive Farbstoffe benötigt. $\mathrm{Zu}$ den neusten Entwicklungen von Solarzellen auf der Basis von Farbstoffen zählt die Kombination von Perylentetracarboxdiimiden mit konjugierten Polymeren ${ }^{46-47}$.

\subsection{Höhere Rylenfarbstoffe}

Die höheren Homologe des Perylens in der Reihe der Rylene, das Terrylen und das Quaterrylen, sind für viele Forscher von großem Interesse, besonderes für diejenigen, die 
auf dem Gebiet der Einzelmolekülspektroskopie arbeiten ${ }^{48-49}$. Bei dieser modernen Technologie wird die Fluoreszenz einzelner Moleküle, die genügend verdünnt und damit räumlich separiert in kondensierter Phase vorliegen, untersucht. Das macht Beobachtungen realisierbar, die bei der klassischen Ensemble-Fluoreszenzmessung verborgen bleiben. Synthesewege für die Terrylen- und Quaterrylenderivate wurden in den letzten Jahren in der Arbeitsgruppe von K. Müllen gefunden ${ }^{50-53}$. Die Synthese des Terrylenderivats, Benzoylterrylenimid 1-15 ist F. Holtrup gelungen, Terrylendiimid 1-16 wurde von G. Müller ${ }^{53}$ hergestellt. Die Absorptionsspektren der höheren Rylenchromophore werden mit der Erweiterung des $\pi$-Systems um eine Naphthalineinheit um ca. $120 \mathrm{~nm}$ bathochrom verschoben. In Abbildung 16 sind die Strukturen von Benzoylterrylenimid 1-15, Terrylendiimid 1-16 und Quaterrylen 1-17 gezeigt.
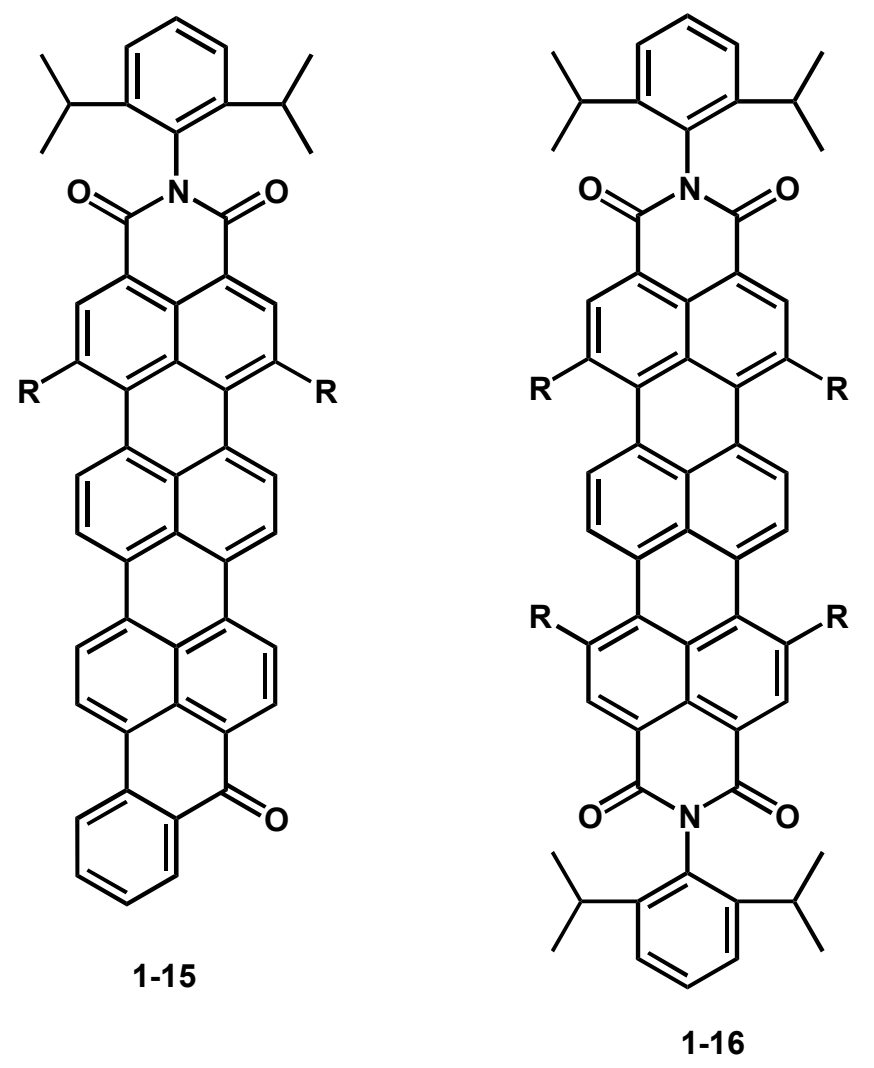

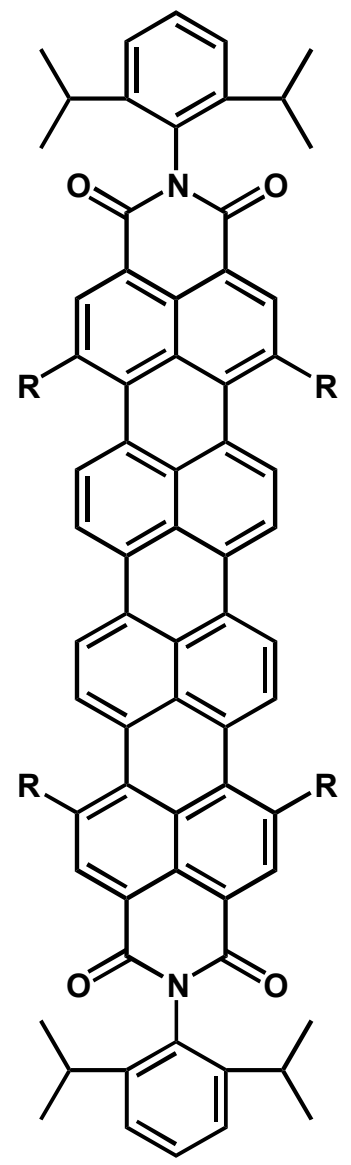

$1-17$

Abbildung 16: Die Struktur der höheren Homologe des Perylens, 4 = H oder O-Aryl 


\subsection{Bibliographie}

[1] P. Ball, Nature 1995, 375, 101.

[2] J. M. Lehn, Supramolecular Chemistry, Concepts and Perspectives, VCH, Weinheim 1995.

[3] C. M. Niemeyer; C. A. Mirkin, Nanobiotechnology, Concepts, Applications and Perspectives, VCH, Weinheim 2004.

[4] M. Muthukumar; C. K. Ober; E. L. Thomas Science 1997, 277, 1225.

[5] D. T. Bong; T. D. Clark; J. R. Granja; M. R. Ghadiri Angew. Chem. Int. Ed. 2001, 40, 988.

[6] J. J. Storhoff; C. A. Mirkin Chem. Rev. 1999, 99, 1848.

[7] C. M. Niemeyer Angew. Chem. Int. Ed. 1997, 36, 585.

[8] L. Stryer Biochemistry W. H. Freeman and Company, New York 1995.

[9] R. K. Murrary; D. K. Granner; P. A. Mayes; V. W. Rodwell Harper's Biochemistry, 1996, $24^{\text {th }}$ Edition, Appleton \& Lange, Stamford, CT, USA.

[10] J. D. Watson; F. H. C. Crick Nature 1953, 171, 737.

[11] F. Würthner, C. Thalacker, A. Sautter, W. Schärtl, W. Ibach, O. Hollricher, Chem. Eur. J. 2000, 6, 3871-3886.

[12] J. Griffith, Chimia 1991, 45, 304.

[13] H. Fukuda, F. M. C. Battle, P. A. Riley, Int. J. Biochem. 1993, 25, 1407.

[14] M. Kriegmair, D. Zaak, R. Knuechel, R. Baumgartner, A. Hofstetter, Urol. Int. 1999, $63,27$.

[15] M. Kardos, D. R. P. 276357, 1913.

[16] W. Herbst, K. Hunger, Insustrial Organic Pigments, VCH, Weinheim, 1993.

[17] Ullmanns Encyclopädie der technischen Chemie, Vol. 13, VCH, Weinheim, 1974.

[18] Y. Nagao, T. Misono, Dyes Pigm. 1984, 5, 171.

[19] A. Rademacher, S. Märkle, H. Langhals, Chem. Ber. 1982, 115, 2927.

[20] F. Graser, DE 2139688, 1973.

[21] M. Kardos, Chem. Zentralbl. 1914, 2, 553.

[22] W. Bradley, F. W. Pexton, J. Chem. Soc. 1954, 4432. 
[23] O. I. Shulepova, E. N. Shelyapine, N. P. Shtanov, I. M. Mosvshovich, G. N. Vorotzhtsov, U.S. 4336383, 1982.

[24] A. P. Hopmeier, Pigments Survey, Wiley-Interscience, New York, 1969.

[25 ] Y. Nagao, Prog. Org. Coatings 1997, 31, 43.

[26] E. Hädicke, F. Graser, Acta Cryst. 1986, C42, 189.

[27] E. Hädicke, F. Graser, Acta Cryst. 1986, C42, 195.

[28] J. M. Duff, A. M. Har, R. O. Loutfy, A. R. M. Eleryk, Chem. Func. Dyes 1992, 2, 564.

[29] G. Seybold, G. Wagenblast, Dyes and Pigments 1989, 11, 303.

[30] H. Langhals, Chem. Ber. 1985, 118, 4641.

[31] S. Demig, H. Langhals, Chem. Ber. 1988, 121, 225.

[32] H. Kaiser, J. Lindner, H. Langhals, Chem. Ber. 1991, 124, 529.

[33] M. Schneider, Dissertation, Johannes-Gutenberg-Universität Mainz, 1998.

[34] H. Quante, Y. Geerts, , K. Müllen, Chem. Mater. 1997, 9, 495.

[35] M. J. Cook, A. J. Thomson, Chem. Ber. 1984, 20, 914.

[36] H. Langhals, Nachr. Chem. Tech. Lab. 1980, 28, 716.

[37] H. G. Löhmannsröben, H. Langhals, Appl. Phys. B 1989, 48, 449.

[38] R. Reisfeld, G. Seybold, Chimia, 44, 295.

[39] H. Langhals, Chem. Ind. 1985, 37, 470.

[40] H. Langhals, Z. Anal. Chem. 1985, 320, 361.

[41] S. Haremsa, Chem. unserer Zeit 1994, 28, 233.

[42] N. Ito, H. Aiga, Chem. Abstr. 1987, 107, 238195v.

[43] K.-Y. Law, Chem. Rev. 1993, 93, 449.

[44] R. O. Loutfy A. M. Har, P. Katzmeier, M. Tam, J. Imag. Sci. 1989, 33, 151.

[45] P. Gregory, High-Technology Applications of Organic Colorants, Plenum Press, New York, 1991.

[46] K. Petritsch, J. J. Dittmer, E. A. Marseglia, R. H. Friend, A. Lux, G. G. Rozenberg, S. C. Moratti, A. B. Holmes, Sol. Energy Mater. Sol. Cells 2000, 61, 63. 
[47] J. J. Dittmer, R. Lazzaroni, P. Leclere, P. Moretti, M. Ganström, K. Petritsch, E. A. Marseglia, R. H. Friend, J. L. Bredas, H. Rost, A. B. Holmes, Sol. Energy Mater. Sol. Cells 1999, 61, 53.

[48] L. Fleury, B. Sick, G. Zumhofen, B. Hecht, U. P. Wild, Mol. Phys. 1998, 95, 1333.

[49] F. Kulzer, F. Koberling, T. Christ, A. Mews, T. Basche, Chem. Phys. 1999, 247, 23.

[50] F. O. Holtrup, G. R. J. Müller, H. Quante, S. D. Feyter, F. C. D. Schryver, K. Müllen, Chem. Eur. J. 1997, 3, 219.

[51] Y. Geerts, H. Quante, H. Platz, R. Mahrt, M. Hopmeier, A. Böhm, K. Müllen, J. Mater. Chem. 1998, 8, 2357.

[52] S. K. Lee, Y. B. Zu, A. Herrmann, Y. Geerts, K. Müllen, A. J. Bard, J. Am. Chem Soc.. 1998, 121, 3513.

[53 ] F. O. Holtrup, G. R. J. Müller, J. Uebe, K. Müllen, Tetrahedron 1997, 53, 6847. 


\section{Motivation und Aufgabenstellung}

In der Einleitung wurden die Struktur und Eigenschaften von Nukleinsäuren erläutert. Die molekularen Erkennungseigenschaften der DNA sind von zentraler Bedeutung für deren Einsatz in der Nanotechnologie, wobei diese gezielt für den Aufbau von Nanostrukturen ausgenutzt werden, indem man anorganische und organische Moleküle mit komplementären DNA-Sequenzen funktionalisiert und durch Selbstorganisation in ein Makromolekül überführt. In dieser Arbeit geht es hauptsächlich um die Kombination von Perylenfarbstoffen mit Oligonucleotiden, die sich zur Bildung linearer Nanostrukturen eignen sollen. Ein anderes Anliegen ist die Funktionalisierung von Perylendiimid mit Biotin. Ein Bis(biotin)-funktionalisiertes Perylen sollte als Baustein für den Aufbau von Oberflächenschichten durch die molekulare Erkennung zwischen Biotin und Proteinen wie Avidin oder Streptavidin dienen. Ein weiteres Ziel dieser Arbeit ist die Überführung von Rylenfarbstoffen in wässrige Lösungen und ihre dortige Verwendung zur Visualisierung von Zellen. So ist die Arbeit in drei Themengebiete gegliedert werden, die im Folgenden kurz beschrieben werden.

Aufbauend auf den Arbeiten zur Bildung von DNA-Nanostrukturen sollten nun verschiedene Bausteine aus Peylendiimid-Oligonucleotid-Konjugaten hergestellt werden, Hierbei werden die lineare Struktur des Perylendiimids und die zugängliche Funktionalisierung des Perylendiimids mit zwei funktionellen Gruppen in der Imidstruktur ausgenutzt. Das erste Ziel dieser Arbeit war somit die Entwicklung chemischer Verknüpfungsmethoden zur Synthese von Perylendiimid-bis(oligonucleotid)konjugaten, die in der Lösung durchgeführt werden sollten. Eine Alternative zur Verknüpfung in Lösungen bietet die Festphasensynthese der Oligonucleotid-Konjugate nach der Phosphoramiditchemie, aber oft lösen sich die zu verknüpfenden Verbindungen teilweise oder gar nicht in Acetonitril, das verwendete Lösungsmittel in der Oligonucleotid-Festphasensynthese, auf, was zur Verstopfung der Leitungen an dem DNA-Synthesizer führen kann. In einem solchen Fall kann die Verknüpfung nur in der 
Lösung durchgeführt werden. Zusätzlich zum Löslichkeitsproblem kommen auch die viel höheren Kosten einer Festphasensynthese unter Verwendung der Phosphoramiditchemie. Zwei an der 5 '-Position verknüpfte Perylendiimid-bis(oligonucleotid)-konjugate sollen so gewählt und synthetisiert werden, dass sie durch Selbstorganisation eine Nanostruktur in der Form eines DNA-Perylen-Polymers ausbilden können. Die Olignucelotidsequenzen sind durch Festphasensynthese mit Hilfe eines automatisierten DNA-Synthesizers herzustellen. Die erzeugte (DNA-Perylen)-Polymerstruktur sollte durch Gelelektrophorese charakterisiert werden. Ergänzend dazu kann die Verknüpfung von Perylendiimid an der 3'-Position des Oligonucleotides anstelle der 5'-Position ermöglichen, dass sich durch die Hybridisierung zwischen einem 3'- und einem 5'verknüpften Konjugat ein DNA-Sandwich ausbildet. Bei diesem DNA-Sandwich bleiben die Oligonucleotidsequenzen im Hybrid parallel zueinander und können keine Polymerstruktur bilden. Dabei soll die Wechselwirkung zwischen zwei Perylendiimidmolekülen, die durch die Hybridisierung parallel zueinander positioniert werden können, studiert werden.

Ein DNA-Farbstoff-Polymer kann durch die Hybridisierung von zwei symmetrischen 5 Konjugaten zugänglich sein. Allerdings kann bei diesem Konzept die Länge des Polymers nicht kontrolliert werden. Diese ist nur möglich, wenn asymmetrische Perylendiimidbis(oligonucleotid)-konjugate hybridisiert werden. Um dieses Ziel zu erreichen, ist die Entwicklung von Kupplungsmethoden zur Synthese von Perylendiimidbis(oligonucleotid)-konjugaten mit zwei unterschiedlichen Sequenzen unabdingbar. Damit könnte die Bildung des DNA-Perylen-Polymers schrittweise und kontrolliert durchgeführt werden. Die Bildung einer (DNA-Perylen)-Ringstruktur kann mit diesem Prinzip auch realisiert werden.

Im Anschluss sollte ein Trisoligonucleotid mit einem starren Kern in Lösung synthetisiert werden. Die Eignung eines solchen Moleküls zur Hybridisierung mit DNA-Hybriden, die „sticky ends“ enthalten, um multidimensionale DNA-Strukturen bilden zu können, muss untersucht werden. 
Im zweiten Teil soll Perylendiimid mit zwei Biotinmolekülen funktionalisiert werden. Biotin ist ein Vitamin, das sich an Proteine wie Avidin oder Streptavidin sehr spezifisch und mit hoher Affinität binden kann. Hierbei liegt ein Augenmerk auf der Eignung des Bis(biotin) funktionalisierten Perylendiimids für die molekulare Erkennung von Proteinen, die an Oberflächen immobilisiert sind, und somit der Bildung einer multischichtigen Nanostruktur. Dabei wird das Perylendiimid-bis(biotin) als bindende Brücken zwischen den Proteinschichten fungieren. Diesem Ziel steht die Wasserunlöslichkeit des Perylendiimid-bis(biotin)s entgegen. Dieses Hindernis soll umgegangen werden, indem man ein Detergenz einsetzt, um das Konjugat in wässrige Lösungen zu überführen.

Da Rylenchromophore eine hohe Fluoreszenzquantenausbeute und exzellente Photostabilität aufweisen, ist es wünschenswert, sie in wässrige Lösungen unter möglichst vollständigem Erhalt der Fluoreszenz zu überführen. Im dritten Teil dieser Arbeit sollen wasserlösliche Rylenchromophore synthetisiert und auf ihre Eignung als Fluoreszenzmarker in biologischen Systemen überprüft werden. Dabei wird vor allem die Anwendung von solchen wasserlöslichen Farbstoffen zur Visualisierung von Zellen untersucht. 
Kapitel 2: Motivation und Aufgabenstellung 


\section{Perylendiimid-Oligonucleotid-Konjugate, Synthese und Selbstorganisation}

\subsection{Einleitung}

Die DNA ist nicht nur aufgrund der auf ihm codierten genetischen Informationen, sondern auch wegen ihrer potentiellen Funktion als molekulares Gerüst für die Bildung von Strukturen im nm-Maßstab ein außerordentlich wichtiges Molekül. Unter Nanotechnologie versteht man den Aufbau von supramolekularen Strukturen aus molekularen Bausteinen. Diese sollen in der Lage sein, sich selbstzuorganisieren ${ }^{1-2}$. Zur Bildung von supramolekularen und selbstorganisierenten Struktureneinheiten scheint DNA ein geeignetes Molekül zu $\operatorname{sein}^{3-7}$. Die wichtigste Eigenschaft der DNA, die die Grundlage für deren Einsatz in der Nanotechnologie darstellt, ist die spezifische molekulare Erkennung oder die Komplementarität, die zwischen den Basenpaaren durch Wasserstoffbrücken besteht und die DNA zusammenhält: Guanin (G) paart mit Cytosin (C) und Adenin (A) mit Thymin (T). Diese Spezifität der Basen macht DNA zu einem idealen Werkzeug, um mit dessen Hilfe andere Moleküle in Makrostrukturen anzuorden.

Die Pioneerarbeiten von Seeman auf dem Gebiet der DNA-Nanotechnologie eröffneten die Tür zur Verwendung von DNA in den Materialwissenschaften ${ }^{8}$. Seine Arbeitsgruppe demonstrierte die Konstruktion von viereckigen Strukturen, Würfeln, abgestumpften Oktaedern und Oberflächenarchitekturen durch die sogennanten ,sticky ends“ und DNALigasen, die zwischen zwei unterschiedlichen DNA-Sequenzen eine kovalente Bindung herbeiführen können (Abb. 17) $)^{9-18}$.

Eine häufig nicht bemerkter aber einschränkender Aspekt für die Planung und erfolgreiche Organisation von Strukturelementen zur Nanoarchitecturen ist die kovalente Verknüpfung von DNA mit organischen und anorganischen Molekülen. 

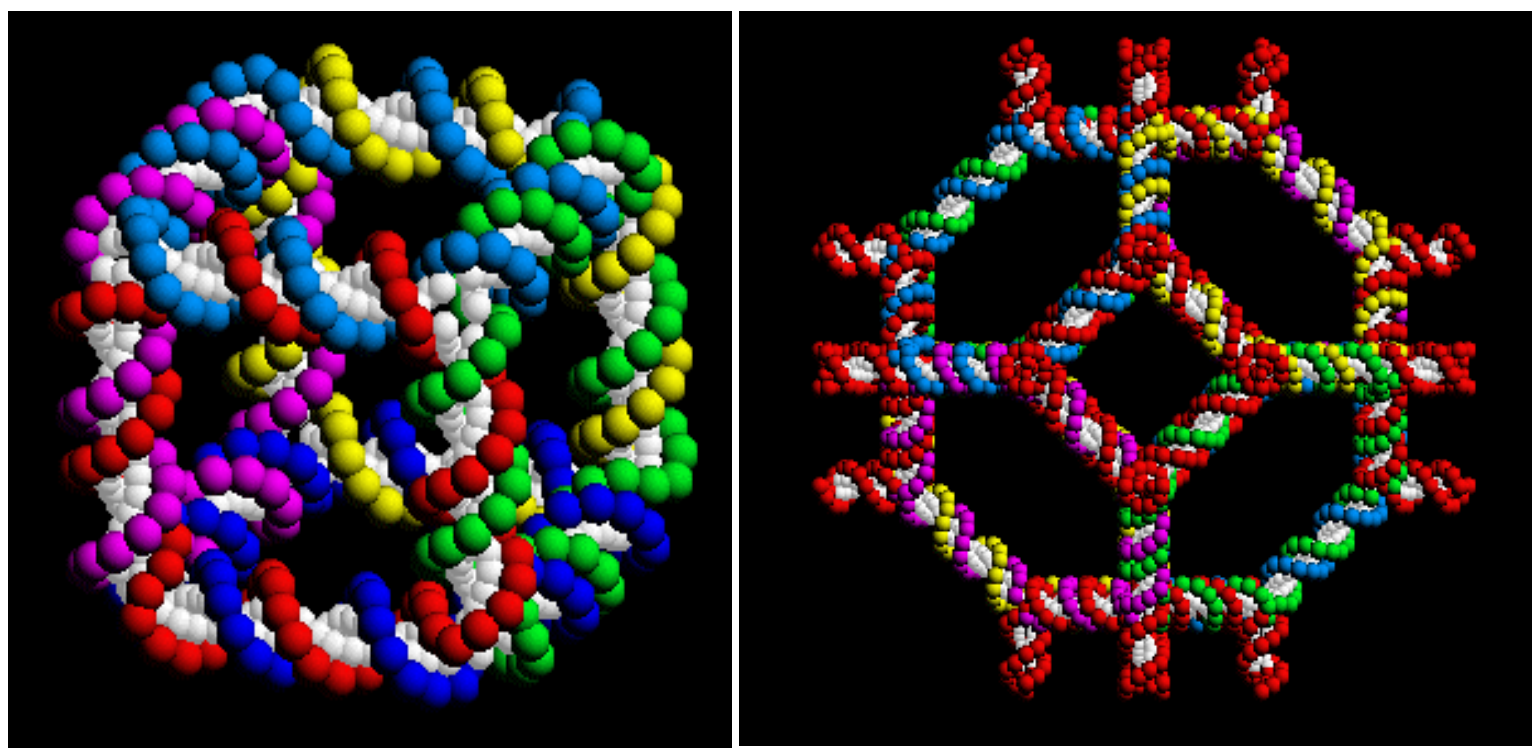

Abbildung 17: Seemans Würfel (links) und abgestumpfter Oktaeder (rechts) ${ }^{19}$

Die Gruppen von Mirkin und Schultz demonstrierten die spezifische Anordnung von Goldnanopartikeln unter Verwendung von Oligonucleotiden. Die Arbeit von Mirkin basiert auf der Zusammenmischung von zwei Goldnanopartikeln, die mit zwei unterschiedlichen, aber nicht-komplementären Oligonucleotiden modifiziert sind. Durch die Zugabe von DNA-Duplexen mit „sticky ends“, bei denen ein Ende komplementär zum Oligonucleotid des einen Nanopartikeles und das andere Ende komplementär zur Sequenz des anderen ist. Die Hybridisierung der Oligonucleotide führte zu einer Farbänderung der Lösung von rot zu violett. Im Anschluss war sogar das Ausfallen eines rosig-grauen DNA-Kolloids ${ }^{20} \mathrm{zu}$ beobachten. Schultz verwandte eine DNA-Vorlage, um die mit Oligonucleotiden funktionalisierten Nanopartikel in Dimeren und Trimeren anzuordnen ${ }^{21}$.

Bergstrom und Shi berichteten über die Selbstorganisation von Oligonucleotidmodifizierten organischen Verbindungen zu DNA-Ringstrukturen ${ }^{22}$. In der Gruppe von Bunz wurden Cyclobutadien(cyclobutadienyl)Kobalt-Komplexe mit Oligonucleotiden modifiziert. Ihre Selbstorganisation führte ebenso zu supramolekularen Strukturen ${ }^{23-24}$. 
DNA wird nicht nur als Konstruktionsmaterial für DNA-Nanoarchitekturen eingesetzt, sondern auch als Templat zum Aufbau von Nanodrähten ${ }^{25}$, obwohl die Frage nach der Leitfähigkeit der DNA immer noch umstritten ist ${ }^{26-31}$.

\subsection{Grundlagen der automatisierten Oligonucleotidsynthese}

Die Phosphoamidit-Methode ist die weitverbreiteste Methode zur Synthese von Oligonucleotiden, welche auch in dieser Arbeit verwendet wurde. Die Grundlage dafür stellt die Festphasensynthese von Peptiden dar, die von Merrifield entwickelt wurde ${ }^{32}$. Letsinger stellte 1975 seine Phosphittriester-Methode zur Synthese von Oligonucleotiden vor $^{33}$. Bei dieser Methode werden Phosphochloridite und -imidazolide als reaktive Spezies eingesetzt. Die extreme Empfindlichkeit der reaktiven Spezies gegen Spuren von Wasser stand einer breiten Anwendbarkeit dieser Methode für die Festphasensynthese von Oligonucleotiden entgegen. Bei der von Beaucage and Caruthers entwickelten Phosphoramidit-Methode ${ }^{34}$ werden Phosphoamidite verwendet, die vergleichbar reaktiv sind, aber sich über Jahre lagern lassen. Ein großer Fortschritt zur Verbesserung der Methode wurde durch die Einführung der Cyanoethoxyschutzgruppe als permanente Schutzgruppe am Phosphoratom erreicht ${ }^{35-37}$. Zur Abspaltung der am Anfang als Schutzgruppe verwendeten Methoxyfunktion war der Einsatz einer Lösung aus Thiophenol und Triethylamin erfordlich ${ }^{38}$. Die Cyanoethoxygruppe kann dagegen durch wässrige Ammoniumhydroxid-Lösung abgespalten werden, d.h. unter den gleichen Bedingungen, die auch zur Abspaltung der Aminschutzgruppen der Basen und des synthetisierten Oligonucleotides vom Trägermaterial verwendet werden. Die Beobachtung einer partiellen Methylierung der Basen bei der Verwendung der Methoxyschutzgruppe (insbesonders in der N3-Position von Thymidin) stellte einen weiteren Nachteil dar ${ }^{39}$.

Der Synthesezyklus beginnt im ersten Schritt mit der Detritylierung (Abbildung 18), bei der die terminale 5 -O-Dimethoxytrityl-Gruppe des am Trägermaterial ${ }^{40-42}$ gebundenen 
Nucleotids mit wasserfreier Dichloressigsäure abgespalten (detrityliert) wird. Durch die intensive Orangefärbung des Tritylkations kann den Verlauf der Synthese verfolgt werden. Der DNA-Synthesizer führt deshalb bei jedem Syntheseschritt eine photometrische Bestimmung der aus der Reaktionssäule erhaltenen Lösung durch. Der erhaltene Tritylpeak gibt einen Hinweis auf den Erfolg und Verlauf der Kopplungsreaktion.

In der Anschließenden Reaktion (Schritt 2, Abb. 19) wird das mit Tetrazol bzw. Tetrazolderivaten ${ }^{43-45}$ aktivierte Phosphoamidit ${ }^{34}$ an der freien und nucleophilen 5 -OHFunktion des letzten Nucleotids gekuppelt. Damit wird eine Phosphittriester-Bindung ausgebildet und die Sequenz um ein Nucleotid verlängert.

Bei den angewendeten Amiditüberschüssen von 1.5-4 Äquivalenten werden Kopplungsraten von bis zu 97-99.9 \% erreicht. Die verbleibenden nicht umgesetzten 5 OH-Funktionen werden in Schritt 3 mit Essigsäureanhydrid, das mit N-Methylimidazol oder Dimethylaminopyridin (DMAP) aktiviert ist, verestert (blockiert) und stehen damit nicht mehr für weitere Reaktionen zur Verfügung (Capping). Ohne diesen Schritt würden bei fortgeschrittener Synthese eine große Zahl von Mutanten (n-1, n-2, n-3, ...) entstehen, die kaum noch vom gewünschten Produkt abgetrennt werden könnten und somit die Aufreinigung des Produkts erschweren. Nachfolgend wird im Schritt 4 der trivalente Phosphittriester mit wässriger Jod-Lösung zum pentavalenten Phosphortriester oxidiert. Dieser Schritt ist notwendig, da der trivalente Phosphittriester instabil gegen basische und sauere Reaktionen, die danach in den nächsten Synthesezyklen erfolgen, ist. Anschließend beginnt ein neuer Synthesezyklus mit der Detritylierung der 5`-OHFunktion. Diese Reaktionsfolge wird solange wiederholt, bis die gewünschte DNASequenz synthetisiert wurde. Die Synthese der DNA verläuft damit von der 3`- zur 5`Position. Die exozyklischen Aminfunktionen der Heterobasen von allen verwendeten Phosphoamiditen, mit Ausnahme des Amidits vom Desoxythymidin, sind geschützt, um die Reaktion der aktivierten Phosphoamidite mit den Aminfunktionen der Basen zu verhindern. 
Kapitel 3: Synthese und Selbstorganisation von Perylen-Oligonucleotid-Konjugaten

Nach Beendigung der Synthese erfolgt die Abspaltung des hergestellten Oligonucleotides vom Trägersupport mit konzentrierter Ammoniumhydroxid-Lösung (28-32 \%). Dabei werden die Esterfunktion am 3'-Ende des synthetisierten Oligonucleotides und damit die Verknüpfungsstelle zum Träger (Festphase) gespalten und gleichzeitig die Phosphatschutzgruppen abgetrennt. Die weitere Abspaltung der exozyklischen Aminschutzgruppen der Basen (Deacylierung) erfordert eine Anschließende Inkubation bei erhöhter Temperatur $\left(55^{\circ} \mathrm{C}\right)$. Eine Aufreinigung der synthetisierten Oligonucleotide ist erforderlich. Sie wird normalerweise mit Hilfe von RP-, Ionenaustausch-HPLC oder Gelelektrophorese, auf die in den kommenden Abschnitten dieses Kapitels eingegangen wird, durchgeführt. 


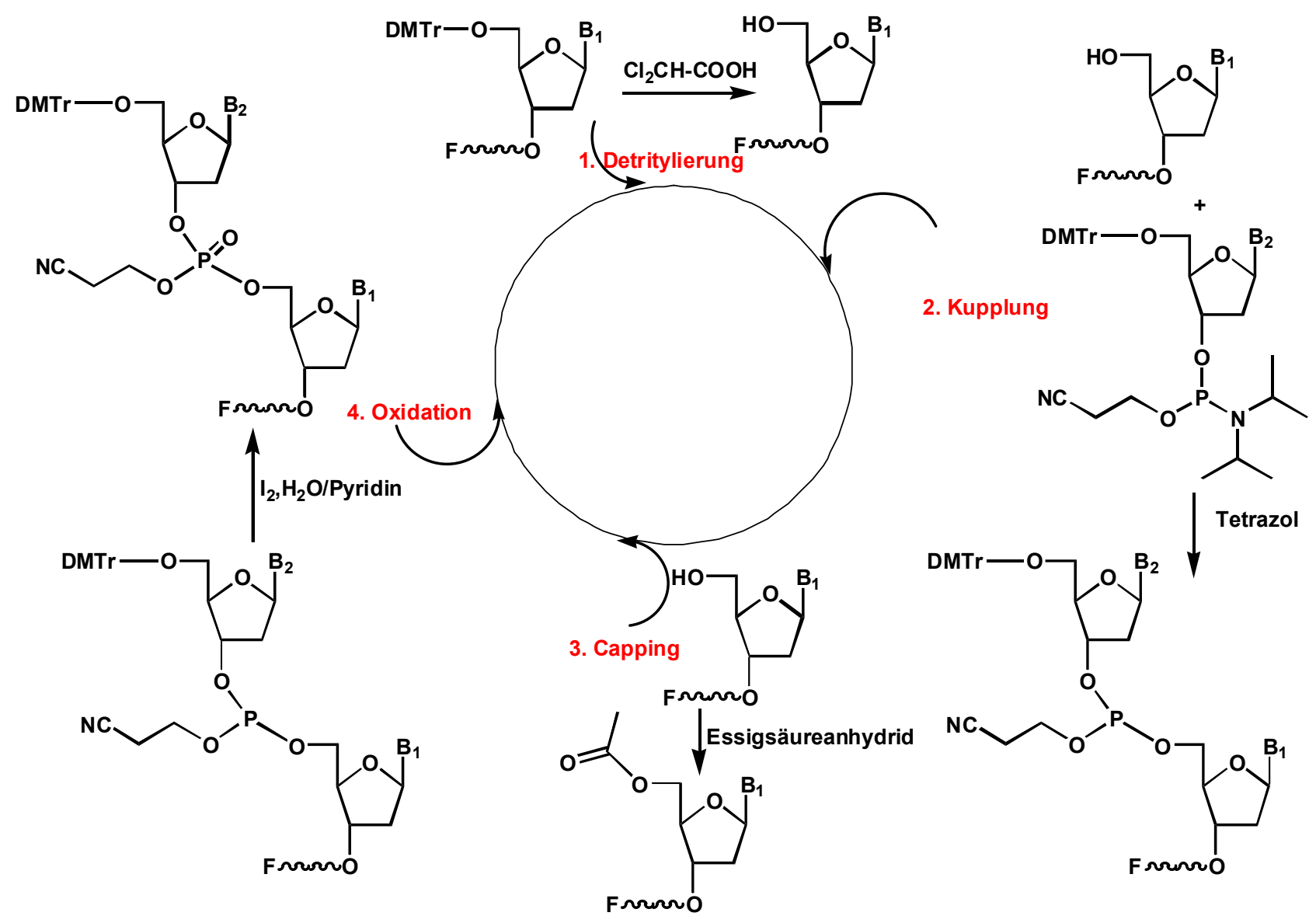

Abbildung 18: Der chemische Synthesezyklus eines Oligonucleotides nach dem automatisierten Festphasenverfahren (die Phosphoamidit-Methode)

Das 3`-Nucleotid wird zunächst an einen inerten Träger verknüpft, den man dann in eine Reaktionssäule füllt. Das Oligonucleotid wächst durch einen Vier-Schritt-Prozess jeweils um ein Nucleotid in $3^{`} \rightarrow 5^{`}$ Richtung. Im ersten Schritt (Detritylierung) entfernt man im saueren Medium die Dimethoxytrityl-(DMTr)Gruppe, die Schutzgruppe für die 5`-OH-Position. Anschließend wird das aktivierte Phosphoamidit (Nucleotid 2) zugegeben. Die 5'-OH-Gruppe des Nucleotids 1 reagiert mit dem 3'-gebundenen und aktivierten Phosphoamidit des Nucleotids 2. Im dritten Schritt (Capping) werden die nicht umgesetzten 5 OH-Gruppen mit Essigsäureanhydrid blockiert. Schließlich wird im vierten Schritt (Oxidation) das instabile dreiwertige Phosphit zum stabilen fünfwertigen Phosphat oxidiert. Damit ist der erste Zyklus abgeschlossen und der Synthesevorgang kann wiederholt werden bis die gewünschte Sequenz synthetisiert wurde. Am Ende spaltet man das fertige Oligonucleotid vom Träger ab und entfernt die Basen- und Phosphatschutzgruppen. 


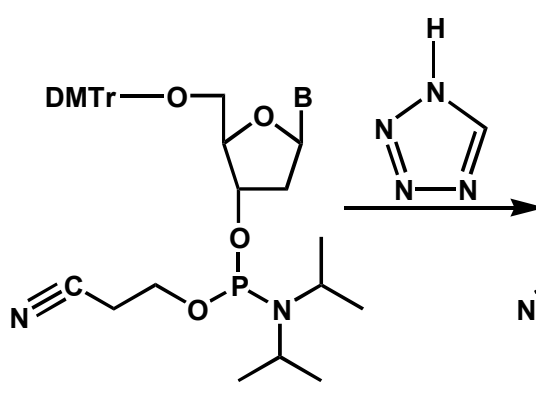

3-1

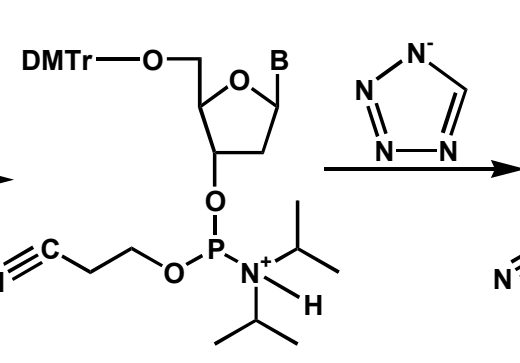

3-2

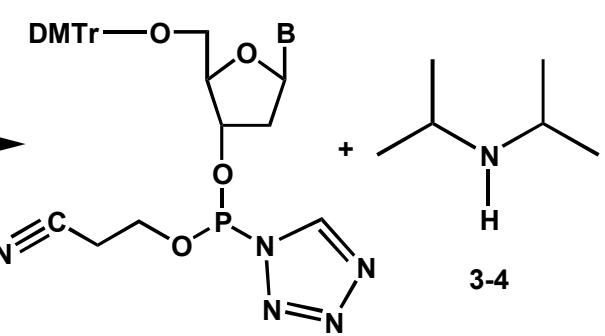

3-3

Abbildung 19: Die Aktivierung des Phosphoamidits mit Tetrazol

Durch den Einsatz modifizierter Amidite kann eine Vielzahl von Oligonucleotiden, die an der 3'- oder 5'-Positionen oder auch an Positionen innerhalb der Sequenz eine Modifikation tragen, synthetisiert $\operatorname{werden}^{46}$. So lassen sich zum Beispiel Oligonucleotidsequenzen mit einer Aminfunktion an der 3`-, 5'-Positionen oder auch innerhalb der Sequenz herstellen. Auch die Anbindung von Fluoreszenzfarbstoffen oder Biotin an Oligonucleotide ist bei der Synthese durch die Verwendung von Farbstoff- oder Biotinamiditen zugänglich, vorausgesetzt, solche Amidite lösen sich in Acetonitril, dem bei der Festphasensynthese verwendeten Lösungsmittel. Oligonucleotide, die mit Fluoreszenzfarbstoffen markiert sind, werden unter anderem in Diagnostik und Genanalyse eingesetzt, Biotin-markierte Sequenzen werden zum Beispiel als Primer in biochemischen Reaktionen, in denen eine Komplexbildung zwischen dem mit Biotin markierten Oligonucleotid und Streptavidin vorgesehen ist, verwendet ${ }^{47-49}$.

\subsubsection{Trägerauswahl für die DNA-Festphasensynthese}

Die Träger für die Festphasensynthese von DNA bestehen in der Regel aus einem 5 -Otritylierten Nucleosid, das über eine basenlabile Bindung an einen aliphatischen Spacer gebunden ist, der seinerseits mit dem Träger kovalent verknüpft ist. Als Träger für die automatisierte DNA-Synthese werden üblicherweise Polystyrol/divinylbenzol- oder CPGbeads $^{43-44,50}$, welche über einen langen Spacer (LCAA, long chain alkylamin) mit dem Nucleosid funktionalisiert sind, eingesetzt. Die Länge des verwendeten Spacers und die 
Porengröße des Trägers haben bei der DNA-Synthese einen erheblichen Einfluss auf die Beladung der Festphase. Unter der Beladung des Trägermaterials versteht man die Zahl der gekoppelten Basen pro Gewichtseinheit des Trägers. Sie wird in der Regel in $\mu \mathrm{mol} / \mathrm{g}$ angegeben. Um einen Polystyrol/divinylbenzol-Träger mit der Starterbase funktionalisieren zu können, wird ein mit einer Aminogruppe funktionalisiertes Polymer eingesetzt. Dies erfolgt wie bei CPG durch die Kopplung von Bernsteinsäure mit der Starterbase (Abb. 20).

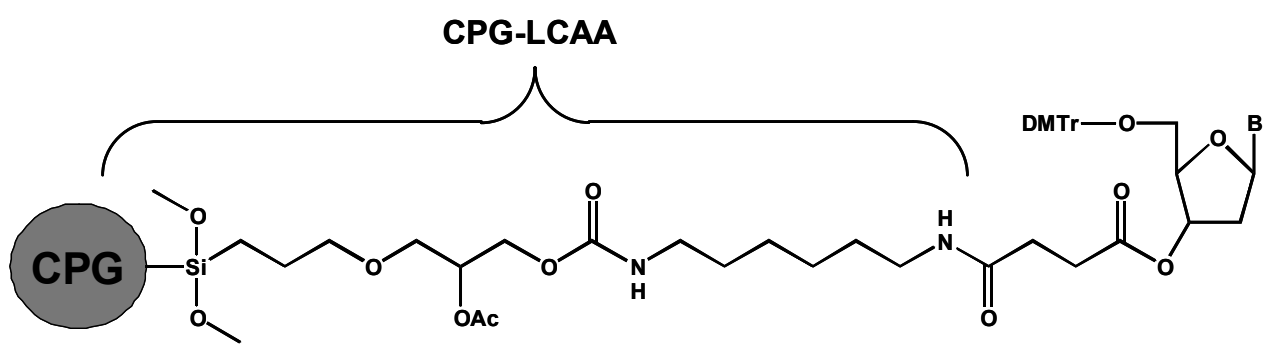

3.5

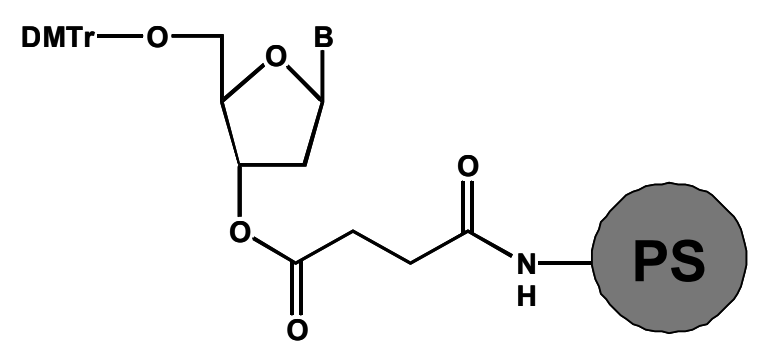

3.6

Abbildung 20: Die Struktur von CPG-LCAA- und Polystyrol/divinylbenzol-Trägern, die jeweils mit mit einem Nucleosid funktionalisiert ${ }^{51}$

Da die DNA-Festphasensynthese von $3^{`}$ - in $5^{`}$-Richtung verläuft, stellt das auf der Festphase gebundene Nucleosid das 3`- Ende des hergestellten Oligonucleotides dar. Dies muss bei der Wahl der zu synthetisierenden Oligonucleotidsequenz berücksichtigt werden. Eine Synthese von längeren Oligonucleotiden gelingt an der Festphase nur dann, wenn diese eine entsprechende Porengröße besitzt. Bei der Synthese kann es zu einer sterischen Behinderung durch die große räumliche Dichte der wachsenden Oligonucleotidsequenzen kommen, was zu einer Verstopfung der Poren führen kann. Deshalb müssen bei der 
Synthese von Oligonucleotiden mit einer Länge von mehr als 40 Basen Träger mit einer Porengröße von $1000 \AA$ eingesetzt werden. In Abbildung 21 ist AFM-Bild vom Träger aus Polystyrol/Divinylbenzol gezeigt.

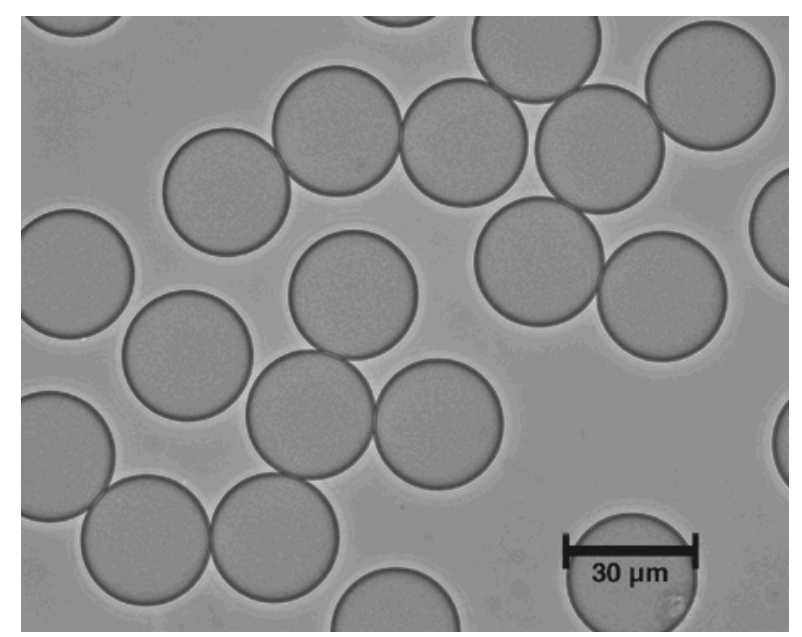

Abbildung 21: AFM-Bild von Polystyrol/divinylbenzol-Träger gequollen in Acetonitril $^{60}$

Seit längerer Zeit werden modifizierte Spacer verwendet, um Oligonucleotide zu synthetisieren, die an ihrer $5{ }^{`}$ - oder $3^{`}$-Position eine chemische Modifikation tragen. Auf diesem Weg konnte man entsprechende Oligonucleotide synthetisieren, die mit Amin-, Thio-, Aldehyd- oder Phosphatgruppen an den unterschiedlichen Enden funktionalisiert sind. So wurden Oligonucleotide mit funktionellen Gruppen zugänglich, die zur Verknüpfung von Oligonucleotiden mit organischen Verbindungen notwendig sind. Allerdings müssen bei der Einführung des modifizierten Spacers Änderungen am Synthesizerprotokoll vorgenommen werden, um die Kopplung des Modifikationsmoleküls an den $\mathrm{OH}-$ Terminus des Oligonucleotids mit maximaler Ausbeute zu erhalten.

Zur Abspaltung des Oligonucleotides vom Träger kann man die Festphase z. B. 17 h bei $55^{\circ} \mathrm{C}$ mit Ammoniak- oder Methylaminlösung behandeln. In dieser Arbeit wurde eine Ammoniaklösung (32\%) verwendet. 


\subsubsection{Die Monomere in der Festphasen-DNA-Synthese}

Für die chemische Synthese von Oligonucleotiden bedarf es einer orthogonalen Schutzgruppenstrategie. Zu den wichtigsten Eigenschaften dabei zählt die Stabilität der Schutzgruppe während der folgenden Reaktionen und der Aufreinigungen. Außerdem müssen sie selektiv und quantitativ abgespalten werden können. Zusätzlich sollten die Basen, Zucker- und Phosphatschutzgruppen kostengünstig, wenig toxisch und vom Produkt gut aufzutrennen sein.

Für den Schutz der exozyklischen Aminogruppen an den Basen haben sich die am meisten verwendeten und basenlabilen Acylschutzgruppen bewährt ${ }^{52-53}$. Der Einsatz der von Khorana eingeführten Isobutyryl- und Benzoylgruppen zum Schutz der exozyklischen Aminofunktionen von Adenin, Guanin und Cytosin geht auf die Entwicklung der Phosphodiestermethode zur Synthese von Oligonucleotiden zurück ${ }^{54}$. Dabei wird die Aminogruppe des Adenin und des Cytosin benzoyliert und die des Guanin isobutyryliert. Die Thymidinbase enthält keine Aminofunktionen und muss daher nicht geschützt werden. Die durch die Einführung dieser Schutzgruppen entstehenden Amidbindungen besitzen eine große Stabilität, so dass eine Abspaltung nur unter harten Bedingungen zugänglich ist $\left(17 \mathrm{~h}\right.$ in konzentrierter Ammoniaklösung bei $55{ }^{\circ} \mathrm{C}$ in verschlossenen Gefäßen). In Abhängigkeit vom G-Gehalt der hergestellten Oligonucleotidsequenz müssen die Bedingungen der Entschützung verändert werden, um die sehr stabilen Isobutyrylgruppen von dem Desoxyguanosinresten quantitativ abzuspalten $^{55}$.

Die 5'-OH-Funktion der Zuckereinheit muss weiterhin mit einer im Laufe des Synthesezyklus selektiv und quantitativ abspaltbaren Schutzgruppe blockiert werden. In der hier beschriebenen Synthese wird die säurelabile Bis(4-methoxyphenyl)phenylmethylgruppe (Dimethoxytrityl-, DMTr-) verwendet ${ }^{56}$. Sie kann selektiv in die gewünschte Position eingeführt werden. Aufgrund ihrer chromatographischen 
Eigenschaften kann man das geschützte Nucleosid sehr gut aufreinigen. Außerdem ermöglicht die DMTr-Gruppe wegen ihrer lipophilen Eigenschaften die Aufreinigung der hergestellten Oligonucleotidsequenzen mit Hilfe von RP-HPLC. Die DMTr-Gruppe besitzt im Vergleich zur unsubstituierten Tritylverbindung eine erhöhte Säurelabilität, die zu deutlich verkürzten Synthesezyklen und einer Minimierung der Depurinierungsgefahr führt.

Für das Phosphor-III-Atom wird die Cyanoethoxyschutzgruppe eingesetzt, die sich im Gegensatz zu anderen Phosphatschutzgruppen leicht und selektiv in Ammoniaklösung als Acrylnitril eliminieren lässt. Dabei greift das Ammoniak am $\beta$-C-Atom und nicht am Phosphor an, so dass ein Bruch der Oligonucleotidkette ausgeschlossen werden kann.

\subsubsection{Exozyklische Aminschutzgruppen : Benzoyl- und Isobutyryl- Gruppe}

Zur selektiven Einführung der Aminschutzgruppe werden zunächst die Hydroxygruppen der Zuckereinheit temporär als Trimethylsilylester geschützt ${ }^{57}$. Die erhaltenen Desoxynucleoside werden danach ohne weitere Aufreinigungsschritte mit dem Acylierungsreagenz (Benzoylchlorid im Falle von Adenosin und Cytidin, Isobuttersäureanhydrid im Falle von Guanosin) versetzt (Abb. 22). Die Hydrolyse der Trimethylsilylgruppen erfolgt Anschließend mit verdünnter Ammoniaklösung. Dabei wird das entstandene Nebenprodukt N,N`-Dibenzoyldesoxynucleosid in das gewünschte monoacylierte Produkt überführt. 


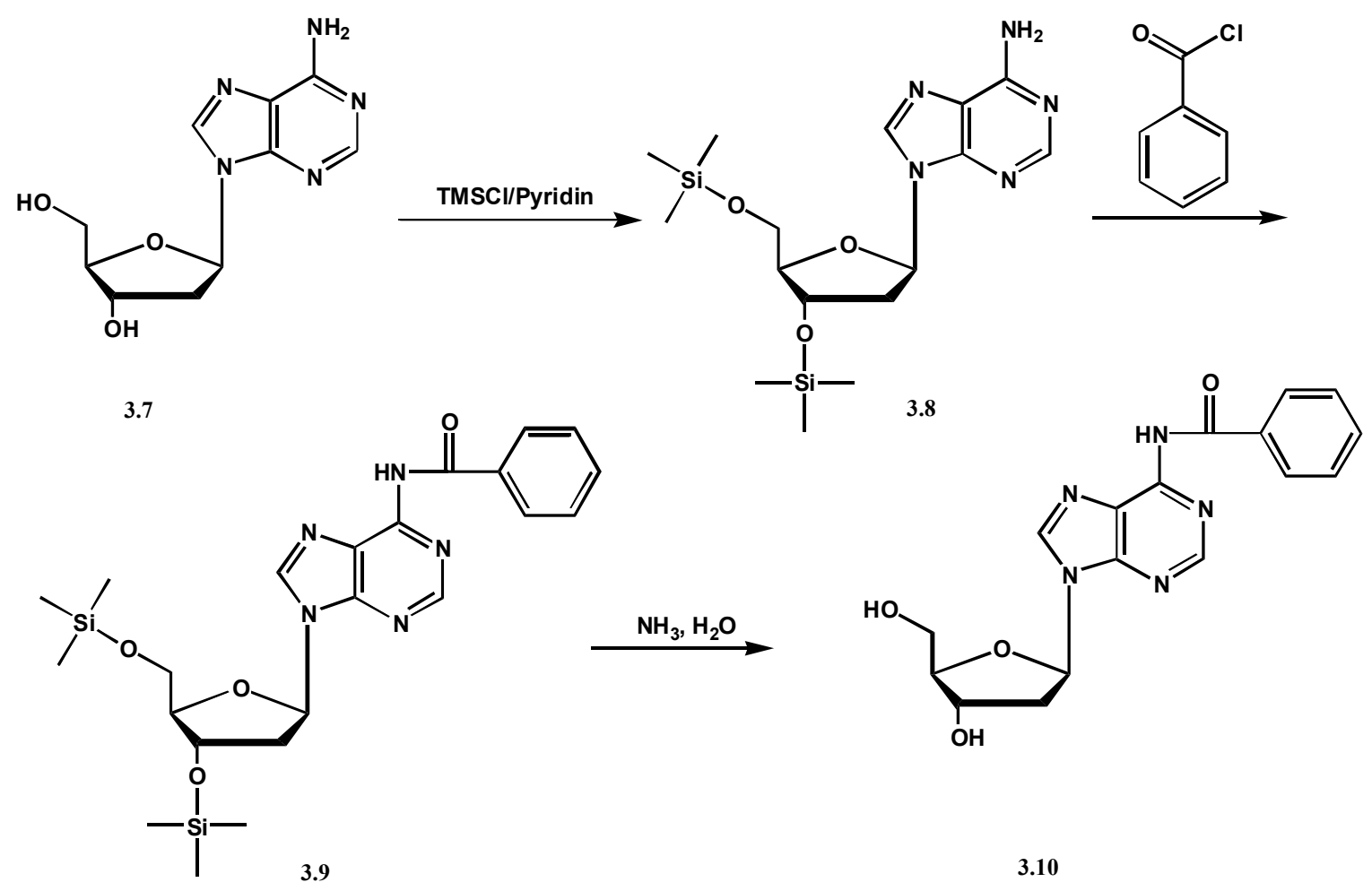

Abbildung 22: Einführung der exozyklischen Aminoschutzgruppe: als Beispiel (Benzoyl-) bei 2'-Desoxyadenosin

\subsubsection{Einführung der 5'-OH-Schutzgruppe (DMTr-)}

Die aminogeschützten Nucleoside können dann mit 4,4`-Dimethoxytritylchlorid (DMTrChlorid) selektiv in der $5^{\prime}$-Position als Ether geschützt werden (Abb. 23). Die Umsetzung erfolgt in Pyridin bei Raumtemperatur. Das erhaltene Produkt kann chromatographisch aufgereinigt werden. 
<smiles>O=C(Nc1ncnc2c1ncn2[C@H]1C[C@@H](O)[C@@H](CO)O1)c1ccccc1</smiles>

3.11
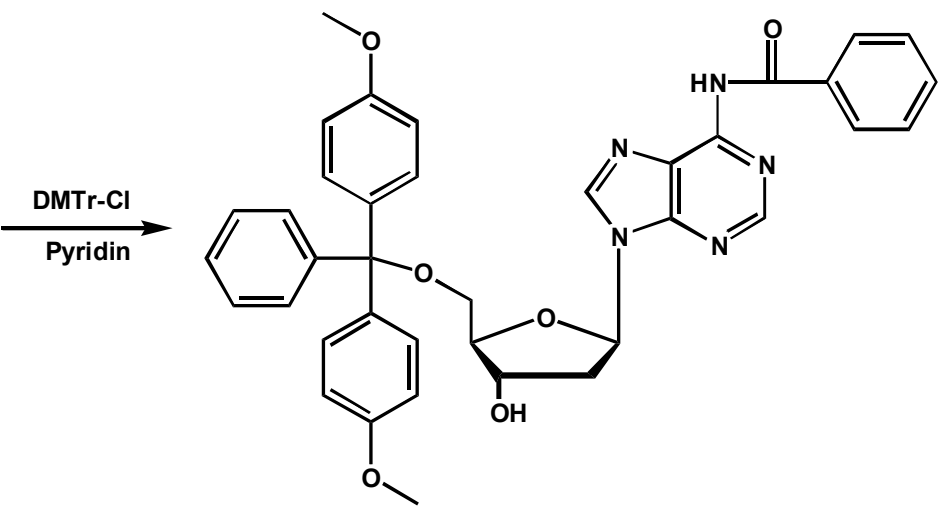

3.12

Abbildung: 23: Schutz der 5`-Hydroxyfunktion des aminogeschützten 2`-Desoxynucleosides mit der DMTr-Gruppe

Im Falle von 2'-Desoxyguanosin wird bei der Acylierung das Isobutyrylchlorid anstelle des Benzoylchlorides verwendet. Beim Thymidin ist die Einführung einer Aminoschutzgruppe unnötig, da es keine Aminogruppe in seiner Struktur enthält (Abb. 24).

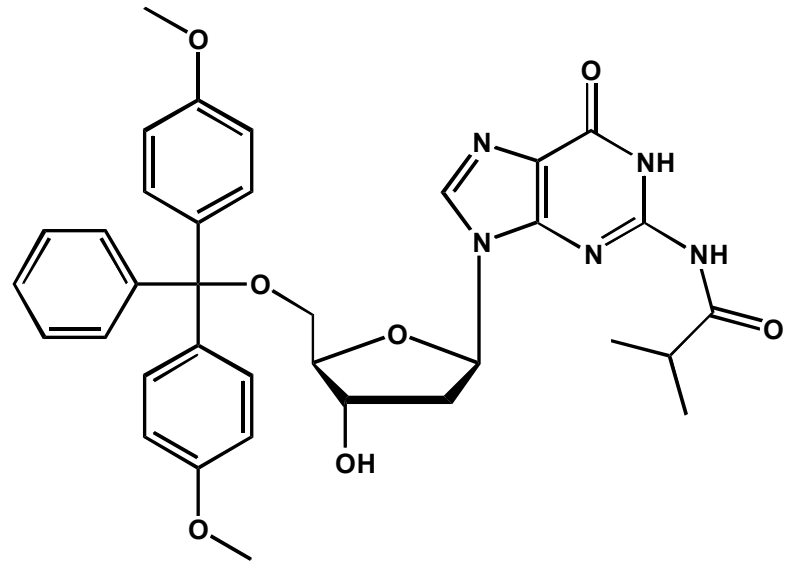

3.13

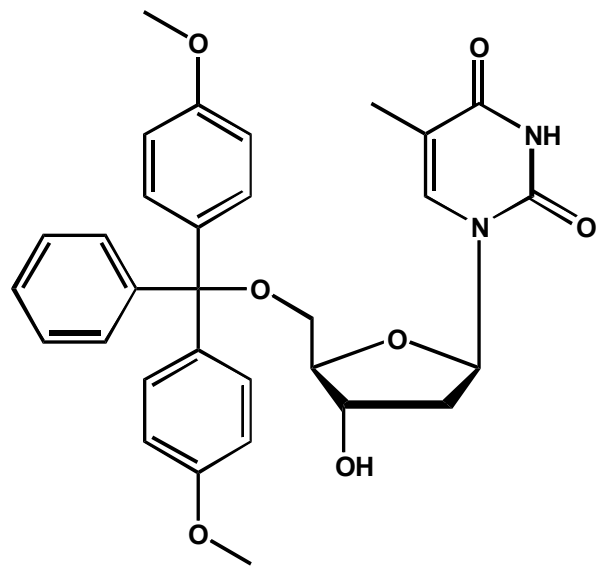

3.14

Abbildung 24: Struktur der geschützten Guanosin- und Thymidinbasen

\subsubsection{Einführung der Phosphoamiditgruppe}

Die Synthese der reaktiven $N, N$-Diisopropyl-cyanoethoxy-phosphoramiditen ist der letzte Schritt zur Herstellung der Monomere, die in der DNA-Festphasensynthese eingesetzt werden. Das geschützte Nucleosid muss vorher im Hochvakuum getrocknet werden. 
Spuren von Wasser können zur Hydrolysierung der Phosphitylierungsreagenz und damit $\mathrm{zu}$ verminderten Ausbeuten bei diesem Syntheseschritt führen. Als Phosphitylierungsreagenz wird Monochlor-N,N-diisopropylamino- $\beta$-cyanoethoxyphosphin in Anwesenheit von DIPEA eingesetzt (Abb. 25). Die Verwendung eines sterisch anspruchsvollen Amins ( $N, N$-Diisopropylamin) anstelle von z.B. der $N, N$ Dimethylaminogruppe erleichtert die Synthese der reaktiven Monomeren erheblich. Die $N, N$-Diisopropylamingruppe ermöglicht neben größerer Stabilität gegen Luftoxidation und Hydrolyse eine wesentlich bessere Löslichkeit des gebildeten Amidits ${ }^{58}$.

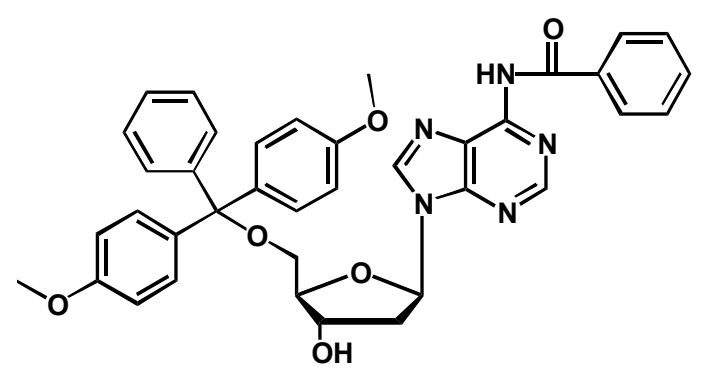

3.15

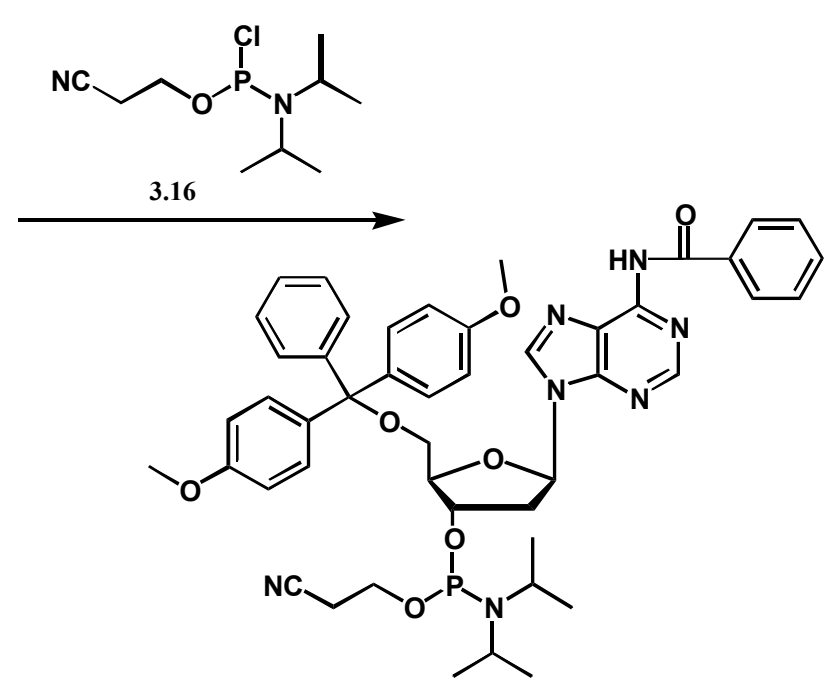

3.17

Abbildung 25: Schematische Darstellung der Einführung der Phosphoamiditgruppe am Beispiel des 2'-Desoxyadenosinphosphoramidit

\subsection{Synthese von Perylendiimid-bis(oligonucleotid)-konjugaten}

Für den Aufbau von DNA-Perylen-Polymeren werden zwei unterschiedliche und komplementäre Perylendiimid-bis-(oligonucleotid)-konjugate benötigt. Um dieses Ziel zu erreichen, müssen zwei komplementäre Oligonucleotidsequenzen synthetisiert und mit dem Perylendiimid verknüpft werden. Für diese Kopplungsreaktion war die Funktionalisierung des Oligonucleotides und des Perylens mit geeigneten funktionellen Gruppen erforderlich. Zunächst wurde die Aktivester-Amin-Kopplung für die Synthese 
der Konjugate gewählt, da die Spacer mit einer Aminfunktion kostengünstiger als anderweitig funktionalisierte Produkte sind. Im folgenden Abschnitt werden die Synthese und Charakterisierung vom Perylendiimid mit zwei Aktivestern in der Imidstruktur dargestellt.

\subsubsection{Synthese eines Perylendiimid-dicarbonsäurederivats}

Ausgehend vom industriell erhältlichen 1,6,7,12-Tetrachlorperylen-3,4:9,10tetracarbonsäuredianhydrid erfolgt die Imidisierung mit 4-Brom-2,6diisopropylphenylamin, einem sterisch anspruchsvollen Amin, dessen Synthese in der Literatur bereits beschrieben wurde ${ }^{59}$. Der Einsatz dieses Amins dient nicht nur zur Verbesserung der Löslichkeit, sondern auch zu einer erhöhten Beständigkeit des synthetisierten Perylendiimids gegen Verseifung. Dabei wird das Edukt 3-18 mit 6 Äquivalenten 4-Brom-2,6-diisopropylphenylamin (3-19) in Propionsäure bei Siedetemperatur zur Reaktion gebracht. Die Reaktionszeit beträgt 15 Stunden. Danach lässt man das Reaktionsgemisch auf Raumtemperatur abkühlen, wobei das Produkt 3-20 ausfällt. Das Produkt wird filtriert und mit einem Lösungsmittelgemisch aus Methanol/Wasser mehrmals gewaschen. Die Aufreinigung des mit 89\%iger Ausbeute erhaltenen Produkts erfolgte durch Säulechromatographie an Kieselgel mit Toluol als Eluent. 


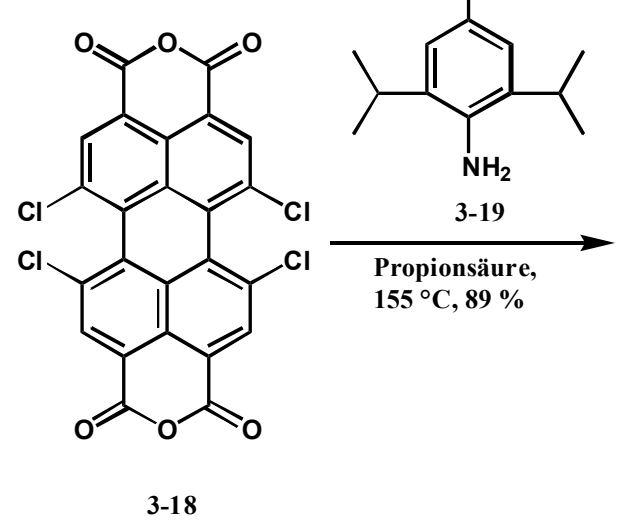

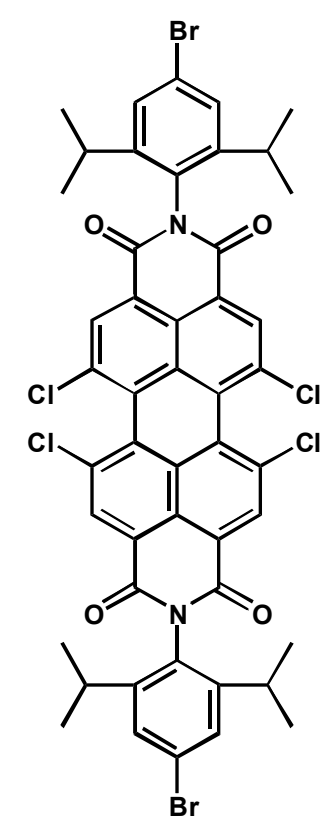

3-20

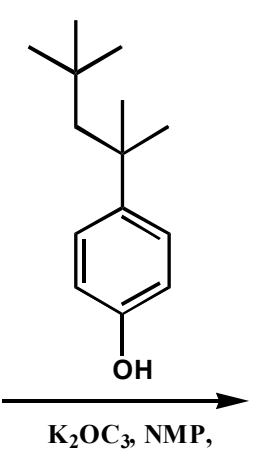

$80{ }^{\circ} \mathrm{C}, 66 \%$<smiles>[R]Oc1cc2c(=O)n(-c3c(C(C)C)cc(Br)cc3C(C)C)c(=O)c3cc(O[R])c4c5c(O[R])cc6c(=O)n(-c7c(C(C)C)cc(Br)cc7C(C)C)c(=O)c7cc(O[R])c(c1c2c34)c5c76</smiles>

3-21

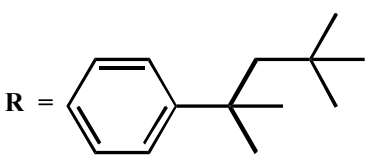

Abbildung 26: Darstellung von $\quad N, N^{\prime}$-bis(4-brom-2,6-diisopropylphenyl)-1,6,7,12tetraphenoxyperylen-3,4:9,10-tetracarbonsäurediimid (3-21)

Die Löslichkeit vom 3-20 in organischen Lösungsmitteln war nicht ausreichend. Zur Verbesserung der Löslichkeit bieten sich die Phenoxylierung mit sterisch anspruchsvollen Substituenten in die bay-Region an. Als Substituent wird das kommerziell verfügbare tert-Octylphenol eingesetzt. 3-20 wird mit 10 Äquivalenten tert-Octylphenol und 6 Äquivalenten Kaliumcarbonat in N-Methylpyrrolidon (NMP) zur Reaktion gebracht. Man lässt das Reaktionsgemisch 20 Stunden bei $80{ }^{\circ} \mathrm{C}$ unter Argonatmosphäre rühren und danach auf Raumtemperatur abkühlen. Die Aufarbeitung des abgekühlten Reaktionsgemisches erfolgte mit verdünnter Salzsäurelösung (0.25 Teil konz. Salzsäure, 3 Teile Methanol, 1 Teil destilliertes Wasser). Das ausgefällte Produkt wurde filtriert und im Vakuum getrocknet. Anschließend wurde eine säulechromatographische Aufreinigung mit einem Lösungsmittelgemisch aus Dichlormethan/Petrolether (1:1.5) als Eluent durchgeführt, aus dem man das Produkt 3-21 mit 66\%er Ausbeute erhielt. 
Kapitel 3: Synthese und Selbstorganisation von Perylen-Oligonucleotid-Konjugaten

Die Struktur der Verbindungen 3-20 und 3-21 lässt sich mit Hilfe von Massenspektrometrie, Elementaranalyse, ${ }^{1} \mathrm{H}$ - und ${ }^{13} \mathrm{C}-\mathrm{NMR}-$ Spektroskopie nachweisen. Die hohe Symmetrie der beiden Verbindungen vereinfacht die Zuordnung der Signale. Die Anzahl, Intensität und Lage der Signale im ${ }^{1}$ H-NMR-Spektrum stimmen mit den erwarteten Peaks für die angenommene Struktur überein (siehe experimentellen Teil).

Die Einführung von zwei Methyl-geschützten Carbonsäure-Gruppen in die Imidstruktur von 3-21 erfolgte durch eine Suzuki-Kopplung. Die Verknüpfung der kommerziell erhältlichen 4-Methoxycarbonyl-phenylboronsäure mit N,N`-Bis(4-brom-2,6diisopropylphenyl)-1,6,7,12- tetraphenoxyperylen-3,4:9,10-tetracarbonsäurediimid (3-21) wurde in einem Lösungsmittelgemisch bestehend aus Toluol, $2 \mathrm{M} \mathrm{K}_{2} \mathrm{CO}_{3}$ und Ethanol bei $75{ }^{\circ} \mathrm{C}$ und 15 Stunden Reaktionszeit durchgeführt. Die mit $\mathrm{Pd}\left(\mathrm{PPh}_{3}\right)_{4}$ katalysierte Reaktion wurde unter Inertgasbedingungen durchgeführt. Die Aufreinigung erfolgte säulenchromatographisch mit einem Lösungsmittelgemisch aus Dichlormethan und Petrolether als Eluent (für genauere Angaben siehe Experimenteller Teil). Die Ausbeute des als dunkelroten Produkts 3-22 beträgt $93 \%$. 


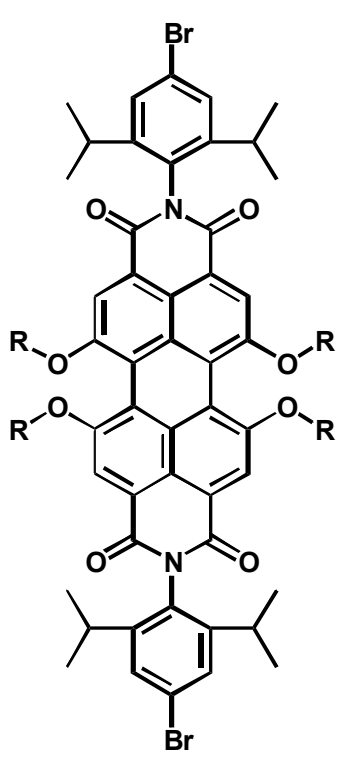

3-21

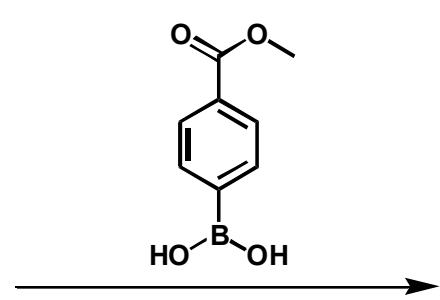

$\mathrm{Pd}\left(\mathrm{PPh}_{3}\right)_{4}, 2 \mathrm{M} \mathrm{K}_{2} \mathrm{CO}_{3}$,

Methanol, Toluol, $75^{\circ} \mathrm{C}, 93 \%$

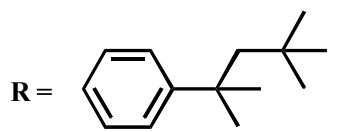<smiles></smiles>

Abbildung 27: Synthese vom Perylendiimids mit zwei geschützten Carbonsäure-Gruppen 3-22

Der Strukturbeweis der Verbindung 3-22 stütz sich auf die korrekte Elementaranalyse, auf das Maldi-Tof-Massen- und das ${ }^{1}$ H-NMR-Spektrum. Der bei des Maldi-Tof-MS erhaltene Peak (Abb. 28) entspricht genau dem berechneten Molekulargewicht von Verbindung 3-22 $\left(\mathrm{M}_{\mathrm{ber}}=1796.35 \mathrm{~g} / \mathrm{mol}\right)$. 


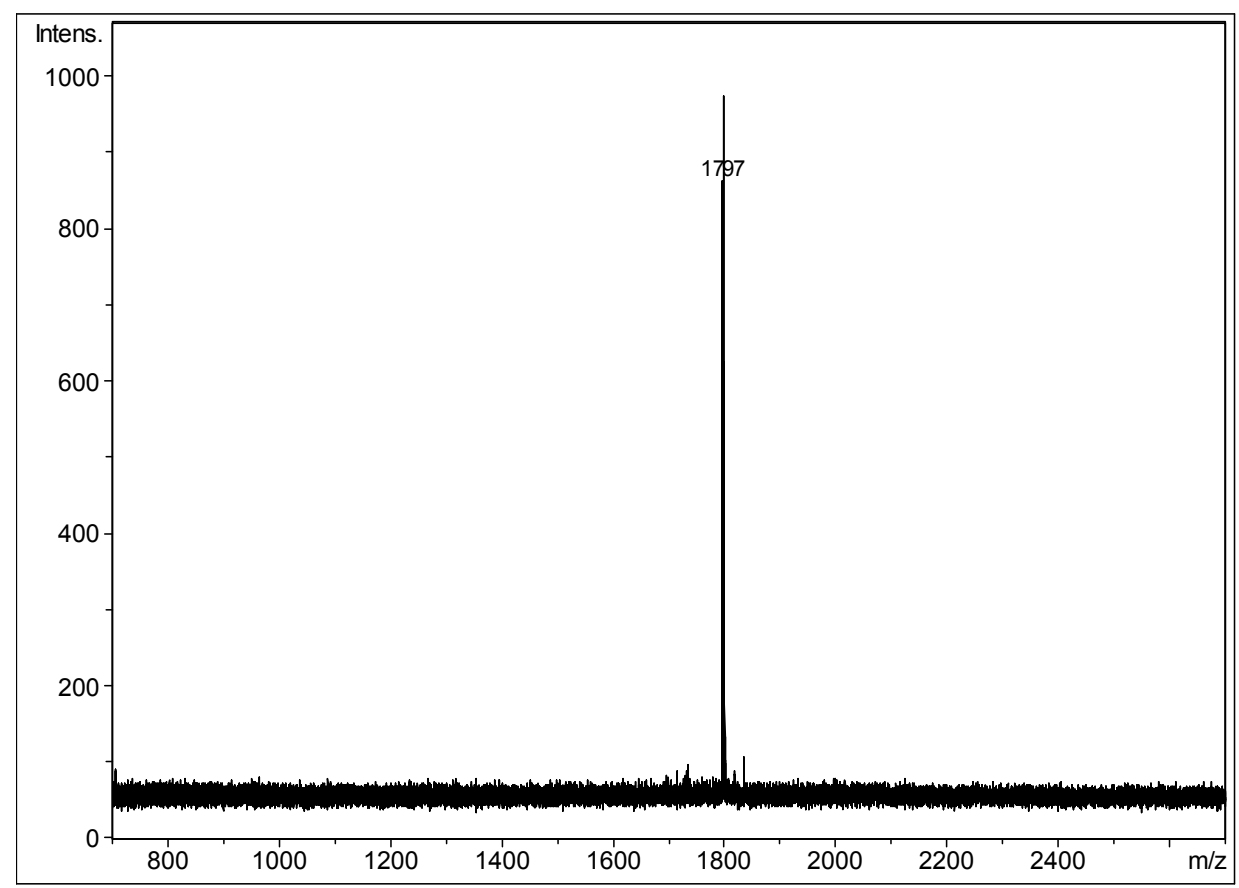

Abbildung 28: Maldi-Tof-Analyse von Verbindung 3-22, $\mathrm{M}_{\mathrm{ber}}=1796.35 \mathrm{~g} / \mathrm{mol}$

Im ${ }^{1} \mathrm{H}-\mathrm{NMR}-$ Spektrum von 3-22 erscheinen die Protonen des Substituenten des PDIChromophors in der bay-Region $\left(\mathrm{H}_{\mathrm{e}, \mathrm{f}}\right)$ zwischen 7.38 und $6.94 \mathrm{ppm}$. Zwischen 8.15 und 8.11 ppm absorbieren die Protonen $\mathrm{H}_{\mathrm{d}}$, die von den Protonen $\mathrm{H}_{\mathrm{a}}$ des Perylens überlagert sind. Das Dublett bei 7.78 ppm entspricht den Protonen $\mathrm{H}_{\mathrm{c}}$. Bei $7.54 \mathrm{ppm}$ treten die Protonen $\mathrm{H}_{\mathrm{b}}$ in Resonanz. Im aliphatischen Bereich treten die Signale der Isopropylgruppen als Septett $\left(\mathrm{H}_{\mathrm{h}}\right)$ bei $2.85 \mathrm{ppm}$ und als Dublett $\left(\mathrm{H}_{\mathrm{i}}\right)$ bei $1.15 \mathrm{ppm}$ in Erscheinung. Das Signal bei 3.93 ppm entspricht den Protonen der Methylschützgruppe der Carbonsäurefunktion. Bei 1,75, 1,38 und $0.76 \mathrm{ppm}$ erscheinen die Signale der Methylgruppen bzw. die Methylengruppe des Phenoxy-Substituenten in der bay-Region $\left(\mathrm{H}_{\mathrm{j}, \mathrm{m}}\right.$ bzw. $\left.\mathrm{H}_{\mathrm{k}}\right)$. 


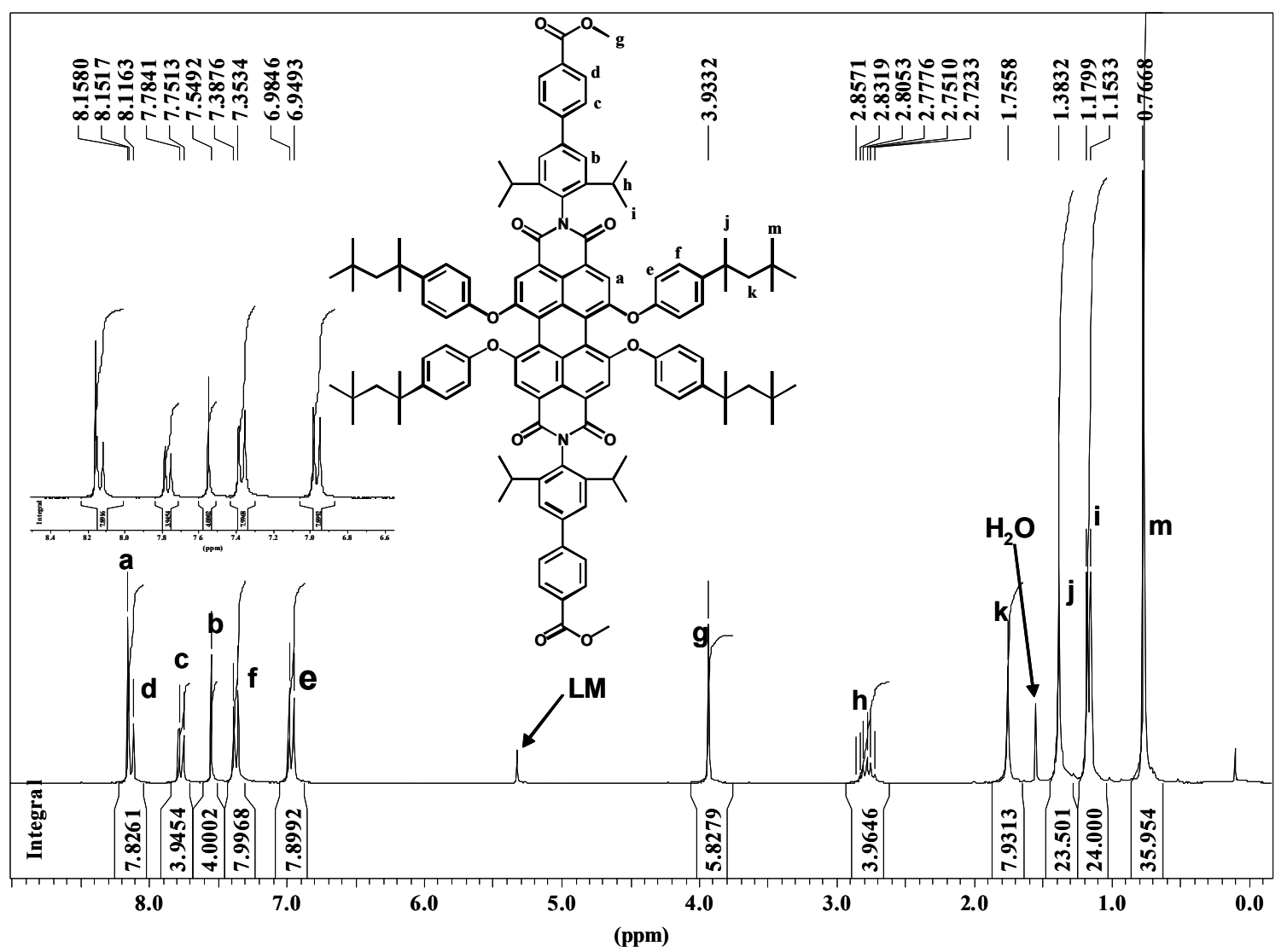

Abbildung 29: ${ }^{1} \mathrm{H}-\mathrm{NMR}-$ Spektrum mit Zuordnung der Signale von Verbindung 3-22 ( 250-MHz, Lösungsmittel: $\mathrm{CD}_{2} \mathrm{Cl}_{2}$ ). Oben: Vergrößerter Ausschnitt des aromatischen Bereichs

Anschließend wurde 3-22 in THF und KOH-Lösung (20 Äquivalente $\mathrm{KOH}$ in $2 \mathrm{ml}$ Wasser) bei $80^{\circ} \mathrm{C}$ nach 24 Stunden Reaktionszeit nahezu quantitativ in die freie Säure 323 überführt. Während der Reaktion wurden nach 12 Stunden geringe Mengen an Wasser zugefügt, um das ausgefallene Produkt wieder in Lösung zu bringen. Die vollständige Spaltung des zweifachen Esters lässt sich gut durch Dünnschichtchromatographie (DC) mit Dichlormethan als Eluent feststellen. Nach der Abkühlung des Reaktionsgemisches wurde die entschützte Perylendiimiddicarbonsäure in $2 \mathrm{M}$ HCl-Lösung gefällt und ohne zusätzliche chromatographische Aufreinigungsschritte weiter verwendet. 

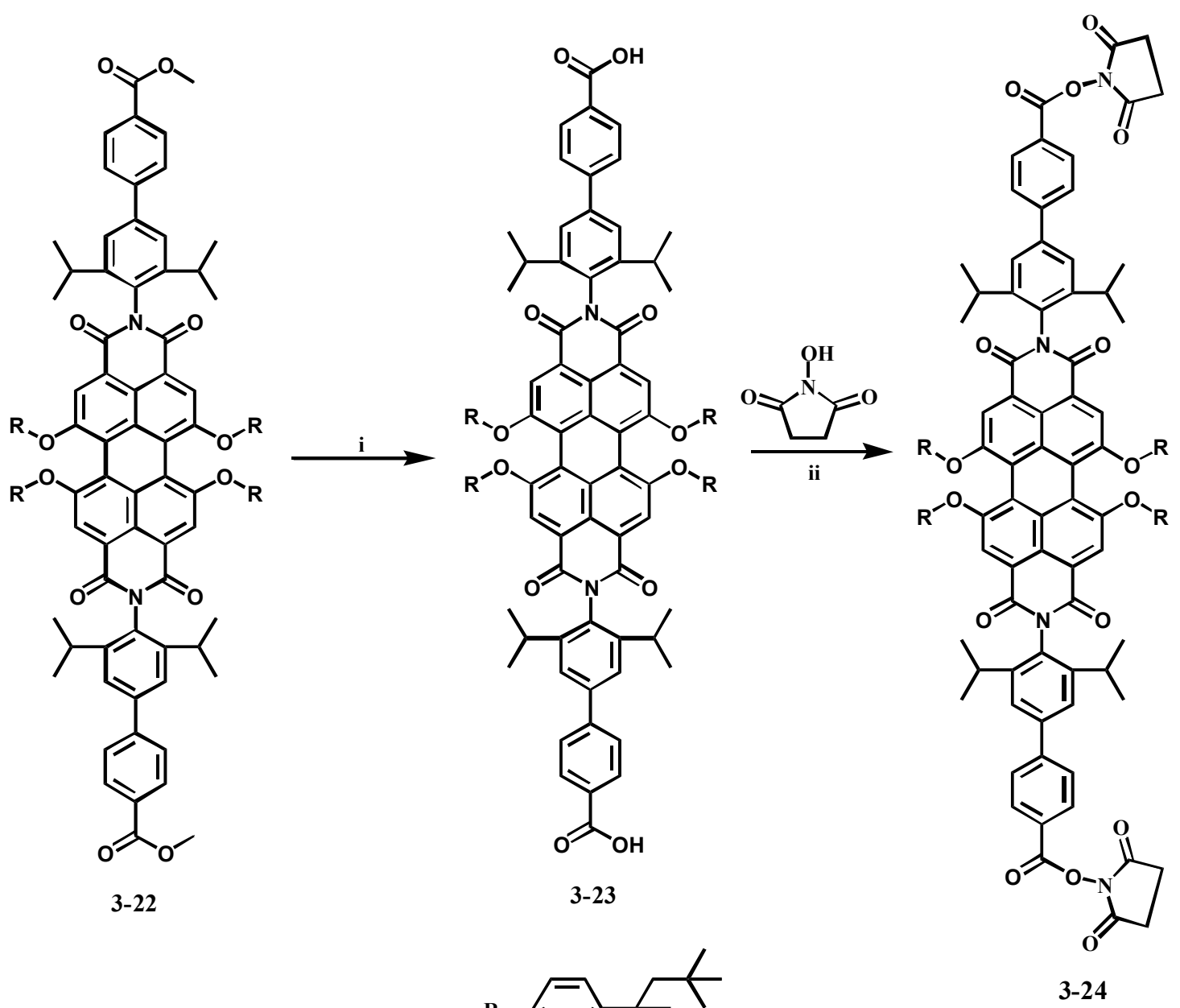

Abbildung 30: Synthese eines Perylendiimid-Chromophors mit zwei Carbonsäurefunktionen, i) 20 Äquivalente $\mathrm{KOH}$ gelöst in $2 \mathrm{ml} \mathrm{H}_{2} \mathrm{O}$, THF, 24 Stunden, $80^{\circ} \mathrm{C}, 96 \%$ ii) $N$-Hydroxy-succinimid, Dicyclohexylcarbodiimid (DCC), DMF, $35^{\circ} \mathrm{C}, 48$ Stunden, $100 \%$

Das ${ }^{1}$ H-NMR-Spektrum vom 3-23 (Abbildung 31) zeigt, dass das Signal bei 3.93 ppm in Abbildung 32, das den Protonen der zwei Methylschutzgruppen entspricht, nicht mehr erscheint, was auf die vollständige Spaltung der Estergruppen hinweist. Die Struktur von 3-23 konnte mit Hilfe von Maldi-Tof-Massenspektrometrie, Elementaranaylse und ${ }^{13} \mathrm{C}$ NMR nachgewiesen werden. 


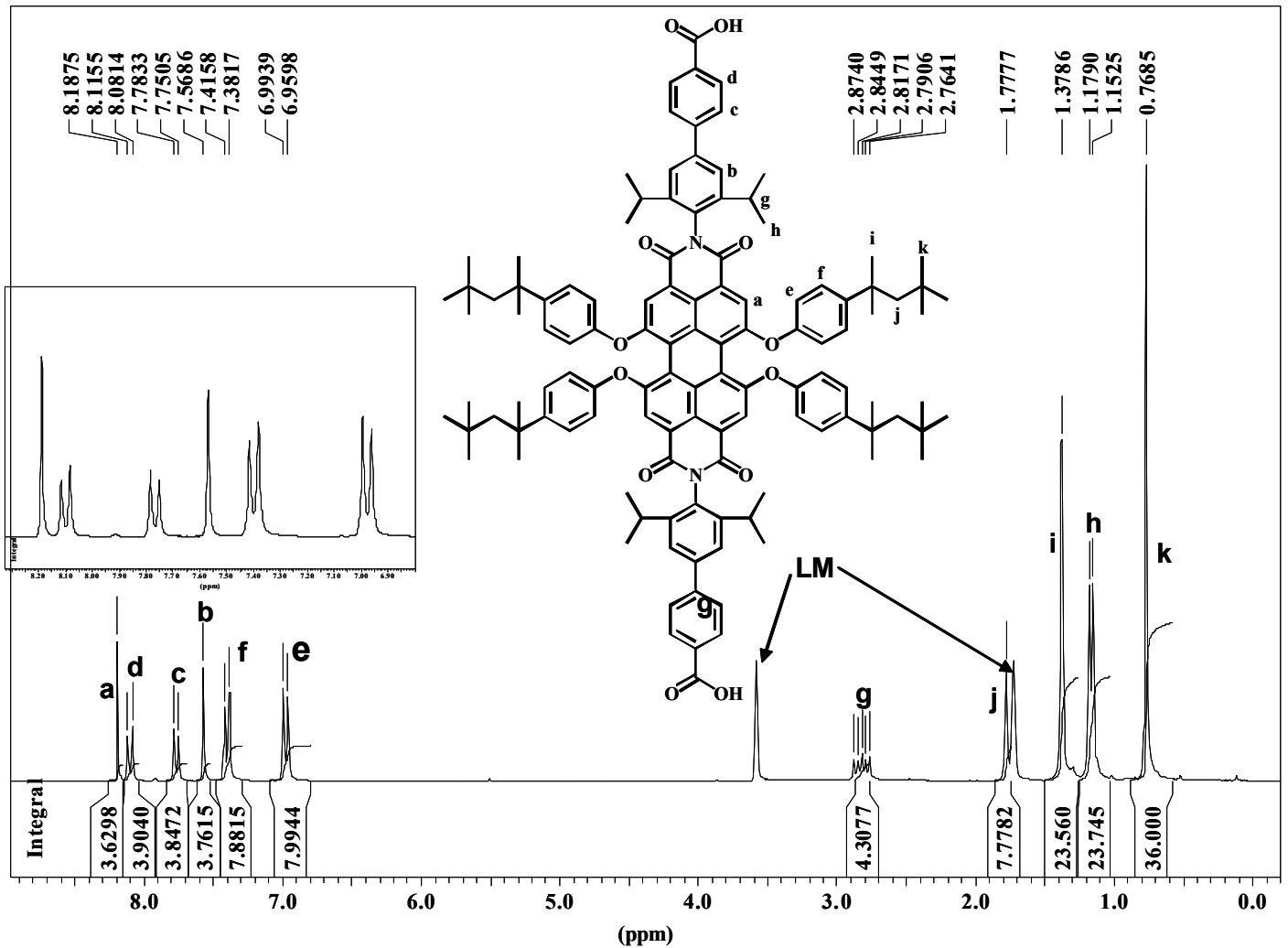

Abbildung 31: ${ }^{1} \mathrm{H}-\mathrm{NMR}-$ Spektrum von Verbindung 3-23 ( 250-MHz, Lösungsmittel: THF-d ${ }^{8}$ ).

Die Abwesenheit des Signals der Methylschutzgruppe ist ein Hinweis auf die vollständige Abspaltung der Schutzgruppe

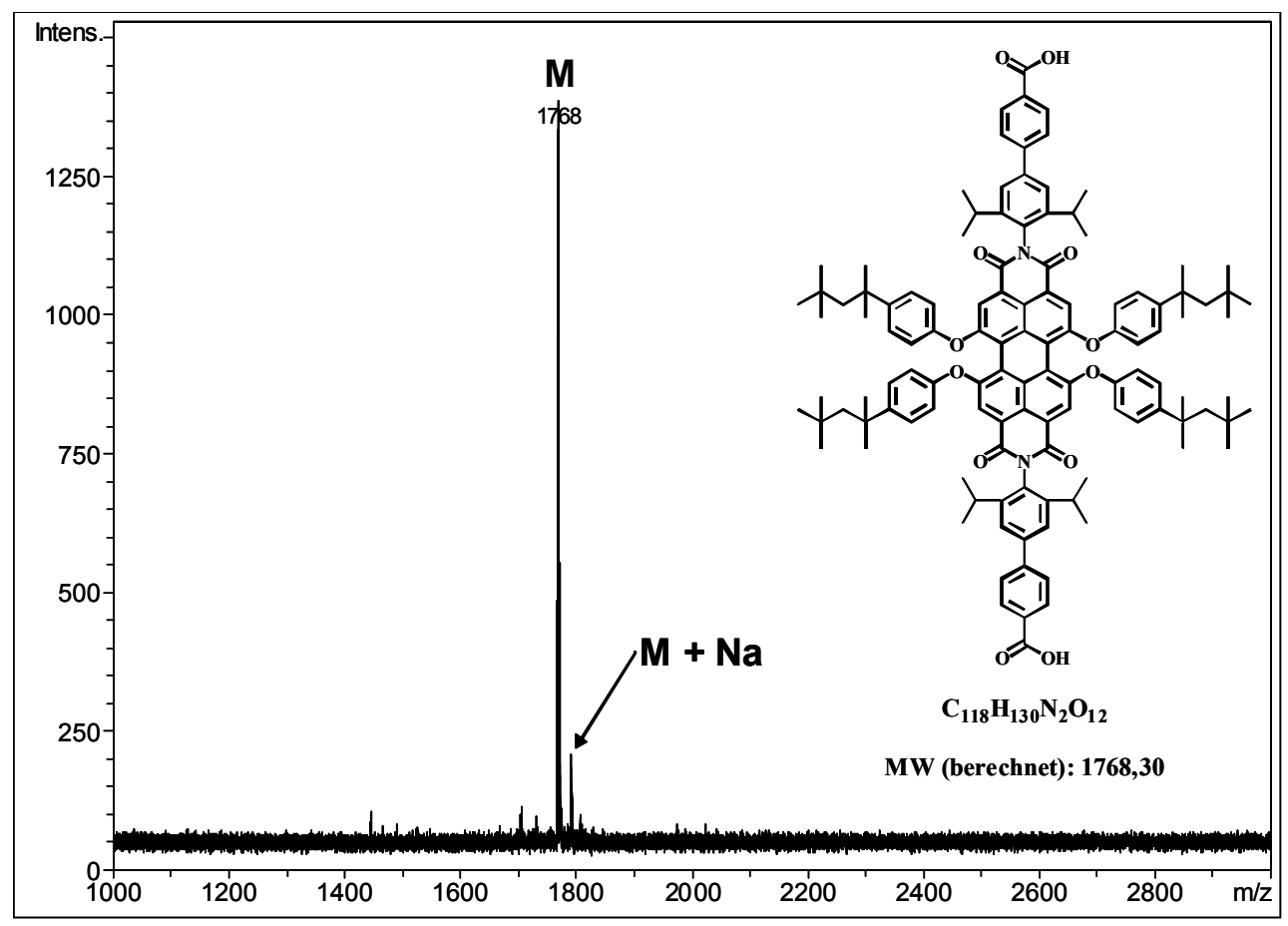

Abbildung 32 :Maldi-Tof-MS von Verbindung 3-23. Die Produktreinheit lässt sich auch hier bestätigen 
Um 3-23 an die freie Aminfunktion eines Oligonucleotides zu verknüpfen, müssen die Carbonsäuregruppen der Verbindung 3-23 in Aktivester überführt werden. Die AminCarbonsäure-Kopplung, die mit Cyclohexylcarbodiimid katalysiert wird, kann hier aufgrund der Hydrolyse des Katalysators in wässriger Lösung nicht verwendet werden. Die Kopplungsreaktion muss wegen des unterschiedlichen Löseverhaltens des Perylenderivats 3-23 auf der einen und dem Oligonucleotid auf der anderen Seite in einem Gemisch aus einer Pufferlösung und einem organischen Lösungsmittel durchgeführt werden.

Die Aktivierung der Carbonsäuregruppen ist durch die Veresterung mit $N$-Hydroxysuccinimid zugänglich. Dabei wird die Perylendiimiddicarbonsäure 3-23 über Nacht im Vakuum getrocknet und Anschließend mit $N$-Hydroxysuccinimid in DMF zur Reaktion gebracht. Die mit Dicyclohexylcarbodiimid (DCC) katalysierte Reaktion wird unter Inertgasbedingungen 48 Stunden bei $35^{\circ} \mathrm{C}$ durchgeführt. Die vollständige Umsetzung des Ausgangstoffs lässt sich gut mit Hilfe von DC mit Dichlormethan als Eluent nachweisen. Während der Reaktionszeit wurden zwei Mal zusätzliche Mengen an $N$ Hydroxysuccinimid und DCC bis zur vollständigen Umsetzung hinzugefügt. Das Reaktionsgemisch wurde eingeengt und schließlich unter Vakuum über Nacht getrocknet. Da das erhaltene Produkt 3-24 gegenüber Luftfeuchtigkeit und Spuren von Wasser labil ist, wurde auf eine chromatographische Aufreinigung verzichtet und direkt bei der nächsten Stufe eingesetzt.

\subsubsection{Synthese und Charakterisierung von Oligonucleotiden}

Um eine gezielte Selbstorganisation von Perylendiimid-Oligonucleotid-Konjugaten zu einem Perylen-DNA-Polymer zu erzielen, sollen zwei komplementäre Perylendiimidbis(oligonucleotid)-konjugate synthetisiert werden. Die Oligonucleotidsequenzen wurden so ausgewählt, dass sich keine Selbstdimere oder Hairpinstrukturen ausbilden können, 
was $\mathrm{zu}$ unerwünschten Aggregationen während der Kopplungsreaktion und damit zu verringerter Reaktionsausbeute oder auch bei der späteren Hybridisierung führen kann.

Zum Beispiel kann die Sequenz 5'-ACCATAGGGT-3` Dimere nach folgendem Muster ausbilden:

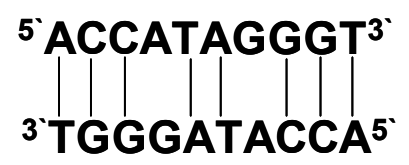

Ein Hairpinstruktur kann z. B. bei folgender Sequenz beobachtet werden:

\section{5'AAACGGTTT-3’}

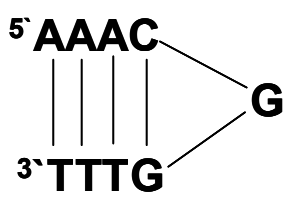

Darüber hinaus ist der Gehalt an G- und C-Basen für die Stabilität der gebildeten Doppelhelix von entscheidender Bedeutung (sehe Kapitel 1). Aus diesen Gründen müssen die Oligonucleotidsequenzen mit entsprechender Sorgfalt ausgewählt werden, so dass sich keine unerwünschten Strukturen ausbilden können.

Zwei Sequenzen mit der Länge von 16 Basen wurden zur Herstellung von zwei komplementären Perylendiimid-Oligonucleotid-Konjugaten syntehtisiert. .

\begin{tabular}{|l|l|l|l|}
\hline \multicolumn{2}{|c|}{ 5 'Sequenz-3 $^{-2}$} & Basenzahl & GC-Gehalt (\%) \\
\hline ODN1 & TAG TTG TGA TGT ACAT & 16 & 31.25 \\
\hline ODN2 & ATG TAC ATC ACA ACTA & 16 & 31.25 \\
\hline
\end{tabular}

Tabelle 3: Zwei komplementäre Oligonucleotidsequenzen zur Erzeugung eines DNA-PerylenPolymers

Durch die Verwendung modifizierter Linker-Amidite lassen sich viele funktionelle Gruppen wahlweise am 5`-, 3`-Ende oder auch an Positionen innerhalb der Oligonucleotidsequenz verknüpfen. Zum Beispiel werden folgende Amiditderivate zur Einführung von Amin-, Thiol-, Hydrazin- oder Aldehydfunktion eingesetzt: 
<smiles>COc1ccc(C(NCCCCCCOP(OCCC#N)N(C(C)C)C(C)C)(c2ccccc2)c2ccccc2)cc1</smiles>

MMTr-C6-Spaceramin<smiles>COc1ccc(C(OCCCCCCSSCCCCCCOP(OCCC#N)N(C(C)C)C(C)C)(c2ccccc2)c2ccc(OC)cc2)cc1</smiles>

DMTr-C6-Thiollinker<smiles>CC(C)N(C(C)C)P(OCCCC#N)OCCCCCC(=O)NNC(c1ccccc1)(c1ccccc1)c1ccccc1</smiles>

Hydrazinamidit<smiles>CC(C)N(C(C)C)P(OCCC#N)OCCCCCCNC(=O)c1ccc(C=O)cc1</smiles>

C6-Aldehydamidit

Abbildung 33: Verschiedene Amiditderivate zur Einführung von funktionellen Gruppen in die Struktur von Oligonucleotiden 
Gegenwärtig ist die Einführung einer Aminofunktion an der 5'-Position die meist verbreitete Modifikation von Oligonucleotiden. Dabei wird ein aliphatischer Spacer mit einer Phosphoamiditgruppe und Aminfunktion, die üblicherweise mit der säurelabilen Monomethoxytrityl- (MMTr-) oder der baselabilen Trifluoracetatgruppe geschützt ist, eingesetzt $^{61-66}$. Die Wahl der Spacerlänge ist vom zu koppelnden Molekül abhängig. Ein kurze Spacer $\left(\mathrm{C} 3,\left(\mathrm{CH}_{2}\right)_{3}\right)$ kann verwendet werden, wenn die Distanz zum Oligonucleotid keine Schwierigkeiten bei der folgenden Kopplungsreaktion verursacht. Die längeren Spacer (C6 und C12) werden dann eingesetzt, wenn das Oligonucleotid einen großen Abstand von der funktionellen Gruppe besitzen muss, um unerwünschte Wechselwirkungen bei kommenden chemischen Reaktionen zu vermeiden ${ }^{67}$. Die MMTrSchutzgruppe wird im sauren Medium nach der Trennung des Oligonucleotides vom Träger abgespalten.

Die Funktionalisierung eines Oligonucleotides mit einer Aldehyd- oder Hydrazinfunktion wird durch den Einsatz von geeigneten Spacern erreicht. So lässt sich auch das Oligonucleotid an eine organische Verbindung, eine Metall- oder Glasoberfläche mit Hydrazin bzw. Aldehydfunktion kovalent binden.

In bestimmten Fällen ist die Funktionalisierung der Oligonucleotide an der 3'-Position erforderlich. Neben der Möglichkeit einer Kopplung von Markermolekülen (z.B. Enzyme, Biotin oder Fluoreszenzfarbstoffe) an der 3`-Position besitzen einige $33^{`}$-aminmodifizierte Oligonucleotide eine deutlich höhere Resistenz gegen Endonuclease, ein Enzym, das eine in die Zelle eingedrungene und fremde DNA abbaut. Dies ermöglicht den Einsatz solcher modifizierten Oligonucleotide in der Forschung auf dem Gebiet der "Antisense"Oligonucleotide ${ }^{68}$.

Die Einführung einer $33^{`}$-Aminfunktion bedarf eine Aminschutzgruppe, die während der ganzen Festphasensynthese stabil bleibt. Sie soll nach der Synthese unter den Standardbedingungen parallel zur Spaltung des Oligonucleotides vom Trägermaterial ebenfalls entfernt werden. In der Regel wird der Träger mit einer geschützten Amin- und einer DMTr- geschützten OH-Gruppe funktionalisiert. Anschließend beginnt die DNA- 
Synthese mit der Detritylierung der OH-Gruppe und der Anschließenden Kopplung des ersten Nucleotides. Von den kommerziell erhältlichen 3`-modifizierten Trägern haben sich Trägermaterialien mit Fmoc- und Pthalimidylschutzgruppen etabliert, wobei die letztere mehr Anwendung findet, da sie während der Festphasensynthese stabiler als die Fmoc-Gruppe ist, was zu einer Verbesserung der Synthesenausbeute führt ${ }^{73-75}$.<smiles>CCOCC(CNC(F)F)O[As]CC(C)(C)C</smiles>

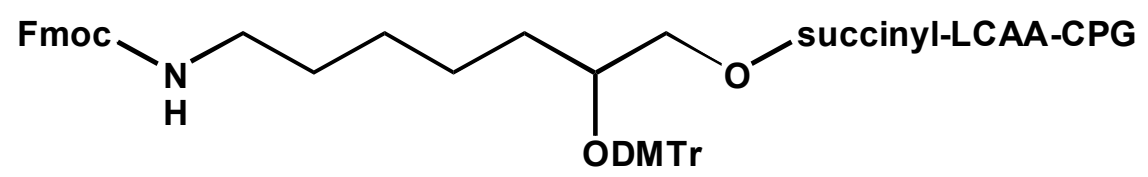<smiles>CCOCCCN1C(=O)c2ccc(C(=O)NCCC(C)F)cc2C1=O</smiles><smiles>COCCCCCCN1C(=O)c2ccc(C(=O)NCCC(F)(F)F)cc2C1=O</smiles>

Abbildung 34 : Fmoc und Pthalimidyl C3 und C6 aminmodifizierter Träger

In dieser Arbeit wurde zur Synthese der Oligonucleotidsequenzen ODN1 und ODN2 mit einer Aminfunktion an der 5'-Position das MMTr-C6-Spaceramin 3-25 verwendet. Die Kopplung des Spacermoleküles wurde unter Erhöhung der Reaktionszeit wie bei der Kopplung einer RNA-Base (15 Minuten) durchgeführt. Dies war erfahrungsgemäß 
erforderlich, da man bei normaler Reaktionszeit (3 Minuten für DNA-Basen) ein Gemisch aus den modifizierten und nicht modifizierten Molekülen (Aminoligonucleotid [n]und Oligonucleotid ohne Aminfunktion [n-1]) erhält, was auch zu einer niedrigen Ausbeute des modifizierten Oligonucleotides führt. Das bei der Synthese verwendete Trägermaterial besitzt eine Beladung von $90 \mu \mathrm{mol} / \mathrm{g}$, d. h. pro Gramm Träger sind 90 $\mu$ mol Basen (das 3'-Ende der zu synthetisierenden Sequenz) kovalent gebunden. Die Amidite (die Monomere für die Festphasen DNA-Synthese) sind sehr labil gegenüber Luftfeuchtigkeit und Spuren von Wasser. Der Synthesizer muss deshalb 24 Stunden vor Beginn der Synthese mit Inertgas (z.B. Argon) gesättigt werden. Die Amidite wurden in Acetonitril gelöst, um eine $0.1 \mathrm{M}$ Lösung zu erhalten (die Konzentration, die üblicherweise am Synthesizer verwendet wird). Die gelösten Amidite wurden sofort an den Synthesizer angeschlossen. Die verschiedenen Amidite und Reagenzen für die Synthese wurden wie folgend vorbereitet und an den Synthesizer angeschlossen:

\begin{tabular}{|l|l|l|}
\hline & Reagenz & Bemerkungen \\
\hline 1 & Amidite (dA-, dC-, dG-, dT-Amidit) & 0.1 M Lösung (in Acetonitril) \\
\hline 2 & Detritylierung & $3 \%$ (V/V) Dichloressigsäure in Toluol \\
\hline 3 & Activator & $0.4 \mathrm{M}$ Tetrazol-Lösung in Acetonitril \\
\hline 4 & Oxidationsreagenz & $\begin{array}{l}50 \mathrm{mM} \text { Jod in 10\% Wasser/Pyridin (wurde } \\
\text { von Amersham Bioscience bezogen }\end{array}$ \\
\hline 5 & Cappingreagenz A & $20 \%$ (V/V) N-Methylimidazol in Acetonitril \\
\hline 6 & Cappingreagenz B & $\begin{array}{l}20 \% \text { (V/V) Essigsäureanhydrid , 30\% syn- } \\
\text { Collidin, 50\% Acetonitril }\end{array}$ \\
\hline 7 & Acetonitril & $\begin{array}{l}\text { Zum Waschen der Synthesesäule zwischen } \\
\text { den Syntheseschritten, vor der Synthese } 24 \\
\text { stunden über Molekularsieb gestellt. }\end{array}$ \\
\hline
\end{tabular}

Tabelle 4: Die verschiedenen Reagenzen für die Oligonucleotidsynthese

Nachdem alle erforderlichen Reagenzien und Amiditlösungen vorbreitet und an den DNA-Synthesizer angeschlossen worden sind, wird die Synthesesäule mit dem Trägermaterial aufgefüllt. Man schliesst die aufgefüllte Säule an einer Vakuumpumpe an, 
um Luftblasen aus dem eingepackten Trägermaterial zu entfernen. Luftblasen können aufgrund der Empfindlichkeit der Amidte gegen Luftfeuchtigkeit die Syntheseausbeute negativ beeinflussen. Sie können auch Unregelmäßigkeiten beim Lösungsdurchfluss herbeiführen. Die Säule soll vor und nach dem Einpacken gewogen werden, um die Trägermaterialmenge und den Synthesemaßstab zu bestimmen, die im Syntheseprotokoll am Synthesizer eingegeben werden muss. Anschließend wird die Synthesesäule angeschlossen und Syntheseparameter eingestellt. Hierbei können Eingabefehler zu unerwünschten Produkten führen, da die Festphase nach Beginn der Synthese und Kopplung der ersten Base nicht mehr wieder verwendet werden kann. Der enzymatischen Syntheserichtung entgegengerichtet werden die Oligonucleotidsequenzen nach dem Phosphoamiditverfahren von der 3'- in die 5'-Richtung synthetisiert. Die Base am 3'Ende der Oligonucleotidsequenz wird nicht im Syntheseprotokoll eingegeben, weil sie bereits am Trägermaterial kovalent gebunden ist.

Nach Ende der Synthese wurde die Synthesesäule mit dem synthetisierten Oligonucleotid entfernt und im Vakuum getrocknet. Im Anschluss wurde das Trägermaterial in ein verschraubbares Gefäß überführt, mit 22 ml einer 32 \%igen Ammoniumhydroxid-Lösung versetzt und $17 \mathrm{~h}$ bei $55^{\circ} \mathrm{C}$ im Trockenschrank gehalten. Danach wurde das Gefäß entfernt und auf Raumtemperatur abgekühlt. Die erhaltene Lösung wurde über eine D4Fritte filtriert und mit $100 \mathrm{ml}$ von einem Lösungsmittelgemisch aus Ethanol/Wasser (1:1) gewaschen. Schließlich wurde das Filtrat eingeengt und im Vakuum über Nacht getrocknet.

Die Struktur der synthetisierten Oligonucleotidsequenzen ist wie folgend:

$\begin{array}{ll}\text { ODN1: } & \mathrm{H}_{2} \mathrm{~N}-\left(\mathrm{CH}_{2}\right)_{6}-\mathrm{p}^{-}{ }^{-}{ }^{-} \text {TAG TTG TGA TGT ACAT } \\ \text { ODN2: } & \mathrm{H}_{2} \mathrm{~N}-\left(\mathrm{CH}_{2}\right)_{6}-\mathrm{p}^{-}{ }^{-}{ }^{-} \text {ATG TAC ATC ACA ACTA }{ }^{-3}\end{array}$

Die Aufreinigung der Oligonucleotide ODN1 und ODN2 wurde mit Hilfe von Ionenaustausch-Hochleistungsflüssig-chromatographie (engl. High Performance Liquid Chromatography) HPLC durchgeführt. Sie ist eine schnelle, leistungsfähige 
säulenchromatographische Methode für die Auftrennung von Substanzgemischen im analytischen und präparativen Maßstab. Dabei werden stationäre Phasen mit sehr kleinen Korngröße (von 3 bis $10 \mu \mathrm{m}$ ) und enger Korngrößenverteilung verwendet. Das Elutionsmittel wird durch die stationäre Phase unter hohem Druck (50 bis 500 bar) gepresst. Das aufzureinigende Substanzgemisch wird am Säulenanfang in den Strom der mobilen Phase injiziert, und die eluierten Stoffe werden am Säulenende durch einen geeigneten Detektor nachgewiesen und registriert. Zur Detektion eignet sich jede analysierbare Eigenschaft des aufzutrennenden Stoffes, z. B. die UV-Absorption, das Elektrodenpotential, die elektrische Leitfähigkeit (bei ionischen Substanzen) oder die Fluoreszenz. Meistens wird die UV-Absorption bei einer bestimmten Wellenlänge, z. B. $254 \mathrm{~nm}$, verwendet. Die aufgetrennten Stoffe erscheinen im Chromatogramm als Peaks (Banden). Die bei der HPLC verwendeten Trägermaterialien sind mit funktionellen Gruppen, welche für die Trennmethode spezifisch sind, funktionalisiert. Das Trägermaterial für die Ionenaustausch-HPLC, die hier in dieser Arbeit verwendet wurde, besteht aus Polystyrol/Polyvinylbenzol. Für die Auftrennung von den negativ geladenen Oligonucleotiden kommen Anionenaustauscher zum Einsatz, z. B. quaternäre Ammoniumverbindungen, Trimethylaminoethyl und Hydroxypropyl-diethylaminoethyl tragen. Die Grundlage für den Ionenaustausch ist die kompetitive Wechselwirkung der geladenen Ionen. Das Probenmolekül konkurriert mit den Salz-Ionen um die geladenen Positionen auf dem Ionenaustauscherträger. Im ersten Schritt bindet sich das Molekül an die fixierten Ladungen der stationären Phase. Beim zweiten Schritt erfolgen die Verdrängung und Elution des Probenmoleküls durch die steigende Salzkonzentration des Eluenten.

Die Stoffmenge, die auf die Säule aufgetragen werden kann, hängt von der Kapazität des Trägermaterials ab. Mit der ionischen Kapazität ist die Stoffmenge geladener Gruppen pro Gramm Austauscher gemeint.

In Abbildung 35 ist das HPLC-Chromatogramm von ODN1 dargestellt. Als Eluent A wurde eine $10 \mathrm{mM}$ Natriumhydroxid-Lösung verwendet. Zum Verdrängen des Oligonucleotides vom Trägermaterial kam eine Lösung aus $10 \mathrm{mM}$ Natriumhydroxid und 2 M Natriumchlorid als Eluent B zum Einsatz. Wie man im Chromatogramm beobachten 
kann, ist der Hauptpeak (Produkt, ODN1) im Vergleich zum kleineren Peak (n-1, Oligonucleotid ohne Aminfunktion) viel größer, was darauf hinweist, dass die Kopplung des Aminspacers erfolgreich war.

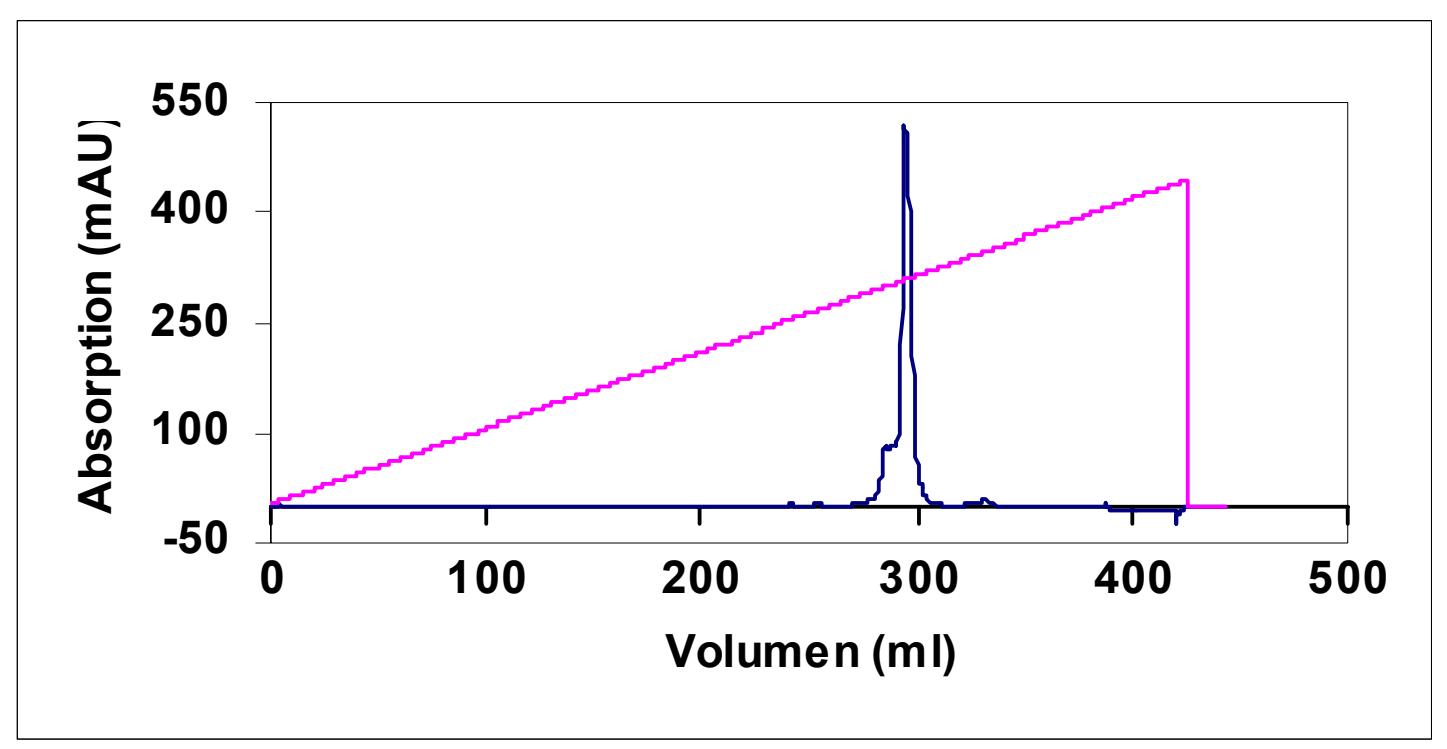

\begin{abstract}
Abbildung 35: HPLC-Chromatogramm von ODN1, Säulematerial: Anionenaustauscher , Eluent A: $10 \mathrm{mM} \mathrm{NaOH}$, Eluent B: $10 \mathrm{mM} \mathrm{NaOH}+2 \mathrm{M} \mathrm{NaCl}$, Gradient: 0-45 \% Eluent B in 40 Säulenvolumen
\end{abstract}

Das HPLC-Chromatogramm von ODN2 zeigt ein ähnliches Bild wie ODN2. Die gesammelten Fraktionen enthalten eine große Menge an Salz, das durch Dialyse entfernt werden muss. Zum Entsalzen wurden die von der HPLC erhaltenen Fraktionen über eine Membran mit einem Cut-Off-Punkt von 3000 g/mol zentrifugiert. Dabei penetrieren die Salzionen durch die Membran, und das hochmolekulare Oligonucleotid bleibt im Überstand. Nach dem ersten Zentrifugeprozess wurde entionisiertes Wasser $\left(\mathrm{dd}_{2} \mathrm{O}\right)$ hinzugefügt und ein zweites Mal zentrifugiert, um den Rest an Salzionen zu entfernen. Der Überstand wurde eingeengt und im Vakuum getrocknet. 


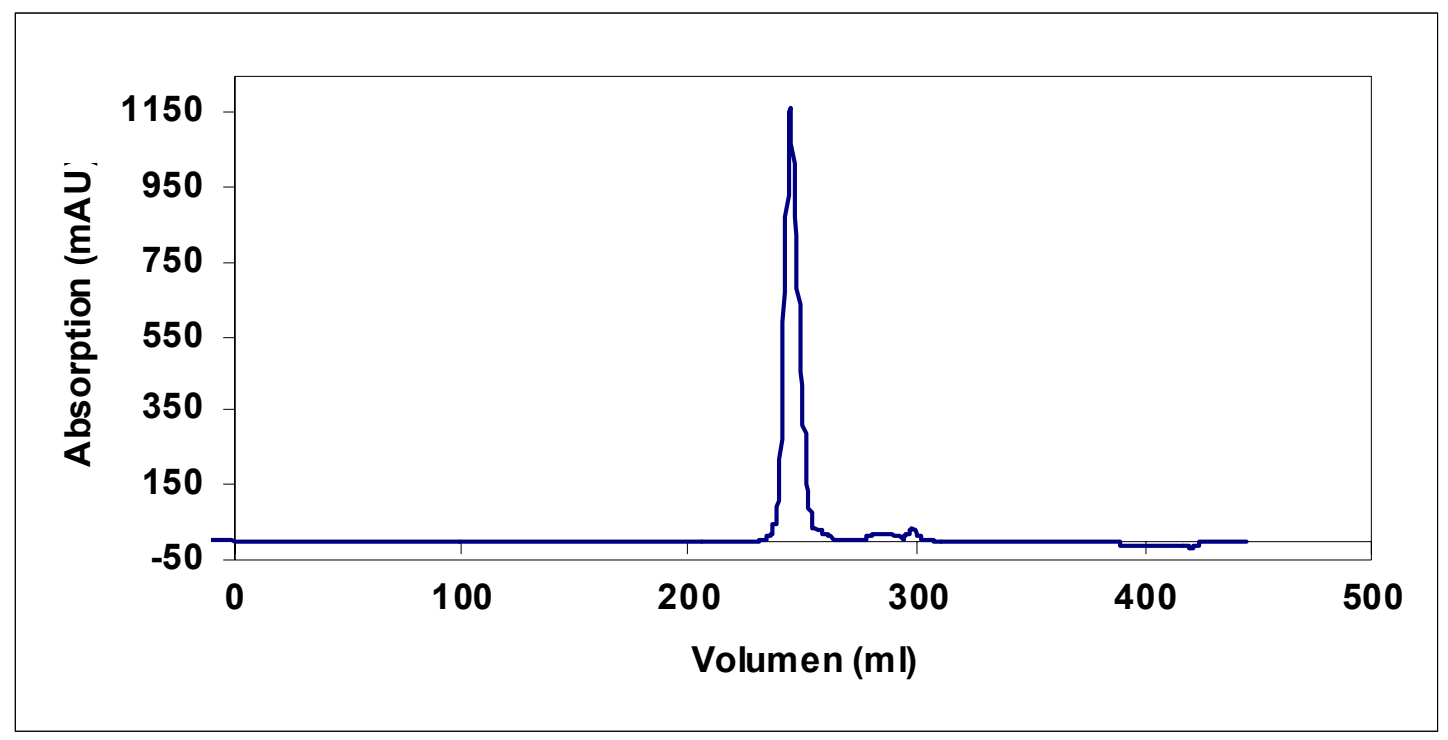

Abbildung 36: HPLC-Chromatogramm von ODN2, Säulematerial: Anionenaustauscher, Eluent A: $10 \mathrm{mM} \mathrm{NaOH}$, Eluent B: $10 \mathrm{mM} \mathrm{NaOH}+2 \mathrm{M} \mathrm{NaCl}$, Gradient: $0-45 \%$ Eluent B in 40 Säulenvolumen

Zur Charakterisierung der synthetisierten Oligonucleotide wurden Maldi-Tof-Analysen durchgeführt. In der Literatur wurde als Matrix die 3-Hydroxypicolinsäure oder 2,4,6Trihydroxyacetophenon zur Molekulargewichtsbestimmung von Oligonucleotiden verwendet $^{76-78}$, wobei die erstere hier zum Einsatz kam. Die Matrix wurde in einem Lösungsmittelgemisch aus Acetonitril und $\mathrm{ddH}_{2} \mathrm{O}$ (1:1) gelöst. 3-5 mg Ammoniumcitrat wurden hinzugefügt. 20-30 $\mu 1$ Probensubstanz wurde mit einem ammoniumhaltigen Harz versetzt, um die Natriumionen in der Probe gegen Ammoniumionen auszutauschen, da diese im Gegenteil zu den Natriumionen in der Maldi-Tof-Messung eine gute Auflösung herbeiführen. In Abbildung 37 sind die Maldi-Tof-Spektren von ODN1 und ODN2 dargestellt. 

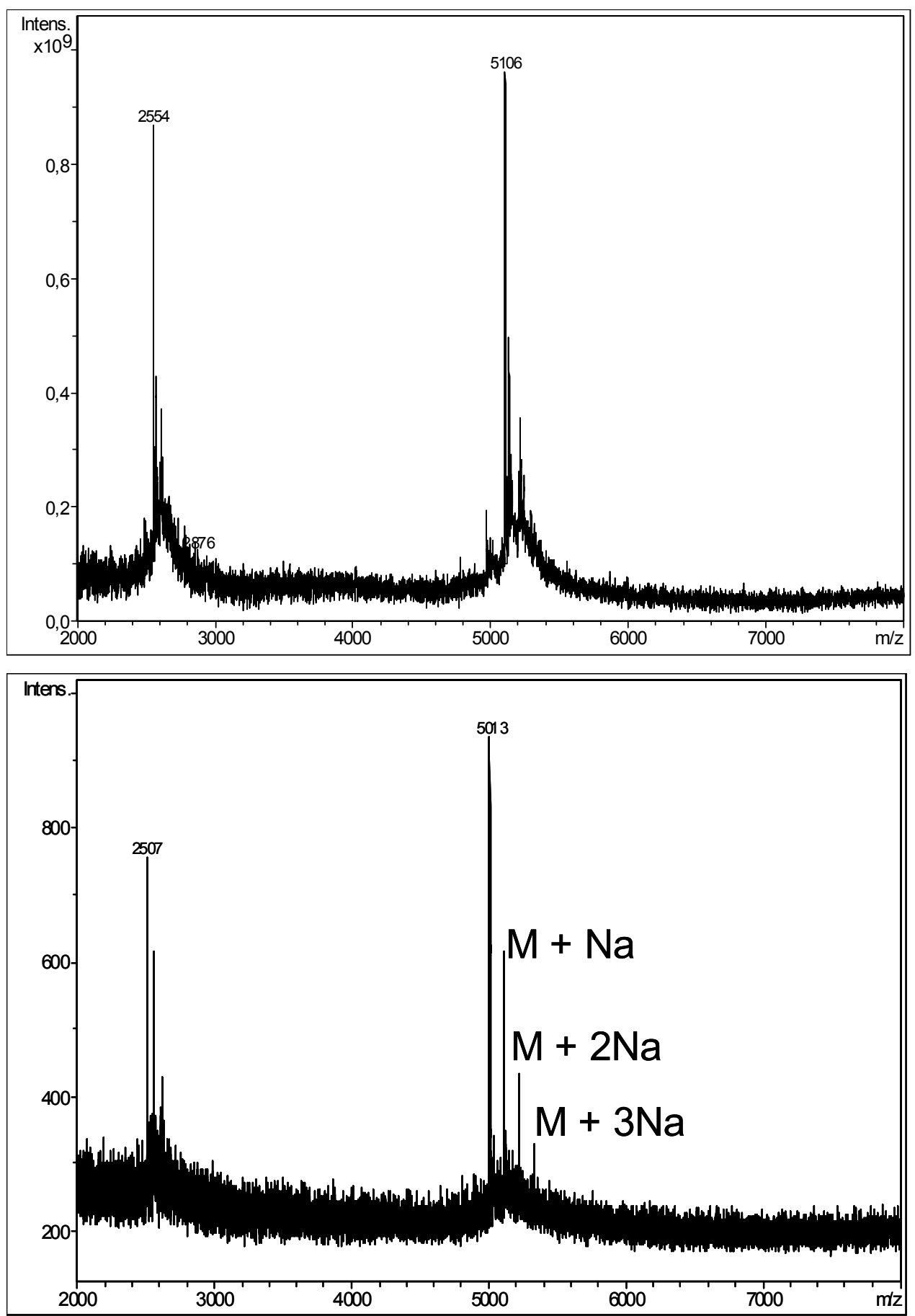

Abbildung 37: Maldi-Tof-Spektren der synthetisierten Oligonucleotide ODN1 (oben), $\mathrm{M}_{\text {ber }}$ berechnet: $5107.8 \mathrm{~g} / \mathrm{mol}$ und ODN2 (unten), $\mathrm{M}_{\text {ber }}$ berechnet: 5014.83, Man sieht den Molekülionenpeak $\mathrm{M}^{+}$sowie das doppelt geladene Molekül $\mathrm{M}^{2+}$

Wie man den Spektren in Abbildung 37 entnehmen kann, stimmen die erhaltenen Peaks mit den berechneten Werten (ODN1: berechnet $5107.8 \mathrm{~g} / \mathrm{mol}$, erhalten $5106 \mathrm{~g} / \mathrm{mol}$, 
ODN2: berechnet $5014.83 \mathrm{~g} / \mathrm{mol}$, erhalten $5013 \mathrm{~g} / \mathrm{mol}$ ) überein. Die kleinen Peaks (in den Spektren rechts vom Molekülionenpeak $\mathrm{M}^{+}$) repräsentieren das Molekülargewicht von ODN1 bzw. ODN2 plus n-Natriumionen ( $n=1,2$ oder 3). Das deutet darauf hin, dass die Konzentration der in den Proben vorhandenen Natriumionen hoch ist, was dann zu unvollständigem Austausch der Natriumionen gegen Ammoniumionen führte. Das positiv geladene Natriumion bildet eine starke elektrostatische Bindung mit der Phosphatgruppe der DNA-Sequenz und tritt deshalb im Maldi-Tof-MS als begleitendes Kation auf. Das Erscheinen der Natriumionen kann man aber vermeiden, indem man die Probe mehrmals mit dem ammoniumhaltigen Harz versetzt, was anderseits zur Probenverlust führt.

\subsubsection{Synthese und Charakterisierung von Perylendiimid- Oligonucleotid-Konjugaten}

Nach der Synthese, Aufreinigung und Charakterisierung der komplementären Oligonucleotide kann nun mit der Synthese der komplementären Konjugate begonnen werden. Es sollen zwei Oligonucleotidmoleküle an die Imidstruktur des Perylendiimids angebunden werden. Das unterschiedliche Löseverhalten der beiden Edukte steht einer Synthese in einem Lösungsmittel (Einphasensystem) entgegen. Während Oligonucleotide sich nur in Wasser lösen, kann das hydrophobe Perylendiimid ausschließlich in organischen Lösungsmitteln gelöst werden.

Um dieses Problem zu umgehen, wurde ein Gemisch aus Wasser und Dimethylformamid verwendet. Die aktivierte Perylendiimiddicarbonsäure 3-24 wurde in DMF gelöst. Das Oligonucleotid hingegen löste man in 0.1 M Natrium-Tetraborat Pufferlösung (pH 8.5-9). Der gelöste Farbstoff wurde in die Oligonucleotidlösung eingetropft. Im Anschluss wurde das Reaktionsgemisch bei $37^{\circ} \mathrm{C}$ über Nacht inkubiert. Die ersten Kopplungsversuche zeigten, dass eine umgekehrte Zugabe der Reaktionslösungen, d. h. das Zutropfen der Oligonucleotidlösung zu der Farbstofflösung, zur Fällung des Perylendiimids und damit zur erheblichen Beeinträchtigung der Reaktionsausbeute führt. Deshalb wurde das in DMF gelöste Perylendiimid zu der Oligonucleotidlösung hinzugefügt. Nach ca. 60 
Minuten konnte eine klare und einphasige Reaktionslösung beobachtet werden. Das Reaktionsgemisch wurde im Vakuum getrocknet. Der erhaltene Feststoff wurde in Wasser gelöst. Man erhielt eine wässrige fluoreszierende Lösung, was darauf hinweist, dass das Perylendiimid mit dem Oligonucleotid verknüpft ist.

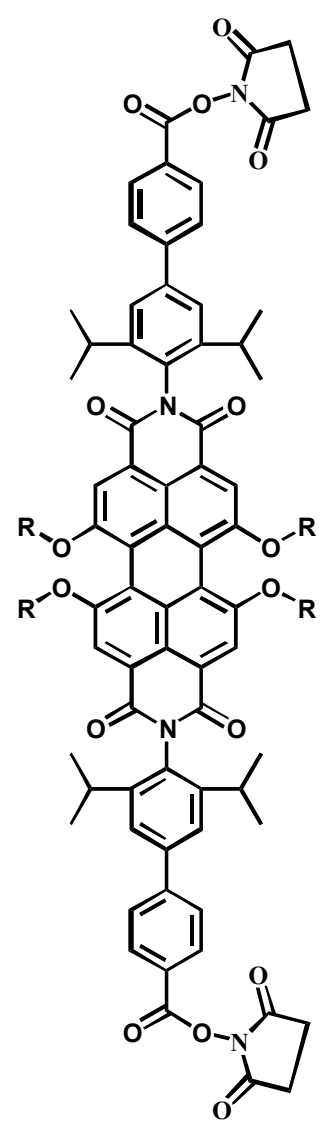

3-24

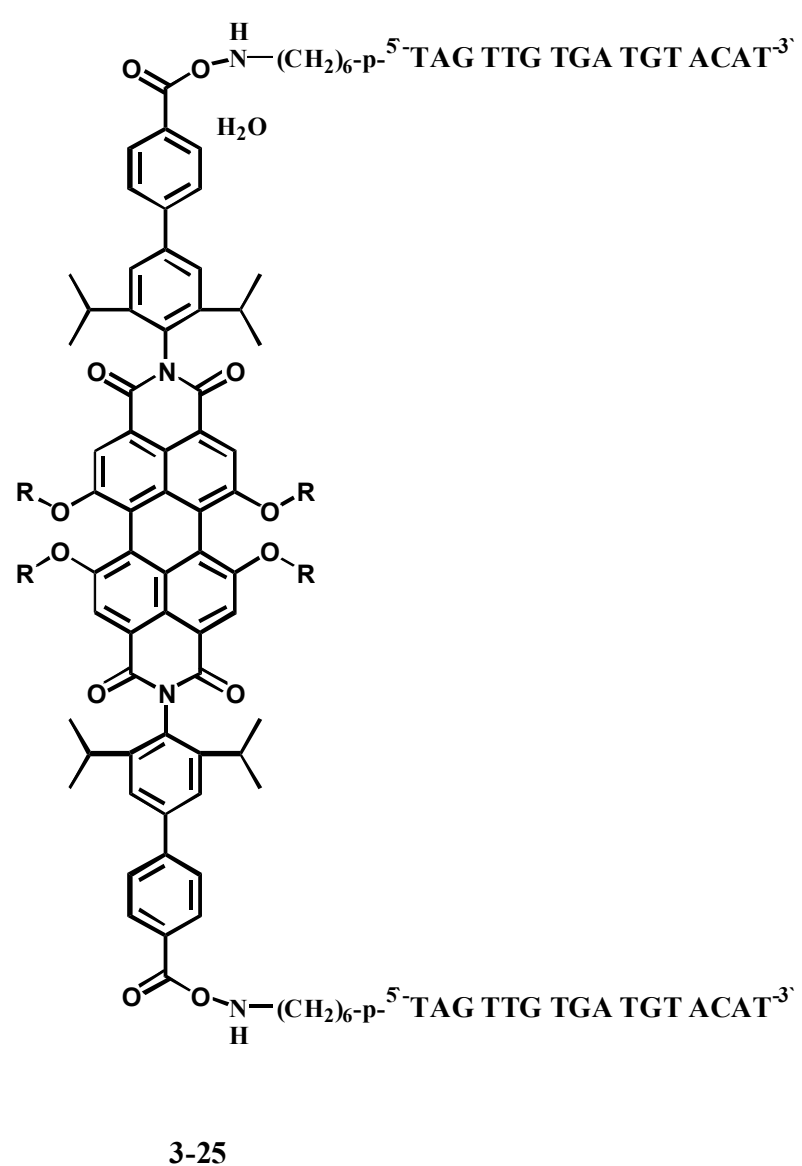

3-25

Abbildung 38: Darstellung von Perylendiimid-bis(oligonucleotid)-konjugat (PODN1), i) ODN1

$\left(\mathrm{H}_{2} \mathrm{~N}-\left(\mathrm{CH}_{2}\right)_{6}-\mathrm{p}^{-{ }^{\circ}}\right.$ TAG TTG TGA TGT ACAT $\left.{ }^{-3}\right)$ gelöst in Tetraborat-Puffer, pH 8.5-9, Perylendiimid (3-24) war in DMF gelöst, über Nacht bei $37^{\circ} \mathrm{C}$

Das UV/Vis- und das Fluoreszenzspektrum des Perylendiimid-bis(oligonucleotid)konjugats PODN1 (3-25, ODN1-PDI-ODN1) ist in Abbildung 39 und 40 zu sehen. Im UV/Vis- Absorptionsspektrum sind die typischen Absorptionsbanden des Perylendiimids im Bereich von 440 bis $615 \mathrm{~nm}$ sowie die Absorptionsbande des Oligonucleotides bei 260 nm zu erkennen. Die nicht mehr aufgelöste Feinstruktur in der Absorption von PODN1 
deutet darauf hin, dass das Konjugat möglicherweise Aggregate in wässriger Lösung bildet.

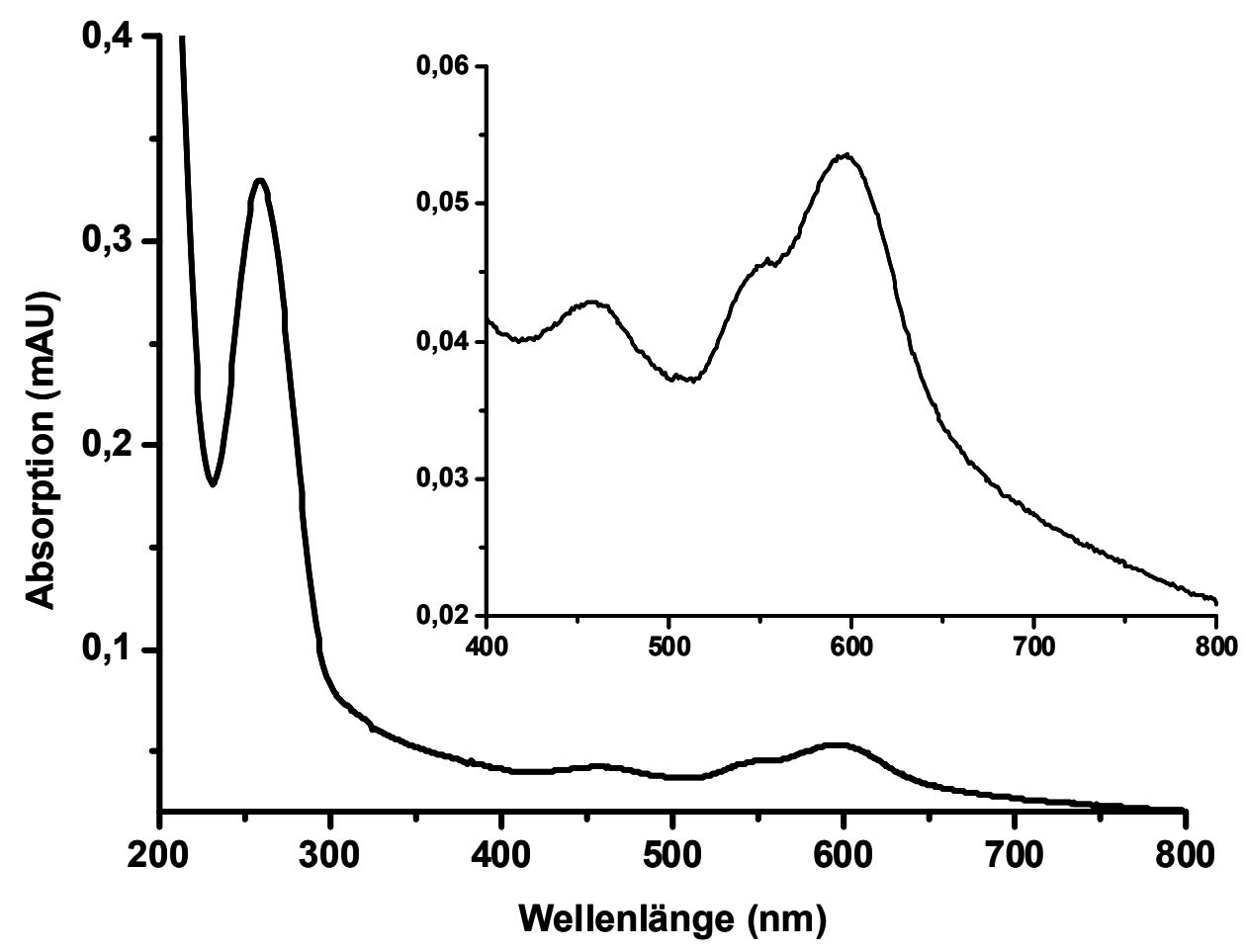

Abbildung 39: UV/VIS-Absorptionsspektrum von ODN1-PDI-ODN1 (nicht aufgereinigt) in Wasser mit Vergrößerung des Wellenlängenbereich zwischen 400 und $800 \mathrm{~nm}$

Darüber hinaus wird sichtbar, dass das Absorptionsmaximum bei $260 \mathrm{~nm}$ viel größer im Vergleich zu der Absorption bei $595 \mathrm{~nm}$ ist. Dies ist darauf zurückzuführen, dass für die Kopplungsreaktion ein großer Überschuss an Oligonucleotid verwendet wurde, um bei der Synthese die Ausbeute an dem Bis(oligonucleotid)-konjugat gegenüber dem monosubstituierten Perylendiimid zu erhöhen. Das nicht reagierte Oligonucleotid absorbiert genauso wie die zwei Oligonucleotidsequenzen in PODN1 bei $260 \mathrm{~nm}$.

Das Fluoreszenzspektrum von Konjugat PODN1 (Abbildung 40) zeigt, dass das Perylendiimid-bis(oligonucleotid)-konjugat im Wasser fluoresziert. 


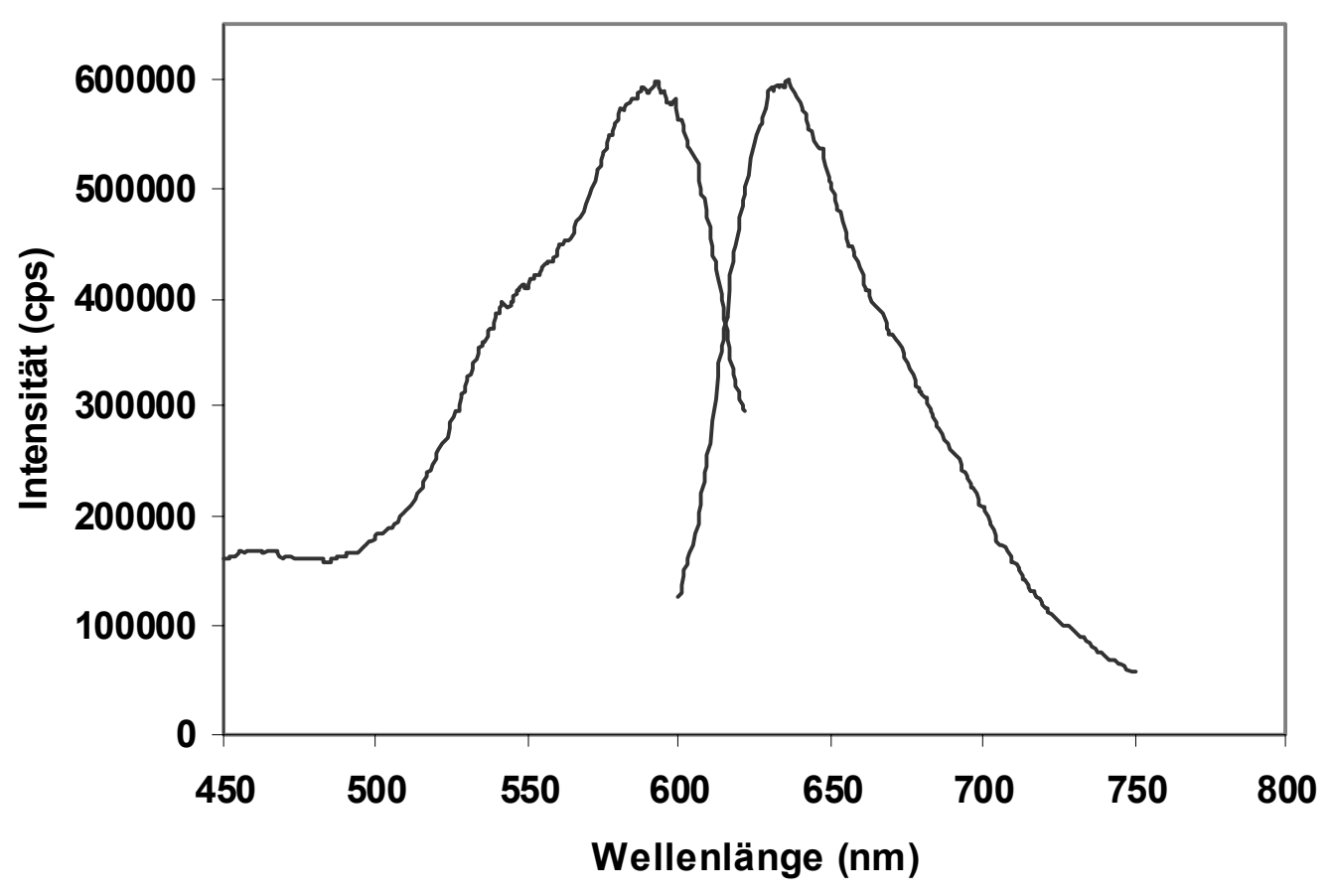

Abbildung 40: Das Fluoreszenzspektrum vom Perylendiimid-bis(oligonucleotid)-konjugat (PODN1), aufgenommen im Wasser, $\lambda_{\mathrm{A}}=540 \mathrm{~nm}, \lambda_{\mathrm{E}}=633 \mathrm{~nm}$

Ein Vergleich zwischen den Absorptions- und Emissionsmaxima der Verbindungen 3-23 und PODN1 (3-25) ist in Abbildung 41 dargestellt. Man erkennt eine bathochrome Verschiebung des Emissionsmaximums von Konjugat PODN1 in wässriger Lösung im Vergleich zu 3-23 in THF.

Um eine Hybridisierung zwischen PODN1 und einem komplementären Oligonucleotid oder Konjugat durchzuführen, muss der für die Kopplungsreaktion eingesetzte Überschuss an Oligonucleotid entfernt werden. Für die Auftrennung von PODN1 und ODN1 wurde die Polyacrylamidgelelektrophorese (PAGE) verwendet. 


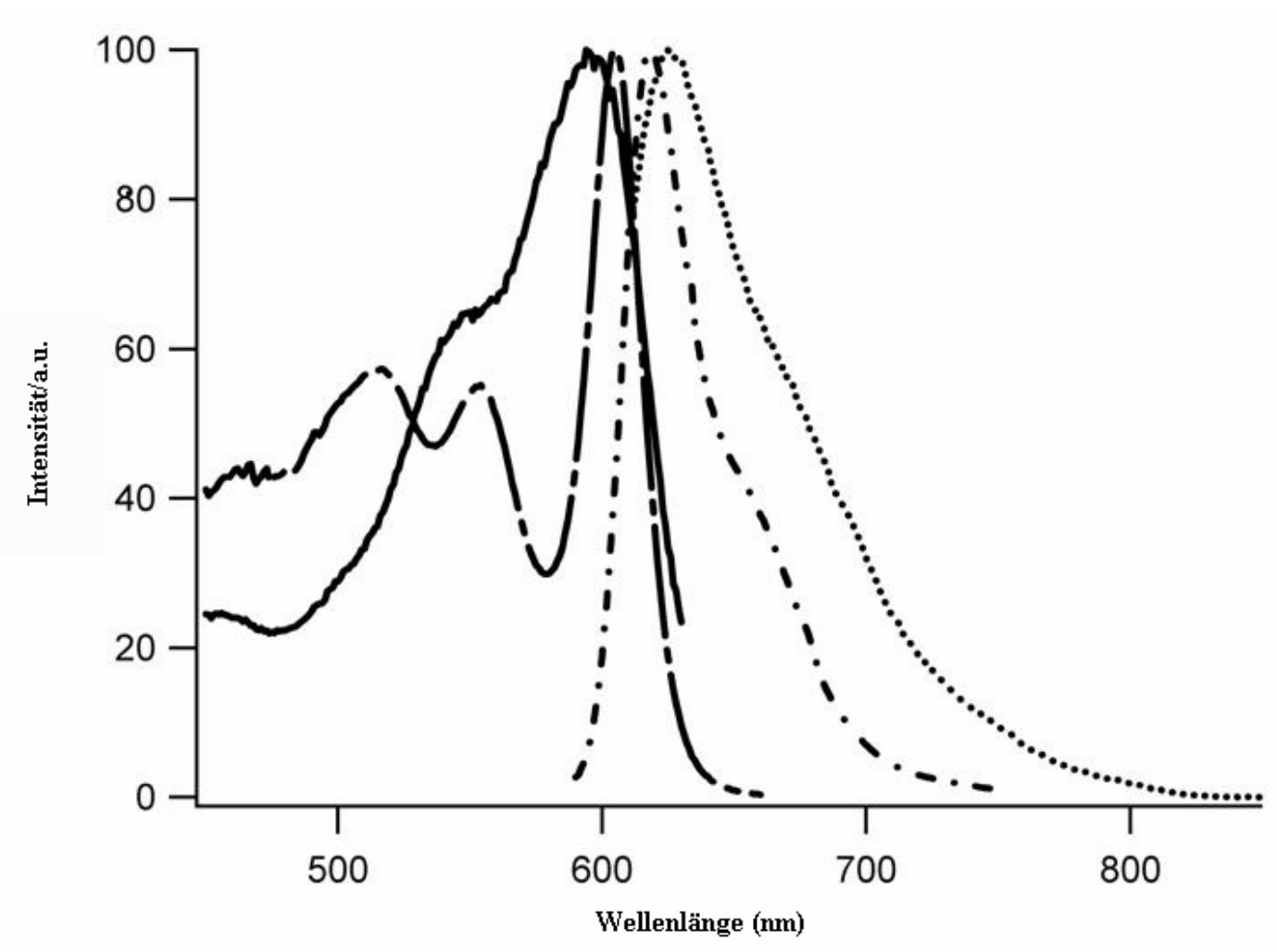

Abbildung 41: Ein Vergleich der Absorptions- und Emissionsspektren von Perylendiimiddicarbonsäure 3-23 (durchbrochene Linie, gestrichelte Linie) in THF und Konjugat PODN1 (3-25) (fette Linie, gepunktete Linie) in Phosphat-Puffer (pH 7.0)

Mit Elektrophorese bezeichnet man die Wanderung geladener Moleküle in einem elektrischen Feld. Moleküle mit unterschiedlichen Ladungen und Größen zeigen eine unterschiedliche elektrophoretische Beweglichkeit ${ }^{79}$. Die elektrophoretische Methode bietet ein sehr hohes Auflösungsvermögen und wird in der Regel in stabilisierenden Matrices (Gele) durchgeführt. Die Wanderungsgeschwindigkeiten der Moleküle werden in diesen porösen Matrices je nach Molekülgröße und Ladung unterschiedlich verlangsamt. Als Trägermaterial werden hauptsächlich Agarose- und Polyacrylamidgele verwendet. Agarosegele werden zur Trennung von großen DNA-Fragmenten und zu quantitativen und spezifischen Detektion von Proteinen eingesetzt. Dem hingegen besitzen Polyacrylamidgele das höhere Auflösevermögen für DNA-Fragmente und Proteine, besonderes bei kleinen Molekülen. 


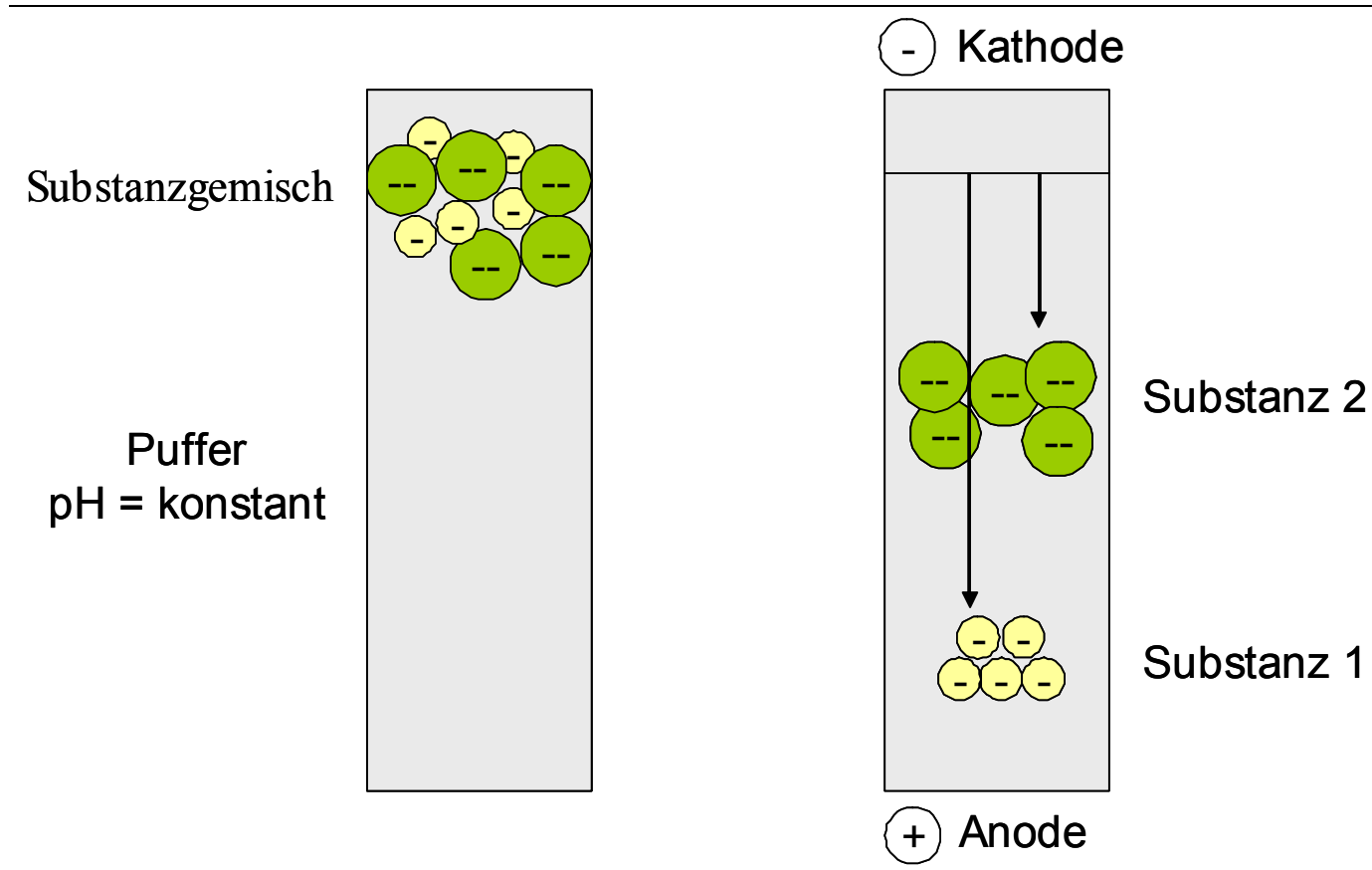

Abbildung 42: Das Trennprinzip der Elektrophorese, die geladenen Moleküle mit unterschiedlichen Ladungen und Größe wandern im elektrischen Feld mit unterschiedlichen Geschwindigkeiten, die einzelnen Substanzen bilden entsprechende Zonen aus

Die elektrophoretische Beweglichkeit oder die Mobilität ist eine substanzspezifische Größe, die die Wanderungsgeschwindigkeit der Substanz im elektrischen Feld bestimmt und damit für die Trennung der Moleküle entscheidend ist. In einem elektrischen Feld wirken auf ein geladenes Molekül verschiedene Kräfte ein, eine beschleunigende $\operatorname{Kraft} F_{e}$, die auf die Ladung $q$ des Moleküls wirkt:

$$
F_{e}=q \cdot E
$$

und eine Reibungskraft $F_{r}$, die bremsend wirkt:

$$
F_{r}=f_{c} \cdot \mathrm{V}
$$

wobei $E$ die elektrische Feldstärke, $f_{c}$ der Reibungskoeffizient und $\mathrm{v}$ die Wanderungsgeschwindigkeit ist. Der Reibungskoeffizient hängt von der Viskosität des Mediums und der Porengröße der Matrix ab.

Das Gleichgewicht zwischen den beiden Kräften bewirkt, dass sich die Moleküle mit einer konstanten Geschwindigkeit im elektrischen Feld wandern: 


$$
F_{e}=F_{r}: \mathrm{q} \cdot \mathrm{E}=f_{c} \cdot \mathrm{v} \quad \Rightarrow \quad \mathrm{v}=\mathrm{q} \cdot \mathrm{E} / f_{c}=\mu \cdot E
$$

wobei der Proportionalitätsfaktor zwischen der Feldstärke und der Wanderungsgeschwindigkeit eine substanzspezifische Größe $\mu$ ist, die man als die Mobilität bezeichnet.

Bei der Elektrophorese werden Puffersysteme aus einer Säure und einer Base eingesetzt, wie z. B. Tris-Borat. Im elektrischen Feld wandern nicht nur die Proben-Ionen, sondern auch im hohen Maße die Ionen der dissoziierten Pufferkomponenten. Deshalb werden an beiden Elektroden Pufferreservoirs benötigt. Diese Puffermengen müssen hochkonzentriert sein, damit der Puffer nicht erschöpft werden kann.

Während der elektrophoretischen Trennung mit Gelelektrophorese wird durch den elektrischen Stromfluss Joulesche Wärme erzeugt, die von der molaren Konzentration des Elektrolyten und der elektrischen Feldstärke abhängig ist. Die Wärmeabfuhr erfolgt durch Flüssigkühlung oder die Wände des Systems.

\section{Trägermedien in der Gelelektrophorese}

\section{Agarose}

Agarosegele sind relativ großporig. Die Porengröße hängt von der Konzentration des Gels ab. Bei einer Konzentration von $1 \%(\mathrm{~g} / \mathrm{ml})$ beträgt die Porengröße $150 \mathrm{~nm}$ und bei 0.16 $\%$ bis $500 \mathrm{~nm}$. Die Gele werden durch Ausgießen der Agaroselösung auf eine horizontale Glasplatte oder Trägerfolie hergestellt. In Abbildung 43 ist die Struktur von Agarose gezeigt.

Agarosegele sind einfach herzustellen, ungiftig und wegen ihrer hohen Porengröße ideal zur Trennung von höhermolekularen Proteinen und Nukleinsäuren über $500 \mathrm{kDa}$. Als Folge dieser hohen Porengröße besitzen Agarosegele eine niedrige Siebwirkung für Moleküle unter $100 \mathrm{kDa}$ und sind deshalb für die Trennung von Oligonucleotiden, niedermolekularen Proteinen und Nukleinsäuren nicht geeignet. 


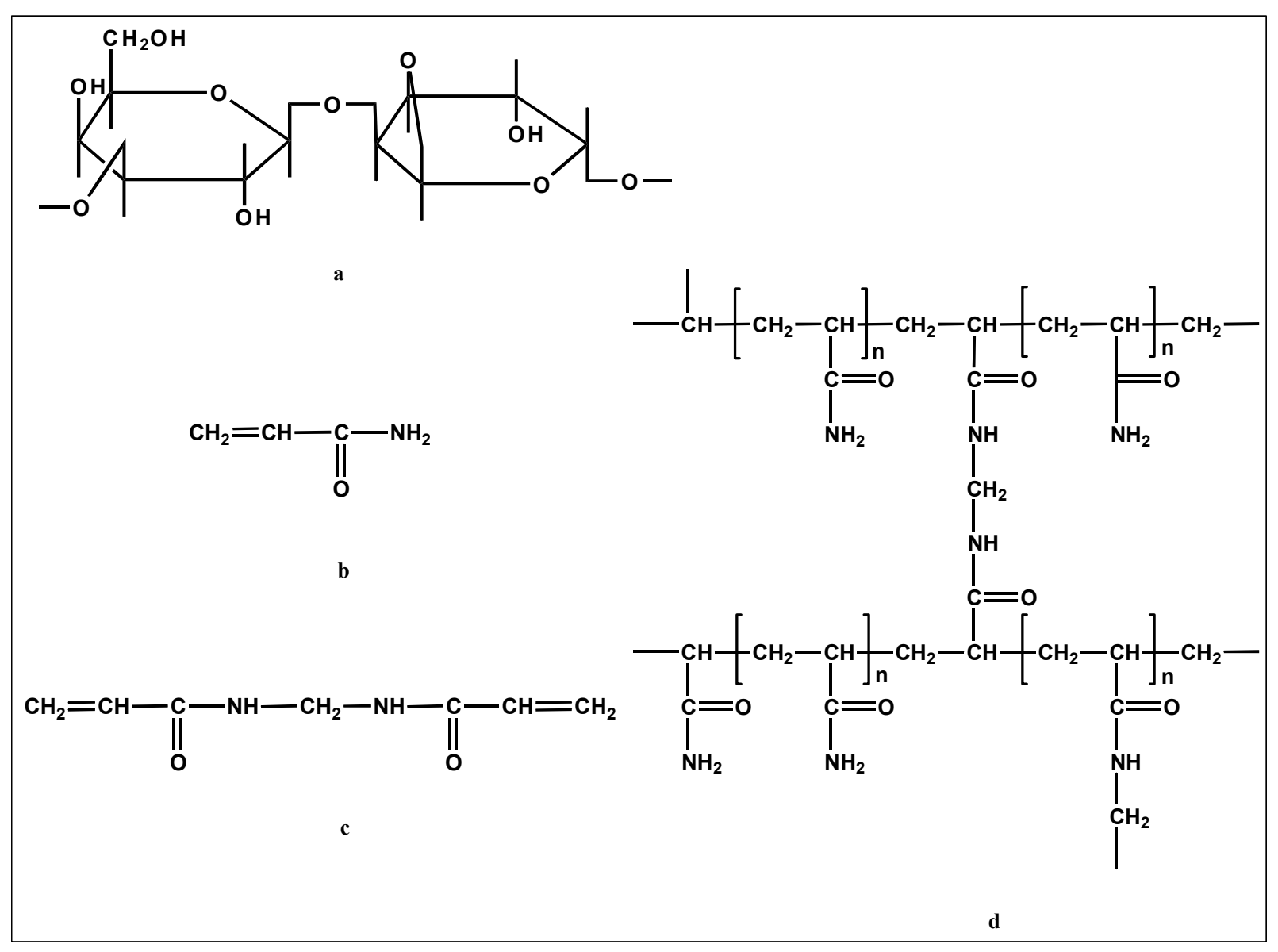

Abbildung 43: Struktur der eingesetzten Trägermaterialien in der Gelelektrophorese: a Agarose (Polysaccharid), ein alternierendes Copolymer von 1,3-gebundener $\beta$-D-Galactose und 1,4gebundener 3,6-Anhydro- $\alpha$-L-Galactose, b-d: Komponente des Polyacrylamidgels, b: Acrylamid, c: $N, N^{\prime}-$ Methylenbisacrylamid, d: vernetztes Polyacrylamidgel

\section{Polyacrylamidgele}

Durch die Copolymerisation von Acrylamidmonomeren mit einem Vernetzer, $N, N$ Methylenbisacrylamid (Bisacrylamid), erhält man ein klares und durchsichtiges Gel. Polyacrylamidgele sind chemisch inert. Die Porengröße wird durch die Gesamtkonzentration des Acrylamids $\mathrm{K}$ und den Vernetzungsgrad C (von englisch Crosslinking) bestimmt ( $\mathrm{g}=$ Gramm Einwaage $)$ : 


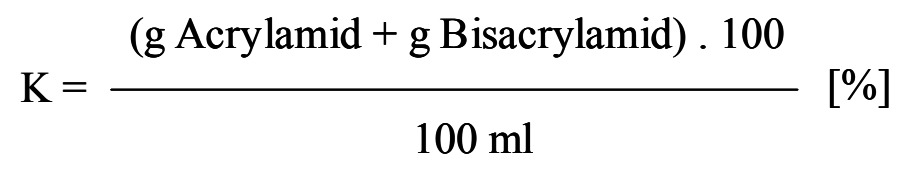

$$
\mathrm{C}=\frac{\mathrm{g} \text { Bisacrylamid } .100}{\mathrm{~g} \text { Acrylamid }+\mathrm{g} \text { Bisacrylamid }}[\%]
$$

Bei konstantem $C$ und steigendem $K$ werden die Poren kleiner. Während ein Gel mit $5 \%$ $K$ und $3 \% C$ einen Porendurchmesser von $5.3 \mathrm{~nm}$ aufweist, erhält man bei einem Gel mit $20 \% K$ und $3 \% C$ einen Durchmesser vom $3.3 \mathrm{~nm}$.

Die Polymerisation erfolgt unter Luftausschluss, da Sauerstoff zum Kettenabbruch führen kann. Zur Minimierung der Luftsauerstoffaufnahme werden die Gele meistens in vertikalen Gießständen aus Glas polymerisiert, Rundgele in Glasröhrchen, Flachgele in Küvetten, die durch zwei Glasplatten und Dichtungen gebildet werden. Die Effektivität der Polymerisation ist abhängig von der Temperatur, dem pH-Wert in der Lösung, dem $K$-Wert und der Katalysatorkonzentration.

Aufgrund ihres kleinen Porendurchmessers bieten Polyacrylamidgele eine gute Siebwirkung über einen weiten Trennbereich für Oligonucleotide, niedermolekulare Proteine und Nukleinsäure.

Die Auftrennung und Charakterisierung der synthetisierten Oligonucleotid-Konjugate wurden mittels denaturierender Gelelektrophorese mit Polyacrylamid als Trägermaterial durchgeführt. Hierfür wurde das Reaktionsgemisch im Vakuum getrocknet und im Anschluss in einer Mischung aus Formamid und Tris-Borat Pufferlösung (pH 8.3) gelöst. Eine 40 \%ige Acrylamid/Bisacrylamid (19/1)-Lösung wurde für den Ansatz des Gels verwendet. Zur Polymerisation kamen Ammoniumpersulfat (APS) als Initiator und $N, N, N^{\prime}, N^{\prime}$-Tetramethylethylendiamin (TEMED) als Katalysator zum Einsatz. Das Gel wurde 90 Minuten polymerisiert, bevor die Probe aufgetragen und mit der Elektrophorese begonnen werden konnte. Die Gesamtkonzentration von Acrylamid in der Gellösung 
betrug $14 \%$. Um den Verlauf der Elektrophorese verfolgen zu können, wurde ein Loading-Puffer eingesetzt. Der Loading-Puffer enthält Farbstoffe, die abhängig von der Gelkonzentration und der verwendeten Feldstärke ins Gel wandert. Durch die sichtbaren Farbstoffe konnte man die Position der zu analysierenden Substanz bestimmen und damit die Elektrophorese rechzeitig beenden, bevor die Probe die untere Kante des Gels erreicht hat.

Nach der Abkühlung der Gele wurden die Glasplatten aus der Apparatur entfernt und die Gelschichten vorsichtig auf eine präparative DC-Platte, die mit Frischhaltefolie zugedeckt war, gelegt. Durch die Einstrahlung von Licht der Wellenlänge $254 \mathrm{~nm}$ wurden die Banden durch Fluoreszenzlöschung sichtbar gemacht.

In Abbildungen 49 und 50 sind die aufgenommenen Bilder der gesichteten Banden von Verbindungen PODN1 (3-25) und PODN2 (3-26) dargestellt.

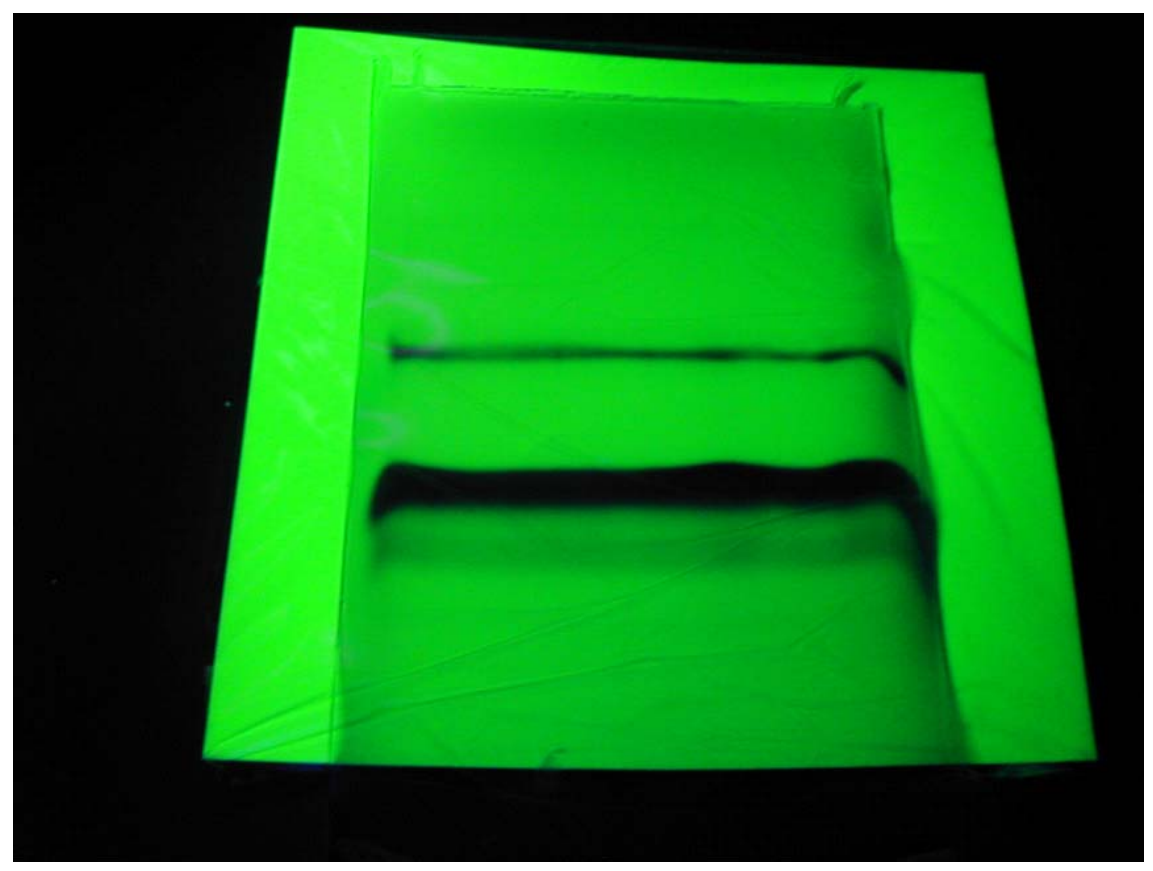

Abbildung 44: Präparatives Polyacrylamidgel von Verbindung PODN1 


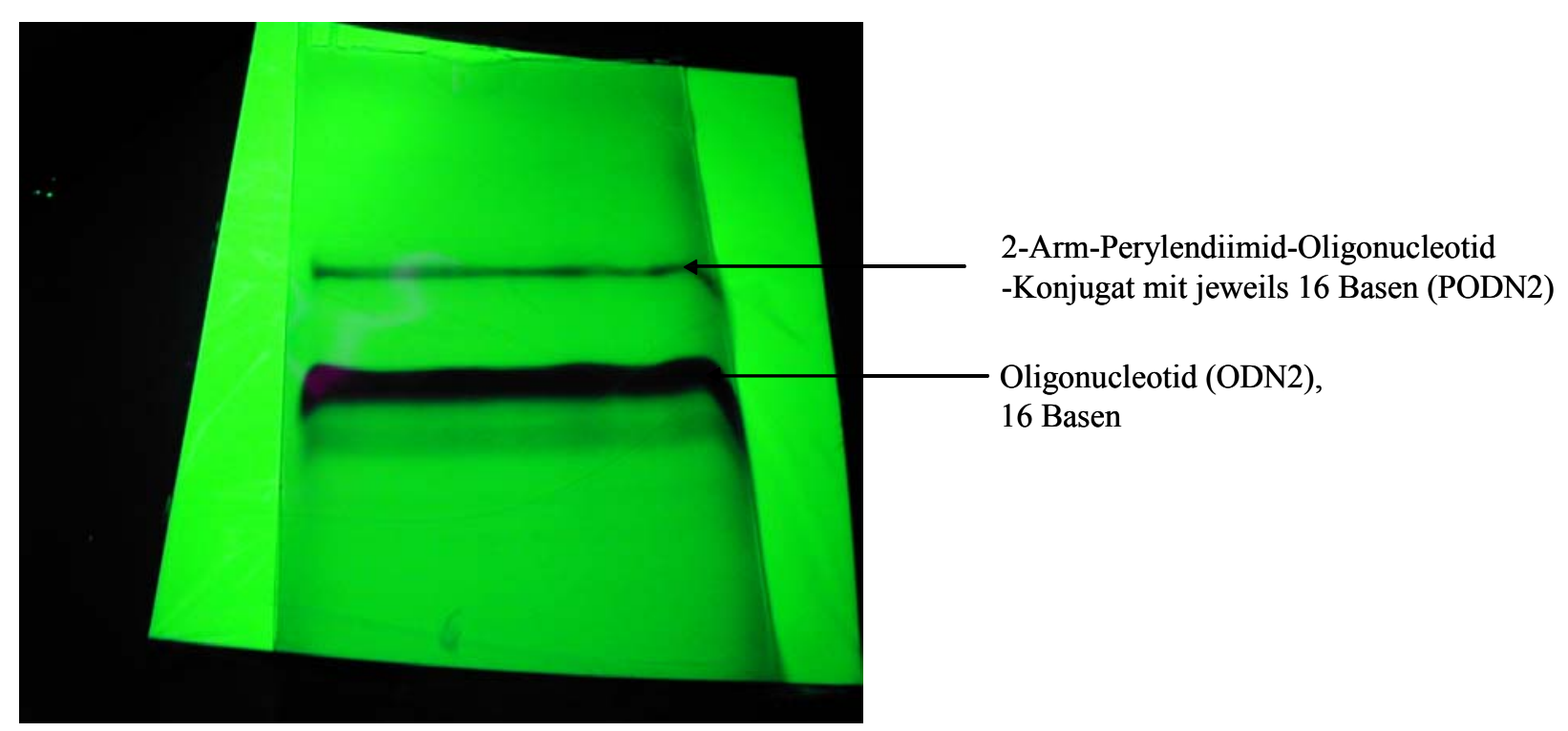

Abbildung 45: Präparatives Polyacrylamidgel von PODN2

Man erkennt zwei Banden, die untere Bande entspricht dem nicht reagierten Oligonucleotid ODN1 bzw. ODN2, die im großen Überschuss für die Kopplungsreaktion eingesetzt wurden, um die Ausbeute an Perylendiimid-bis(oligonucleotid) (PODN1 und PODN2) gegenüber dem monosubstituierten Konjugat (z. B. 3-27) zu erhöhen. Die zweite Bande sollte entweder das Perylendiimid-bis(Oligonucleotid)- oder das monosubstituierte Konjugat (PDI-ODN) sein. Es war damit zu rechnen, dass in der Gelelektrophorese drei Banden auftreten (ODN, PDI-ODN und ODN-PDI-ODN). Tatsächlich sind nur zwei Banden zu sehen. Am oberen Ende der Gelschicht waren farbige Überreste vom Reaktionsgemisch zu sehen, die sich im Gegensatz zu den anderen zwei Banden vom Gelmaterial nicht extrahieren liessen. Diese sind möglicherweise der bei der Zusammenführung der Farbstoff- und Oligonucleotidlösung ausgefallene und nicht umgesetzte Farbstoff. Aufgrund der hydrophoben Eigenschaften des Perylendiimids und der Tatsache, dass Perylendiimid keine Ladung enthält, sollte es im Gelmaterial nicht wandern können. Des weiteren könnte es sich auch bei dem unlöslichen Material um das monosubstituierte Konjugat 3-27 handeln, das wegen seiner amphiphilen Struktur große Aggregate bildet und deshalb im Trägermaterial nicht wandern kann. 


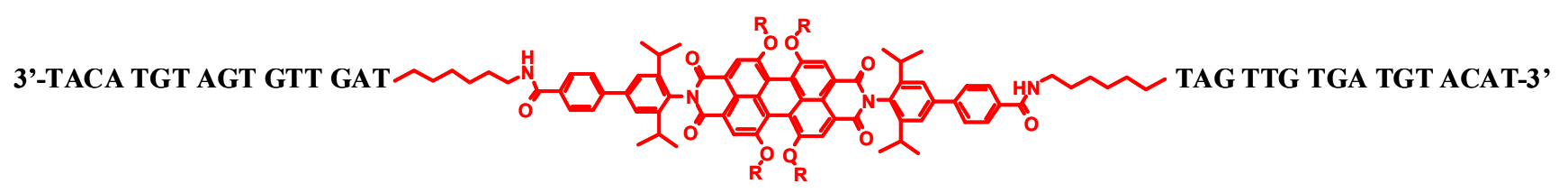

3-25, PODN1 (ODN1-PDI-ODN1)

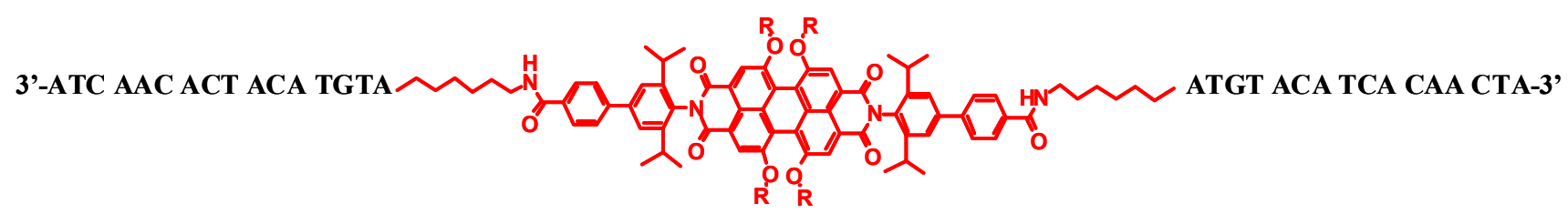

3-26, PODN2 (ODN2-PDI-ODN2)
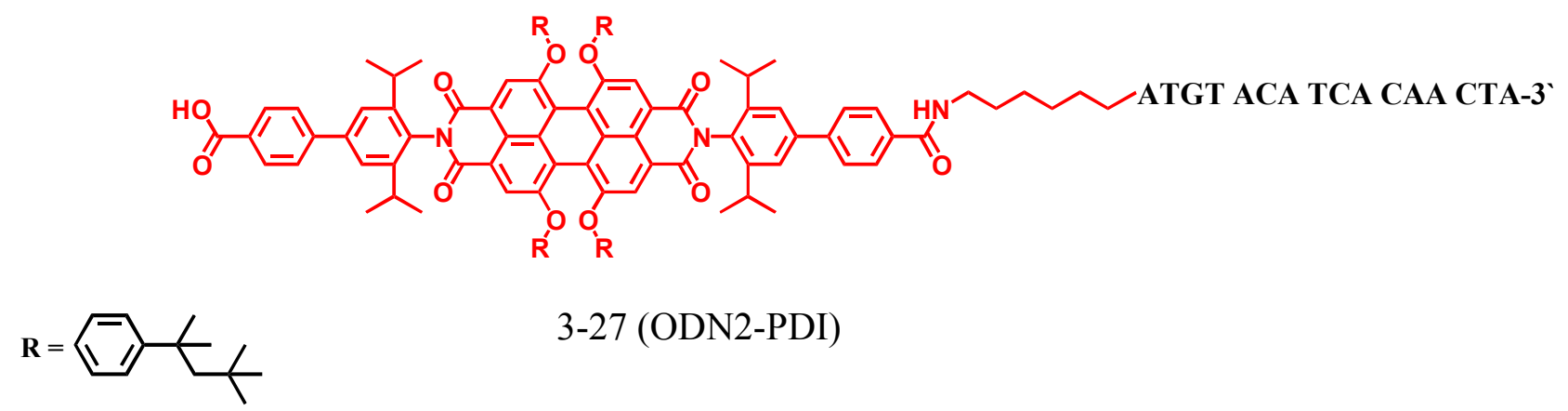

3-27 (ODN2-PDI)

Abbildung 46: Schematische Struktur der hergestellten Konjugate

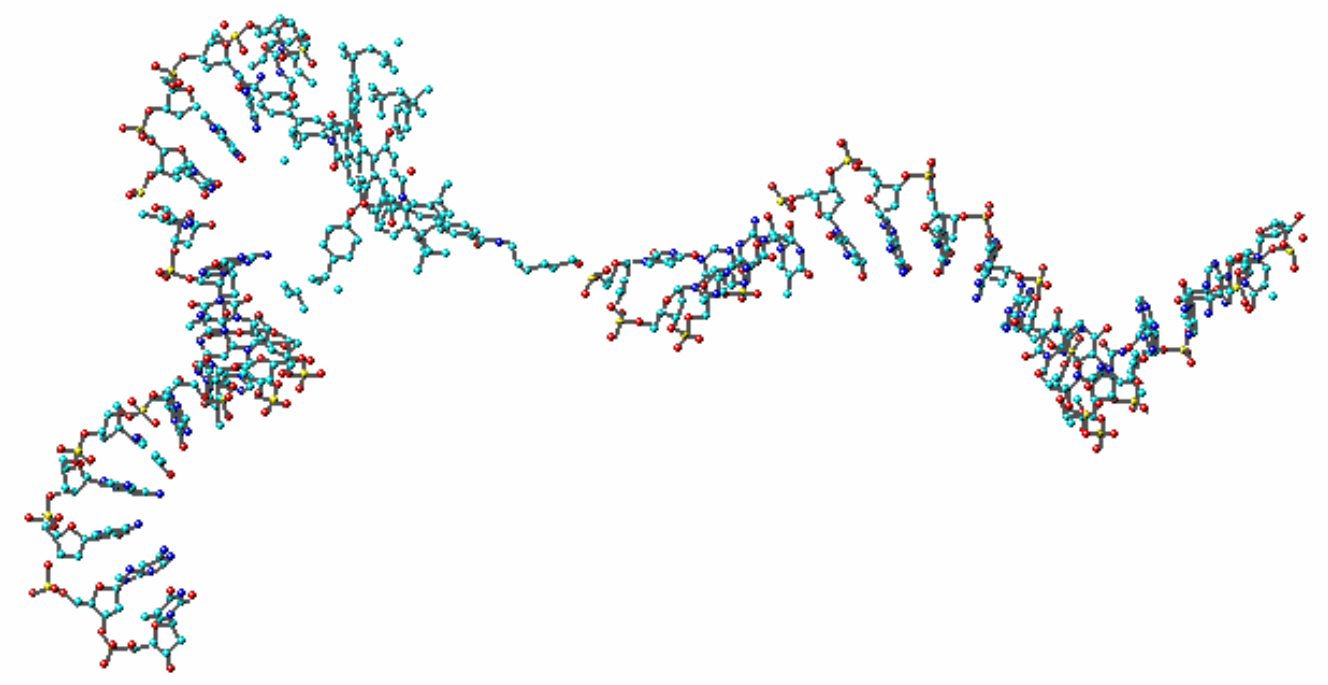

Abbildung 47: Die optimierte Struktur von PODN1 (HyperChem 7.0) 
Um die Banden zu identifizieren, wurden sie aus dem Gel ausgeschnitten und im Wasser bei $37^{\circ} \mathrm{C}$ extrahiert. Die erhaltene Gellösung wurde zentrifugiert und im Anschluss der erhaltene Überstand entsalzt. Durch die Maldi-Tof-Analysen konnte lediglich die Struktur der unteren Bande (ODN1 oder ODN2) nachgewiesen werden. Es war nicht möglich, von der aus der oberen Bande extrahierten Substanz einMaldi-Tof-MS aufzunehmen. Versuche zum Strukturbeweis von PODN1 und PODN2 sollen im folgenden Abschnitt dargestellt werden.

Um die Struktur des Perylendiimid-bis(oligonucleotid)-konjugats nachzuweisen, sollte zunächst ein Perylendiimid-mono(oligonucleotid) synthetisiert werden, in dem das Perylendiimid nur mit einer Oligonucleotidsequenz kovalent gebunden ist. Das Laufverhalten dieses Konjugats sollte sich aufgrund des kleineren Inhalts an Basen von dem des Bis(oligonucleotid)-konjugats unterscheiden. Um dieses Ziel zu erreichen, sollte zunächst ein Perylendiimid mit einer Carbonsäurefunktion synthetisiert werden. Diesem Ziel stand die Desymmetrisierung des Perylendiimids entgegen. Im Falle der Imidisierung vom 1,6,7,12-Tetrachlorperylen-3,4:9,10-tetracarbonsäuredianhydrid (3-18) wurde 4Brom-2,6-diisopropylphenylamin (3-19) eingesetzt, um Perylendiimid mit zwei Bromfunktionen (3-20) in der Imidstruktur zu erhalten. Setzt man bei dieser Reaktion statt Verbindung 3-18 ein Gemisch aus 4-Brom-2,6-diisopropylphenylamin und dem kommerziell erhältlichen 2,6-Diisopropylphenylamin ein, sollte ein statistisches Produkt aus drei möglichen Reaktionsprodukten erhalten werden, die sich chromatographisch auftrennen lassen. Die Imidisierung von Perylendiimid 3-18 mit den zwei aromatischen Aminen wurde in Propionsäure unter Rückfluss für 17 Stunden bei $155^{\circ} \mathrm{C}$ durchgeführt. Mit einem 2.5-fachen Überschuss von jedem Amin (3-19 und 2,6-Diisopropylphenylamin) pro Perylentetracarbonsäuredianhydrid 3-18 wurde die beste Ausbeute erzielt (43\%).

Die Aufarbeitung dieser Reaktion wurde analog zu der Synthese von Verbindung 3-20 durchgeführt. Eine DC-Kontrolle zeigte, dass die drei erhaltenen Produkte (3-29, 3-20 und PDI ohne Bromfunktion in der Imidstruktur) mit Toluol als Laufmittel chromatographisch aufgetrennt werden können. Aufgrund des DC-Ergebnisses wurde eine säulenchromatographische Aufreinigung auf Kieselgel mit Toluol als Elutionsmittel 
durchgeführt. Die Reinheit und die Struktur von 3-29 konnten mit Hilfe von Dünnschichtchromatographie, FD-Massenspektrometrie und ${ }^{1} \mathrm{H}-\mathrm{NMR}$ nachgewiesen werden.<smiles>O=C1OC(=O)c2cc(Cl)c3c4c(Cl)cc5c6c(cc(Cl)c(c7c(Cl)cc1c2c73)c64)C(=O)OC5=O</smiles>

3-18
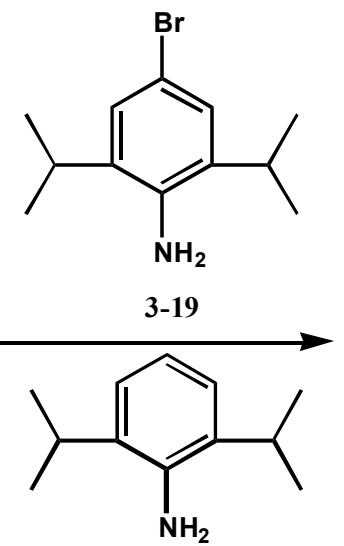

Propionsäure, $155^{\circ} \mathrm{C}, 15 \mathrm{hr}$,

$43 \%$<smiles>CC(C)c1cccc(C(C)C)c1N1C(=O)c2cc(Cl)c3c4c(Cl)cc5c6c(cc(Cl)c(c7c(Cl)cc(c2c37)C1=O)c64)C(=O)N(c1c(C(C)C)cc(Br)cc1C(C)C)C5=O</smiles>

3-29

Abbildung 48 : Darstellung von asymmetrischem Perylendiimid mit einer Bromfunktion in der Imidstruktur

Zur Verbesserung der Löslichkeit lassen sich tert.-Octylphenoxygruppen in die bayRegion einführen. Die Chloratome in den bay-Positionen können leicht nucleophil substituiert werden, da die Positionen 1, 6, 7, 12 durch die elektronenziehende Wirkung der Imidstruktur stark aktiviert werden. Für die gewünschte vierfache Veretherung in den bay-Positionen wurde das Perylendiimid 3-29 mit einem 10-fachen Überschuss an tert Octylphenol und einem 5-fachen an Kaliumcarbonat als Base in N-Methylpyrrolidon bei $90{ }^{\circ} \mathrm{C}$ umgesetzt. Nach der Abkühlung auf Raumtemperatur mischte man das Reaktionsgemisch mit verdünnter Salzsäure (3 Teile Methanol, 1 Teil destilliertes Wasser, 0.25 Teil konz. Salzsäure) und liess die Lösung 2 Stunden rühren. 
<smiles>CC(C)c1cccc(C(C)C)c1N1C(=O)c2cc(Cl)c3c4c(Cl)cc5c6c(cc(Cl)c(c7c(Cl)cc(c2c37)C1=O)c64)C(=O)N(c1c(C(C)C)cc(Br)cc1C(C)C)C5=O</smiles>

3-29
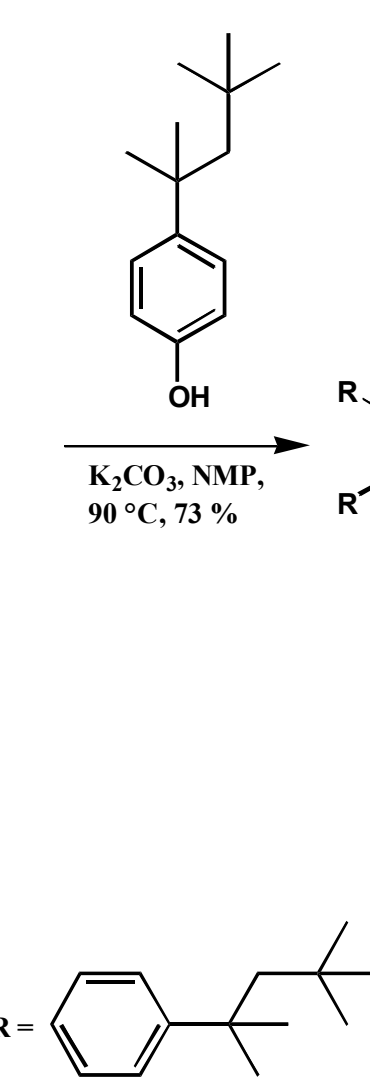<smiles>[R]Oc1cc2c3c(cc(O[R])c4c5c(O[R])cc6c7c(cc(O[R])c(c1c34)c75)C(=O)N(c1c(C(C)C)cc(Br)cc1C(C)C)C6=O)C(=O)N(c1c(C(C)C)cccc1C(C)C)C2=O</smiles>

3-30

Abbildung 49: Synthese eines phenoxylierten Perylendiimid mit einer Bromfunktion

Der ausgefallene Farbstoff wurde über einer D4-Fritte filtriert. Die Aufreinigung erfolgte auf einer Chromatographiesäule aus Kieselgel mit einem Lösungsmittelgemisch aus Dichlormethan/Petrolether als Eluent. Man erhielt das Produkt 3-30 mit einer Ausbeute von 73 \%. In Abbildung 50 ist dasMaldi-Tof-MS dargestellt. Der erhaltene Peak bei 1608 g/mol stimmt mit dem berechneten Molekulargewicht von Verbindung 3-30 (1607.0 $\mathrm{g} / \mathrm{mol})$ überein.

Neben der Maldi-Tof- und Elementaranalyse als Struktur- und Reinheitsnachweis für das asymmetrische Perylendiimid 3-30 wurden auch ${ }^{1} \mathrm{H}-$ und ${ }^{13} \mathrm{C}-\mathrm{NMR}-$ Spektren aufgenommen. In Abbildung 51 ist das ${ }^{1} \mathrm{H}-\mathrm{NMR}-$ Spektrum $\mathrm{zu}$ sehen. Die genaue Zuordnung und Intensitätsverhältnisse der aromatischen und aliphatischen Signale liefern einen weitern Strukturbeleg. Im aliphatischen Bereich können sowohl das Septett (Proton g) als auch das Duplett (Proton h) der Isopropylgruppe als auch die Singuletts (i, j, k) identifiziert werden. Als charakteristisches Merkmal sind die Signale der Protonen c und 
Kapitel 3: Synthese und Selbstorganisation von Perylen-Oligonucleotid-Konjugaten

$\mathrm{d}$ bei $\delta=6.85$ und $7.36 \mathrm{ppm}$, was dieses asymmetrische Molekül von der symmetrischen

Verbindung 3-21 (zwei Bromfunktionen in der Imidstruktur) unterscheidet.

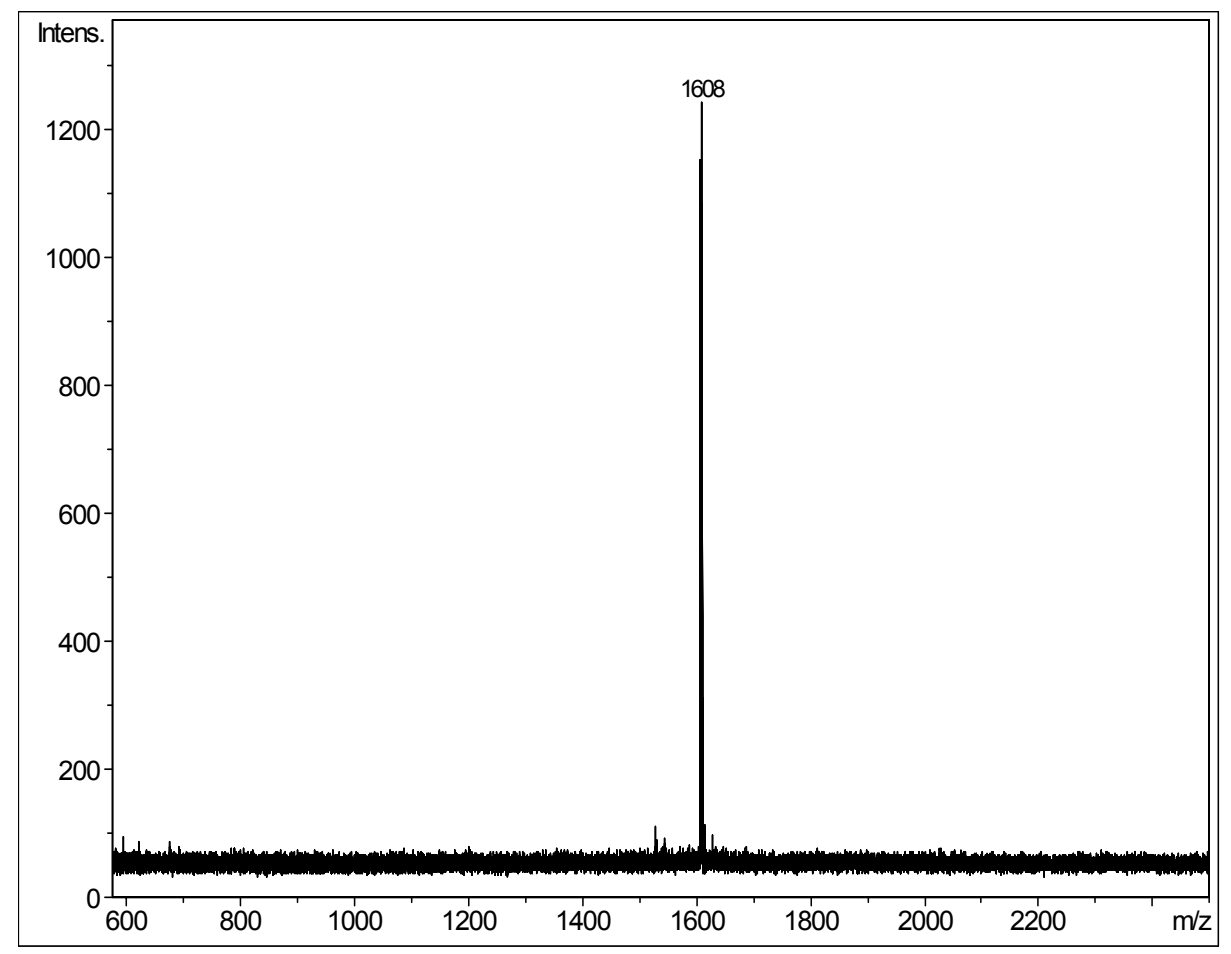

Abbildung 50: Maldi-Tof-Analyse für das asymmetrische Perylendiimidderivat 3-30 $\left(\mathrm{M}_{\mathrm{ber}}=\right.$ $1607.0 \mathrm{~g} / \mathrm{mol}$ )

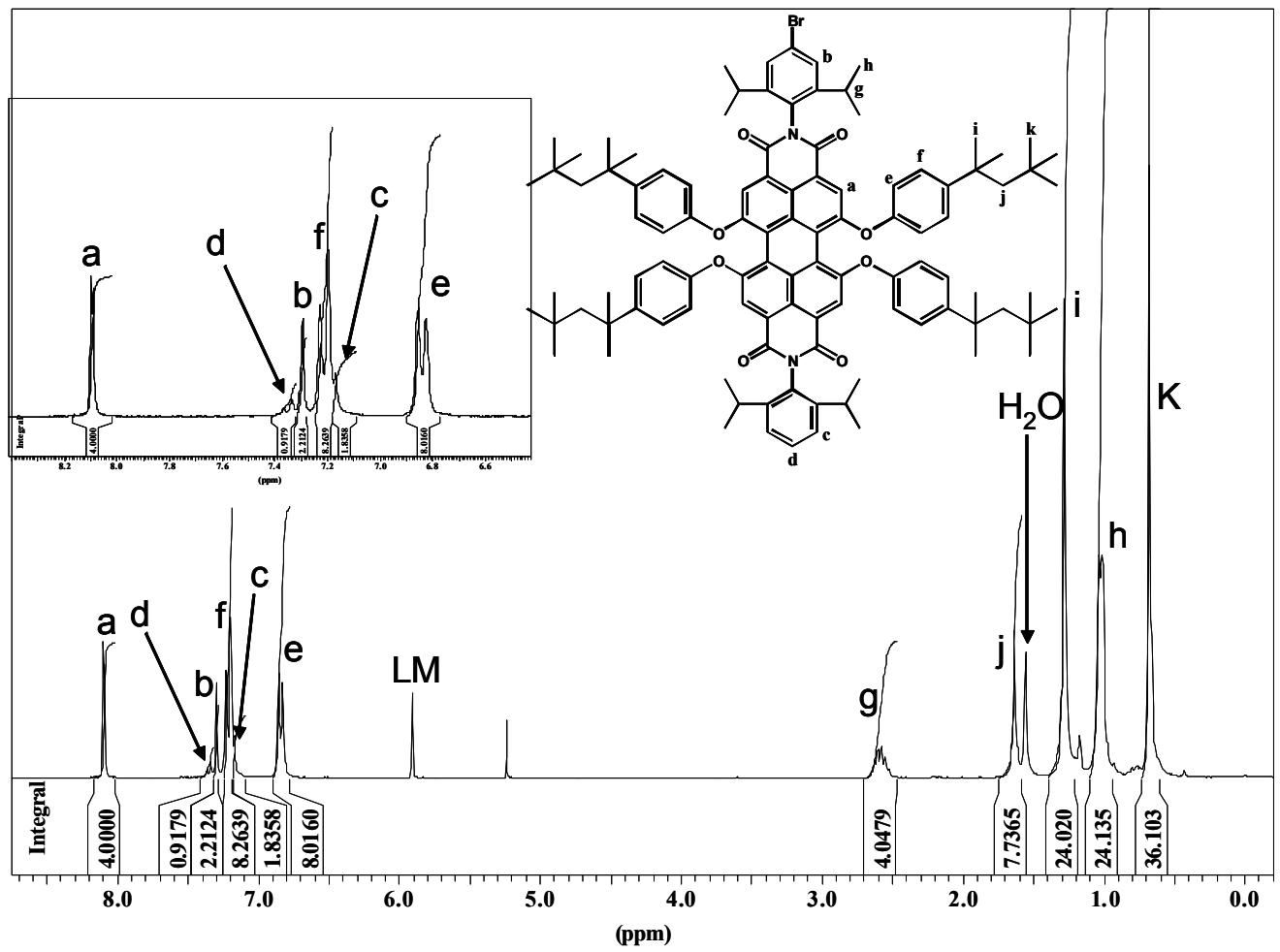

Abbildung 51: ${ }^{1} \mathrm{H}-\mathrm{NMR}-$ Spektrum mit Zuordnung der Signale von 3-30 (250-MHz, Lösungsmittel: $\mathrm{C}_{2} \mathrm{D}_{2} \mathrm{Cl}_{4}$ ) 
Die Einführung von einer Carbonsäurefunktion in die Imidstruktur des Perylendiimids 3-30 erfolgte ganz analog zur Darstellung von Verbindung 3-22 durch die palladiumkatalysierte Suzuki-Kopplung, in der die kommerziell verfügbare 4Methoxycarbonylphenylboronsäure mit dem Perylenderivat 3-30 in ein Lösungsmittelgemisch aus Toluol, Methanol und 2M Kaliumcarbonatlösung und $\mathrm{Pd}\left(\mathrm{PPh}_{3}\right)_{4}$ als Katalysator bei $75{ }^{\circ} \mathrm{C}$ unter Inertgasatmosphäre zur Reaktion gebracht wurden (Abb. 52). Nachdem FD-Massenspektrometrie und DC die vollständige Umsetzung bestätigten, erfolgte die Aufreinigung säulenchromatographisch mit Dichlormethan als Eluent, aus dem das Produkt 3-31 mit einer Ausbeute von 82 \% gewonnen werden konnte.

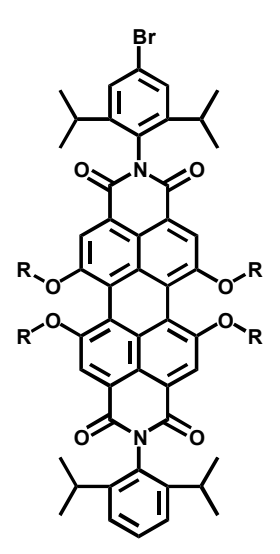

3-30

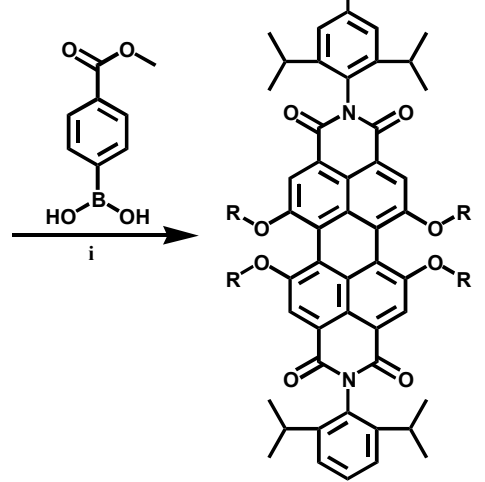

3-31

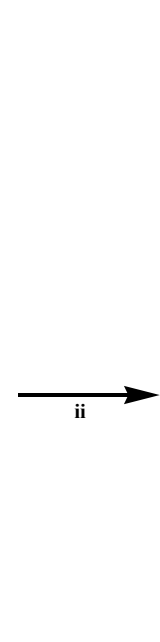

$3-32$

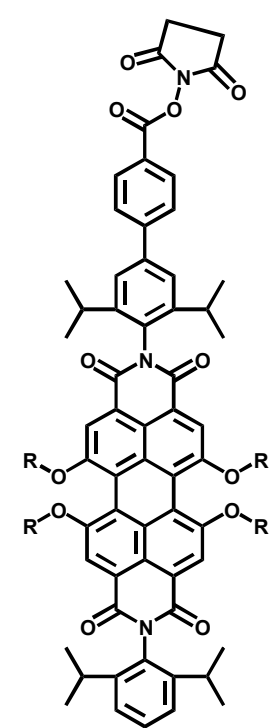

3-33

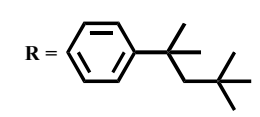

Abbildung 52: Synthese von Perylendiimid mit einer Säurefunktion und Aktivierung mit NHydroxysuccinimid i) $\mathrm{Pd}\left(\mathrm{PPh}_{3}\right)_{4}, 2 \mathrm{M} \mathrm{K}_{2} \mathrm{CO}_{3}$, Methanol, Toluol, $15 \mathrm{~h}, 75{ }^{\circ} \mathrm{C}, 82 \%$ ii) $\mathrm{KOH}$, THF/Wasser, $24 \mathrm{~h}, 80^{\circ} \mathrm{C}, 88 \%$ iii) DCC, DMF, RT, über Nacht, $100 \%$

Anschließend wurde die Abspaltung der Methylschutzgruppe mit 10 Äquivalenten Kaliumhydroxid in einem Lösungsmittelgemisch bestehend aus THF und Wasser bei 80 ${ }^{\circ} \mathrm{C}$ durchgeführt. Nach einer Reaktionszeit von 24 Stunden liess man das Reaktionsgemisch auf Raumtemperatur abkühlen und das Produkt 3-32 in einer 
verdünnten Salzsäurelösung (2 M) ausfallen. Das Produkt wurde filtriert und 24 Stunden unter Vakuumbedingungen getrocknet. Die Ausbeute des in analytischer Reinheit erhaltenen Produkts 3-32 beträgt $88 \%$. Die Strukturen sowohl der methylgeschützten Säure 3-31 als auch der freien Säure 3-32 lassen sich durch Molekülionenpeaks im FDund Maldi-Tof-Massenspektrum, Elementaranaylse und NMR-Spektroskopie belegen. Im ${ }^{1}$ H-NMR-Spektrum von 3-31 erscheinen die Protonen der Methylschützgruppe als Singulett bei $\delta=3.87 \mathrm{ppm}$. Im aromatischen Bereich treten die Protonen $\mathrm{H}_{\mathrm{b}}$ und $\mathrm{H}_{\mathrm{c}}$ als zwei Dubletts bei $\delta=8.09$ und $\delta=7.78 \mathrm{ppm}$. Die Zuordnung und die Intensität der Signale stehen im Einklang mit der angenommenen Struktur.

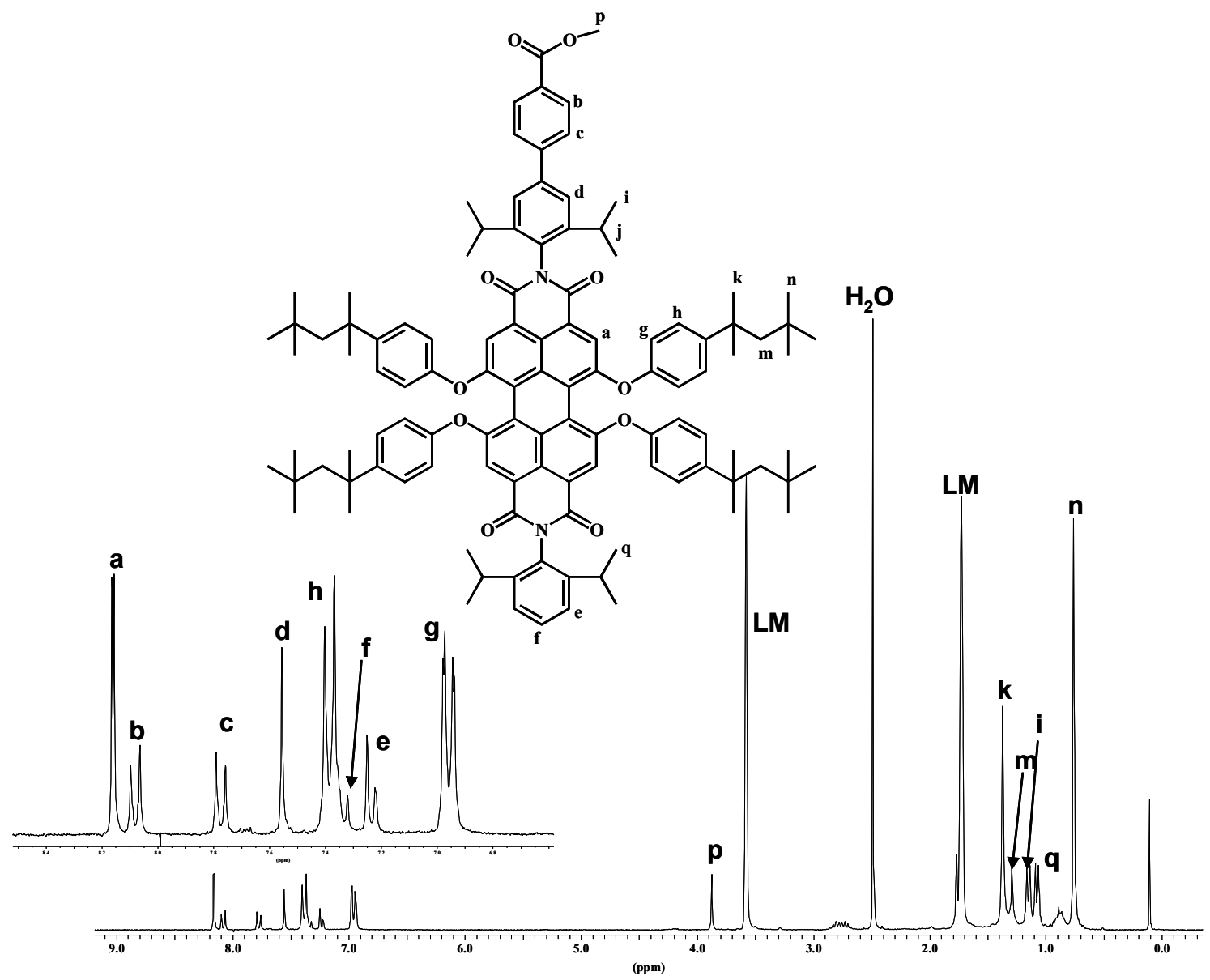

Abbildung 53: ${ }^{1} \mathrm{H}-\mathrm{NMR}-$ Spektrum von Verbindung 3-31 ( 250-MHz, Lösungsmittel: THF-d ${ }^{8}$ )

Beim ${ }^{1}$ H-NMR-Spektrum des carboxyfunktionalisierten Perylendiimids 3-32 (Abb. 54) verschwindet der Peak der Methylschutzgruppe. Die Lage und Anzahl der Signale der aliphatischen und aromatischen Protonen bestätigen ebenfalls die Struktur. $\mathrm{Im}{ }^{13} \mathrm{C}$ - 
Spinechoexperiment (siehe Experimenteller Teil) findet man die charakteristischen Signale der zwei Carbonylkohlenstoffatome bei $\delta=166.9$ sowie $\delta=163.6 \mathrm{ppm}$.

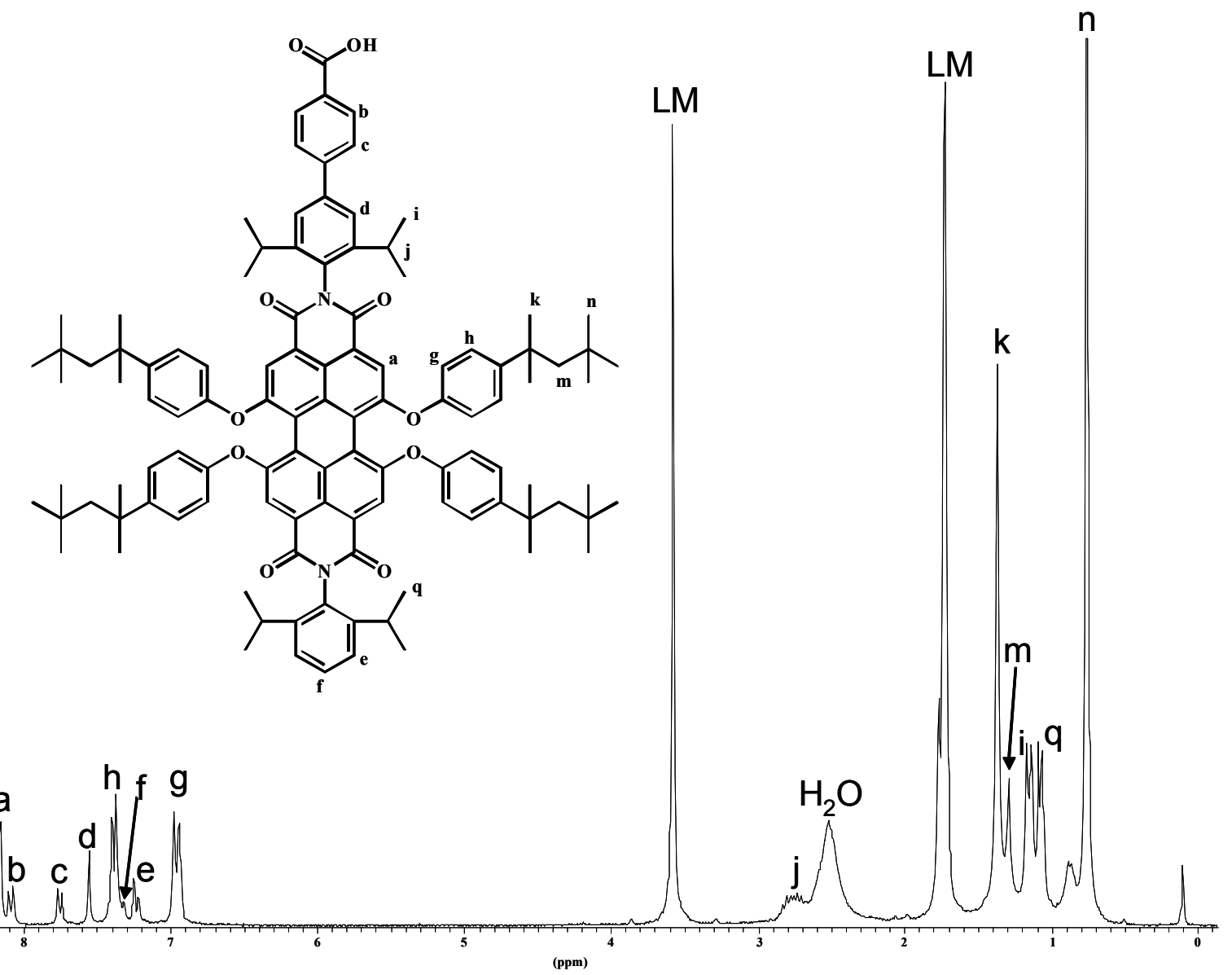

Abbildung 54: ${ }^{1} \mathrm{H}-\mathrm{NMR}-$ Spektrum mit Zuordnung der Signale von 3-32 ( $250-\mathrm{MHz}$, Lösungsmittel: THF-d ${ }^{8}$ ). Die Abwesenheit des Signals der Methylschutzgruppe ist ein Hinweis auf die vollständige Abspaltung

DasMaldi-Tof-MS von 3-32 ist in Abbildung 55 dargestellt. Als Matrix wurde Dithranol verwendet. Man erkennt nur ein Signal bei m/z = $1649 \mathrm{~g} / \mathrm{mol}$, das mit dem berechneten Molekulargewicht von 3-32 im Einklang steht $\left(\mathrm{M}_{\text {berechnet }}=1648.22 \mathrm{~g} / \mathrm{mol}\right)$. 


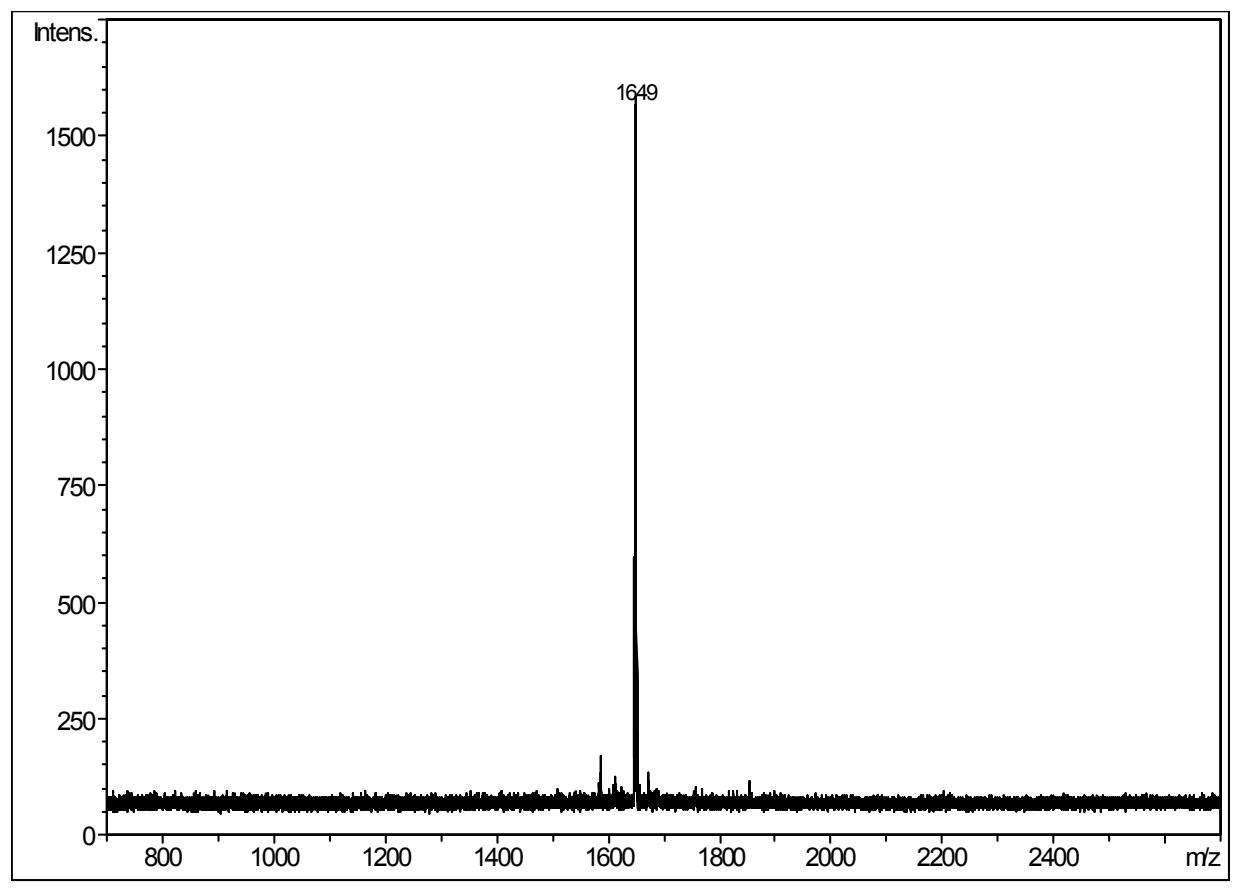

Abbildung 55: Maldi-Tof-MS vom carboxyfunktionalisierten Perylentetracarboxdiimid 3-32

Zur Kopplung von 3-32 an Aminoligonucleotid soll die Carbonsäuregruppe in den Aktivester (Succinimidester) überführt werden, um die Carboxyfunktion für die nucleophile Substitution durch die Aminfunktion des Oligonucleotides zu aktivieren. Das carboxyfunktionalisierte Perylendiimid 3-32 wurde mit drei Äquivalenten NHydroxysuccinimid (NHS) und Dicylohexylcarbodiimid (DCC) in trockenem DMF bei Raumtemperatur zur Reaktion gebracht (Abb. 52). Nach einer Reaktionszeit von 20 Stunden wurde eine DC-Kontrolle in Dichlormethan als Laufmittel durchgeführt. Dabei wurde festgestellt, dass die Umsetzung in den Aktivester noch nicht vollständig abgelaufen war. Aus diesem Grund wurden zusätzliche Mengen an NHS und DCC zugesetzt, und das Reaktionsgemisch wurde weitere 24 Stunden gerührt. Eine neue DCKontrolle und eine FD-Massenspektroskopieanalyse zeigten nun eine vollständige Umsetzung von 3-32 in den Aktivester 3-33. Schließlich wurde die Reaktionsmischung eingeengt und im Vakuum getrocknet. Das Produkt 3-33 wurde für die Reaktion mit dem Aminoligonucleotid ODN1 ohne zusätzliche Aufreinigungsmaßnahmen weiter verwendet. Fünf Äquivalente vom Aminoligonucleotid ODN1 wurden in $0.1 \mathrm{M}$ Natriumtetraboratlösung gelöst und mit dem in DMF gelösten Aktivester 3-33 gemischt. 
Das Reaktionsgemisch liess man bei $37^{\circ} \mathrm{C}$ über Nacht rühren. Dabei konnte keine klare Reaktionslösung beobachtet werden. Dies ist darauf zurückzuführen, dass ein mit einer Oligonucleotidsequenz monofunktionalisiertes Perylendiimid keine ausreichende Wasserlöslichkeit besitzt und zu Aggregation neigt.

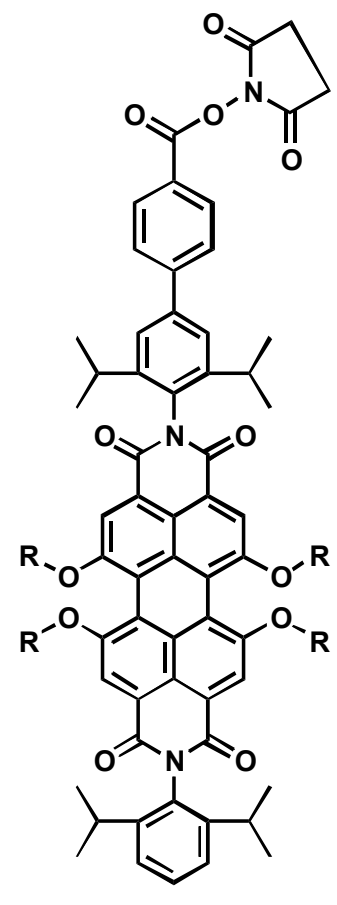

3-33

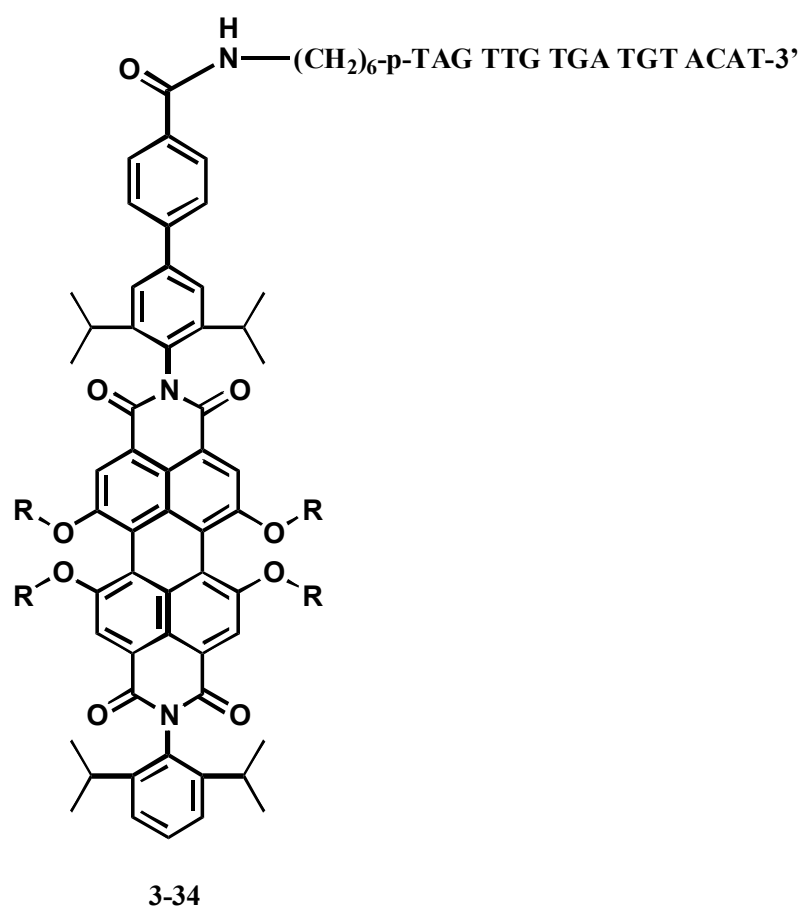

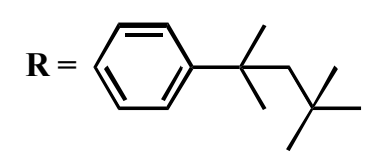

Abbildung 56: Synthese von Perylendiimid-Oligonucleotid-Konjugat 3-34 i) $\mathrm{H}_{2} \mathrm{~N}-\left(\mathrm{CH}_{2}\right)_{6}$-p-TAG TTG TGA TGT ACAT-3`, 0.1 M Natriumtetraborat-Lösung, pH 8.5-9, bei $37^{\circ} \mathrm{C}$ über Nacht

Einen Beleg für die ausgebildeten Aggregate lieferte die denaturierende Polyacrylamidgelelektrophorese (PAGE). Eine 12\%ige PAGE wurde unter denaturierenden Bedingungen (Vorheizen der zu analysierenden Oligonucleotidprobe 5 Minuten bei $95^{\circ} \mathrm{C}$ ) durchgeführt. Wie man in Abbildung 57 erkennen kann, tritt im Gegensatz zu den bereits beschriebenen zwei Banden im Falle vom Perylendiimidbis(oligonucleotid) (Abb. 44 und 45) hier nur eine Bande auf, die dem nicht reagierten Oligonucleotid ODN1 entspricht. Dies wurde durch das Auftragen von gereinigtem ODN1 in einer getrennten Geltasche neben dem Reaktionsprodukt bestätigt. In Abbildung 
57 ist nur eine Bande (in beiden Taschen) zu sehen, d.h. ODN1 ist parallel zum Reaktionsgemisch im Gel gewandert. Vergleicht man die hier aufgetretene Bande mit Abbildung 44, kann man feststellen, dass ein mit Oligonucleotiden bifunktionalisiertes Perylendiimid PODN1 im Gegensatz zum monosubstituierten Konjugat 3-33 eine deutlich bessere Löslichkeit in wässrigen Medien und eine geringere Neigung zur Aggregatbildung aufweist. Bei der Elektrophorese wurde eine rot gefärbte Schicht an der oberen Kante des Gels beobachtet, die sich aus dem Gel nicht extrahieren lässt. Das deutet darauf hin, dass sich sehr große Aggregate ausbildeten, die durch die Poren des Gels nicht wandern können.

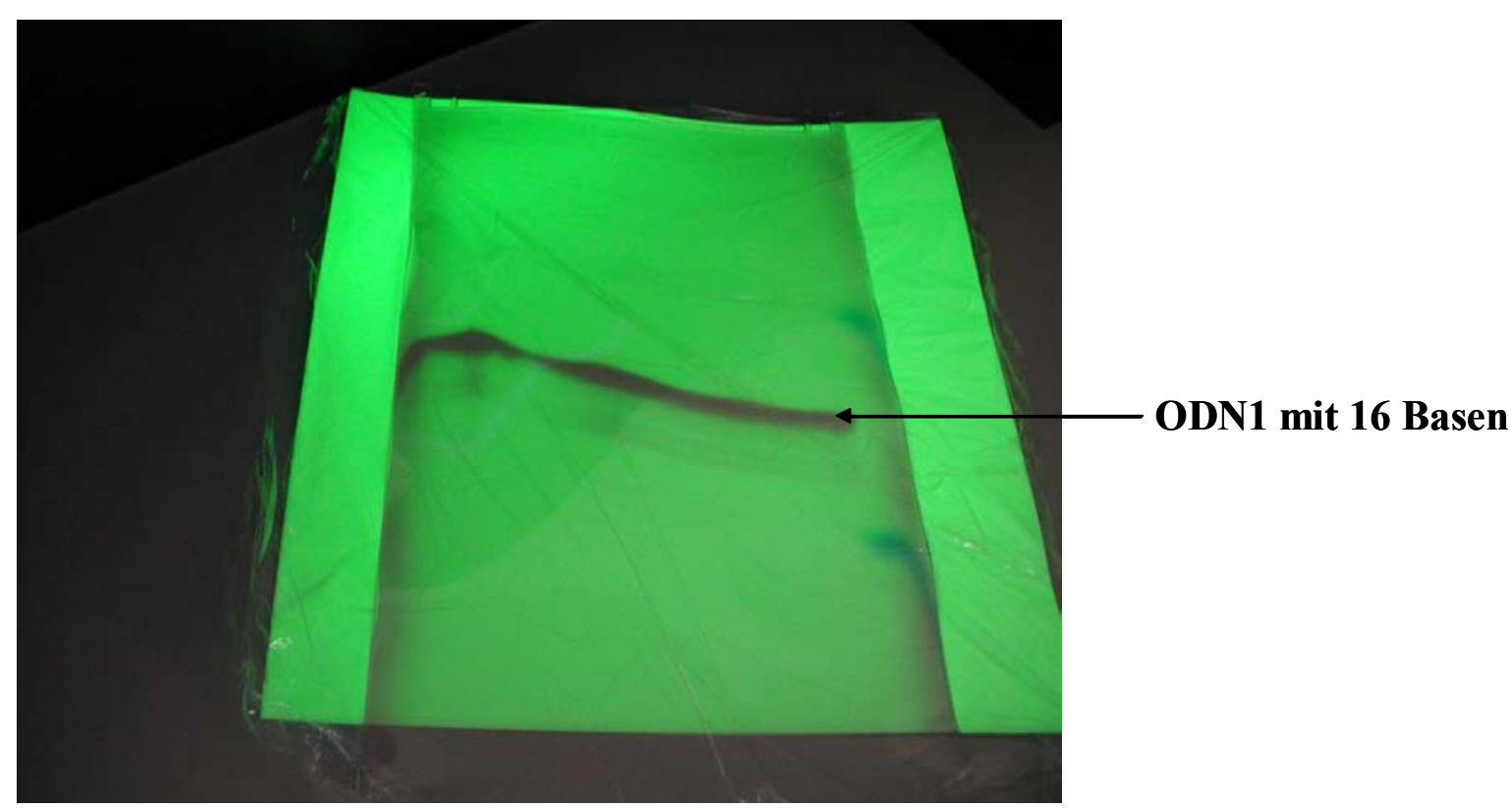

Abbildung 57: Denaturierende Polyacrylamidgelelektrophorese (PAGE) von 3-34, 12 \% Acrylamidlösung, Spannung 450 V, 5 Stunden in 1x TBE-Puffer

Aufgrund der gebildeten großen Aggregate konnte das Konjugat 3-34 (PDI-ODN1) nicht aufgereinigt und isoliert werden. In Abbildung 58 ist ein Modell dargestellt, das einen Eindruck vermittelt, wie solche Aggregate in wässriger Lösung aussehen könnten. Man kann sich das aggregierte Konjugat PDI-ODN1 in wässriger Lösung als mizellare Strukturen vorstellen, wobei die hydrophoben Perylendiimidmoleküle sich im Inneren der Mizelle positionieren, um vom polaren Lösungsmittel, Wasser, abgeschirmt zu werden. 


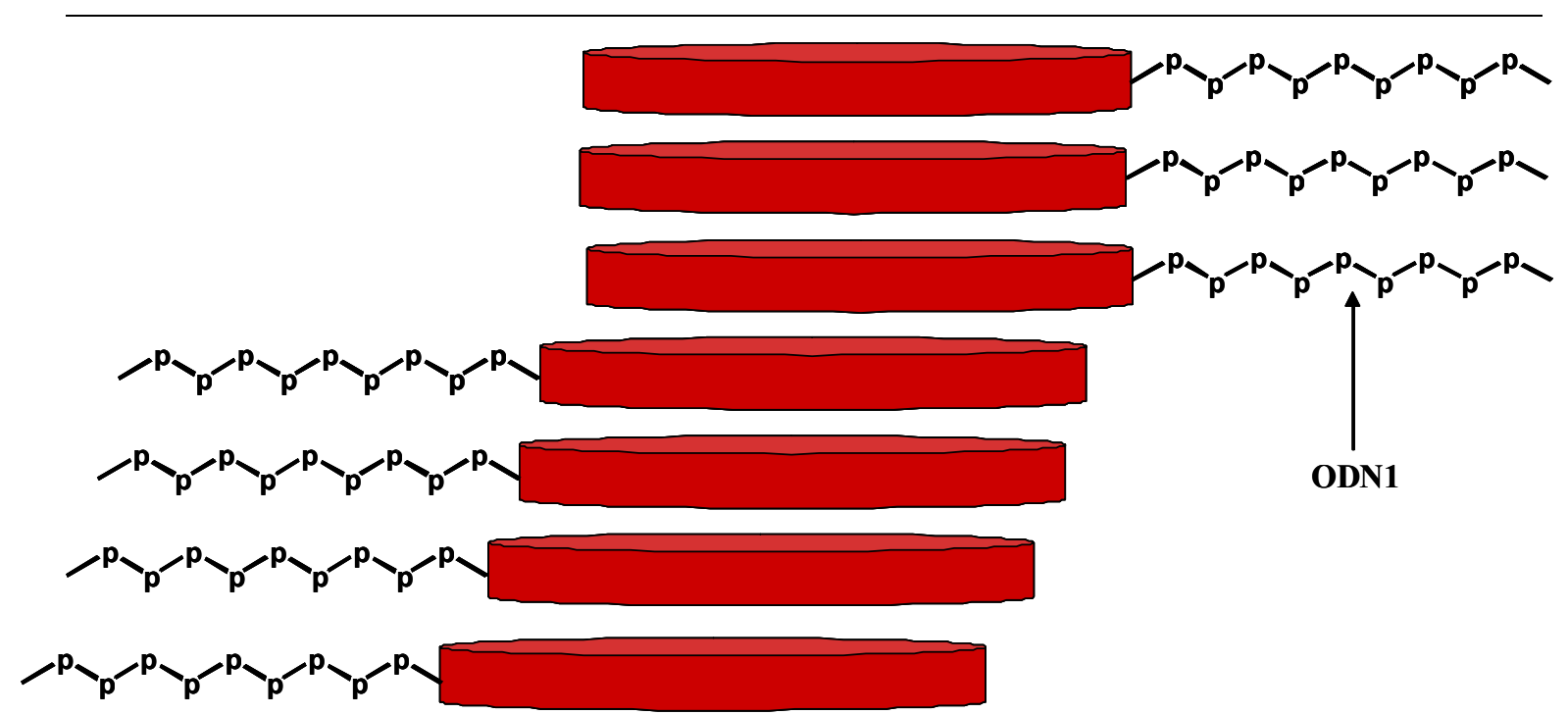

Abbildung 58: Hypothetische Darstellungen für das Verhalten von 3-34 in wässriger Lösung (P: die Phosphatgruppen des DNA-Rückrats)

Durch die Umsetzung von 3-24 mit dem Oligonucleotid in alkalischer Pufferlösung könnte ein Hydrolyseprodukt entstehen. Aus diesem Grund sollte geprüft werden, ob sich bei der Kopplungsreaktion das Dinatriumsalz 3-35 (das Hydrolyseprodukt von Verbindung 3-23) bildet. Dieses Produkt 3-35 gewinnt durch die zwei anionischen Gruppen eine moderate Polarität, die das Molekül trotz des großen und hydrophoben Grundgerüsts in wässrige Lösung überführen und deshalb bei der Gelelektrophorese im Gelmaterial beweglich machen. So wurde der Aktivester 3-24 in DMF gelöst, mit Natriumtetraborat-Pufferlösung gemischt und unter den gleichen Bedingungen ( $\mathrm{pH}$ 8.5-9, $37^{\circ} \mathrm{C}$ ), unter den die Kopplung ans Aminoligonucleotid durchgeführt wurde, über Nacht gerührt. Nach einer Reaktionszeit von 20 Stunden war ein roter Niederschlag und keine farbige und klare Reaktionslösung $\mathrm{zu}$ sehen, d.h. die Hydrolyse der zwei Carboxyfunktionen in der Imidstruktur des Perylens konnte keine Wasserlöslichkeit bei 3-35 herbeiführen. Aufgrund dieses Ergebnisses kann man die Aggregatsbildung von 323 in Wasser auf seine hydrophobe Struktur zurückführen. 


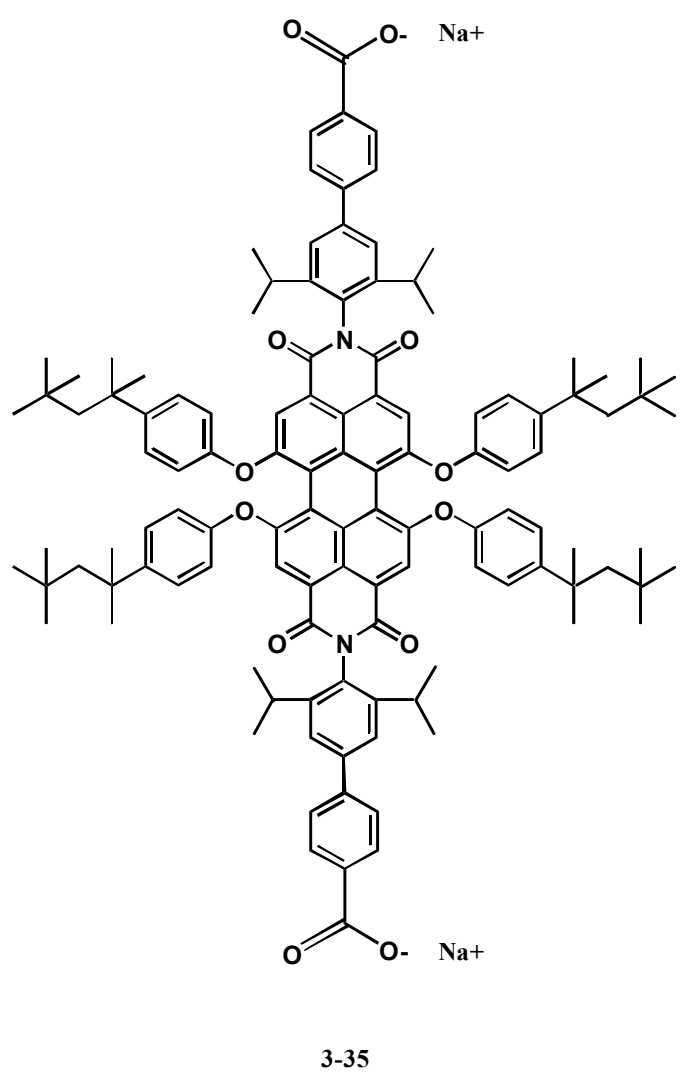

Abbildung 59: Die Struktur des Dinatriumsalzes von Perylendiimid mit zwei ionisierten Säurefunktionen in der Imidstruktur

Die Wechselwirkungen organischer Verbindungen mit Nukleinsäuren werden intensiv untersucht $^{80-81}$. Vor allem wird den Wechselwirkungen von polycyclischen Aromaten mit DNA großes Interesse entgegengebracht. Die Bestrahlung von DNA in Gegenwart von Farbstoffen, die sich an das Biomolekül nicht kovalent binden können, führt häufig zur Schädigung der Nukleinsäure ${ }^{82-83}$. Farbstoffe und andere organische Verbindungen mit einer derartigen Funktion werden als Photonucleasen bezeichnet. Diese lichtinduzierten Prozesse können phototherapeutisch zur selektiven Schädigung der DNA konstruktiv genutzt werden $^{81}$. Um eine effiziente Photoschädigung von DNA zu erreichen, muss die entsprechende Verbindung zuerst eine bindende Wechselwirkung mit der DNA eingehen. In der Regel besitzen polycyclische heteroaromatische Verbindungen eine erhöhte Tendenz zur Interkalation in das DNA-Molekül. Unter Interkalation versteht man, dass Moleküle sich zwischen die DNA-Basen schieben und mit ihnen hydrophobe oder elektrostatische Wechselwirkungen erzeugen. Vertreter derartiger Farbstoffe sind 
Ethidiumbromid $^{84}$ und Proflavin ${ }^{85}$. Diese charakteristische Eigenschaft wird bei den elektrophoretischen Trennmethoden genutzt, um die DNA-Banden nach der Trennung zu visualisieren. Methylblau, Coralyn, Cyaninfarbstoffe vom Typ Monomethin und Acridinorange weisen auch solche bindenden Wechselwirkungen mit der DNA (Doppelhelix) oder ssDNA (engl. single strand DNA) auf ${ }^{86-93}$. Perylendiimidderivate wie 3-22 oder 3-23 mit ihrer polycyclischen Eigenschaft und Heteroatome könnten solche bindende Wechselwirkungen mit der DNA eingehen.

Da bei der Kopplung des Perylendiimids ans Oligonucleotid keine denaturierenden Bedingungen verwendet wurden und somit das Oligonucleotid sekundäre Strukturen ausbilden kann (zum Beispiel Selbsthybridisierung durch kleine komplementäre Stücke in derselben Sequenz), sollte untersucht werden, ob das Perylendiimid in die DNA interkalieren kann. Um dieser Frage nachzugehen, wurde das geschützte Perylendiimidderivat 3-22 (mit zwei methylgeschützten Carboxyfunktionen) mit dem Aminoligonucleotid, wie bereits beschrieben, zur Reaktion gebracht. So kann man ausschliessen, dass es $\mathrm{zu}$ einer chemischen Reaktion zwischen der geschützten Säurefunktion und der Amingruppe des Oligonucleotids kommen kann. Eine Bindung zwischen 3-22 und dem Oligonucleotid kann nur dann stattfinden, wenn das Perylendiimid sich zwischen die Basen der DNA schieben (interkalieren) kann. So konnte bei diesem Experiment keine physikalischen Bindungen beobachtet werden, da sich das Perylendiimid 3-22 im Wasser nicht löste und in der Reaktionslösung ausfiel. Das Molekül ist wahrscheinlich sterisch so anspruchsvoll, dass es sich nicht zwischen die Basen der DNA schieben kann. 


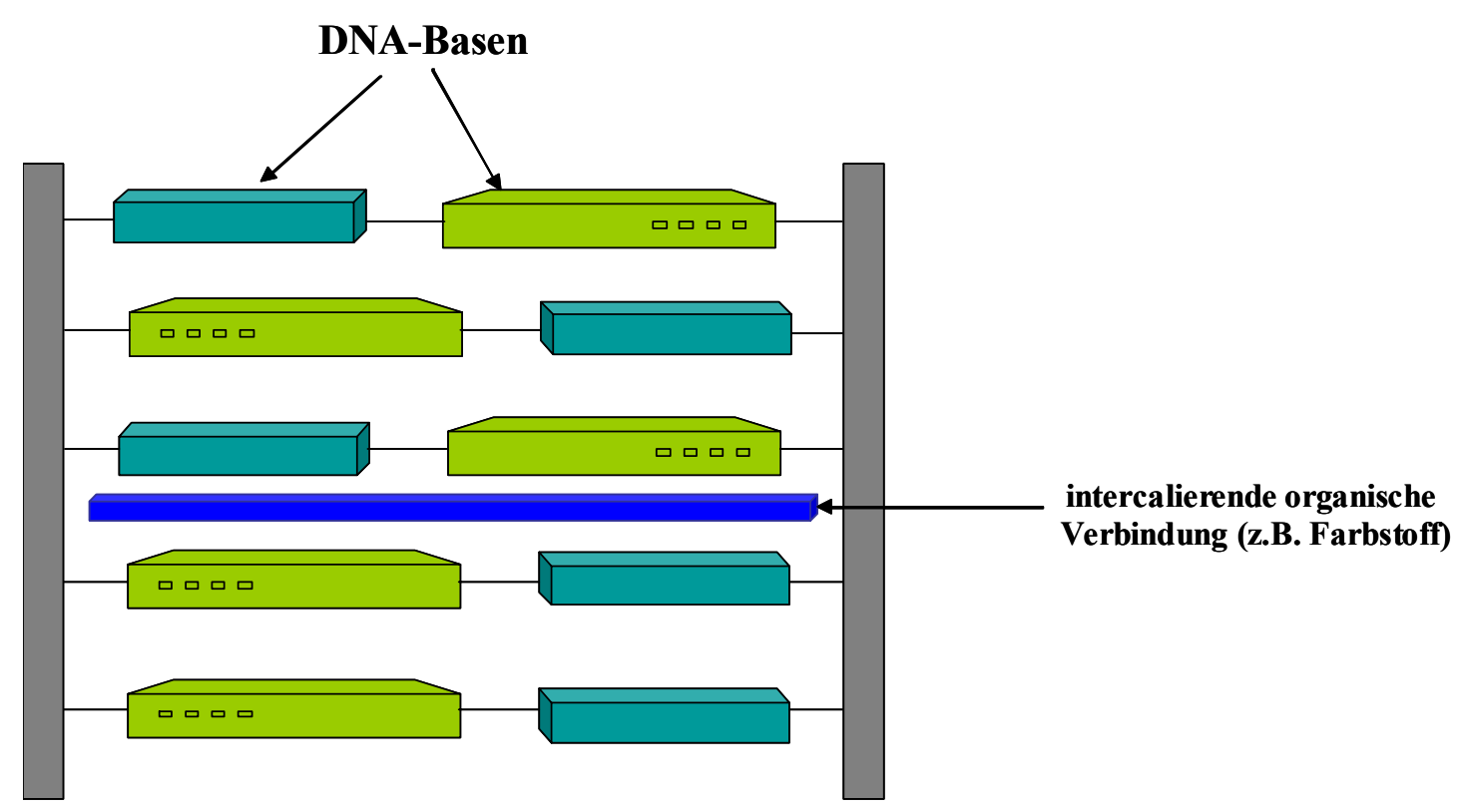

Abbildung 60: Schematische Darstellung der Intercalation einer organischen Verbindung in die DNA

Diese Ergebnisse liefern neben dem Resultat der Gelelektrophorese von 3-34 (Abb. 57) den Beweis dafür, dass die obere Bande in den Abbildungen 44 und 45 nur dem Perylendiimid-bis(oligonucleotid)-Konjugat PODN1 bzw. dem komplementären Konjugat PODN2 entsprechen kann.

Bei der Synthese von Perylendiimid-bis(oligonucleotid)-konjugaten konnte eine Ausbeute von 20-30 \% erzielt werden. Weitere Versuche zur Verbesserung der Ausbeute durch die Änderung der Reaktionsbedingungen führten nicht zum gewünschten Erfolg. Obwohl bei dieser Reaktion das eingesetzte und nicht reagierte Oligonucleotid durch die präparative Gelelektrophorese zurückgewonnen werden konnten, ist es wünschenswert, eine höhere Ausbeute zu erhalten. Andere Kopplungsmethoden könnten helfen, um die Ausbeute zu verbessern. In einer Kooperation mit dem Arbeitskreis von Professor von Kiedrowski an der Universität Bochum sollte eine nucleophile Addition von einem mit Hydrazid funktionalisierten Oligonucleotid an ein Perylendiimidderivat, das eine Aldehydfunktion enthält, durchgeführt werden. Das Oligonucleotid mit einer Hydrazidfunktion wurde im AK von Kiedrowski synthetisiert und aufgereinigt. 


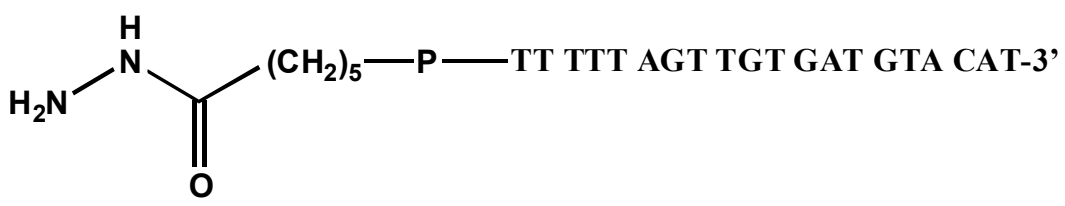

3-35

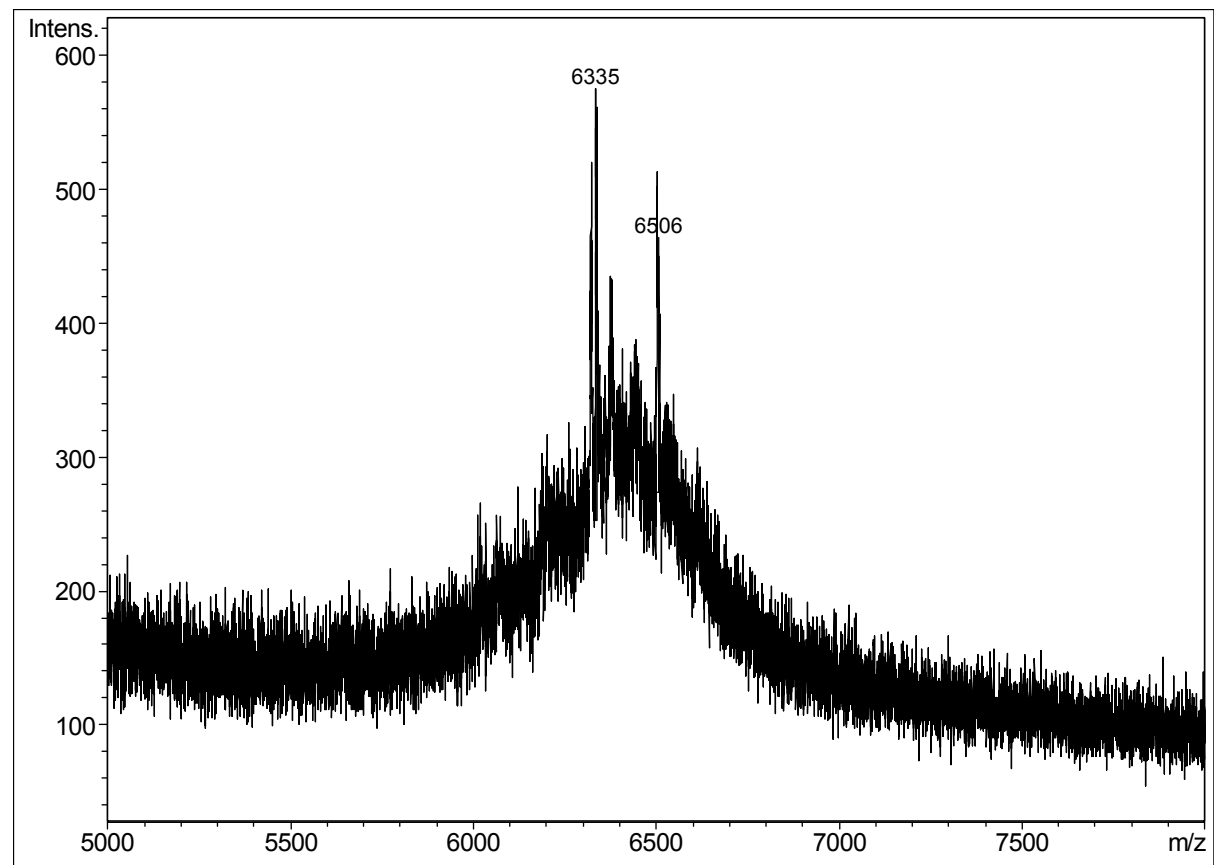

Abbildung 61: Maldi-Tof-MS des Oligonucleotids mit Hydrazidfunktion 3-35, Matrix: 3Hydroxypicolinsäure

Das berechnete Molekulargewicht von 3-35 beträgt $6336 \mathrm{~g} / \mathrm{mol}$ und stimmt mit dem erhaltenen Peak bei $6335 \mathrm{~g} / \mathrm{mol}$ im Maldi-Tof-MS (Abb. 61) überein. Der zweite Peak bei $6506 \mathrm{~g} / \mathrm{mol}$ entspricht dem Molekulargewicht von nicht vollständig entschütztem Produkt mit einer Benzoyl- und einer Cyanoethylschutzgruppe (für die exozyklische Aminfunktion der Base bzw. die Phosphatgruppe). Der Auftritt dieses Peaks deutet darauf hin, dass die Konzentration der Ammoniaklösung, die für die Abspaltung sowohl der hergestellten Oligonucleotidsequenz vom Träger als auch der Amin- und Phosphatschutzgruppen verwendet wurde, nicht ausreichend war, um eine vollständige Abspaltung der Schutzgruppen zu ermöglichen. Normalerweise wurde in dieser Arbeit eine 32.5 \%iger Ammoniaklösung verwendet, und deshalb trat ein solches Nebenprodukt 
bisher nicht auf. In der Literatur wurden Maldi-Tof-Spektren von hochmolekularen Oligonucleotiden (z. B. Poly $(\mathrm{dG})_{30}$, Poly $(\mathrm{dA})_{40}$, Poly(dC)30 und auch Oligonucleotide mit den vier verschiedenen Basen) gezeigt ${ }^{154-155}$. Bei vielen Spektren traten die Signale in der Form eines Bergs auf. Es scheint, dass diese Bergform vorkommt, wenn der Molekülionenpeak mit anderen benachbarten Peaks überlappt ist. Im Maldi-Tof-MS von 3-35 (Abb. 61) sind durch die unvollständige Entschützung der Schutzgruppen und das nicht ausreichende Enzsalzen der Oligonucleotidlösung mehrere Peaks (Ein einziges Natriumion genügt, um das Molekül schwerer zu machen) neben dem Molekülionenpeak zu sehen, was die Intensität des Hauptsignals verkleinert. Dadurch erhält man ein schlechteres Signalrauschverhältnis, was dazu führen kann, dass eine Signalverbreiterung im Fußbereich der Peaks vorkommt.

Die Synthese eines Perylendiimids mit zwei Aldehydfunktionen wurde analog zur Darstellung der Verbindung 3-22 über eine Suzuki-Kopplung durchgeführt, wobei die kommerziell erhältliche 4-Aldehyd-phenylboronsäure an der Stelle von 4Methoxycarbonyl-phenylboronsäure eingesetzt wurde.
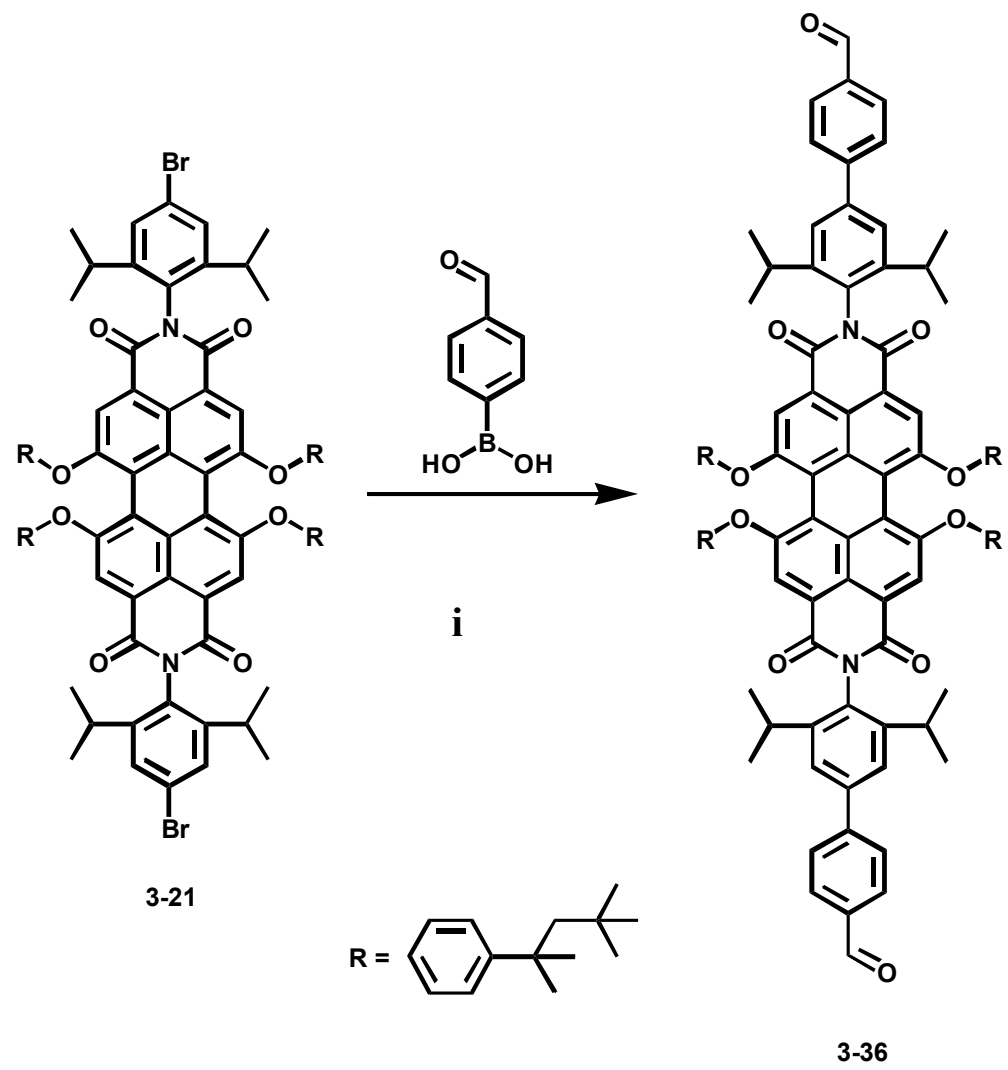

Abbildung 62: Darstellung eines Perylenfarbstoffs mit zwei Aldehyd-Gruppen i) $\mathrm{Pd}\left(\mathrm{PPh}_{3}\right)_{4}, 2 \mathrm{M}$ $\mathrm{K}_{2} \mathrm{CO}_{3}$, Methanol, Toluol, $15 \mathrm{~h}, 75^{\circ} \mathrm{C}, 77 \%$ 
Die Aufreinigung des Produkts 3-36 erfolgte durch Säulechromatographie mit Dichlormethan als Eluent (für genauere Angaben siehe Experimenteller Teil). Die Ausbeute von als dunkelrotem Farbstoff erhaltenem Produkt beträgt $77 \%$. Der Strukturbeweis lässt sich sowohl mit Elementaranalyse und Maldi-Tof-Spektroskopie als auch mit ${ }^{1} \mathrm{H}$ - und ${ }^{13} \mathrm{C}-\mathrm{NMR}-$ Spektroskopie führen. Im Maldi-Tof-MS erkennt man nur einen Peak bei 1737 g/mol, der mit dem berechneten Molekulargewicht (1736 g/mol) im Einklang steht.

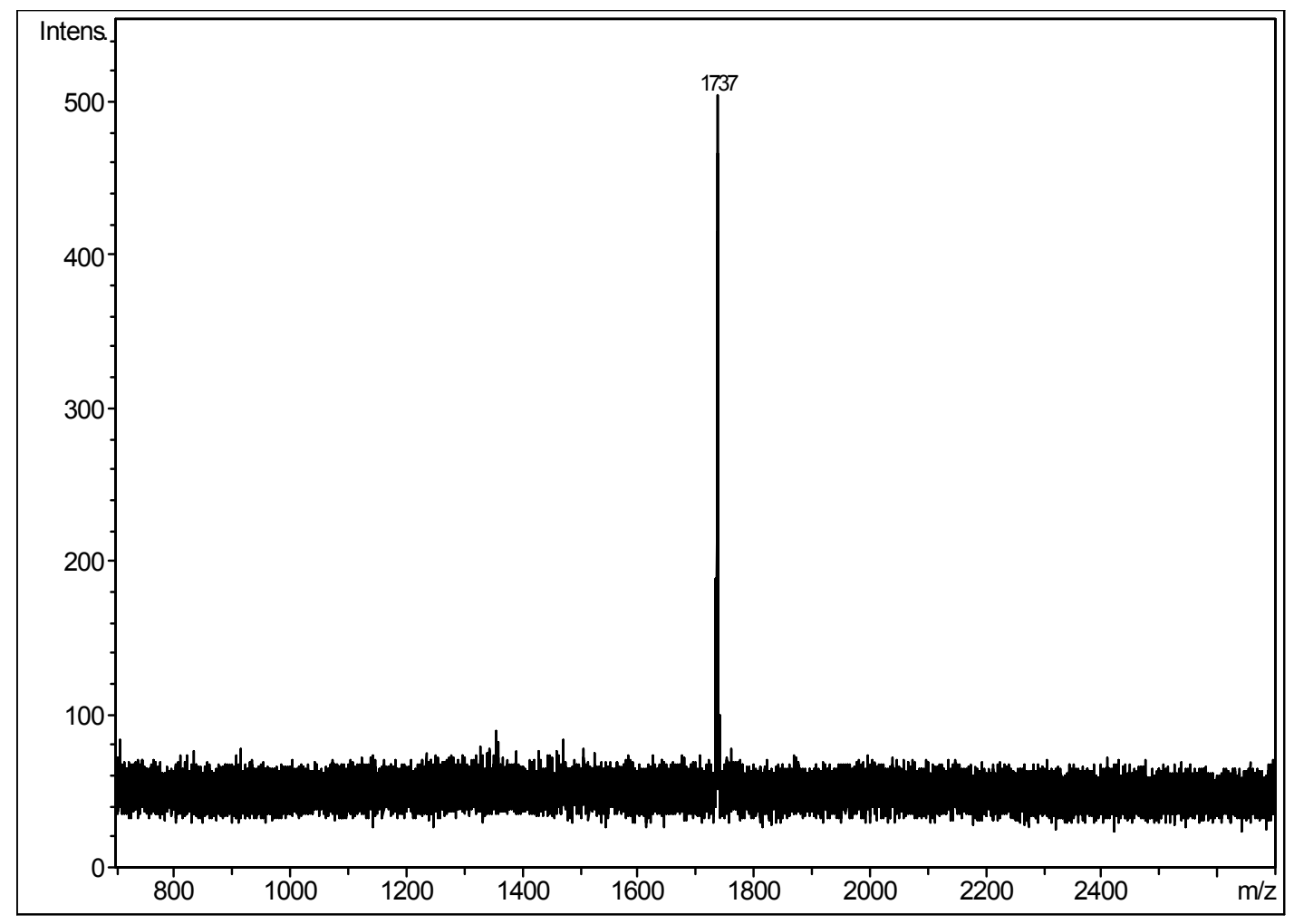

Abbildung 63:Maldi-Tof-MS von 3-36; als Matrix wurde Dithranol verwendet

Einen weiteren Beleg für die Struktur und Reinheit von 3-36 ist die ${ }^{1}$ H-NMRSpektroskopie (Abb. 64). Aufgrund der hohen Symmetrie des Moleküls war die Zuordnung der Signale sehr einfach. In Übereinstimmung mit der angenommenen Struktur zeigt das ${ }^{1}$ H-NMR-Spektrum im aromatischen Bereich 3 Singulett und 4 Dublets. Kennzeichnend ist das Singulett bei $\delta=10.22 \mathrm{ppm}$, das den Protonen der Aldehydfunktion $\mathrm{H}_{\mathrm{a}}$ entspricht. Im aliphatischen Bereich des Spektrums treten alle 
Signale des 2,6-Diisopropylphenylrestes und der tert-Octylgruppe auf. Die Intensitätsverhältnisse der Signale stehen im Einklang mit der angenommenen Struktur.



Abbildung 64: ${ }^{1}$ H-NMR-Spektrum mit Zuordnung der Signale von 3-36 in Dichlormethan $(250$ $\mathrm{MHz}, \mathrm{CD}_{2} \mathrm{Cl}_{2}$ )

Im ${ }^{13} \mathrm{C}$-Spinechoexperiment können aufgrund der Molekülsymmetrie ein Signal für das Carbonylkohlenstoffatom der Aldehydfunktion und ein Signal für die Carbonylkohlenstoffatome des Perylentetracarboxdiimids erkannt werden. Im nächsten Schritt soll die Kopplung zwischen 3-36 und dem 5'-hydrazidmodifizierten Oligonucleotid 3-35 beschrieben werden. Diese Kopplungschemie ${ }^{94}$ basiert auf der Kondensation des Hydrazides mit der Carbonylgruppe der Aldehydfunktion in 3-36 zu einer Hydrazonbindung. 


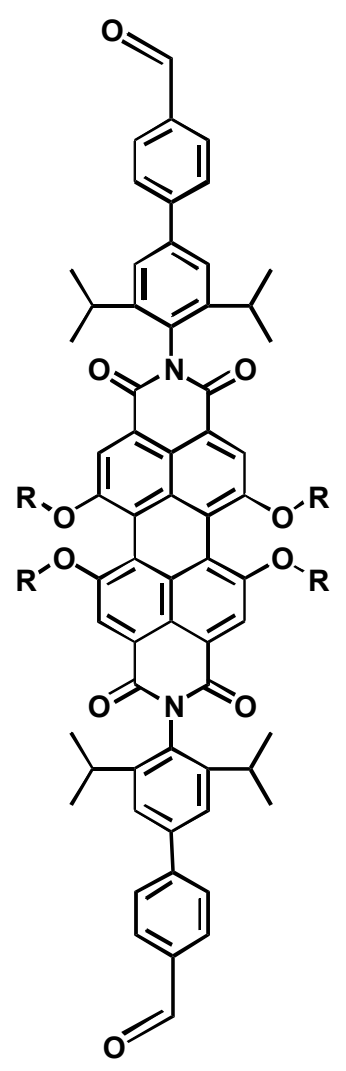

3-36

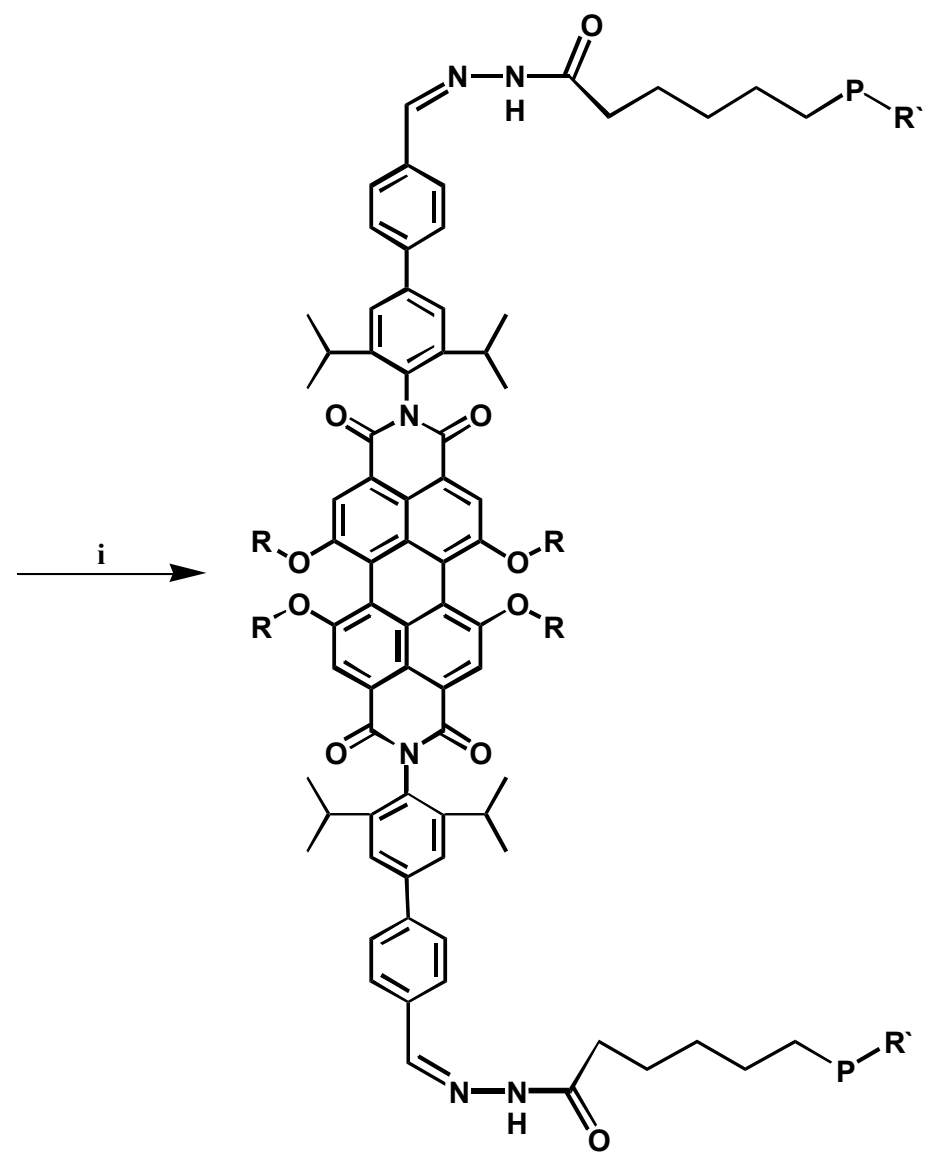

3-37

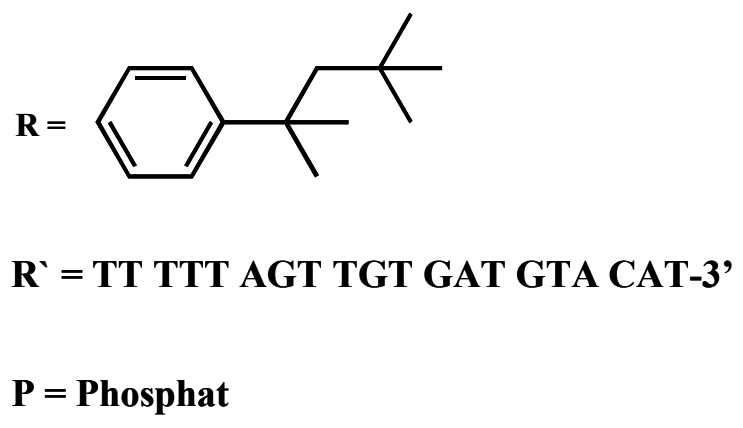

Abbildung 65: Darstellung eines Perylendiimid-bis(oligonucleotid)-Konjugats nach der Hydrazid-Aldehyd-Kopplungschemie i) $\mathrm{R}^{\prime}=\mathrm{H} 2 \mathrm{~N}-\mathrm{NH}-\mathrm{CO}-(\mathrm{CH} 2) 5-\mathrm{p}-\mathrm{TT}$ TTT AGT TGT GAT GTA CAT-3' (3-35), 10mM Ammoniumacetatpuffer, $\mathrm{pH}$ 4-4.5, $\mathrm{NaBH}_{3} \mathrm{CN}$, über Nacht bei RT, 336 war in $20 \%$ DMF vom Gesamtansatzvolumen gelöst

Im Reaktionsgefäß wurden ein rot ausgefallener Farbstoff und eine trübe Lösung beobachtet. Eine Analyse des Reaktionsprodukts durch Polyacrylamidgelelektrophorese zeigte lediglich das Hydrazidoligonucleotid und keine Produktbanden. Der Ansatz wurde mit einem erhöhten Anteil an DMF (40 \% des Gesamtansatzvolumens) wiederholt. Mit 
dieser Änderung erhielt man auch kein Produkt. Auf eine weitere Erhöhung des DMFAnteils wurde verzichtet, da diese zum Ausfallen des Oligonucleotides führen kann. Im Vergleich zu der Reaktivität vom Amin zu Aktivester ist die Reaktivität des Hydrazids gegenüber der Aldehydfunktion des Perylendiimids wahrscheinlich zu gering, um eine kovalente Bindung zu bilden, bevor der hydrophobe Farbstoff in der wässrigen Reaktionslösung ausfällt.

Eine weitere Alternative zur Verbesserung der Ausbeute des Perylendiimidbis(oligonucleotid)-konjugats bietet die Synthese eines asymmetrischen Perylendiimidderivats mit zwei Hydroxylgruppen in der Imidstruktur. Eine der beiden Hydroxylfunktionen soll mit einer Phosphoamidit- und die andere mit der DMTr-Gruppe geschützten werden. Abbildung 66 gibt eine schematische Darstellung der verschiedenen Synthesestufen des Phosphoamiditderivats von Perylendiimid 3-40. Diese Zielverbindung 3-40 kann dann direkt in die Festphasensynthese am DNA-Synthesizer als Monomer, wie entsprechend auch die DNA-Nucleotide, integriert werden. So sollte die Bildung des monosubstituierten Perylendiimids 3-34 vermieden und damit die Ausbeute erhöht werden. Desweiteren können mit dem Phosphoamiditderivat zwei unterschiedliche Oligonucleotidsequenzen an das Perylendiimid geknüpft werden.

Zur Synthese vom Perylendiimid mit zwei OH-Gruppen in der Imidstruktur wurde mit 321 als Ausgangstoff eine Hagihara-Kopplung durchgeführt (für experimentelle Details siehe den Experimentellen Teil, Kapitel 6). Die Ausbeute dieser Reaktion betrug 68 \%.

Die Strukturtreue der Verbindung 3-38 belegt die NMR-Spektroskopie (Abbildung 67) mit der Position der gemessenen Signale, ihren Kopplungen und Intensitätsverhältnissen. Bei $\delta=0.668$ ppm tritt das Signal der insgesamt 36 Protonen (Proton n) der tert.Octylgruppe auf. Weiterhin erkennt man im aliphatischen Bereich die Signale der Protonen e, f, g, und h. 


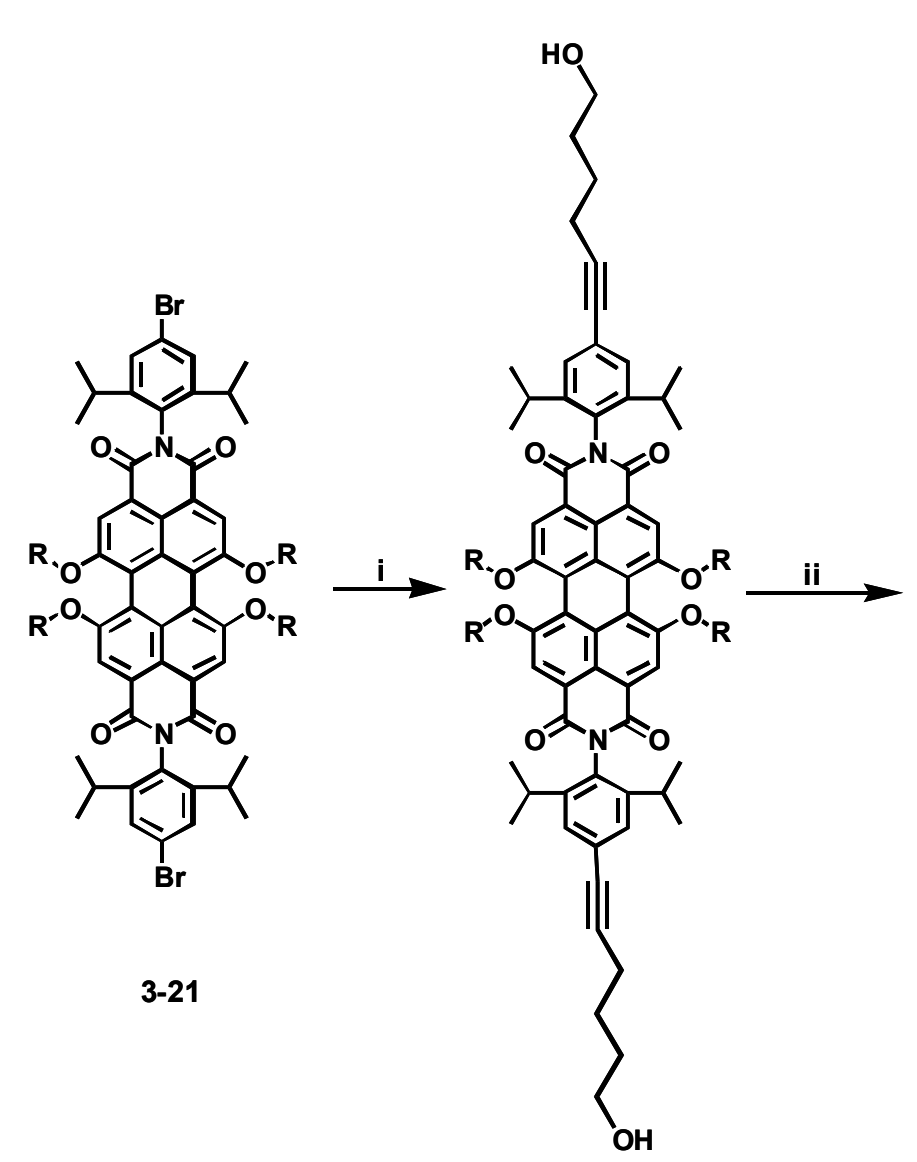

3-38

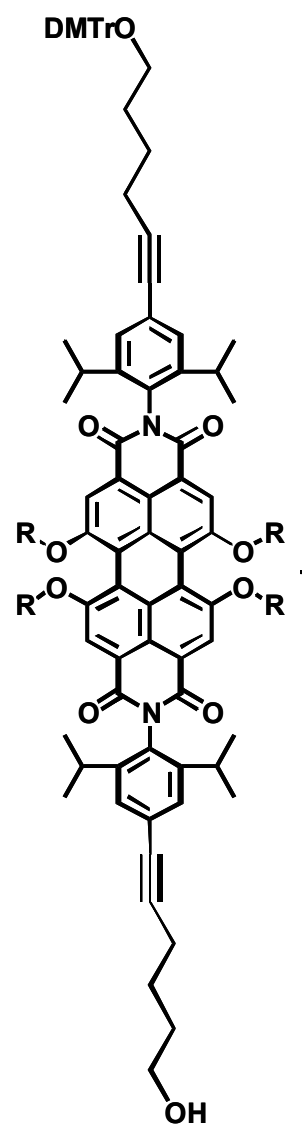

3-39

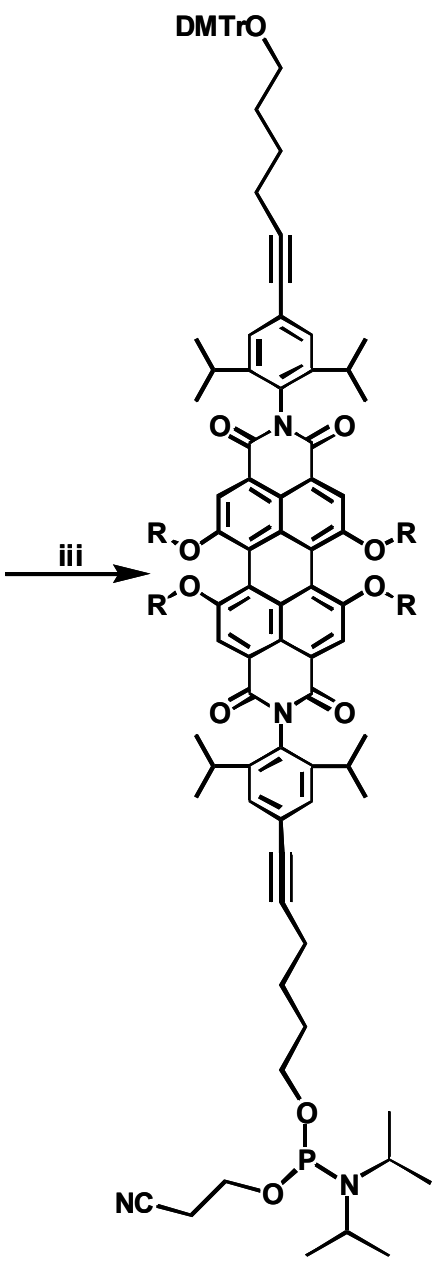

$3-40$

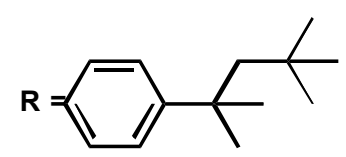<smiles>COc1ccc(C(c2ccccc2)(c2ccc(OC)cc2)c2ccc([N+](=O)[O-])cc2)cc1</smiles>

Abbildung 66: Schematische Darstellung des bifunktionellen Perylendiimid-phosphoamidits i) 5Hexyn-1-ol, CuI, Pd-Kat, trockenes THF, Et 3 N, bei $80{ }^{\circ} \mathrm{C}$ über Nacht, $68 \%$ ii) DMTrCl, Pyridin, 24 Stunden bei RT, dann bei $120^{\circ} \mathrm{C} 24$ Stunden. 

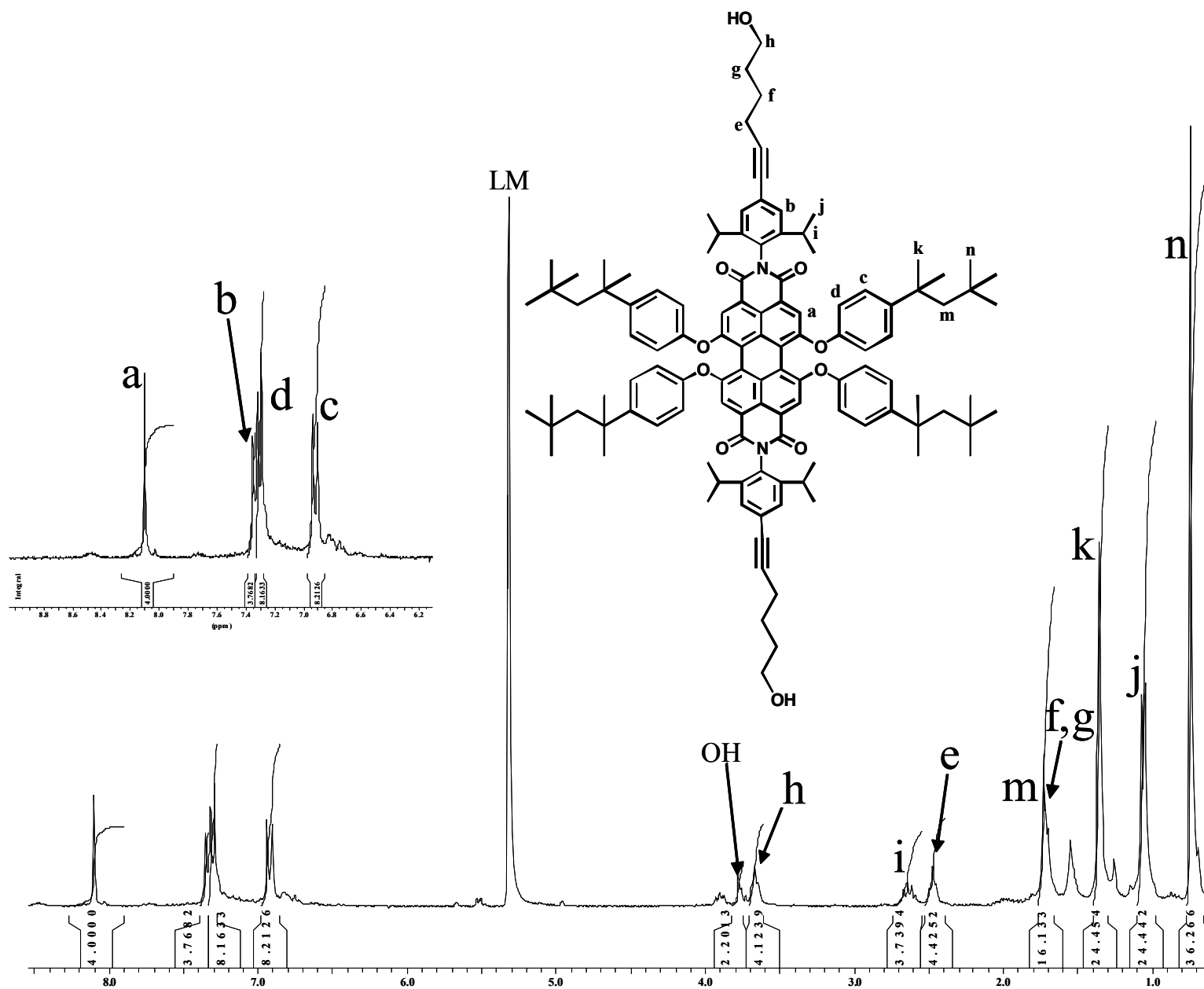

(ppm)

Abbildung 67: ${ }^{1} \mathrm{H}-\mathrm{NMR}-S p e k t r u m$ von 3-38 (LM: CD2Cl2, $\left.250 \mathrm{MHz}, 25{ }^{\circ} \mathrm{C}\right)$

Im Anschluss wurde 3-38 mit DMTrCl in Pyridin zur Reaktion gebracht. Im Allgemeinen ist die Reaktion zwischen einer primären $\mathrm{OH}-F u n k t i o n$ und $\mathrm{DMTrCl}$ in Pyridin bei Raumtemperatur in zwei Stunden vollendet. Im Falle von 3-38 wurde nach einer Reaktionszeit von 48 Stunden lediglich eine sehr kleine Menge vom Ausgangstoff umgesetzt. Eine Erhöhung der Reaktionstemperatur bis auf $120{ }^{\circ} \mathrm{C}$ steigerte den Umsatz. Die FD-Massenspektrometrie zeigte neben dem Peak des Ausgangstoffs einen Peak für das zweifach umgesetzte Perylendiimid (die zwei OH-Funktionen in 3-38 wurden mit DMTr-gruppe geschützt). Das gewünschte asymmetrische Produkt 3-39 konnte allerdings weder bei DC-Kontrollen noch bei FD-Messungen festgestellt werden.

Aufgrund der erfolglosen Desymmetrisierung von 3-38 konnte das Phosphoamiditderivat 3-40 nicht synthetisiert werden, und es musste deshalb auf die Integration von 
Perylendiimid in die DNA-Festphasensynthese verzichtet werden. Damit führten alle bisher versuchten alternativen Reaktionswege nicht zu der gewünschten Erhöhung der Reaktionsausbeute.

\subsection{Selbstorganisation der Perylendiimid-bis(oligonucleotid) - konjugate}

In diesem Abschnitt sollen die Hybridisierung der synthetisierten PODN und die Charakterisierung der erhaltenen Hybride beschrieben werden. Aufgrund der hydrophoben Eigenschaften des Perylendiimids (das Kernmolekül von PODN1 und PODN2) können Aggregate in wässriger Lösung gebildet werden. Deshalb sollten die Konjugate PODN1 und PODN2, bevor man mit der Hybridisierung beginnen kann, untersucht werden, ob sie in wässriger Lösung als monodisperse Objekte vorliegen. Diese Untersuchungen sind erforderlich, da Aggregate den Hybridisierungsvorgang behindern oder womöglich sogar verhindern können. Das Verhalten der Konjugate in wässrigen Lösungen wurde mit Hilfe der Fluoreszenz-Korrelations-Spektroskopie (FCS) untersucht.

\subsubsection{Fluoreszenz-Korrelations-Spektroskopie (FCS)}

FCS stellt eine große Hilfe dar, um kinetische Prozesse zu detektieren. Hierbei werden Gleichgewichtsfluktuationen des Fluoreszenzintensitätssignals von Farbstoffen analysiert, die aus den unterschiedlichen Zuständen des beobachteten Systems, wie zum Beispiel der Teilchendiffusion oder des Triplettzerfalls, resultieren. Die Autokorrelationsfunktion dieser Fluktuationen gibt einen detaillierten Einblick in die charakteristischen Zeitskalen und Übergänge innerhalb des Systems, wie zum Beispiel die Diffusionszeit und die Teilchenzahl, welche mit entsprechenden Modellen ermittelt werden können.

Mit der Messung der chemischen Bindungsrate von Ethidiumbromid und DNA wurde das erste Mal FCS eingeführt ${ }^{95}$ und die entsprechende Theorie ausgearbeitet ${ }^{96}$. Dennoch blieb die Methode auf Grund der mangelnden Intensität der Anregungssysteme und der 
unzureichenden Sensitivität der Detektionssysteme auf hohe Teilchenzahlen beschränkt. Erst mit der Verwendung von konfokaler Optik wurde die Detektion von einzelnen Molekülen möglich. Dies machte diese Technik für Einzelmolekülanalysen in sehr verdünnten Lösungen interessant ${ }^{97}$.

Entscheidend bei dieser Methode ist die Detektion der Intensitätsfluktuationen, die durch die fluoreszierenden Proben im konfokalen Volumen $(<1 \mathrm{fl})$ induziert werden. Dazu werden die diffundierenden Teilchen mit einem Laser, der mit dem Objektiv fokussiert wird, angeregt. Das rotverschobene Fluoreszenzlicht wird durch das Objektiv gesammelt und durch einen dichroitischen Spiegel vom Anregungslicht getrennt. Mit Hilfe einer weiteren Fokussierungsoptik wird das Detektionsvolumen auf ein Pinehole abgebildet, was das Beobachtungsvolumen in Strahlrichtung begrenzt und somit die Tiefenauflösung erhöht. Ein zusätzlicher Filter verhindert, dass neben dem zu detektierenden Fluoreszenzsignal noch Streulicht auf die Avalanchephotodiode (APD) fällt. Hier wird die Intensität in Abhängigkeit der Zeit aufgenommen.

Die Intensität in Abhängigkeit der Zeit $I(t)$ stellt die einzige Messgröße dar, in der bereits alle involvierten Prozesse beinhaltet sind, allerdings sind diese noch nicht direkt zugänglich. Aus diesem Grund wendet man auf das ursprüngliche Signal eine Autokorrelation an, die die unterschiedlichen kinetischen Prozesse offen legt.

$$
g(\Delta t)=\frac{\langle I(t) \cdot I(t+\Delta t\rangle}{\left\langle I(t)^{2}\right\rangle}
$$

Die so ermittelte experimentelle Autokorrelationsfunktion kann nun mit theoretischen Modellfunktionen verglichen werden.

Frei diffundierende Teilchen zeigen charakteristische Abfälle in der Autokorrelationsfunktion, die theoretisch abgeleitet werden können. Unter Verwendung der Diffusionsgleichung für einzelne, nicht-wechselwirkende Partikel wird die Autokorrelationsfunktion bestimmt zu 


$$
g(\Delta t)=1+\frac{1}{N} \cdot \frac{1}{1+\frac{\Delta t}{\tau_{\mathrm{D}}}} \cdot \frac{1}{\sqrt{\left(1+\frac{\Delta t}{f^{2} \tau_{\mathrm{D}}}\right)}}
$$

wobei $\mathrm{N}$ der Anzahl der Teilchen im konfokalen Volumen, $\tau_{D}$ der charakteristischen Translationsdiffusionszeit und $f$ dem Verhältnis aus axialer $\left(z_{0}\right)$ und lateraler $\left(r_{0}\right)$ Ausdehnung des Gaussschen Detektionsfunktion entspricht.

Für Fluorophore ist es allerdings von entscheidender Bedeutung, den strahlungslosen Übergang in den Triplettzustand zu berücksichtigen, da dieser Vorgang ebenso in der gemessenen Autokorrelationsfunktion sichtbar wird. Dadurch ist folgende modifizierte Autokorrelationsfunktion auf die Daten anzuwenden, die einen zusätzlichen Triplettabfall beinhaltet, der durch den Triplettanteil $T$ und die Triplettzeit $\tau_{T}$ charakterisiert wird.

$$
g(\Delta t)=1+\frac{1}{N} \cdot\left[1+\frac{T}{(1-T)}\right] e^{-\frac{\Delta t}{\tau_{T}}} \cdot \frac{1}{1+\frac{t}{\tau_{\mathrm{D}}}} \cdot \frac{1}{\sqrt{\left(1+\frac{\Delta t}{f^{2} \tau_{\mathrm{D}}}\right)}}
$$

Aus der charakteristischen Diffusionszeit $\tau_{D}$, die genau der mittleren Zeit entspricht, die das Teilchen benötigt, um durch den Fokus zu diffundieren, kann bei bekannten Dimensionen des Fokus direkt auf die Diffusionskonstante $D_{t}$ der analysierten Objekte geschlossen werden.

$$
D_{\mathrm{t}}=\frac{r_{0}^{2}}{4 \tau_{\mathrm{D}}}
$$

In viskosen Medien ist es möglich, mit Hilfe der Einstein-Gleichung die diffusiven Eigenschaften einer Probe mit deren geometrischen Proportionen zu verbinden. Im Fall von Kugeln kann der Zusammenhang zwischen $D_{t}$, der Viskosität $\eta$, der thermischen Energie $\left(k_{B} T\right)$ und dem hydrodynamischen Radius $r_{H}$ analytisch berechnet werden.

$$
D_{\mathrm{t}}=\frac{k_{\mathrm{B}} T}{6 \pi \eta R_{\mathrm{H}}}
$$

Für einen steifen Stab kann dieser Zusammenhang nur noch näherungsweise angegeben werden, wobei $L$ der Länge und $d$ den Durchmesser des Objektes angibt ${ }^{98}$. 


$$
D_{t}=\frac{A \cdot k_{B} \cdot T}{3 \pi \cdot \eta \cdot L}
$$

mit

$$
A=\ln \left(\frac{L}{d}\right)+0.312+0.565 \cdot\left(\frac{L}{d}\right)^{-1}-0.1 \cdot\left(\frac{L}{d}\right)^{-2}
$$

\subsubsection{FCS-Messungen von PODN1 und PODN2}

Die Autokorrelationsfunktionen von PODN1 $(\approx 1 \mu \mathrm{M})$ bezüglich der Zeit wurden in $\mathrm{ddH}_{2} \mathrm{O}$ gemessen. Die experimentell ermittelte Kurve kann sehr gut durch eine theoretische Autokorrelationsfunktion für frei diffundierende monodisperse Teilchen beschrieben werden. Hierbei wurde eine mittlere Diffusionszeit $\tau_{\mathrm{D}}$ von $41.4 \pm 5.0 \mu \mathrm{s}$ ermittelt, welche einem Diffusionskoeffizienten $D_{\mathrm{t}}$ von $257 \pm 35 \mu^{2} \mathrm{~s}^{-1}$ entspricht. Unter der Annahme, dass sich PODN1 als kugelförmige Partikel beschreiben lässt, ergibt sich ein hydrodynamischer Radius von $0.85 \pm 0.12 \mathrm{~nm}$, welcher sehr gut mit dem erwarteten Wert übereinstimmt. Die Messdaten zeigen keinerlei Hinweise auf größere Aggregate, was darauf hindeutet, dass die Konjugate in wässrigen Lösungen Fluoreszenz erzeugen und als monodisperse Partikeln vorliegen. Dies ist von großer Bedeutung für die Hybridisierungsfähigkeit der Konjugate, was wiederum für die Herstellung eines Perylendiimid-DNA-Polymers entscheidend ist. 


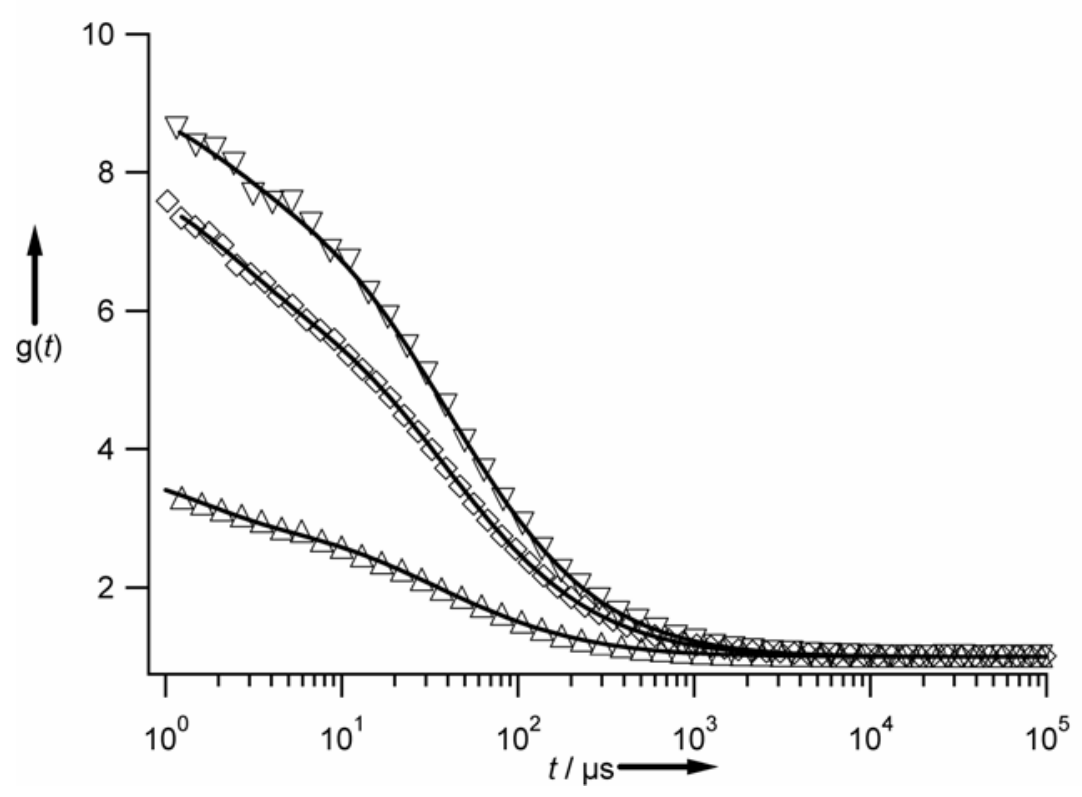

Abbildung 68: Die Autokorrelationsfunktion $g(t)$ für verschiedene PODN1-Proben (Konz. $\approx 1 \mu \mathrm{M}$ ) in $\mathrm{ddH}_{2} \mathrm{O}$

\subsection{3 Überführung von PODN in organische Lösungsmittel}

Aufgrund der hydrophoben Eigenschaften vom Perylendiimid löst es sich sehr gut in nichtpolaren Lösungsmitteln. Die Verknüpfung von zwei Oligonucleotidsträngen in der Imidstruktur des Perylens verleiht dem Molekül Löslichkeit in polaren Lösungsmitteln (z.B. Wasser). Diese Wasserlöslichkeit ist nur auf die polyanionische Eigenschaft des Oligonucleotids zurückzuführen. Bekanterweise lösen sich Oligonucleotide oder große DNA-Moleküle nicht in nicht-polaren Lösungsmitteln (z.B. n-Decan). In diesem Abschnitt wird erläutert, ob ein Perylendiimid-bis(oligonucleotid)-konjugat in n-Decan überführt werden und dabei seine fluoreszierenden Eigenschaften behalten kann.

PODN wurde mit Hilfe von Lipid-Mischungen aus kationischem 1,2-Dioleoyl-3Trimethylammonium-Propan (DOTAP) und neutralen 1,2-Dioleoyl-sn-Glycero-3Phosphocholin $($ DOPC $)$-Lipiden $(\mathrm{m}(\mathrm{DOPC}) /[\mathrm{m}(\mathrm{DOPC})+\mathrm{m}($ DOTAP $)]=0.86)$ in $\mathrm{n}$-Decan überführt. Hierbei wurde das Ladungsverhältnis zwischen den Phosphatgruppen der PODN und den kationischen Lipiden zu 1:1 eingestellt. Die Lipide wurden zusammen mit PODN1 zuerst in Wasser vermischt, n-Decan dazugegeben und schließlich über Nacht 
vorsichtig geschüttelt. Der Transfer der PODN1/Lipid-Komplexe konnte mit blossem Auge wahrgenommen werden, da sich die wässrige Phase nach dem Schütteln aufgeklärt hatte. Die gemessenen FCS-Autokorrelationskurven entsprechen sehr gut einem Einkomponentenfit mit einer Diffusionszeit von $270 \pm 29 \mu$ s (Abb. 70) Theoretische Berechnungen des Diffusionskoeffizienten für stäbchenförmige Partikel ${ }^{98}$, welche den PODN1-Lipid-Komplex als einen Zylinder mit der Länge von $18 \mathrm{~nm}$ und einem Durchmesser von $6 \mathrm{~nm}$ annehmen (Abb. 69), ergeben einen Diffusionskoeffizienten von $42 \mu \mathrm{m}^{2} \mathrm{~s}^{-1}$. Dies ist in sehr guter Übereinstimmung mit dem experimentell ermittelten mittleren Diffusionskoeffizienten $\left(39.0 \pm 5.1 \mu \mathrm{m}^{2} \mathrm{~s}^{-1}\right)$.

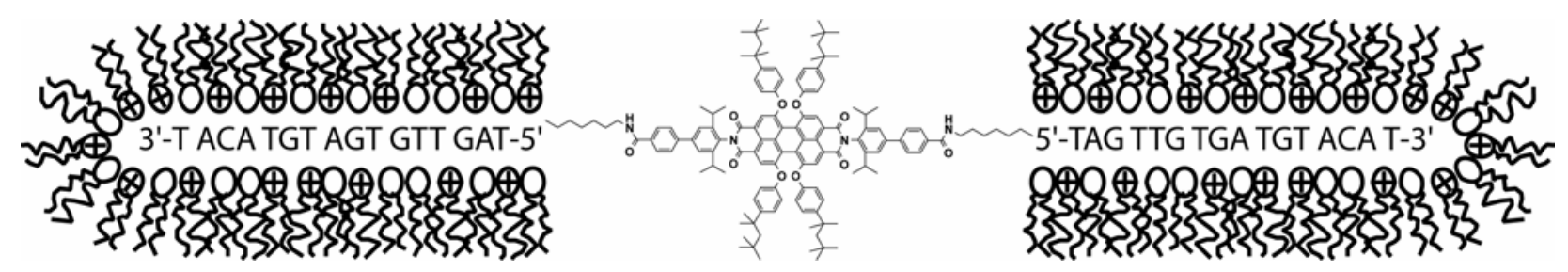

Abbildung 69: Schematische Darstellung von PODN1 in n-Decan; die Kopfgruppen der Lipide sind in Richtung der hydrophilen ODN ausgerichtet, während die unpolaren Schwanzgruppen in Kontakt mit dem n-Decan stehen

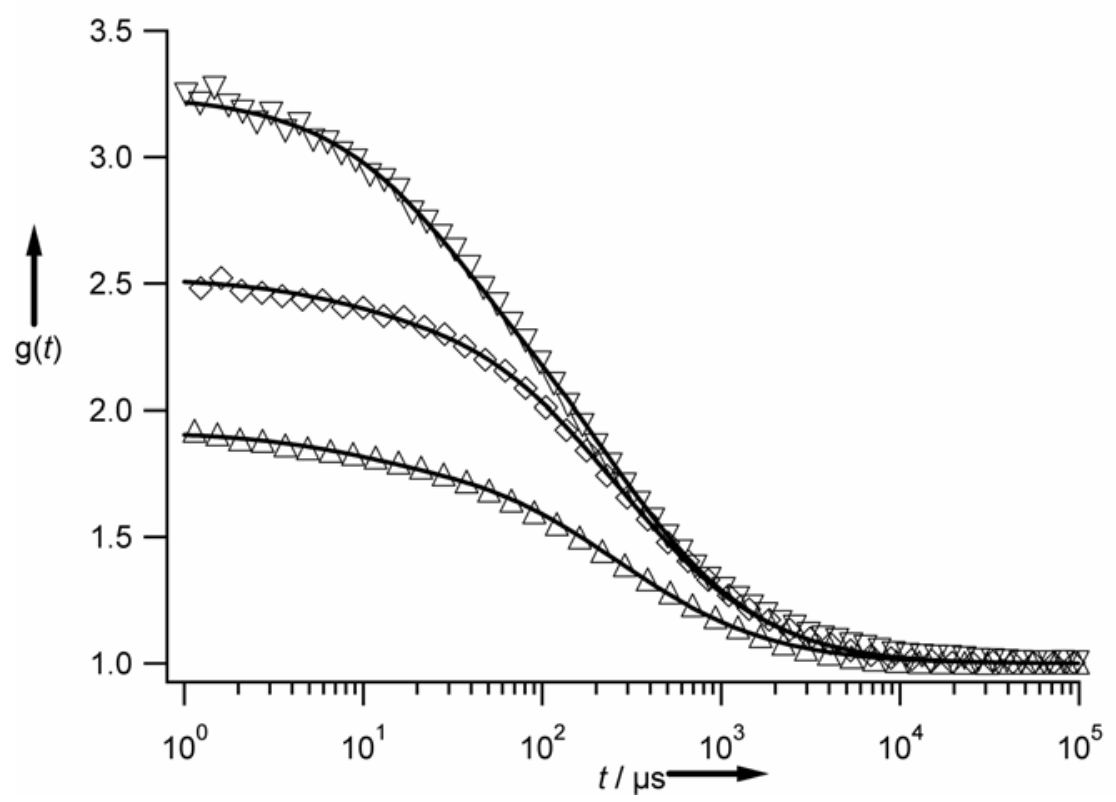

Abbildung 70: Die gemessene Autokorrelationskurve g(t) für PODN1 $(1 \mu \mathrm{M})$ in n-Decan. Die Diffusionszeit $\mathrm{t}$ beträgt $270 \pm 29) \mu$ s und stimmt mit dem mittleren Difusionskoefizienten überein $39.0 \pm 5.1) \mu \mathrm{m}^{2} \mathrm{~s}^{-1}$ 
Im Falle des einfachen Perylendiimids (ohne Oligonucleotidsequenzen) wäre Diffusionszeit viel kleiner und die Diffusionskonstante größer als beim PODN1, da die Größe des Perylendiimidmoleküls viel kleiner als das PODN1 ist.

Unterschiedliche Methoden wurden für den Transfer von PODN1 aus der wässrigen Lösung in n-Decan angewandt. Neben der bereits beschriebenen wurde im anderen Fall das Detergenz zuerst in n-Decan gelöst und dann zu einer wässrigen PODN1-Lösung gegeben. Die FCS-Messungen konnten keine sich signifikant unterscheidenden Teilchenzahlen zwischen den unterschiedlich präparierten Proben in der unpolaren Phase feststellen. Nach der Überführung des PODN1-Lipid-Komplexes in die organische Phase nahm die Fluoreszenz zu. Die Umhüllung des PODN1 mit dem Lipid trennte das polyanionische PODN1 von der unpolaren Umgebung (n-Decan), was sich auf die Fluoreszenzintensität positiv auswirkte. Die überführten Teilchen in der organischen Phase wurden gezählt. Die Zahl der in der wässrigen Phase verleibenden Teilchen wurde ermittelt und $\mathrm{zu}$ der Zahl derjenigen in der wässrigen Phase addiert. Die Transferwahrscheinlichkeit von PODN1 in die organische Phase kann so berechnet werden, indem man die Zahl der überführten Teilchen durch die Gesamtzahl der Teilchen in beiden Phasen dividiert.

Als Kontrollexperiment wurde ein Cy5-markiertes 30mer ODN (Cy5-GCC GTC TCT GAC TGC TGA CTA CTA TCG) nach der verwendeten Methode in n-Decan überführt. Durch den Vergleich der erhaltenen Ergebnisse im Falle von PODN1 (32mer) und Cy5markiertem 30mer konnte eine Transferwahrscheinlichkeit für den Übergang aus der wässrigen Lösung in n-Decan mit ca. 80\% für PODN1 ermittelt werden, d.h. 80 \% der gebildeten PODN1-Lipid-Komplexe konnten in die organische Phase überführt werden. Die übrigen $20 \%$ der Teilchen blieben in der wässrigen Phase, was man auch im Hinblick auf die polyanionische Eigenschaft von PODN1 sehen muss.

\subsubsection{Hybridisierung der Konjugate}

Die Grundlagen der Hybridisierung zwischen komplementären DNA-Strängen wurden im Kapitel 1 ausführlich erläutert. Die Hybridisierungsexperimente wurden in 
unterschiedlichen wässrigen Lösungen durchgeführt: TE Puffer (10mM Tris-HCl, $1 \mathrm{mM}$ EDTA, pH 7.5), TE/0.1M NaCl Puffer, TE/0.8M NaCl Puffer, and 0.1 M NaCl Puffer. PODN1 und das komplementäre cODN1 (c = engl. complementary) wurden im stöchiometrischen Verhältnis von 1:2 gemischt, wobei die Konzentration von PODN1 auf ca. $1 \mu \mathrm{M}$ eingestellt wurde. Die Sequenz cODN1 (5'-ATG TAC ATC ACA ACTA-3') wurde analog zu ODN1 synthetisiert und aufgearbeitet. Bei der Synthese wurde das gleiche Syntheseprotokoll verwendet ohne den Einsatz eines aliphatischen Spaceramins im letzten Synthesezyklus.

DasMaldi-Tof-MS von cODN1 ist in Abbildung 71 gezeigt. Man erkennt den Molekülionenpeak $\mathrm{M}^{+}$bei $4835 \mathrm{~g} / \mathrm{mol}$ (berechnet: $4836.68 \mathrm{~g} / \mathrm{mol}$ ) ebenso wie das doppelt geladene Molekül $\mathrm{M}^{2+}$ bei $2418 \mathrm{~g} / \mathrm{mol}$. Die kleinen Peaks rechts vom Molekülionenpeak entsprechen dem erwarteten Peak von cODN1 und Na-Kationen $\left(1 \mathrm{Na}^{+}\right.$, $\left.2 \mathrm{Na}^{+}, 3 \mathrm{Na}^{+} \ldots.\right)$.

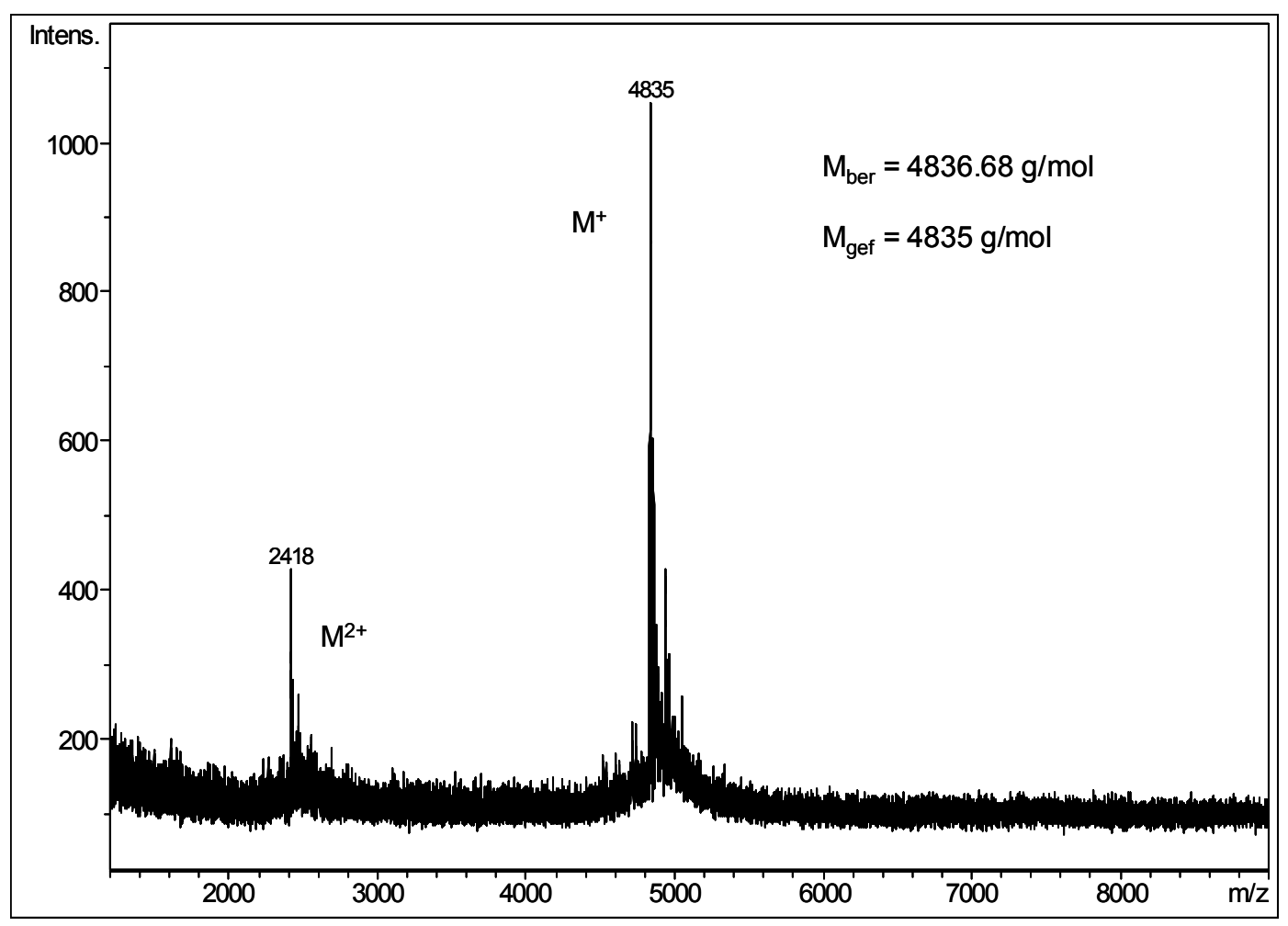

Abbildung 71:Maldi-Tof-MS von der cODN1 (komplementär zu ODN1) 
UV-Absorptionsexperimente bei $260 \mathrm{~nm}$ zeigen einen deutlichen Nachweis der Hybridisierung in allen Pufferlösungen. Ein tiefergehendes Verständnis der Hybridisierungseigenschaften von PODN erhält man aus temperaturabhängigen Absorptionsmessungen im TE/60 mM-NaCl-Puffer. Unmittelbar nach dem Vermischen von PODN1 und PODN2 wurden Absorptionsspektren sowohl bei $90^{\circ} \mathrm{C}$ als auch bei $0^{\circ} \mathrm{C}$ aufgenommen. Ein Vergleich der beiden Spektren zeigt, dass sich die Absorption bei höheren Temperaturen vergrößert. Die aufgenommenen Schmelzkurven bei $260 \mathrm{~nm}$ bestätigen die oben beschrieben Ergebnisse und weisen einen einzigen scharfen Übergang auf. Die Schmelztemperatur beträgt $45^{\circ} \mathrm{C}$.

Da bei den Perylendiimid-bis(oligonucleotid)-konjugaten (PODN1 und PODN2) das Perylenediimid an beiden Bindungsstellen symmetrisch mit komplementären Oligonucleotidsequenz funktionalisiert ist, sollte eine Mischung der beiden Konjugate zu kettenartigen supramolekularen Strukturen in der Form eines alternierenden Polymers (...ABABABAB...) hybridisieren. Zur Bestätigung dieser Annahme wurden analoge Schmelzexperimente mit Mischungen aus PODN1 und PODN2 durchgeführt, wobei in diesem Fall das stöchiometrische Verhältnis zwischen PODN1 und PODN2 auf 1:1 eingestellt wurde. Die Schmelzkurvenexperimente der PODN-Mischungen zeigen im Vergleich zu den Messungen an den ODN/cODN-Proben ähnliche Merkmale.

\section{XDOOC Konjugat 1 XDOCC Konjugat 2 XDOCD Konjugat 3 XDOCC}

Abbildung 72: Schematische Darstellung für kettenartige supramolekularen Strukturen in der Form eines alternierenden Polymers (...ABABABAB ...) 


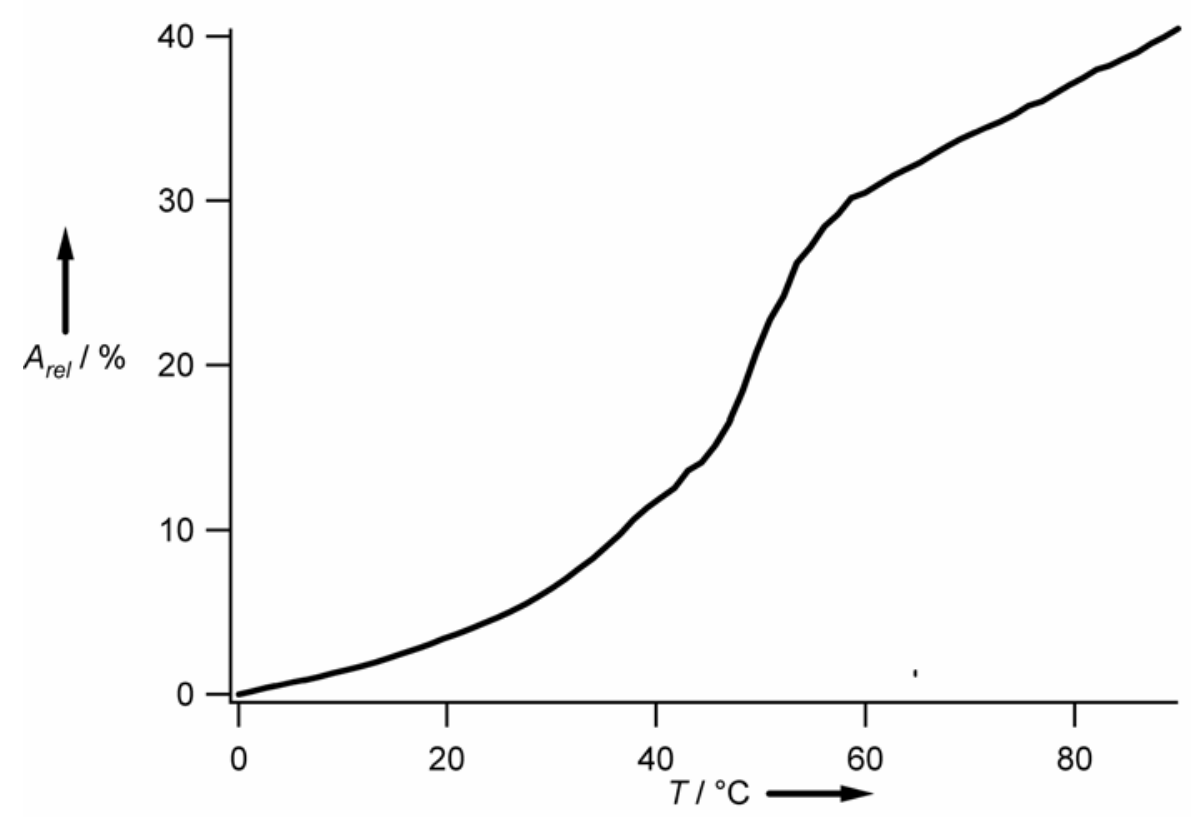

Abbildung 73: Schmelzkurve einer äquimolaren Mischung aus PODN1 und PODN2. Die Schmelztemperatur beträgt $47^{\circ} \mathrm{C}$

Lediglich die Schmelztemperatur ist zu leicht höheren Temperaturen $\left(47^{\circ} \mathrm{C}\right)$ verschoben (Abbildung 73). Dies weist darauf hin, dass der Perylendiimid-Kern die Hybridisierungseigenschaften der assoziierten PODN nicht wesentlich verändert.

PAGE-Experimente dienten zur Unterscheidung der Hybridisierung zwischen PODN und der komplementären Sequenz cODN (Abbildung 74) auf der einen und der polymerartigen Kettenbildung zwischen den beiden Konjugaten (PODN1 und PODN2) (Abbildung 75) auf der anderen Seite. Die Proben wurden jeweils in TE/60 mM-NaCl gelöst und zur Steigerung der Hybridisierungswahrscheinlichkeit gut durchmischt, auf $70^{\circ} \mathrm{C}$ erhitzt und langsam über Nacht auf eine Endtemperatur von $4^{\circ} \mathrm{C}$ abgekühlt. Am darauf folgenden Tag wurde die Gelelektrophorese durchgeführt, wobei SYBR Gold (in die DNA interkalierender Farbstoff, kommerziell erhältlich) als direktes Färbemittel der PODN1/PODN2-Hybride verwendet wurde. 
Im Vergleich zu Proben, die aus einem Konjugat und derselben Oligonucleotidsequenz bestehen (Ia, IVa), weisen Mischungen aus PODN und der komplementären Sequenz cODN mit einem stöchiometrischen Verhältnis von 1:2 (IIa, IIIa) zwei zusätzliche Banden mit höherem Molekulargewicht auf, wobei die cODN-Bande (IIa, IIIa) und die PODN-Bande (IIa) verschwinden. Die zusätzlichen Banden entsprechen mono- und dihybridisiertem PODN, deren Bildung durch die Änderung des stöchiometrischen Verhältnisses zwischen PODN und dem komplementären Oligonucleotid cODN beeinflusst wird. Dies zeigt sich bei denjenigen Proben, bei denen das Teilchenverhältnis zwischen PODN und cODN von 1:2 (IIa, IIIa) auf 1:1 (VIa, VIIIa) geändert wurde. In diesen Fällen schwächt sich die Bande des dihybridisierten Produktes zu Gunsten des monohybridisierten $\mathrm{ab}$.

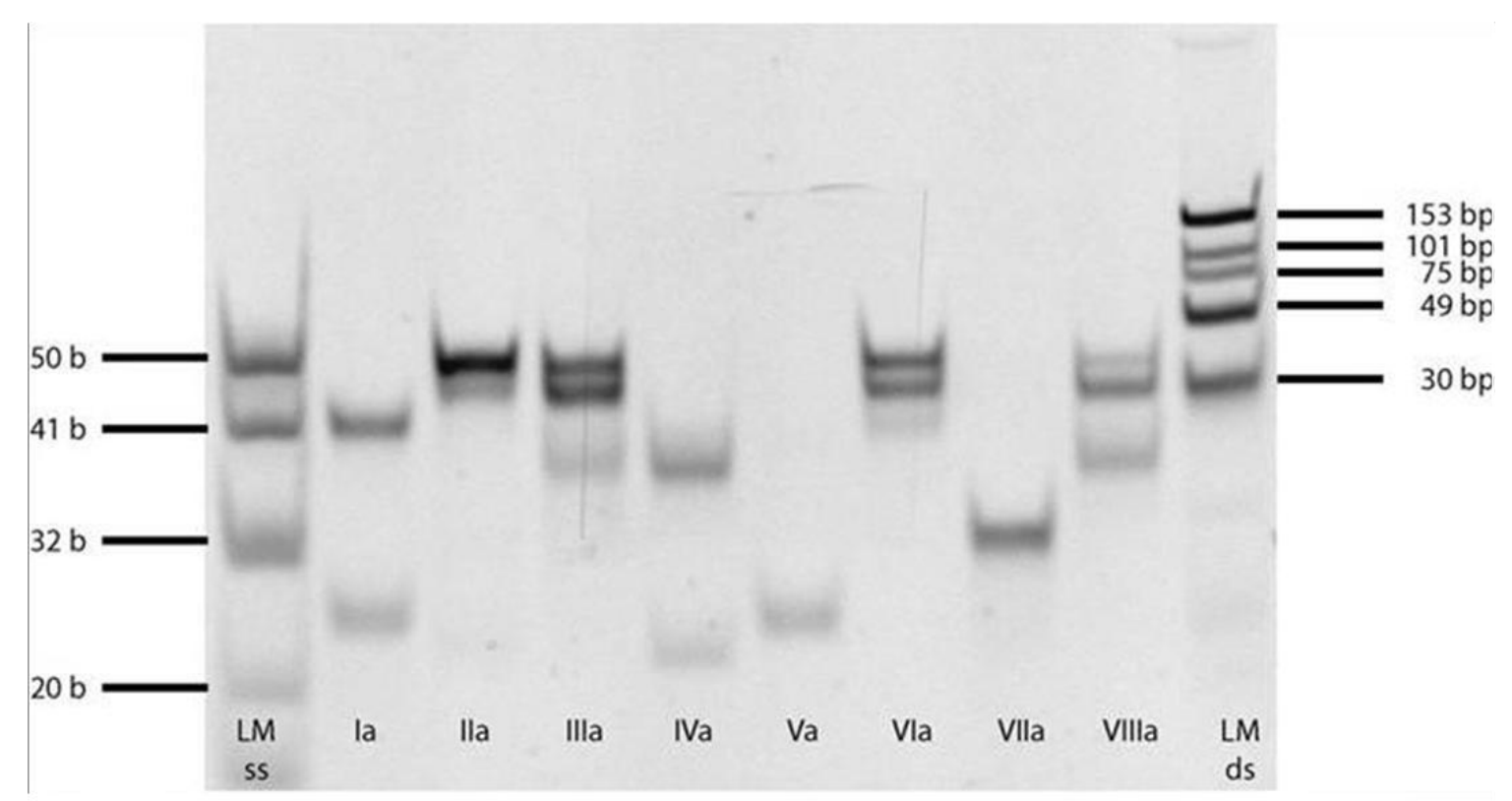

Abbildung 74: Polyacrylamidgelelektrophorese (TBE Puffer (Tris-basisch, Borat, EDTA), pH 8.3): Linien wie folgt: Ia, PODN1/cODN1; IIa, PODN1/cODN2 (stöchiometrisches Verhältnis = 1:2); IIIa, PODN2/cODN1 (stöchiometrisches Verhältnis = 1:2); IVa, PODN2/cODN2; Va, cODN1; VIa, PODN1/cODN2 (stöchiometrisches Verhältnis = 1:1); VIIa, cODN1/cODN2 (stöchiometrisches Verhältnis = 1:1); VIIIa, PODN2/cODN1 (stöchiometrisches Verhältnis = 1:1); LM: DNA-Marker 
Im Gegensatz zu dem oben beschriebenen Auftreten von zwei zusätzlichen Banden im Fall der Mischungen aus PODN und der komplementären Sequenz cODN tritt bei den Proben, die aus den zwei komplementären Perylendiimid-bis(oligonucleotid)-konjugaten (PODN1 und PODN2) bestehen, eine leiterartige Bandestruktur bei höheren Molekulargewichten auf. Diese Banden können kettenartigen Polymerstrukturen unterschiedlicher Länge zugeordnet werden (IIIb-VIIb). Mit Hilfe des Gels kann die Entstehung von PODN-Dimeren, -Trimeren, -Tetrameren und -Pentameren nachgewiesen werden. Die Bande, die bei ca. 800 bp läuft, könnte einer ringförmigen Struktur entsprechen. Die Kettenbildung tritt bei Proben aus PODN und dem komplementären Oligonucleotid cODN nicht auf. Die Variation des stöchiometrischen Verhältnisses zwischen PODN1 und PODN2 beeinflusst kaum die Entstehung von Poly-PODN bestimmter Länge, was im symmetrischen Charakter der PODN begründet liegt. Des Weiteren weist eine Mischung aus beiden PODN und beiden cODN Banden auf, die cODN1/cODN2-Hybriden, PODN, PODN/cODN-Hybriden und PODN-Ketten unterschiedlicher Länge entsprechen (VIIIb). Dies deutet darauf hin, dass der Perylendiimidkern die Hybridisierung des angebunden ODN nicht behindert. Weiterführende Experimente zeigen auch, dass die Salzstärke die Kettenbildung nicht signifikant beeinflusst.

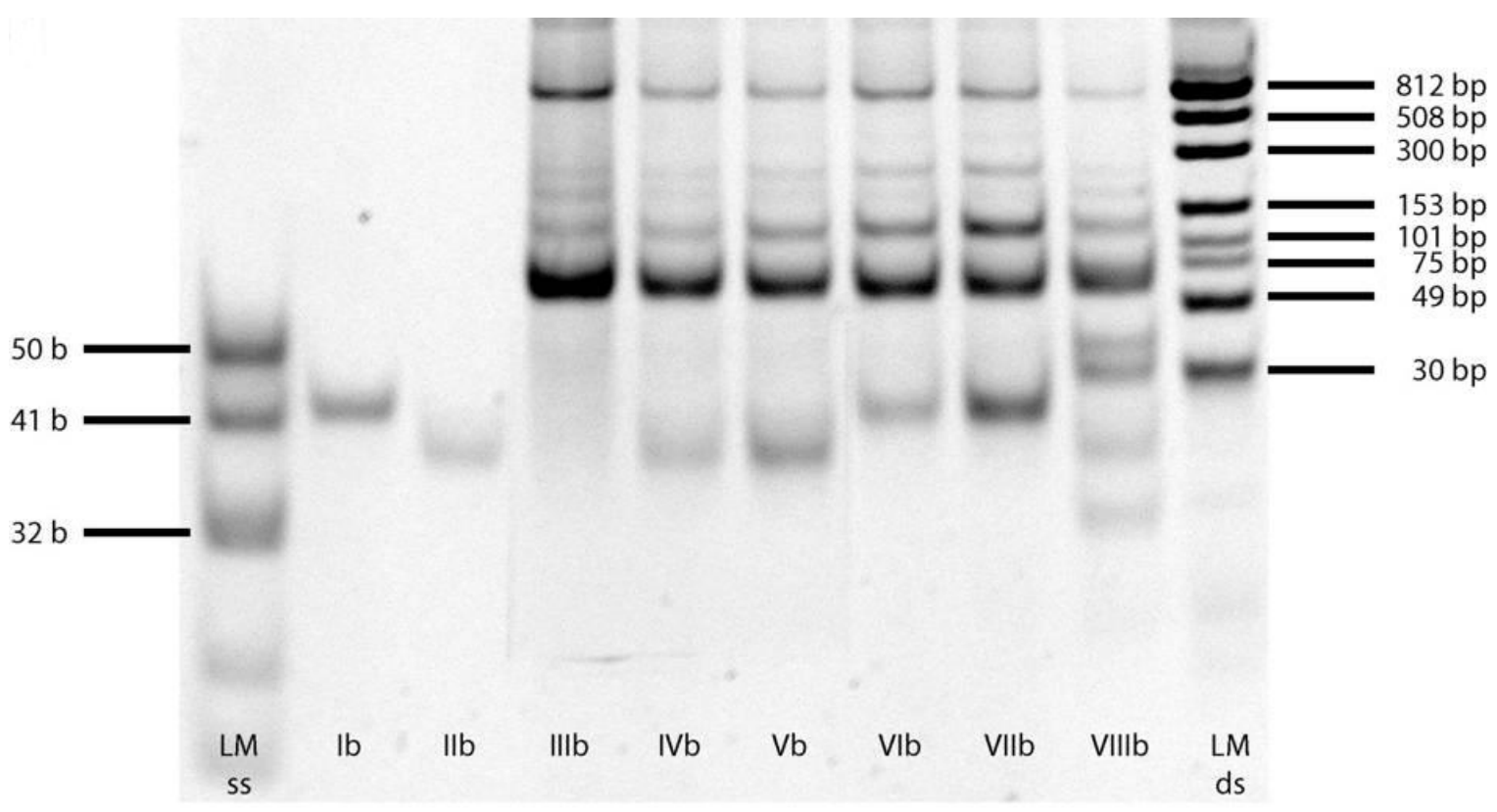

Abbildung 75: Polyacrylamidgel der PODN1/PODN2-Hybride: Linien wie folgt: 
Ib, PODN1; IIb, PODN2; IIIb, PODN1/PODN2 (stöchiometrisches Verhältnis = 1:1); IVb, PODN1/PODN2 (stöchiometrisches Verhältnis = 1:2); Vb, PODN1/PODN2 (stöchiometrisches Verhältnis = 1:3); VIb, PODN1/PODN2 (stöchiometrisches Verhältnis $=2: 1$ ); VIIb, PODN1/PODN2 (stöchiometrisches Verhältnis = 3:1); VIIIb, PODN1/PODN2/cODN1/cODN2 (stöchiometrisches Verhältnis $=1: 1: 1: 1)$

\subsection{Synthese und Selbstorganisation eines Perylendiimid-DNA- Sandwichs}

Die Synthese von Perylendiimid-bis(oligonucleotid)-konjugaten (PODN1 und PODN2) und ihre Selbstorganisation zu Polyperylendiimidketten zeigten, dass die verwendeten Bausteine, die jeweils mit zwei identischen Sequenzen funktionalisiert sind, ...ABABAB...-artige lineare supramolekulare Strukturen ausbilden können. Prinzipiell kann eine beliebige Basensequenz als Verkettungselement für den Aufbau polymerer Strukturen verwendet werden. Eine kontrollierte Kettenbildung definierter Länge oder gar eine Dimerbildung ohne weitere Verknüpfungsmöglichkeit (DNASandwich) kann mit den Konjugaten PODN1 und PODN2 nicht erreicht werden. Dieses DNA-Sandwich ist nur möglich, wenn die zwei Sequenzen entgegenstehend (eine Sequenz $55^{`} \rightarrow 3^{`}$ und die zweite Sequenz $3^{`} \rightarrow 5^{\prime}$ ) parallel zueinander liegen. Um zwei Perylendiimid-bis(oligonucleotid)-konjugate einander gegenüber durch Hybridisierung positionieren zu können (DNA-Sandwich), muss einer der beiden komplementären Oligonucleotide (PODN1 und PODN2) an der 3`' statt an der 5'-Position an das Perylendiimid angebunden sein. Dafür ist die Synthese eines Oligonucleotides mit einer Aminfunktion am 3'-Ende (ODN3) erforderlich. Es soll ermittelt werden, wie zwei einander gegenüber liegende Perylendiimidmoleküle miteinander in Wechselwirkung stehen, ob sich bei diesem Hybrid Aggregate ausbilden werden oder das Hybrid monosdispers bleibt. In Abbildung 76 ist eine schematische Darstellung für das Hybrid aus PODN1 und PODN3 (3-41, ODN3-PDI-ODN3). 


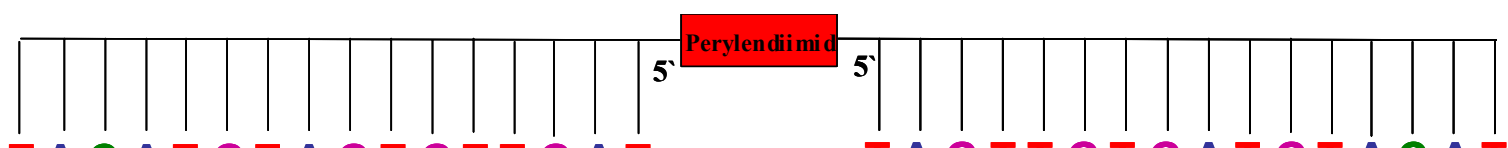

TA C A T G T A G T G T T G A T TA G T T G T G A T G T A C A T

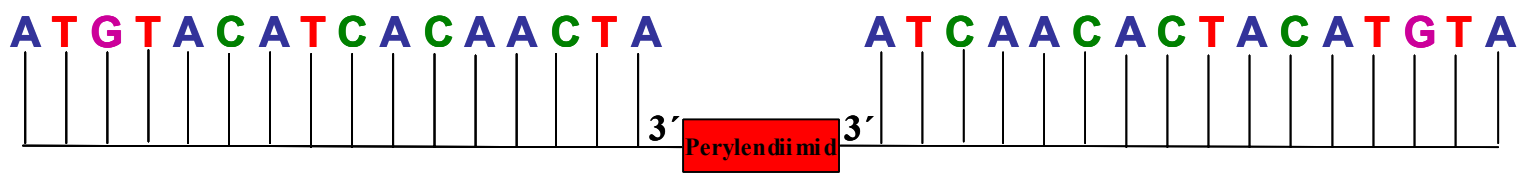

Abbildung 76: Schematische Darstellung eines DNA-Sandwiches bestehend aus zwei Perylendiimid-bis(oligonucleotid)-konjugaten, während ein der beiden Konjugate an der 5`Position verknüpft ist, ist das zweite Konjugat am 3`-Ende angebunden

Zur Synthese von ODN3 soll ein Trägermaterial verwendet werden, das zwei Funktionen trägt, eine geschützte Aminfunktion und eine DMTr-geschützte Hydroxylgruppe. Die DNA-Synthese wird an der geschützten OH-Gruppe gestartet. Die Aminogruppe bleibt geschützt bis die Synthese vollständig ist. Das verwendete Trägermaterial ist ein Pthalimidyl-C6-aminmodifizierter Träger (siehe Abbildung 34) und basiert auf CPG. Er ist mit $45 \mu \mathrm{mol}$ Hydroxyfunktionen pro Gram beladen. Im Falle von Trägermaterialien, die auf Polystyrol/divinylbenzol basieren, ist eine Beladung bis $200 \mu \mathrm{mol} / \mathrm{g}$ möglich. Aufgrund der geringen Beladungsfähigkeit des CPG ist die Ausbeute von einem Oligonucleotid, das auf CPG synthetisiert wird, deutlich geringer als beim Einsatz von Polystyrol/divinylbenzol, das mit einer solchen Modifikation kommerziell nicht verfügbar ist. Die Synthese beginnt mit der Abspaltung der Hydroxylschutzgruppe und der Einführung des ersten Nucleotids. Danach erfolgt die Synthese nach dem gleichen Syntheseprotokoll für ODN1 und ODN2, bis das letzte Oligonucleotid verknüpft wurde. Die Abspaltung war nach 17 Stunden bei $55^{\circ} \mathrm{C}$ in $32 \%$ iger Ammoniaklösung vollständig. ODN3 wurde mit Hilfe von Ionenaustausch-HPLC aufgereinigt. In Abbildung 77 ist das HPLC-Chromatogramm dargestellt. Das Chromatogramm bestätigt die erfolgreiche Synthese und veranschaulicht die Reinheit des Produkts. $225 \mathrm{mg}$ (45 $\mu \mathrm{mol})$ von gereinigtem Produkt ODN3 wurden erhalten ( 63\%ige Ausbeute 


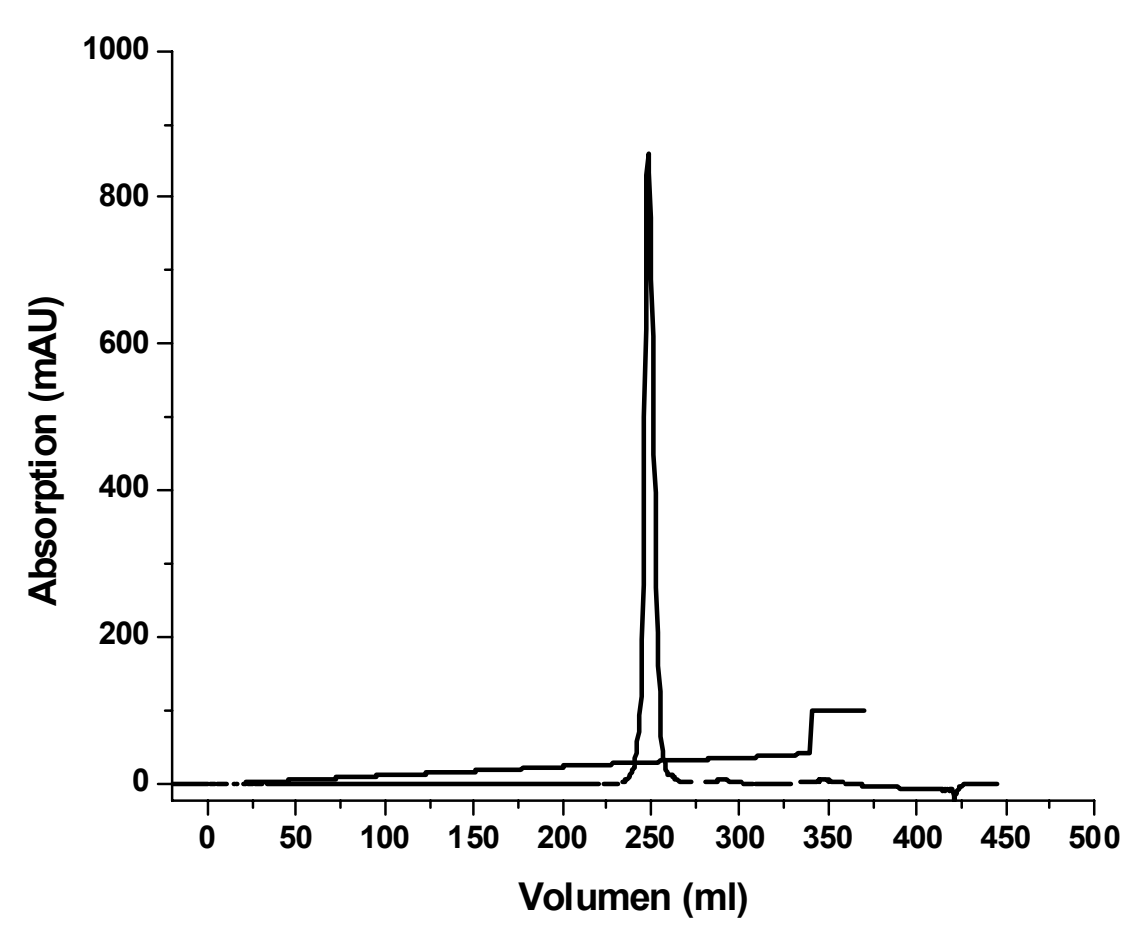

Abbildung 77: HPLC-Chromatogramm von ODN3 (5 '-ATGT ACA TCA CAA CTA-p- $\left(\mathrm{CH}_{2}\right)_{6}$ $\mathrm{NH}_{2}$ ). Die aliphatische Aminfunktion ist am 3`-Ende verknüpft, Eluent A: $10 \mathrm{mM} \mathrm{NaOH}$, Eluent B: $10 \mathrm{mM} \mathrm{NaOH}+2 \mathrm{M} \mathrm{NaCl}$, Gradient: 0-45 \% Eluent B in 45 Säulevolumen

Der Strukturbeweis für ODN3 liefert die Maldi-Tof-Analyse. In Abbildung 78 ist dasMaldi-Tof-MS von ODN3 zu sehen. Der Molekülionenpeak bei $5017 \mathrm{~g} / \mathrm{mol}$ stimmt mit dem berechneten Wert $\left(\mathrm{M}_{\mathrm{ber}}=5014.83 \mathrm{~g} / \mathrm{mol}\right)$ überein.

Die Synthese von PODN3 erfolgt analog zu PODN1 und PODN2. Das 3'Aminoligonukeotid wurde in frisch vorbreitete $0.1 \mathrm{M}$-Natriumtetraboratlösung gelöst und 5 Minuten geschüttelt. Der Aktivester 3-24 wurde in trockenes DMF gelöst und zu der Oligonucleotidlösung langsam zugegeben. Das Reaktionsgemisch wurde bei $37{ }^{\circ} \mathrm{C}$ über Nacht gerührt. Die UV-Vis- und Fluoreszenzspektren vom PODN3 geben ein ähnliches Bild wie beim PODN1 (Abbildungen 39 und 40), d.h. analog zu PODN1 und PODN2 ist auch bei PODN3 die Fluoreszenzquantenausbeute (FQA) in wässrigen Medien im Vergleich zu FQA von Perylendiimid in organischen Lösungsmitteln sehr stark zurückgegangen. Die Aufreinigung von PODN3 wurde mit Hilfe von 12 \%iger Polyacrylamidgelelektrophorese durchgeführt. 


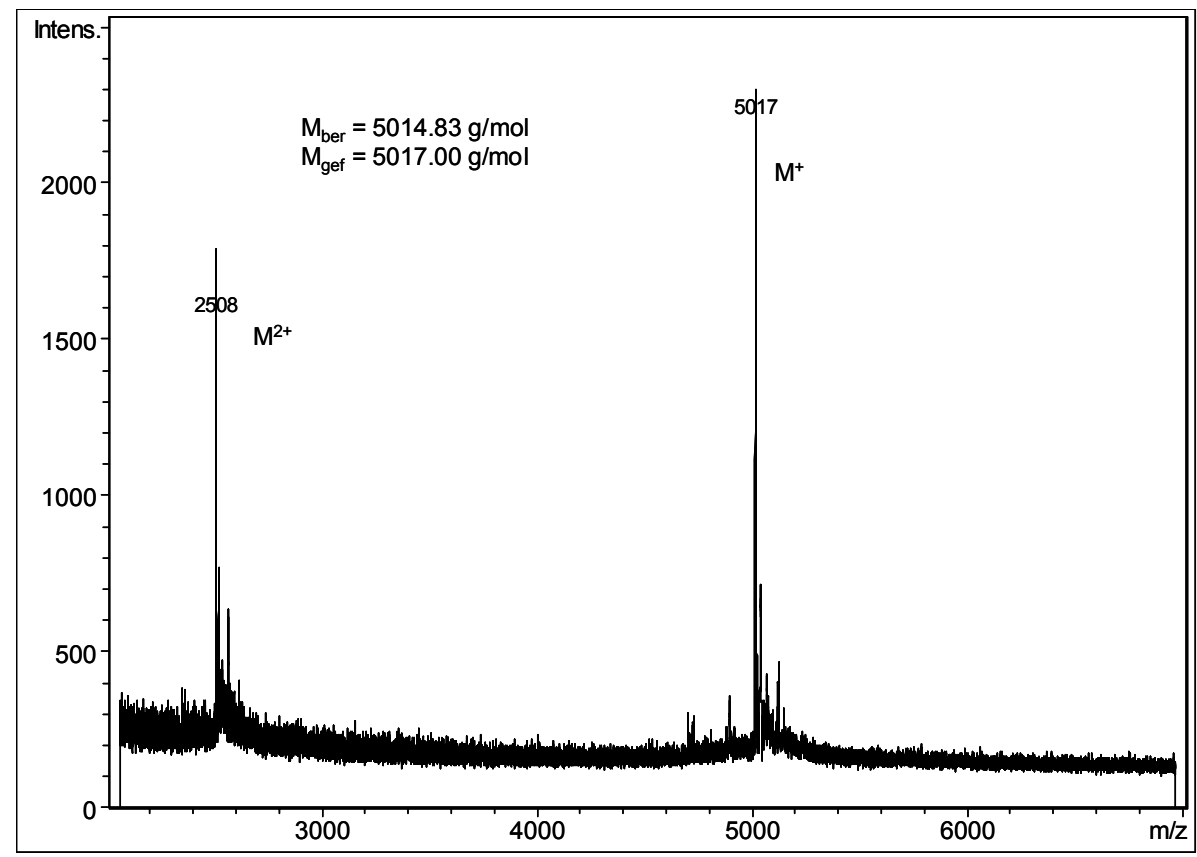

Abbildung 78:Maldi-Tof-MS von ODN3, Matrix: 3-Hydroxypicolinsäure gelöst in Acetonitril und $\mathrm{ddH}_{2} \mathrm{O}$

Das Bild der Gelelektrophorese ist in Abbildung 79 gezeigt. Hier sind wieder zwei Banden zu erkennen. Die untere und stärkere Bande entspricht dem Oligonucleotid ODN3, das bei der Reaktion in großem Überschuss eingesetzt wurde. Die obere Bande geht auf das erwartete Konjugat PODN3 zurück. Die Ausbeute betrug 28 \%. Auch hier wurde bei der Elektrophorese ein monosubstituiertes Konjugat beobachtet, das aufgrund der Aggregatbildung durch das Gelmaterial nicht wandern konnte. PODN3 und das nicht reagierte ODN3 wurden aus dem Gel ausgeschnitten und in Wasser bei $37^{\circ} \mathrm{C}$ extrahiert. Die Quantifizierung des erhaltenen Produkts erfolgte nach dem Entsalzen und Zentrifugieren der gesammelten Lösung. 


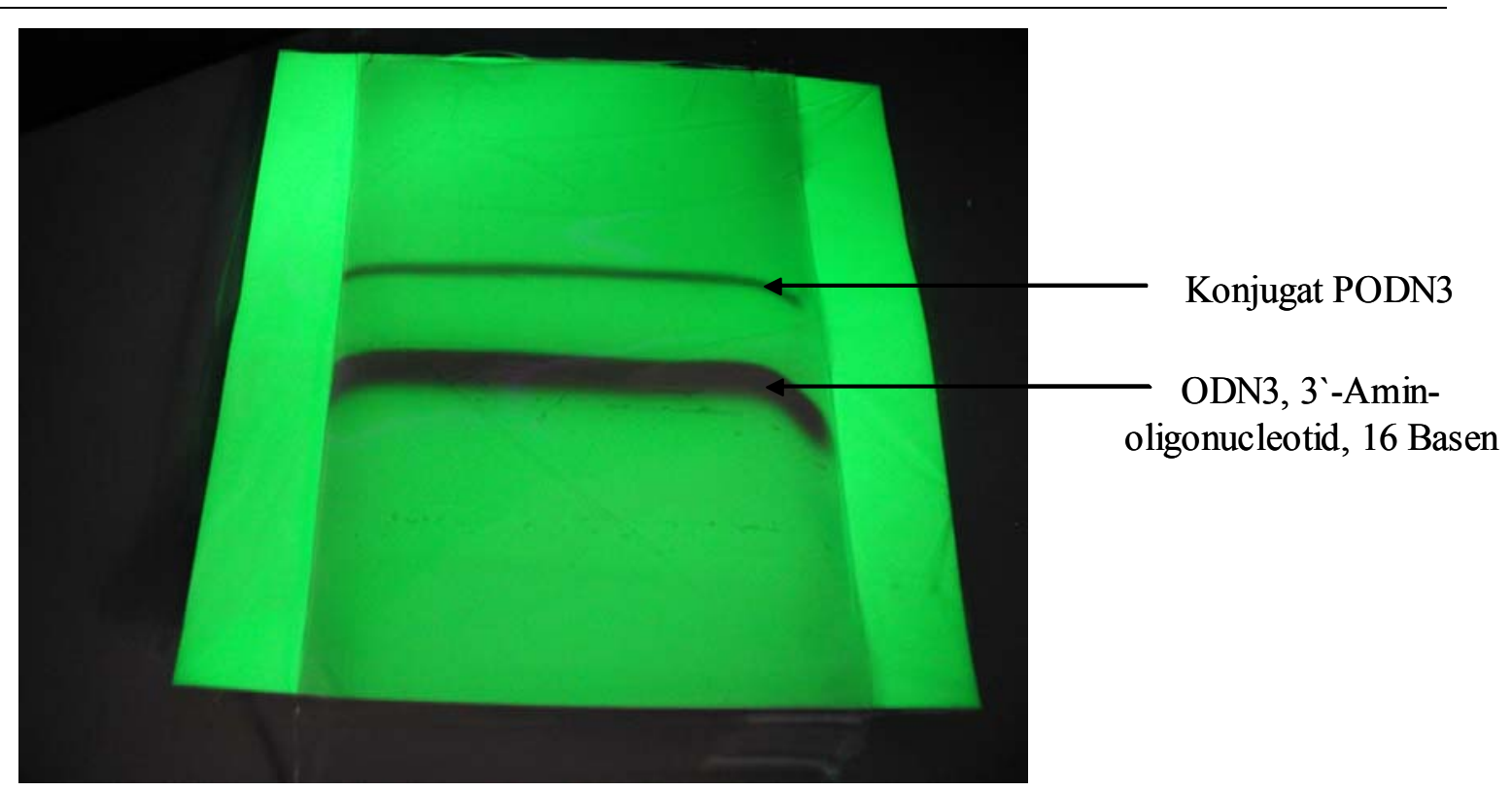

Abbildung 79: PAGE-Bild von PODN3 (ODN3-PDI-ODN3), Perylendiimid mit zwei Oligonucleotidsequenzen jeweils 16 Basen (5'-ATGT ACA TCA CAA CTA-p- $\left(\mathrm{CH}_{2}\right)_{6}$-NH-COPDI-CO-NH-(CH2)6-p-ATC AAC ACT ACA TGTA-5')

Die Hybridisierung zwischen den komplementären Konjugaten PODN1 und PODN3 wurde in TE/0.8M NaCl Puffer durchgeführt. Die erhaltenen Hybride wurden mit Hilfe von PAGE untersucht. Wie man in Abbildung 80 erkennen kann, ist neben den Banden der Monomere (PODN1 und PODN3) die Banden des Dimeren PODN1-PODN3 zu erkennen (die dicke obere Bande in III-VI). In V war das Mischverhältnis von PODN1 und PODN3 2:1. In VI wurde PODN3 und die doppelte Menge an ODN1, die komplementär zu ODN3 (cODN3) ist, zusammengemischt. In VII wurden beide in gleicher Konzentration hybridisiert. Man kann in V feststellen, dass lediglich zwei Banden vorhanden sind. Die untere Bande in V liegt auf dem Gelbild auf der gleichen Höhe wie PODN1 (I), d. h. sie repräsentiert den Überschuss an PODN1 in der Mischung. Die obere Bande, die im höheren Molekularbereich liegt, ist für das Hybrid aus PODN1 und PODN3. Die oberste Bande in VI (PODN3 + 2 ODN1 (cODN3)). In VII hingegen ist die mittlere Bande die Stärkste (PODN3 + cODN3). Durch den Überschuss an cODN3 in VI wird die Hybridisierung beide Oligonucleotidarme in PODN3 ermöglicht. Bei gleicher Konzentration in VII (PODN3 + cODN3) erhält man ein Gemisch aus zwei Hybriden, in dem einen ist lediglich ein Arm in PODN3 hybridisiert (die mittlere Bande in VII) und in 
dem anderen sind beide Oligonucleotidarme mit cPODN3 gepaart (die oberste Bande in VI and VII). Der Vergleich zwischen der Bandenzuordnung in V auf der einen Seite und die in VI und VII auf der anderen Seite zeigt, dass die obere Bande in V dem Hybrid (Dimer) PODN1-PODN3 entsprechen kann. Nicht unerwähnt bleiben soll, ist das Design der Konjugate PODN1 und PODN3. Während im ersten Konjugat (PODN1) das Oligonucleotid am 5'-Ende angebunden ist, wurde im zweiten Konjugat das Perylendiimid am 3'-Ende verknüpft. Dieses Design der Konjugate ermöglicht im Falle einer Hybridisierung beider Konjugate, nur die Bildung eines Hybrids in der Form eines Sandwichs, da in einem DNA-Doppelhelix das 3'-Ende einer Sequenz mit dem 5'-Ende der zweiten Sequenz (und umgekehrt) hybridisiert.

In der Literatur wurde über die Synthese und Hybridisierung von einem DNA-Dimeren in der Form eines Sandwichs auf der Basis von Stilben berichtet ${ }^{146}$. Durch die Hybridisierung wurden zwei Stilbenmoleküle einander gegenüber positioniert. Durch die Bestrahlung des Hybrids resultierte eine Excimer-Emission.

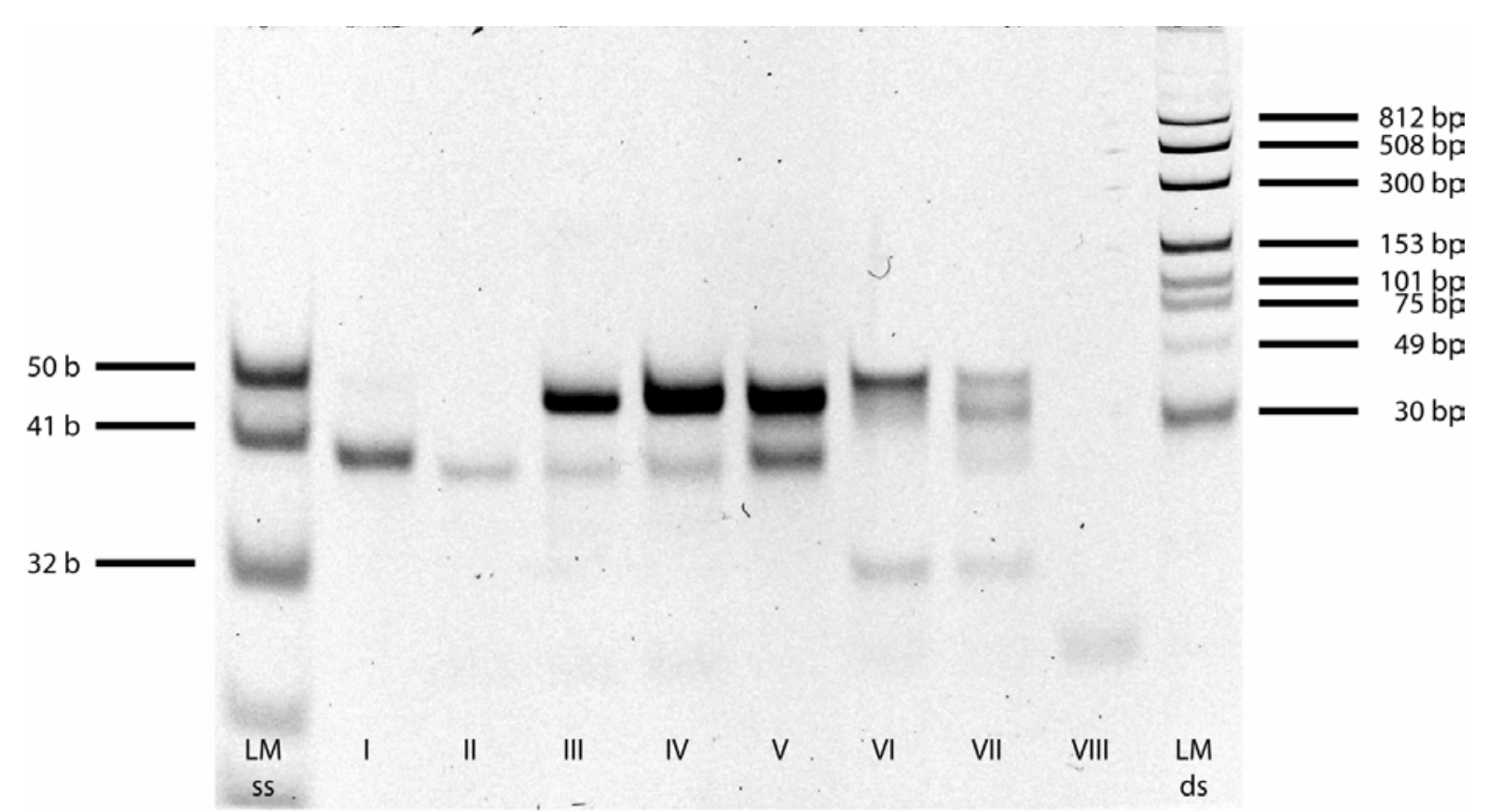

Abbildung 80: PAGE vom Hybridisierungsexperiment zwischen PODN1 und PODN3 zum DNA-Sandwich, I: PODN1, II: PODN3, III: PODN1 + PODN3 (Hybrid), IV: PODN1 + 2 PODN3, V: 1.5 PODN1 + 0.75 PODN3, VI: PODN3 + 2 ODN1 (cODN3), VII: PODN3 + ODN1 
Das Konzept des DNA-Sandwichs wurde entwickelt, um zwei unterschiedliche organische Verbindungen parallel gegenüber einander $\mathrm{zu}$ positionieren. Zum Beispiel kann durch die Synthese eines Terrylendiimid-bis(oligonucleotid)-Konjugats (TODN) und dessen Hybridisierung mit einem PODN ein DNA-Sandwich und damit DonorAkzeptor-System gebildet werden, das zur Erzeugung von Energietransfer (FRET) verwendet werden könnte. Doch diesem Ziel stand die schwierige und mehrstufige Synthese von Terrylendiimid mit zwei Säurefunktionen in der Imidstruktur entgegen und stellt eine weitere experimentelle Herausforderung dar, die nicht mehr Gegenstand dieser Arbeit war. Dieses Prinzip ist aber auf andere Moleküle übertragbar, die mögliche Kandidaten zur Erzeugung von FRET sind.

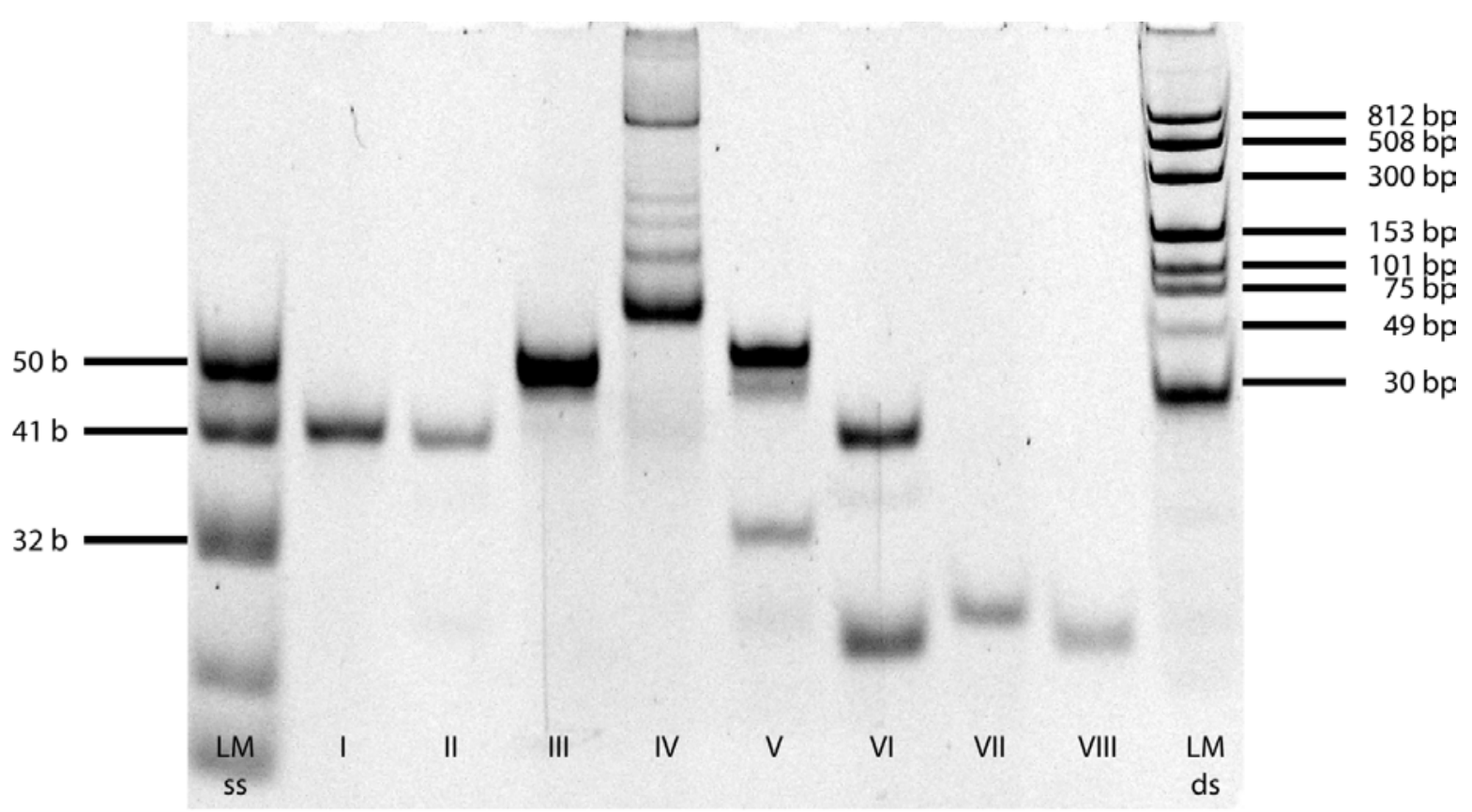

Abbildung 81: Vergleich zwischen den Hybriden von Perylen-DNA-Polymer und DNASandwich, I: PODN1, II: PODN3, III: PODN1 + PODN3, IV: PODN1 + PODN2, V: PODN3 + 2 ODN1 (cODN3), VI: PODN3 + 2 ODN3, VII: ODN1, VIII: ODN3

Einen weiteren Nachweis für die Bildung des Dimers in der Form eines DNA-Sandwichs liefert die PAGE (Abbildung 81). Wie man in Abb. 81 sehen kann, führt die Hybridisierung zwischen zwei komplementären Perylendiimid-bis(oligonucleotid)konjugaten, die an der 5 '-Position verknüpft sind, zu einem Perylen-DNA-Polymer (IV, 
Polymer mit unterschiedlichen Kettenlängen, PODN1 + PODN2), im Gegensatz dazu resultiert aus das Hybrid (III), das aus PODN1 und PODN3 entstand, lediglich eine Bande im höheren Molekularbereich. Dies zeigt, dass keine Kettenbildung stattfand und nur ein Dimer (DNA-Sandwich) gebildet wurde (Bande III in Abb. 81).

Die FCS-Messungen des DNA-Sandwichs (des Hybrids PODN1 + PODN3) zeigten, dass das Hybrid keine Aggregate ausbildete und dass keine Beeinträchtigung der Fluoreszenzintensität auftrat. Somit behindert die Anwesenheit von zwei Perylendiimidmoleküle, die in der Mitte eines DNA-Hybrids einander gegenüber liegen, die Hybridisierung nicht und führt auch nicht zum Verlust ihrer optischen Eigenschaften.

\subsection{Synthese eines asymmetrischen Perylendiimid-bis(oligonucleotid)-}

\section{konjugats}

Die gelungene Dekorierung des Perylendiimids mit zwei Oligonucleotidsequenzen und die erfolgreiche Hybridisierung mit einem komplementären Konjugat führten zur Bildung eines Perylen-DNA-Polymers. Aufgrund der Symmetrie in der Struktur von PODN1 und PODN2 konnte die Länge des gebildeten Polymers ebenso wie der mögliche Ringschluss durch die zwei Polymerenden nicht bestimmt werden. Diese Ergebnisse erweckten das Interesse an der Synthese eines asymmetrischen Konjugats. Ein asymmetrisches PODN wird ermöglichen, sowohl die Länge des Perylen-DNA-Polymers als auch den Ringschluss zu kontrollieren. Bisher konnten organische Verbindungen mit zwei unterschiedlichen Oligonucleotidsequenzen nur durch Festphasensynthese synthetisiert werden. Die zu konjugierenden Moleküle müssen zwei aktive Gruppen enthalten, um an den DNA-Synthesizer integriert zu werden, d.h. solche Moleküle sollen mit einer DMTrgeschützten $\mathrm{OH}$ - und Phosphoamiditgruppe modifiziert werden. Des Weiteren müssen sich die modifizierten Verbindungen in dem verwendeten Lösungsmittel (meistens Acetonitril) gut lösen können. Verbindungen, die solche Voraussetzungen nicht erfüllen, können nicht mit zwei unterschiedlichen Oligonucleotiden dekoriert werden. 
Kapitel 3: Synthese und Selbstorganisation von Perylen-Oligonucleotid-Konjugaten

Nach der erfolglosen Desymmetrisierung von Perylendiimid 3-38 für die Festphasensynthese soll jetzt versucht werden, ein asymmetrisches PODN in der Lösung zu synthetisieren. Für die Herstellung eines asymmetrischen Konjugats PODN5 (3-42) wurde neben ODN1 eine längere Oligonucleotidsequenz (ODN4, 24 Basen) ausgewählt, um später ein deutlich anderes Laufverhalten der Oligonucleotide in der Gelelektrophorese zu gewährleisten. Das Oligonucleotid ODN4 $\left(5^{\prime}-\mathrm{H}_{2} \mathrm{~N}-\left(\mathrm{CH}_{2}\right)_{6}\right.$-p-AGC GGA TAA CAA TTT CAC ACA GGA-3') wurde nach dem bereits verwendeten Protokoll für die Synthese von 5'-Aminoligonucleotid am DNA-Synthesizer hergestellt. Bei der Synthese dieser Sequenz wurde ein neues Tetrazolderivat (5Benzylmercaptotetrazol), das neulich entwickelt und publiziert wurde ${ }^{45}$, als Katalysator für die Kopplungsreaktion eingesetzt. Durch den Einsatz dieses Katalysators wurde eine bessere Kopplungsausbeute erzielt. Die Aufarbeitung wurde analog zu ODN1 durchgeführt. Die Aufreinigung erfolgte mit Hilfe von Ionenaustausch-HPLC. In Abbildung 82 ist das HPLC-Chromatogramm von ODN4 gezeigt. Die erfolgreiche Synthese von ODN4 wird durch die Abwesenheit von (n-1)-Peaks im Chromatogramm und Maldi-Tof-Analyse bestätigt. Nach der HPLC-Aufreinigung und der darauf folgenden Aufarbeitung der erhaltenen Fraktionen wurden $827 \mathrm{mg}(109.5 \mu \mathrm{mol})$ erhalten. Die Ausbeute von ODN4 beträgt damit $72 \%$. 


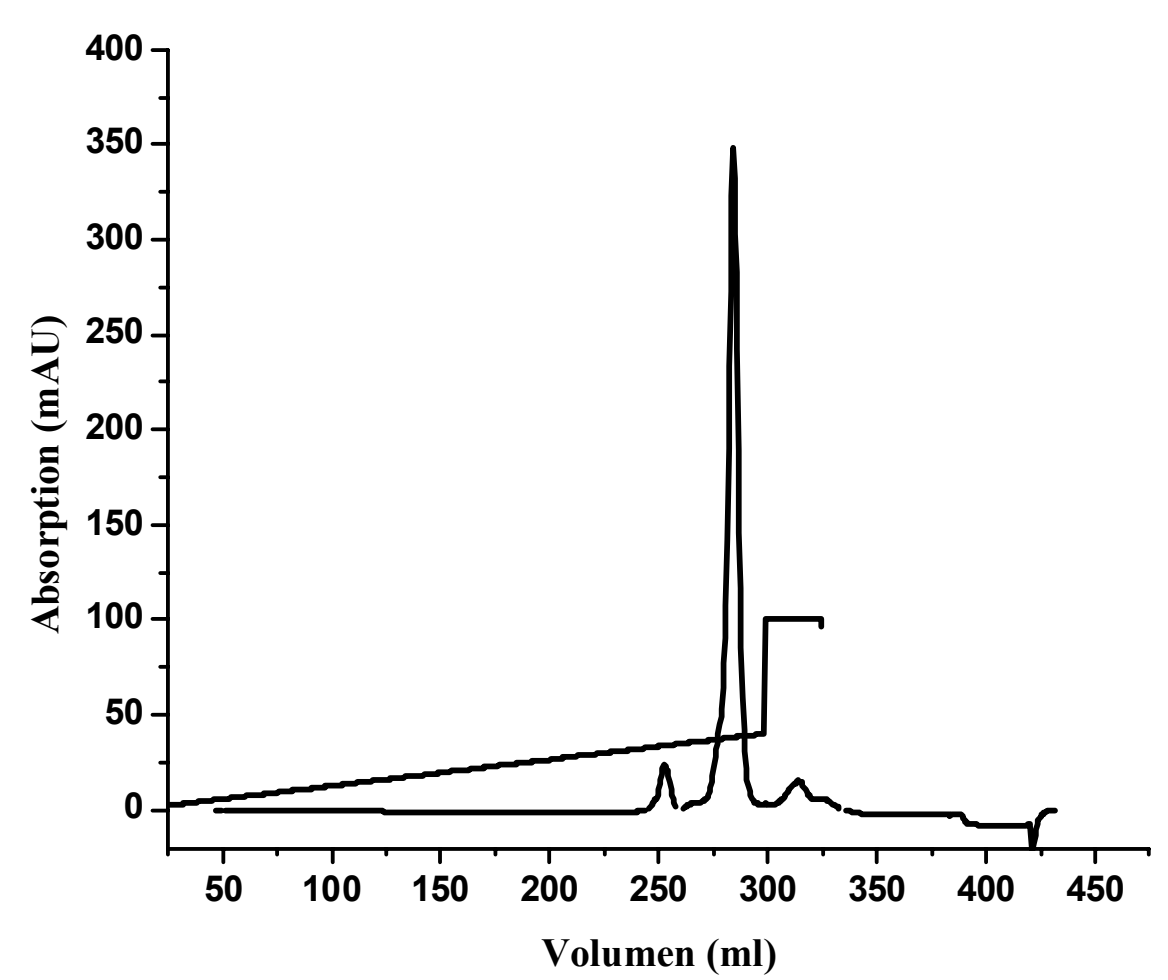

Abbildung 82: HPLC-Chromatogramm von ODN4 (24mer mit einer Aminfunktion am 3’-Ende, Eluent A: $10 \mathrm{mM} \mathrm{NaOH}$, Eluent B: $10 \mathrm{mM} \mathrm{NaOH}+2 \mathrm{M} \mathrm{NaCl}$, Gradient: 0-65 \% Eluent B in 50 Säulevolumen

Den Strukturnachweis liefert die Maldi-Tof-Spektroskopie. In Abbildung 83 ist der Molekülionenpeak $\mathrm{M}^{+}$bei $7556 \mathrm{~g} / \mathrm{mol}\left(\mathrm{M}_{\mathrm{ber}}=7552.72 \mathrm{~g} / \mathrm{mol}\right)$ ebenso wie einen Peak bei $3780 \mathrm{~g} / \mathrm{mol}$, der dem doppelt geladenen Molekül $\mathrm{M}^{2+}$ entspricht, zu erkennen. Die kleineren Peaks, die rechts neben dem Hauptmaximum auftauchen, repräsentieren das Molekül ODN4 mit mehreren Natrium-Ionen, die nach der HPLC-Aufreinigung nicht vollständig entfernt werden konnten (das ODN4, 24 Basen, kann bis zu 23 Natrium-Ionen als Gegenionen aufnehmen). 


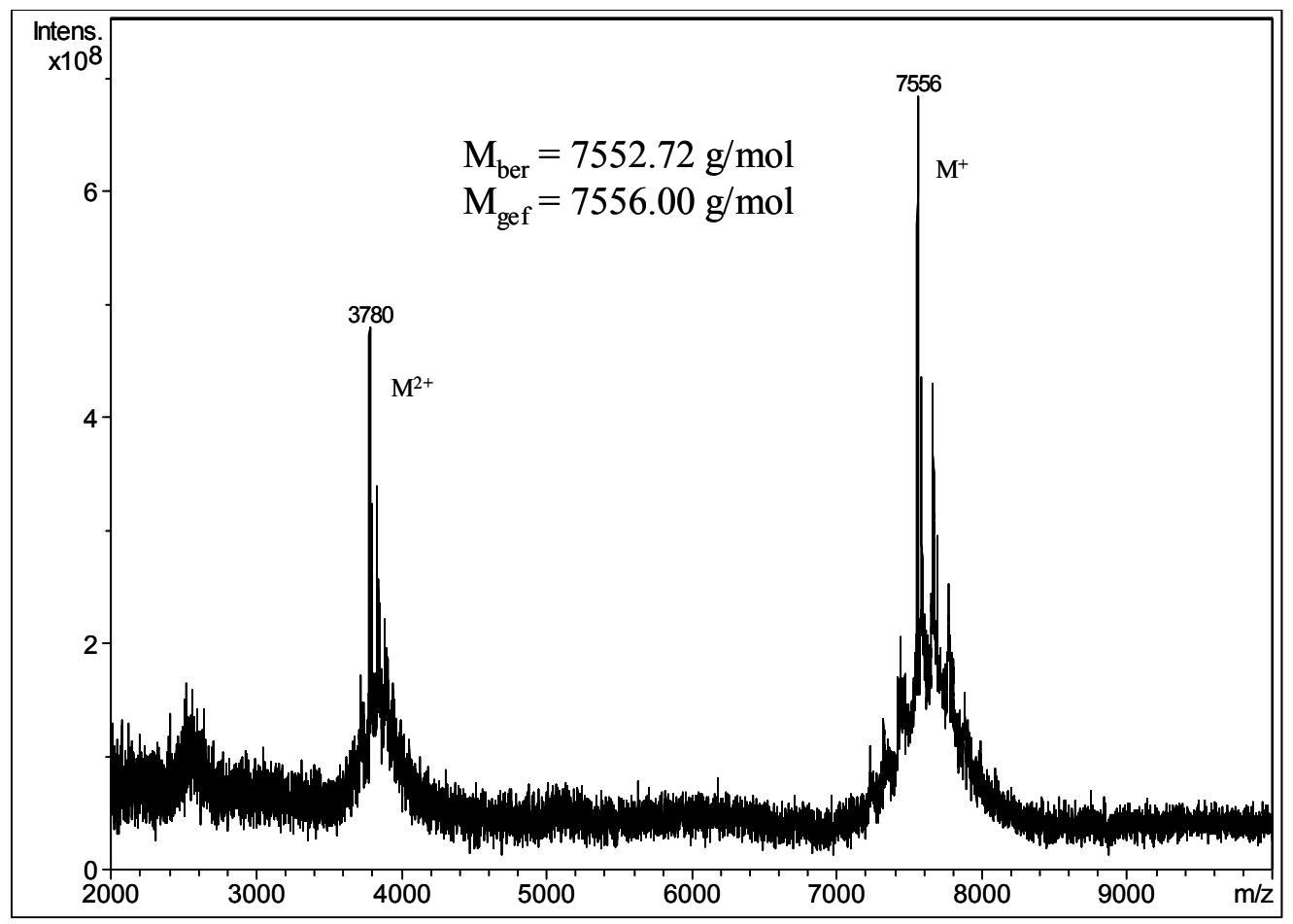

Abbildung 83:Maldi-Tof-MS von ODN4 $\left(5^{\prime}-\mathrm{H}_{2} \mathrm{~N}-\left(\mathrm{CH}_{2}\right)_{6}\right.$-p-AGC GGA TAA CAA TTT CAC ACA GGA-3’)

Das Auftauchen des Signals für das zweifach geladene Molekül (in Abb. 83 liegt es bei $3780 \mathrm{~g} / \mathrm{mol}$ ) wurde bereits bei der Maldi-Tof-Messung von Oligonucleotiden und Oligonucleotid-Peptid-Konjugaten in der Literatur gezeigt ${ }^{156}$.

Es ist sehr schwierig, die Oligonucleotidproben nach der Aufreinigung vollständig zu entsalzen. Deshalb tauchen Signale im Maldi-Tof-MS auf, die dem Molekulargewicht des Molekülionenpeaks plus Natriumionen $(1,2, \ldots n)$ entsprechen. Die Signale liegen dann im höheren Molekularbereich im Vergleich zu dem Molekülionenpeak (Abb. 83). Das führt zu einer Verkleinerung der Intensität des Hauptsignals und damit zu einem schlechteren Signalrauschverhältnis, was sich in der Form des Hauptsignals bemerkbar macht.

Zur Synthese des asymmetrischen PODN5 (3-42, ODN1-PDI-ODN4) in Lösung wurden von ODN1 und ODN4 jeweils 5 Äquivalenten getrennt in $0.1 \mathrm{M}$ Lösung von Natriumtetraborat ( $\mathrm{pH}$ 8.3) gelöst und geschüttelt. Die entsprechende Stoffmenge vom Aktivester 3-24 wurde in DMF gelöst. Die Lösungen von ODN1 und ODN4 wurden zusammengeführt, bevor der Farbstoff in die Oligonucleotidmischung eingetropft wurde. 
Das Reaktionsgemisch wurde bei $45{ }^{\circ} \mathrm{C}$ über Nacht gerührt. Die Reaktionstemperatur wurde von $37{ }^{\circ} \mathrm{C}$ auf $45{ }^{\circ} \mathrm{C}$ erhöht, um sekundäre Strukturen zwischen den Oligonucleotiden ODN1 und ODN4 zu vermeiden, die die Kopplung verhindern könnten. Nach einer Reaktionszeit von zwei Stunden wurden keine Ausfällungen und eine relativ klare Reaktionslösung beobachtet. Nach dem Einengen des Reaktionsgemisches im Vakuum wurde eine präperative PAGE durchgeführt. Nach der Abkühlung der Elektrophorese und Visualisierung der Gelschicht unter UV-Licht bei $254 \mathrm{~nm}$ konnten 5 Banden beobachtet werden (Abbildung 85), die im Falle einer erfolgreichen Synthese auftreten mussten. Zwei der Banden entsprechen dem Überschuss an ODN1 und ODN4, zwei den symmetrischen Konjugaten PODN1 und PODN4 und eine Bande dem asymmetrischen Konjugat PODN5 (ODN1-PDI-ODN4). Das Monokonjugat, das bei dieser Reaktion als Nebenprodukt erhalten wird, konnte aufgrund seiner hydrophoben Eigenschaften nicht über PAGE isoliert werden und blieb unbeweglich auf dem Gelmaterial.

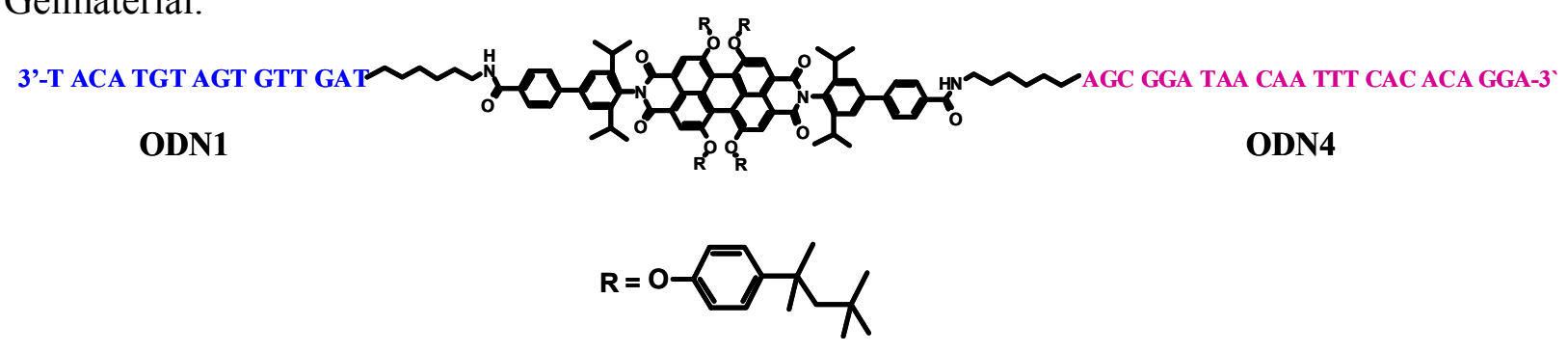

3-42

Abbildung 84: Struktur des asymmetrischen Konjugats 3-42, PODN5 (ODN1-PDI-ODN4

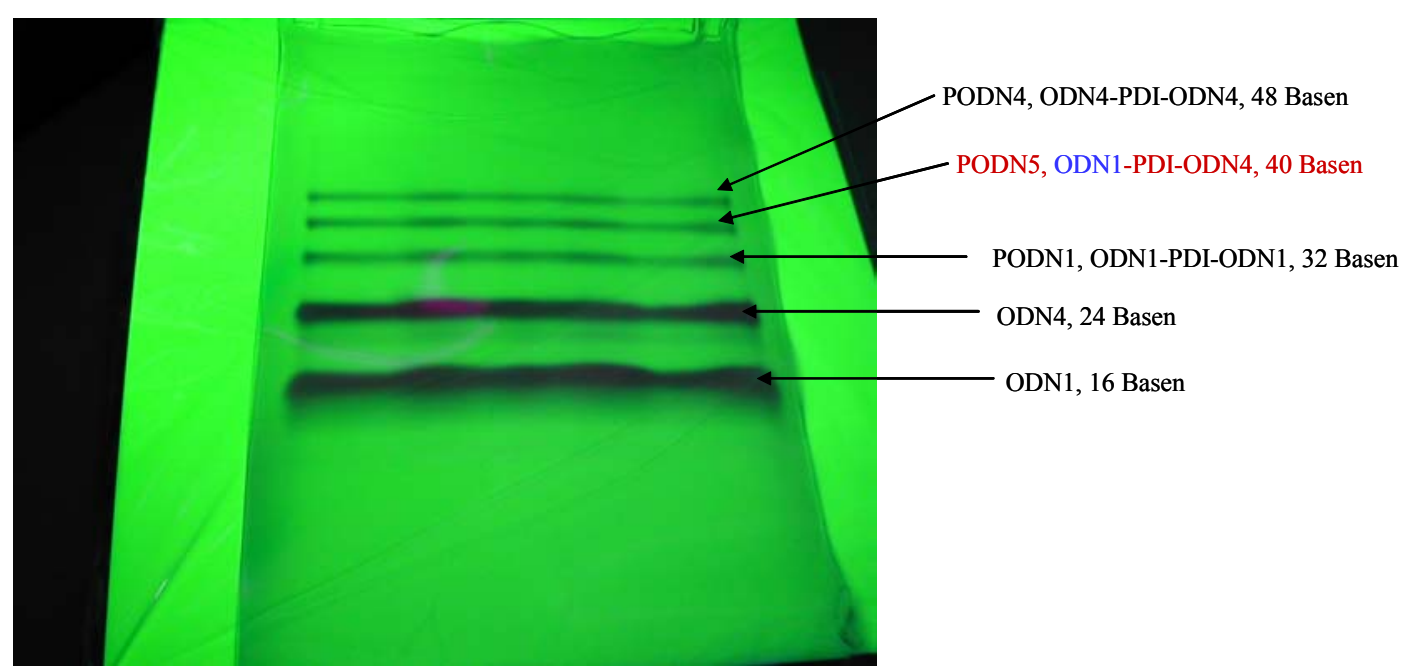

Abbildung 85: Präperative PAGE von 3-42 (PODN5, ODN1-PDI-ODN4), man erkennt 5 Banden 
Die Differenz in der Basenzahl zwischen den verschiedenen Verbindungen im statistischen Produkt von PODN5 beträgt 8 Basen. Zur kontrollierten Bildung eines Dimers soll ein zweites komplementäres und ebenso asymmetrisches Konjugat synthetisiert werden. Analog zu PODN5 wurde das asymmetrische Konjugat PODN6 (343, ODN2-PDI-ODN4) hergestellt und aufgereinigt. Bei der 12\%iger PAGE erhält man ebenso die erwarteten fünf Banden. In Abbildung 86 ist das Resultat einer analytischen Gelelektrophorese gezeigt. Während man bei der Synthese eines symmetrischen Konjugats lediglich zwei Banden bekommt (7 und 9), erkennt man im Falle der asymmetrischen Konjugate PODN5 und PODN6 (6 und 8) fünf Banden. Die zwei asymmetrischen und komplementären Konjugate zeigen ein ähnliches Laufverhalten, da sie sich in ihrer chemischen Struktur nur in der Reihenfolge einer Oligonucleotidsequenz unterscheiden.

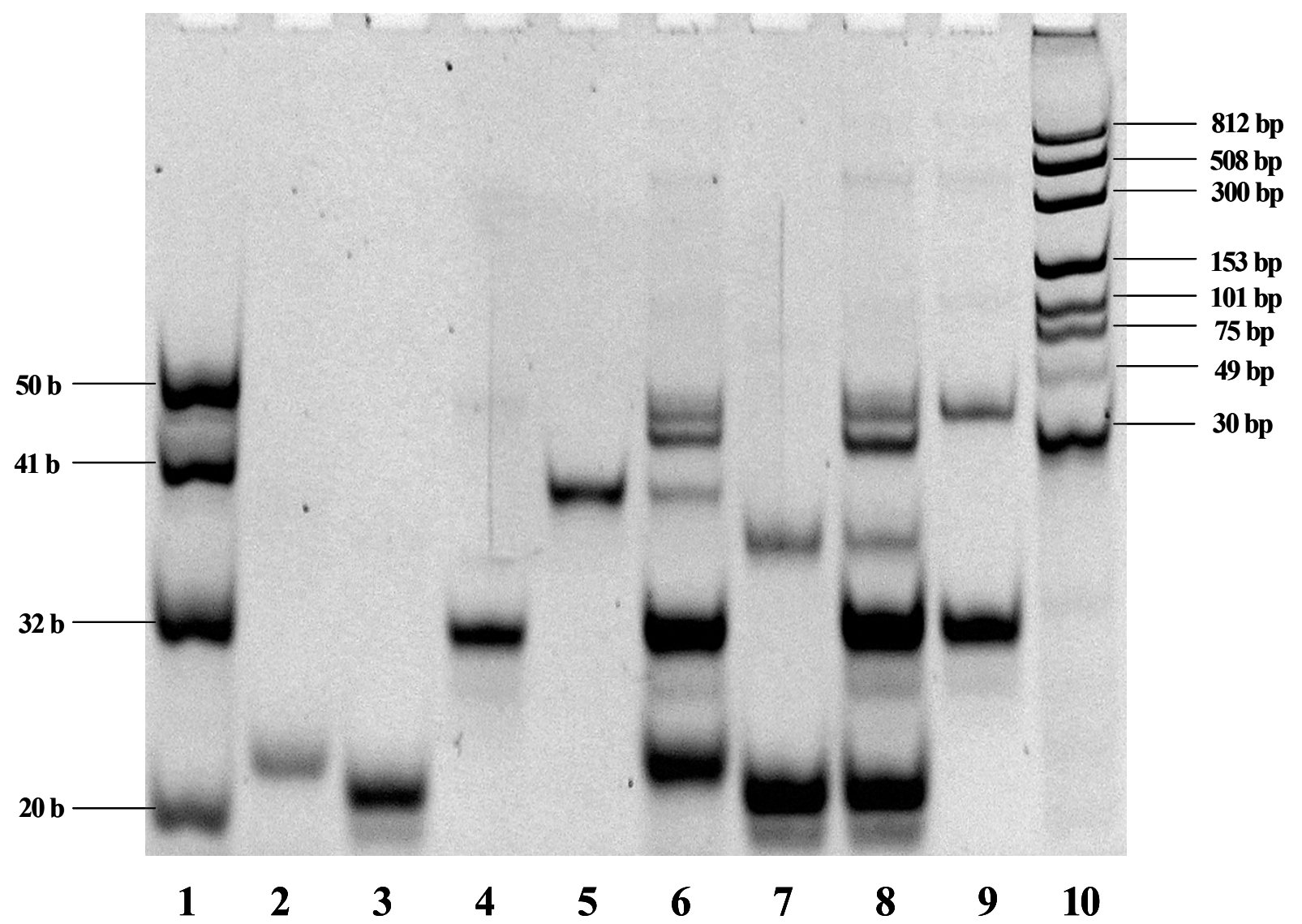

Abbildung 86: Analytische PAGE der zwei asymmetrischen und komplementären Konjugate PODN5 und PODN6; 1: Längenstandard ss, 2: ODN1, 3: ODN2, 4: ODN4, 5: PODN1, 6: PODN5 (Reaktionsgemisch), 7: PODN2 + ODN2, 8: PODN6 (Reaktionsgemisch), 9: PODN4 + ODN4, 10: Längenstandard dsDNA (Doppelstrang) 
Zur Synthese des asymmetrischen Konjugats wurde ein Synthesekonzept entwickelt, mit dem man ein statistisches Produkt erhält. Dabei basiert die Bandenzuordnung der Reaktionsprodukte auf den Unterschieden in der Sequenzlänge. Im Falle von PODN5 und PODN6 beträgt die Differenz in der Sequenzlänge zwischen dem ODN1- bzw. ODN2und dem ODN4-Oligonucleotid 8 Basen. Diese 8 Basen verursachten das unterschiedliche Laufverhalten der 5 Reaktionsprodukte, was die Auftrennung der Konjugate ermöglichte. Die gelelektrophoretische Aufreinigung von DNA und Proteinen basiert auf der Differenz in der Ladungszahl zwischen dem aufzureinigenden Molekül und den Verunreinigungen (z.B. kleinere DNA- bzw. Proteinsequenzen) ${ }^{79}$. Durch die Unterschiede in der Ladungszahl wandern die Moleküle im Gelmaterial mit unterschiedlichen Geschwindigkeiten, was auch sehr deutlich in Abbildungen 85 und 86 gezeigt ist.

\subsubsection{Hybridisierung}

Die Hybridisierung von PODN5 und PODN6 zu einem Dimer wurde in in TE/0.8M NaCl Puffer durchgeführt. Die analytische PAGE des gebildeten Hybrids (Abb. 88) zeigt lediglich Banden für die zwei nicht hybridisierten Konjugate PODN5 und PODN6 und das Hybrid PODN5-PODN6 (III-V) aber keine Banden bei höheren Molekulargewichten wie das bei der Bildung des Perylen-DNA-Polymers der Fall war. Dies ist auf die kontrolierte Dimerisierung zurückzuführen. Würde man ein weiteres Konjugat herstellen, bei dem ein Strang komplementär zu ODN4 (das freie Ende in PODN6) ist, so könnte ein Trimer entstehen. Mit dieser Methode kann man schrittweise ein Polymer in der Form von A-PDI-B-PDI-C-PDI-D-PDI-E-PDI-F-PDI-) $)_{\mathrm{n}}$ ausbilden. 


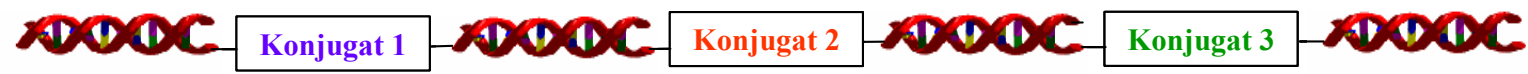

(a)

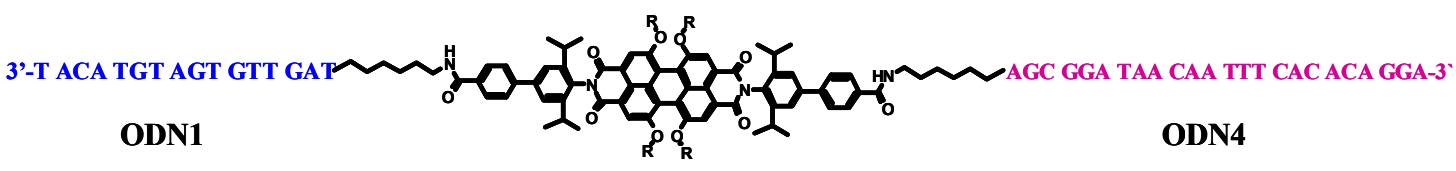

3-42

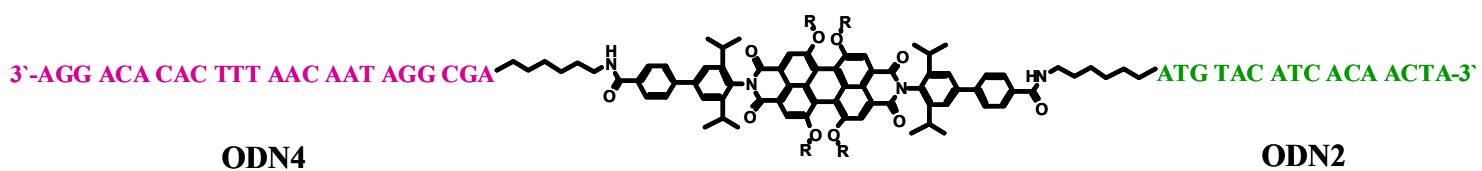

3-42

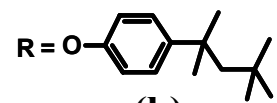

(b)

Abbildung 87: (a) Schematische Struktur einer kontrollierten Selbstorganisation von asymmetrischen Konjugaten und (b) die Struktur der asymmetrischen Konjugate PODN5 und PODN6 (3-42 und 3-43), die zur Bildung eines DNA-Perylen-Dimers eingesetzt wurden

Die Selbstorganisation einer Reihe komplementärer Konjugate, bei den verschiedene organische Verbindungen mit der Oligonucleotiden geknüpft sind, können zur Bildung eines Polymers, in dem verschiedene organische Verbindungen in einer supramolekularen Struktur mit DNA als bindende Moleküle (Brücken) organisiert sind. Auch die Reihenfolge der organischen Verbindung kann beliebig gewählt werden. 


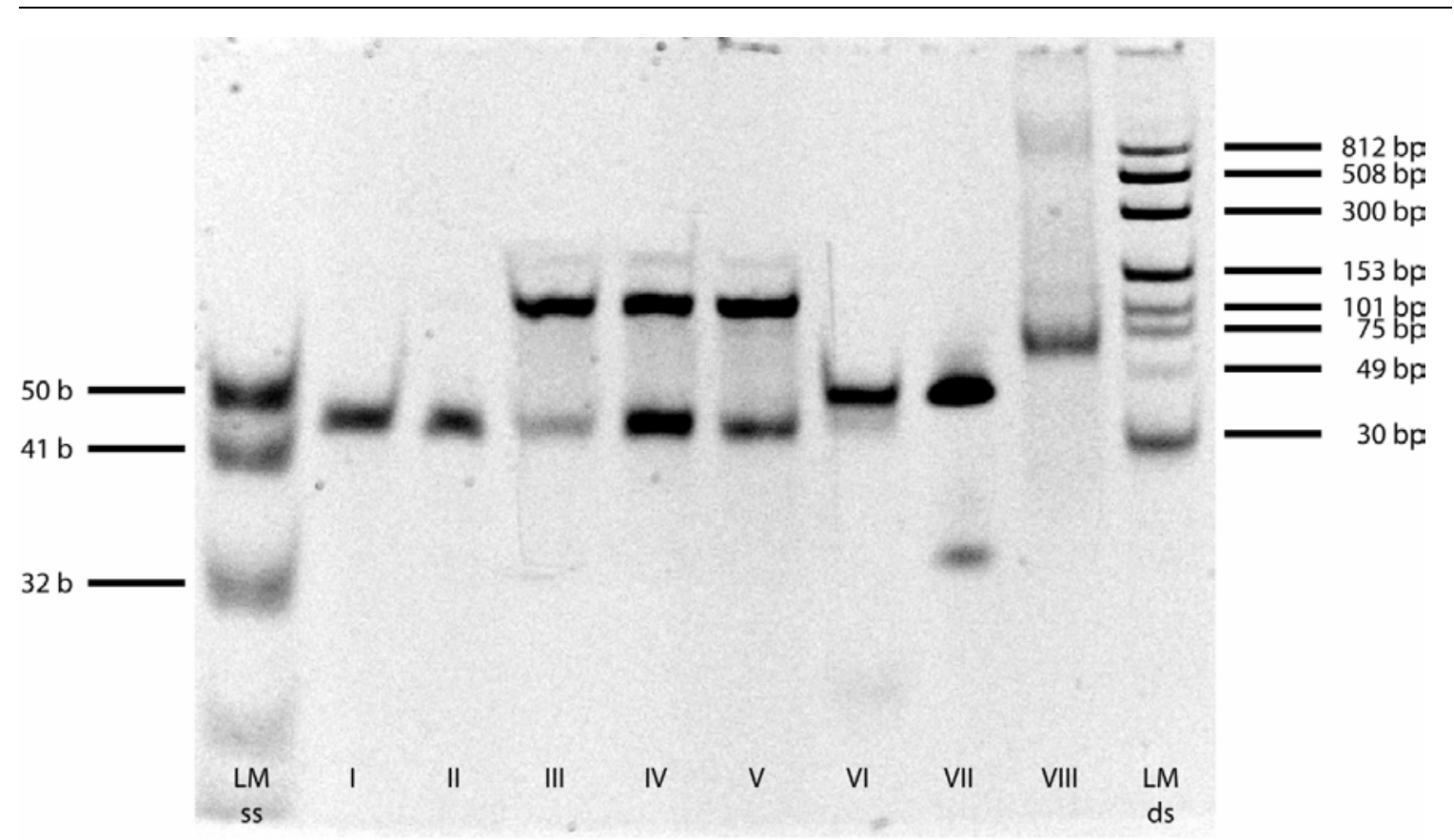

Abbildung 88: PAGE der Hybride PODN5 und PODN6, I: PODN5, II: PODN6, III: PODN5 + PODN6, IV: 2 PODN5 + PODN6, V: PODN5 + 2 PODN6, VI: PODN5 + 2 cODN2 (teilweise komplementär zu PODN5), VII: PODN5 + ODN2 + ODN4, VIII: PODN1 + PODN2

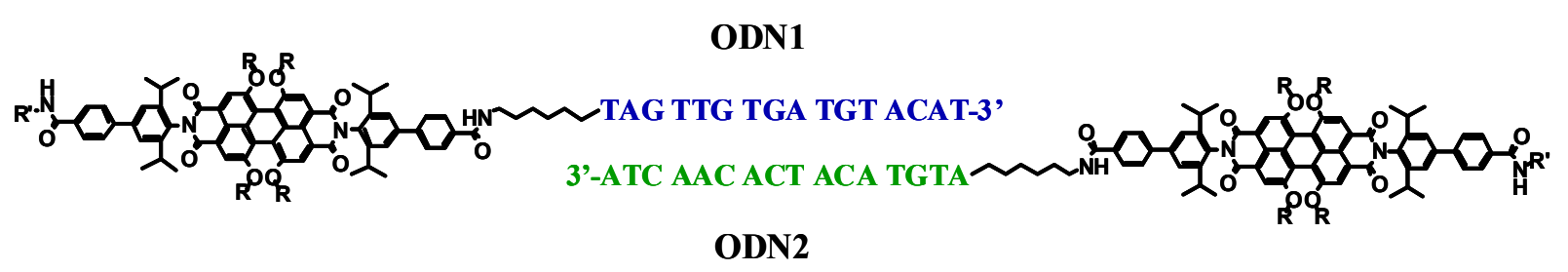

R` = ODN4 = 5'-AGC GGA TAA CAA TTT CAC ACA GGA-3`

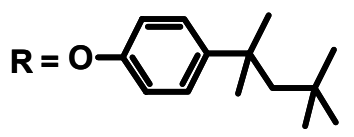

Abbildung 89: Struktur des selbstorganisierten Dimers aus zwei asymmetrischen Konjugaten (PODN5 und PODN6)

Die Struktur der zwei asymmetrischen Konjugate PODN5 und PODN6 wurde so gewählt, dass die zwei Konjugate nur mit einem Oligonucleotidarme (ODN1 in PODN5, ODN2 in PODN6) gepaart werden können. Wie man anhand der Banden in Abbildung 88 sehen kann, wird durch die Mischung der zwei asymmetrischen Konjugate PODN5 und PODN6 eine zusätzliche Bande im hochmolekularen Bereich (die oberste Bande in III-V) erhalten, 
während sich im Falle eines Gemischs aus PODN5 und ODN2 (VI und VII) eine Bande im mittelmolekularen Bereich bildete. Aus der Mischung von PODN5 mit ODN2 (komplementär nur zu dem kürzeren Arm im PODN5) kann lediglich eine Bande resultieren, die dem Hybrid des Konjugats PODN5 mit der komplementären Oligonucleotidsequenz ODN2 entspricht. Das Laufverhalten der beiden Hybride PODN5PODN6 und PODN5-ODN2) in V und VI ist auf die Differenz in der Basenzahl zwischen den beiden Hybriden, die 24 Basen beträgt, zurückzuführen.

\subsubsection{Einbau des Perylendiimids in die DNA-Sequenz}

Setzt man bei der Synthese des asymmetrischen Konjugats an der Stelle von zwei 5 Aminooligonucleotiden ein Gemisch aus zwei Aminoligonucleotiden, wobei eines mit einer Aminfunktion an der 3'- und das andere an der 5 '-Position funktionalisiert ist, erhält man ein asymmetrisches Konjugat mit einer Oligonucleotidsequenz an der 5'-Position verknüpft, während die andere Sequenz am 3'-Ende angebunden ist. Ziel der Synthese einer solchen Verbindung ist $\mathrm{zu}$ demonstrieren, dass mit dem entwickelten Desymmetrisierungskonzept das Perylendiimid in die DNA-Sequenz eingebaut werden kann, indem die Kopplung mit zwei unterschiedlichen Oligonucleotiden in der Lösung durchgeführt wird. Mit der hier vorgestellten Kopplungsmethode können Oligonucleotidkonjugate synthetisiert werden, ohne die schwierige und zeitaufwendige Einführung von orthogonalen Schutzgruppen durchführen zu müssen. Darüber hinaus können organische Verbindungen in Oligonucleotidkonjugate überführt werden, die wegen der Unzugänglichkeit ihrer Phosphoramiditderivate oder aufgrund ihrer unzureichenden Löslichkeit die kostenträchtige DNA-Festphasensynthese nicht erlauben. 


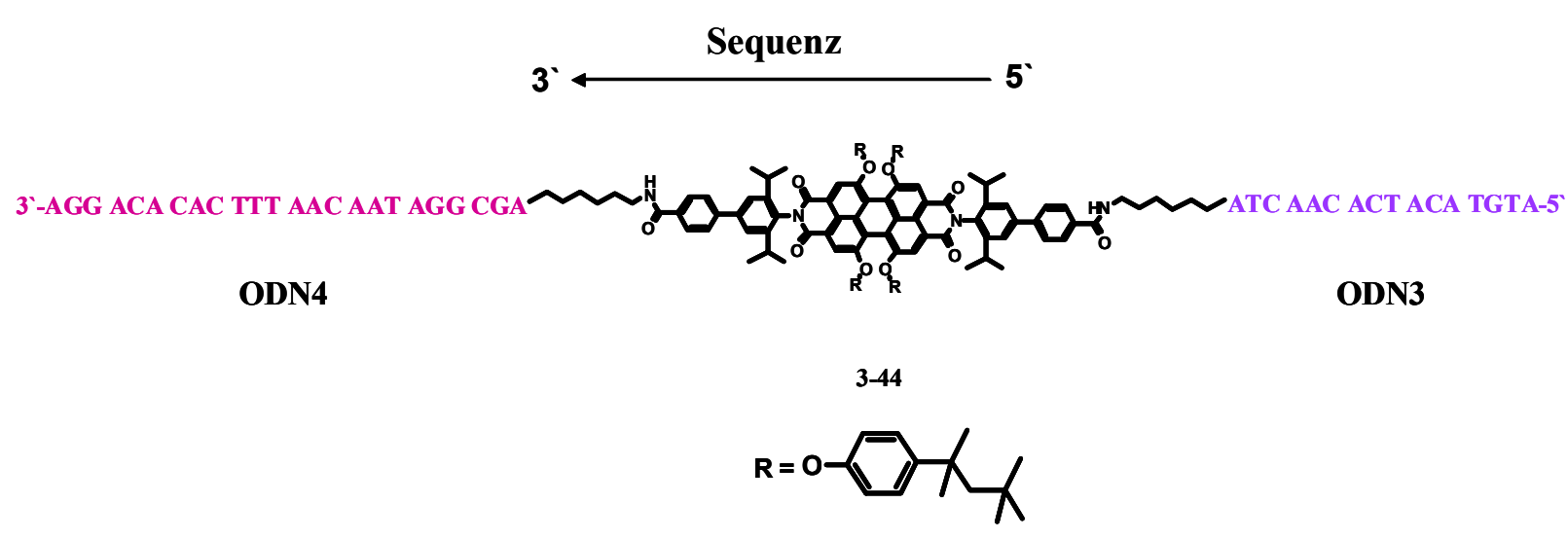

Abbildung 90: Perylendiimid eingebaut in einer DNA-Sequenz PODN7 (5 $\rightarrow 3^{`}$, ODN3-PDIODN4 = 40 Basen) synthetisiert nach der Desymmetrisierungsmethode in der Lösung

Die Struktur von 3-44 (PODN7) ermöglicht nicht nur eine kontrollierte Selbstorganisation mit komplementären Konjugaten, sondern auch die Hybridisierung mit einer langen ssDNA (Abb. 91). Zusätzlich kann PODN7 mit einer dsDNA, die sogenannte „StickyEnds“ enthält, hybridisiert werden und als Bindeglied zwischen zwei großen dsDNAMolekülen fungieren, was zur Bildung von supramolekularen Strukturen eingesetzt werden kann. Dies kann nur gelingen, wenn das Perylendiimid-bis-(oligonucleotid)konjugat die Struktur einer DNA-Sequenz besitzt, d.h. ein $3^{`}$ - und ein 5'-Ende mit dem Perylendiimidmolekül innerhalb der Sequenz. 


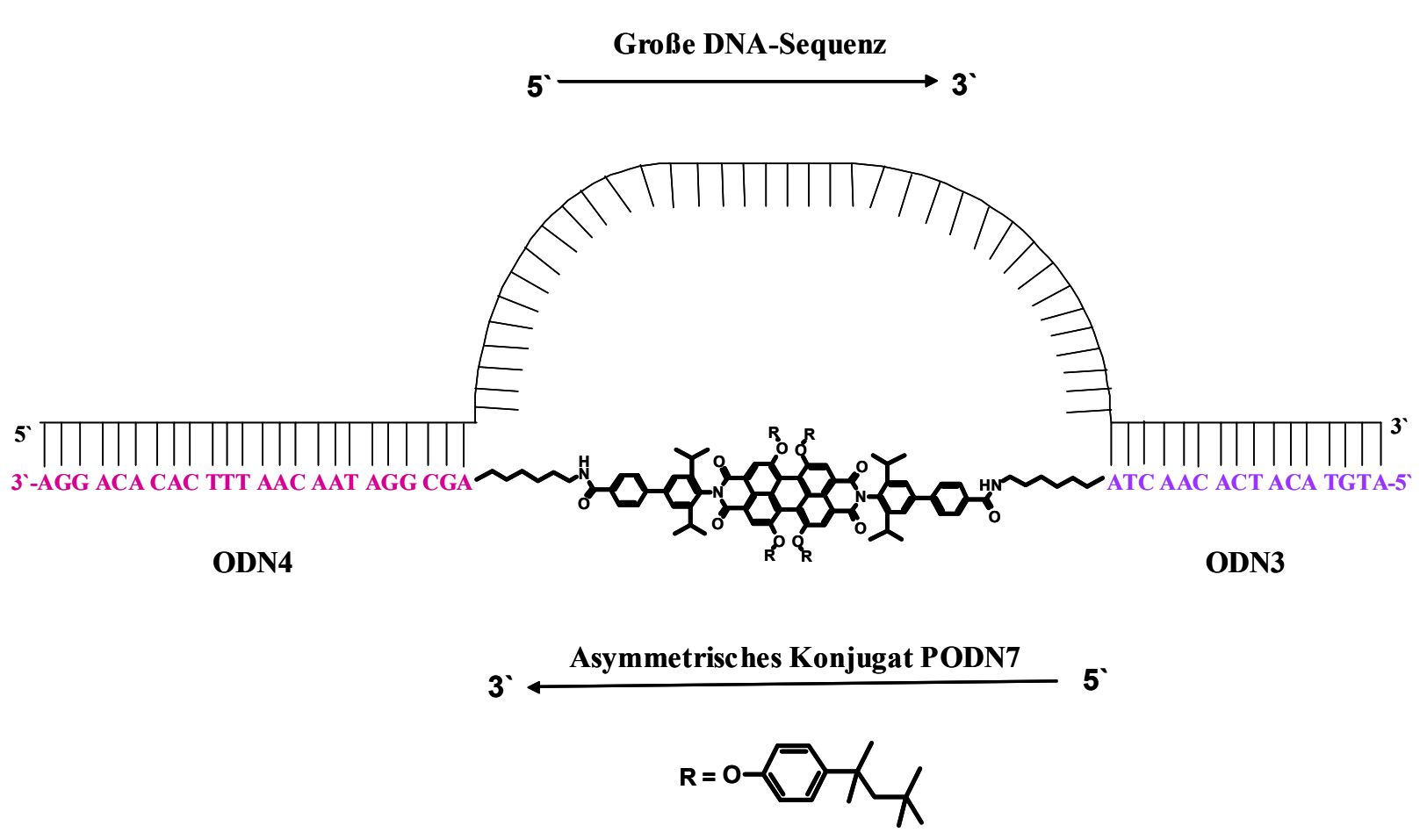

\begin{abstract}
Abbildung 91: Schematische Darstellung eines Hybrids bestehend aus ssDNA und dem asymmetrischen PODN7. Die ssDNA und das PODN7 (40 Basen) laufen antiparallel zueinander, was für die Hybridisierung notwendig ist.
\end{abstract}

Die analytische PAGE des Reaktionsgemischs ist in Abbildung 92 gezeigt. Zum Vergleich befinden sich in I das aufgereinigte Oligonucleotid ODN3 und in der Bahn II das ODN4. Das getrennt synthetisierte PODN3 ist in III aufgetragen. Man erkennt in IV die zwei unteren Banden, die parallel zu den Banden der Oligonucleotide ODN3 und ODN4 liegen, d.h. sie entsprechen dem Überschuss an ODN3 bzw. ODN4, der bei der Kopplungsreaktion eingesetzt wurde. Erwartungsgemäß ist auch eine schwache Bande parallel zum symmetrischen Konjugat PODN3 (ODN3-PDI-ODN3, 32 Basen) zu erkennen. Die oberen zwei Banden stehen für die Zielverbindung PODN7 (40 Basen, asymmetrisch) und das symmetrische PODN4 (ODN4-PDI-ODN4, 48 Basen). 


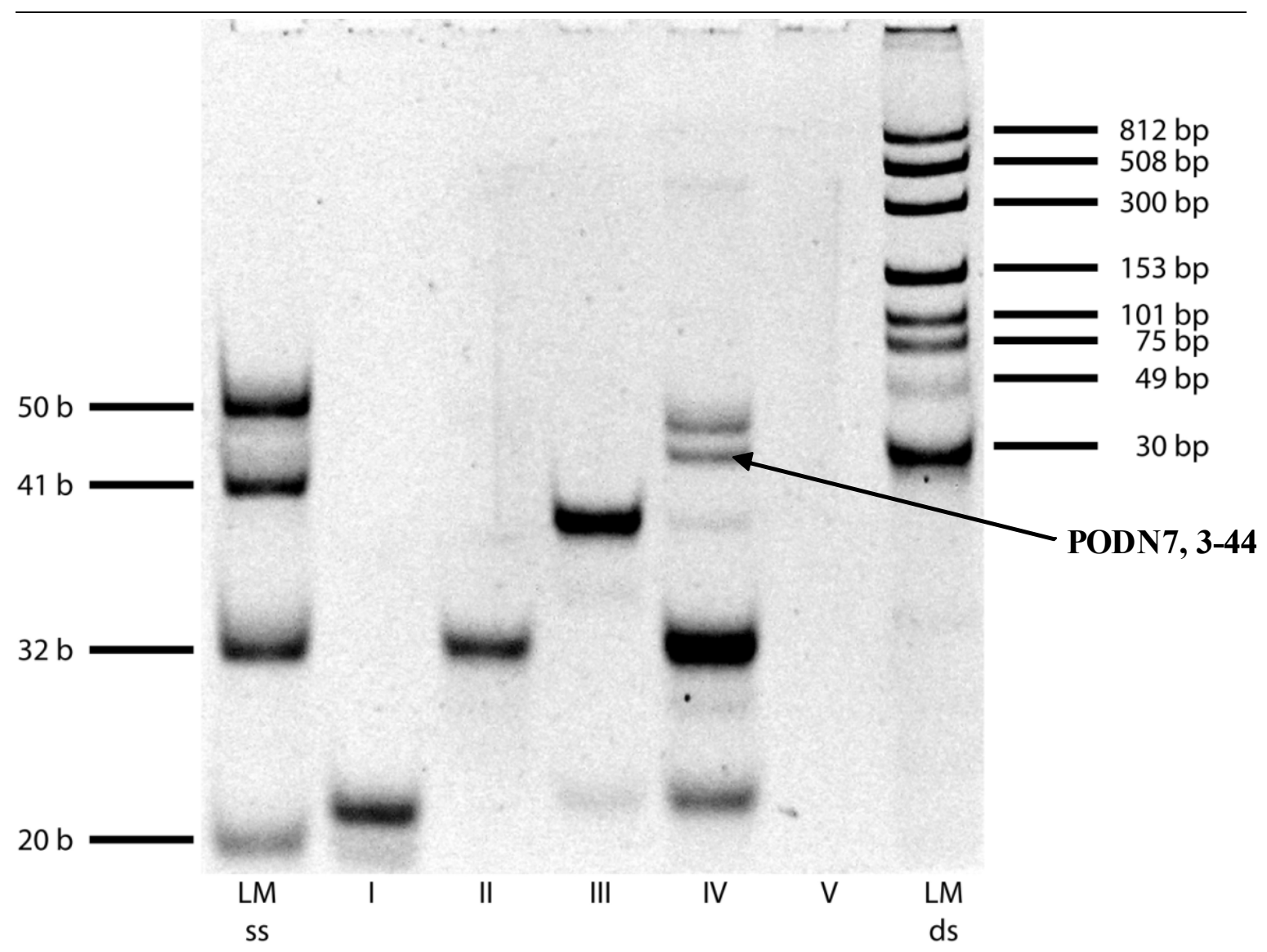

Abbildung 92: PAGE vom Reaktionsgemisch 3-44 (PODN7), LM: Längenstandard, I: ODN3, II: ODN4, III: PODN3, IV: PODN7 (Reaktionsgemisch)

Die PAGE-Analyse gilt in der Literatur als die gut etablierte und aussagekräftigste Methode, DNA bzw. DNA-Hybride aufzureinigen oder ihre Struktur nachzuweisen. Ein weiterer Strukturbeweis wäre natürlich wünschenswert. Für die Maldi-Tof-Anaylse vom PODN7 wurden drei Matrices, 3-Hydroxypicolinsäure, 2,5-Dihydroxybenzolsäure und 2,4,6-Trihydroxyacetophenon verwendet. Die Konjugatprobe wurde nach der gleichen Vorschrift wie bei den Oligonucleotiden vorbereitet. Nach vielen Versuchen konnten leider keine Spektren aufgenommen werden. In vielen publizierten Ergebnissen von Oligonucleotidkonjugaten wurde meistens keine Maldi-Tof-Spektren gezeigt ${ }^{23-24,}$ 147-151. Als Strukturbeweis wurde stattdessen meistens PAGE vorgestellt ${ }^{23-24}$, da mit dieser Methode genaue Aussagen über die Basen- bzw. Basenpaarungszahl in der DNA getroffen werden können. Darüber hinaus können durch die denaturierende PAGE mögliche DNA-Sekundärstrukturen minimiert werden, was auch in einer Maldi-TofAnalyse die Messung behindern könnte. 
Kapitel 3: Synthese und Selbstorganisation von Perylen-Oligonucleotid-Konjugaten

Durch die Untersuchung des aufgereinigten Konjugats (PODN7) mittels FCS-Messungen wurden keine Hinweise auf gebildete Aggregate festgestellt. Auch die Fluoreszenzeigenschaften des asymmetrischen Konjugats PODN7 unterscheiden sich im Wesentlichen nicht von denen der symmetrischen Konjugate PODN1 und PODN2. 


\subsection{Synthese von hoch fluoreszierenden Perylendiimid- oligonucleotid-konjugaten}

Die Perylendiimidchromophore besitzen eine hohe Fluoreszenzquantenausbeute und eine exzellente photo- und thermische Stabilität. Sie haben aber eine sehr geringe Löslichkeit in wässrigen Medien. Versucht man sie durch die Modifizierung mit hydrophilen Gruppen in wässrigen Medien zu überführen, nimmt ihre Fluoreszenzintensität sehr stark ab. Diese kann mit einer möglichen Neigung zur Aggregatbildung in wässrigen Medien erklärt werden. Vor kurzem wurde ein wasserlösliches Molekül mit einem Perylendiimidkern und vier Polylysinseitenketten synthetisiert und veröffentlicht ${ }^{99}$. Diese Verbindung zeigte in Wasser eine sehr geringe Fluoreszenzquantenausbeute, obwohl das Gerüst des Chromophors durch die vier Polylysinketten von der polaren Umgebung isoliert ist, kam es zu Fluoreszenzlöschung. Ein wasserlösliches Perylenmonoimid wurde durch die Anbindung von Polyethylenglykol synthetisiert und dessen Fluoreszenzeigenschaften untersucht. Dabei wurde eine Fluoreszenzquantenausbeute von $15 \%$ erhalten $^{100}$. Vor kurzem wurden Sulfonatgruppen in die bay-Region des Perylendiimids eingeführt, was zur Überführung des Perylendiimid-Chromophors in wässrige Lösungen führte. Dabei konnte eine starke Erhöhung der Fluoreszenzquantenausbeute in Wasser bis zu $58 \%$ realisiert werden ${ }^{101-103}$. In vorherigen Abschnitten wurden die Synthese und Hybridisierung von Perylendiimid-bis(oligonucleotid)-konjugaten und ihre Selbstorganisation zu supramolekularen Strukturen dargestellt. Während die Fluoreszenzquantenausbeute von PODN1 (ODN1-PDI-ODN1) vor der Aufreinigung im Wasser $4.3 \%$ betrug (Standardfarbstoff: Kristalviolet gelöst in Methanol, Anregungswellenlänge: $540 \mathrm{~nm}$ ), konnte die Fluoreszenzintensität nach der Aufreinigung nur mit der Hilfe von FCS detektiert werden. Die höhere Fluoreszenz vor der Aufreinigung konnte auf das monosubstituierte Produkt (PDI-ODN1) zurückgeführt werden. Durch die Verknüpfung von zwei Oligonucleotidsequenzen in der Imidstruktur des Perylendiimids wurde der hydrophobe Kern vom polaren Medium (Wasser) abgeschirmt, aber es wurde eine sehr stark verminderte Fluoreszenzintensität in wässrigen 
Medien erhalten. Durch die FCS-Untersuchungen (Abb. 68) wurde festgestellt, dass das Konjugat im Wasser als monodisperse Partikeln vorliegt. So kann die Aggregatbildung als Grund für den Verlust der Fluoreszenzintensität ausgeschlossen werden. Eine mögliche hydrophobe Wechselwirkung zwischen dem lipophilen Grundgerüsts des Perylendiimids und den aromatischen Basen der polyanionischen Oligonucleotide im Konjugat könnte die Ursache für die Fluoreszenzlöschung sein. In diesem Abschnitt soll versucht werden, Perylendiimid-oligonucleotid-konjugate, die eine höhere Fluoreszenzquantenausbeute besitzen, $\mathrm{zu}$ synthetisieren. Ein solches hoch fluoreszierendes Oligonucleotid kann als DNA-Sonde zur Detektion von DNA in der Diagnostik oder Genanalyse eingesetzt werden ${ }^{104-107}$. Im ersten Versuch zur Herstellung eines hoch fluoreszierenden Perylendiimid-oligonucleotid-konjugats wurde ein Perylendiimid, an das eine Polyethylenkette $(\mathrm{n} \approx 5000)$ an der Imidstruktur angebunden ist und das eine freie Carbonsäurefunktion besitzt, synthetisiert. Die Fluoreszenzquantenausbeute dieser Verbindung beträgt $19 \%$ (Anregungswellenlänge: $540 \mathrm{~nm}$, Standardfarbstoff: Kristalviolet gelöst in Methanol). Auf die Synthese und Charakterisierung von 4-10 wird im nächsten Kapitel 4 ausführlich eingegangen.

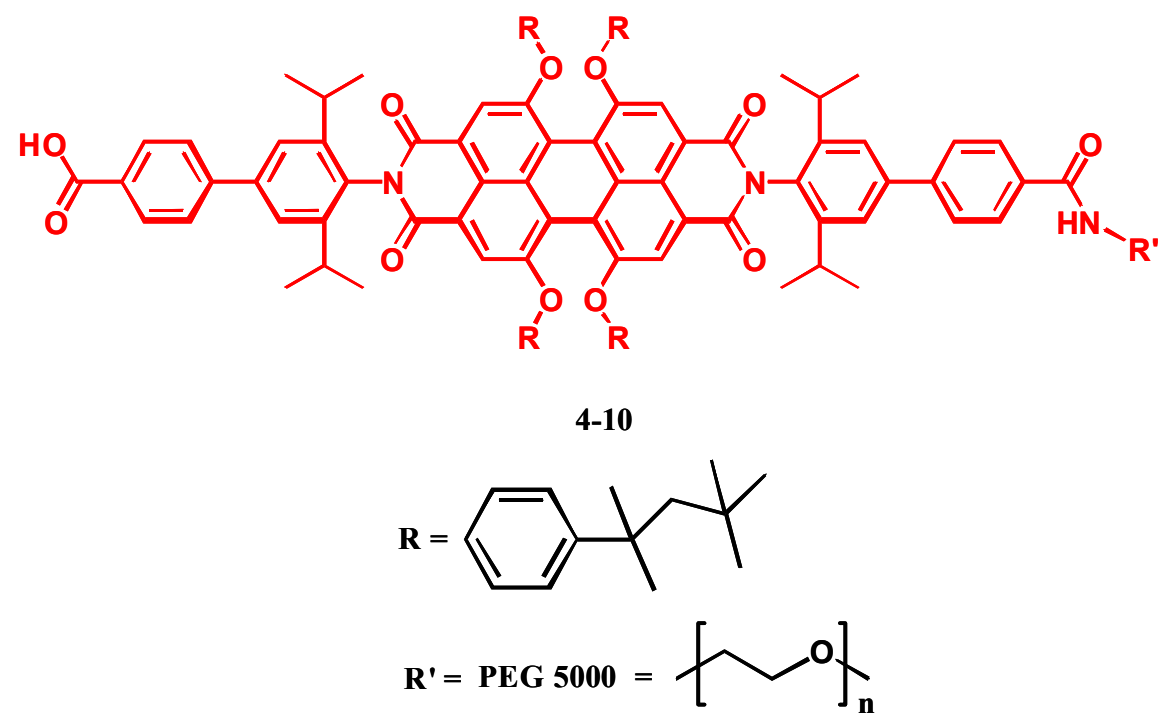

Abbildung 93: Die Struktur eines Perylendiimids, monosubstituiert mit Polyethylenglykol, die freie $\mathrm{COOH}-G r u p p e$ in der Imidstruktur wurde in den Aktivester überführt und mit Aminoligonucleotid gekoppelt. 
Das wasserlösliche Perylendiimidderivat 4-10 wurde mit N-Hydroxysucciniimid und DCC in DMF zur Reaktion gebracht. Der erhaltene Aktivester wurde unter Vakuum eingeengt, in trockenem DMF gelöst und in die Natriumtetraborat-Lösung des Aminoligonucleotides ODN1 eingetropft. Das Reaktionsgemisch wurde bei $37{ }^{\circ} \mathrm{C}$ über Nacht gerührt. Die präperative PAGE des Reaktionsprodukts ist in Abbildung $94 \mathrm{zu}$ sehen.

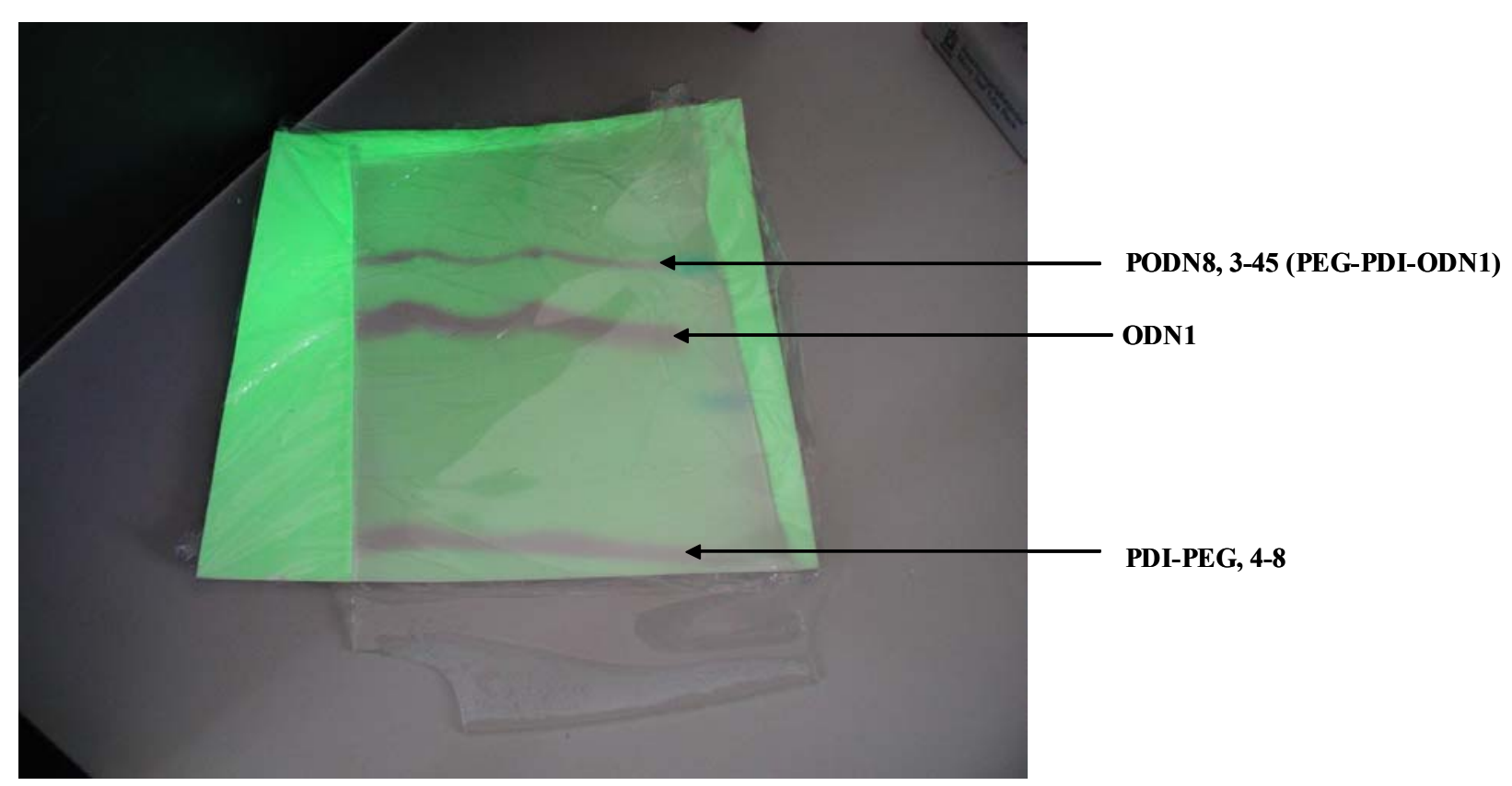

Abbildung 94: Präperative PAGE zur Auftrennung von PODN8 (PEG-PDI-ODN1)

Man erkennt drei Banden. Das unterste Bande entspricht dem Perylentetracarboxydiimid mit Polyethylenglykolkette in der Imidstruktur (4-10). Diese wurde durch eine getrennte PAGE festgestellt. Die mittlere Bande ist für das nicht reagierte ODN1 und das obere Bande ist das PODN8 (PEG-PDI-ODN1). Nach der Extraktion von PODN8 aus Wasser wurde ein Fluoreszenzspektrum aufgenommen, wobei die PODN8-Lösung farblos erschien. Auch hier war die Fluoreszenzintensität sehr gering und unterscheidet sich nicht vom PODN1. So führte die Verknüpfung von PDI mit einem Oligonucleotid in der Imidstruktur von 4-10 zur Fluoreszenzlöschung in wässrigen Medien. Durch dieses Ergebnis wird bestätigt, dass die Wechselwirkung zwischen der DNA-Sequenz und dem Perylendiimid zur Löschung der Fluoreszenz führt. Durch den Ersatz einer Oligonucleotidsequenz im Konjugat PODN1 (Perylendiimid-bis(oligonucleotid)) mit 
einer polaren und wasserlöslichen Polyethylenglykolkette $(n=5000)$ konnte die Fluoreszenzquantenausbeute nicht erhöht werden. Nun soll versucht werden, ein analoges Molekül zu dem bereits in unserem Arbeitskreis entwickelten und publizierten Derivat von Perylentetracarboxydiimid ${ }^{101-103}$, das vier Sulfonsäuregruppen in der bay-Region und zwei Carboxyfunktionen in der Imidstruktur enthält, zu synthetisieren. Die Synthese eines Perylendiimids mit vier Sulfonylgruppen in der bay-Region wurde zuerst von Quante beschrieben $^{108}$. In den neuen Arbeiten von C. Kohl und J. Qu wurden in die Imidstruktur die sterisch anspruchsvolle 2,6-Diisopropylphenysubstituenten eingeführt, was die Löslichkeit des Perylendiimids in organischen Lösungsmitteln deutlich verbesserte. Durch die Einführung von vier Sulfonylgruppen in der bay-Region wurde dann das Perylendiimid in wässrige Medien überführt. Dabei erhielt man eine Fluoreszenzquantenausbeute von bis zu $55 \%$.

Ausgehend von Tetrachlor-N,N`-Bis(4-brom-2,6-diisopropylphenyl)perylendiimid (3-20) erfolgte die Phenoxylierung in der bay-Region mit Phenol. Mit dem tetraphenoxylierten Perylendiimid 3-46 als Ausgangstoff wurden analog $\mathrm{zu}$ der bereits beschriebenen Darstellung von 3-23 zwei Carbonsäuregruppen in die Imidstruktur eingeführt. Die Sulfonierung von 3-48 erfolgte in konzentrierter Schwefelsäure und Rühren bei Raumtemperatur. Dabei muss eine geringe Menge an Schwefelsäure eingesetzt werden, andererseits kommt es bei der späteren Aufarbeitung des Reaktionsgemischs in wässrigen Medien zu Ausbeuteverlusten. Man liess die Reaktion über Nacht laufen. Das Produkt wurde dann mit möglichst wenig eiskaltem Wasser ausgefällt, filtriert und unter Vakuum getrocknet. Eine schematische Darstellung zum Syntheseverlauf ist in Abbildung 95 gezeigt. Den Strukturbeweis lieferten die ${ }^{1} \mathrm{H}-,{ }^{13} \mathrm{C}-\mathrm{NMR}-$ Spektroskopie und Maldi-TofMassenspektrometrie. Im ${ }^{1}$ H-NMR-Spektrum von 3-48 (Abbildung 96) stehen die Lage, Intensität und Zuordnung der Signale im Einklang mit der angenommenen Struktur. Das Signal von Proton $\mathrm{H}_{\mathrm{g}}$, das als Septett erscheinen soll, wird vom Signal des Wassers überlagert. 


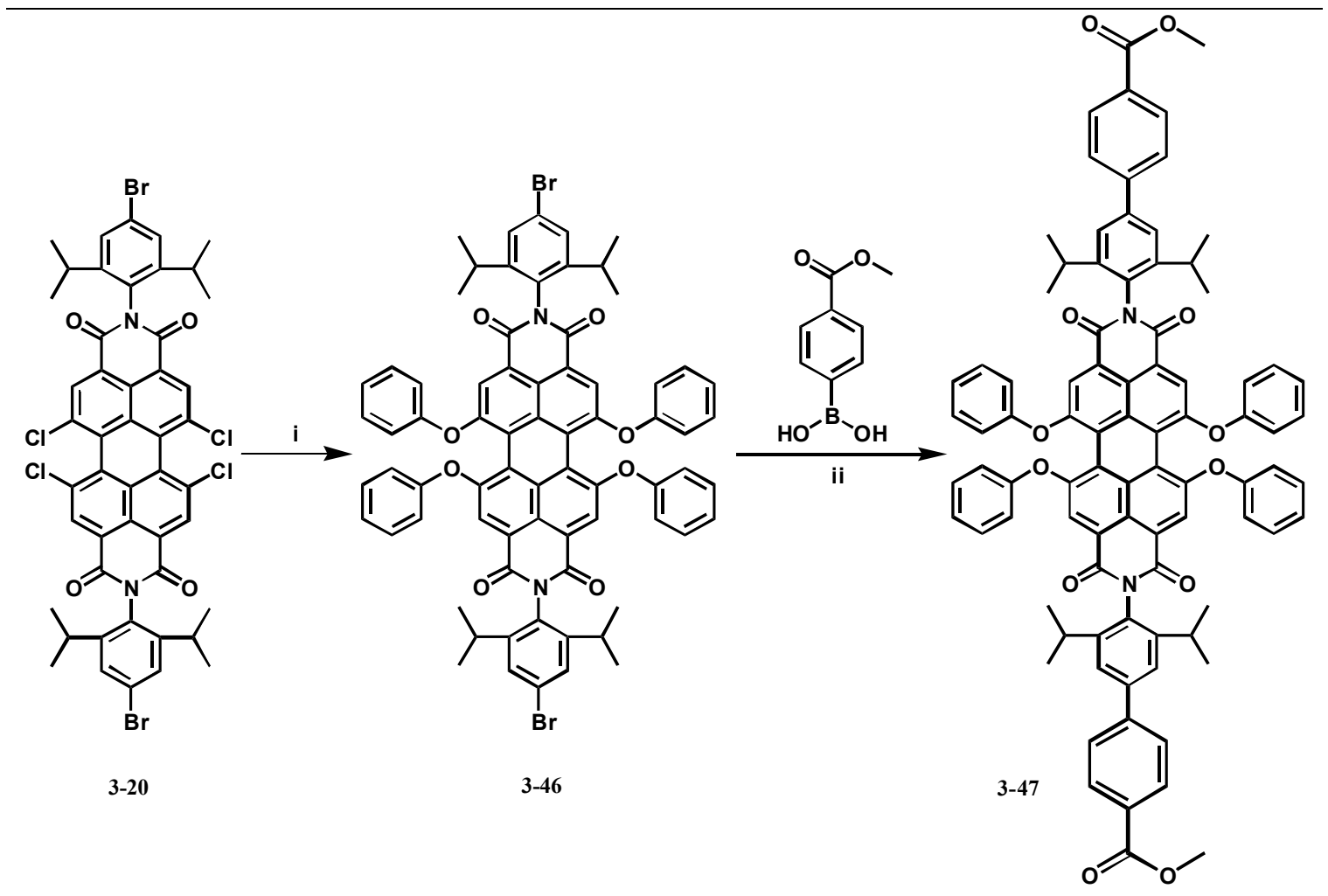

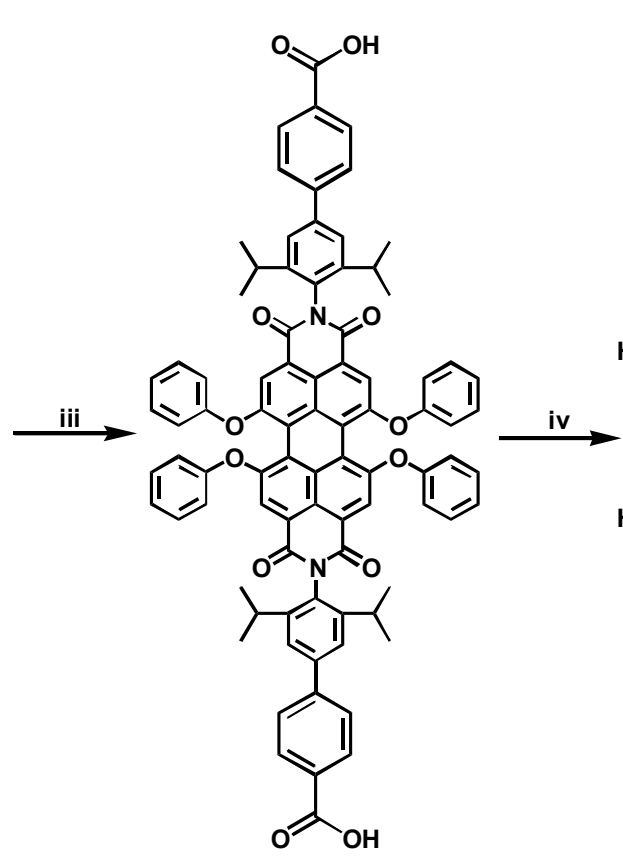

$3-48$
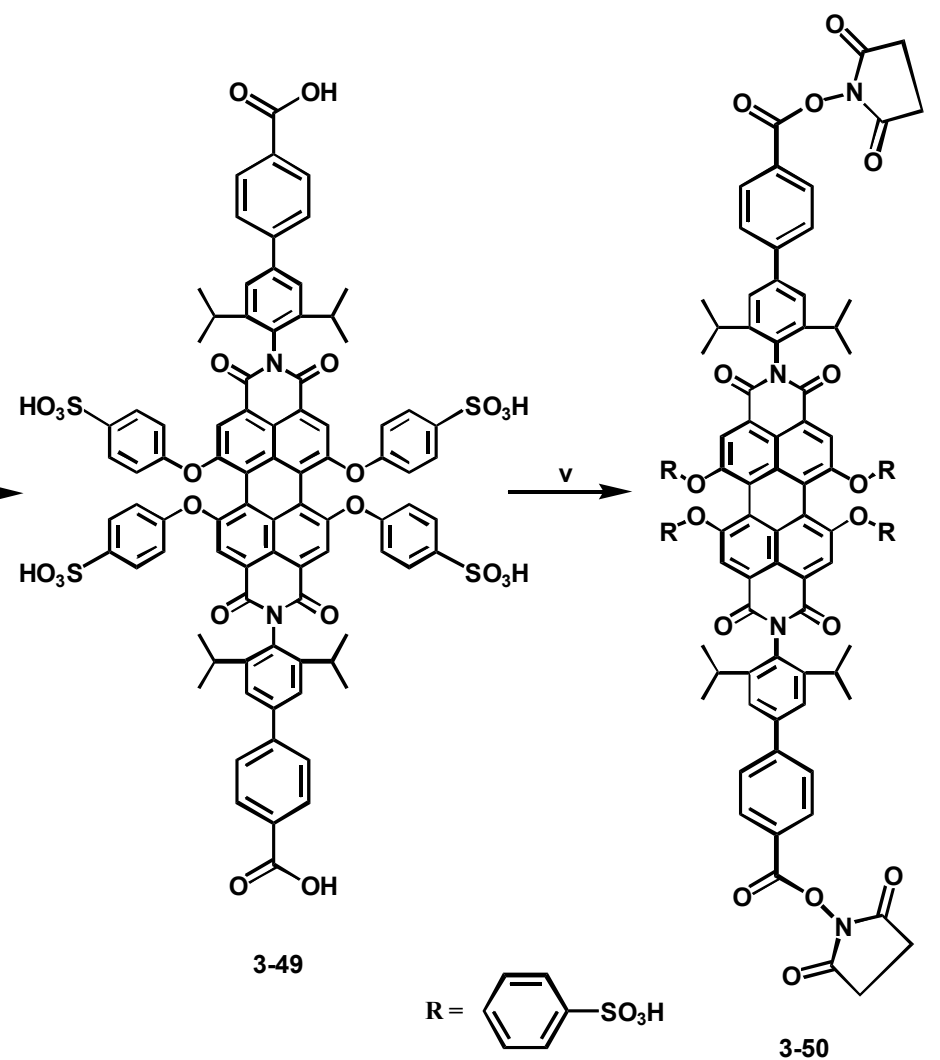

Abbildung 95: Darstellung des wasserlöslichen Perylendiimids mit vier Sulfonylgruppen i) Phenol, $\mathrm{K}_{2} \mathrm{CO}_{3}$, NMP, $90{ }^{\circ} \mathrm{C}, 12$ Stunden, $91 \%$ ii) $2 \mathrm{M} \mathrm{K}_{2} \mathrm{CO}_{3}$, Methanol, Toluol, $\mathrm{Pd}\left(\mathrm{PPh}_{3}\right)_{4}, 15 \mathrm{~h}$, $75{ }^{\circ} \mathrm{C}, 78 \%$ iii) $\mathrm{KOH}$ gelöst in $\mathrm{H}_{2} \mathrm{O}$, THF, $80{ }^{\circ} \mathrm{C}, 24 \mathrm{~h}, 91 \%$ iv) konz. Schwefelsäure, RT, über Nacht $58 \%$ v) N-Hydroxysuccinimid, DCC, DMF, $35^{\circ} \mathrm{C}, 48 \mathrm{~h}$ 


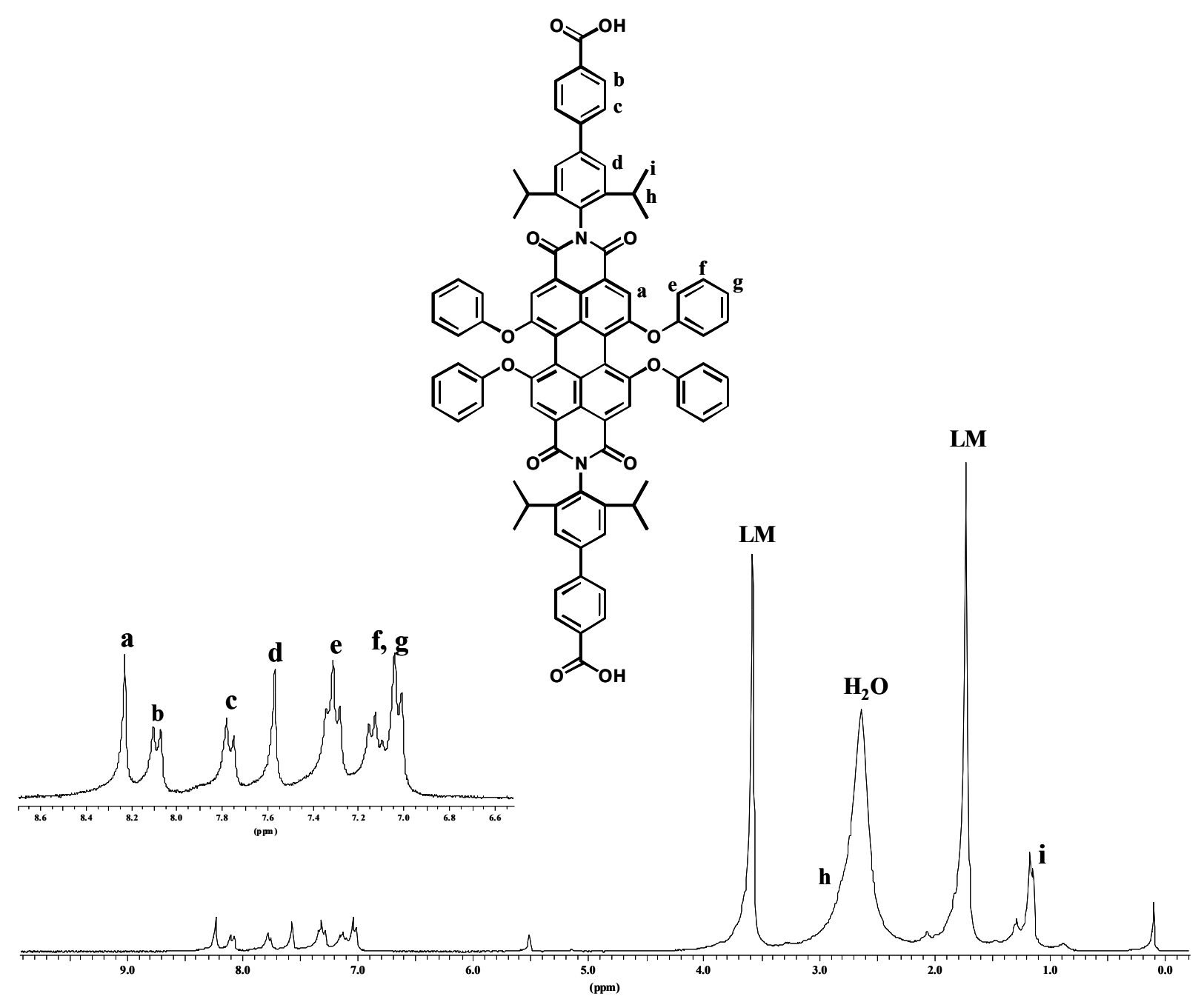

Abbildung 96: ${ }^{1} \mathrm{H}-\mathrm{NMR}-$ Spektrum von 3-48 (250 MHz, THF-d $\left.{ }^{8}\right)$, die Intensität und Zuordung der Signale stimmen mit der angenommenen Struktur überein

Im Maldi-Tof-MS von 3-49 (Abbildung 97) erkennt man einen Molekülionenpeak bei 1642 g/mol (berechnet: 1640 g/mol). Das Absorptions- und Fluoreszenzspektrum von 349 in Abbildung 98 zeigt, dass das Perylendiimid mit vier Sulfonyl-Gruppen in wässriger Lösung fluoresziert. Die Bestimmung der Fluoreszenzquantenausbeute von 3-49 ergab eine Quantenausbeute von 56 \% (Anregungswellenlänge: $540 \mathrm{~nm}$, als Standard wurde der Farbstoff Kristalviolet gelöst in Methanol genommen) Die erhöhte Fluoreszenzquantenausbeute von 3-49 zeigt, dass die Aggregation des hydrophoben aromatischen Perylendiimidgrundkörpers im Wasser durch die ionischen Gruppen in der Bay-Region verhindert ist. Die Aggregation kann nicht nur die Löslichkeit des 
Perylendiimids in Wasser beeinträchtigen, sondern auch eine geringe Fluoreszenzquantenausbeute verursachen. Mit der Einführung der vier Sulfonylgruppen in der Bay-Region wurde der Perylendiimidgrundkörper in eine hydrophile Hülle eingeschlossen, was die Aggregation erschwerte und damit die Fluoreszenzquantenausbeute erhöhte.

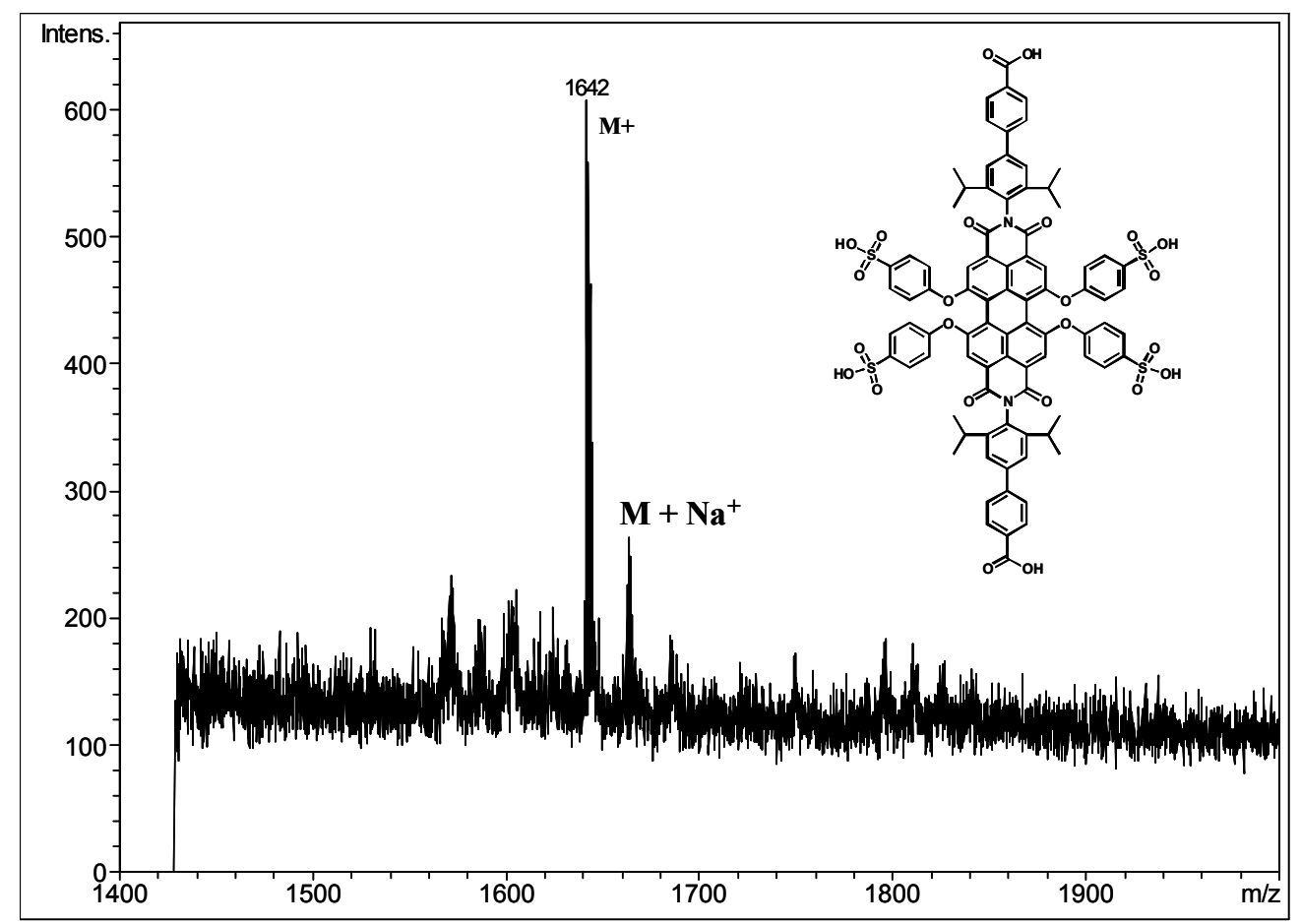

Abbildung 97:Maldi-Tof-MS von 3-49

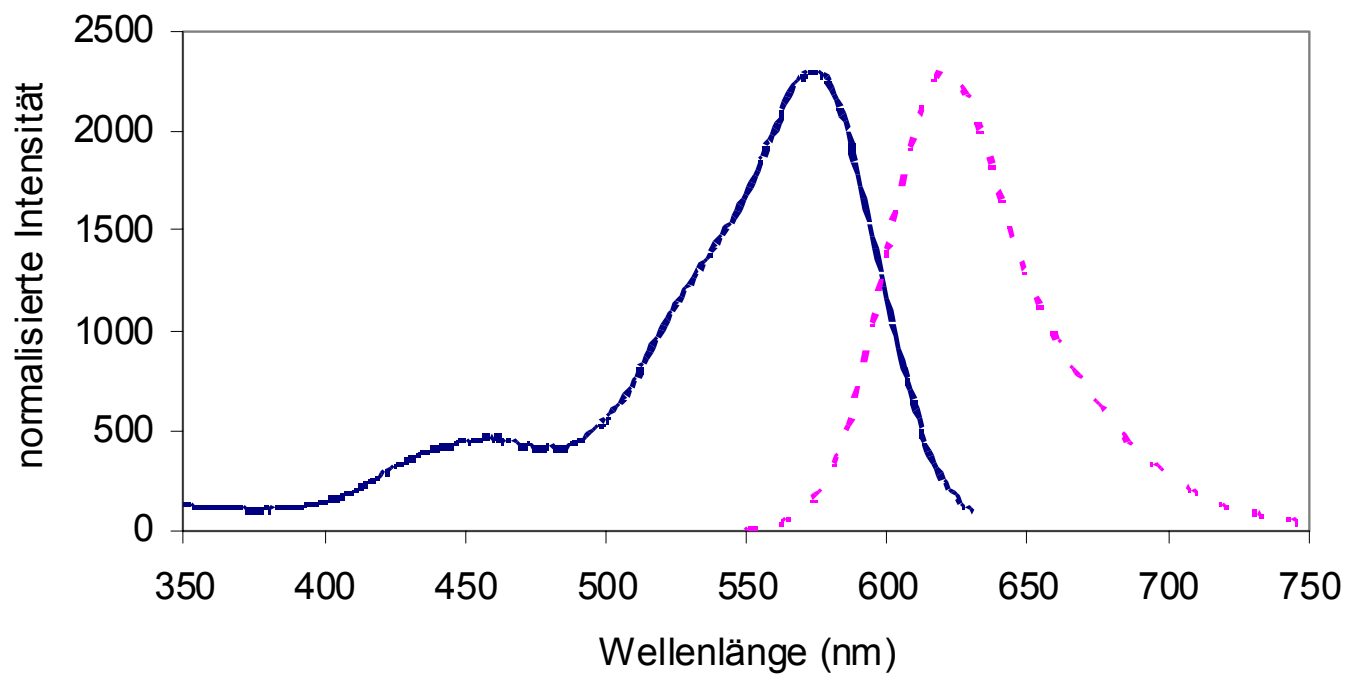

Abbildung 98: Normiertes Absorptions- und Fluoreszenzspektrum von Perylendiimid mit vier Sulfonyl-Gruppen (3-49) in wässriger Lösung, Anregungswellenlänge bei 540 nm, Konzentration $\left.\approx 10^{-5} \mathrm{M}\right)$ 
Vergleicht man die Absorptions- und Fluoreszenzspektren von tetraphenoxyliertem Perylendiimid in organischen Lösungsmitteln mit 3-49, besitzt das wasserlösliche Perylendiimid mit vier Sulfonyl-Funktionen eine weniger stark ausgeprägte Feinstruktur, was auf eine geringe Neigung zur Aggregation zurückgeführt werden kann.

Der Aktivester vom Perylendiimid (3-50) mit vier Sulfonyl-Gruppen wurde durch die Reaktion von 3-49 mit N-Hydroxysuccinimid in DMF und mit DCC als Katalysator bei Raumtemperatur gewonnen. Nach 24 Stunden Reaktionszeit wurde das Reaktionsgemisch 48 Stunden im Vakuum getrocknet. Die Kopplung von 3-50 an Aminoligonucleotid wurde analog zu den hergestellten Perylendiimid-bis(oligonucleotid)-konjugaten in einem Lösungsmittelgemisch aus DMF und $0.1 \mathrm{M}$ Natriumtetraboratlösung bei $37{ }^{\circ} \mathrm{C}$ durchgeführt.

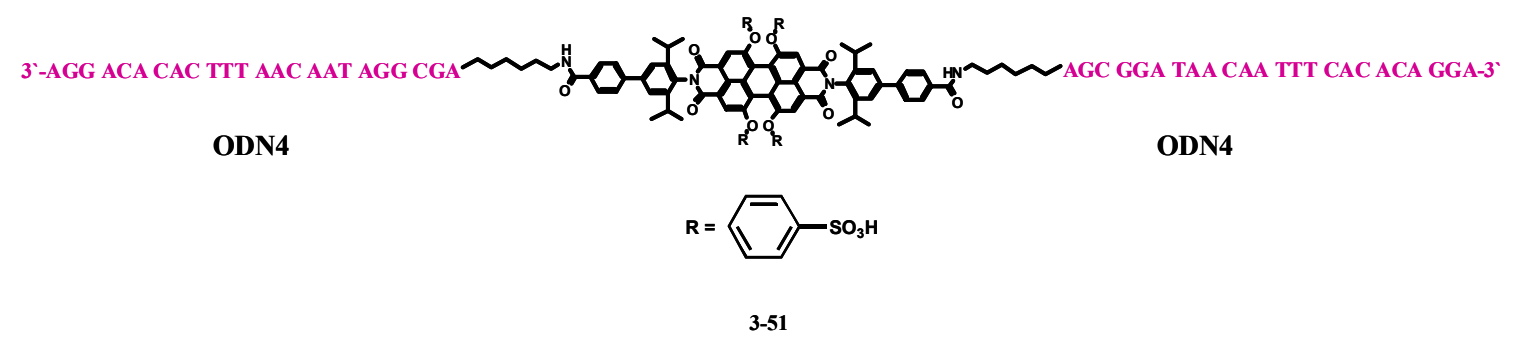

Abbildung 99: Die Struktur der Zielverbindung 3-51, Perylentetracrboxydiimid mit vier Sulfonylgruppen in der bay-Region und zwei Oligonucleotidsequenzen verknüpft in der Imidstruktur

In Abbildung 100 ist die PAGE vom Reaktionsprodukt 3-51 zu sehen. Wie man auf dem Gel erkennen kann, erhielt man bei der PAGE vom Reaktionsgemisch mehrere Banden. Banden 1 und 2 besitzen keine Absorption bei $254 \mathrm{~nm}$, d.h. sie können kein Oligonucleotid in ihrer Struktur enthalten. Sie entsprechen wahrscheinlich der Verbindung 3-48 mit zwei bzw. drei Sulfonyl-Gruppen, die bei der Sulfonierungsreaktion wegen der unvollständigen Umsetzung entstanden und nicht vom vierfachen sulfonierten Perylendiimid aufzutrennen sind. Bande 3 ist für das nicht reagierte ODN4 und Bande 4 enthält eine hoch fluoreszierende Bande mit einer Absorption bei $254 \mathrm{~nm}$, die mit der Oligonucleotidbande überlappt. Dies könnte das monobustituierte Produkt sein (3-48 mit einer Oligonucleotidsequenz ODN4). Bande 5 entspricht dem erwarteten Konjugat 3-51. 
Anderes als erwartet, ist bei der Bande von 3-51 auf dem Gel keine hohe Fluoreszenz zu erkennen.

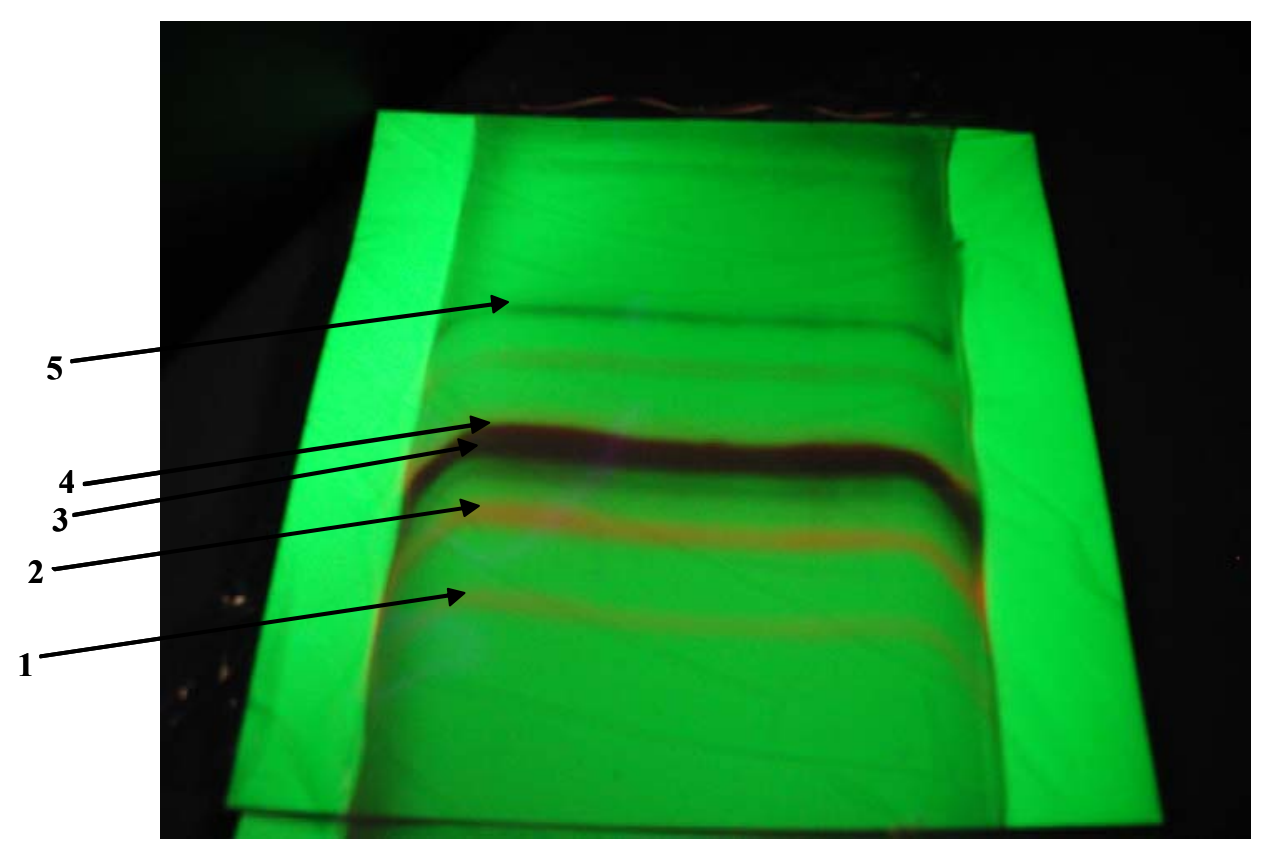

Abbildung 100: PAGE zur Auftrennung von 3-51, Bandenzuordnung : 1, 2: Teilweise sulfonierte Perylendiimid, Bande 3: ODN4, Bande 4: möglicherweise das monosubstituierte Produkt, Bande 5 das Bis(oligonucleotid)-konjugat 3-51

Ein Konjugat aus 3-48 und ODN2 (16 Basen) statt ODN4 (24 Basen) wurde zum Vergleich synthetisiert. PAGE gab das gleiche Bild, eine hoch fluoreszierende Bande überlappt mit dem nicht reagierten ODN4. Das könnte die Bildung des monosubstituierten Produkts bei der Synthese von 3-51 bestätigen. Auch eine nicht fluoreszierende Bande für das Bis(oligonucleotid)-konjugat wurde beobachtet. Diese Fluoreszenzlöschung trotz der vier Sulfonylgruppen ist auf die zwei verknüpften Oligonucleotidsequenzen zurückzuführen. Im folgenden Abschnitt sollen die Gründe der aufgetretenen Fluoreszenzlöschung diskutiert werden.

In der Literatur wurde eine Fluoreszenzlöschung bei Oligonucleotiden, die mit einigen Fluoreszenzfarbstoffen an der 5`-, 3`-Position oder innerhalb der Sequenz kovalent gebunden (markiert) sind, beschrieben ${ }^{109-114}$. Die Anwendung von markierten Oligonucleotiden in der DNA-Detektion und Genanalyse zeigten, dass einige konjugierte Fluoreszenzfarbstoffe sensibel auf die Umgebung der Verknüpfungsstelle ansprechen, 
was ihre fluoreszierenden Eigenschaften beeinflusst ${ }^{115-119}$. Die Fluoreszenzlöschung wurde sowohl bei markierten Oligonucleotiden (ssDNA) als auch nach der Hybridisierung mit einer komplementären Sequenz festgestellt. Teilweise wird die Fluoreszenzlöschung bei mit Fluoreszenzfarbstoffen markierten Oligonucleotiden mit der fluoreszenzlöschenden Eigenschaft des Guanosins, das wegen der Aminfunktion an dem Purinring elektronenspendende Eigenschaften besitzt, begründet ${ }^{120-121}$. Diese Eigenschaft ermöglicht einen Ladungstransfer zwischen der Nucleobase (Purin) und dem nahe liegenden Fluoreszenzfarbstoff, was zu der Fluoreszenzlöschung führt. In vielen Fällen wurde festgestellt, dass die Fluoreszenzeigenschaften eines markierten Oligonucleotides sequenzspezifisch sind ${ }^{122-123}$. Als Beispiel wurde die Fluoreszenz vom 2-Aminopurin und Pteridin (DNA-Basen-Analogen) gelöscht, als sie an die DNA kovalent gekoppelt wurden. Dabei war die Fluoreszenzlöschung von der Nähe einer Purinbase (G oder A) zu der Bindungsstelle abhängig ${ }^{124-126}$. Die Auswirkung der einzelnen Nucleotide, die in der Nähe des Verknüpfungspunkts liegen, auf die Fluoreszenz einiger bekannter Farbstoffe wurde untersucht, wie zum Beispiel Pyren ${ }^{127-128}$, Rhodamin 6G ${ }^{129}$, Oxazin ${ }^{118}$, Cumarin $^{120}$. Bei allen diesen Farbstoffen wurde ein Ladungstransfer zwischen dem Farbstoff und dem Nukelotid angenommen, der bei der Fluoreszenzlöschung eine entscheidende Rolle spielt. Man geht von einer Fluoreszenzlöschung der meisten untersuchten Farbstoffe durch Guanosin aus, was auf die elektronenspendenden Eigenschaften des Guanosines zurückzuführen $\quad$ ist $^{120-121}$. Stilbendicarboxamid-bis(oligonucleotid)- und monooligonucleotid-konjugate wurden hergestellt und auf ihre Fluoreszenzeigenschaften untersucht $^{147-148}$. Dabei wurde die Basenreihenfolge innerhalb der Sequenz in vier hergestellten Konjugaten so gewählt, dass in einem der Konjugate eine Guaninbase direkt angebunden ist und in den anderen drei Konjugaten eine, zwei oder drei Basen zwischen dem Stilbendicarboxamid und der nächsten Guaninbase liegen. Bei allen vier Konjugaten wurde die Fluoreszenz gelöscht ${ }^{149-150}$. Die Fluoreszenzlöschung war bei dem Stilbendicarboxamid-monooligonucleotid-Konjugat weniger ausgeprägt als bei den Bis(oligonucleotid)-konjugaten. Die Nähe der nächsten Guaninbase und ihre Präsens an einer oder beiden Seiten des Stilbens wurden als die möglichen Gründe für die Abnahme der Fluoreszenzintensität vermutet ${ }^{150}$. Die genaue Betrachtung der erhaltenen 
Fluoreszenzquantenausbeuten der Konjugate stärkt diese Vermutung. Während bei dem monosubstituierten Stilben-oligonucleotid-konjugat die Fluoreszenzquantenausbeute bei $8 \%$ lag, betrug sie lediglich $2 \%$ bei dem Stilben-bis(oligonucleotid)-konjugat, in dem nur eine Adeninbase zwischen dem Stilben und der nächsten Guaninbase lag. Bei einem anderen Konjugat trennten zwei Pyrimidinbasen (Cytosin und Thymin) und eine Purinbase (Adenin) das Stilben von der nächsten Guaninbase. Dabei wurde eine Fluoreszenzquantenausbeute von $7 \%$ erhalten. Man ging von einem Elektronentransfermechanismus zwischen den elektronenreichen Purinbasen als Elektronenspender (Guanin bzw. Adenin) und dem Stilben als Elektronenakzeptor aus ${ }^{150}$. In der Literatur wurde die Synthese von Bis(oligonucleotid)-Konjugaten mit Naphthalindicarboxamid als Brücke zwischen zwei Oligonucleotidsequenzen beschrieben $^{152}$. Auch hier trat eine Fluoreszenzlöschung auf. Die Fluoreszenzquantenausbeuten sind für alle hergestellten Naphthalindicarboxamidbis(oligonucleotid)-konjugate wie auch bei dem Stilbenkonjugat viel kleiner als die für Naphthalindicarboxamid. Die größte Fluoreszenzquantenausbeute wurde mit einem Konjugat, das nur Thyminbasen an beiden Seiten enthält, erhalten. Konjugate, die über eine Thyminbase mit zwei Oligonucleotidsequenzen angebunden sind, besitzen eine höhere Fluoreszenzquantenausbeute (3-6 \%) als die Konjugate mit einer Adeninbase als die nächste Base zum Naphthalindicarboxamid ( $<$ o.1 \%). Sogar innerhalb solcher Konjugate gibt es Unterschiede, was darauf hindeutet, dass neben der benachbarten Base auch andere Basen eine Fluoreszenzlöschung bei Naphthalindicarboxamid herbeiführen können ${ }^{152}$. Seidel berichtete, dass die Fluoreszenz von Farbstoffen, die am 3'-Ende einer Oligonucleotidsequenz angebunden sind, hauptsächlich durch die letzten zwei Basen am 3'-Ende der Oligonucleotidsequenz gelöscht wird ${ }^{153}$.

Wie bereits beschrieben, wurde die Fluoreszenz der Stilbendicarboxamidbis(oligonucleotid)-konjugate durch eine Guaninbase stärker als durch eine Adeninbase gelöscht $^{148,151-152}$, was man mit dem niedrigeren Oxidationspotential des Guanins im Vergleich zum Adenin erklären kann. Auch Adenin ist ein stärkerer Fluoreszenzlöscher als Thymin. Im allgemeinen besitzen Pyrimidinbasen (Cytosin und Thymin) höhere 
Oxidationspotentiale als die Purinbasen (Adenin und Guanin), d.h. Adenin und Guanin können Fluoreszenz viel stärker löschen als Cytosin oder Thymin ${ }^{150}$. Sowohl bei den Stilbendicarboxamid-bis(oligonucleotid)-konjugaten als auch bei den Naphthalindicarboxamid-bis(oligonucleotid)-konjugaten wurde ein aliphatischer C3Spacer eingesetzt. In dieser Arbeit wurden Oligonucleotide mit einem Amin-C6-Spacer an der 5'- bzw. 3'-Position synthetisiert, um die Aminfunktion für den Aktivester des Perylendiimids bei der Kopplungsreaktion zugänglich zu machen. Ein zweites Ziel war die Minimierung der Wechselwirkung (z.B. Ladungstransfer) zwischen dem angebundenen Farbstoff und den Basen innerhalb der Sequenz, um die Fluoreszenzeigenschaften des Perylendiimids im synthetisierten PODN zu behalten. Die aufgetretene Fluoreszenzlöschung kann nicht nur auf die Anwesenheit von Guanosin in der Nähe der Bindungsstelle zwischen dem Oligonucleotid und dem Perylendiimid zurückgeführt werden. Bei PODN1 und PODN2 liegen neben dem C6-Spacer zwei Nucleotide (TA bzw. AT) zwischen dem Perylenfarbstoff und der nächsten Guansoinbase und bei PODN5 nur ein Nucleotid (A). Im Falle von PODN3 (3`-verknüpftes Konjugat) trennen 13 Nucleotide das Perylendiimid von der Guansoinbase. Bei allen diesen Konjugaten wurde eine Fluoreszenzlöschung (Fluoreszenzquantenausbeute $<1 \%$ ) festgestellt. Die Anwesenheit von Purinbasen (Adenin- oder Guaninbase), die direkt an das Perylendiimid angebunden bzw. nur eine bis vier Basen von der Bindungsstelle entfernt sind, könnte auch zu Fluoreszenzlöschung führen, da diese ein niedrigeres Oxidationspotential als das Thymin oder Cytosin besitzen, wobei das Guanin stärkere elektronenspendenden Eigenschaften als das Adenin aufweist. In einem solchen Fall kann die Guanin- bzw. die Adeninbase als Donor für das Perylendiimid (Akzeptor) fungieren. Aufgrund der großen Distanz zwischen dem Perylendiimid und der Guaninbase kann man jedoch ausschließen, dass es zu Elektronentransfer zwischen dem elektronenspendenden Guanin und dem Farbstoff kommt ${ }^{120-121}$. Deshalb kann man die Guaninbase nicht als den einzigen Grund für die Fluoreszenzlöschung betrachten. Die Sensibilität des Perylendiimids gegenüber den polaren Eigenschaften des verknüpften Oligonucleotides und der Polarität des Lösungsmittels ist im Zusammenhang mit der hydrophoben Struktur des Chromophorgrundgerüsts zu sehen. 
In der Vergangenheit wurden tetraphenoxylierte Perylendiimide mit vier Peptidketten (z. B. vier Poly(L-lysin)-ketten unterschiedlicher Länge in der bay-Region verknüpft) synthetisiert und ihre Fluoreszenzeigenschaften untersucht ${ }^{130-131}$. Dabei war die erhaltene Fluoreszenzquantenausbeute weiterhin sehr gering. Sie betrug in wässriger Lösung $<3 \%$. Damit wurde wegen der Einführung der wasserlöslichen Peptidketten in die Struktur des Perylendiimids eine Fluoreszenzlöschung erhalten. Durch die Anbindung von zwei Oligonucleotidsequenzen bzw. vier Poly(L-lysin)-ketten ans Perylendiimid wurde das Farbstoffmolekül von der Umgebung abgeschirmt, was auch aufgrund der sehr guten Wasserlöslichkeit von Oligonucleotid bzw. Poly(L-lysin) den hydrophoben Kern (Perylendiimid) in wässrige Medien überführte. Mit der Abschirmung des Chromophores vom umgebenden polaren Lösungsmittel wurde die Neigung des hydrophoben Perylendiimids zur Aggregatbildung minimiert. Im Falle von Perylendiimid 3-23 (ohne Sulfonyl-Gruppen) war dies erforderlich, um das Molekül wasserlöslich zu machen. Obwohl das Perylendiimid mit vier Sulfonyl-Gruppen (3-49) bereits vor der Kopplung mit dem Oligonucleotid wasserlöslich war, wurde die Fluoreszenz durch die angebundenen Oligonucleotidsequenzen gelöscht. Bei 3-34 (Perylendiimid mit einer Oligonucleotidsequenz) wurde eine höhere Fluoreszenzquantenausbeute in wässrigen Medien (4.3\%) festgestellt. Bei PAGE konnte sich das Produkt aufgrund seiner starken Neigung zur Aggregatsbildung nicht in das Gel hinein bewegen und blieb auf der oberen Kannte der Gelschicht. Ein Versuch, das Produkt aus dem Gelmaterial zu extrahieren, war auch nicht erfolgreich. Die einseitige Abschirmung des Perylendiimids führte eine verminderte Fluoreszenzlöschung herbei.

Es scheint, dass das Perylendiimid nicht vollständig vom polaren Lösungsmittel abgeschirmt werden muss, damit es ein Teil seiner Fluoreszenzstärke behalten kann. Wahrscheinlich tritt das Perylendiimid in hydrophoben Wechselwirkungen mit den langen und flexiblen verknüpften Oligonucleotidsequenzen, was zur Fluoreszenzlöschung führt. 


\subsection{Synthese und Hybridisierung von Trisoligonucleotiden}

In den vorherigen Abschnitten wurde die Synthese von Perylendiimidbis(oligonucleotid)-konjugaten beschrieben. Dabei konnten zwei Oligonucleotidsequenzen an das Perylendiimid angebunden werden. Mit diesem Konzept konnte zum Beispiel durch die Hybridisierung von zwei symmetrischen und komplementären Konjugaten (PODN1 und PODN2) ein DNA-Perylendiimid-Polymer mit Perylendiimid als Wiederholungseinheit nachgewiesen werden. Nun soll das Konzept der Selbstorganisation auf die Erzeugung von verzweigten supramolekularen Strukturen erweitert werden, d.h. nach dem gebildeten linear supramolekularen Objekt (mit PODN1 und PODN2) ein Trisoligonucleotid (Kern + 3-Arme) in der Lösung zu synthetisieren und seine Selbstorganisation $\mathrm{zu}$ untersuchen. Das Konzept der Synthese von Trisoligonucleotiden ist aus der Literatur bekannt. Ein Benzolring, der an den Positionen 1,3 und 5 drei Aldehydgruppen trägt, wurde mit 5'-Hydrazid-modifizierten Oligonucleotiden gekoppelt ${ }^{157}$. Die Hybridisierung dieses Moleküls mit größeren DNAMolekülen und ihre Selbstorganisation wurden bis $\mathrm{zu}$ diesem Zeitpunkt nicht veröffentlicht. Aliphatische Verbindungen vom Typ 3-52 wurden zur Darstellung von Trisoligonucleotiden verwendet ${ }^{132-136}$. Durch den selektiven Schutz von jeweils zwei der drei Hydroxylfunktionen mit der DMTr-Gruppe und die Aktivierung der dritten Funktion als Phosphoamidit konnte dieses Amidit direkt bei der Festphasensynthese am DNASynthesizer eingesetzt und die entsprechenden Trisoligonucleotide synthetisiert werden.

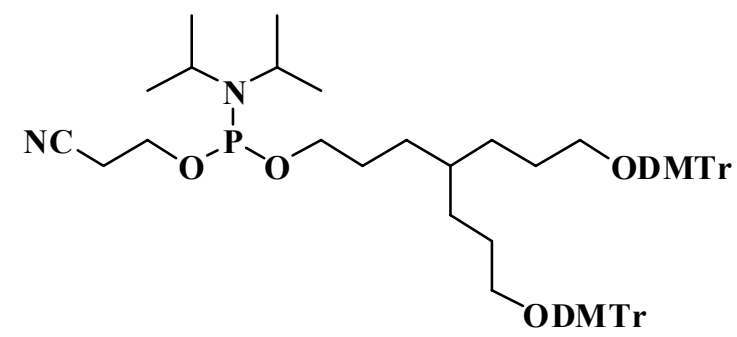

3-52

Ein Beispiel für einen Spacer zur Synthese von Trisoligonucleotiden 
Aufgrund der Flexibilität der aliphatischen Verbindungen vom Typ 3-52 kann es zu Wechselwirkungen zwischen den einzelnen angebundenen Oligonucleotidsequenzen kommen, so dass diese zum Beispiel durch Selbsthybridisierung sekundäre Strukturen ausbilden können. Dadurch wird die Eignung des Trisoligonucleotides als Verkupplungsmolekül mit drei Anknüpfungsstellen deutlich vermindert. Nur mit dem kleinen und steifen Benzolring als Kern wird es wegen sterischer Hinderung sehr schwierig sein, große DNA-Moleküle zu hybridisieren. Diese Hinderung könnte durch die Verwendung einer größeren aromatischen Verbindung als Kern des Trisoligonucleotides reduziert werden. Die Steifigkeit bei einem solchen Trisoligonucleotid kann zur Minimierung interner Wechselwirkungen (sekundärer Strukturen), in die die drei angebundenen Oligonucleotidsequenzen treten könnten, beitragen.

Aufbauend auf die bereits erwähnten Arbeiten zu Trisoligonucleotiden sollte nun ein Trisoligonucleotid auf der Basis von 1,3,5-Tribrombenzolderivat in der Lösung synthetisiert werden. Bisher wurden Trisoligonucleotide nur durch die Festphasensynthese mit einem Amiditderivat (z.B. 3.52) synthetisiert. In diesem Abschnitt werden die Synthese und die Hybridisierung eines neuen Trisoligonucleotidtyps dargestellt.

\subsubsection{Synthese und Charakterisierung}

Ausgehend von 1,3,5-Tribrombenzol 3-53 erfolgt die Suzuki-Kopplung mit 7 Äquivalenten der kommerziell verfügbaren 4-Methoxycarbonylphenylboronsäure in ein Lösungsmittelgemisch aus Toluol, Methanol und 2M Kaliumcarbonatlösung und $\operatorname{Pd}(\mathrm{PPh} 3) 4$ als Katalysator. Die Reaktion wurde 15 Stunden bei $75{ }^{\circ} \mathrm{C}$ unter Inertgasbedingungen gerührt. Die Aufreinigung des Produkts wurde mit Hilfe von Säulenchromatographie durchgeführt. Als Eluent wurde Dichlormethan verwendet, aus dem sich das Produkt 3-54 mit einer Ausbeute von 91 \% gewinnen lässt. 
Die Abspaltung der Carboxylmethylschutzgruppe wurde in THF mit Kaliumhydroxid innerhalb von 24 Stunden bei $80{ }^{\circ} \mathrm{C}$ erreicht. Das Produkt 3-55 wurde in $2 \mathrm{M} \mathrm{HCl-Lösung}$ gefällt, filtriert und unter Vakuum getrocknet. Die Überführung der freien Carboxyfunktionen in den Aktivester wurde durch die Reaktion von 3-55 mit NHydroxysucciniimid mit DCC als Katalysator bewerkstelligt. Nachdem DC- und FDKontrolle eine vollständige Umsetzung zeigten, wurde das Reaktionsgemisch im Vakuum getrocknet. Der Strukturbeweis für 3-54 und 3-55 lässt sich mit Hilfe von FDMassenspektrometrie, Elementaranalyse, ${ }^{13} \mathrm{C}$ - und ${ }^{1} \mathrm{H}-\mathrm{NMR}-$ Spektroskopie führen.<smiles>COC(=O)c1ccc(B(O)c2ccc(Br)cc2Br)cc1</smiles>

3-53<smiles>COC(=O)c1ccc(-c2cc(-c3ccc(C(=O)OC)cc3)cc(-c3ccc(C(=O)OC)cc3)c2)cc1</smiles>

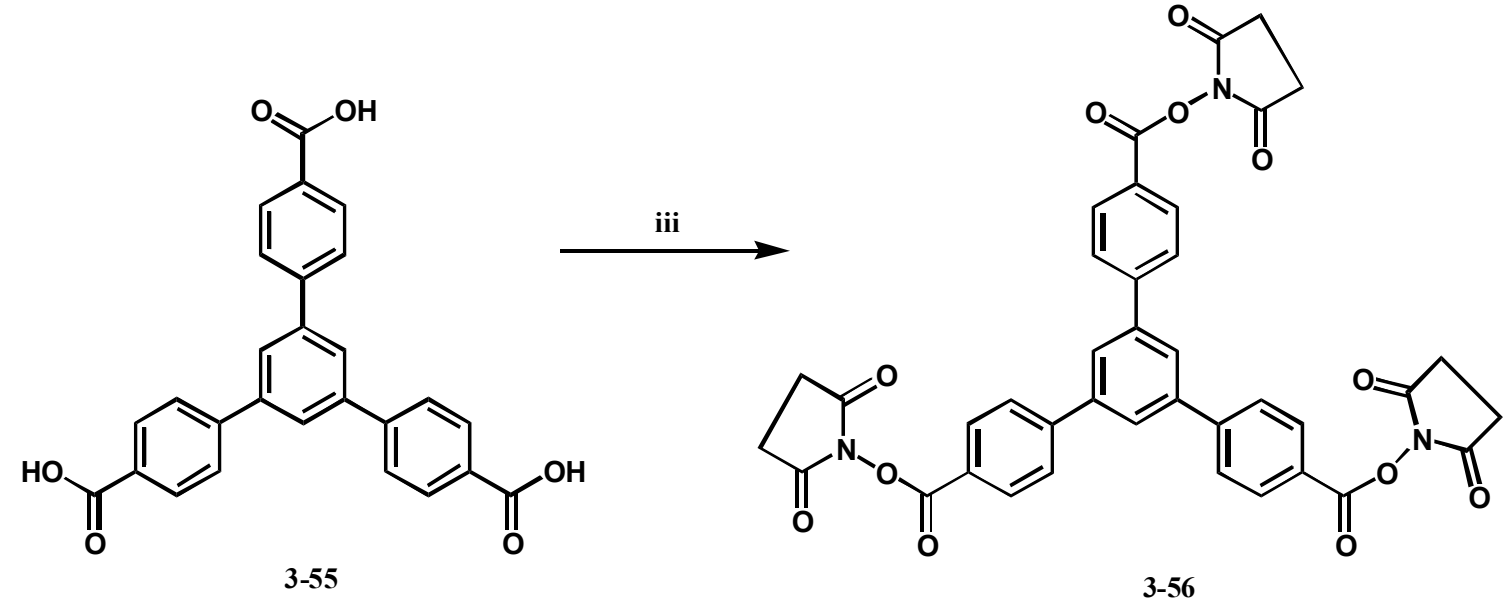

Abbildung 101: Synthese von 1,3,5-Tri(p-carboxyphenyl)benzol als Kern für die Herstellung eines Trisoligonucleotides i) $\mathrm{Pd}(\mathrm{PPh} 3) 4,2 \mathrm{M} \mathrm{K}_{2} \mathrm{CO}_{3}$-Lösung, Toluol, Methanol, $15 \mathrm{~h}$ bei $75{ }^{\circ} \mathrm{C}$, $91 \%$ ii) 30 Äquivalente $\mathrm{KOH}$ gelöst in $2 \mathrm{ml} \mathrm{H}$ O, THF, 24 h bei $80^{\circ} \mathrm{C}, 87 \%$ iii) 10 Äquivalente N-Hydroxysucciniimid, DCC, DMF, $35^{\circ} \mathrm{C}, 48$ Stunden, $100 \%$

Die Symmetrie der Verbindungen 3-54 vereinfachte die Zuordnung der Signale im ${ }^{1} \mathrm{H}$ NMR-Spektrum (Abbildung 102). Im aromatischen Bereich findet man die Signale der 
Kapitel 3: Synthese und Selbstorganisation von Perylen-Oligonucleotid-Konjugaten

Protonen $\mathrm{H}_{\mathrm{a}}, \mathrm{H}_{\mathrm{b}}$ und $\mathrm{H}_{\mathrm{c}}$. Bei $\delta=3.92$ ppm tritt das Signal der Methylschutzgruppe auf.

Die Intensität der Signale stimmt mit der angenommenen Struktur überein.
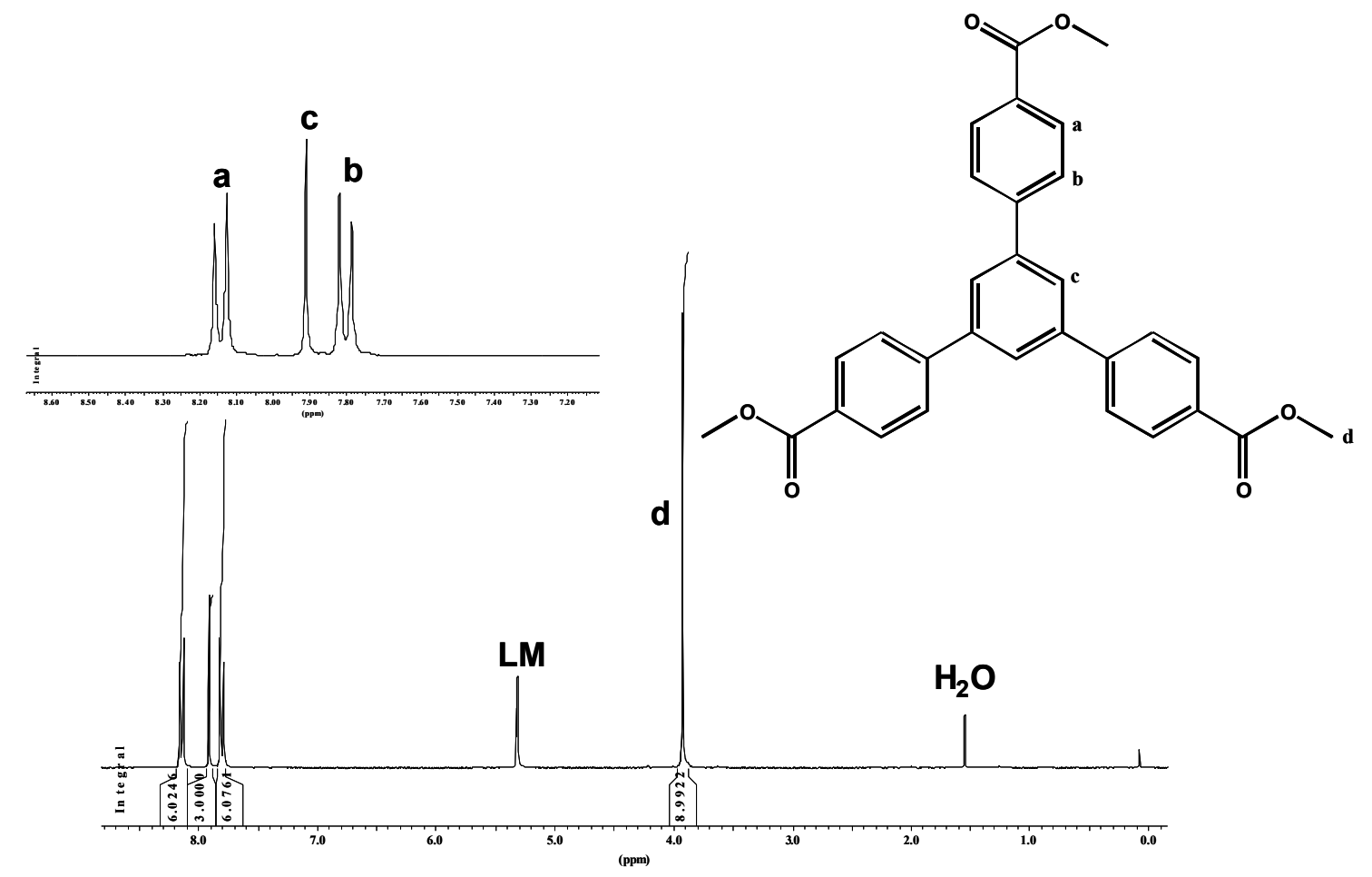

Abbildung 102: ${ }^{1} \mathrm{H}-\mathrm{NMR}-$ Spektrum von 3-54 $\left(250 \mathrm{MHz}, \mathrm{CD}_{2} \mathrm{Cl}_{2}, 25{ }^{\circ} \mathrm{C}\right)$

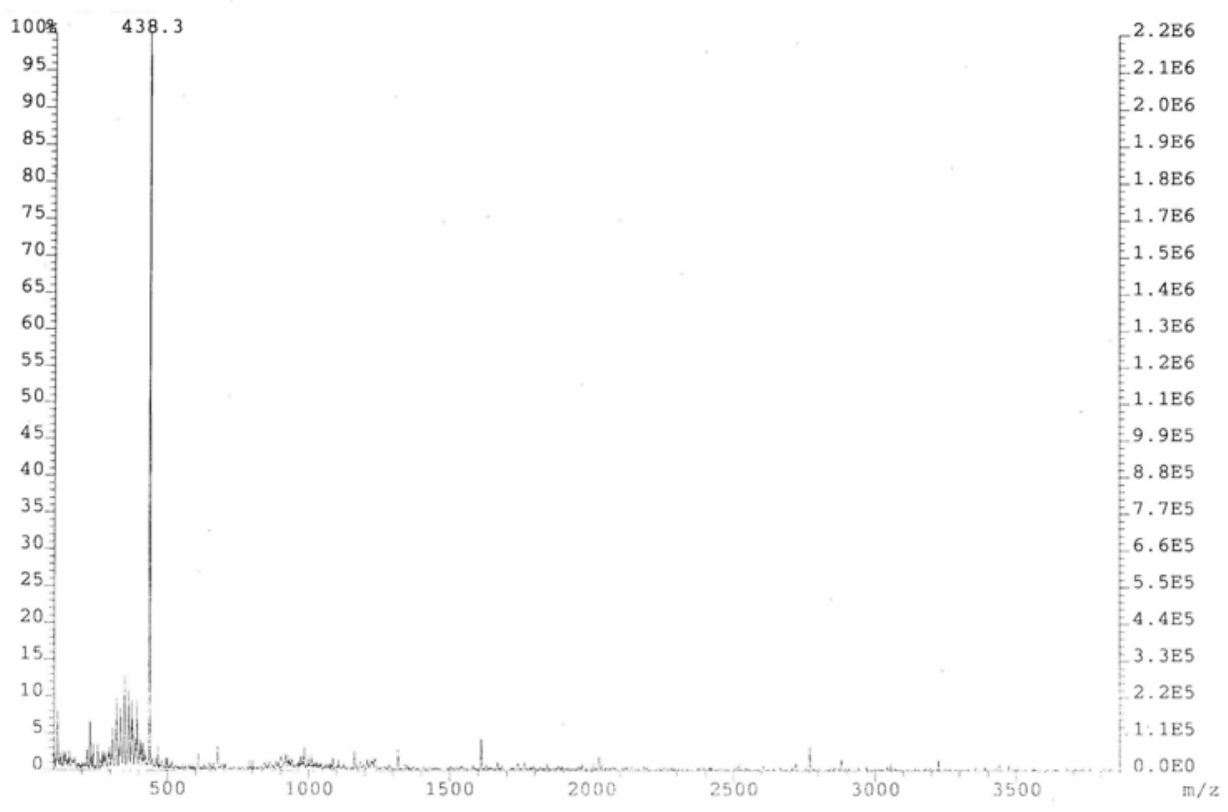

Abbildung 103: FD-Massenspektrum von 4-55 $\mathrm{M}_{\mathrm{ber}}=438.43 \mathrm{~g} / \mathrm{mol}$ 
Die Synthese vom Trisoligonucleotid wurde analog zum PODN durchgeführt. 15 Äquivalente von ODN2 wurden in $400 \mu$ l einer frisch angesetzten $0.1 \mathrm{M}$ Natriumtetraboratlösung gelöst und bei $40{ }^{\circ} \mathrm{C} 5$ Minuten gerührt. Die entsprechende Menge von 3-56 wurde in 50 $\mu 1$ DMF gelöst und in die ODN1-Lösung eingetropft. Nach einer Reaktionszeit von 24 Stunden wurde das Reaktionsgemisch vom Thermomixer entfernt, eingeengt und im Vakuum getrocknet. Im Anschluss erfolgte eine 10\% PAGE. In Abbildung 104 erkennt man zusätzlich zu der ODN2-Bande drei weitere Banden für das mono-, bis- und trisubstituierte Produkt. Aufgrund der kleinen Molekülgröße von 1,3,5-Tri(p-carboxyphenyl)benzol sind die Nebenprodukte im Gelmaterial gewandert, anderes als bei den Perylendiimid-bis(oligonucleotid)-konjugaten (Die Molekülgröße von 3-23 ist viel größer als 3-55). Durch die Hydrolyse der Aktivester in der Pufferlösung konnten nicht alle drei Aktivestergruppen mit dem Aminoligonucleotid reagieren. Die Ausbeute betrug deshalb nur $17 \%$, was sich auch in der Intensität der Banden in PAGE (Abbildung 104) erkennen lässt.

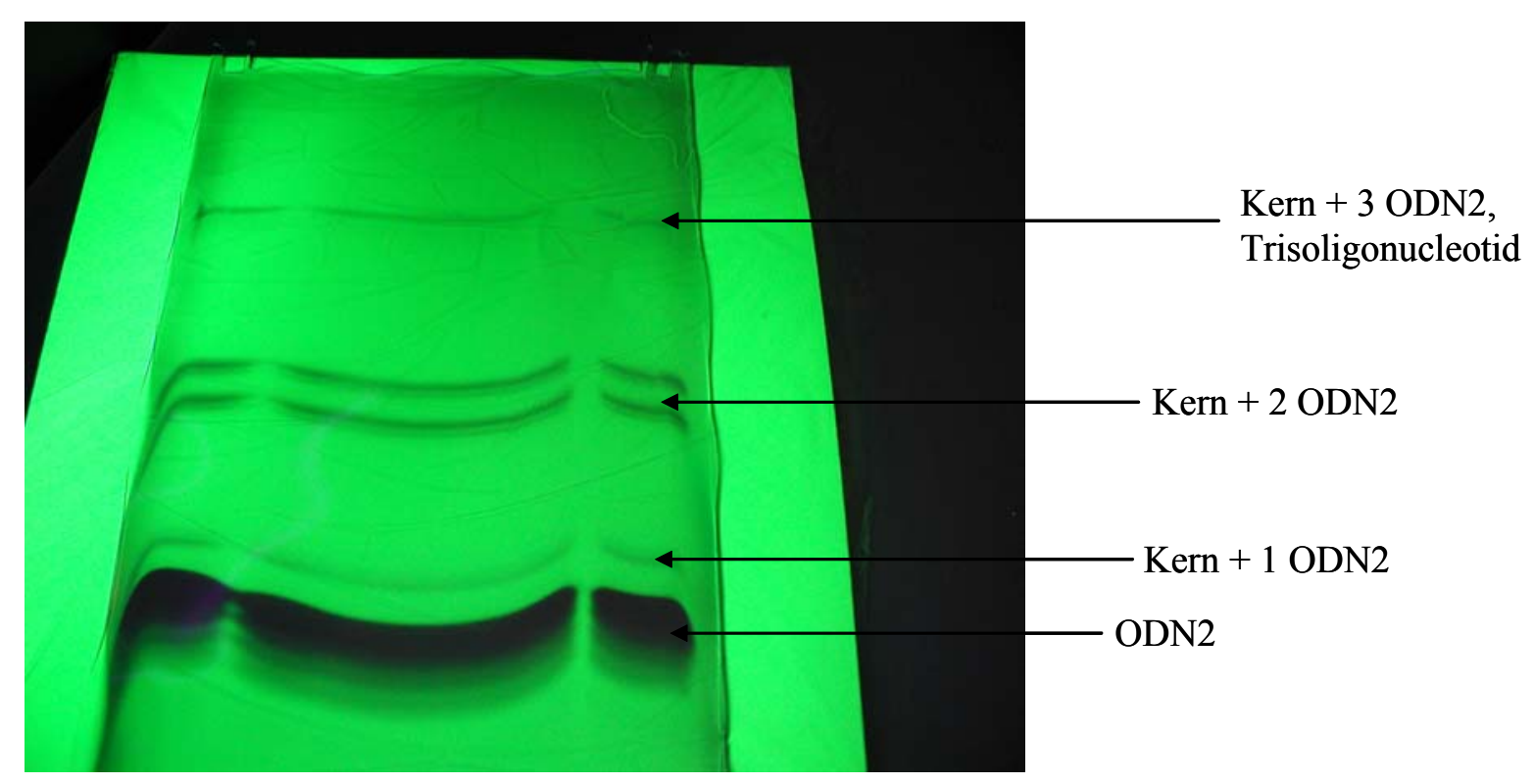

Abbildung 104: Präperative PAGE vom Trisoligonucleotid 3-57, Gelkonzentration $10 \%$, Spannung 450 v, 5 Stunden 


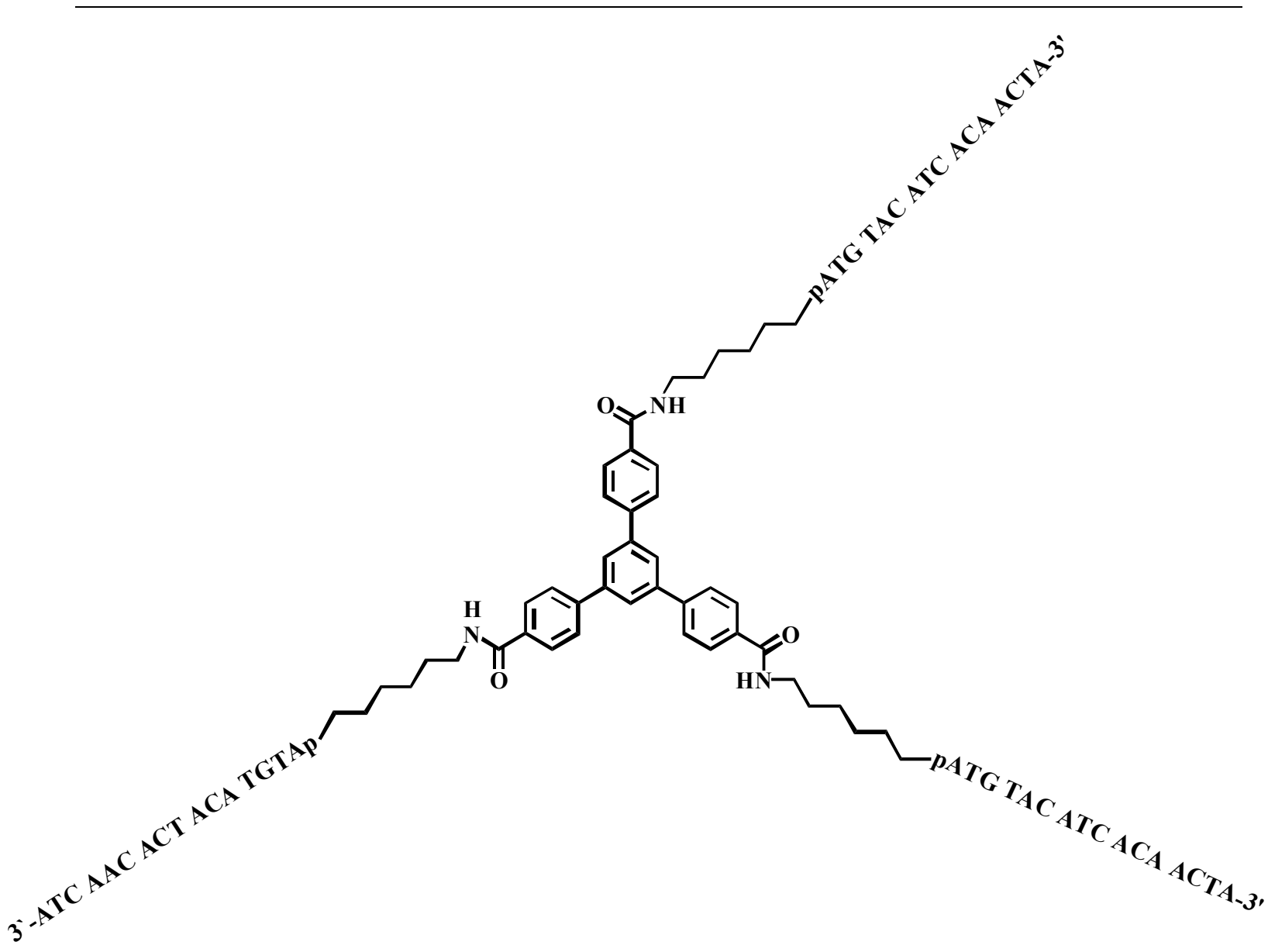

Abbildung 105: Struktur des synthetisierten Trisoligonucleotides $3-57 \quad$ (1,3,5-Tri(pcarboxyphenyl)benzol + 3 ODN2)

\subsubsection{Hybridisierung}

Nachdem das aufgereinigte Trisoligonucleotid vom Gelmaterial extrahiert wurde, konnte mit der Hybridisierung begonnen werden. Eine 50 b-ssDNA wurde so ausgewählt, dass sie an einem Ende komplementärer zu ODN2 (cODN2) ist. Ein Hybridisierungsprodukt wurde erhalten, bei dem alle drei Enden des Trisoligonucleotides 3-57 durch die Hybridisierung mit der 50 b-ssDNA verlängert sind. In Abbildung 106 ist das Ergebnis der analytischen PAGE zu sehen. In I wurden die 50 b-ssDNA und in II das aufgereinigte Trisoligonucleotid zum Vergleich aufgetragen. 


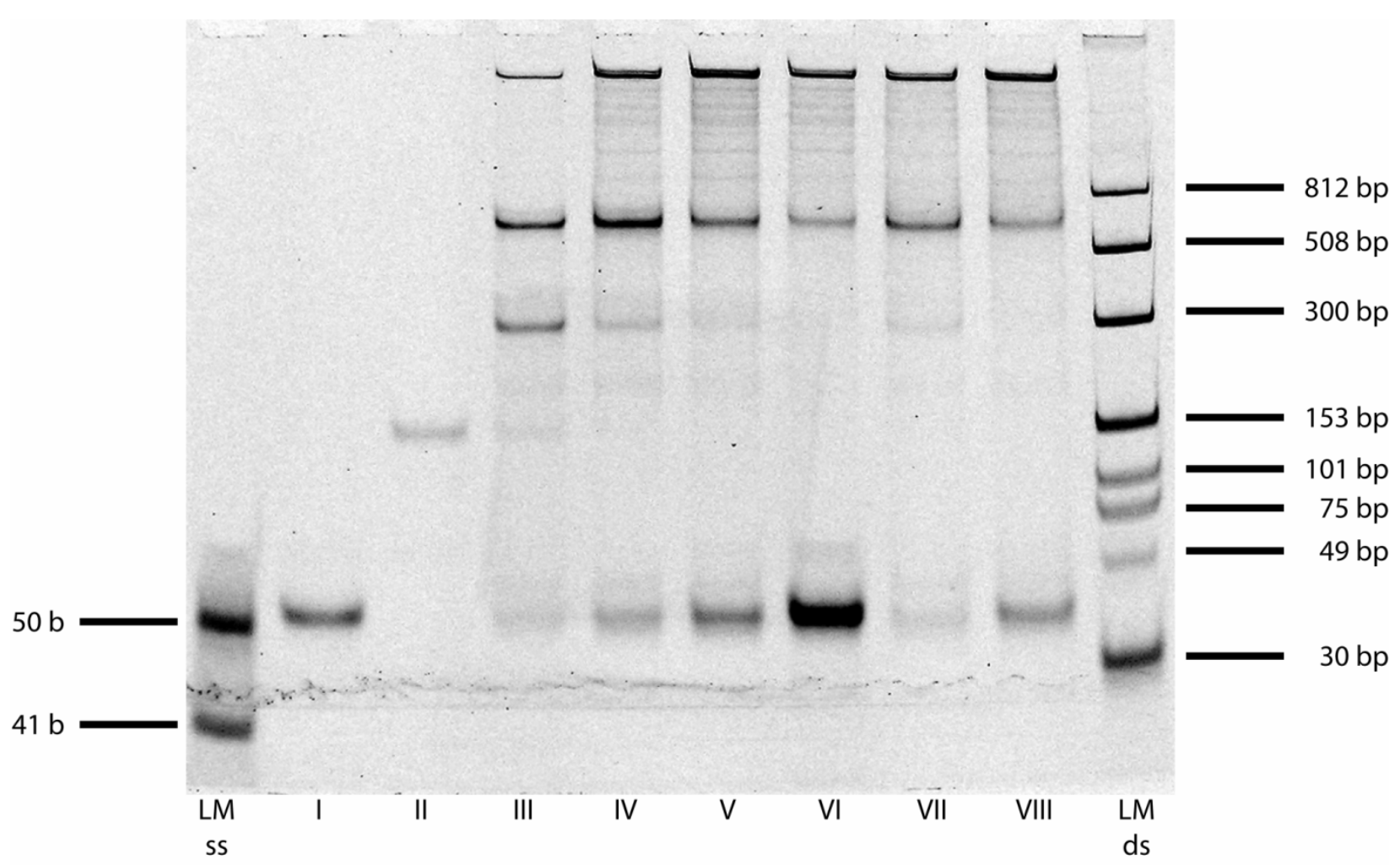

Abbildung 106: Die Hybridisierung von Trisoligonucleotid mit einer 50b-ssDNA, I: 50b-ssDNA, II: Trisoligo, III: 50b-ssDNA + Trisoligo (1:1), IV: 50b-ssDNA + Trisoligo (2:1), V: 50b-ssDNA + Trisoligo (3:1), VI: 50b-ssDNA+ Trisoligo (4:0.5), VII: 50b-ssDNA + Trisoligo (2:1), VIII: 50b-ssDNA+ Trisoligo (3:1)

Wenn das Mischverhältnis zwischen der 50b-ssDNA und dem Trisoligonucleotid 1:1 beträgt, erhält man ein Gemisch aus 3 Hybriden. Beim ersten Hybrid (die untere Bande in III) wurde nur eine Sequenz im Trisoligonucleotid mit der 50 b-ssDNA gepaart, und bei dem zweiten Hybrid (die mittlere Bande in III) sind zwei Sequenzen des Trisoligonucleotides mit zwei 50 b ss-DNA hybridisiert. Bei dem dritten handelt es sich um das dreifach und vollständig hybridisierte Trisoligonucleotid (das gewünschte Hybrid). In IV wurde der Anteil an die 50 b-ssDNA erhöht, um eine vollständige Hybridisierung der drei Sequenzen im Trisoligonucleotid mit der ssDNA zu erzielen. Die Intensität der drei Banden in IV zeigt, dass durch die Erhöhung der Konzentration der 50 b-ssDNA die Bande des monohybridisierten Trisoligonucleotid sehr schwach wird, d.h. die Anteile an dem zweifach und dem dreifach hybridisierten Trisoligonucleotid (im höheren Molekularbereich) wurden erhöht. Die weitere Erhöhung der 50 b-ssDNA-Konzentration 
macht sich in der Intensität der oberen zwei Banden in V-VIII (Abb. 106) bemerkbar. Die höchste Ausbeute an gewünschtem Hybrid (dreifach hybridisiert) wurde bei einem Mischverhältnis zwischen dem Trisoligonucleotid und der 50 b-ssDNA von 1:8 (VI) erzielt, was man auch an der Intensität der Banden deutlich sehen kann, d.h. je größer das Mischverhältnis von 50 b-ssDNA zu dem Trisoligonucleotid wird, desto vollständiger wird die Hybridisierung sein.

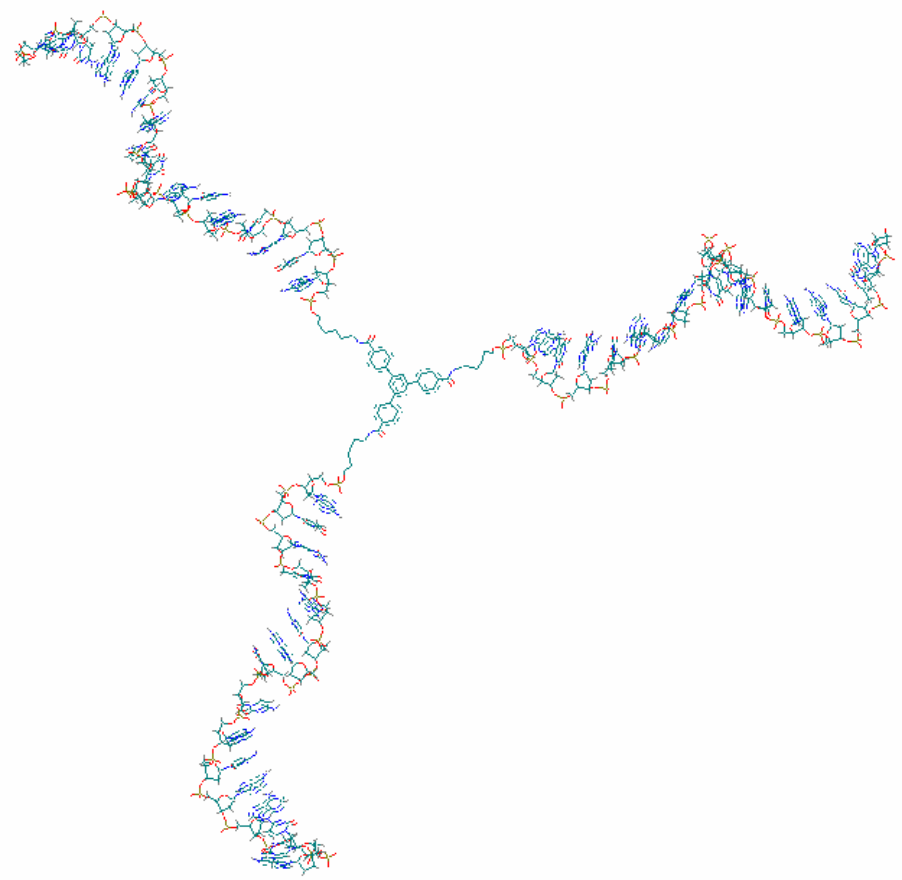

Abbildung 107: Die optimierte Struktur vom Trisoligonucleotid 3-57 (Hyperchem 7.0)

Nachdem die dreifache Hybridisierung des Trisoligonucleotides mit einem 50 b-ssDNA nachgewiesen wurde, sollte nun versucht werden, längere DNA-Fragmente (650 bp) zu koppeln. Hierbei war das DNA-Fragment mit einem ssDNA-Ende (20b) versehen (Sticky End). Über ein weiteres ssDNA-Fragment (50b), das zum einen komplementär zum angekoppelten ODN des Trisoligonucleotides und zum anderen komplementär zum "Sticky End" des 650bp-Fragmentes war, sollte die Bildung eines dreiarmigen DNASternes nachgewiesen werden.

Unsere Experimente zeigten allerdings, dass es nur möglich war, an zwei Anknüpfungsstellen längere DNA anzubinden. Es scheint so zu sein, dass die Hybridisierung einer dritten DNA-Sequenz sterisch gehindert ist. Ein Hinweis dafür ist, 
dass es weder über eine primäre Anbindung des vermittelten ODN an das Trisoligonucleotid noch an das 650bp DNA-Fragment gelungen ist, das gewünschte Hybrid zu erreichen. Die zwei großen hybridisierten DNA-Moleküle sind wahrscheinlich sterisch sehr anspruchsvoll, was die Hybridisierung einer dritten DNA-Doppelhilex behinderte. In den bereits publizierten Ergebnissen mit Trisoligonucleotiden, die einen aliphatischen Linker mit vier Armen enthalten, wurde die Struktur vor Beginn der Festphasensynthese erweitert, so dass man neuen Oligonucleotidsequenzen mit dem Linker verknüpfen und damit eine Struktur in der Form eines Dendrimers erhalten konnte $^{135}$. Als mögliches Anwendungsgebiet für diese Oligonucleotid-DendrimerStrukturen wurde PCR (Polymerase Chain Reaction) genannt. Über die Markierung des Oligonucleotid-Dendrimers mit Enzymen wurde auch berichtet ${ }^{135}$. Dabei konnte die Markierung mit dem Enzym erst erfolgreich verlaufen, wenn die Distanz zwischen dem Verzweigungspunkt und dem 5'-Ende des angebundenen Oligonucleotides vergrößert wird. Während man dabei eine achtfache Markierung im Vergleich zu den normalen Oligonucleotiden erzielte, konnte man bei der verzweigten Struktur mit einem kürzeren Spacer (auch neuen Oligonucleotidsequenzen angebunden) lediglich eine zweifache Markierung (im Vergleich zu den normalen Oligonucleotiden) erreichen ${ }^{135}$. Als Grund dafür wurde die unzureichende Zugänglichkeit der 5'-Enden im OligonucleotidDendrimer mit dem kürzeren Spacer genannt, da die Sequenzen dicht aneinander liegen. Über die Hybridisierung des Oligonucleotid-Dendrimers mit größeren dsDNA-Molekülen wurde bis zu diesem Zeitpunkt nicht berichtet.

Bei dem in dieser Arbeit synthetisierten Trisoligonucleotid konnten nur zwei der angebundenen Oligonucleotidsequenzen mit größeren dsDNA-Molekülen (650 bpdsDNA) hybridisiert werden. Dies konnte darauf zurückgeführt werden, dass die zwei bereits hybridisierten dsDNA-Moleküle die Paarung der dritten Sequenz im Trisoligonucleotid mit dem 650 bp-dsDNA sterisch behinderten. Eine Bestätigung dafür ist die erfolgreiche Hybridisierung der drei Sequenzen im Trisoligonucleotid mit einer 50 b-ssDNA. 


\subsection{Bis(biotin)-funktionalisiertes Perylendiimid als Baustein für Nanostrukturen an Oberflächen}

Avidin oder Streptavidin sind Proteine mit vier Bindungsstellen, die sich sehr spezifisch und mit einer hohen Bindungskonstante an Biotin, ein wasserlösliches Vitamin, binden können. Diese Erkennungseigenschaft eignet sich für die Selbstorganisation und Bildung von Strukturen im Nanomaßstab sowohl in der Lösung als auch an Oberflächen, die mit Streptavidin oder Biotin beschichtet sind ${ }^{137-144}$. Fluoreszenzfarbstoffe, die mit zwei Biotinmolekülen dekoriert werden können, sind im Kontext der Nanostrukturen auf der Basis von Streptavidin-Biotin-Komplexen sehr wichtig. Dabei können Fluoreszenzfarbstoffe in supramolekulare Strukturen angeordnet und an bestimmten Stellen auf einer Oberfläche immobilisiert werden. Dabei bieten die lineare Struktur des Perylendiimids und die Möglichkeit, in seine Imidstruktur funktionelle Gruppen einzuführen, einen idealen Kandidaten für eine solche Anwendung.

In diesem Abschnitt werden die Synthese von N,N`-Bis[4-(biotinyl-3-6,9,trioxaundecanyl)aminocarbonylphenyl]-1,6,7,12-tetra[4-(1,1,3,3-tetramethylbutyl)phenoxy]-3,4,9,10-perylentetracarbonsäurediimid, (PDI(Biotin) $)_{2}$, und zusammen mit Streptavidin von Bausteinen für die Bildung von Nanostrukturen an Goldoberflächen vorgestellt.

Ausgehend von 1,6,7,12-Tetrachlor-3,4,9,10-perylentetracarbonsäuredianhydrid (3-18) erfolgte die Imidisierung mit 4-Amin-tert-butylbenzolsäureester in Propionsäure. Eine Kontrolle des Reaktionsgemisches mit Hilfe von FD-Massenspektrometrie zeigte, dass die tert-Butylschutzgruppe im Produkt 3-58 durch die saueren Bedingungen während der Imidisierungsreaktion teilweise abgespalten wurde. Die Löslichkeit von 3-58 in organischen Lösungsmitteln war nicht ausreichend, um eine säulenchromatographische Reinigung durchzuführen. Zur Verbesserung der Löslichkeit wurde eine tertOctylphenoxygruppe in die bay-Region eingeführt. N,N'-Bis(p-tertbutylbenzolsäureester)-1,6,7,12-tetrachlor-3,4,9,10-perylentetracarbonsäurediimid (3-58) 
Kapitel 3: Synthese und Selbstorganisation von Perylen-Oligonucleotid-Konjugaten

wurde mit 4-(1,1,3,3-Tetramethyl-butyl)-phenol in NMP in der Anwesenheit von Kaliumcarbonat zur Reaktion gebracht. DC- und FD-Kontrolle bestätigten die vollständige Umsetzung des Ausgangstoffs und die Anwesenheit eines Produktgemischs aus 3-59 und 3-60. Die Abspaltung der tert-Butylschutzgruppe erfolgte in einem Gemisch aus Trifluoressigsäure und Dichlormethan (1:1). Nach zweistündigem Rühren bei Raumtemperatur, Einengen, Trocknen und säulenchromatographischer Reinigung erhielt man das Produkt 3-60 in 68 \%er Ausbeute. Der Strukturbeweis von 3-60 basiert auf FDMassenspektrometrie, Elementaranalyse, ${ }^{1} \mathrm{H}$ - und ${ }^{13} \mathrm{C}$-NMR-Spektroskopie. 
<smiles></smiles>

3-18<smiles></smiles><smiles></smiles><smiles>[R]Oc1cc2c3c(cc(O[R])c4c5c(O[R])cc6c7c(cc(O[R])c(c1c34)c75)C(=O)N(c1ccc(C(=O)O)cc1)C6=O)C(=O)N(c1ccc(C(=O)O)cc1)C2=O</smiles>

3-58 $\quad \mathrm{O}^{\mathrm{H}-\mathrm{R}^{\prime}}$

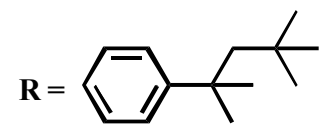

$\mathbf{R}^{\prime}=$

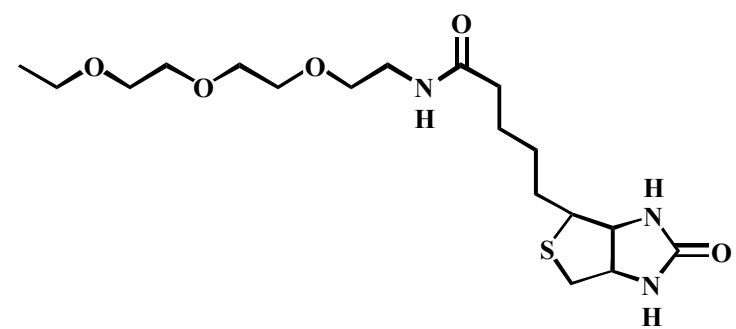

Abbildung 108: Synthese von $\mathrm{PDI}(\text { Biotin) })_{2}$ 3-61 i) 4-Amin-tert-butylbenzolsäureester, Propionsäure, unter Rückfluss, $20 \mathrm{~h}$ ii) 4-(1,1,3,3-Tetramethyl-butyl)-phenol, $\mathrm{K}_{2} \mathrm{CO}_{3}, \mathrm{~N}$ Methylpyrrolidon (NMP), 12 h bei $90^{\circ} \mathrm{C}$ iii) Trifluoressigsäure, Dichlormethan, RT, 2 h $76 \%$ iv) Biotin-PEO-Amin, EDC, DMAP, DMF, RT, 4 Tage, Ausbeute $68 \%$. 
Schließlich wurde 3-60 mit Biotin, das eine PEO-Kette mit einer Aminfunktion trägt, 1Ethyl-3-(3-dimethylaminopropyl)-carbodiimid (EDC) als Katalysator und Dimethylaminopyridine (DMAP) in DMF gelöst. Die Reaktionslösung wurde mehrmals evakuiert, mit Argon gefüllt und 5 Tage bei Raumtemperatur gerührt. Nach einer DCKontrolle wurde das Reaktionsgemisch einrotiert und unter Vakuum getrocknet. Das Produkt 3-61 wurde in n-Pentan ausgefällt. Den Strukturbeweis von 3-61 lieferten die Maldi-Tof-Analyse, ${ }^{1} \mathrm{H}$ - und ${ }^{13} \mathrm{C}-\mathrm{NMR}$-Spektroskopie. In Abbildung 109 ist dasMaldiTof-MS von 3-61 zu sehen. Der erhaltene Peak bei 2286 m/z entspricht dem berechneten Molekulargewicht von 3-61 (2248.86 g/mol) plus einem Kaliumion, das bei der MaldiTof-Messung als Salz eingesetzt wurde.

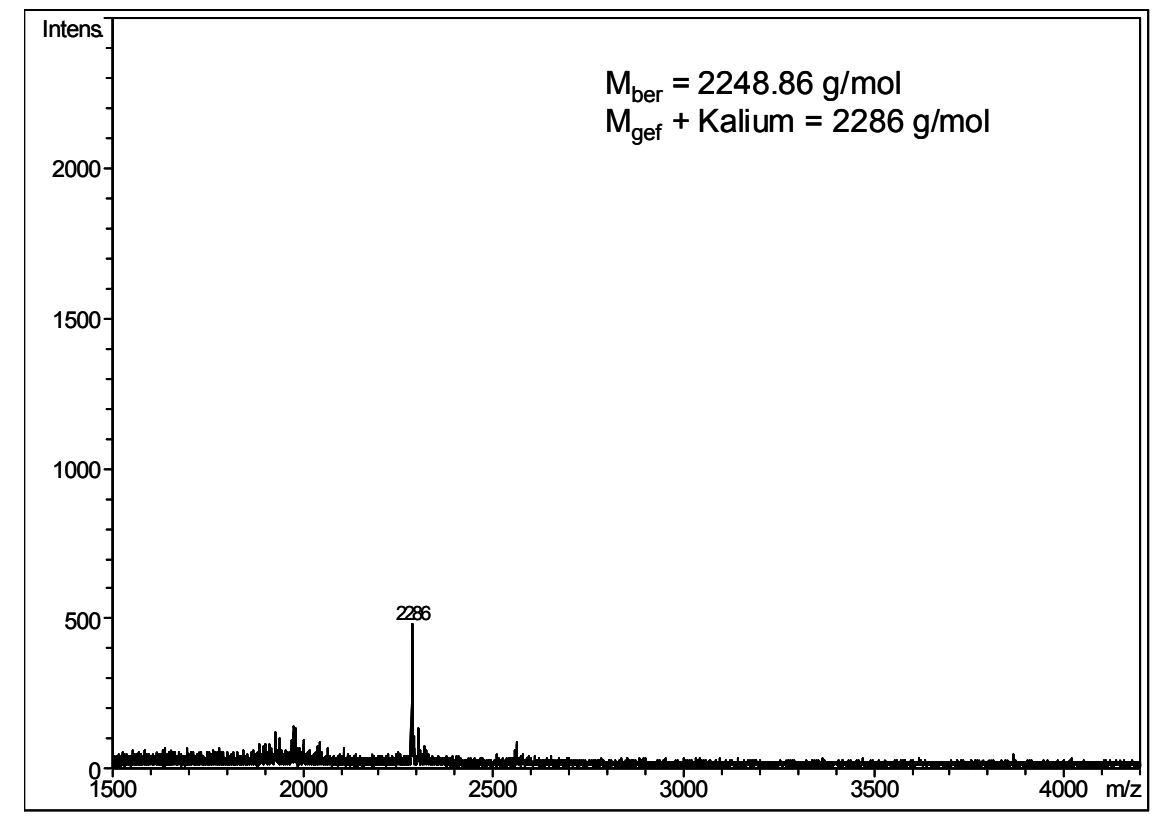

Abbildung 109:Maldi-Tof-MS von PDI(Biotin) 2 3-61

\subsection{1 Überführung von PDI(Biotin $)_{2}$ in wässriger Lösung}

Die Solubilisierung eines Polyphenyldendrimers der ersten Generation, das ein Biotinund drei Perylenmonoimidmoleküle an seiner Oberfläche trägt, wurde unter Verwendung eines Detergenzes erfolgreich in wässrigen Medien gelöst ${ }^{145}$. Da die Molekülgröße von 
3-61 viel kleiner als das Dendrimer ist, sollte die Solubilisierung von 3-61 mit Hilfe eines Detergenzes möglich sein. Eine DMSO-Lösung von 3-61 wurde mit dem kommerziell verfügbaren Tween 20 gemischt und mit einer Pufferlösung (20 mM Tris-HCl, $150 \mathrm{mM}$ $\mathrm{NaCl}, 5 \mathrm{mM}$ EDTA, $\mathrm{pH}=7.5$ ) verdünnt. Die Endkonzentration von 3-61 in der DMSOPufferlösung betrug $4.5 \mu \mathrm{M}$. Durch die Verwendung von Tween 20 wurde das $\mathrm{PDI}(\text { Biotin })_{2}$ in wässrige Lösung überfuhrt. In Abbildung 110 ist das normierte Absorptions- und Fluoreszenzspektrum gezeigt. Überraschend war die erhaltene Fluoreszenzquantenausbeute (38 \%) von 3-61 in der Pufferlösung, wenn man die hydrophobe Struktur und die Wasserunlöslichkeit von 3-61 betrachtet.

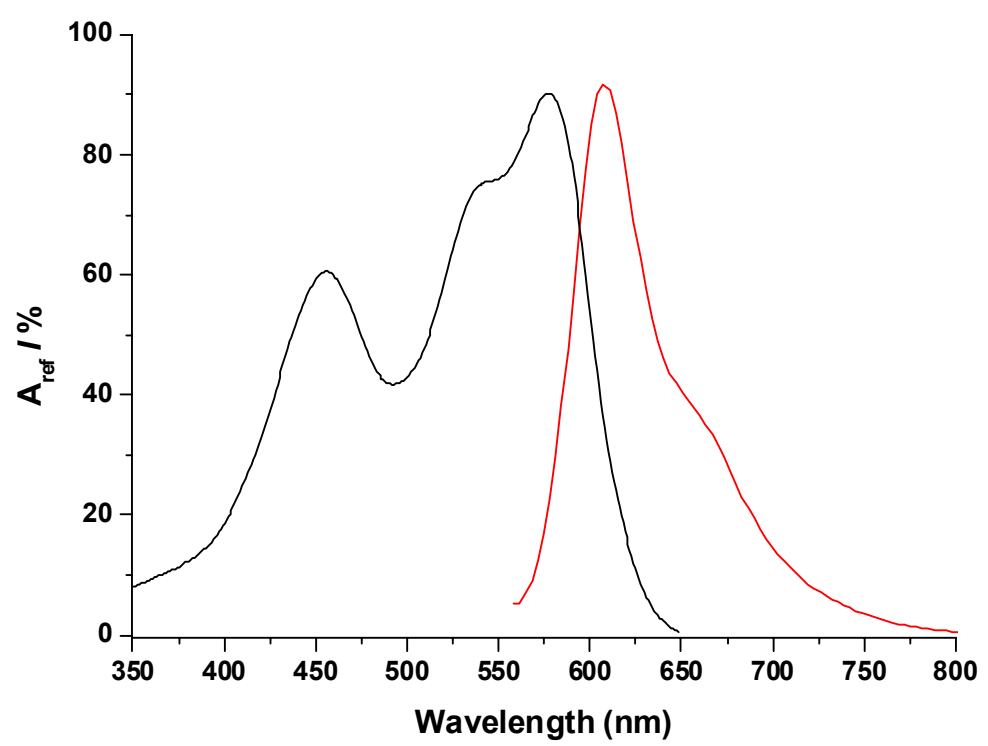

Abbildung 110: Absorptions- und Fluoreszenzspektrum von PDI(Biotin) $)_{2} 3-61$ in $4.5 \mu \mathrm{M}$ DMSO-Pufferlösung (20 mM Tris-HCl, $150 \mathrm{mM} \mathrm{NaCl,} 5 \mathrm{mM}$ EDTA, $\mathrm{pH}=7.5$, Anteil von DMSO in der Pufferlösung $1.5 \%$ )

\subsubsection{Bindung zwischen dem PDI(Biotin $)_{2}$ und Streptavidin}

Als Oberfläche für die Bildung der multilagigen Nanostruktur wurde ein Au/Ag-Substrat gewählt. Im ersten Schritt zur Anbindung der ersten Streptavidinschicht an die Goldoberfläche wurde ein kommerziell erhältliches Biotin, das eine Thiolgruppe trägt, an das Goldsubstrat gebunden, wobei ein Gemisch aus Sulfhydryl-funktionalisiertem Biotin und 6-Mercapto-hexan-1-ol (ohne Biotin) als Verdünner (1:9) verwendet wurde, um 
einen Abstand zwischen den angebundenen Streptavidinmolekülen an der Oberfläche zu halten und mögliche sterische Hinderungen $\mathrm{zu}$ vermeiden. Im Anschluss wurde Streptavidin zugegeben, um mit dem immobilisierten Biotin eine Bindung einzugehen und damit die erste Streptavidinschicht zu bilden. Da sich Streptavidin an vier Biotinmoleküle binden kann, bleiben noch drei freie Bindungsstellen, die von PDI(Biotin) $)_{2}$ erkannt werden können. Nachdem die DMSO-Pufferlösung vom 3-61 zugegeben und die nicht gebundenen PDI(Biotin) $)_{2}$-Moleküle ausgewaschen wurden, konnte man eine sehr starke Fluoreszenzintensität detektieren, was auf eine Bindung zwischen dem PDI(Biotin $)_{2}$ und dem immobilisierten Streptavidin hindeutet. Die Reaktion und die optischen Eigenschaften des neuen Komplexes zwischen PDI(Biotin) 2 und Streptavidin wurden mit Hilfe von Oberflächenplasmonenfluorszenzspektroskopie ${ }^{146}$ (SPFS, engl. Surface Plasmon Fluorescence Spectroscopy) in Kooperation mit dem Arbeitskreis von Prof. Knoll verfolgt. Ein Kontrollexperiment wurde mit Sulfhydrylfunktionalisiertem Biotin durchgeführt. Dabei konnte keine Fluoreszenz detektiert werden. Daraus kann man schliessen, dass das PDI(Biotin) $)_{2}$ das Streptavidin erkennen kann und dass die kovalente Verknüpfung von Biotin ans Perylendiimid den Biotinrest nicht hindert, sich an Streptavidin zu binden. Durch die erneute Zugabe von Streptavidin und PDI(Biotin) $)_{2}$-Lösung wurde eine neue Schicht von Streptavidin-PDI(Biotin) $)_{2}$ gebildet. Hier konnte man eine Zunahme der Fluoreszenzintensität nach der Bindung der zweiten Schicht detektieren. Dieser Prozess wurde drei Mal wiederholt, wobei nach jeder Doppelschicht eine erhöhte Fluoreszenzintensität erhalten wurde. Insgesamt fünf Doppelschichten aus Streptavidin und PDI(Biotin) $)_{2}$ wurden erfolgreich gebildet. Nach jeder Schichtbildung wurde die Oberfläche vermessen. In Abbildung 111 ist das Oberflächenplasmonenfluoreszenzspektrum der erhaltenen Oberflächenstruktur dargestellt. 


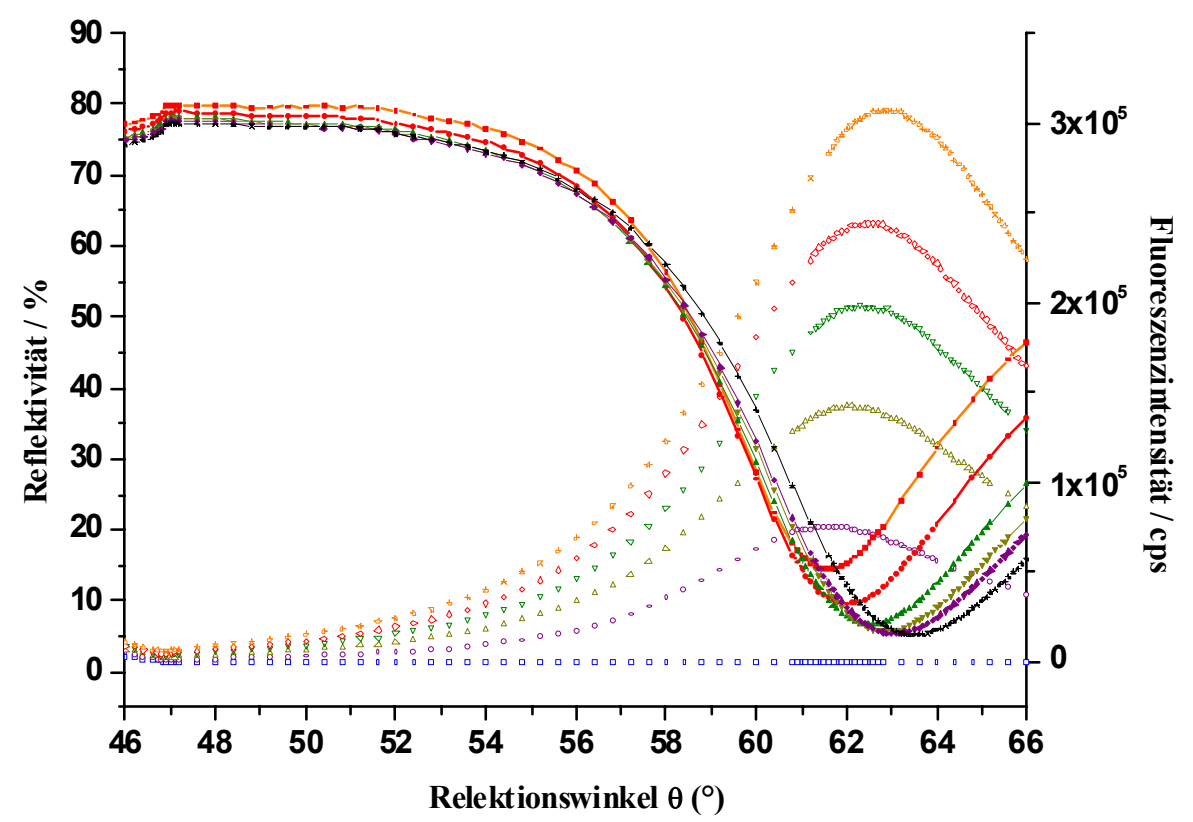

Abbildung 111: Oberflächenplasmonenfluoreszenzspektrum von der gebildeten multilagigen Struktur. Die Fluoreszenzintensität nimmt mit der jeder neuen Doppelschicht zu

Aus den aufgenommenen Reflexionsspektren (Abb. 111) und den nach einem FresnelFormalismus simulierten Spektren können die Schichtdicken [Au/Ag-Substrat/ Biotinschicht/ Streptavidin/ $\{\text { PDI(Biotin })_{2}+$ Streptavidin $\left.\}_{5}\right]$ ermittelt werden. Mit jeder Schicht wurde eine Zunahme der Dicke der Oberflächenstruktur beobachtet. Gleichzeitig nahm die Materialmenge (Streptavidinmenge), die nach jeder Schicht von Perylendiimidbis(biotin) gebunden wurde, ab. Dies kann damit erklärt werden, dass sich das freie Biotin aus einigen der angebundenen PDI(Biotin) $)_{2}$-Moleküle an dem benachbarten Streptavidin bindet und damit eine Terminierung der einzelnen supramolekularen Ketten bewirkt, was zur Abnahme der Zahl der wachsenden Ketten führt. Diese unerwünschte Bindung von 361 zum benachbarten Streptavidin kann man mit der Flexibilität des PEO-Spacers erklären. Das freie und ungebundene Biotin im $\mathrm{PDI}(\text { Biotin) })_{2}$ neigt aufgrund der Flexibilität des Spacers dazu, sich an das benachbarte Streptavidin anzubinden. Der PEOSpacer wurde aber verwendet, um die Wasserlöslichkeit von PDI(Biotin) $)_{2}$ zu fördern, die für seine Anbindung an Streptavidin erforderlich ist. In Abbildung 112 ist eine optimierte Struktur von 3-61 dargestellt. 

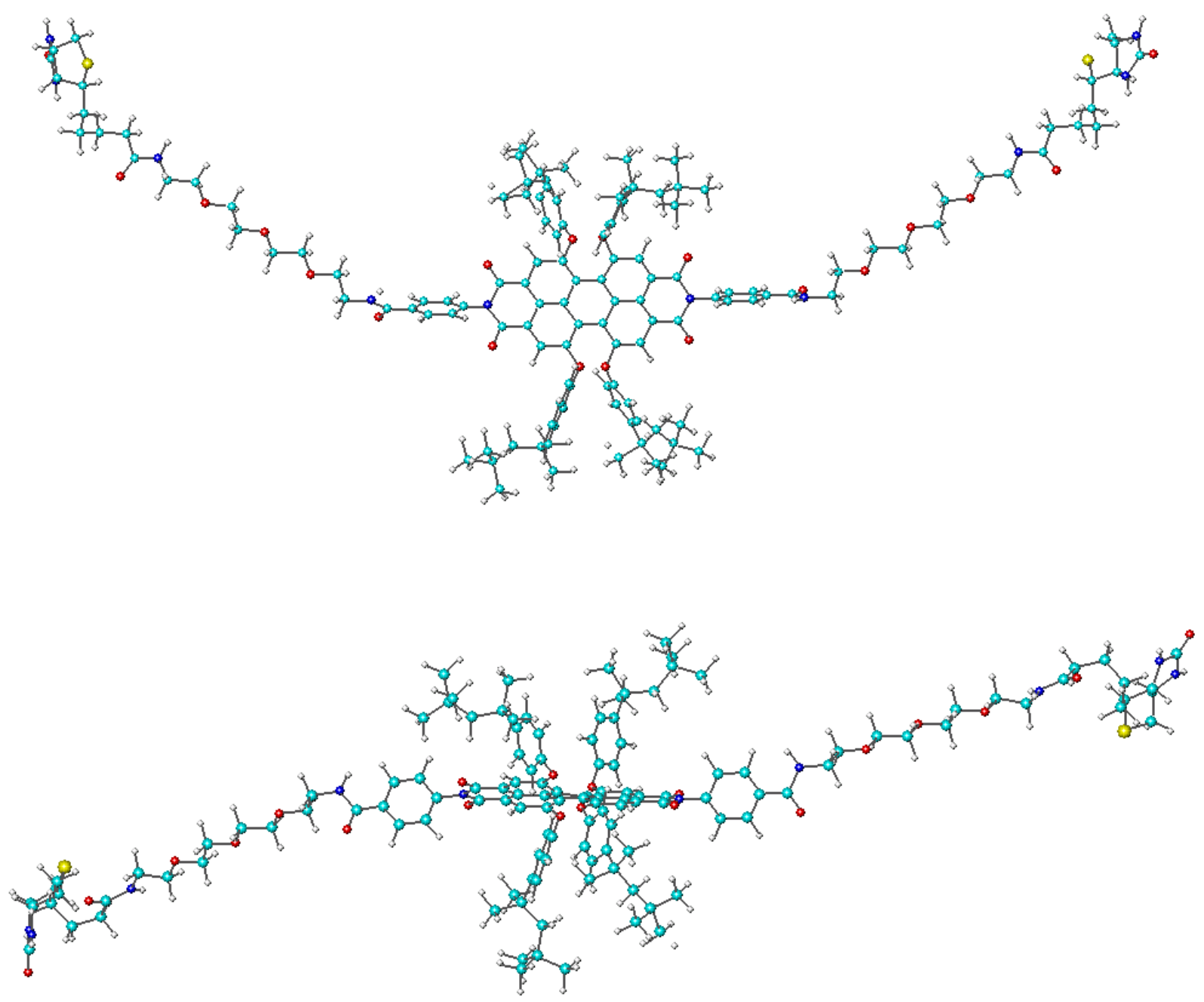

Abbildung 112: Optimierte Struktur von $\mathrm{PDI}(\text { Biotin) })_{2}$, Vorder- und Seitenansicht, die größte Distanz von einem Ende zum anderen Ende ist ca. $61 \AA$

Obwohl sich die immobilisierte Streptavidinmenge nach jeder zusätzlichen Schicht vermindert, wächst die Fluoreszenzintensität linear. Diese Verstärkung der Fluoreszenz ist sowohl auf die vermehrte Zahl der angebundenen PDI(Biotin) $)_{2}$-Moleküle als auch auf die wachsende Distanz zu der fluoreszenzlöschenden Goldoberfläche zurückzuführen. Eine schematische Darstellung von der erhaltenen Oberflächenarchitektur ist in Abbildung 113 gezeigt. 

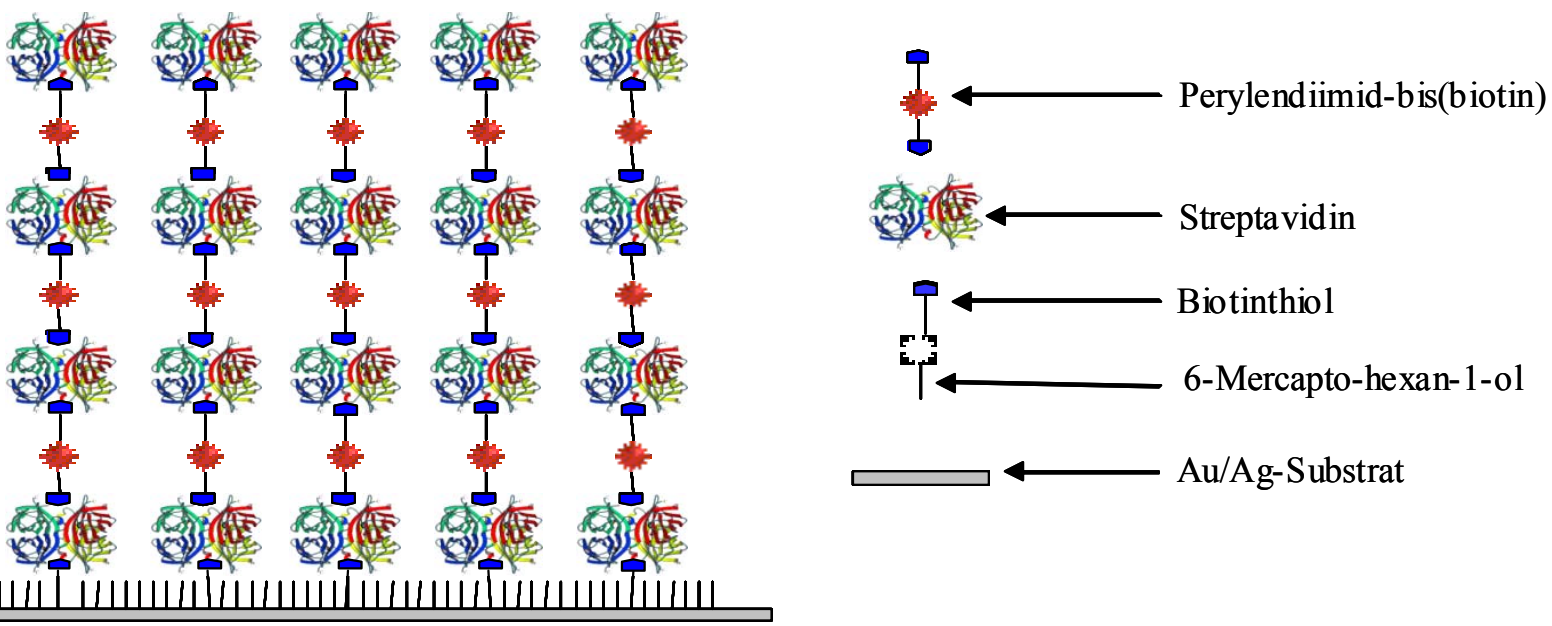

Abbildung 113: Schematische Darstellung von der gebildeten multilagigen Struktur

Die erhaltenen Schichtdicken sind in Tabelle 4 zusammengestellt. Die Gesamtgröße von der gebildeten Oberflächenstruktur beträgt $11 \mathrm{~nm}$.

\begin{tabular}{|c|c|c|}
\hline Schicht & Brechungsindex & Dicke (nm) \\
\hline SAM & 1.5 & 1.6 \\
\hline Streptavidin & 1.45 & 3.1 \\
\hline $\begin{array}{c}\text { 1. PDI(Biotin) })_{2}, 3-61 / \text { Streptavidin } \\
\text { Doppelschicht }\end{array}$ & 1.45 & 1.9 \\
\hline 2.Schicht & 1.45 & 1.4 \\
\hline 3.Schicht & 1.45 & 1.2 \\
\hline 4.Schicht & 1.45 & 1.0 \\
\hline 5.Schicht & 1.45 & 0.8 \\
\hline Summe & & 11.0 \\
\hline
\end{tabular}

Tabelle 4: Die gemessenen Werte für die Dicke der einzelnen Schichten und der erhaltenen multilagigen Oberflächenstruktur

Wie man in Tabelle 4 feststellen kann, nimmt die Dicke der Oberflächenstruktur mit der Zahl der immobilisierten Molekülschichten zu. Die parallele Zunahme in der Fluoreszenzintensität zeigt, dass die Solubilisierung von PDI(Biotin $)_{2}$ in Wasser mittels eines Detergenzes keinen negativen Einfluss auf die Bindungseigenschaften von Biotin, das in der Imidstruktur des Perylendiimids kovalent gebunden ist, verursachte. Der Übertragung dieses Konzepts (Solubilisierung und Immobilisierung) auf andere hydrophobe Farbstoffe oder auf mit Farbstoffen dekorierte Dendrimere, die mit zwei Biotinmolekülen kovalent gebunden sind, steht nichts entgegen, vorausgesetzt, sie lösen 
sich mittels eines Detergenzes im Wasser auf. Hierfür sind Dendrimere, die an ihrer Oberfläche Farbstoffmolekülen und zwei Biotinmoleküle tragen, besonderes vielversprechend im Hinblick auf eine sehr starke Fluoreszenzintensität, die durch die Bildung einer multilagigen Oberflächenstruktur herbeigeführt werden kann.

\subsection{Bibliographie}

[1] V. Balzani, A. Credi, F. M. Raymo, J. F. Stoddart Angew. Chem. Int. Ed. 2000, 112, 3484.

[2] L. R. MacGillivray, J. L. Atwood Angew. Chem. Int. Ed. 1999, 111, 1080.

[3] E. D. Mauro, C. P. Hollenberg Adv. Mater. 1993, 5, 384.

[4] C.M. Niemeyer Angew. Chem. Int. Ed. 1997, 109, 603.

[5] N. C. Seeman, H. Wang, X. Yang, F. Liu, Mao, W. Sun, L. Wenzler, Z. Shen, R. Sha, H. Yan, M. H. Wong, P. Sa-Ardyen, B. Liu, H. Qiu, X. Li, J. Qi, S. M. Du, Y. Zhang, J. E Mueller, T.-J. Fu, Y. Wang, J. Chen Nanotechnology 1998, 9, 257-273.

[6] N. C. Seeman Nanotechnology 1999, 17, 437-443.

[7] C. Seeman Synlett 2000, 11, 1536-1548.

[8] C. M. Niemeyer Angew. Chem. Int. Ed. 1997, 36, 585.

[9] R. I., Ma, N. R. Kallenbach, R. D. Sheardy, M. L. Petrillo, N. C. Seeman Nucleic Acids Res. 1986, 14, 9745.

[10] M. L. Petrillo, C. J. Newton, R. P. Cunningham, R.-I. Ma, N. R. Kallenbach, N. C. Seeman Biopolymers 1988, 27, 1337.

[11] Y. Wang, J. E. Mueller, B. Kemper, N.C. Seeman Biochemistry 1991, 30, 5667.

[12] J.-H. Chen, N. R. Kallenbach, N. C. Seeman J. Am. Chem. Soc. 1989, 111, 6402.

[13] J.-H. Chen, N. C. Seeman Nature 1991, 350, 631.

[14] Y. Zhang, N. C. Seeman J. Am. Chem. Soc. 1994, 116, 1661.

[15] C. Mao, W. Sun, Z. Shen, N. C. Seeman Nature 1999, 397, 144.

[16] E. Winfree; F. Liu, L. A. Wenzler, N. C. Seeman Nature 1998, 394, 539.

[17] F. Liu , R. Sha, N. C. Seeman J. Am. Chem. Soc. 1999, 121, 917. 
[18] C. Mao, W. Sun, N. C. Seeman Nature 1997, 386, 137.

[19] N. C. Seeman Biochemistry 2003, 42 (24), 7259-7269.

[20] C.A. Mirkin, R. L. Letsinger, R. C. Mucic, J. J. Storhoff Nature 1996, 382, 607.

[21] P. A. Alivisatos, K. P. Johnsson, X. Peng, T. E. Wilson, C. J. Loweth, M. P. Bruchez Jr., P. G. Schultz Nature 1996, 382, 609.

[22] D. E. Bergstrom, J. Shi Angew. Chem., Int. Ed. 1997, 36, 111.

[23] S. M. Waybright, C. P. Singleton, J. M. Tour, C.J. Murphy, U. H. F. Bunz Organaometallics 2000, 19, 368-370.

[24] S. M. Waybright, C. P. Singleton, K. Wachter, C.J. Murphy, U.H.F. Bunz J. Am. Chem. Soc. 2001, 123, 1828-1833.

[25] E. Braun, Y. Eichen, U. Sivan, G. Ben-Yoseph Nature 1998, 391, 775.

[26] H.-W. Fink, C. Schönenberger Nature, 1999, 398, 407.

[27] E. R. Holmlin, P. J. Dandliker, J. K. Barton Angew. Chem. Int. Ed. 1997, 109, 2830.

[28] S. A. Kelley, J. K. Barton Science, 1999, 283, 375.

[29] M. W. Grinstaff Angew. Chem. Int. Ed. 1999, 111, 3845.

[30] M. Bixon, B. Giese, S. Wessely, T. Langenbacher, M. E. Michel-Beyerle, J. Jortner Proc. Natl. Acad. Sci. U. S. A. 1999, 96, 11713.

[31] B. Giese Acc. Chem. Res. 2000, 33, 631.

[32] R. B. Merrifield J. Am. Chem. Soc. 1963, 85, 2149.

[33] R. L. Letsinger, W. B. Lunsford J. Am. Chem. Soc. 1976, 98, 3655-61.

[34] S. L. Beaucage, M. H. Caruthers Tetrahedron Lett. 1981, 22, 1859-62.

[35] United States Patent, Ser. No. 4,725,677, 1988, Feb. 16.

[36] N. D. Sinha, J. Biernat, J. McManus, H. Köster Tetrahedron Lett. 1983, 24, 5843.

[37] N. D. Sinha, J. Biernat, J. McManus, H. Köster Nucleic Acids Res. 1984, 12 (11), 4539.

[38] G. W. Daub, E. van Tamelen J. Am. Chem. Soc. 1977, 99, 3526-8.

[39] X. Gao, B. L. Gaffney, M. Senior, R. Riddle, R. A. Jones Nucleic Acids Res. 1985, 13 573-84.

[40] N. D. Sinha, V. Großbruchhaus, H. Köster Tetrahedron Lett. 1983, 24, 877-80.

[41] F. Cramer, H. Köster Angew. Chem. Int. Ed. 1968, 7 (6), 473-74. 
[42] Literatur für Polystyrol/divinylbenzol als Träger

[43] H. Köster, A. Stumpe, A. Wolter Tetrahedron Lett. 1983, 24, 747-50.

[44] B. S. Sproat, W. Bannwarth Tetrahedron Lett. 1983, 24, 5771-74.

[45] R. Welz, S. Müller Tetrahedron Lett. 2002, 43, 795-97.

[46] S. L. Beaucage, M. H. Caruthers Tetrahedron Lett. 1993, 49 (10), 1925-63.

[47] S. Cobbe, S. Connolly, D. Ryan, L. Nagle, R. Eritja, D. Fitzmaurice J. Phys. Chem. B 2003, 107, 470-77.

[48] C. M. Niemeyer, M. Adler, B. Pignataro, S. Lehnhert, S. Gao, L. F. Chi, H. Fuchs, D. Blohm Nucleic Acids Res. 1999, 27, 4553-4561.

[49] C. M. Niemeyer, M. Adler, S. Gao, L. Chi Angew. Chem. Int. Ed. 2000, 39, 30553059 .

[50] G. R. Gough, M. J. Brunden, P. T. Gilham Tetrahedron Lett. 1981, 22, 4177.

[51] M. J. Gait, Oligonucleotide Synthesis, a practical approach, IRL Press, Oxford University Press, New York, USA 1990.

[52] K. L. Agarwal, A. Yamazaki, P. J. Cashion, H. G. Khorana Angew. Chem. 1972, 84, 489.

[53] V. Kohli, H. Blöcker, H. Köster Tetrahedron Lett. 1980, 21, 2683-6.

[54] H. Schaller, G. Weimann, B. Lerch, H. G. Khorana J. Am. Chem. Soc. 1963, 85, $3821-7$.

[55] J. C. Schulhof, D. Molko, R. Teoule Nucleic Acids Res. 1987, 15, 397-416.

[56] J. Stawinski, T. Hozumi, S. A. Narang, C. P. Bahl, R. Wu Nucleic Acids Res. 1977, 4,353 .

[57] B. L. Gaffney, G. S. Ti, R. A. Jones J. Am. Chem. Soc. 1982, 104, 1316-19.

[58] L. C. McBrigde, M. H. Caruthers Tetrahedron Lett. 1980, 21, 3243-46.

[59] S. Becker Dissertation Johannes-Guttenberg Mainz 2000.

[60] Bild von Amersham Biosciences Europe, Freiburg, Deutschland.

[61] T. W. Greene, G. M. Wuts, Protective Groups in Organic Synthesis 3rd Ed. John Wiley \& Sons, Inc. New York.

[62] B. A. Connolly Nucleic Acids Res. 1987, 15, 3131.

[63] B. A. Connolly, P. Rider Nucleic Acids Res. 1985, 13, 4485. 
[64] R. Zuckerman, D. Corey, P. Shultz Nucleic Acids Res. 1987, 15, 5305.

[65] T. Kempe, W. I. Sundquist, F. Chow, S. L. Hu Nucleic Acids Res. 1985, 13 (1), 4557.

[66] G. B. Dreyer, P. B. Dervan Proc. Natl. Acad. Sci. USA 1985, 82, 968.

[67] R. I. Hogrefe, H. Mackie, M. L. Powell Amer. Biotechnologies News 1988 Ed. 6, 47.

[68] H. Vu, N. Joyce, M. Rieger, D. Walker, I. Goldknopt, T. S. Hill, K. Jayaraman, D. Mulvey Bioconjugate Chem. 1995, 6, 599.

[69] B. S. Sproat, B. S. Beijer, P. Rider, P. Neuner Nucleic Acids Res. 1987, 15, 4837.

[70] G. T. Hermanson Bioconjugate Techniques, Acedemic Press, London, 1996.

[71] M. Antopolsky, A. Azhayev Nucleosides, Nucleotides \& Nucleic Acids 2001, 20, 539.

[72] S. O. Doronina, A. P. Guzaev, M. Monoharan Nucleosides, Nucleotides \& Nucleic Acids 2001, 20, 1007.

[73] A. Avino, R. G. Garcia, F. Albericio, M. Mann, M. Wilm, G. Nebauer, R. Eritja, Bioorgan. Med. Chem. 1996, 4 (10), 1649-1658.

[74] C. R. Petrie, M. W. Reed, A. D. Adam, R. B. Meyer Bioconjugate Chem. 1992, 3 (1), 85-87.

[75] M. W. Reed, R. B. Jr. Meyer, C.R. Petrie, J. C. Tobone, U.S. Patent 5,419,966 (1995).

[76] K. J. Wu, T. A. Shaier and C. H. Becker Anal. Chem. 1994, 66, 1637-45.

[77] E. A. Stemmier Anal. Chem. 1994, 66, 1274-105.

[78] G. Narayanaswami and R. J. Levis J. Am. Chem. Soc. 1997, 119, 6888-90.

[79] D. Tietz, Nucleic Acid Electrophoresis, Springer Verlag, 1998.

[80] Wilson W. D. Nucleic Acids in Chemistry and Biology, IRL Press, Oxford, UK, 2. Auflage, 1996

[81] G. Colmenarejo, M. C. Gutiérrez-Alonso, M. Bárcena, J. M. Kelly, F. Montero, G. Orellana J. Biomol. Struct. Dyn. 1995, 12, 827.

[82] C. J. Burrows, J. G. Muller Chem. Rev. 1998, 98, 1109.

[83] B. Armitage Chem. Rev. 1998, 98, 1171. 
[84] J. B. Lepecq, C. Paoletti J. Mol. Biol. 1967, 27, 87.

[85] L. S. Lermann J. Mol. Biol. 1961, 3, 18.

[86] E. Tuite, B. Nordén J. Am. Chem. Soc. 1994, 116, 7548.

[87] D. S. Pilch, C. Yu, D. Makhey, E. J. LaVoie, A. R. Srinivasan, W. K. Olson, R. S. Sauers, K. J. Breslauer, N. E. Geacintov, L. F. Liu Biochemistry 1997, 36, 12542.

[88] Y. Kubota, Y. Fujisaki, Bull. Chem. Soc. Jpn. 1977, 50, 297.

[89] T. Deligeorgiev, N. Gadjev, I. Timtcheva, V. Maximova, H. E. Katerinopoulos, E. Foukaraki Dyes and Pigments 2000, 44, 131-136.

[90] I. Timtcheva, V. Maximova, T. Deligeorgiev, N. Gadjev, K. H. Drexhage, I Petkova J. Photochem. Photobio. B: Biology 2000, 58, 130-135.

[91] R. Rohs, H. Sklenar, R. Lavery, B. Röder J. Am. Chem. Soc. 2000, 122, 2860-2866.

[92] I. Timtcheva, V. Maximova, T. Deligeorgiev, N. Gadjev, R. Sabnis, I. Ivanov FEBS Letters 1997, 405, 141-144.

[93] J. Bunkenborg, N. Gadjev, T. Deligeorgiev, J. P. Jacobsen Bioconj. Chem. 2000, 11, 861-867.

[94] S. Raddatz, J. Mueller-Ibeler, J. Kluge, L. Wäß, G. Burdinski, J. R. Havens, T. J. Onofrey, D. Wang, M. Schweitzer Nucleic Acids Res. 2002, 30, 4793-4802.

[95] D. Magde, E. L. Elson, W. W. Webb Phys. Rev. Lett. 1972, 29, 705-708.

[96] R. Rigler, U. Mets, J. Widengren, P. Kask Eur. Bioph. J. 1993, 22, 169-175.

[97] O. Krichevsky and G. Bonnet, Rep. Prog. Phys. 2002, 65 (2), 251.

[98] J. Garcia del a Torre, M. C. Lopez Martinez, M. M. Tirado, Biopolymers 1984, 23, 611-615.

[99] H.-A. Klok, J. R. Hernandez, S. Becker, K. Müllen J. Polym. Science A 2001, 39, 1572 .

[100] T. Weil, Dissertation, Johannes Gutenberg Universität Mainz, 2002.

[101] J. Qu, C. Kohl, M. Pottek, K. Müllen Angew. Chem. Int. Ed. 2004, 43, 1528-1531.

[102] K. Kohl, Dissertation, Johannes Gutenberg Universität Mainz, 2003.

[103] J. Qu, Dissertation, Johannes Gutenberg Universität Mainz, 2004.

[104] B. Mullah, A. Andrus Tetrahedron Letters 1997, 38 (33), 5751-54.

[105] R. Vinayak Tetrahedron Letters 1999, 40, 7611-13. 
[106] W. T. Markiewicz, G. Gröger, R. Rösch, A. Zebrowska, M. Markiewicz, M. Klotz, M. Hinz, P. Godzina, H. Seliger Nucleic Acids Res. 1997, 25 (18), 3672-80.

[107] M. L. M. Anderson, Nucleic Acid Hybridization, 1999, 91-95, Bios Scientific Publishers limited, Oxford, UK.

[108] H. Quante, P. Schlichting, U. Rohr, Y. Geerts, K. Müllen Macromol. Chem. Phys. 1996, 197, 4029 .

[109] R. A Cardullo, S. Agrawal, C. Flores, P. C. Zamecnik, D. E. Wolf Proc. Natl. Acad. Sci. USA 1988, 85, 8790-94.

[110] S. P. Lee, D. Porter, J. G. Chirikjian, J. R. Knutson, M. K. Han Anal. Biochem. 1994, 220, 377-383.

[111] J. P. Knemeyer, N. Marme, M. Sauer Anal. Chem. 2000, 72, 3717-3724.

[112] A. O. Crockett, C. T. Wittwer Anal. Biochem. 2001, 290, 89-97.

[113] S. Kurata, T. Kanagawa, K. Yamada, M. Torimura, T. Yokomaku, Y. Kamagata, R. Kurane Nucleic Acids Res. 2001, 29, e34.

[114] I. Nazarenko, R. Pires, B. Lowe, M. Obaidy, A. Rashtchian Nucleic Acids Res. 2002, 30, 2089-2095.

[115] A. I. H. Murchie, R. M. Clegg, R. M. von Kitzing, D. R. Duckkett, S. Diekmann, D. M. J. Lilley Nature 1989, 341, 763-766.

[116] J. P. Cooper, P. J. Hagerman Biochemistry 1990, 29, 9261-9268.

[117] R. M. Clegg, A. I. H. Murchie, , A. Zechel, C. Carlberg, S. Diekmann, D. M. J. Lilley Biochemistry 1992, 31, 4846-4856.

[118] M. Sauer, K. H. Drexhage, U. Lieberwirth, R. Muller, S. Nord, C. Zander Chem. Phys. Lett. 1998, 284, 153-163.

[119] N. G. Walter, J. M. Burke RNA 1997, 3, 392-404.

[120] C. A. M. Seidel, A. Schultz, M. H. M. Sauer J. Phys. Chem. 1996, 100, 5541-5553.

[121] S. Steenken, V. Jovanovic J. Am. Chem. Soc. 1997, 119, 617-618.

[122] C. Zimmer, U. Wähnert Prog. Biophys. Mol. Biol. 1986, 47, 31-112.

[123] F. G. Loontiens, P. Regenfuss, A. Zechel, L. Dumortier, R. M. Clegg Biochemistry 1990, 29, 9029-9039.

[124] D. Xu, K. O. Evans, T. M. Nordlund Biochemistry 1994, 33, 9592-9599. 
[125] M. E. Hawkins, W. Pfeiderer, F. M. Balis, D. Porter, J. R. Knutson Anal. Biochem. 1997, 244, 86-95.

[126] T. M. Nordlund, S. Andersson, L. Nilsson, R. Rigler, A. Graslund, L. W. McLaughlin Biochemistry 1989, 28, 9095-9103.

[127] P. Lianos, S. Georghiou Photochem. Photobiol. 1979, 29, 13-21.

[128] V. Y. Shafirovich, S. H. Courtney, N. Ya, N. E. Geacintov J. Am. Chem. Soc. 1995, 117, 4920-4929.

[129] J. Widengren, J. Dapprich, R. Rigler Chem. Phys. 1997, 216, 417-426.

[130] H. -A. Klok, J. Rodriguez Hernandez, S. Becker, K. Müllen J. Polym. Sci. 2001, 39, 1572.

[131] J. Rodriguez Hernandez, Dissertation, Johannes Gutenberg-Universität Mainz 2003.

[132] T. Horn, M. S. Urdea Nucleic Acids Res. 1989, 17, 6959.

[133] T. Horn, B. D. Warner, J. A. Running, K. Downing, J. Clyne, M. S. Urdea Nucleosides \& Nucleotides 1989, 8, 875.

[134] R. Horn, C. -A. Chang, M. S. Urdea Nucleic Acids Res. 1997, 25, 4842.

[135] M. S. Shchepinov, I. A. Udalova, A. J. Bridgman, E. M. Southern, Nucleic Acids Res.1997, 25, 4447.

[136] M. Scheffler, A. Dorenbeck, S. Jordan, M. Wüstefeld, G. von Kiedrowski, Angew. Chem., 1999, 111, 3513.

[137] D. Philp, J. F. Stoddart, Angew. Chem. Int. Ed. 1996, 35, 17, 1155-1196.

[138] J.-M. Lehn, supramolecular chemistry: Concepts and Perspectives VCH, Weinheim, Germany, 1995.

[139] C. M. Niemeyer, M. Adler, B. Pignataro, S. Lehnhert, S. Gao, L. F. Chi, H. Fuchs, D. Blohm, Nucleic Acids Res. 1999, 27, 4553-4561.

[140] C. M. Niemeyer, Chem.Eur. J. 2001, 7, 3188-3195.

[141] C. M. Niemeyer, W. Bürger, J. Peplies, Angew. Chem. Int. Ed. 1998, 37, 2265-2268.

[142] C.. M. Niemeyer, M. Adler, S. Gao, L. Chi, Angew. Chem. Int. Ed. 2000, 39, 30553059. 
[143] C. M. Niemeyer, W. Bürger, R. M. J. Hoedemakers Bioconjugate Chem. 1998, 9, 168-175.

[144] S. Cobbe, S. Connolly, D. Ryan, L. Nagle, R. Eritja, D. Fitzmaurice J. Phys. Chem. B 2003, 107, 470-477.

[145] T. Weil, Dissertation, Johannes Gutenberg-Universität Mainz 2002.

[146] T. Neumann, M. L. Johansson, D. Kambhampati, W. Knoll, Adv. Funct. Mater. 2002, 12 (9), 575-586.

[147] R. L. Letsinger, T. Wu, J. Am. Chem. Soc. 1994, 116, 811-812.

[148] R. L. Letsinger, T. Wu, J. Am. Chem. Soc. 1995, 117, 7323-7328.

[149] F. D. Lewis, T. Wu, Y. Zhang, R. L. Letsinger, S. R. Greenfield, M. R. Wasielewski, Science 1997, 227, 673-676.

[150] F. D. Lewis, R. L. Letsinger, J. Biol. Inorg. Chem. 1998, 3, 215-221.

[151] F. D. Lewis, T. Wu, E. L. Burch, D. M. Bassani, J.-S. Yang, S. Schneider, W. Jäger, R. L. Letsinger, J. Am. Chem. Soc. 1995, 117, 8785-8792.

[152] F. D. Lewis, Y. Zhang, X. Liu, N. Xu, R. L. Letsinger J. Phys. Chem. B 1999, 103, $2570-2578$.

[153] C. Seidel, K. Rittinger, J. Cortes, R. S. Goody, M. Koellner, J. Wolfrum, K. O. Gruelich, Proc. SPIE-Int. Soc. Opt. Eng. 1991, 1432, 105-116.

[154] K. Tang, S. L. Allman, C. H. Chen, Rap. Comm. Mass Spec. 1993, 7, 943-948.

[155] W. Tang, J. Krause, L. Zhu, L. M. Smith, Int. J. Mass Spec. Ion Proc. 1997, 169/170, 301-311.

[156] J. Olejnik, H.-C. Lüdermann, E. Krzymanska- Olejnik, S. Berkenkamp, F. Hillenkamp, K. J. Rothschild, Nucl. Acids Res. 1999, 27 (23), 4626-3631.

[157] L. H. Eckardt, K. Naumann, W. M. Pankau, M. Rein, M. Schweitzer, N. Windhab, G. von Kiedrowski, Nature, 2002, 420, 286. 
Kapitel 3: Synthese und Selbstorganisation von Perylen-Oligonucleotid-Konjugaten 


\section{Wasserlösliche Rylenfarbstoffe für die Anwendung in biologischen Systemen}

\subsection{Einleitung}

Das Interesse an wasserlöslichen Fluoreszenzfarbstoffen in biologischen Untersuchungen nahm in den letzten Jahren stark $\mathrm{zu}^{1-3}$. Die hohe Empfindlichkeit, die leichte Ausführbarkeit und die Selektivität der Fluoreszenzverfahren machten sie für in vitro- und in vivo-Untersuchungen in biologischen Systemen besonderes reizvoll ${ }^{4}$. Solche Verfahren bieten eine geeignete Methode zur Lokalisierung und Verfolgung von individuellen Biomolekülen in Zellen $a^{5-9}$. So kann man Informationen nicht nur über den Verbleib von markierten Biomakromolekülen im $\mu$ m-Maßstab, sondern auch über die molekulare Umgebung im nm-Bereich gewinnen. Bei analytischen Nachweisverfahren in biologischen Systemen werden radioaktive Markierungen eingesetzt, wenn dabei hohe Empfindlichkeiten benötigt werden. Eine niedrige Empfindlichkeitsgrenze kann auch mit der optischen Fluoreszenz erreicht werden. Während beim ersten Verfahren die radioaktiv markierten Moleküle nur einmal eingesetzt werden können, da die Moleküle nur einmal zerfallen können, kann man mit photostabilen Fluoreszenzfarbstoffen sehr oft Anregungs- und Fluoreszenzprozesse durchführen. Ein weiterer Vorteil ist die gefahrlose Handhabung der mit Fluoreszenzfarbstoffen markierten Moleküle im Gegensatz zu den radioaktiv markierten Molekülen. Darüber hinaus verursachen sie eine geringere Störung für empfindliche Systeme, da bei den Untersuchungen keine Strahlen freigesetzt werden, die ionisierend auf die zu untersuchenden Systeme wirken könnten.

Rylenfarbstoffe sind bekannt für ihre hohe Fluoreszenzquantenausbeute, die sie neben ihrer chemischen und thermischen Beständigkeit $\mathrm{zu}$ einem der interessanten funktionellen Farbstoffklassen machte ${ }^{10-16}$. Da im Kapitel 1 die Struktur und Eigenschaften der Rylenfarbstoffe erläutert wurden, wird in diesem Kapitel nicht mehr 
darauf eingegangen. Aufgrund ihrer sehr geringen Wasserlöslichkeit fanden Perylenfarbstoffe bisher wenige Anwendungen in biologischen Systemen. Während man bei Perylendiimiden eine Fluoreszenzquantenausbeute von bis $100 \%$ in organischen Lösungsmitteln erzielen kann, lösen sich Perylendimide nicht im Wasser. Perylendiimidfarbstoffe emittieren oberhalb $610 \mathrm{~nm}$. In diesem Wellenlängenbereich kann die Signalstörung, die durch Autofluoreszenz von Zellen, Geweben und biologischen Flüssigkeiten entstehen, vernachlässigt werden, was neben den bereits erwähnten optischen Eigenschaften von Perylenfarbstoffen eine Anwendung in biologischen Systemen begünstigt. Diese Anwendung setzt aber voraus, dass man sie unter Erhalt ihrer Fluoreszenzeigenschaften in wässrige Lösung überführen kann.

Die Einführung von wasserlöslichen Substituenten in den Grundkörper des Perylenmoleküls ist Ziel vieler Forschungsarbeiten. Mehrere Versuche zur Synthese von wasserlöslichen Perylenfarbstoffen wurden in der Literatur beschrieben. Beispielsweise wurde das Perylendiimid mit vier Carboxygruppen funktionalisiert. Der Chromophor konnte dadurch wasserlöslich gemacht werden, wies aber keine Fluoreszenz in alkalischer Lösung auf ${ }^{17}$. Weiterhin wurde ein Perylendiimid, wie bereits in Kapitel 3.9 erläutert wurde, mit vier Poly(L-lysin)-ketten in der bay-Region (4-1) erfolgreich synthetisiert $^{18}$. Allerdings war die Fluoreszenzquantenausbeute enttäuschend (unter $3 \%$ ).

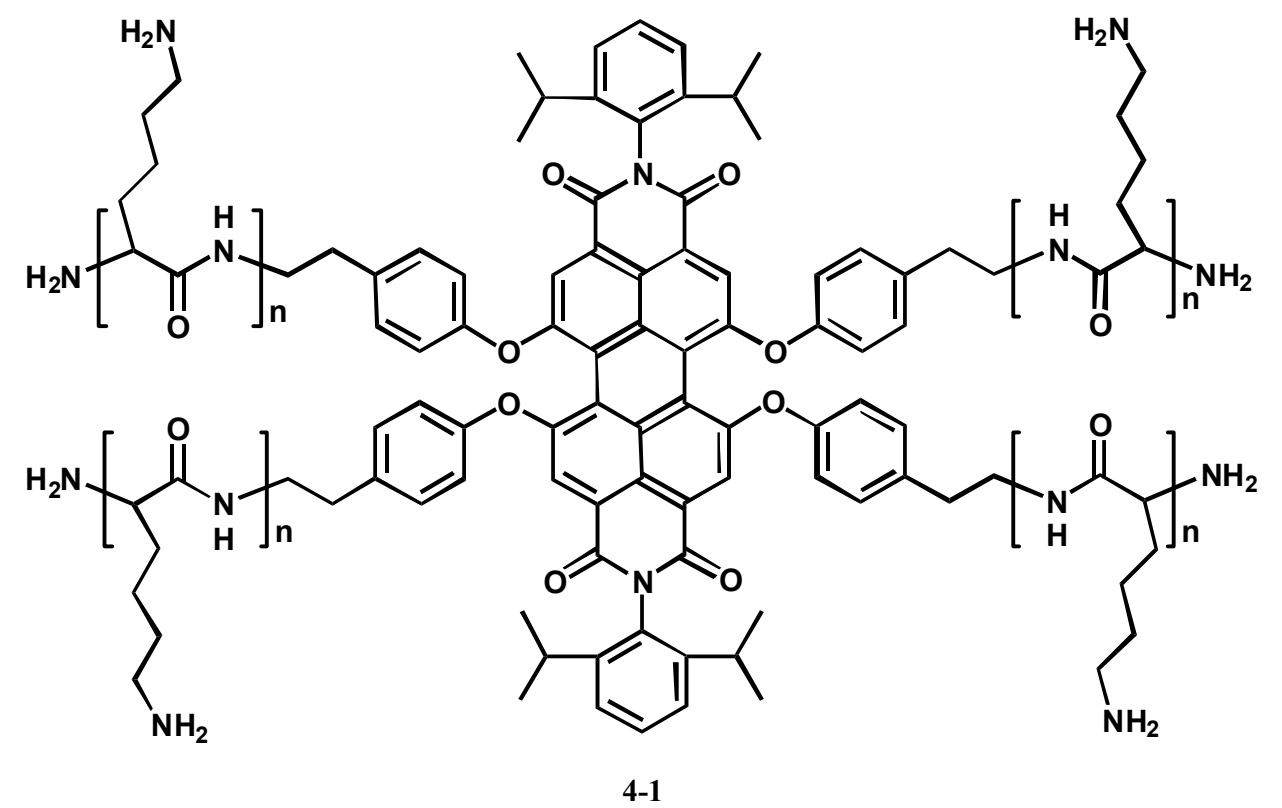

Abbildung 114: Perylendiimidkern mit vier Polylysinketten in der bay-Region 
Durch die Anknüpfung von hydrophilen Polymerketten (z. B. Polyethylenglykolketten) in die Position 9 des Perylenmonoimids (PMI) konnte ein wasserlöslicher Chromophor (4-2) hergestellt werden ${ }^{19}$.

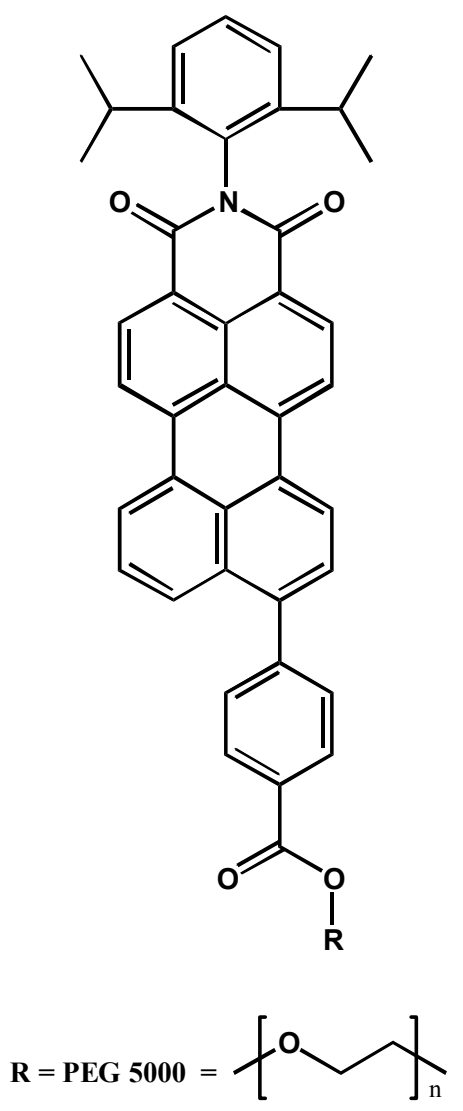

4-2

Abbildung 115: Perylenmonoimidchromophor mit einer Polyethylenglykolkette

Die Fluoreszenzquantenausbeute von 4-2 beträgt $15 \%{ }^{19}$. Vergleicht man die Fluoreszenzintensität von Perylenfarbstoffen in organischen Lösungsmitteln mit 4-1 oder 4-2 in wässrigen Lösungen, kann man eine starke Fluoreszenzlöschung feststellen. Diese verminderte Fluoreszenzquantenausbeute ist wahrscheinlich auf die Neigung des hydrophoben Perylenchromophors, in wässrigen Lösungen Aggregate auszubilden ${ }^{19}$, zurückzuführen. Polyethylenglykol ist ein wasserlösliches Polymer, das biologisch abbaubar und biokompatibel ist. Ein Fluoreszenzfarbstoff mit einer solchen Polymerkette in seiner Struktur könnte deshalb in biologischen Systemen eine Anwendung finden.

Bei den beiden wasserlöslichen Chromophoren 4-1 und 4-2 fehlt eine funktionelle Gruppe, die die Anbindung von biologisch aktiven Molekülen ermöglichen kann, was für 
eine selektive Detektion des Biomoleküls (Zielmolekül) erforderlich ist. Aus diesem Grund wären Fluoreszenzfarbstoffe, die neben Erhaltung der Fluoreszenzeigenschaften in wässrigen Lösungen eine zusätzliche funktionelle Gruppe besitzen, wünschenswert. Der Synthese eines solchen Perylenchromophors stand die Desymmetrisierung des Perylenchromophores mit zwei unterschiedlichen Gruppen entgegen. In diesem Kapitel soll versucht werden, wasserlösliche Rylenfarbstoffe zu synthetisieren, die über $620 \mathrm{~nm}$ emittieren und eine zusätzliche funktionelle Gruppe enthalten.

Perylenmonoimid mit einer Polyethylenglykolkette wurde erfolgreich synthetisiert und zur Anfärbung von Zellen in biologischen Systemen verwendet. In diesem Abschnitt sollen Perylendiimide mit Polyethylenglykol synthetisiert werden. Hierfür ist es wichtig, eine hohe Fluoreszenzquantenausbeute zu erhalten und eine zusätzliche chemische Gruppe in die Imidstruktur des Perylenchromophores einzuführen.

Ausgehend von 1,6,7,12-Tetrachlorperylen-3,4:9,10-tetracarbonsäuredianhydrid (3-18) wurde ein Gemisch aus den kommerziell verfügbaren 4-Amin-tert-butylbenzolsäureester (4-3) und 4-Brom-Anilin (4-4) in Propionsäure zur Reaktion gebracht. Nach einer Reaktionszeit von 20 Stunden bei $160{ }^{\circ} \mathrm{C}$ wurde das Reaktionsgemisch auf Raumtemperatur abgekühlt und mit Wasser gemischt. Eine chromatographische Aufreinigung war aufgrund der schlechten Löslichkeit des statistischen Produkts in organischen Lösungsmitteln nicht möglich. Im nächsten Schritt wurden Phenoxysubstituenten eingeführt, die die Löslichkeit deutlich verbessern und eine chromatographische Aufreinigung ermöglichen sollen. So wurde 4-5 in NMP 10 Minuten bei $80{ }^{\circ} \mathrm{C}$ gelöst. Nach der Zugabe von tert-Octylphenol 4-6 und Kaliumcarbonat wurde die Reaktionslösung 12 Stunden bei $90{ }^{\circ} \mathrm{C}$ gerührt. Die DC- Kontrolle zeigte, dass im Produkt fünf Verbindungen enthalten sind. In einem Teil von 4-7 wurde die tertButylschutzgruppe durch die Propionsäure im ersten Schritt abgespalten wurde, was die Aufreinigung erschweren sollte. Eine säulechromatographische Aufreinigung wurde erst nach der vollständigen Abspaltung der tert-Butylschutzgruppe durchgeführt. 


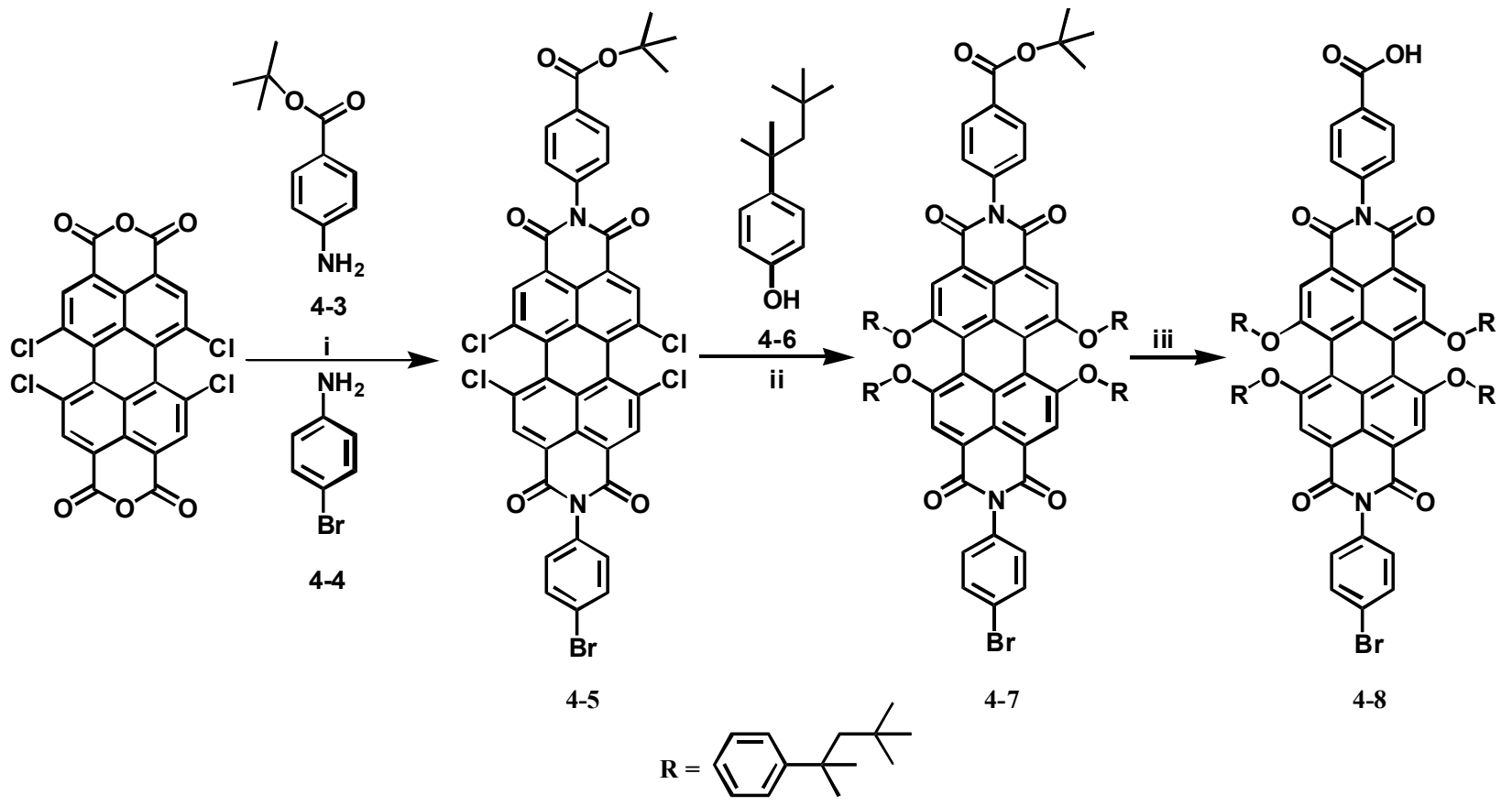

Abbildung 116: Synthese vom Perylendiimid mit zwei unterschiedlichen Funktionen in der Imidstruktur (eine Brom- und Carboxyfunktion) i) Propionsäure, $20 \mathrm{~h}$ bei $160{ }^{\circ} \mathrm{C}$ ii) $\mathrm{K}_{2} \mathrm{CO}_{3}, \mathrm{NMP}$, $12 \mathrm{~h}$ bei $90{ }^{\circ} \mathrm{C}$ iii) Trifluoressigsäure, Dichlormethan, $2 \mathrm{~h}$ bei Raumtemperatur, Ausbeute von 4-8 beträgt $32 \%$

Die Abspaltung der tert-Butylschutzgruppe wurde in einem Gemisch aus Trifluoressigsäure und Dichlormethan bei Raumtemperatur erreicht (für nähere Angaben siehe Experimentelle Teil). Die Ausbeute von 4-8 beträgt $32 \%$. Zur Charakterisierung von 4-8 wurden Elementaranalyse, Maldi-Tof, ${ }^{1} \mathrm{H}-$ und ${ }^{13} \mathrm{C}-\mathrm{NMR}-$ Spektroskopie verwendet. In Abbildung 117 ist das Maldi-Tof-Spektrum von 4-8 dargestellt. 


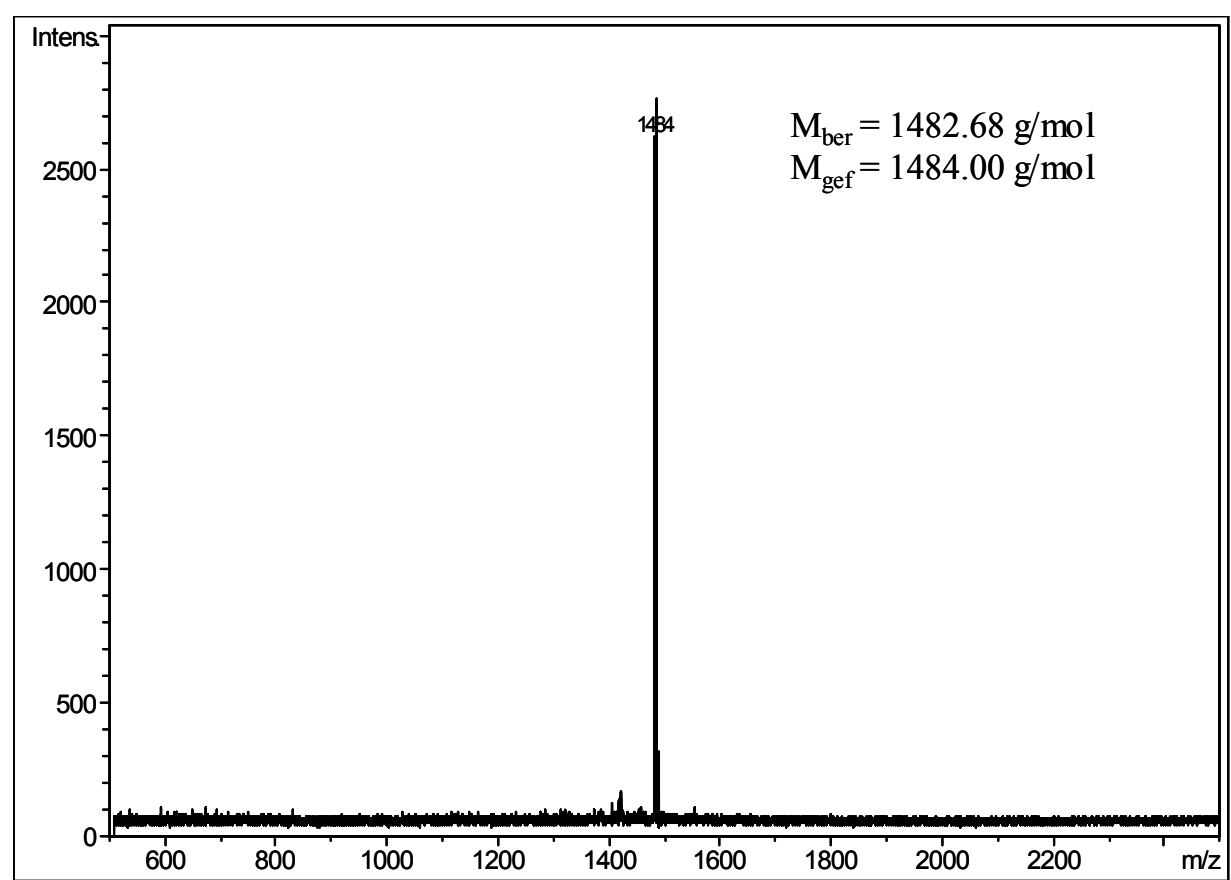

Abbildung 117: Maldi-Tof-spektrum von 4-8 (Matrix: Dithranol)

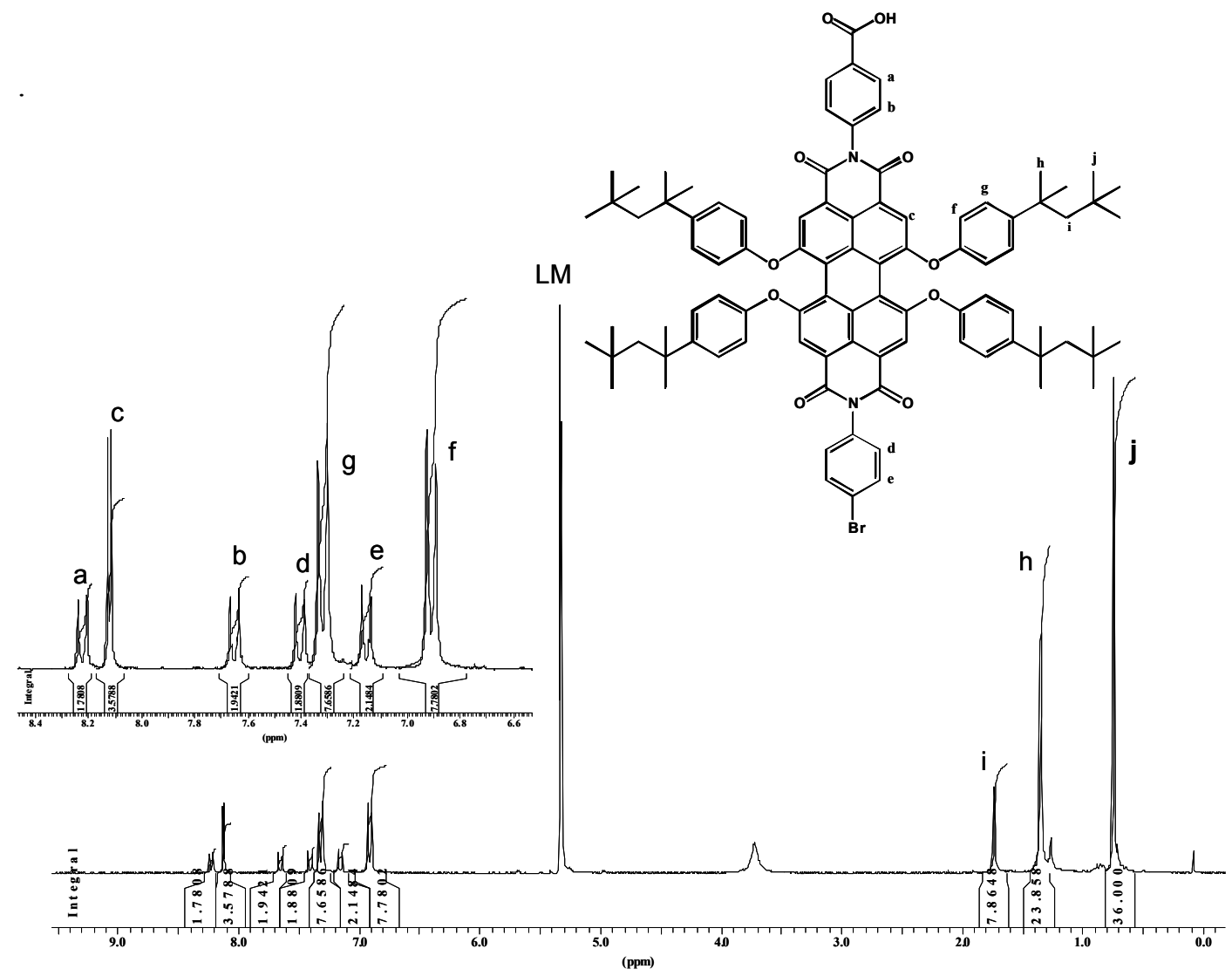

Abbildung 118: ${ }^{1} \mathrm{H}-\mathrm{NMR}-\mathrm{Spektrum}$ von $4-8\left(250 \mathrm{MHz}, \mathrm{CD}_{2} \mathrm{Cl}_{2}, 25{ }^{\circ} \mathrm{C}\right)$

Im ${ }^{1}$ H-NMR-Spektrum von 4-8 (Abb. 118) stimmen die Lage und die Intensität der Signale mit der angenommenen Struktur überein. Im aromatischen Bereich erkennt man 
vier Dubletts. Die Protonen a und b absorbieren bei $\delta=8.24$ ppm bzw. $\delta=7.66$ ppm, und ihre Signale sind damit im Vergleich zu denen der Protonen d und e tieffeldverschoben.

Um die Wasserlöslichkeit einzuführen, wurde über die Carboxygruppe des Perylendiimids 4-8 eine Polyethylenkette angekoppelt. Hierfür wurde 4-8 mit einem kommerziell erhältlichen Polyethylenglykol (PEG-NH 2$)$, das eine Aminfunktion trägt und ein mittleres Molekulargewicht vom $5253 \mathrm{~g} / \mathrm{mol}$ besitzt, unter Verwendung von EDC und DMAP in DMF umgesetzt. Nach einer Reaktionsdauer von fünf Tagen wurde die Reaktionslösung mit Wasser gemischt, das nicht reagierte Perylendiimid 4-8 fällte im Wasser aus und konnte damit entfernt werden. Das Produkt 4-9 wurde getrocknet und durch Dialyse in DMF aufgereinigt. Man erhielt das Produkt in ca. 41 \%iger Ausbeute. Den Strukturbeweis von 4-9 lieferten die ${ }^{1} \mathrm{H}$-, ${ }^{13} \mathrm{C}$ - und Maldi-Tof-Spektroskopie. In Abbildung 120 ist das Maldi-Tof-Spektrum von 4-9 gezeigt.

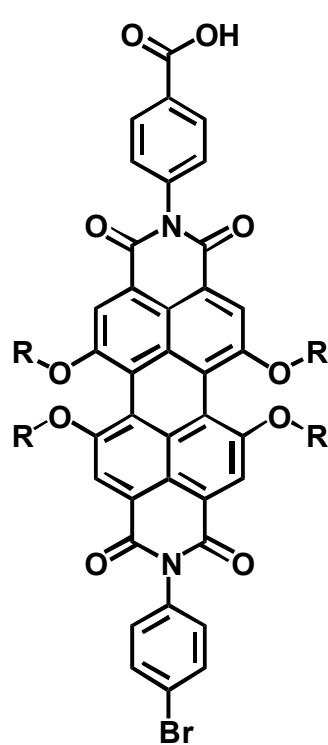

4-8

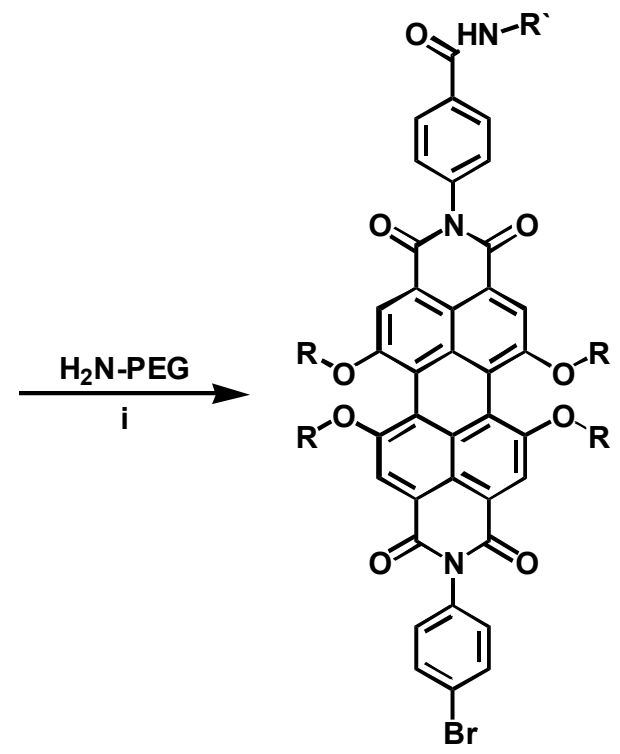

4-9

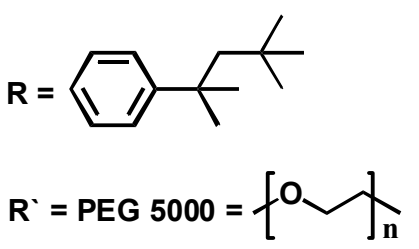

Abbildung 119: Synthese von Perylendiimid mit einer Polyethylenglykolkette i) EDC, DMAP, DMF, 5 Tage bei Raumtemperatur, $41 \%$ 


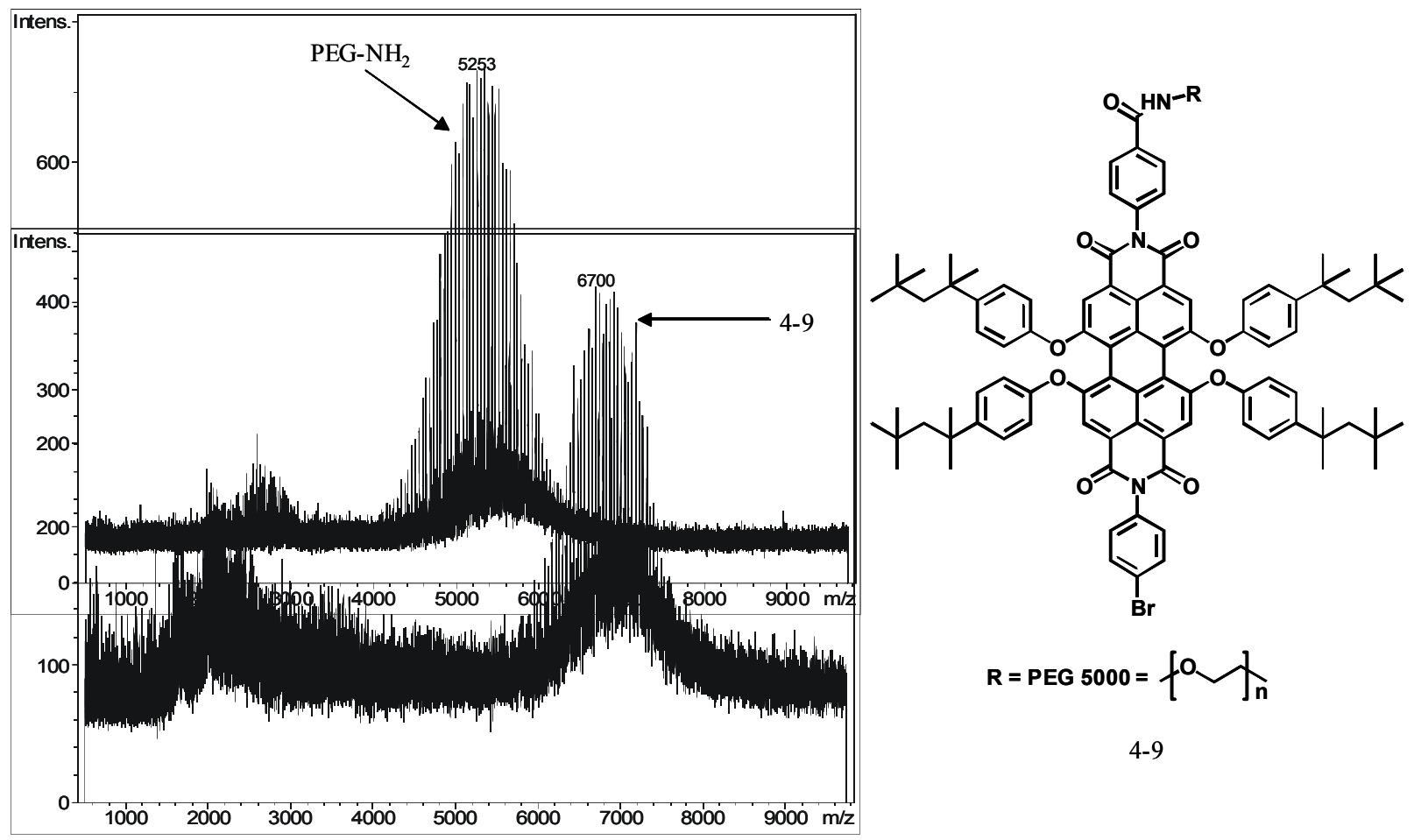

Abbildung 120: Maldi-Tof-Spektrum von 4-9 im Vergleich zum Spektrum von PEG-NH${ }_{2},\left(\mathrm{M}_{n}\right.$ berechnet für 4-9=6702 g/mol, $\mathrm{M}_{\mathrm{n}}$ gefunden $=6700 \mathrm{~g} / \mathrm{mol}$ )

Wie man im Maldi-Tof-Spektrum von 4-9 feststellen kann, entspricht die Differenz zwischen PEG-NH$H_{2}$ und 4-9 genau dem Molekulargewicht vom 4-8.

Durch die Synthese eines Perylendiimids 4-9 mit einer Polyetgylenglykolkette und einer Bromfunktion wurde ein wasserlösliches Perylendiimid erhalten, das an ein Biomolekül über die Bromfunktion geknüpft werden kann. Eine zweite Variante zur Verknüpfung von Biomolekülen mit wasserlöslichen Perylendiimiden ist die Synthese eines Perylendiimids mit einem Polyethylenglykolkette und einer Carboxyfunktionm, da viele Biomoleküle eine freie Aminfunktion besitzen. Zur Herstellung einer solchen Verbindung könnte das im Kapitel 3.3 dargestellte Perylendiimid 3-23 mit zwei Carboxyfunktionen in der Imidstruktur eingesetzt werden. Hierfür wurde 3-23 mit PEG-NH${ }_{2}$ unter Verwendung von EDC und DMAP in DMF umgesetzt. Das Reaktionsgemisch wurde 5 Tage bei Raumtemperatur gerührt. Die Aufarbeitung und Aufreinigung des Reaktionsprodukts 
wurde analog zur 4-9 durchgeführt. Zur Charakterisierung von $4-10$ wurden ${ }^{1} \mathrm{H}-,{ }^{13} \mathrm{C}$ NMR- und Maldi-Tof-Spektroskopie verwendet.

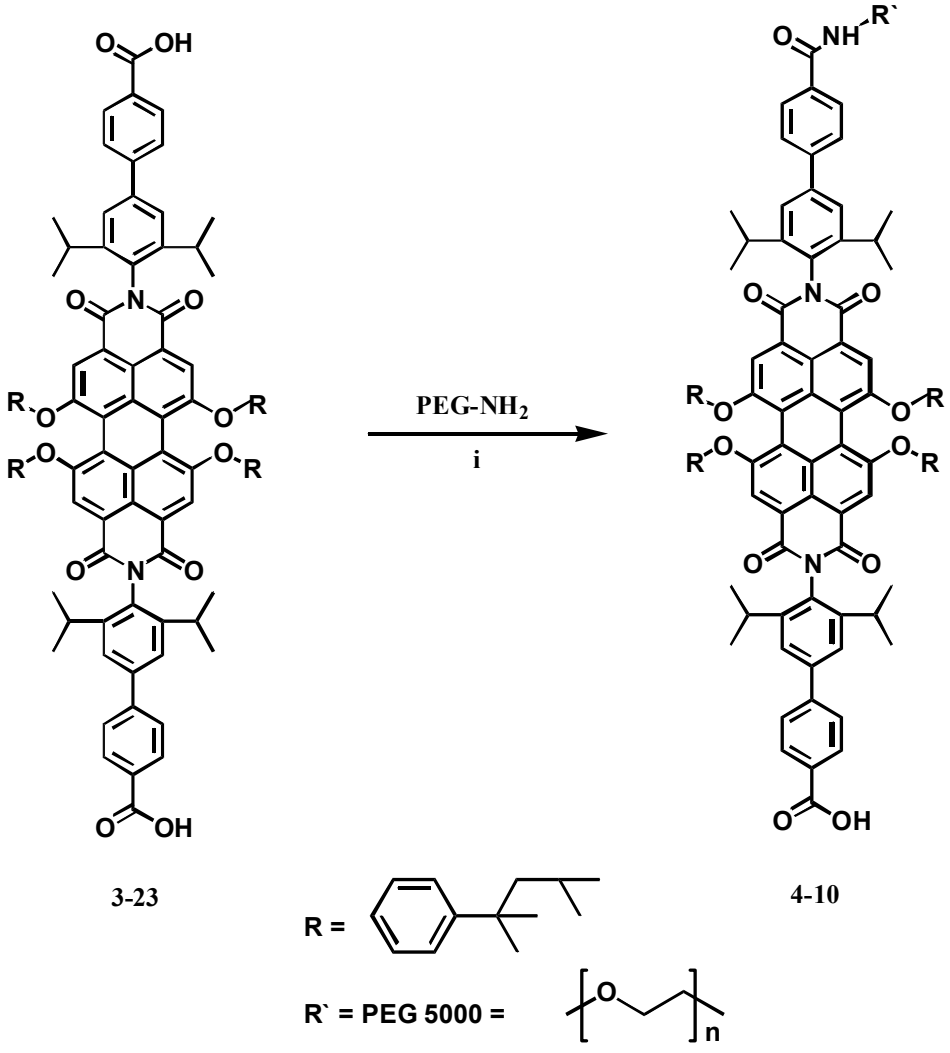

Abbildung 121: Darstellung eines Perylendiimidchromophors, der eine Polyethylenglykolkette und eine Carboxyfunktion trägt i) EDC, DMAP, DMF, 5 Tage, RT, $110 \mathrm{mg}$

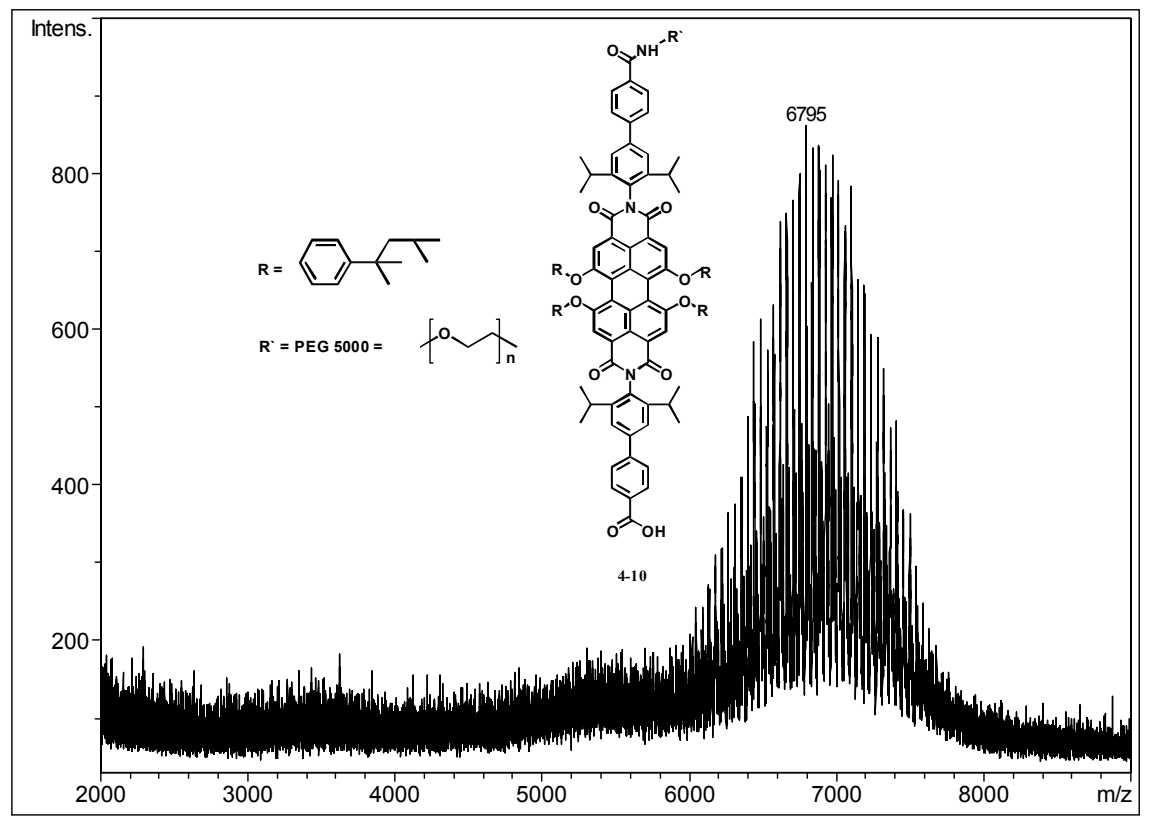

Abbildung 122: Maldi-Tof-Spektrum von 4-10 
Das Maldi-Tof-Spektrum von 4-10 ist in Abbildung 122 dargestellt. Die erhaltene Molekulargewichtsverteilung steht im Einklang mit dem berechneten Molekulargewicht für 4-9.

Durch die Synthese von 4-9 und 4-10 wurden wasserlösliche Fluoreszenzfarbstoffe erhalten, die zusätzliche funktionelle Gruppen (Brom- bzw. Carboxyfunktion) in der Imidstruktur besitzen. 4-9 und 4-10 emittieren oberhalb $610 \mathrm{~nm}$. Farbstoffe, die im nahen Infrarotbereich emittieren, könnten auch für die Anfärbung von Zellen und die Untersuchung von biologischen Systemen geeignet sein, da in diesem Bereich die Autofluoreszenz der Zellen vernachlässigt werden kann. Es ist deshalb wünschenswert, einen wasserlöslichen Farbstoff, der oberhalb 660 nm emittieren kann, herzustellen. Das höhere Homologe von Perylendiimid, das Terrylen, erfüllt diese Voraussetzungen. Die Synthese des Terrylenderivats BTI, das eine Bromfunktion trägt, wurde schon in der Literatur beschrieben ${ }^{20-21}$. Die Umsetzung von BTI-Br mit der käuflichen 4Methoxycarbonyl-phenylboronsäure über die palladiumkatalysierte Suzuki-Kopplung führte zur Einführung einer methylgeschützten Carboxyfunktion, die dann im Anschluss unter basischen Bedingungen $(2 \mathrm{M} \mathrm{KOH})$ in THF bei $80{ }^{\circ} \mathrm{C}$ abgespalten werden konnte. Um die Wasserlöslichkeit zu induzieren, wurde 4-13 mit Methoxy-poly(ethylenoxid)Amin unter Verwendung von EDC und DMAP in DMF zur Reaktion gebracht. Nach einer Reaktionszeit von 5 Tage bei Raumtemperatur wurde das Reaktionsgemisch mit Wasser gemischt, um den nicht umgesetzten Farbstoff durch Filtration zu entfernen, da er im Gegenteil zum Produkt 4-14 nicht wasserlöslich ist. In Abbildung 124 ist das MaldiTof-Spektrum von 4-14 gezeigt. Auch hier entspricht die Differenz zwischen Molekulargewichtsverteilung von 4-14 und PEG- $\mathrm{NH}_{2}$ genau dem Moleukargewicht von 3-13 (1124.32 g/mol). 


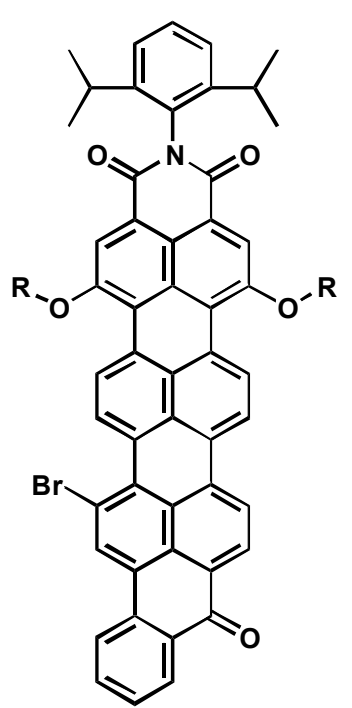

4-11

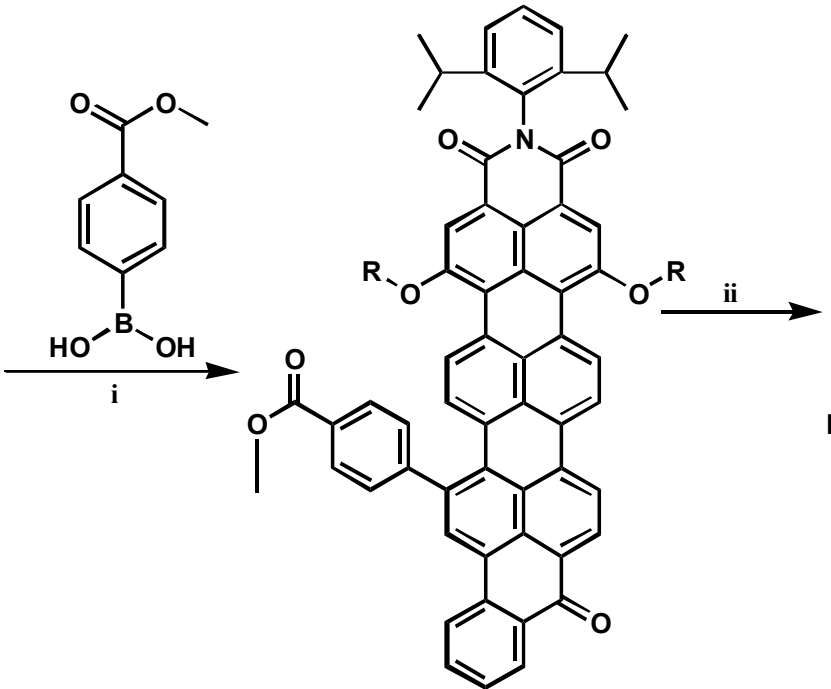

4-12

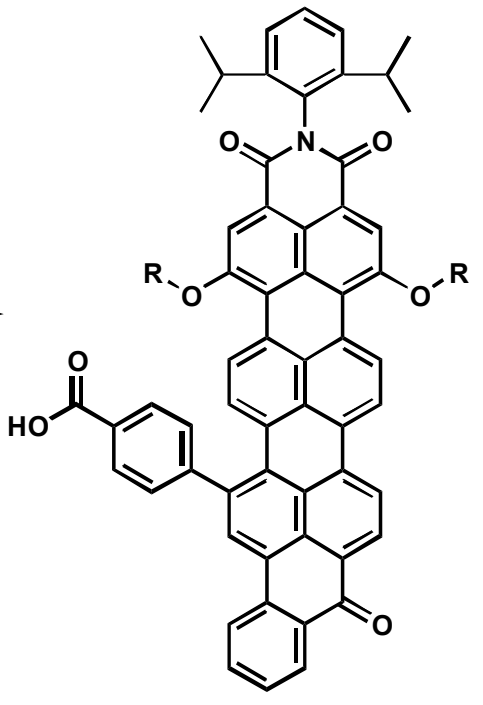

4-13

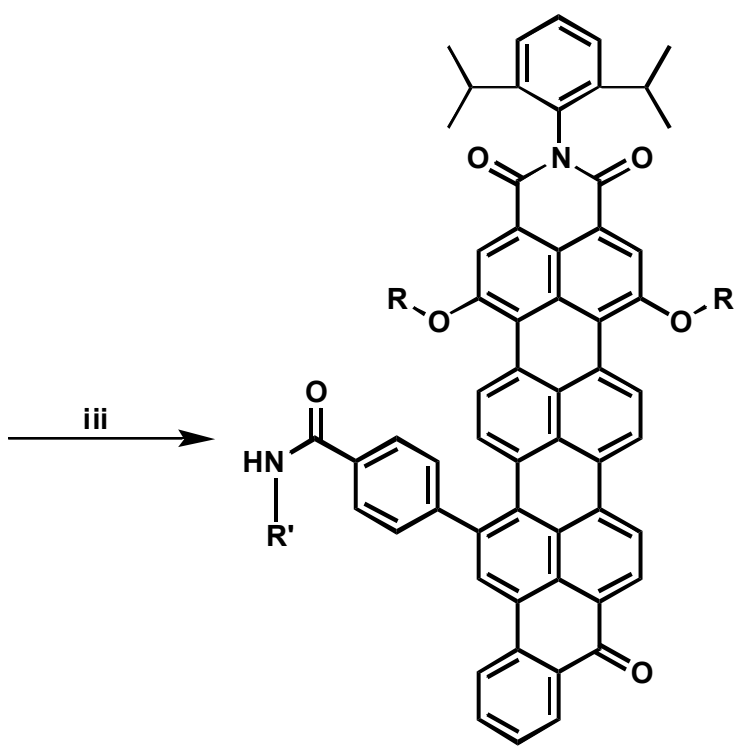

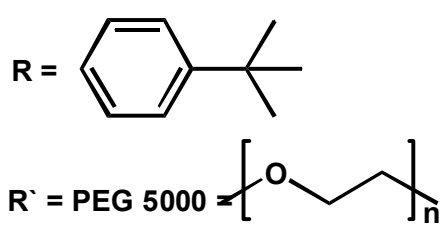

Abbildung 123: Synthese von BTI-PEG 4-14 i) $2 \mathrm{M} \mathrm{K}_{2} \mathrm{CO}_{3}, \mathrm{Pd}\left(\mathrm{PPh}_{3}\right)_{4}$, Methanol, Toluol, $15 \mathrm{~h}$ bei $75{ }^{\circ} \mathrm{C}, 38 \%$ ii) $\mathrm{KOH}$, THF, 24 h bei $80{ }^{\circ} \mathrm{C}, 61 \%$ iii) PEG-NH${ }_{2}$, EDC, DMAP, DMF, 5 Tage bei Raumtemperatur, $38 \mathrm{mg}$ 


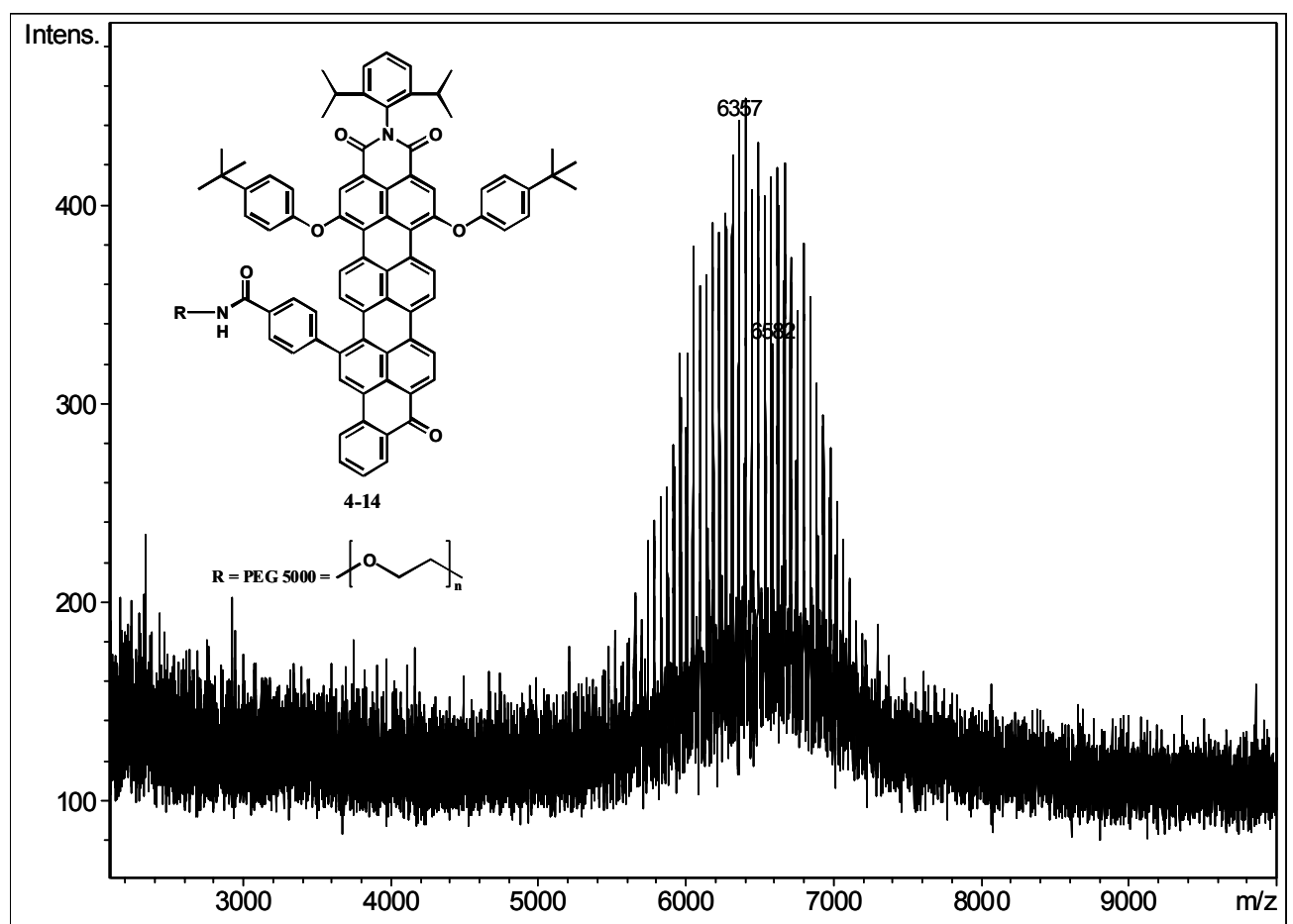

Abbildung 124: Maldi-Tof-Spektrum von 4-14 (Metrix: Dithranol)

\subsection{Optische Charakterisierung}

In diesem Abschnitt soll erläutert werden, ob die Einführung der Polyethylenglykolkette in die Struktur des Perylendiimids bzw. Benzoylterrylenmonoimids zur Wasserlöslichkeit bei gleichzeitigem Erhalt der Fluoreszenz führt. 4-9 und 4-10 zeigen eine gute Löslichkeit sowohl in organischen Lösungsmitteln wie Toluol, Chloroform, Dichlormethan (DCM) and THF als auch in Wasser. In Abbildung 125 und 126 sind die Absorptions- und Fluoreszenzspektren von 4-9 und 4-10 in wässriger Lösung dargestellt. Die Absorptionsspektren in Wasser zeigen eine ausgeprägte Feinstruktur. Daraus könnte man schliessen, dass sie eine nur geringe Tendenz besitzen, in wässriger Lösung zu aggregieren. Die Absorptions- und Fluoreszenzspektren von 4-9 in verschiedenen Lösungsmitteln sind in Abbildung 127 gezeigt. 


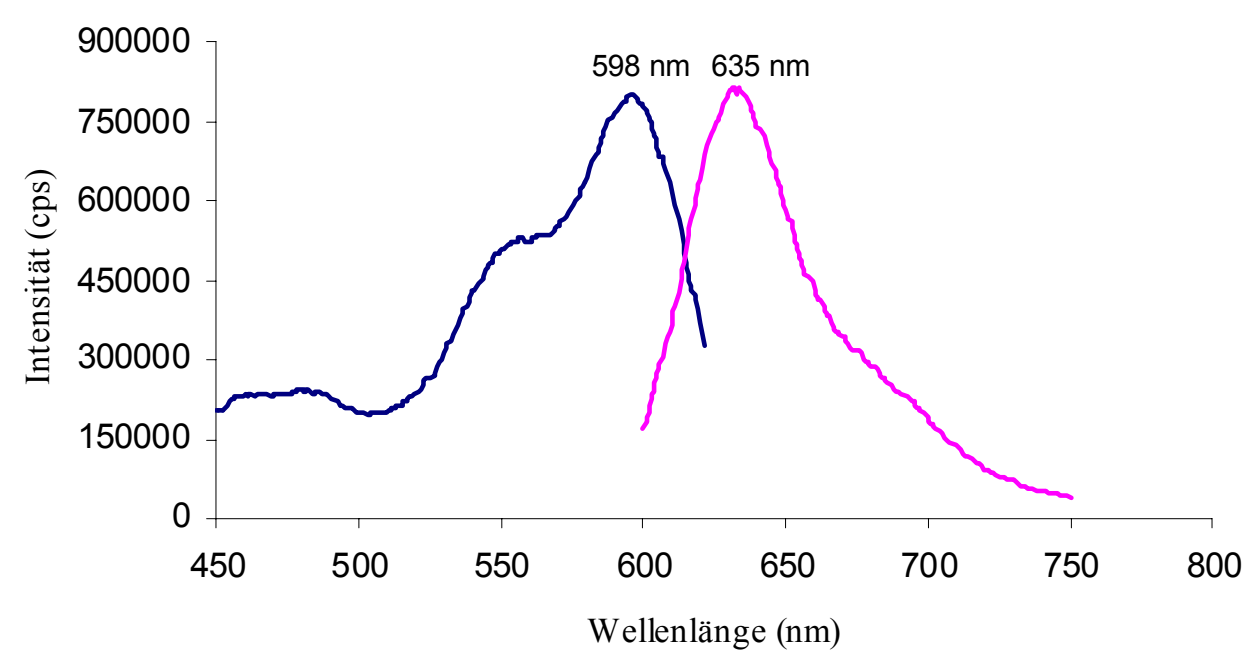

Abbildung 125: Absorptions- und Fluoreszenzspektrum von 4-9 in wässriger Lösung (Konzentration $\approx 10^{-5} \mathrm{M}$, Anregungswellenlänge $=540 \mathrm{~nm}$, Messung bei Raumtemperatur durchgeführt)

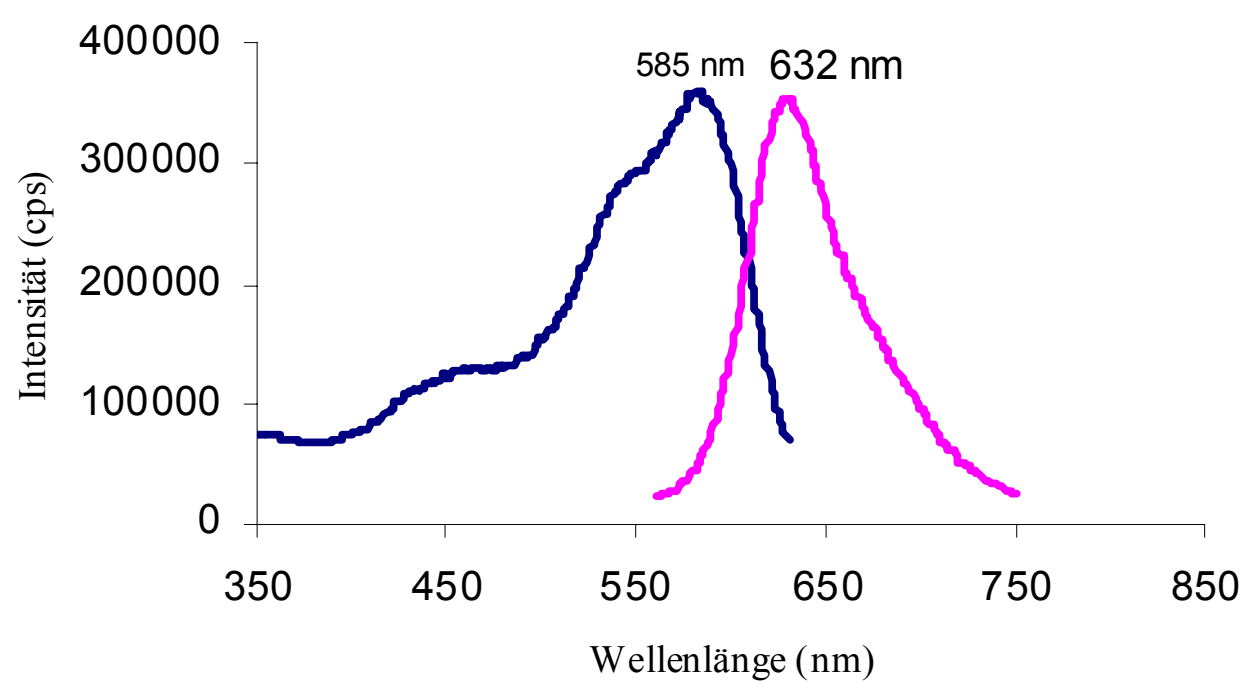

Abbildung 126: Absorption und Fluoreszenz von 4-10 im Wasser (Konzentration $\approx 10^{-5} \mathrm{M}$, Anregungswellenlänge $=540 \mathrm{~nm}$, Messung bei Raumtemperatur durchgeführt)

Wie man in Abbildung 127 feststellen kann, wurden die Absorptions- und Fluoreszenzmaxima je nach der Polarität des verwendeten Lösungsmittels verschoben. Während im Toluol ein Fluoreszenzmaximum bei $605 \mathrm{~nm}$ erhalten wurde, ist eine bathochrome Verschiebung von $11 \mathrm{~nm}$ in Chloroform und $28 \mathrm{~nm}$ in Wasser $\mathrm{zu}$ beobachten. Die Neigung von 4-9, bei zunehmender Polarität des Lösungsmittels 
Aggregate zu bilden, ist wahrscheinlich der Grund für dieses Verhalten. Im Falle von 410 wurde ein ähnliches Absorptionsspektrum in Toluol und Wasser erhalten. In Chloroform hingegen tritt eine bathochrome Verschiebung von $9 \mathrm{~nm}$ auf.
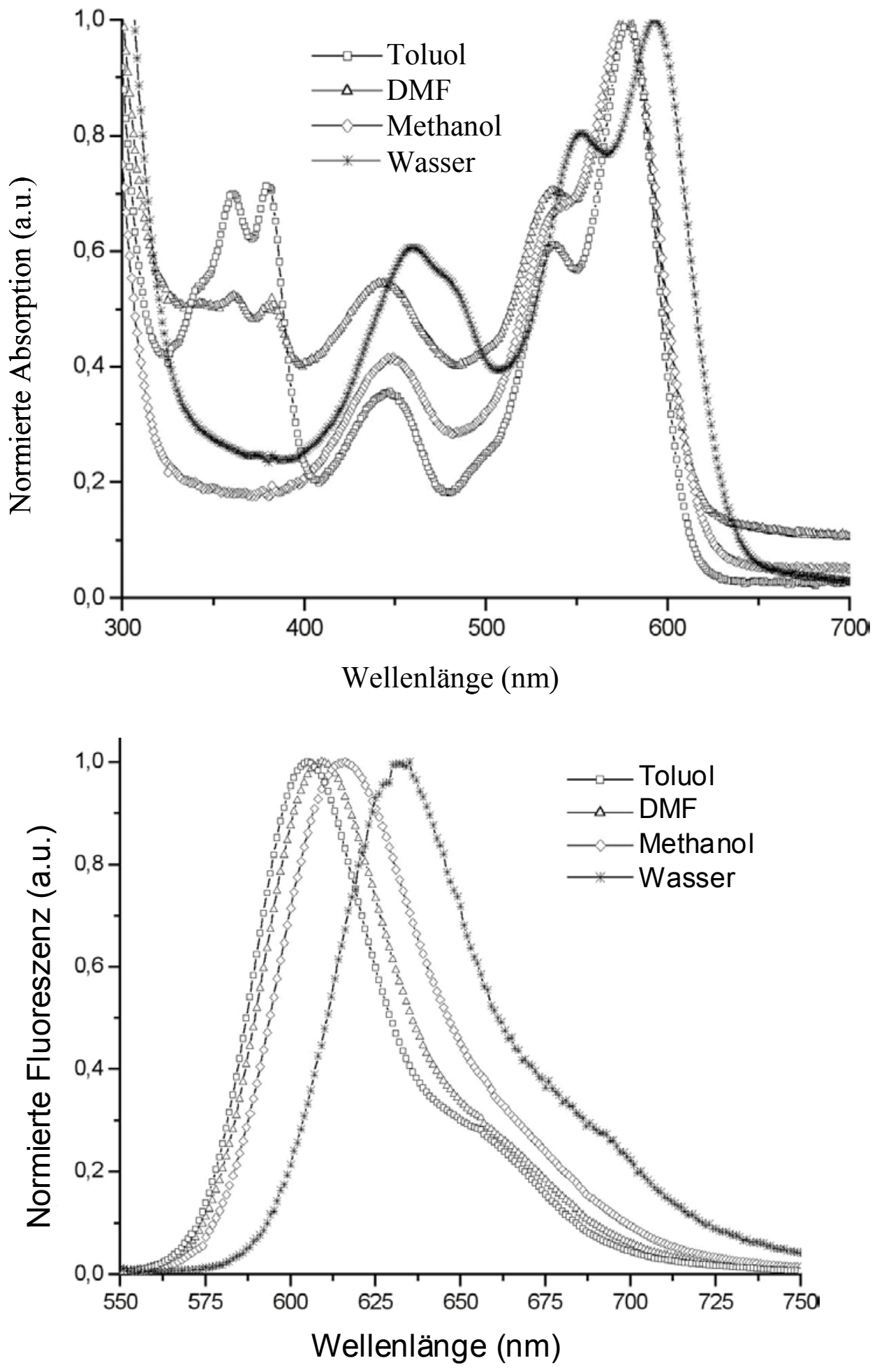

Abbildung 127: Die Absorptions- (a) und Fluoreszenzspektren (b) von 4-9 in verschiedenen Lösungsmitteln (Toluol, DMF. Methanol, Wasser), $\lambda_{\mathrm{exc}}=540 \mathrm{~nm}$ 
Im Fluoreszenzspektrum wurde eine bathochrome Verschiebung von $10 \mathrm{~nm}$ in Toluol gefunden, während in Chloroform und Wasser keine Verschiebung des Fluoreszenzmaximums beobachtet werden konnte.

Im Vergleich zwischen 4-9 und 4-10 ist das Fluoreszenzmaximum von 4-10 in Toluol bathochrom $(5 \mathrm{~nm})$ verschoben. Im Wasser hingegen tritt bei 4-10 eine hypsochrome Verschiebung von $14 \mathrm{~nm}$ im Absorptions- und $12 \mathrm{~nm}$ im Fluoreszenzmaximum auf. Dieses Verhalten kann im Zusammenhang mit den Strukturunterschieden von 4-9 und 410 stehen. Im nichtpolaren Lösungsmittel Toluol sollte sich 4-9 aufgrund der Bromfunktion in der Imidstruktur besser lösen und deshalb weniger als in Wasser aggregieren. Die Anwesenheit einer hydrophilien Carboxyfunktion in der Imidstruktur von 4-10 sollte im Vergleich zu 4-9 eine Verbesserung der Löslichkeit in Wasser bewirken.

Im Falle von 4-14 wurde in Wasser ein unstrukturiertes Absorptionsspektrum (Abb. 128) und keine Fluoreszenz erhalten. Daraus kann man schließen, dass das BTI-PEG Aggregate in Wasser bildet und von daher keine Feinstruktur im Absorptionsspektrum oder Fluoreszenz aufweisen konnte.

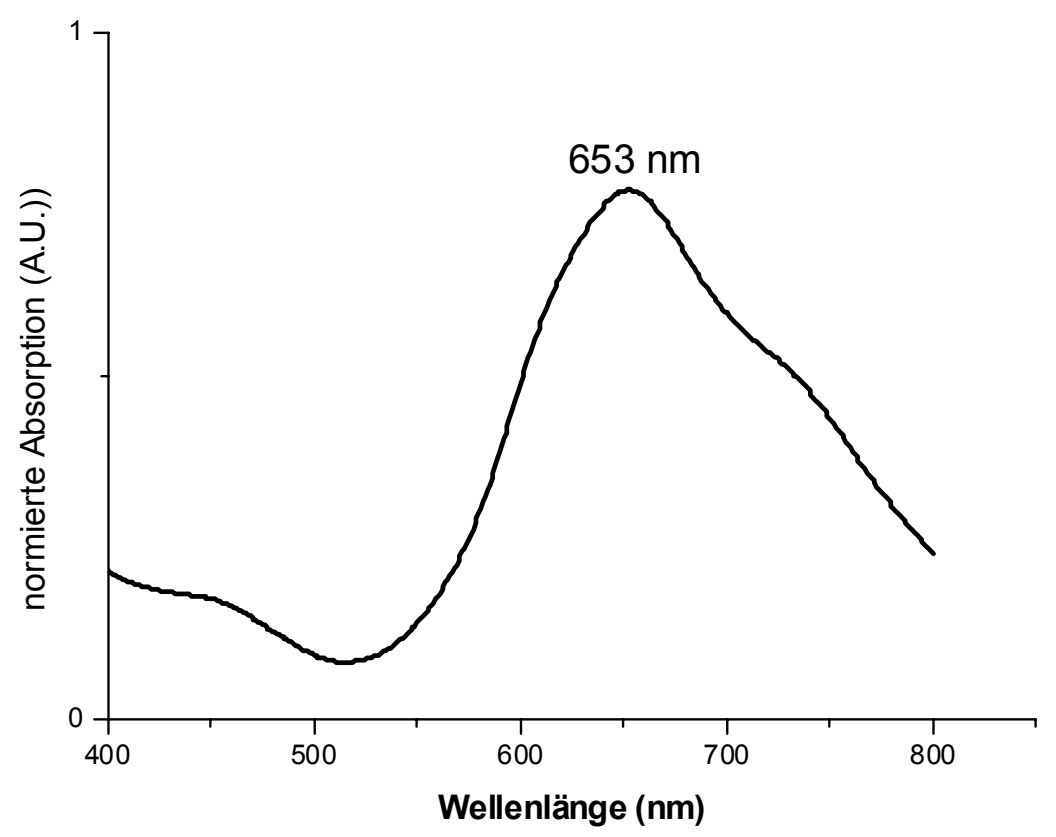

Abbildung 128: Absorptionsspektrum con BTI-PEG 4-14 im Wasser, eine formlose Feonstruktur deutet auf Aggregatbildung hin 
In Tabelle 5 sind die Absorptions- und Fluoreszenzmaxima von 4-9, 4-10 und 4-14 in Toluol, Chloroform und Wasser zusammengestellt.

\begin{tabular}{|c|c|c|c|}
\hline & $4-9$ & 4-10 & 4-14 \\
\hline $\begin{array}{c}\text { Toluol } \\
\lambda_{\max , \text { abs }}[\mathrm{nm}]\end{array}$ & $447,538,578$ & $453,542,580$ & unlöslich \\
\hline $\begin{array}{c}\text { Toluol } \\
\lambda_{\max , \mathrm{em}}[\mathrm{nm}]\end{array}$ & 605 & 610 & unlöslich \\
\hline $\begin{array}{l}\text { Chloroform } \\
\lambda_{\max , \text { abs }}[\mathrm{nm}]\end{array}$ & $453,549,585$ & $452,545,587$ & $(643), 699$ \\
\hline $\begin{array}{l}\text { Chloroform } \\
\lambda_{\max , \mathrm{em}}[\mathrm{nm}]\end{array}$ & 622 & 620 & 742 \\
\hline $\begin{array}{c}\text { Wasser } \\
\lambda_{\text {max }, \text { abs }}[\mathrm{nm}]\end{array}$ & $460,553,592$ & $448,540,578$ & 650 \\
\hline Wasser & 633 & 621 & nicht feststellbar \\
\hline $\begin{array}{c}\lambda_{\max , \text { em }}[\mathrm{nm}] \\
\phi_{\mathrm{F}}, \text { Toluol } \\
{[\%]}\end{array}$ & 86 & 86 & $26^{*}$ \\
\hline $\begin{array}{c}\phi_{\mathrm{F}}, \text { Wasser } \\
{[\%]}\end{array}$ & 16 & 19 & nicht feststellbar \\
\hline
\end{tabular}

Tabelle 5: Absorptions- und Fluoreszenzmaxima von 4-9, 4-10 und 4-14 in verschiedenen Lösunsmitteln, * gemessen in Chlorform

Anhand der Tabelle ist es zu erkennen, dass die Fluoreszenzquantenausbeute der synthetisierten Farbstoffen in polaren Lösungsmitteln abnimmt. Während 4-10 in Toluol eine Quantenausbeute von $86 \%$ aufweist, wurde in Wasser lediglich $19 \%$ erhalten. Auch bei 4-9 und 4-14 ist die gleiche Tendenz zu erkennen. In Tabelle 6 ist die Fluoreszenzquantenausbeute von 4-9 in fünf verschiedenen Lösungsmitteln dargestellt. 


\begin{tabular}{|c|c|c|c|c|c|}
\hline Lösungsmittel & Wasser & Methanol & DMF & Chloroform & Toluol \\
\hline $\begin{array}{c}\text { FQA (\%) von } \\
4-9\end{array}$ & $16 \pm 0.1$ & $66 \pm 0.1$ & $64 \pm 0.1$ & $86 \pm 0.1$ & $87 \pm 0.1$ \\
\hline
\end{tabular}

Tabelle 6: Die Fluoreszenzquantenausbeute von 4-9 in verschiedenen Lösungsmitteln

Die Abnahme der Fluoreszenzintensität mit zunehmender Polarität des Lösungsmittels könnte mit der Neigung des Farbstoffs, in polaren Lösungsmitteln zu aggregieren, erklärt werden. Vor kurzem wurden Perylendiimide mit geladenen Gruppen funktionalisiert und in wässrige Lösung überführt ${ }^{22-24}$. Auch dabei war eine weniger ausgeprägte Fluoreszenzlöschung festzustellen. Die Ursachen der Fluoreszenzlöschung in wässrigen Medien wurden bisher noch nicht vollständig geklärt. Weitere photophysikalische Untersuchungen müssen durchgeführt werden, um diese Fluoreszenzlöschungsprozesse zu verstehen. Im folgenden Abschnitt wird die Eignung der wasserlöslichen Farbstoffe zur Anfärbung von Zellen überprüft.

\subsection{Anfärben von Zellen}

Die Anfärbungsexperimente wurden in Zusammenarbeit mit Dr. T. Weil aus der Firma Merz Pharmaceuticals in Frankfurt am Main durchgeführt. Die Farbstoffe 4-9, 4-10 und 4-14 wurden jeweils in Dimethylsulfoxid (DMSO) in einer Konzentration von $1 \mathrm{mM}\left(10^{-3}\right.$ M) gelöst. Die Lösungen wurden mit einem Phosphatpuffer auf eine Konzentration von $10^{-4} \mathrm{M}, 10^{-5} \mathrm{M}$ und $10^{-6} \mathrm{M}$ verdünnt. Der DMSO-Anteil in den verdünnten Lösungen beträgt $1 \%$. Für die Anfärbungsstudien wurden Zellen vom Typ Chinese hamster ovarian cell line $\mathrm{CHO}$ verwendet, die auf einem Glasträger gewachsen sind. Die Zellen wurden zunächst mit den verdünnten Farbstofflösungen von 4-9, 4-10 und 4-14 gespült. Im Anschluss wurden die Farbstofflösungen auf die Zellen gegeben. Die Zellen wurden dann 30 Minuten bei $37{ }^{\circ} \mathrm{C}$ inkubiert. Nach Ablauf der Inkubationszeit wurden die 
Farbstofflösungen entfernt und die Zellen sorgfältig mit dem Phosphatpuffer gewaschen. Abbildung 129 zeigt eine Aufnahme von inkubierten Zellen (mit einer Pufferlösung von 4-14) durch ein Lichtmikroskop. Die 30-minutige Inkubation der Zellen mit der Farbstofflösung von 4-14 führte zu einer homogenen Anfärbung der Zellen, wobei die äußere Membran der Zellen stark angefärbt war.

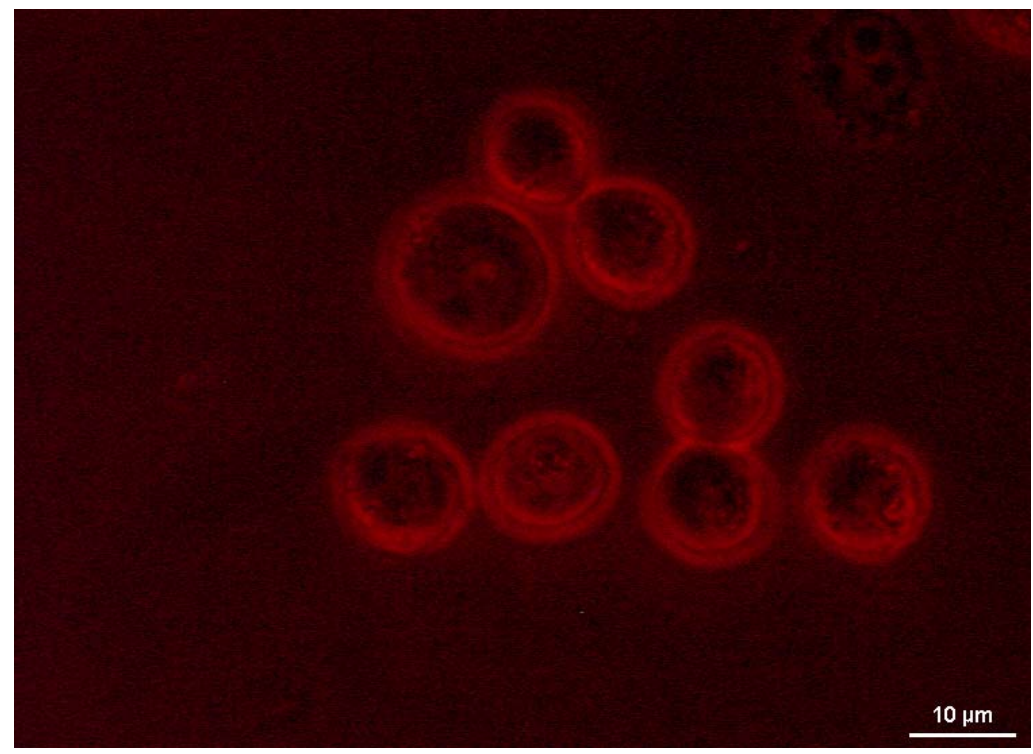

Abbildung 129: Zellen vom Typ Chinese hamster ovarian cell line $C H O$, die 30 Minuten mit der Farbstoffpufferlösung von 4-14 $\left(\mathrm{C}=10^{-5} \mathrm{M}\right)$ inkubiert wurden. Die Aufnahme erfolgte durch ein Lichtmikroskop

Man erkennt deutlich die homogene Anfärbung der Zellen, die äußere Membran ist stärker angefärbt. Im Falle von 4-9 und 4-10 wurden verschiedene Farbstoffkonzentrationen $\left(10^{-4}, 10^{-5}\right.$ und $\left.10^{-6} \mathrm{M}\right)$ eingesetzt. Nur eine kleine Zahl von Zellen lassen sich bei einer Konzentration von $10^{-6} \mathrm{M}$ anfärben. Weiterhin wurde festgestellt, dass 4-9 und 4-10 bei hohen Konzentrationen $\left(10^{-4}\right.$ und $\left.10^{-5} \mathrm{M}\right)$ zelltoxisch sind. Nach einer langen Inkubationszeit konnte eine Diffusion der Farbstoffe durch die Zellmembran nicht festgestellt werden. Das unterschiedliche Verhalten der Farbstoffe im Hinblick auf ihre Fähigkeit, durch die Zellmembran in das Innere der Zellen zu diffundieren, was auch zur Anfärbung der Zellen führte, ist wahrscheinlich auf die unterschiedliche 3D-Struktur der Farbstoffe zurückzuführen. Während 4-14 zwei Phenoxysubstituenten mit tert-Butylgruppen in der p-Position trägt, sind 4-9 und 4-10 mit 
vier tert-Octylphenoxygruppen funktionalisiert. Im Falle von 4-9 und 4-10 ist das Chromophorgerüst mit einem Winkel von $28^{\circ}$ verdreht $^{25}$. Die Diffusion eines Moleküls durch die Zellmembran wird durch eine flache Struktur bevorzugt. Die Anwesenheit von anspruchsvollen Substituenten ist entscheidend für die Diffusionsfähigkeit durch die Zellmembran. Da bei 4-9 und 4-10 vier und bei 4-14 lediglich zwei Phenoxysubstituenten in ihrer Struktur enthalten sind, konnte eine deutliche Diffusion von 4-14 in die Zellmembran beobachtet werden.

In diesem Kapitel wurde die Synthese von drei wasserlöslichen Rylenfarbstoffen vorgestellt. Diese Farbstoffe zeichnen sich durch eine hohe Fluoreszenzquantenausbeute in Toluol und Chloroform aus, diese Fluoreszenzquantenausbeute sinkt aber stark bei Überführung in wässrige Medien. Diese Verminderung der Quantenausbeute kann auf die Bildung von Aggregaten zurückgeführt werden. Diese Verminderung der Quantenausbeute scheint auf den ersten Blick ein Nachteil zu sein, dies kann aber positiv im Hinblick auf die selektive Visualisierung von hydrophoben Bereichen in den Zellen gewertet werden.

Bei den Zellanfärbungsexperimenten mit 4-9 und 4-10 konnte eine kleine Zahl von Zellen bei niedrigen Konzentrationen $\left(\mathrm{c} \approx 10^{-6} \mathrm{M}\right)$ angefärbt werden. In hohen Konzentrationen $\left(\mathrm{c} \approx 10^{-4}-10^{-5} \mathrm{M}\right)$ sind 4-9 und 4-10 zelltoxisch. Bei 4-14 konnte keine Fluoreszenz in wässriger Lösung detektiert werden. Wegen der fehlenden Fluoreszenz im Wasser konnte 4-14 die hydrophobe Zellmembran mit einem hohen Kontrast $\mathrm{zu}$ der hydrophilen Umgebung anfärben.

Mit diesen Experimenten konnte gezeigt werden, dass sich einer der drei synthetisierten Farbstoffe (4-14) zur Anfärbung von Zellen eignet, da einige Voraussetzungen wie beispielsweise eine hohe Fluoreszenzintensität und ein guter Kontrast zum umgebenden Medium erfüllt sind. Die Farbstoffe verhalten sich sehr sensibel auf die Unterschiede in der Polarität des umgebenden Mediums, d.h. die Fluoreszenzspektren der Chromophore können einen direkten Eindruck von der Polarität der Umgebung vermitteln. Die Verbindungen 4-9 und 4-10 können für die Markierung von Biomolekülen (Analytmolekülen) eingesetzt werden, da hierfür eine funktionelle Gruppe (Brom- bzw. 
Carboxyfunktion), die zur Kopplung des Analytmoleküls verwendet werden können, vorhanden ist.

\subsection{Bibliographie}

[1] A. Waggoner, Methods in Enzymology 1995, Academic Press, San Diego, CA

[2] L. M. Smith, S. Fung, M. W. Hunkapillar, L. E. Hood, Nuecleic Acids Res. 1985, 13, $2328-2410$.

[3] R. P. Haugland Handbook of Fluorescnet Probes and Research Products, Ninth Edition 2002, Molecular Probes

[4] R. Hovius, P. Vallotton, T. Wohland, H. Vogel Trends Pharmacol. Sci. 2000, 21, 266-273.

[5] K. Peck, L. Stryer, A. N. Glazer, R. A. Mathies Proc. Natl. Acad. Sci. USA 1989, 86, 4087.

[6] S. Weiss Science 1999, 283, 1676.

[7] D. C. Nguyen, R. A. Keller, J. H. Jett, J. C. Martin, Anal. Chem. 1987, 59, 2158.

[8] W. E. Moerner, M. Orrit Science 1999, 283, 1670.

[9] P. I. H. Bastiaens, A. Squire Trends in Cell Biology 1999, 9, 48-52.

[10] F. Würthner, C. Thalacker, A. Sautter, W. Schärtl, W. Ibach, O. Hollricher, Chem. Eur. J. 2000, 6, 3871-3886.

[11] H. Zollinger Color Chemistry, 3rd ed., VCH, Weinheim 2003.

[12] H. Langhals, Heterocycles 1995, 40 (1), 477-500

[13] U. Rohr, P. Schlichting, A. Böhm, M. Groß, K Meerholz, C, Bräuchle, K. Müllen, Angew. Chem. Int. Ed. 1998, 37, 1434-1437.

[14] G. Seybold, G. Wagenblast, Dyes Pigm. 1989, 11, 303-317 
[15] D. Dotscheva, M. Klapper, K. Müllen, Macromol. Chem. Phys. 1994, 195, $1905-$ 1911.

[16] H. Quante, P. Schlichting, U. Rohr, Y Geerts, K. Müllen, Macromol. Chem. Phys. 1996, 197, 4029-4044.

[17] H. Langhals, J. Karolin, L. B. A. Johannson, J. Chem. Soc. Faraday Trans. 1998, 94, 2919.

[18] J. Rodriguez-Hernandez, Dissertation, Johannes Gutenberg-Universtät Mainz 2003.

[19] T. Weil, Dissertation, Johannes Gutenberg-Universtät Mainz 2002.

[20] H. Quante, K Müllen Angew. Chem. 1995, 107, 1487.

[21] T. Weil, U. M. Wiesler, A. Herrmann, R. Bauer, J. Hofkens, F. C. D. Schryver, K. Müllen J. Am. Chem. Soc. 2001, 123, 8101-8108.

[22] J. Qu, C. Kohl, M. Pottek, K. Müllen Angew. Chem. Int. Ed. 2004, 43, 1528-1531.

[23] K. Kohl, Dissertation, Johannes Gutenberg Universität Mainz, 2003.

[24] J. Qu, Dissertation, Johannes Gutenberg Universität Mainz, 2004.

[25] J. Hofkens, T. Vosch, M. Maus, F. Köhn, M. Cotlet, T. Weil, A. Herrmann, K. Müllen, F. C. De Schryver Chem. Phys. Lett. 2001, 333, 255-263. 


\section{Zusammenfassung}

Im Rahmen dieser Arbeit wurde eine Methode entwickelt, Perylendiimidfarbstoffe mit Oligonucleotiden in der Lösung zu verknüpfen. Das Ziel der Arbeit war die nichtkovalente Synthese von Perylendiimid-DNA- und Protein- supramolekularen Strukturen. Dabei werden die molekularen Erkennungseigenschaften von DNA und Proteinen zunutze gemacht. Insgesamt drei Themenbereiche wurden dabei betrachtet:

1. Synthese und Hybridisierung von symmetrischen und asymmetrischen Perylendiimid-bis(oligonucleotid)-konjugaten für die Bildung supramolekularer Strukturen,

2. Erzeugung von Oberflächenstrukturen auf der Basis von StreptavidinPerylendiimid-Komplexen,

3. Synthese wasserlöslicher Rylenfarbstoffe für Anwendungen in biologischen Systemen.

Zur Synthese und Hybridisierung von Perylendiimid-Oligonucleotid-Konjugaten wurde eine neue Idee verfolgt und, wie im Kapitel 3 dargestellt, erfolgreich realisiert. Dabei handelt es sich um die Synthese von Perylendiimid-DNA-Polymeren durch nichtkovalente Bindungen. Basis des entwickelten Konzepts ist die Ausnutzung der Erkennungseigenschaften der DNA, um Perylendiimidmoleküle in eine lineare Makrostruktur $\mathrm{zu}$ organisieren, was sonst nur durch komplizierte chemische Polymersynthese zugänglich wäre. Die Selbstorganisation von zwei komplementären Perylendiimid-bis(oligonucleotid)-konjugaten (PODN1 und PODN2), die an der 5'Position verknüpft sind, führte zu einem linearen Perylendiimid-DNA-Polymer in der Form von ...ABABABAB...., das mit Hilfe von Gelelektrophorese charakterisiert wurde. Eindrucksvoll war dabei die erfolgreiche Kopplung des hydrophoben Perylendiimids mit dem polyanionischen Oligonucleotid in Lösung. Die in dieser Arbeit verwendeten Oligonucleotidsequenzen wurden mit Hilfe des DNA-Synthesizers nach der 
Kapitel 5: Zusammenfassung

Phosphoamiditmethode hergestellt. Insgesamt wurden 5 Oligonucleotide synthetisiert. In

Tabelle 7 sind die synthetisierten Oligonucleotidsequenzen zusammengestellt.

\begin{tabular}{|c|c|}
\hline \multicolumn{2}{|r|}{ Oligonucleotidsequenz } \\
\hline ODN1 & $\mathrm{H}_{2} \mathrm{~N}-\left(\mathrm{CH}_{2}\right)_{6}-\mathrm{p}-5^{\prime}-\mathrm{TAG}$ TTG TGA TGT ACAT-3` \\
\hline ODN2 & $\mathrm{H}_{2} \mathrm{~N}-\left(\mathrm{CH}_{2}\right)_{6}-\mathrm{p}-5^{\prime}-\mathrm{ATG}$ TAC ATC ACA ACTA-3` \\
\hline cODN1 & 5'-ATG TAC ATC ACA ACTA-3` \\
\hline ODN3 & 5`-ATGT ACA TCA CAA CTA-3`-p-( $\left(\mathrm{CH}_{2}\right)_{6}-\mathrm{NH}_{2}$ \\
\hline ODN4 & $\mathrm{H}_{2} \mathrm{~N}-\left(\mathrm{CH}_{2}\right)_{6}-\mathrm{p}-5^{`}-\mathrm{AGC}$ GGA TAA CAA TTT CAC ACA GGA-3` \\
\hline
\end{tabular}

Tabelle 7: Die Oligonucleotidsequenzen, die in dieser Arbeit synthetisiert und zur Hybridisierung verwendet wurden

Die Polymerstruktur wurde durch die Hybridisierung von zwei komplementären Perylendiimid-bis(oligonucleotid)-konjugaten (PODN1 und PODN2) (Abb. 130) erhalten.

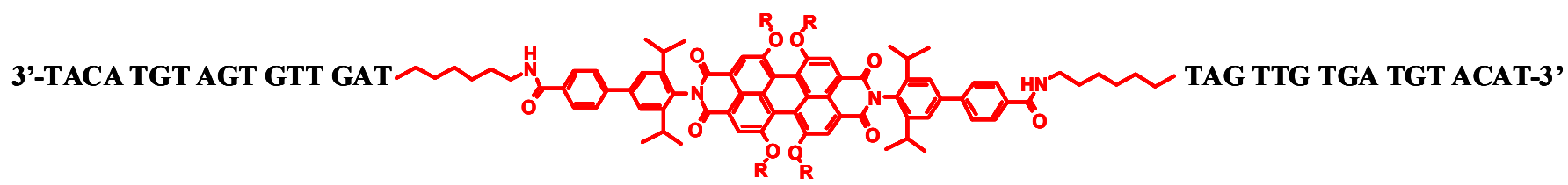

\section{PODN1}

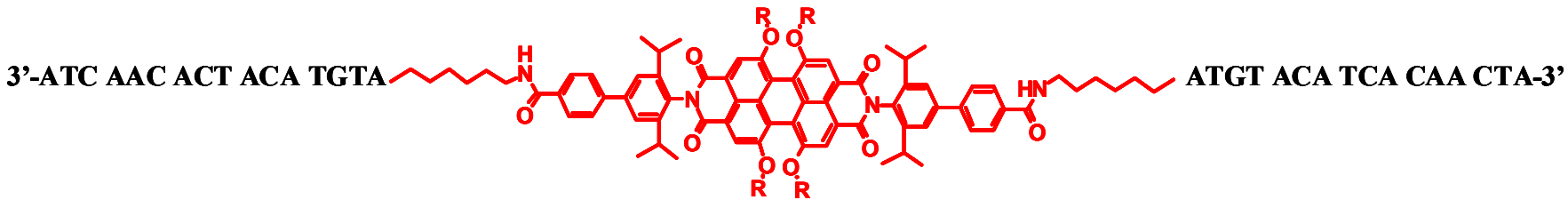

PODN2
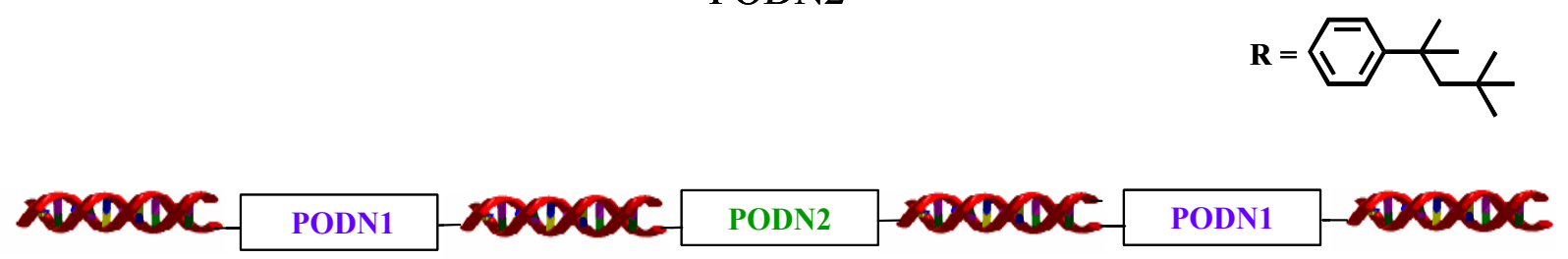

Abbildung 130: Die Struktur von PODN1 und PODN2 und eine schematische Darstellung des gebildeten Perylendiimid-DNA-Polymers 
Die entwickelte Kopplungsmethode von Perylendiimid mit zwei

Oligonucleotidsequenzen in der Imidstruktur ist übertragbar auf hydrophobe organische Verbindungen, die an die DNA verknüpft werden sollen, aber aus chemischen Gründen nicht in die Festphasensynthese integriert werden können. Desweiteren kann mit diesem Konzept die teuere Phosphoramiditchemie zur Synthese von Oligonucleotid-Konjugaten umgegangen werden, da die Kopplungseffizienz einer organischen Verbindung in der Festphasensynthese viel niedriger im Vergleich zu den DNA-Nucleotiden ist, was zum Verlust der hergestellten Oligonucleotidsequenz führen kann.

Die Charakterisierung der erhaltenen Polymerstruktur zeigte, dass die Länge des durch die Hybridisierung gebildeten Polymers mit diesem Konzept nicht zu kontrollieren ist. Darüber hinaus könnte eine Ringstruktur unkontrolliert gebildet werden. Aus diesem Grund wurde ein Konzept entwickelt, um kontrollierbare Polymerbildung zu erzielen. Dieses Konzept basiert auf der Synthese von asymmetrischen Konjugaten, d. h das Perylendiimid muss zwei unterschiedliche Oligonucleotidsequenzen in seiner Imidstruktur besitzen, um selektiv nur eine Sequenz hybridisieren zu können. Bisher war die Synthese eines asymmetrischen Konjugates nur über die Festphasensynthese realisierbar $^{1-3}$. Vorausgesetzt die Verbindung, die mit zwei Oligonucleotidsequenz gekoppelt werden soll, muss sich gut löslich in dem bei der Festphasensynthese verwendeten Lösungsmittel (meistens Acetonitril) und die Synthese ihres Phosphoramiditderivates muss chemisch zugänglich sein. Für alle Verbindungen, die solche Vorraussetzungen nicht erfüllen, muss einen synthetischen Weg in der Lösung gefunden werden. Die in dieser Arbeit entwickelte Methode zur Synthese von asymmetrischen Perylendiimid-bis(oligonucleotid)-konjugaten in Lösung ist übertragbar auf organische Verbindungen, die eine gewisse Löslichkeit in DMF, THF oder DMSO aufweisen. Durch die Synthese von zwei asymmetrischen Konjugaten (Abb. 131), die nur eine komplementäre Sequenz besitzen (statt zwei im Falle von PODN1 und PODN2), konnte man ein kontrolliertes Dimer bilden, das auch zu einem Trimer oder zu höheren Homologe verlängert werden kann. Dadurch sollte es möglich sein, einen DNA-Ring zu bilden. Zum Beispiel könnten 5 oder 6 asymmetrische Konjugate zusammengemischt werden. Durch die sehr spezifische Erkennungseigenschaft der DNA wird jedes 
asymmetrische Konjugat lediglich das passende Stück erkennen können. So kann man eine DNA-Ringstruktur bilden, in der das Perylendiimid in festgelegten Abständen innerhalb der DNA-Doppelhelix liegt.

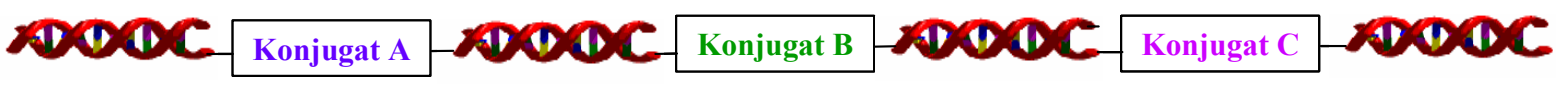

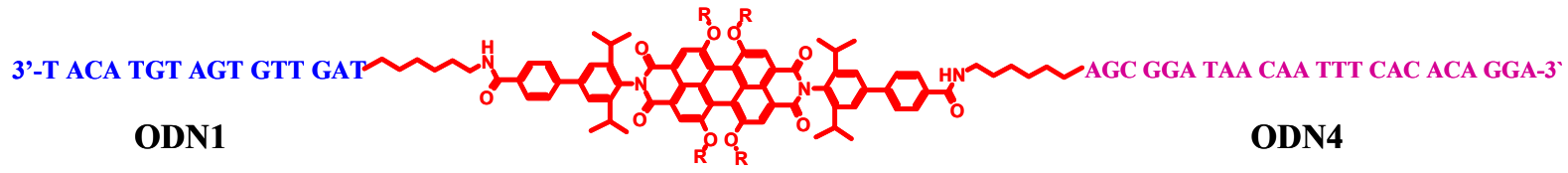

3-42

3'AGG ACA CAC TTT AAC AAT AGG CGA ODN2
ODN4

3-42

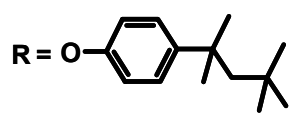

Abbildung 131: Schematische Darstellung eines Perylendiimid-DNa-Polymers, das aus asymmetrischen Perylendiimid-bis(oligonucleotid)-konjugaten hergestellt werden kann, und die Struktur der zwei synthetisierten asymmetrischen Perylendiimid-bis(oligonucleotid)-konjugate

Eine weitere interessante Einsatzmöglichkeit wäre es, verschiedene asymmetrische Oligonucleotid-Konjugate mit verschiedenen organischen Verbindungen herzustellen und dadurch eine DNA-Ringstruktur zu bilden. Als Beispiel kämen Terrylendiimid und Naphthalindiimid in Frage. Dieses Konzept ist aber generell auf bifunktionelle organische Verbindungen übertragbar. In Abbildung 132 ist eine schematische Darstellung für eine solche DNA-Ringstruktur gezeigt. Desweiteren konnte gezeigt werden, dass durch die entwickelte Methode zur Synthese asymmetrischer Oligonucleotid-Konjugate das Perylendiimid in eine DNA-Sequenz eingebaut werden kann. Dies wurde durch den 
Einsatz von zwei 5'- und 3'-Aminoligonucleotid bei der Kopplungsreaktion erreicht. Das Perylendiimid kann in diesem Konjugat als eine Struktureinheit innerhalb einer DNASequenz gesehen werden.

Die in dieser Arbeit erhaltenen supramolekularen Strukturen zeigen, dass die Verknüpfung des Perylendiimids an Oligonucleotide die Hybridisierungseigenschaften der DNA-Sequenzen nicht beeinflusst.

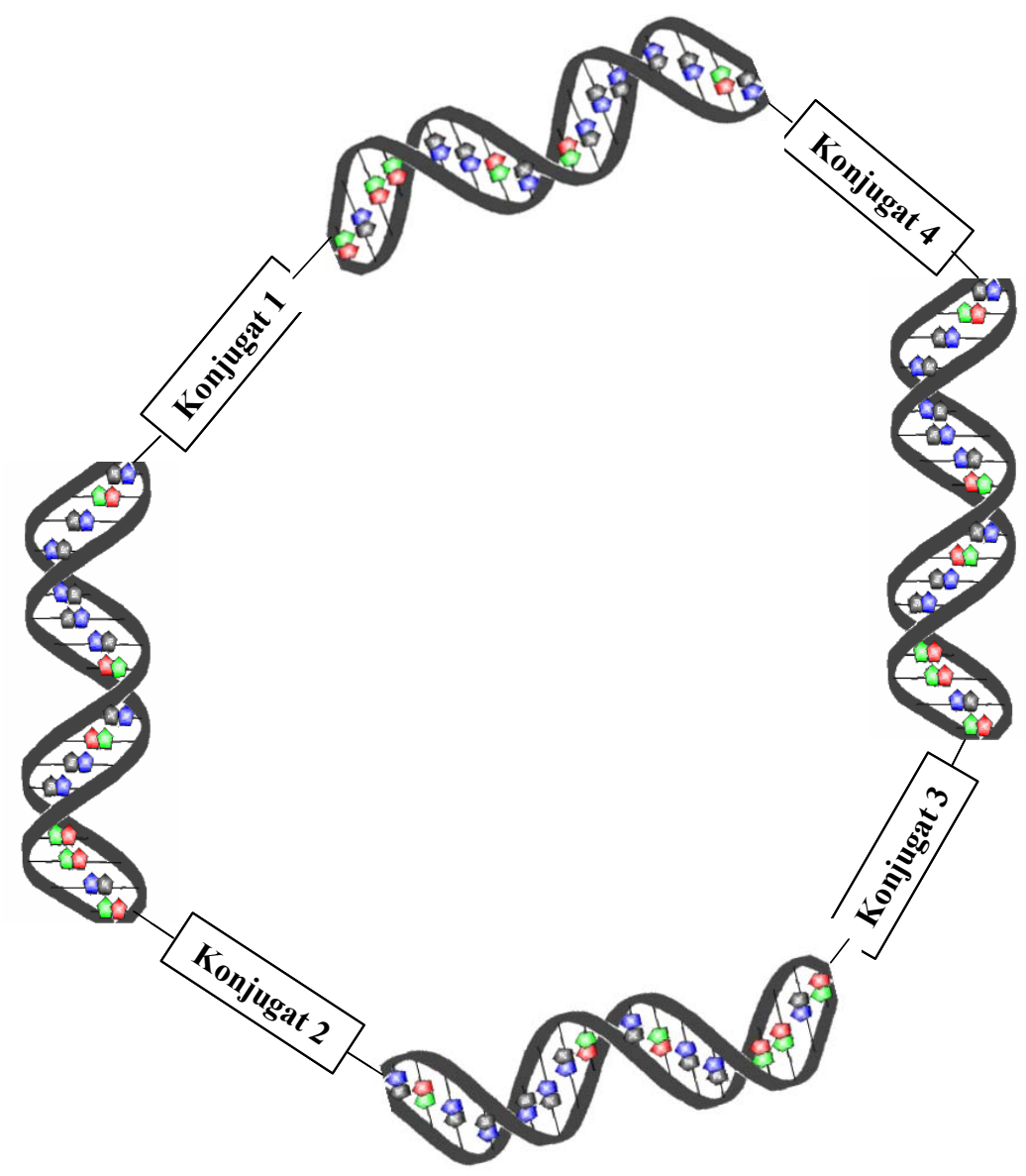

Abbildung 132: Schematische Darstellung einer DNA-Ringstruktur, die durch die Hybridisierung mehrerer asymmetrischer Perylendiimid-bis(oligonucleotid)-konjugate gebildet werden kann

Weiterhin wurde im Kapitel 3 die Synthese und Selbstorganisation eines Trisoligonucleotids beschrieben. Das Ziel dieser Synthese war, ein neues Molekül bereitzustellen, das sich für die Bildung von verzweigten supramolekularen Strukturen eignen sollte. Die Hybridisierung von 3-57 (Abb. 133) mit kürzeren ssDNA-Sequenzen wurde erfolgreich durchgeführt und mit Polyacrylamidgelelektrophorese (PAGE) charakterisiert. Die durchgeführten Experimente zur Hybridisierung eines längeren 
dsDNA-Fragmentes (650 Basenpaare) zeigten, dass zwei der drei angebundenen Oligonucleotidsequenzen in 3-57 hybridisieren können, während die dritte Sequenz wahrscheinlich wegen sterischer Hinderung nicht hybridisieren kann. Dabei spielt die Molekülgröße von 3-55 eine wesentliche Rolle. Aus diesem Grund könnte zum Beispiel Polyphenylendendrimere, die in unserem Arbeitskreis entwickelt wurden, als Kern eines Trisoligonucleotides zum Einsatz kommen, wobei die Größe des Dendrimers entscheidend sein könnte, drei dsDNA-Fragmente mit einem Trisoligonucleotid zu hybridisieren.

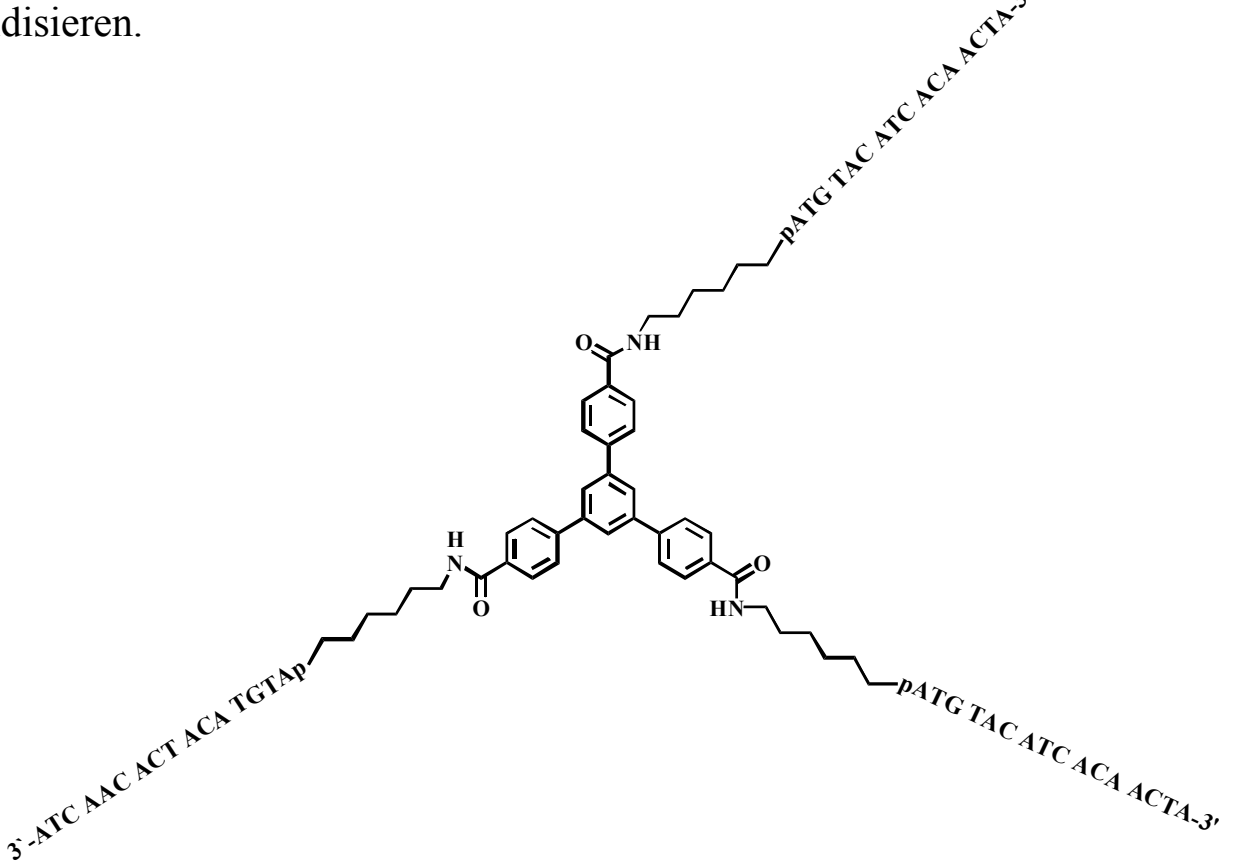

Abbildung 133: Struktur des hergestellten Trisoligonucleotides 3-57

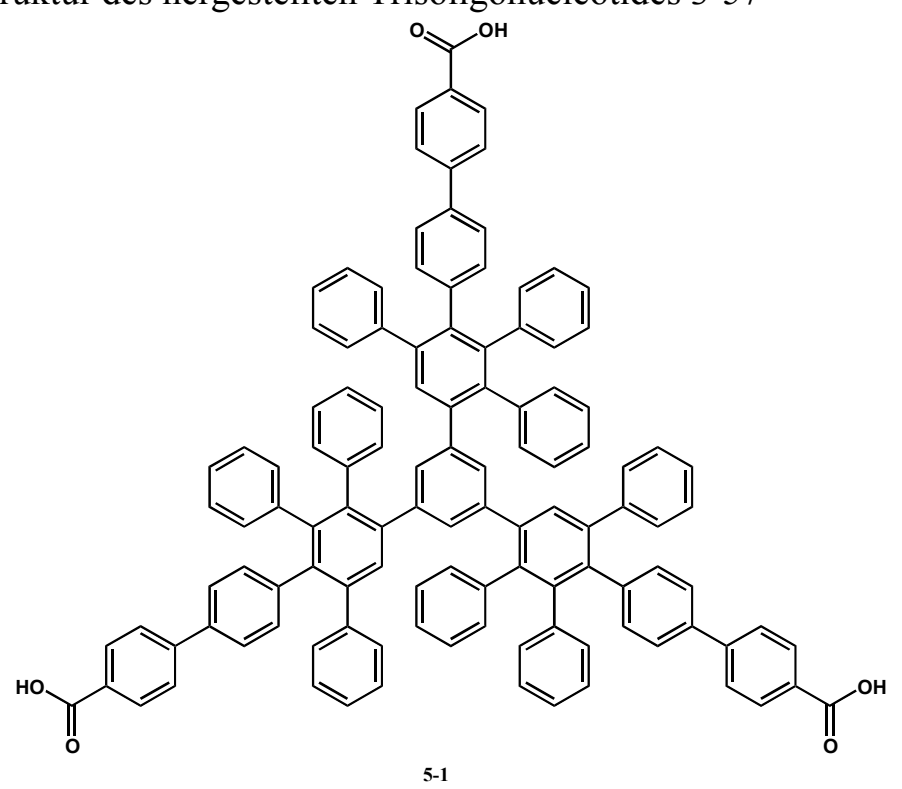

Abbildung 134: Polyphenylendendrimer der ersten Generation mit 3 Carboxyfunktionen an der Oberfläche 
Im letzten Teil von Kapitel 3 wurde die Synthese von PDI-(biotin) $)_{2}$ vorgestellt. Durch die spezifische Erkennungseigenschaft zwischen Biotin und Streptavidin ist es möglich, eine Oberflächenstruktur zu bilden. Diesem Ziel stand die Wasserunlöslichkeit von 3-61 entgegen. Durch den Einsatz eines Detergenzes (Tween 20) konnte 3-61 in wässrige Lösung überführt und seine Fluoreszenzeigenschaften beibehalten werden. Dabei wurde eine Fluoreszenzquantenausbeute von 38 \% erzielt. Die Immobilisierungsexperimente zeigten, dass das PDI (biotin) $)_{2}$ Streptavidin erkennen und binden kann. Dabei konnte eine multischichtige Nanostruktur (5 Doppelschichten) auf einer Goldoberfläche erzielt und eine zunehmende Fluoreszenzintensität detektiert werden.

Wasserlöslichen Rylenfarbstoffen mit kovalent gebundenen Polyethylenglykolketten war das Kapitel 4 dieser Dissertation gewidmet. Aufbauend auf der Idee, Rylenfarbstoffe durch die Verknüpfung von Polyethylenglykolketten in wässrige Lösungen zu überführen, wurden drei synthetisierte Rylenfarbstoffe (4-9, 4-10, 4-14, Abb. 135) vorgestellt und ihre Eignung zur Visualisierung von biologischen Zellen überprüft. Die Wasserlöslichkeit wurde erfolgreich in die drei Farbstoffe eingeführt. Die erhaltene Fluoreszenzquantenausbeute in Wasser lag zwischen 15 und $20 \%$ bei 4-9 und 4-10. Bei 4-14 konnte keine Fluoreszenz in Wasser detektiert werden. Die durchgeführten Versuche zeigten, dass die sterisch anspruchsvolleren 4-9 und 4-10 viel langsamer durch die Zellmembran diffundieren, während 4-14 schneller durch die Zellmembran geht. Im Falle von 4-14 konnte auch Fluoreszenz in den eingefärbten Zellen detektiert werden. Die hydrophobe Umgebung in der Zellmembran stellte die Fluoreszenz wieder her, da 4-14 in wässriger Lösung sehr stark zur Aggregation neigt. Durch die erfolgreiche Synthese der Farbstoffe konnten wasserlösliche Rylenchromophore hergestellt werden, die oberhalb von $620 \mathrm{~nm}$ emittieren, wo die Autofluoreszenz der Zellen und des Gewebes vernachlässigt werden kann. Zusätzlich konnten neben der Verknüpfung der Polyethylenglykolkette in 4-9 und 4-10 funktionelle Gruppen eingeführt werden, die es ermöglichen, Biomoleküle an 4-9 bzw. 4-10 anzubinden und als Fluoreszenzmarker in biologischen Systemen anzuwenden. 

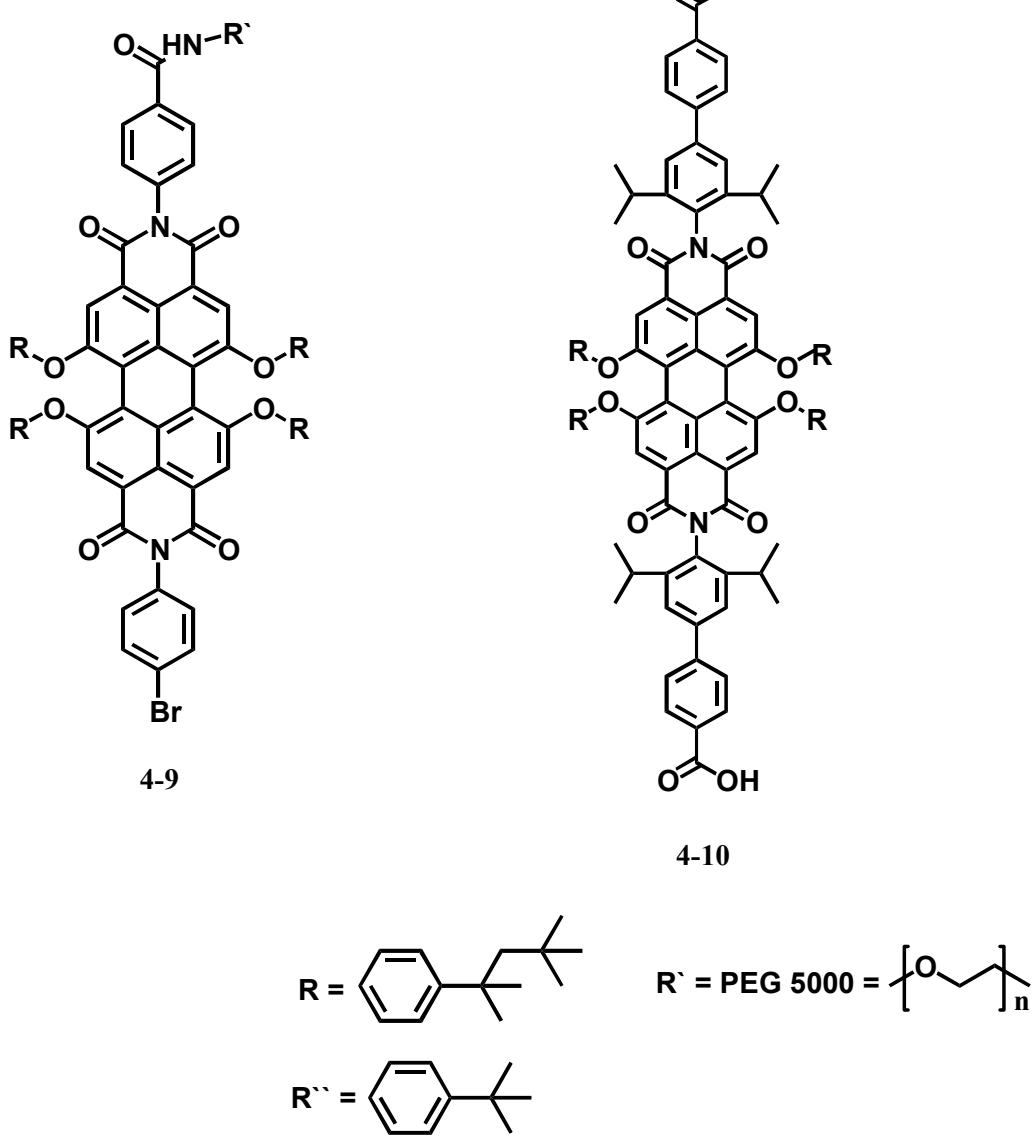

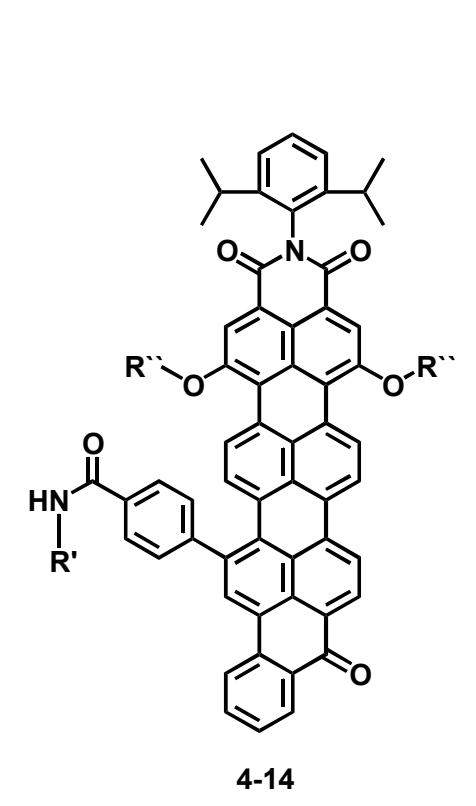

Abbildung 135: Die Struktur der synthetisierten wasserlöslichen Rylenfarbstoffe

\section{Bibliographie:}

[1] R. L. Letsinger, T. Wu, J. Am. Chem. Soc. 1994, 116, 811-812.

[2] R. L. Letsinger, T. Wu, J. Am. Chem. Soc. 1995, 117, 7323-7328.

[3] F. D. Lewis, T. Wu, Y. Zhang, R. L. Letsinger, S. R. Greenfield, M. R. Wasielewski, Science 1997, 227, 673-676. 
Kapitel 5: Zusammenfassung 


\section{Experimenteller Teil}

\subsection{Geräte}

Die Analytik der im experimentellen Teil beschriebenen Verbindungen wurde mit Hilfe vonfolgenden Geräte durchgeführt:

\section{Hochaufgelöste ${ }^{1} \mathrm{H}$ - und ${ }^{13} \mathrm{C}-\mathrm{NMR}-$ Spektroskopie}

- Bruker Avance 250

- Bruker AMX 300

- Bruker DRX 500

- Bruker Avance 700

Als interner Standard diente bei ${ }^{1} \mathrm{H}-\mathrm{NMR}-\mathrm{Messungen}$ das Protonensignal des deuterierten

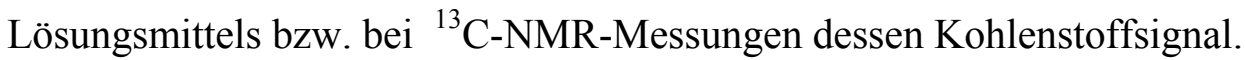

\section{Massenspektrometrie}

Als Field-Desorption-Messungen (FD-MS) diente ein „ZAB 2-SE-FPD“ von VG Instruments.

MALDI-TOF-Spektren wurden mit dem Spektrometer „Reflex 2“ der Firma Bruker im Reflektionsmodus unter Verwednung eines LSI-N ${ }_{2}$-Lasers gemessen.

Für die Massenberechnung der Oligonucleotide wurden folgende Masseninkremente verwendet:

\begin{tabular}{|c|c|}
\hline Name & Masse \\
\hline Deoxyadenosin (A) & 249.24 \\
\hline Deoxycytidin (C) & 225.21 \\
\hline Deoxyguanosin (G) & 265.24 \\
\hline Thymidin (T) & 240.23 \\
\hline
\end{tabular}

Masse eines Oligonucleotids $=\left(\mathrm{n}_{\mathrm{A}} * \mathrm{~A}+\mathrm{n}_{\mathrm{C}} * \mathrm{C}+\mathrm{n}_{\mathrm{G}} * \mathrm{G}+\mathrm{n}_{\mathrm{T}} * \mathrm{~T}\right)+\mathrm{n}-1 * 63$

$\mathrm{n}($ Zahl aller Basen $)=\mathrm{n}_{\mathrm{A}}+\mathrm{n}_{\mathrm{C}}+\mathrm{n}_{\mathrm{G}}+\mathrm{n}_{\mathrm{T}}$

63: Phosphatgruppe 
Bei Oligonucleotiden mit einer Amino- oder Thiolfunktion an der 5`- oder 3 '-Position wurde das Molekulargewicht des Spacer-Amins zu der oberen Gleichung addiert werden. Als Matrix für die Maldi-Tof-Analyse von Oligonucleotiden wurde 3Hydroxypicolinsäure (gelöst in einem Acetonitril/Wasser-Gemsich (1:1) verwendet, für alle anderen Verbindungen wurde Dithranol eingesetzt.

\section{UV/Vis-Spektroskopie}

Perkin Elmer Spektrometer „Lambda 9“ und „Lambda 15“.

\section{Fluoreszenzspektroskopie}

Anregung: Xenon-Bogenlampe Osram XBO (450 w)

Spektrometer: SPEX USA Fluorolog 2 Typ F212

Detektion: Hamamatsu PMT R 508 bzw. PMT R 928

Für Lösungen wurden Quarzglasküvetten (Suprasil) der Firma Hellma, für Feststoffilme Quarzglassubstrate der Firma Heraeus verwendet.

\section{Schmelzpunkte}

Die angegeben Schmelzpunkte wurden mit der Apparatur „Büchi Melting Point B545 “ in offenen Glaskapillaren gemessen und sind nicht korrigiert.

\section{Elementaranalyse}

Die Elementaranalysen wurden am Institut für Organische Chemie der Johannes Gutenberg-Universität Mainz mittels der Apparatur „Foss Heraeus Vario EL“ durchgeführt. 


\subsection{Geräte für die Synthese und Aufreinigung der DNA- Sequenzen}

\subsubsection{DNA-Synthese}

Oligonucleotide wurden mit einem Äkta Pilot 100 der Firma Amersham Biosiences synthetisiert.

\subsubsection{Chemikalien für die Synthese am DNA-Synthesizer}

Amidite:

Träger:

Aminmodifier
Amersham Biosciences oder Perbio

Polystyrol: Amersham Biosciences

CPG: GlöenResearch

Perbio oder GlenResearch

\subsubsection{Hochleistungsflüssigchromatographie (HPLC)}

Äktapurifier System:

Steuerungssoftware: Unicorn 3.1

Die Detektion erfolgte bei $260 \mathrm{~nm}$

Verwendete Säulen:

Source $6 \mathrm{ml}$ : für analytische Verwendung

Source $22 \mathrm{ml}$ : für das präparative Verfahren, wurde zur Aufreinigung der synthetisierten

Oligonucleotide eingesetzt.

Elutionsmittel :

Eluent $\mathrm{A}: 10 \mathrm{~m} \mathrm{NaOH}, \mathrm{pH} 12$

Eluent B :10 mM NaOH $+2 \mathrm{M} \mathrm{NaCl}, \mathrm{pH} 12$

\subsubsection{Gelelektrophorese}

Für denaturierende Gelelektrophoresen wurden präperative Gelelektrophoresekammern und ein Powersupply von der Firma Amersham Biosciences verwendet. 
Geldokumentation: Zur Geldokumentation wurden Bilder der erhaltenen Gelschichten mit Hilfe einer Digitalkammera aufgenommen.

\subsection{4 weitere Geräte für molekularbiologische Arbeiten}

Eppendorf-Thermomixer

Vortexmixer Bio-Rad

Eppendorf-Pipetten

Zentrifugen: Megafuge 1.0 von der Firma Heraeus

\subsection{Allgemeine experimentelle Bedingungen}

\subsubsection{Chemikalien und Lösungsmittel}

Lösungsmittel wurden in den Reinheiten „zur Analyse“ bzw. „zur Chromatographie“ verwendet und soweit notwendig nach einschlägigen Literaturvorschriften absolutiert. Deuterierte Lösungsmittel stammten von Aldrich, Cambridge Stable Isotopes und Deutero. Die übrigen Chemikalien wurden von den Firmen Acros, Aldrich, Fluka, Lancaster, Merck, Riedel de Haen, , Sigma, Amersham Biosciences, Perbio, Glenresearch und Fermentas. bezogen und wurden - soweit nicht anders angegeben - ohne weitere Reinigung eingesetzt. 1,5,6,12-Tetrachlorperylen3,4,9,10-tetracarbonsäuredianhydrid stellte freundlicherweise das Farbenlabor der BASFAG (Ludwigshafen) zur Verfügung. Entionisiertes Wasser wurde mit Hilfe einer Wasserdestillationsapparatur der Firma Millipore hergestellt.

\subsubsection{Chromatographie}

Für die präparative Säulenchromatographie kam Kieselgel der Firma Merck mit der Korngröße $0.063-0.200 \mathrm{~mm}$ zur Verwendung. Als Eluenten dienten Lösungsmittel der Reinheiten „,zur Analyse“ bzw. „zur Chromatographie“. Zur analytischen Dünnschichtchromatographie dienten kieselgelbeschichtete Aluminiumfolien mit Fluoreszenzindikator F254 der Firmen Merck. Die Detektion erfolgte anhand der 
Eigenfarbe bzw. durch Fluoreszenzlöschung bei Anregung mit $254 \mathrm{~nm}$ sowie durch Eigenfluoreszenz bei $360 \mathrm{~nm}$.

\subsubsection{Schutzgas:}

Als Inertgas diente ausschließlich Argon der Firma Linde, das mittels Hydrosorb- und Oxysorbfiltern der Firma Messer-Griessheim von Wasser- und Sauerstoffspuren befreit wurde.

\subsection{Synthese, Aufarbeitung und Aufreinigung der Oligonucleotide}

\subsubsection{Synthese und Aufarbeitung}

Der Aufbau einer Oligonucleotidsequenz erfolgte nach dem Syntheseprotokoll des Synthesizerherstellers mit eigenen Modifikationen bei der Einführung einer funktionellen Gruppe am 5'- oder 3'-Ende. Alle Amidite und Modifikationsverbindungen wurden als 0.1 M Acetonitrillösung eingesetzt. Die Synthesen der 5'-Aminoligonucleotide wurden im $160 \mu$ molaren Maßstab durchgeführt. Im Falle des 3`-Aminoligonucleotids betrug der Synthesemaßstab $81 \mu$ molar. Die Kopplungszeit eines Spaceramins wurde im Vergleich zu den DNA-Amiditen (3 Minuten) auf 15 Minuten erhöht. Die Synthese erfolgte unter Inertgasbedingungen, wobei die Amiditlösungen und Reagenzien einen Tag vor der Synthese am Synthesizer angeschlossen und 24 Stunden unter Inertgas gehalten wurden. Die Synthesesäule wurde unter Vakuum mit dem Trägermaterial gefüllt.

Nach der Kopplung der letzten Base bzw. des Spaceramins wurde die Synthesesäule mit dem hergestellten Oligonucleotid entfernt und in ein verschraubbares Gefäß überführt, mit $22 \mathrm{ml}$ einer 32 \%igen Ammoniumhydroxid-Lösung versetzt und 17 Stunden bei 55 ${ }^{\circ} \mathrm{C}$ gehalten. Danach wurde das Gefäß vorsichtig entfernt und 15 Minuten bei $-20{ }^{\circ} \mathrm{C}$ gehalten. Daraufhin wurde die Lösung filtriert und mit $100 \mathrm{ml}$ eines Lösungsmittelgemischs aus Ethanol und Wasser (1:1) gewaschen. Bei den 5'aminmodifizierten Oligonucleotiden erfolgte die Abspaltung der MMTrAminschutzgruppe des Spaceramins erst nach der Trennung des Aminoligonucleotids 
vom Trägermaterial in Ammoniaklösung. Hierfür wurde das 5`-aminmodifizierte Oligonucleotid mit $100 \mathrm{ml}$ eines Lösungsmittelsgemisches aus Essigsäure (97 \%) und Wasser (8:2) versetzt und zwei Stunden gerührt. Im Anschluss wurde die Lösung eingeengt. Der erhaltene Rückstand mit dem synthetisierten Oligonucleotid wurde in wenig Wasser gelöst und mit Hilfe von Ionenaustausch-HPLC aufgereinigt. Die aus der HPLC erhaltenen Fraktionen wurden über eine Membran mit einer Trenngrenze von 3000 $\mathrm{g} / \mathrm{mol}$ zentrifugiert, bis der $\mathrm{pH}-$ Wert im Überstand 7 betrug. Der Überstand wurde gesammelt, eingeengt und im Vakuum 2 Tage getrocknet.

\subsubsection{Charakterisierung der hergestellten Oligonucleotidsequenzen}

In Tabelle 7 sind die synthetisierten Sequenzen mit den erhaltenen Ausbeuten und den Ergebnissen der Maldi-Tof-Anaylsen zusammengestellt.

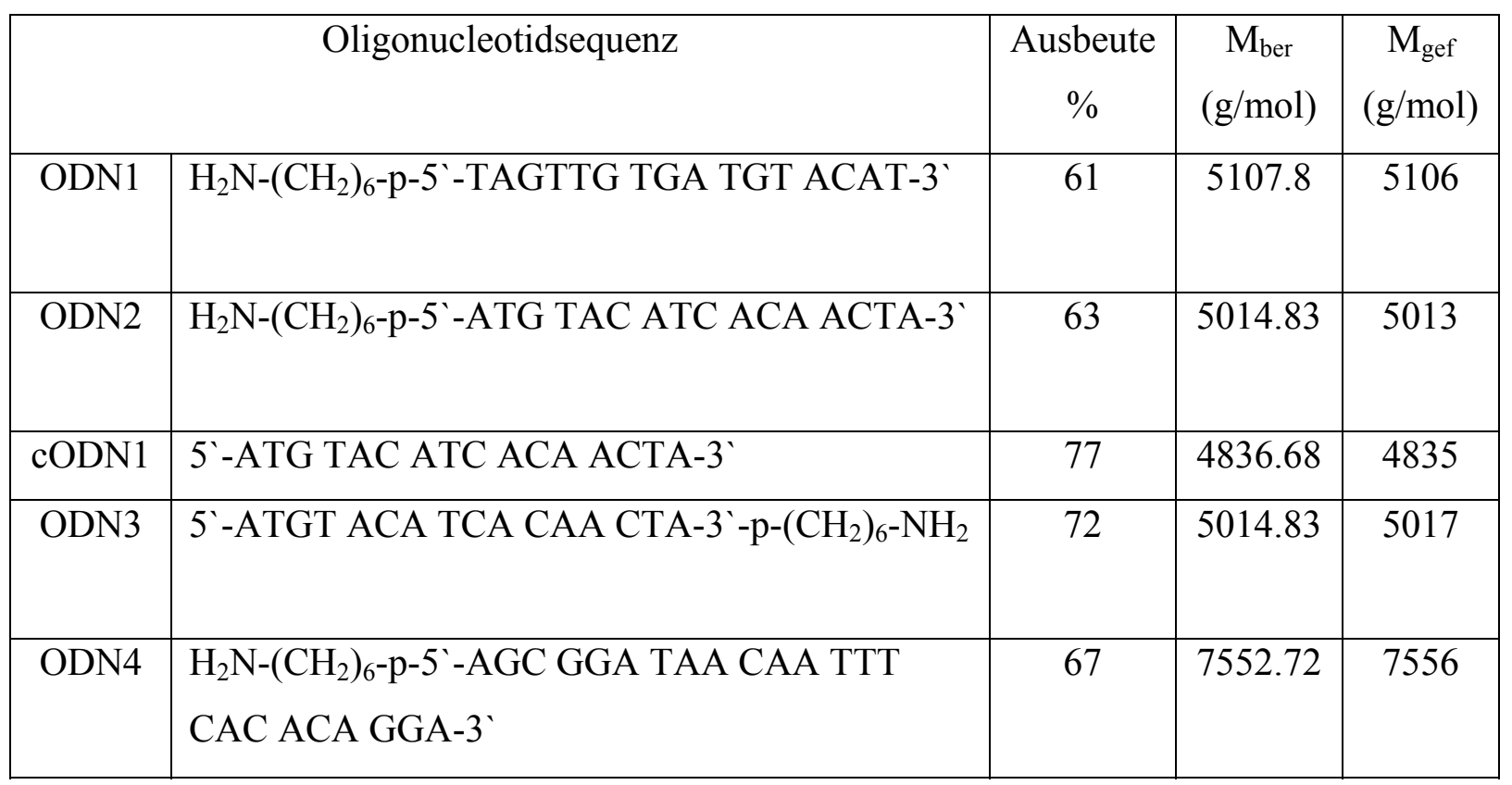

Tabelle 7: Die in dieser Arbeit synthetisierten Oligonucleotidsequenzen mit den erhaltenen Syntheseausbeuten und den Ergebnissen der Maldi-Tof-Analyse

\subsubsection{Aufreinigung der Oligonucleotid-Konjugaten}

Die Auftrennung der synthetisierten Oligonucleotid-Konjugaten vom Überschuss des Oligonucleotides, der bei der Synthese verwendet wurde, erfolgt mit Hilfe von Polyacrylamidgelelektrophorese (PAGE) ${ }^{1-3}$. 


\subsubsection{Elektrophoresepufferlösung}

Als Puffer für die Elektrophorese wurde 1 x TBE (Tris, Borsäure, EDTA) eingesetzt. Der $1 \mathrm{x}$ TBE Puffer wurde jeweils frisch aus einer $10 \mathrm{x}$ TBE Stammlösung hergestellt.

$\begin{array}{lll}10 \text { x TBE-Lösung: } & \text { Tris } & 107.6 \mathrm{~g} / 1 \\ & \text { Borsäure } & 55 \mathrm{~g} / 1 \\ & \text { EDTA } & 5.84 \mathrm{~g} / 1\end{array}$

\subsubsection{Polyacrylamidlösung}

Als Polyarylamidlösung wurde eine 40 \%ige Acrylamidlösung der Firma Merck mit einem Acrylamid-/Bisacrylamid-Mischverhältnis von 19:1 verwendet.

Acrylamidlösung: $\quad 380 \mathrm{~g} / 1$ Acrylamid

10 g/l N, N`-Methylen-Bisacrylamid

\subsubsection{Denaturierende Polyacrylamidgelelektrophorese}

Die Polyacrylamidgelelektrophorese (PAGE) wurde in Gelschichten einer Größe von 18 x $24 \mathrm{~cm}$ bei einer Spannung von $450 \mathrm{~V}$ durchgeführt. Die Gele wurden wie folgt angesetzt:

\begin{tabular}{|c|c|c|c|c|}
\hline $\begin{array}{c}\text { Gelkonzentration } \\
(\%)\end{array}$ & $\begin{array}{c}\text { Acrylamidlösung } \\
(\mathrm{ml})\end{array}$ & $\begin{array}{c}\text { Harnstoff } \\
(\mathrm{g})\end{array}$ & $\begin{array}{c}5 \times \mathrm{TBE} \\
(\mathrm{ml})\end{array}$ & $\begin{array}{c}\mathrm{H}_{2} \mathrm{O} \\
(\mathrm{ml})\end{array}$ \\
\hline 8 & 36 & 90 & 36 & 36 \\
\hline 10 & 45 & 90 & 36 & 27 \\
\hline 12 & 54 & 90 & 36 & 18 \\
\hline 14 & 63 & 90 & 36 & 9 \\
\hline
\end{tabular}

Die Gelkonzentration ist die Endkonzentration von Acrylamid in der Gesamtlösung. Das Endvolumen betrug $180 \mathrm{ml}$. Die Polymerisation erfolgte durch die Zugabe von $500 \mu 110$ \%iger Ammoniumperoxidsulfatlösung (APS) und $200 \mu 1$ TEMED. Man lässt die Gele 90 Minuten polymerisieren. $200 \mu \mathrm{lder}$ im Wasser gelösten Proben wurden mit $800 \mu 1$ Formamid gemischt und 5 Minuten bei $95{ }^{\circ} \mathrm{C}$ denaturiert. Bevor man die Proben auf das Gel auftrug, wurden die Proben zuerst auf Raumtemperatur abgekühlt. Eine 50 nmol Synthese wurde auf zwei Gele verteilt, andernfalls tritt eine Überladung des Gelmaterials 
auf, die sich durch verminderte Auflösung der Banden auszeichnet. Als Markierung zum Verlauf der Elektrophorese wurde ein Gel loading buffer der Firma MBI-Fermentas verwendet.

Die gelelektrophoretische Trennung wurde bei Raumtemperatur unter Spannung von 450 V durchgeführt. Die Visualisierung der Banden erfolgte mittels Fluoreszenzlöschung. Das Gel wurde auf Frischhaltfolie gelegt, die auf einer präparativen DC-Platte lag. Durch Licht der Wellenlänge $\lambda=254 \mathrm{~nm}$ wurden die Banden durch Fluoreszenzlöschung sichtbar gemacht. Die identifizierten Produktbande wurde ausgeschnitten und drei Mals mit jeweils $1 \mathrm{ml}$ Wasser 15 Stunden bei $37{ }^{\circ} \mathrm{C}$ extrahiert. Die erhaltenen wässrigen Lösungen wurden durch Dialyse entsalzt.

\subsection{Versuchsbeschreibungen}

\section{N,N'-Bis(4-brom-2,6-diisopropylphenyl)-1,6,7,12-tetrachlor-3,4,9,10- perylentetracarbonsäurediimid (3-20)}

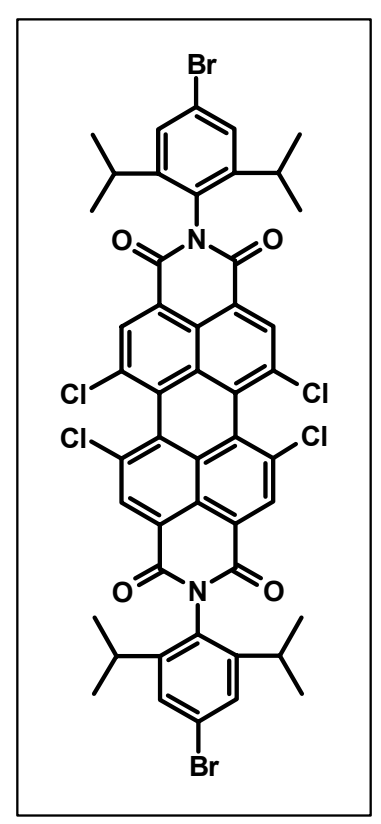

$1.5 \mathrm{~g} \quad(2.82 \mathrm{mmol}) \quad$ 1,6,7,12-Tetrachlorperylen-3,4,9,10tetracarbonsäuredianhydrid und $2.17 \mathrm{~g}(8.46 \mathrm{mmol})$ 4-Brom-2,6diisopropyl-phenylamin wurden in $80 \mathrm{ml}$ Propionsäure suspendiert. Anschließend wurde der Kolben mehrmals entgast und mit Argon gefüllt. Man lässt die Reaktionslösung unter Argon und Rückfluss bei $160^{\circ} \mathrm{C}$ für 20 Stunden rühren. Nachdem das Reaktionsgemisch auf Raumtemperatur abgekühlt war, wurde das Produkt in $120 \mathrm{ml}$ Wasser ausgefällt. Der Feststoff wurde abfiltriert und unter Vakuum getrocknet.

Ausbeute: $2.39 \mathrm{~g}(2.37 \mathrm{mmol})$ als orangeroter Farbstoff, 84 \%

FD-Massenspektrum (8 kV):

$\mathrm{m} / \mathrm{z}\left(\mathrm{u} \mathrm{e}_{0}^{-1}\right)=1006.1\left(100 \%, \mathrm{M}^{+}\right)$

(berechnet für $\mathrm{C}_{48} \mathrm{H}_{36} \mathrm{Br}_{2} \mathrm{Cl}_{4} \mathrm{~N}_{2} \mathrm{O}_{4}=1006.45 \mathrm{~g} / \mathrm{mol}$ ) 
Schmelzpunkt: $>300{ }^{\circ} \mathrm{C}$

${ }^{1} \mathrm{H}-\mathrm{NMR}\left(250 \mathrm{MHz}, \mathrm{C}_{2} \mathrm{D}_{2} \mathrm{Cl}_{4}, 2^{\circ} \mathrm{C}\right)$ :

$\delta=8.64(\mathrm{~s}, 4 \mathrm{H}), 7.25(\mathrm{~s}, 4 \mathrm{H}, \mathrm{H}-\mathrm{b}), 2.58\left(\mathrm{sep},{ }^{3} \mathrm{~J}=6.4 \mathrm{~Hz}, 4 \mathrm{H}\right), 1.15 \mathrm{ppm}\left(\mathrm{d},{ }^{3} \mathrm{~J}=4.62 \mathrm{~Hz}\right.$, 24H)

${ }^{13}$ C-NMR Spinechoexperiment (62.5 MHz, $d^{8}$-THF, $\left.298 \mathrm{~K}\right)$ :

$\delta=162.89(\mathrm{C}=\mathrm{O}), 149.59,136.17,133.80,132.72,130.80,129.60,128.27,125.34$, $124.63,110.21,30.09,24.03 \mathrm{ppm}$

Elementaranalyse $\left(\mathrm{C}_{48} \mathrm{H}_{36} \mathrm{Br}_{2} \mathrm{Cl}_{4} \mathrm{~N}_{2} \mathrm{O}_{4}\right)$ :

Berechnet: C $57.28 \%$, H $3.61 \%$, N $2.78 \%$

Gefunden: C $56.93 \%$, H $3.51 \%$, N $2.64 \%$

N,N'-Bis(4-bromdiisopropylphenyl)-1,6,7,12-tetra[4-(1,1,3,3-tetramethylbutyl)phenoxy]-3,4,9,10-perylentetracarboxdiimid (3-21)

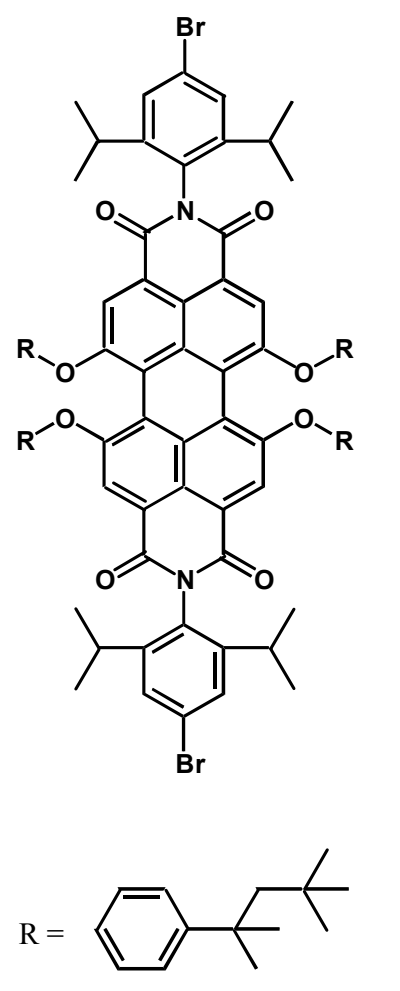

In einem 250ml-Kolben wurden $500 \mathrm{mg}(0.497 \mathrm{mmol})$ von 3-20 in $50 \mathrm{ml}$ NMP aufgelöst und bei $80^{\circ} \mathrm{C}$ für 15 Minuten gerührt. Man gibt 1.1 g $(5.33 \mathrm{mmol})$ 4(1,1,3,3-Tetramethyl-butyl)-phenol und $0.345 \mathrm{~g}(2.5$ mmol) Kaliumcarbonat hinzu und lässt die Reaktionslösung 12 Stunden bei $90^{\circ} \mathrm{C}$ unter Argon und Rückfluss rühren. Nachdem das Reaktionsgemisch auf Raumtemperatur abgekühlt war, wurde die Reaktionslösung mit $800 \mathrm{ml}$ 2N HCl-Lösung versetzt und zwei Stunden gerührt. Das ausgefallene Produkt wurde über eine D4 Fritte abfiltriert, unter Vakuum getrocknet und flash-chromatographisch mit Dichlormethan/Petrolether als Eluent gereinigt. 
Kapitel 6: Experimenteller Teil

Ausbeute: $553 \mathrm{mg}(0.316 \mathrm{mmol})$ als oranger Feststoff $65.9 \%$

FD-Massenspektrum $(8 \mathrm{kV})$ :

$\mathrm{m} / \mathrm{z}\left(\mathrm{u} \mathrm{e}_{0}^{-1}\right)=1686\left(100 \%, \mathrm{M}^{+}\right)$

(berechnet für $\mathrm{C}_{104} \mathrm{H}_{120} \mathrm{Br}_{2} \mathrm{~N}_{2} \mathrm{O}_{8}=1685,88$ )

Schmelzpunkt: $>300{ }^{\circ} \mathrm{C}$

${ }^{1}$ H-NMR-Spektrum,(250 MHz, $\left.\mathrm{CD}_{2} \mathrm{Cl}_{2}, 298 \mathrm{~K}\right)$ :

$\delta(\mathrm{ppm})=8.11(\mathrm{~s}, 4 \mathrm{H}) ; 7.41(\mathrm{~s}, 4 \mathrm{H}) ; 7.36\left(\mathrm{~d},{ }^{3} \mathrm{~J}=8.85 \mathrm{~Hz}, 8 \mathrm{H}\right) ; 6.94\left(\mathrm{~d},{ }^{3} \mathrm{~J}=8.52 \mathrm{~Hz}, 8\right.$ H); 2.72 (septett, $\left.{ }^{3} \mathrm{~J}=6.62 \mathrm{~Hz}, 4 \mathrm{H}\right) ; 1.73$ (s, $\left.8 \mathrm{H}, \mathrm{H}-6\right) ; 1.36(\mathrm{~s}, 24 \mathrm{H}) ; 1.08$ (d, ${ }^{3} \mathrm{~J}=6.65$ $\mathrm{Hz}, 24 \mathrm{H}) ; 0.75$ (s, $36 \mathrm{H})$

${ }^{13}$ C-NMR-Spektrum, Spinechoexperiment (62.5 MHz, $d^{8}$-THF, $\left.298 \mathrm{~K}\right)$ :

$\delta(\mathrm{ppm})=163.54(\mathrm{q}) ; 157.28(\mathrm{q}) ; 153.77(\mathrm{q}) ; 149.53(\mathrm{q}) ; 147.50$ (q); $134.06(\mathrm{q}) ; 131.51$ (q); 128.80 (t); 127.97 (t); 124.15 (q); 123.84 (q); 121.06 (q); 120.87 (q); 120.46 (t); $119.91(\mathrm{t}) ; 57.87(\mathrm{q}) ; 39.11(\mathrm{q}) ; 33.07(\mathrm{q}) ; 32.27(\mathrm{t}) ; 32.05(\mathrm{t}) ; 30.07(\mathrm{t}) ; 23.98(\mathrm{t})$

\section{Elementaranalyse $\left(\mathrm{C}_{104} \mathrm{H}_{120} \mathrm{Br}_{2} \mathrm{~N}_{2} \mathrm{O}_{8}\right)$ :}

Berechnet: C $74.09 \%$, H $7.17 \%$, N $1.66 \%$

Gefunden: C $74.27 \%$, H $7.26 \%$, N $1.61 \%$ 


\section{N,N'-Bis(4-(4'-methoxycarbonylphenyl)-2,6-diisopropylphenyl)-1,6,7,12-tetra[4-}

\section{(1,1,3,3-tetramethylbutyl)phenoxy]-3,4,9,10-perylentetracarbonsäurediimid (3-22)}

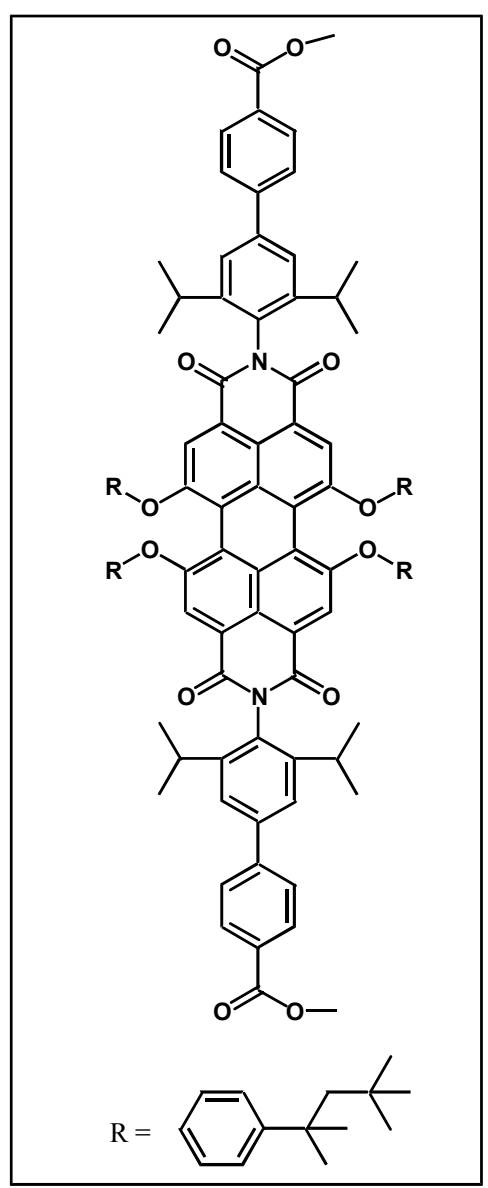

In einem $250 \mathrm{ml}$ Schlenkrohr mit Magnetrüher wurden $400 \mathrm{mg}(0.237 \mathrm{mmol})$ von $3-21$ und $256 \mathrm{mg}(1.422 \mathrm{mmol})$ 4-Methoxycarbonylphenylboronsäure in $60 \mathrm{ml}$ Toluol und $10 \mathrm{ml}$ Methanol gelöst. Anschließend fügte man $10 \mathrm{ml} 2$ M Kaliumcarbonatlösung und $55 \mathrm{mg}(0.0476 \mathrm{mmol})$ Tetrakis(triphenylphosphin)-Palladium $\quad(0) \quad\left(\mathrm{Pd}\left(\mathrm{PPh}_{3}\right)_{4}\right.$ hinzu. Nachdem die Reaktionslösung mehrmals entgast und mit Argon gefüllt wurde, wurde auf $75{ }^{\circ} \mathrm{C}$ erhitzt und unter Lichtausschluss und Rückfluss 15 Stunden gerührt. DC-Kontrolle zeigte vollständige Umsetzung. Das Reaktionsgemisch wurde auf Raumtemperatur abgekühlt. In einem Scheidetrichter wurde die wässrige Phase von der organischen Phase abgetrennt. Die organische Phase wurde mehrmals mit Wasser geschüttelt und wieder von der wässrigen Phase abgetrennt, über Magnesiumsulfat getrocknet und unter Vakuum eingeengt. Das Produkt wurde mit Hilfe von Säulechromatographie mit Dichlormethan/Pertrolether (2:1) vom Rückstand gewonnen.

Ausbeute: 395 mg (0.22 mmol) dunkelroter Farbstoff 93 \%.

Schmelzpunkt: $>300^{\circ} \mathrm{C}$

\section{FD-Massenspektrum (8 kv):}

$\mathrm{m} / \mathrm{z}\left(\mathrm{u} \mathrm{e}_{0}^{-1}\right)=1796.0\left(100 \%, \mathrm{M}^{+}\right)$

(berechnet für $\mathrm{C}_{120} \mathrm{H}_{134} \mathrm{~N}_{2} \mathrm{O}_{12}=1796,35$ ) 


\section{${ }^{1}$ H-NMR-Spektrum,(250 MHz, $\left.\mathrm{CD}_{2} \mathrm{Cl}_{2}, 298 \mathrm{~K}\right)$ :}

$\delta(\mathrm{ppm})=8.14\left(\mathrm{~d},{ }^{3} \mathrm{~J}=\mathrm{Hz}, 4 \mathrm{H}\right) ; 8.10(\mathrm{~s}, 4 \mathrm{H}) ; 7.77\left(\mathrm{~d},{ }^{3} \mathrm{~J}=8.2 \mathrm{~Hz}, 4 \mathrm{H}\right) ; 7.54(\mathrm{~s}, 4 \mathrm{H})$; $7.37\left(\mathrm{~d},{ }^{3} \mathrm{~J}=8.52 \mathrm{~Hz}, 8 \mathrm{H}\right) ; 6.97\left(\mathrm{~d},{ }^{3} \mathrm{~J}=8.82 \mathrm{~Hz}, 8 \mathrm{H}\right) ; 3.92(\mathrm{~s}, 6 \mathrm{H}) ; 2.84-2.71$ (septett, ${ }^{3} \mathrm{~J}$ $=6.65 \mathrm{~Hz}, 4 \mathrm{H}) ; 1.74(\mathrm{~s}, 8 \mathrm{H}) ; 1.37(\mathrm{~s}, 24 \mathrm{H}) ; 1.17\left(\mathrm{~d},{ }^{3} \mathrm{~J}=6.62 \mathrm{~Hz}, 24 \mathrm{H}\right) ; 0.75(\mathrm{~s}, 36 \mathrm{H})$

\section{${ }^{13}$ C-NMR-Spektrum, Spinechoexperiment (62.5 MHz, $d^{8}$-THF, 298 K):}

$\delta(p p m)=166.84(q) ; 163.62(q) ; 157.22(q) ; 153.81(q) ; 147.47(q) ; 147.37(q) ; 146.59$ (q); 141.59 (q); 134.05 (q); 132.46 (q); 130.58 (t); 130.10 (q); 128.72 (t); 127.95 (t); $123.93(\mathrm{q}) ; 123.55(\mathrm{t}) ; 121.03(\mathrm{q}) ; 120.89(\mathrm{q}) ; 120.4(\mathrm{t}) ; 119.91(\mathrm{t}) ; 57.83(\mathrm{q}) ; 52.04(\mathrm{t}) ;$ $39.05(\mathrm{q}) ; 33.03(\mathrm{q}) ; 32.22(\mathrm{t}) ; 32.01(\mathrm{t}) ; 30.10(\mathrm{t}) ; 24.18(\mathrm{t})$

\section{Elementaranalyse $\left(\mathrm{C}_{120} \mathrm{H}_{134} \mathrm{~N}_{2} \mathrm{O}_{12}\right)$ :}

Berechnet: C $80.23 \%$, H $7.52 \%$, N $1.56 \%$

Gefunden: C 80.19\%, H $7.67 \%$, N $1.41 \%$ 
N,N'-Bis(4-(4'-carboxyphenyl)-2,6-diisopropylphenyl)-1,6,7,12-tetra[4-(1,1,3,3tetramethylbutyl)phenoxy]-3,4,9,10-perylentetracarbonsäurediimid (3-23)

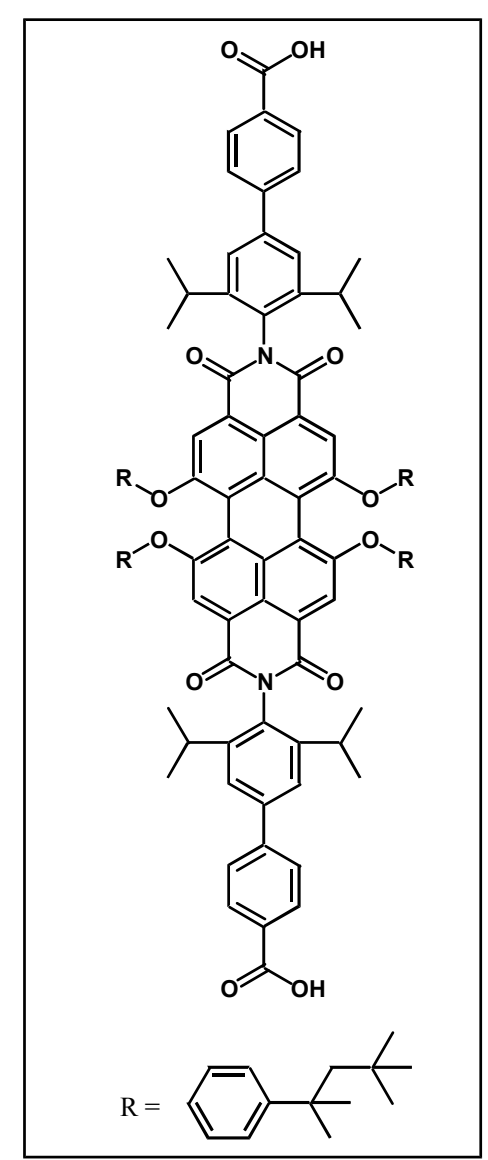

$180 \mathrm{mg}(0.1 \mathrm{mmol}) 3-22$ wurden in $15 \mathrm{ml}$ THF gelöst. Man fügte $114 \mathrm{mg}(2.026 \mathrm{mmol}) \mathrm{KOH}$ gelöst in $2.5 \mathrm{ml}$ dest. Wasser hinzu. Anschließend wurde der Kolben mehrmals entgast und mit Argon gefüllt. Die Reaktionslösung wurde für 24 Stunden bei $80^{\circ} \mathrm{C}$ gerührt. DC-Kontrolle zeigte vollständige Reaktion. Nachdem man die Reaktionslösung auf Raumtemperatur abkühlte, wurde das Produkt in $300 \mathrm{ml}(2 \mathrm{~N}) \mathrm{HCl}$ ausgefällt. Im Anschluss wurde das Produkt abfiltriert und unter Vakuum getrocknet.

Ausbeute: $169 \mathrm{mg}$ (0.095 mmol), $96 \%$, als dunkelroter Feststoff

\section{FD-Massenspektrum (8 kv):}

$\mathrm{m} / \mathrm{z}\left(\mathrm{u} \mathrm{e}_{0}^{-1}\right)=1767.6\left(100 \%, \mathrm{M}^{+}\right)$

(berechnet für $\mathrm{C}_{118} \mathrm{H}_{130} \mathrm{~N}_{2} \mathrm{O}_{12}=1768,30$ )

Schmelzpunkt: $>300{ }^{\circ} \mathrm{C}$

\section{${ }^{1}$ H-NMR-Spektrum,(250 MHz, $d^{8}$-THF, 298 K):}

$\delta(\mathrm{ppm})=8.18(\mathrm{~s}, 4 \mathrm{H}) ; 8.15\left(\mathrm{~d},{ }^{3} \mathrm{~J}=8.52 \mathrm{~Hz}, 4 \mathrm{H}\right) ; 7.78\left(\mathrm{~d},{ }^{3} \mathrm{~J}=8.2 \mathrm{~Hz}, 4 \mathrm{H}\right) ; 7.56(\mathrm{~s}, 4$

$\mathrm{H}) ; 7.41\left(\mathrm{~d},{ }^{3} \mathrm{~J}=8.52 \mathrm{~Hz}, 8 \mathrm{H}\right) ; 6.99\left(\mathrm{~d},{ }^{3} \mathrm{~J}=8.52 \mathrm{~Hz}, 8 \mathrm{H}\right) ; 2.87\left(\right.$ septett, ${ }^{3} \mathrm{~J}=6.62 \mathrm{~Hz}, 4$

$\mathrm{H}) ; 1.72(\mathrm{~s}, 8 \mathrm{H}) ; 1.37(\mathrm{~s}, 24 \mathrm{H}) ; 1.17\left(\mathrm{~d},{ }^{3} \mathrm{~J}=6.62 \mathrm{~Hz}, 24 \mathrm{H}\right), 0.76(\mathrm{~s}, 36 \mathrm{H})$ 
${ }^{13}$ C-NMR-Spektrum, Spinechoexperiment (62.5 MHz, $d^{8}$-THF, 298 K):

$\delta(p p m)=167.46(q) ; 163.62(q) ; 157.21(q) ; 153.8(q) ; 147.41(q) ; 146.26(q) ; 141.77(q) ;$ $134.05(\mathrm{q}) ; 132.32$ (q); 130.85 (t); $130.77(\mathrm{q}) ; 128.71(\mathrm{t}) ; 127.81(\mathrm{t}) ; 123.92(\mathrm{q}) ; 123.54$ (t); $121.02(\mathrm{q}) ; 120.88(\mathrm{q}) ; 120.39(\mathrm{t}) ; 119.91(\mathrm{t}) ; 57.82(\mathrm{q}) ; 39.04(\mathrm{q}) ; 33.02(\mathrm{q}) ; 32.21(\mathrm{t}) ;$ $32.01(\mathrm{t}) ; 30.09(\mathrm{t}) ; 24.18(\mathrm{t})$

Elementaranalyse $\left(\mathrm{C}_{118} \mathrm{H}_{130} \mathbf{N}_{2} \mathrm{O}_{12}\right)$ :

Berechnet: C $80.15 \%$, H $7.41 \%$, N $1.58 \%$

Gefunden: C $79.33 \%$, H $7.59 \%$, N $1.66 \%$

N-(4-Brom-2,6-diisopropylphenyl)-N'-(2,6-diisopropylphenyl)-1,6,7,12-tetrachlor3,4,9,10-perylentetracarbonsäurediimid (2-29)

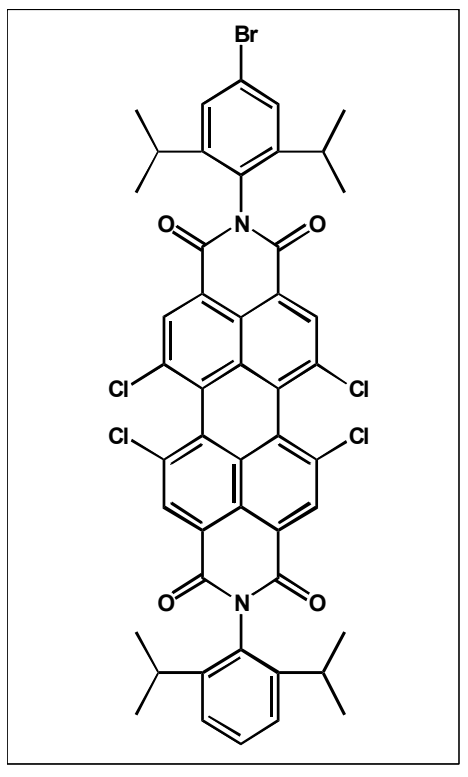

Analog zu 3-20 wurden 2g von 1,6,7,12Tetrachlorperylen3,4,9,10-tetracarbonsäuredianhydrid $(3.77 \mathrm{mmol}) \mathrm{mit} 2.416$ g von 4-Brom-2,6-diisopropyl-phenylamin $(9.43 \mathrm{mmol})$ und $1.67 \mathrm{~g}$ von 2,6-diisopropyl-phenylamin $(9.43 \mathrm{mmol})$ in Propionsäure umgesetzt. Die Löslichkeit von 3-29 in organischen Lösungsmitteln wurde durch die Phenoxylierung (siehe die Synthese von 3-30) verbessert. Durch die Aufreinigung mit Hilfe von Säulechromatographie (Eluent: Toluol) wurde 3-29 zum großen Teil aufgereinigt. Man erhielt ein Gemisch aus den drei möglichen Produkten mit 3-29 als dem Hauptprodukt. Deshalb wurde auf die Charakterisierung dieses Produkts mit Hilfe von NMR-Spektroskopie verzichtet, da die Spektren Verunreinigungen enthalten würden.

Ausbeute: $1.36 \mathrm{~g}(1.47 \mathrm{mmol})$ oranger Feststoff, $39 \%$ 


\section{FD-Massenspektrum (8 kv):}

$\mathrm{m} / \mathrm{z}\left(\mathrm{u} \mathrm{e}_{0}^{-1}\right)=927.4\left(100 \%, \mathrm{M}^{+}\right)$

(berechnet für $\mathrm{C}_{48} \mathrm{H}_{37} \mathrm{BrCl}_{4} \mathrm{~N}_{2} \mathrm{O}_{4}=927,53$ )

Schmelzpunkt: $>300^{\circ} \mathrm{C}$

N-(4-Brom-2,6-diisopropylphenyl)-N'-(2,6-diisopropylphenyl)-1,6,7,12-tetra[4(1,1,3,3-tetramethylbutyl)phenoxy]-3,4,9,10-perylentetracarbonsäurediimid (3-30)

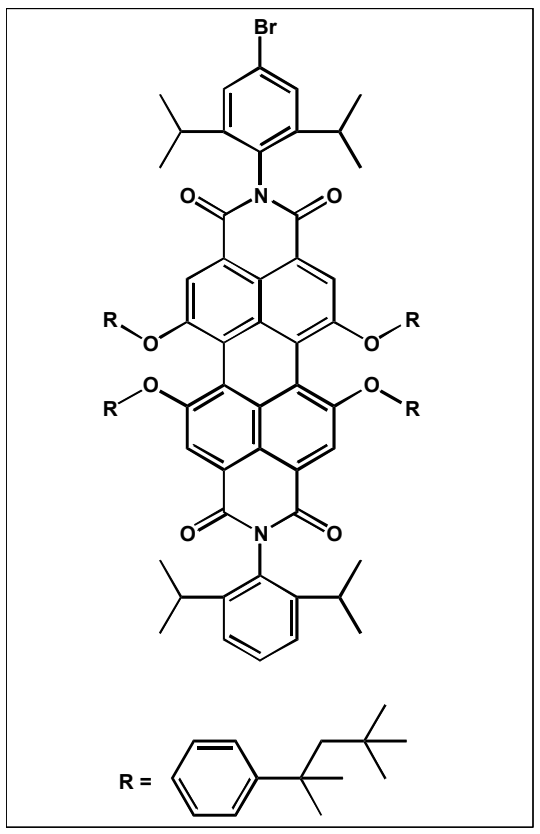

Analog zu 3-21 wurde $1 \mathrm{~g}$ von 3-29 (1.078 mmol) mit $2.224 \mathrm{~g}$ von 4-(1,1,3,3-Tetramethyl-butyl)-phenol (10.78 mmol) und $0.745 \mathrm{~g}$ Kaliumcarbonat $(5.39 \mathrm{mmol})$ in NMP zur Reaktion gebracht. Die Aufreinigung erfolgte säulechromatographisch mit Dichlormethan/ Petrolether (1:1.5) als Eluent.

Ausbeute: $1.26 \mathrm{~g}(1.47 \mathrm{mmol})$ roter Farbstoff, $73 \%$

\section{Maldi-Tof-Massenspektrum:}

$\mathrm{m} / \mathrm{z}_{\left(\mathrm{u} \mathrm{e}_{0}^{-1}\right)}=1608.0\left(100 \%, \mathrm{M}^{+}\right)$

(berechnet für $\mathrm{C}_{104} \mathrm{H}_{121} \mathrm{BrN}_{2} \mathrm{O}_{8}=1606.99$ )

Schmelzpunkt: $>300{ }^{\circ} \mathrm{C}$

\section{${ }^{1} \mathrm{H}-\mathrm{NMR}-$ Spektrum,(250 MHz, $\left.\mathrm{C}_{2} \mathrm{D}_{2} \mathrm{Cl}_{4}, 298 \mathrm{~K}\right)$ :}

$\delta(\mathrm{ppm})=8.09(\mathrm{~s}, 4 \mathrm{H}) ; 7.36\left(\mathrm{~m},{ }^{3} \mathrm{~J}=7.6 \mathrm{~Hz} 1 \mathrm{H}\right) ; 7.29(\mathrm{~s}, 2 \mathrm{H}) ; 7.22\left(\mathrm{~d},{ }^{3} \mathrm{~J}=8.2 \mathrm{~Hz} 8 \mathrm{H}\right)$;

$7.16(\mathrm{~s}, 2 \mathrm{H}) ; 6.85\left(\mathrm{~d},{ }^{3} \mathrm{~J}=6.95 \mathrm{~Hz}, 8 \mathrm{H}\right) ; 2.65$ (septett, $\left.{ }^{3} \mathrm{~J}=6.62 \mathrm{~Hz}, 4 \mathrm{H}\right) ; 1.63$ (s, $\left.8 \mathrm{H}\right)$; $1.27(\mathrm{~s}, 24 \mathrm{H}) ; 1.03\left(\mathrm{~d},{ }^{3} \mathrm{~J}=5.37 \mathrm{~Hz}, 24 \mathrm{H}\right) ; 0.67(\mathrm{~s}, 36 \mathrm{H})$ 


\section{${ }^{13}$ C-NMR-Spektrum, Spinechoexperiment (62.5 MHz, $d^{8}$-THF, 298 K):}

$\delta(\mathrm{ppm})=163.55(\mathrm{q}) ; 157.26(\mathrm{q}) ; 157.16(\mathrm{q}) ; 153.77(\mathrm{q}) ; 149.50(\mathrm{q}) ; 147.41(\mathrm{q}) ; 146.67$ (q) ; 134.05 (q); 132.14 (q); 131.50 (q); 129.77 (t); 128.72 (t); 127,92 (t); 124.31 (t); 124.07 (q); 123.69 (q); $121.12(\mathrm{q}) ; 120.86(\mathrm{q}) ; 120.38(\mathrm{t}) ; 119.89(\mathrm{t}) ; 57.83(\mathrm{q}) ; 39.06(\mathrm{q})$; $33.03(\mathrm{q}) ; 32.23(\mathrm{t}) ; 32.01(\mathrm{t}) ; 30.02(\mathrm{t}) ; 29.88(\mathrm{t}) ; 24.23(\mathrm{t}) ; 23.93(\mathrm{t})$

\section{Elementaranylse $\left(\mathrm{C}_{104} \mathrm{H}_{121} \mathrm{BrN}_{2} \mathrm{O}_{8}\right)$ :}

Berechnet: C $77.73 \%$, H $7.59 \%$, N $1.74 \%$

Gefunden: C $77.69 \%$, H $7.56 \%$, N $1.66 \%$

\section{N-(4-(4'-Methoxycarbonylphenyl)-2,6-diisopropylphenyl)-N'-(2,6-} diisopropylphenyl)-1,6,7,12-tetra[4-(1,1,3,3-tetramethylbutyl)phenoxy]-3,4,9,10perylentetracarbonsäurediimid (3-31)

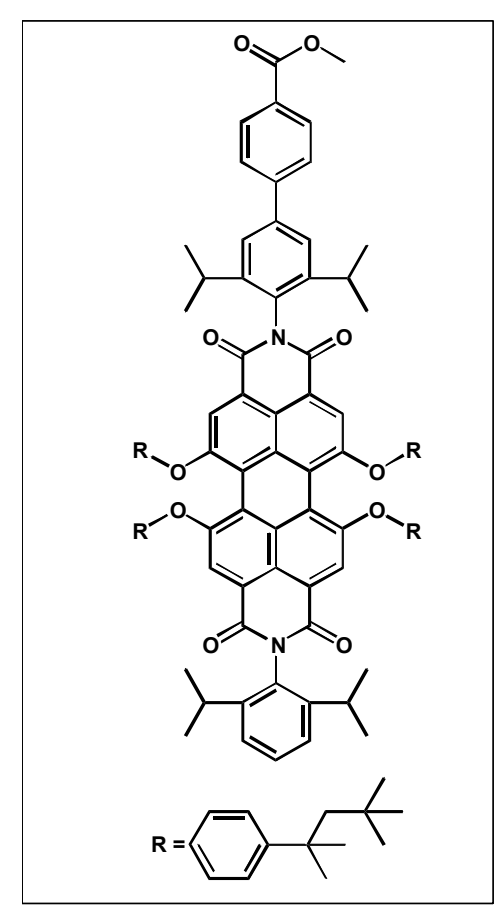

Analog zu 3-22 wurde $1 \mathrm{~g}$ von 3-30 (0.622 mmol) mit 0.56 g von 4-Methoxycarbonylphenylboronsäure $(3.11 \mathrm{mmol})$, $0.0359 \mathrm{~g} \mathrm{Pd}(\mathrm{PPh} 3) 4-$ Katalysator $(0.0311 \mathrm{mmol})$ und $2 \mathrm{M}$ Kaliumcarbonat in einem Gemisch aus Methanol und Toluol zur Reaktion gebracht. Das Produkt wurde mit Hilfe von Säulechromatographie mit Dichlormethan als Eluent aufgereinigt.

Ausbeute: $0.84 \mathrm{~g}(0.505 \mathrm{mmol})$ roter Farbstoff, $82 \%$

\section{Maldi-Tof-Massenspektrum:}

$\mathrm{m} / \mathrm{z}\left(\mathrm{u} \mathrm{e}_{0}^{-1}\right)=1663.0\left(100 \%, \mathrm{M}^{+}\right)$

(berechnet für $\mathrm{C}_{112} \mathrm{H}_{128} \mathrm{~N}_{2} \mathrm{O}_{10}=1662.22 \mathrm{~g} / \mathrm{mol}$ )

Schmelzpunkt: $>300^{\circ} \mathrm{C}$ 


\section{${ }^{1}$ H-NMR-Spektrum,(250 MHz, $d^{8}$-THF, 298 K):}

$\delta(\mathrm{ppm})=8.16(\mathrm{~s}, 4 \mathrm{H}) ; 8.09\left(\mathrm{~d},{ }^{3} \mathrm{~J}=8.52 \mathrm{~Hz}, 2 \mathrm{H}\right) ; 7.78\left(\mathrm{~d},{ }^{3} \mathrm{~J}=8.22 \mathrm{~Hz}, 2 \mathrm{H}\right) ; 7.55(\mathrm{~s}$, $2 \mathrm{H}) ; 7.39\left(\mathrm{~d},{ }^{3} \mathrm{~J}=8.52 \mathrm{~Hz}, 8 \mathrm{H}\right) ; 7.31(\mathrm{~m}, 1 \mathrm{H}) ; 7.24\left(\mathrm{~d},{ }^{3} \mathrm{~J}=6.95 \mathrm{~Hz}, 2 \mathrm{H}\right) ; 6.97\left(\mathrm{~d},{ }^{3} \mathrm{~J}=\right.$ $8.52 \mathrm{~Hz}, 8 \mathrm{H}) ; 3.87$ (s, $3 \mathrm{H}) ; 2.85$ (septett, $\left.{ }^{3} \mathrm{~J}=6.3 \mathrm{~Hz}, 4 \mathrm{H}\right) ; 1.76$ (s, $\left.8 \mathrm{H}\right) ; 1.36$ (s, $\left.24 \mathrm{H}\right)$; $1.16\left(\mathrm{~d},{ }^{3} \mathrm{~J}=6.62 \mathrm{~Hz}, 12 \mathrm{H}\right) ; 1.08\left(\mathrm{~d},{ }^{3} \mathrm{~J}=6.62 \mathrm{~Hz}, 12 \mathrm{H}\right) ; 0.75(\mathrm{~s}, 36 \mathrm{H})$

${ }^{13}$ C-NMR-Spektrum, Spinechoexperiment (62.5 MHz, $d^{8}$-THF, 298 K):

$\delta(\mathrm{ppm})=166.85(\mathrm{q}) ; 163.64(\mathrm{q}) ; 157.20$ (q); 153.82 (q); 147.49 (q); 147.37 (q); 146.69 (q) ; 146.61 (q); 141.6 (q) 134.05 (q); 132.48 (q); 132.16 (q); 130.60 (t); 130.11 (q); $129.77(\mathrm{t}) ; 128.72(\mathrm{t}) ; 127,97(\mathrm{t}) ; 124.31(\mathrm{t}) ; 124.03(\mathrm{q}) ; 123.89(\mathrm{t}) ; 123.56(\mathrm{t}) ; 121.07(\mathrm{q}) ;$ $120.93(\mathrm{q}) ; 120.43(\mathrm{t}) ; 120.38(\mathrm{t}) 119.92(\mathrm{t}) ; 57.84(\mathrm{q}) ; 52.05(\mathrm{t}) ; 39.06(\mathrm{q}) ; 33.04(\mathrm{q})$ $32.02(\mathrm{t}) ; 30.11(\mathrm{t}) ; 29.89(\mathrm{t}) ; 24.24(\mathrm{t}) ; 24.19(\mathrm{t})$

\section{Elementaranalyse $\left(\mathrm{C}_{112} \mathrm{H}_{128} \mathrm{~N}_{2} \mathrm{O}_{10}\right)$ :}

Berechnet: C $80.93 \%$, H 7.76 \%, N $1.69 \%$

Gefunden: C $80.92 \%$, H $7.71 \%$, N $1.58 \%$ 
N-(4-(4 '-Carboxyphenyl)-2,6-diisopropylphenyl)-N'-(2,6-diisopropylphenyl)-

1,6,7,12-tetra[4-(1,1,3,3-tetramethylbutyl)phenoxy]-3,4,9,10perylentetracarbonsäurediimid (3-32)

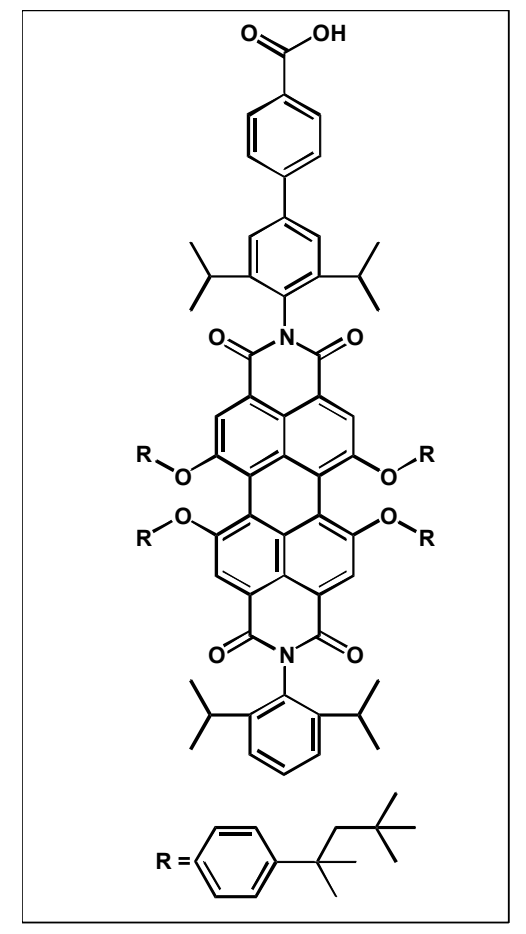

$500 \mathrm{mg}$ (0.3 mmol) 3-31 wurden in $15 \mathrm{ml}$ THF gelöst und mit $169 \mathrm{mg}(3.01 \mathrm{mmol}) \mathrm{KOH}$ gelöst in $2.5 \mathrm{ml}$ dest. Wasser gemischt. Anschließend wurde der Kolben mehrmals entgast und mit Argon gefüllt. Die Reaktionslösung wurde für 24 Stunden bei $80^{\circ} \mathrm{C}$ gerührt. DC-Kontrolle zeigte vollständige Reaktion. Nach der Abkühlung der Reaktionslösung auf Raumtemperatur wurde das Produkt in $300 \mathrm{ml}(2 \mathrm{~N}) \mathrm{HCl}$ ausgefällt. Anschließend wurde das Produkt filtriert und unter Vakuum getrocknet.

Ausbeute: $0.435 \mathrm{~g}(0.264 \mathrm{mmol})$ roter Farbstoff, $88 \%$

\section{Maldi-Tof-Massenspektrum:}

$\mathrm{m} / \mathrm{z}\left(\mathrm{u} \mathrm{e}_{0}^{-1}\right)=1649.0\left(100 \%, \mathrm{M}^{+}\right)$

(berechnet für $\mathrm{C}_{111} \mathrm{H}_{126} \mathrm{~N}_{2} \mathrm{O}_{10}=1648.20 \mathrm{~g} / \mathrm{mol}$ )

Schmelzpunkt: $>300{ }^{\circ} \mathrm{C}$

\section{${ }^{1}$ H-NMR-Spektrum,(250 MHz, $d^{8}$-THF, 298 K):}

$\delta(\mathrm{ppm})=8.17(\mathrm{~s}, 4 \mathrm{H}) ; 8.10\left(\mathrm{~d},{ }^{3} \mathrm{~J}=8.22 \mathrm{~Hz}, 2 \mathrm{H}\right) ; 7.77\left(\mathrm{~d},{ }^{3} \mathrm{~J}=7.90 \mathrm{~Hz}, 2 \mathrm{H}\right) ; 7.56(\mathrm{~s}$, $2 \mathrm{H}) ; 7.40\left(\mathrm{~d},{ }^{3} \mathrm{~J}=8.52 \mathrm{~Hz}, 8 \mathrm{H}\right) ; 7.32(\mathrm{~m}, 1 \mathrm{H}) ; 7.25\left(\mathrm{~d},{ }^{3} \mathrm{~J}=7.27 \mathrm{~Hz}, 2 \mathrm{H}\right) ; 6.98\left(\mathrm{~d},{ }^{3} \mathrm{~J}=\right.$ $7.87 \mathrm{~Hz}, 8 \mathrm{H}) ; 2.83$ (septett, $\left.{ }^{3} \mathrm{~J}=6.95 \mathrm{~Hz}, 4 \mathrm{H}\right) ; 1.77(\mathrm{~s}, 8 \mathrm{H}) ; 1.37$ (s, $\left.24 \mathrm{H}\right) ; 1.17\left(\mathrm{~d},{ }^{3} \mathrm{~J}=\right.$ $6.62 \mathrm{~Hz}, 12 \mathrm{H}) ; 1.09\left(\mathrm{~d},{ }^{3} \mathrm{~J}=6.62 \mathrm{~Hz}, 12 \mathrm{H}\right) ; 0.76(\mathrm{~s}, 36 \mathrm{H})$ 


\section{${ }^{13}$ C-NMR-Spektrum, Spinechoexperiment (62.5 MHz, $d^{8}$-THF, 298 K):}

$\delta(\mathrm{ppm})=167.35(\mathrm{q}) ; 164.42(\mathrm{q}) ; 157.71(\mathrm{q}) ; 154.12(\mathrm{q}) ; 147.84(\mathrm{q}) ; 147.67(\mathrm{q}) ; 146.96$ (q) ; 146.63 (q); 134.02 (q); 132.62 (q); 132.22 (q); 130.83 (t); 130.46 (q); 129.98 (t); $128.88(\mathrm{t}) ; 128,20(\mathrm{t}) ; 124.56(\mathrm{t}) ; 124.21(\mathrm{q}) ; 124.07(\mathrm{t}) ; 123.78(\mathrm{t}) ; 121.24(\mathrm{q}) ; 121.09(\mathrm{q}) ;$ $120.68(\mathrm{t}) ; 120.57(\mathrm{t}) 120.08(\mathrm{t}) ; 57.82(\mathrm{q}) ; 39.31(\mathrm{q}) ; 33.26(\mathrm{q}) ; 32.18(\mathrm{t}) ; 30.23(\mathrm{t}) ; 30.15$ $(\mathrm{t}) ; 24.68(\mathrm{t}) ; 24.36(\mathrm{t})$

Elementaranalyse $\left(\mathrm{C}_{111} \mathrm{H}_{126} \mathrm{~N}_{2} \mathrm{O}_{10}\right)$ :

Berechnet: C $80.89 \%$, H $7.71 \%$, N $1.70 \%$

Gefunden: C $79.90 \%$, H $7.65 \%$, N $1.52 \%$

\section{N-(4-(4 -Aldehyd-phenyl)-2,6-diisopropylphenyl)-N'-(2,6-diisopropylphenyl)- 1,6,7,12-tetra[4-(1,1,3,3-tetramethylbutyl)phenoxy]-3,4,9,10- perylentetracarbonsäurediimid (3-36)}

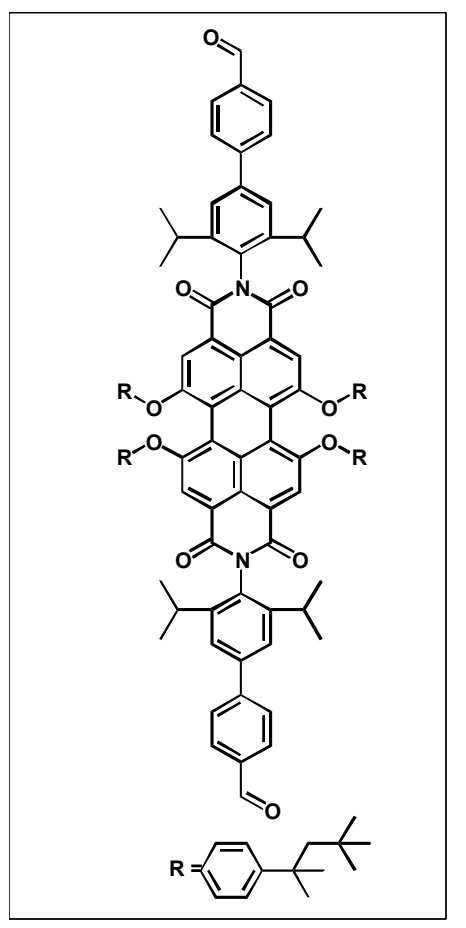

In einem $250 \mathrm{ml}$ Schlenkrohr mit Magnetrührer wurden 500 $\mathrm{mg}(0.296 \mathrm{mmol})$ von $3-21$ und $267 \mathrm{mg}$ (1.78 mmol) 4Aldehyd-phenylboronsäure in $70 \mathrm{ml}$ Toluol und $12 \mathrm{ml}$ Methanol gelöst und mit $10 \mathrm{ml} 2 \mathrm{M}$ Kaliumcarbonatlösung gemischt. Im Anschluss wurden $51.3 \mathrm{mg}$ (0.044 mmol) Tetrakis(triphenylphosphin)-Palladium(0), $\quad \mathrm{Pd}\left(\mathrm{PPh}_{3}\right)_{4}$ hinzugefügt. Nachdem die Reaktionslösung mehrmals entgast und mit Argon gefüllt wurde, erhitzte man auf $75^{\circ} \mathrm{C}$ und ließ die Reaktionslösung unter Lichtausschluss und Rückfluss 15 Stunden rühren. DC-Kontrolle zeigte vollständige Umsetzung. Nach der Abkühlung auf Raumtemperatur wurde das Reaktionsgemisch mit einem Gemisch aus Dichlormethan und Wasser geschüttelt und in einem Scheidetrichter die wässrige Phase von der organischen Phase abgetrennt. Die organische Phase wurde 
mehrmals mit Wasser geschüttelt und wieder von der wässrigen Phase abgetrennt, über Magnesiumsulfat getrocknet und unter Vakuum eingeengt. Das Produkt wurde mit Hilfe von Säulechromatographie mit Dichlormethan als Eluent aufgereinigt.

Ausbeute: $0.395 \mathrm{~g}(0.227 \mathrm{mmol})$ roter Farbstoff, $77 \%$

\section{Maldi-Tof-Massenspektrum:}

$\mathrm{m} / \mathrm{z}_{\left(\mathrm{u} \mathrm{e}_{0}^{-1}\right)}=1737.0\left(100 \%, \mathrm{M}^{+}\right)$

(berechnet für $\mathrm{C}_{118} \mathrm{H}_{130} \mathrm{~N}_{2} \mathrm{O}_{10}=1736.30 \mathrm{~g} / \mathrm{mol}$ )

Schmelzpunkt: $>300^{\circ} \mathrm{C}$

\section{${ }^{1}$ H-NMR-Spektrum,(250 MHz, $\left.\mathrm{CD}_{2} \mathrm{Cl}_{2}, 298 \mathrm{~K}\right)$ :}

$\delta(\mathrm{ppm})=10.22(\mathrm{~s}, 2 \mathrm{H}) ; 8.29(\mathrm{~s}, 4 \mathrm{H}) ; 8.15\left(\mathrm{~d},{ }^{3} \mathrm{~J}=8.52 \mathrm{~Hz} 4 \mathrm{H}\right) ; 8.02\left(\mathrm{~d},{ }^{3} \mathrm{~J}=8.52 \mathrm{~Hz}\right.$ 4H); $7.70(\mathrm{~s}, 4 \mathrm{H}) ; 7.52\left(\mathrm{~d},{ }^{3} \mathrm{~J}=8.52 \mathrm{~Hz}, 8 \mathrm{H}\right) ; 7.12\left(\mathrm{~d},{ }^{3} \mathrm{~J}=8.82 \mathrm{~Hz}, 8 \mathrm{H}\right) ; 2.97$ (septett, $\left.{ }^{3} \mathrm{~J}=6.62 \mathrm{~Hz}, 4 \mathrm{H}\right) ; 1.89(\mathrm{~s}, 8 \mathrm{H}) ; 1.52(\mathrm{~s}, 24 \mathrm{H}) ; 1.32\left(\mathrm{~d},{ }^{3} \mathrm{~J}=6.62 \mathrm{~Hz}, 24 \mathrm{H}\right) ; 0.90(\mathrm{~s}, 36$ H)

\section{${ }^{13}$ C-NMR-Spektrum, Spinechoexperiment (62.5 MHz, $d^{8}$-THF, $\left.298 \mathrm{~K}\right)$ :}

$\delta(p p m)=169.93(q) ; 163.64(q) ; 157.23(q) ; 153.82(q) ; 147.7(q) ; 147.37(q) ; 146.69$ (q); 141.18 (q); 134.07 (q); 132.92 (q); 132.16 (q); 131,43 (t); 129.79 (t); 128.73 (t); $128.54(\mathrm{t}) ; 125.36(\mathrm{q}) ; 124.33(\mathrm{t}) ; 124.04(\mathrm{q}) ; 123.86(\mathrm{q}) ; 123.73(\mathrm{t}) ; 121.11(\mathrm{q}) ; 120.93$ (q); $120.44(\mathrm{t}) ; 119.94(\mathrm{t}) ; 57.83(\mathrm{q}) ; 49.00(\mathrm{t}) ; 39.07(\mathrm{q}) ; 34.86(\mathrm{q}) ; 33.05(\mathrm{q}) ; 32.24(\mathrm{t})$; $32.03(\mathrm{t}) ; 29.09(\mathrm{t}) ; 24.25(\mathrm{t})$

\section{Elementaranalyse $\left(\mathrm{C}_{118} \mathrm{H}_{130} \mathrm{~N}_{2} \mathrm{O}_{10}\right)$ :}

Berechnet: C $81.63 \%$, H $7.55 \%$, N $1.61 \%$

Gefunden: C $81.68 \%$, H $7.73 \%$, N $1.66 \%$ 
N,N'-Bis(4-(5-hexyn-1-ol))-2,6-diisopropylphenyl)-1,6,7,12-tetra[4-(1,1,3,3tetramethylbutyl)phenoxy]-3,4,9,10-perylentetracarbonsäurediimid (3-38)

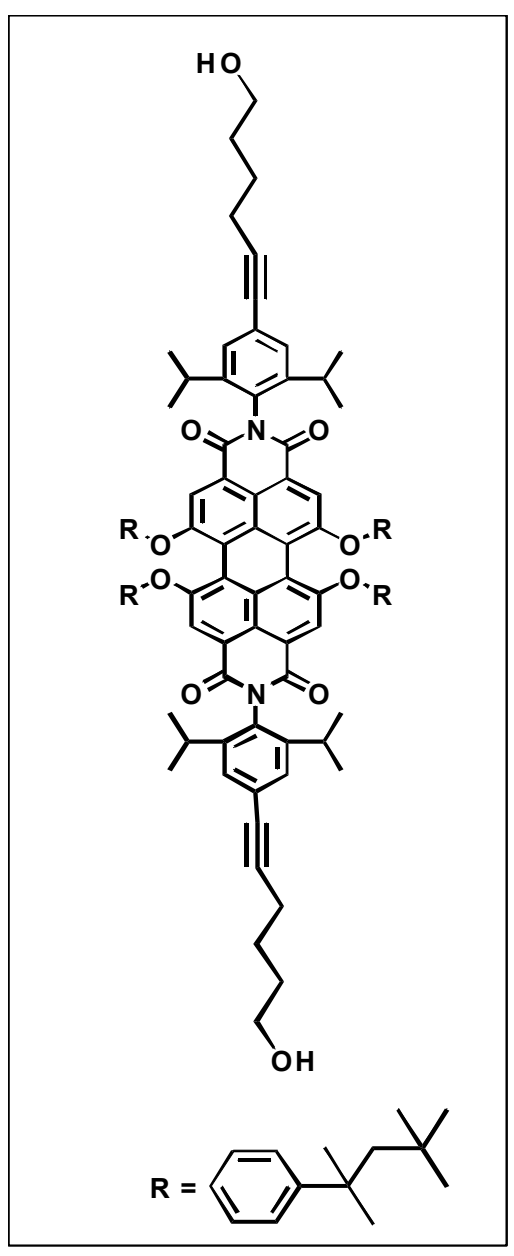

In einem sorgfältig inertisierten Schlenkkolben wurden $500 \mathrm{~g}$ von 3-21 (0.296 mmol) und $0.65 \mathrm{ml}$ 5-Hexyn-1-ol (5.92 mmol), $22.9 \mathrm{mg} \mathrm{CuI} \mathrm{(0.12} \mathrm{mmol),} 31.5 \mathrm{mg}$ PPh3

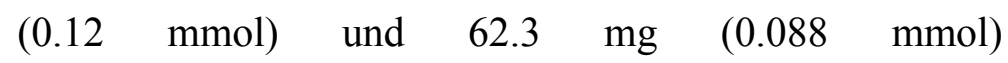
Bis(triphenylphosphin)palladium(II)-dichlorid-Katalysator $\left(\mathrm{Pd}\left(\mathrm{PPh}_{3}\right)_{2} \mathrm{Cl}_{2}\right)$ in $60 \mathrm{ml}$ THF (trocken) und $20 \mathrm{ml}$ Triethylamin (trocken) zur Reaktion gebracht. Nach einer Reaktionszeit von 24 Stunden bei $80{ }^{\circ} \mathrm{C}$ und der Besttätigung der Umsetzung des Ausgangstoffs mit Hilfe von FD-Massenspektrum wurde die Reaktion abgebrochen. Das Reaktionsgemisch wurde mit Wasser und anschließend mit 2N Salzsäure versetzt. Man extrahierte mehrmals mit Dichlormethan und schüttelte die organische Phase mit kalt gesättigter, wässriger Ammoniumchloridlösung aus. Im Anschluss wurde die organische Phase mit Wasser gewaschen und über Magnesiumsulfat getrocknet. Die Aufreinigung erfolgte säulenchromatographisch mit einem Lösungsmittelgemisch aus Ethylacetat und Dichlormethan (1:1.5) als Eluent. Nach dem Einengen der erhaltenen Fraktionen wurde das Produkt im Ölpumpenvakuum getrocknet.

Ausbeute: $0.346 \mathrm{~g}(0.201 \mathrm{mmol})$ roter Farbstoff, $68 \%$

\section{Maldi-Tof-Massenspektrum:}

$\mathrm{m} / \mathrm{z}\left(\mathrm{u} \mathrm{e}_{0}^{-1}\right)=1721.0\left(100 \%, \mathrm{M}^{+}\right)$

(berechnet für $\mathrm{C}_{118} \mathrm{H}_{130} \mathrm{~N}_{2} \mathrm{O}_{10}=1720.34 \mathrm{~g} / \mathrm{mol}$ )

Schmelzpunkt: $>300^{\circ} \mathrm{C}$ 


\section{${ }^{1} \mathrm{H}-\mathrm{NMR}-$ Spektrum,(250 MHz, $\left.\mathrm{CD}_{2} \mathrm{Cl}_{2}, 298 \mathrm{~K}\right)$ :}

$\delta(\mathrm{ppm})=8.02(\mathrm{~s}, 4 \mathrm{H}) ; 7.27(\mathrm{~s}, 4 \mathrm{H}) ; 7.24\left(\mathrm{~d},{ }^{3} \mathrm{~J}=6.3 \mathrm{~Hz}, 8 \mathrm{H}\right) ; 6.86\left(\mathrm{~d},{ }^{3} \mathrm{~J}=8.52 \mathrm{~Hz}, 8 \mathrm{H}\right)$

$3.59\left(\mathrm{~m},{ }^{3} \mathrm{~J}=6.0 \mathrm{~Hz}, 4 \mathrm{H}\right) ; 2.59$ (septett, $\left.{ }^{3} \mathrm{~J}=6.95 \mathrm{~Hz}, 4 \mathrm{H}\right) ; 2.42\left(\mathrm{t},{ }^{3} \mathrm{~J}=6.0 \mathrm{~Hz}, 4 \mathrm{H}\right)$; $1.65(\mathrm{~s}, 8 \mathrm{H}) ; 1.62(\mathrm{~m}, 8 \mathrm{H}) ; 1.28(\mathrm{~s}, 24 \mathrm{H}) ; 0.99\left(\mathrm{~d},{ }^{3} \mathrm{~J}=6.95 \mathrm{~Hz}, 24 \mathrm{H}\right) ; 0.66(\mathrm{~s}, 36 \mathrm{H})$

\section{${ }^{13} \mathrm{C}-\mathrm{NMR}-$ Spektrum, Spinechoexperiment (62.5 $\left.\mathrm{MHz}, \mathrm{CD}_{2} \mathrm{Cl}_{2}, 298 \mathrm{~K}\right)$ :}

$\delta(p p m)=164.81(q) ; 158.14(q) ; 154.29(q) ; 150.06(q) ; 147.96(q) ; 134.73(q) ; 132.09$ (q); $129.44(\mathrm{t}) ; 128.61$ (t); 124.78 (q); 124.33 (q); 121.85 (q); 121.26 (q); 120.91 (t); $120.25(\mathrm{t}) ; 88.32$ (q); 77.92 (q); 61.54 (q); 57.37 (q); 39.02 (q); 33.55 (q); 32.39 (t); 32.18 $(\mathrm{t}) ; 31.75(\mathrm{q}) ; 30.07(\mathrm{t}) ; 25.88(\mathrm{q}) ; 23.77(\mathrm{t}) ; 19.66(\mathrm{q})$

Elementaranalyse $\left(\mathrm{C}_{118} \mathrm{H}_{130} \mathrm{~N}_{2} \mathrm{O}_{10}\right)$ :

Berechnet: C $80.99 \%$, H $8.09 \%$, N $1.63 \%$

Gefunden: C $80.14 \%$, H $8.23 \%$, N $1.55 \%$

\section{N,N'-Bis(4-bromdiisopropylphenyl)-1,6,7,12-tetraphenoxy-3,4,9,10-} perylentetracarboxdiimid (3-46)

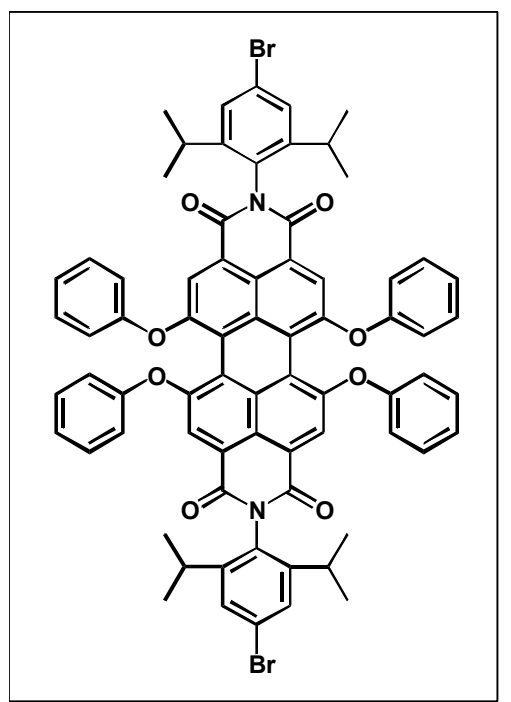

Analog zu 3-21 wurde $1 \mathrm{~g}$ von 3-20 (0.99 mmol) mit 1.12 g Phenol (11.9 mmol) und 0.684 g Kaliumcarbonat (4.95 mmol) in NMP umgesetzt. Nach einer Reaktionsdauer von 12 Stunden bei $90{ }^{\circ} \mathrm{C}$ und DC-Kontrolle wurde die Reaktion abgebrochen. Die Aufreinigung erfolgte säulechromatographisch mit Dichlormethan als Eluent.

Ausbeute: 1.12 g (0.90 mmol) roter Farbstoff, $91 \%$ 
Kapitel 6: Experimenteller Teil

FD-Massenspektrum (FD, 8kV):

$\mathrm{m} / \mathrm{z}\left(\mathrm{u} \mathrm{e}_{0}^{-1}\right)=1238.10\left(100 \%, \mathrm{M}^{+}\right)$

(berechnet für $\mathrm{C}_{72} \mathrm{H}_{56} \mathrm{Br}_{2} \mathrm{~N}_{2} \mathrm{O}_{8}=1237.03 \mathrm{~g} / \mathrm{mol}$ )

Schmelzpunkt: $>300^{\circ} \mathrm{C}$

${ }^{1} \mathrm{H}-\mathrm{NMR}-$ Spektrum,(250 MHz, $\left.\mathrm{CD}_{2} \mathrm{Cl}_{2}, 298 \mathrm{~K}\right)$ :

$\delta(\mathrm{ppm})=8.18(\mathrm{~s}, 4 \mathrm{H}) ; 7.41(\mathrm{~s}, 4 \mathrm{H}) ; 7.35(\mathrm{~m}, 8 \mathrm{H}) ; 7.18\left(\mathrm{t},{ }^{3} \mathrm{~J}=7.25 \mathrm{~Hz}, 4 \mathrm{H}\right) ; 7.02(\mathrm{~d}$, $\left.{ }^{3} \mathrm{~J}=7.57 \mathrm{~Hz}, 8 \mathrm{H}\right) ; 2.74\left(\right.$ septett, $\left.{ }^{3} \mathrm{~J}=6.62 \mathrm{~Hz}, 4 \mathrm{H}\right) ; 1.08\left(\mathrm{~d},{ }^{3} \mathrm{~J}=6.65 \mathrm{~Hz}, 24 \mathrm{H}\right)$

${ }^{13} \mathrm{C}-\mathrm{NMR}-S p e k t r u m$, Spinechoexperiment (62.5 $\left.\mathrm{MHz}, \mathrm{CD}_{2} \mathrm{Cl}_{2}, 298 \mathrm{~K}\right)$ :

$\delta(p p m)=163.42(q) ; 156.24(q) ; 155.68(q) ; 148.82(q) ; 133.49(q) ; 130.56(q) ; 130.39$ $(\mathrm{t}) ; 127.80(\mathrm{t}) ; 125.04(\mathrm{t}) ; 123.99$ (q); $123.04(\mathrm{q}) ; 121.25$ (q); 120.67 (q); 120.59 (t); $120.26(\mathrm{t}) ; 29.54$ (t); 23.83 (t) C, 69,91; H, 4,56; Br, 12,92; N, 2,26; O, 10,35

Elementaranylse $\left(\mathrm{C}_{72} \mathrm{H}_{56} \mathrm{Br}_{2} \mathrm{~N}_{2} \mathrm{O}_{8}\right)$ :

Berechnet: C $69.91 \%$, H $4.56 \%$, N $2.26 \%$

Gefunden: C 69.38 \%, H 4.55 \%, N $1.96 \%$ 
N,N'-Bis(4-methoxycarbonylphenyl)-2,6-diisopropylphenyl)-1,6,7,12-tetraphenoxy-

\section{3,4,9,10-perylentetracarboxdiimid (3-47)}

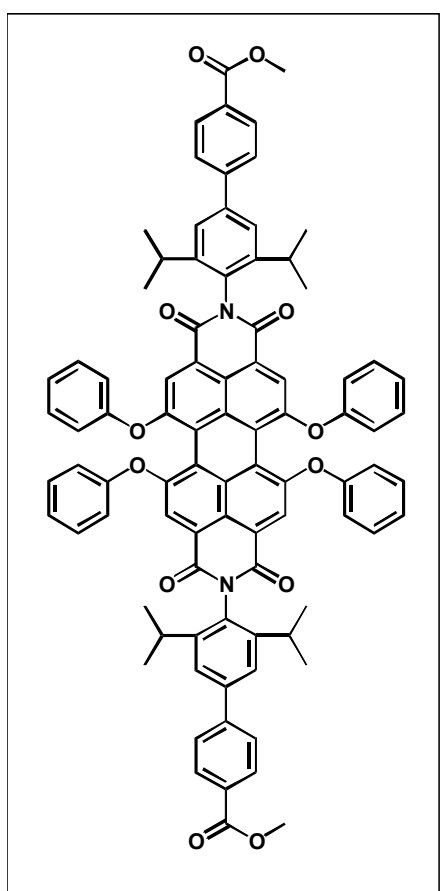

Analog zu 3-22 wurden $300 \mathrm{mg}$ von 3-46 (0.24 mmol) mit $261 \mathrm{mg}$ von 4-Methoxycarbonylphenylboronsäure (1.45 mmol), $56 \mathrm{mg} \mathrm{Pd(PPh3)4-Katalysator}(0.048 \mathrm{mmol})$ und $6 \mathrm{ml}$ 2 M Kaliumcarbonat in einem Gemisch aus Methanol $(11 \mathrm{ml})$ und Toluol (60 ml) umgesetzt. Nach einer Reaktionszeit von 15 Stunden bei $75{ }^{\circ} \mathrm{C}$ und einer Kontrolle mittels FDMassenspektrometrie wurde das Reaktionsgemisch auf Raum Temperatur abgekühlt. Man wäschte die Reaktionslösung mehrmals mit Wasser und Dicklormethan und trennte die organische Phase von der wässrigen Phase ab. Das Produkt erhielt man nach einer säulechromatographische Reinigung mit Dichlormethan als Eluent.

Ausbeute: $252 \mathrm{mg}(0.187 \mathrm{mmol})$ roter Farbstoff, $78 \%$

FD-Massenspektrum (FD, 8kV):

$\mathrm{m} / \mathrm{z}\left(\mathrm{u} \mathrm{e}_{0}^{-1}\right)=1347.10\left(100 \%, \mathrm{M}^{+}\right)$

(berechnet für $\mathrm{C}_{88} \mathrm{H}_{70} \mathrm{~N}_{2} \mathrm{O}_{12}=1347.50 \mathrm{~g} / \mathrm{mol}$ )

Schmelzpunkt: $>300^{\circ} \mathrm{C}$

\section{${ }^{1}$ H-NMR-Spektrum,(250 MHz, $\left.\mathrm{CD}_{2} \mathrm{Cl}_{2}, 298 \mathrm{~K}\right)$ :}

$\delta(\mathrm{ppm})=8.21(\mathrm{~s}, 4 \mathrm{H}) ; 8.13\left(\mathrm{~d},{ }^{3} \mathrm{~J}=8.52 \mathrm{~Hz}, 4 \mathrm{H}\right) ; 7.77\left(\mathrm{~d},{ }^{3} \mathrm{~J}=8.52 \mathrm{~Hz}, 4 \mathrm{H}\right) ; 7.54(\mathrm{~s}, 4$ $\mathrm{H}) ; 7.36(\mathrm{~m}, 8 \mathrm{H}) ; 7.19\left(\mathrm{t},{ }^{3} \mathrm{~J}=7.25 \mathrm{~Hz}, 4 \mathrm{H}\right) ; 7.04\left(\mathrm{~d},{ }^{3} \mathrm{~J}=7.57 \mathrm{~Hz}, 8 \mathrm{H}\right) ; 3.92(\mathrm{~s}, 6 \mathrm{H})$; 2.85 (septett, $\left.{ }^{3} \mathrm{~J}=6.95 \mathrm{~Hz}, 4 \mathrm{H}\right) ; 1.17\left(\mathrm{~d},{ }^{3} \mathrm{~J}=6.95 \mathrm{~Hz}, 24 \mathrm{H}\right)$ 


\section{${ }^{13} \mathrm{C}-\mathrm{NMR}-$ Spektrum, Spinechoexperiment (62.5 $\left.\mathrm{MHz}, \mathrm{CD}_{2} \mathrm{Cl}_{2}, 298 \mathrm{~K}\right)$ :}

$\delta(\mathrm{ppm})=166.86(\mathrm{q}) ; 163.60(\mathrm{q}) ; 156.76(\mathrm{q}) ; 156.56(\mathrm{q}) ; 147.50(\mathrm{q}) ; 146.54(\mathrm{q}) ; 141.64$ $(\mathrm{q}) ; 132.34(\mathrm{q}) ; 130.85(\mathrm{t}) ; 130.62(\mathrm{t}) ; 130.16(\mathrm{q}) ; 127.97(\mathrm{t}) ; 125.37(\mathrm{t}) ; 124.22(\mathrm{q}) ;$ $123.57(\mathrm{t}) ; 121.58(\mathrm{q}) ; 121.39(\mathrm{q}) ; 120.81(\mathrm{t}) ; 120.58(\mathrm{t}) ; 52.07(\mathrm{t}) ; 30.15(\mathrm{t}) ; 24.20(\mathrm{t})$

\section{Elementaranylase $\left(\mathrm{C}_{88} \mathrm{H}_{70} \mathrm{~N}_{2} \mathrm{O}_{12}\right)$ :}

Berechnet: C $78.44 \%, \mathrm{H}, 5.24 \%$, N $2.08 \%$

Gefunden: C $77.93 \%$, H, $5.30 \%$, N $1.84 \%$

\section{N,N'-Bis(4-carboxyphenyl)-2,6-diisopropylphenyl)-1,6,7,12-tetraphenoxy-3,4,9,10-}

\section{perylentetracarboxdiimid (3-48)}

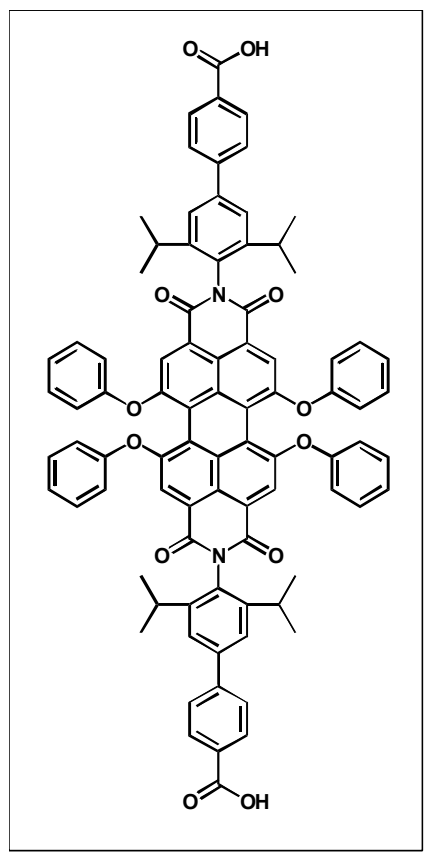

$100 \mathrm{mg}$ von 3-47 (0.074 mmol) wurden in $15 \mathrm{ml}$ THF gelöst und mit $83.3 \mathrm{mg} \mathrm{KOH}(1.48 \mathrm{mmol}$, gelöst in $2.5 \mathrm{ml}$ dest. Wasser) gemischt. Die Reaktionslösung wurde 24 Stunden bei $80^{\circ} \mathrm{C}$ gerührt. Die DC-Kontrolle zeigte eine vollständige Reaktion. Nach Abkühlung der Reaktionslösung auf Raumtemperatur, wurde das Produkt in 300 ml (2 N) Salzsäure ausgefällt, anschließend filtriert und unter Vakuum getrocknet.

Ausbeute: $88.8 \mathrm{mg}(0.067 \mathrm{mmol})$ roter Farbstoff, $91 \%$

FD-Massenspektrum (FD, 8kV):

$\mathrm{m} / \mathrm{z}\left(\mathrm{u} \mathrm{e}_{0}^{-1}\right)=1320.10\left(100 \%, \mathrm{M}^{+}\right)$

(berechnet für $\mathrm{C}_{86} \mathrm{H}_{66} \mathrm{~N}_{2} \mathrm{O}_{12}=1319.45 \mathrm{~g} / \mathrm{mol}$ )

Schmelzpunkt: $>300{ }^{\circ} \mathrm{C}$ 


\section{${ }^{1}$ H-NMR-Spektrum,(250 MHz, $d^{8}$-THF, 298 K):}

$\delta(\mathrm{ppm})=8.23(\mathrm{~s}, 4 \mathrm{H}) ; 8.10\left(\mathrm{~d},{ }^{3} \mathrm{~J}=8.2 \mathrm{~Hz}, 4 \mathrm{H}\right) ; 7.78\left(\mathrm{~d},{ }^{3} \mathrm{~J}=8.2 \mathrm{~Hz}, 4 \mathrm{H}\right) ; 7.57(\mathrm{~s}, 4 \mathrm{H})$; $7.34(\mathrm{~m}, 8 \mathrm{H}) ; 7.15\left(\mathrm{t},{ }^{3} \mathrm{~J}=7.25 \mathrm{~Hz}, 4 \mathrm{H}\right) ; 7.04\left(\mathrm{~d},{ }^{3} \mathrm{~J}=7.57 \mathrm{~Hz}, 8 \mathrm{H}\right) ; 2.82$ (septett, ${ }^{3} \mathrm{~J}=$ $6.95 \mathrm{~Hz}, 4 \mathrm{H}) ; 1.17\left(\mathrm{~d},{ }^{3} \mathrm{~J}=6.32 \mathrm{~Hz}, 24 \mathrm{H}\right)$

\section{${ }^{13} \mathrm{C}-\mathrm{NMR}-S p e k t r u m$, Spinechoexperiment (62.5 $\left.\mathrm{MHz}, \mathrm{CD}_{2} \mathrm{Cl}_{2}, 298 \mathrm{~K}\right)$ :}

$\delta(\mathrm{ppm})=167.47(\mathrm{q}) ; 163.59(\mathrm{q}) ; 156.73(\mathrm{q}) ; 156.53(\mathrm{q}) ; 147.42(\mathrm{q}) ; 146.19(\mathrm{q}) ; 141.78$

$(\mathrm{q}) ; 132.19(\mathrm{q}) ; 130.84(\mathrm{t}) ; 127.81(\mathrm{t}) ; 125.36(\mathrm{t}) ; 124.20(\mathrm{q}) ; 123.54(\mathrm{t}) ; 121.55(\mathrm{q})$; $120.67(\mathrm{t}) ; 120.78(\mathrm{t}) ; 120.56(\mathrm{t}) ; 30.13(\mathrm{t}) ; 24.19(\mathrm{t})$

\section{Elementaranylse $\left(\mathrm{C}_{86} \mathrm{H}_{66} \mathrm{~N}_{2} \mathrm{O}_{12}\right)$ :}

Berechnet: C $78.28 \%$, H $5.04 \%$, N $2.12 \%$

Gefunden: C $77.39 \%$, H $5.26 \%$, N $2.31 \%$

\section{N,N'-Bis(4-carboxyphenyl)-2,6-diisopropylphenyl)-1,6,7,12-tetra(4-}

\section{sulfonylphenoxy)-3,4,9,10-perylentetracarboxdiimid (3-49)}

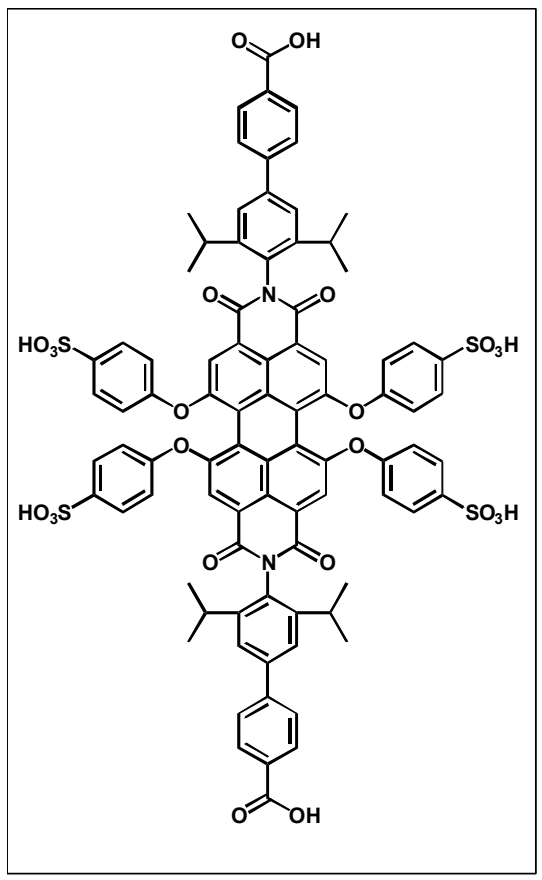

In einem Schlenkrohr wurden $30 \mathrm{mg}$ von 3-48 $(0.022$ mmol) bei Raumtemperatur in $2 \mathrm{ml}$ konz. Schwefelsäure gelöst, wobei ein Farbumschlag von rot nach blau zu beobachten war. Das Reaktionsgemisch wurde 6 Stunden gerührt. Im Anschluss fällte man das Produkt mit $3 \mathrm{ml}$ Wasser aus. Der ausgefallene Farbstoff wurde filtriert und unter Vakuum getrocknet.

Ausbeute: $21 \mathrm{mg}$ (0.012 mmol) roter Farbstoff, $58 \%$ 
Maldi-Tof-Massenspektrum:m/z $\left(\mathrm{u} \mathrm{e}_{0}^{-1}\right)=1642.00\left(100 \%, \mathrm{M}^{+}\right)$

(berechnet für $\mathrm{C}_{86} \mathrm{H}_{66} \mathrm{~N}_{2} \mathrm{O}_{24} \mathrm{~S}_{4}=1639.71 \mathrm{~g} / \mathrm{mol}$ )

Schmelzpunkt: $>300{ }^{\circ} \mathrm{C}$

\section{${ }^{1}$ H-NMR-Spektrum,(250 MHz, $d^{7}$-DMF, 298 K):}

$\delta(\mathrm{ppm})=8.17(\mathrm{~s}, 4 \mathrm{H}) ; 8.13\left(\mathrm{~d},{ }^{3} \mathrm{~J}=8.22 \mathrm{~Hz}, 4 \mathrm{H}\right) ; 7.97\left(\mathrm{~d},{ }^{3} \mathrm{~J}=8.52 \mathrm{~Hz}, 4 \mathrm{H}\right) ; 7.78\left(\mathrm{~d},{ }^{3} \mathrm{~J}\right.$ $=8.82 \mathrm{~Hz}, 8 \mathrm{H}) ; 7.74(\mathrm{~s}, 4 \mathrm{H}) ; 7.16\left(\mathrm{~d},{ }^{3} \mathrm{~J}=8.52 \mathrm{~Hz}, 8 \mathrm{H}\right) ; 2.96$ (septett, ${ }^{3} \mathrm{~J}=6.95 \mathrm{~Hz}, 4$ $\mathrm{H}) ; 1.18\left(\mathrm{~d},{ }^{3} \mathrm{~J}=6.95 \mathrm{~Hz}, 24 \mathrm{H}\right)$

\section{${ }^{13}$ C-NMR-Spektrum, Spinechoexperiment (75 MHz, $d^{7}$-DMF, 398 K):}

$\delta(p p m)=172.83(q) ; 168.76(q) ; 161.48(q) ; 152.75(q) ; 150.93(q) ; 150.58(q) ; 146.43$ $(\mathrm{q}) ; 138.96(\mathrm{q}) ; 137.23(\mathrm{q}) ; 135.59(\mathrm{t}) ; 133.66(\mathrm{t}) ; 132.66(\mathrm{t}) ; 129.13(\mathrm{q}) ; 128.38(\mathrm{t})$; $126.51(\mathrm{q}) ; 126.30(\mathrm{q}) ; 125.67(\mathrm{t}) ; 124.67(\mathrm{t}) ; 30.13(\mathrm{t}) ; 24.19(\mathrm{t})$

\section{1,3,5-Tris(4-methoxycarbonylphenyl)-benzol (3-54)}

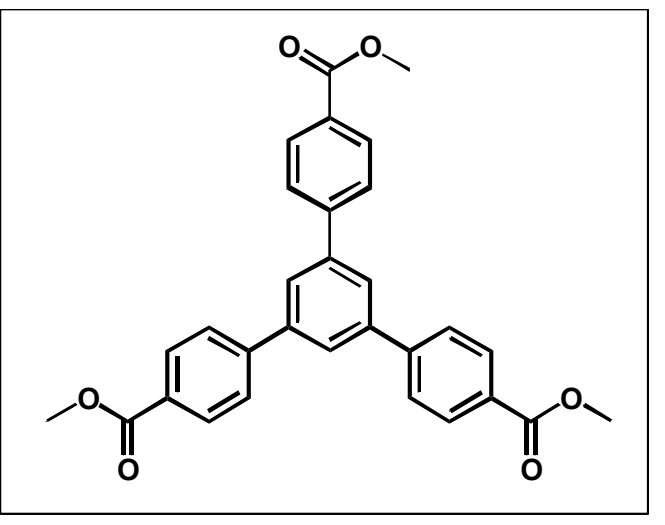

$200 \mathrm{mg}$ von $1,3,5$-Tribrombenzol $(0.63 \mathrm{mmol})$ wurden in einem $250 \mathrm{ml}$ Schlenkrohr mit $2.27 \mathrm{~g}$ 4-Methoxycarbonylphenylboronsäure mmol) in $50 \mathrm{ml}$ Toluol und $12 \mathrm{ml}$ Methanol gelöst. Das Gemisch wurde mehrmals evakuiert und mit Argon gefüllt. Im Anschluss fügte man $6 \mathrm{ml} 2 \mathrm{M}$ Kaliumcarbonatlösung und $219 \mathrm{mg}$ $(0.19 \mathrm{mmol})$ vom $\left(\mathrm{Pd}\left(\mathrm{PPh}_{3}\right)_{4}\right.$-Katalysator hinzu. Man ließ die Reaktion 15 Stunden bei 75 ${ }^{\circ} \mathrm{C}$ unter Lichtausschluss und Rückfluss rühren. Die Umsetzung des Ausgangstoffs ließ sich durch DC und mit Hilfe von FD-Massenspektrometrie bestätigen. Nach der Abkühlung auf Raumtemperatur wurde das Reaktionsgemisch mit Wasser und Dichlormethan geschüttelt. In einem Scheidetrichter wurde die wässrige Phase von der 
organischen Phase abgetrennt, über Magnesiumsulfat getrocknet und schließlich unter Vakuum getrocknet. Das Produkt wurde mittels Säulechromatographie mit Dichlormethan aufgereinigt.

Ausbeute: $274 \mathrm{mg}(0.57 \mathrm{mmol})$ roter Farbstoff, $91 \%$

FD-Massenspektrum (FD, 8kV):

$\mathrm{m} / \mathrm{z}\left(\mathrm{u} \mathrm{e}_{0}^{-1}\right)=480.20\left(100 \%, \mathrm{M}^{+}\right)$

(berechnet für $\mathrm{C}_{30} \mathrm{H}_{24} \mathrm{O}_{6}=480.51 \mathrm{~g} / \mathrm{mol}$ )

Schmelzpunkt: $242{ }^{\circ} \mathrm{C}$

${ }^{1} \mathrm{H}-\mathrm{NMR}-$ Spektrum,(250 MHz, $\left.d^{2}-\mathrm{CD}_{2} \mathrm{Cl}_{2}, 298 \mathrm{~K}\right)$ :

$\delta(\mathrm{ppm})=8.16\left(\mathrm{~d},{ }^{3} \mathrm{~J}=8.52 \mathrm{~Hz} 6 \mathrm{H}\right) ; 7.91(\mathrm{~s}, 3 \mathrm{H}) ; 7.82\left(\mathrm{~d},{ }^{3} \mathrm{~J}=8.22 \mathrm{~Hz}, 6 \mathrm{H}\right) ; 3.92(\mathrm{~s}, 9$ $\mathrm{H)}$

\section{${ }^{13}$ C-NMR-Spektrum, Spinechoexperiment (62.5 MHz, $d^{8}$-THF, 298 K):}

$\delta(p p m)=166.83(q) ; 145.86(q) ; 142.41(q) ; 130.84(\mathrm{t}) ; 130.59(\mathrm{q}) ; 128.14(\mathrm{t}) ; 126.78(\mathrm{t}) ;$

$52.18(\mathrm{t})$

\section{Elementaranalyse:}

berechnet: C $74.99 \%$, H 5,03 \%

gefunden: C $74.14 \%, \mathrm{H} 4,91 \%$

\section{1,3,5-Tris(4-carboxylphenyl)-benzol (3-55)}

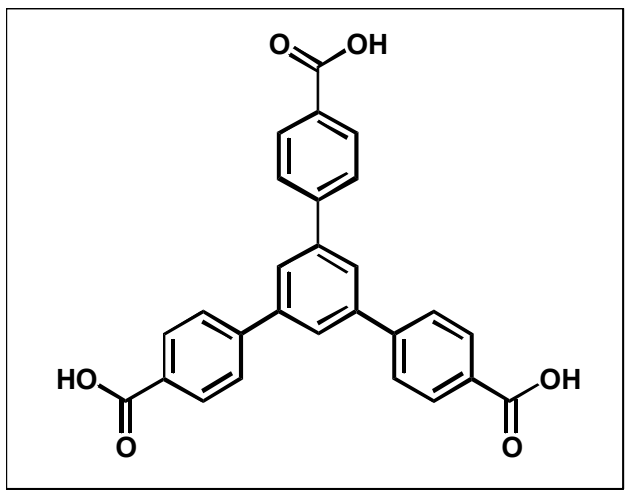

$200 \mathrm{mg}$ (0.416 mmol) 3-54 wurden in THF gelöst und mit einer wässrigen $\mathrm{KOH}$-Lösung $(0.7 \mathrm{~g}$ in 2.5 $\mathrm{ml}$ dest. Wasser, $12.5 \mathrm{mmol}$ ) gemischt. Das Reaktionsgemisch wurde 24 Stunden bei $80^{\circ} \mathrm{C}$ gerührt. Nach einer DC-Kontrolle wurde die Reaktion gestoppt. Nachdem die Reaktionslösung 
auf Raumtemperatur abgekühlt wurde, fällte man das Produkt in $300 \mathrm{ml}$ (2 N) Salzsäure aus. Schließlich wurde der erhaltene Niederschlag filtriert und im Ölpumpenvakuum getrocknet.

Ausbeute: $158 \mathrm{mg}(0.36 \mathrm{mmol})$ roter Farbstoff, $87 \%$

FD-Massenspektrum (FD, 8kV):

$\mathrm{m} / \mathrm{z}\left(\mathrm{u} \mathrm{e}_{0}^{-1}\right)=438.3\left(100 \%, \mathrm{M}^{+}\right)$

(berechnet für $\mathrm{C}_{27} \mathrm{H}_{18} \mathrm{O}_{6}=438.43 \mathrm{~g} / \mathrm{mol}$ )

Schmelzpunkt: $321^{\circ} \mathrm{C}$

${ }^{1}$ H-NMR-Spektrum,(250 MHz, $d^{8}$-THF, 298 K):

$\delta(\mathrm{ppm})=8.15\left(\mathrm{~d},{ }^{3} \mathrm{~J}=8.2 \mathrm{~Hz} 6 \mathrm{H}\right) ; 8.05(\mathrm{~s}, 3 \mathrm{H}) ; 7.93\left(\mathrm{~d},{ }^{3} \mathrm{~J}=8.55 \mathrm{~Hz}, 6 \mathrm{H}\right)$

${ }^{13}$ C-NMR-Spektrum, Spinechoexperiment (62.5 MHz, $d^{7}$-DMF, $\left.298 \mathrm{~K}\right)$ :

$\delta(p p m)=172.95(q) ; 150.06(q) ; 146.95(q) ; 136.14(q) ; 135.75(\mathrm{t}) ; 133.19(\mathrm{t}) ; 131.53(\mathrm{t})$

Elementaranaylse $\left(\mathrm{C}_{27} \mathrm{H}_{18} \mathrm{O}_{6}\right)$ :

berechnet: C $73.97 \%$, H $4,14 \%$

gefunden: C $73.11 \%, \mathrm{H} \mathrm{3,} 76 \%$ 


\section{N,N`-Bis(4-carboxyphenyl)-1,6,7,12-tetra[4-(1,1,3,3-tetramethylbutyl)phenoxy]- $3,4,9,10$-perylentetracarbonsäurediimid (3-60)}

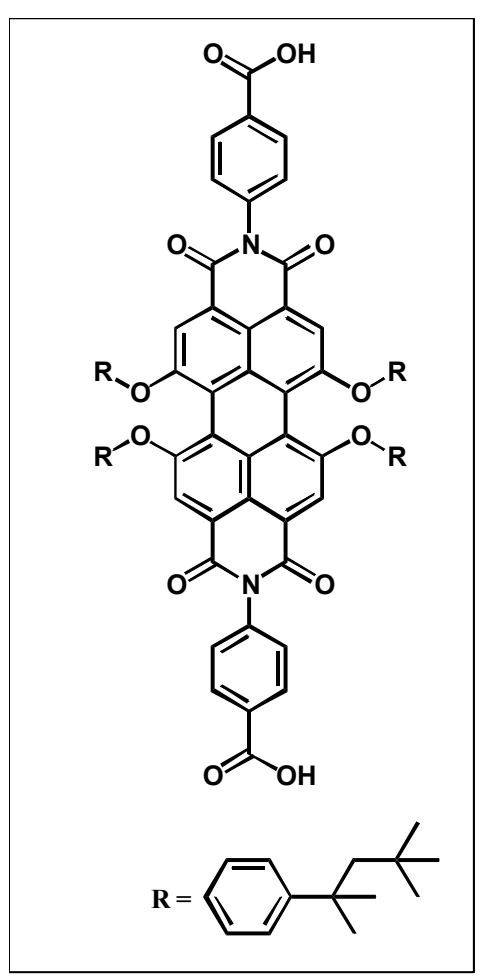

$2 \mathrm{~g}(3.77 \mathrm{mmol}) \quad 1,6,7,12-$ Tetrachlorperylen-3,4,9,10tetracarbonsäuredianhydrid (3-18) und $2.18 \mathrm{~g}$ (11.3 mmol) 4-Amino-benzoesäure-tert.-butylester werden in $50 \mathrm{ml}$ Propionsäure suspendiert. Im Anschluss wird der Kolben mehrmals entgast und mit Argon gefüllt. Man lässt die Reaktionslösung 20 Stunden unter Rückfluss bei $155^{\circ} \mathrm{C}$ rühren. Nach Abkühlung der Reaktionslösung auf Raumtemperatur wird das Produkt in $80 \mathrm{ml}$ Wasser ausgefällt. Der erhaltene Niederschlag wird filtriert und unter Vakuum getrocknet. Direkt Im Anschluss wird die nächste Stufe durchgeführt, da die Löslichkeit des erhaltenen Produkts in organischen Lösungsmitteln für eine Aufreinigung nicht ausreichend war. $1.55 \mathrm{~g}$ (1.76 mmol)

vom Produkt 3-58 wird in $80 \mathrm{ml}$ NMP gelöst und 15 Minuten bei $80{ }^{\circ} \mathrm{C}$ gerührt. Im Anschluss werden $1.57 \mathrm{~g}$ (8.8 mmol) 4-(1,1,3,3-Tetramethyl-butyl)-phenol und $1.22 \mathrm{~g}$ (8.82 mmol) Kaliumcarbonat hinzugefügt. Man heizt auf $90{ }^{\circ} \mathrm{C}$ auf und rührt das Reaktionsgemisch 12 Stunden unter Inertgasbedingungen gerührt. Die Reaktionslösung wird auf Raumtemperatur abgekühlt, mit $800 \mathrm{ml} 2 \mathrm{~N}$ Salzsäure-Lösung versetzt und zwei Stunden gerührt. Der erhaltene Niederschlag wird über eine D4-Fritte filtriert und unter Vakuum getrocknet. Die Charakterisierung dieses Produktes zeigt, dass die tertButylgruppe teilweise durch die Propionsäure während der Imidisierung abgespalten ist. Deshalb wird die Aufreinigung erst nach der vollständigen Abspaltung der tertButylgruppe durchgeführt. Das Produkt 3-59 wird in $100 \mathrm{ml}$ von einem Gemisch aus Dichlormethan/Trifluoressigsäure gelöst bei Raumtemperatur gerührt. Nach einer Reaktionsdauer von 2 Stunden wird die Reaktionslösung eingeengt. Die Aufreinigung des verbleibenden Produkts erfolgt mittels Säulenchromatographie mit Ethylacetat/Dichlormethan (1.5:1) als Eluent. 
Kapitel 6: Experimenteller Teil

Ausbeute: $4.15 \mathrm{~g}$ (2.86 mmol) dunkeler Farbstoff, $76 \%$

\section{FD-Massenspektrum (FD, 8kV):}

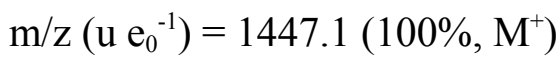

(berechnet für $\mathrm{C}_{94} \mathrm{H}_{98} \mathrm{~N}_{2} \mathrm{O}_{12}=1447.79 \mathrm{~g} / \mathrm{mol}$ )

Schmelzpunkt: $>300^{\circ} \mathrm{C}$

${ }^{1}$ H-NMR-Spektrum,(250 MHz, $d^{7}$-DMF, 298 K):

$\delta(\mathrm{ppm})=8.13\left(\mathrm{~d},{ }^{3} \mathrm{~J}=8.22 \mathrm{~Hz}, 4 \mathrm{H}\right) ; 7.98(\mathrm{~s}, 4 \mathrm{H}) ; 7.61\left(\mathrm{~d},{ }^{3} \mathrm{~J}=8.52 \mathrm{~Hz}, 4 \mathrm{H}\right) ; 7.42\left(\mathrm{~d},{ }^{3} \mathrm{~J}\right.$ $=8.82,8 \mathrm{H}) 7.03\left(\mathrm{~d},{ }^{3} \mathrm{~J}=8.85 \mathrm{~Hz}, 8 \mathrm{H}\right) ; 1.71(\mathrm{~s}, 8 \mathrm{H}) ; 1.31(\mathrm{~s}, 24 \mathrm{H}) ; 0.69(\mathrm{~s}, 36 \mathrm{H})$

${ }^{13}$ C-NMR-Spektrum, Spinechoexperiment (62.5 MHz, $d^{7}$-DMF, $\left.298 \mathrm{~K}\right)$ :

$\delta(\mathrm{ppm})=167.66(\mathrm{q}) ; 162.42(\mathrm{q}) ; 156.29(\mathrm{q}) ; 154.84(\mathrm{q}) ; 147.61$ (q); $139.98(\mathrm{q}) ; 135.90$ $(\mathrm{q}) ; 134.45(\mathrm{t}) ; 133.73(\mathrm{q}) ; 133.38(\mathrm{t}) ; 132.19(\mathrm{t}) ; 128.42(\mathrm{t}) ; 124.59(\mathrm{q}) ; 123.56(\mathrm{q}) ;$ $122.93(\mathrm{q}) ; 120.62(\mathrm{t}) ; 57.40(\mathrm{q}) ; 32.31(\mathrm{q}) ; 31.09(\mathrm{t})$

Elementaranaylse $\left(\mathrm{C}_{94} \mathrm{H}_{98} \mathrm{~N}_{2} \mathrm{O}_{12}\right)$ :

Berechnet: C 77.98 \%, H $6.82 \%$ N $1.93 \%$

Gefunden: C $77.06 \%$, H $6.94 \%$ N $1.72 \%$ 
N,N`-Bis[4-(Biotinyl-3-6,9,-trioxaundecanyl)aminocarbonylphenyl]-1,6,7,12-tetra[4(1,1,3,3-tetramethylbutyl)phenoxy]-3,4,9,10-perylentetracarbonsäurediimid (3-61)

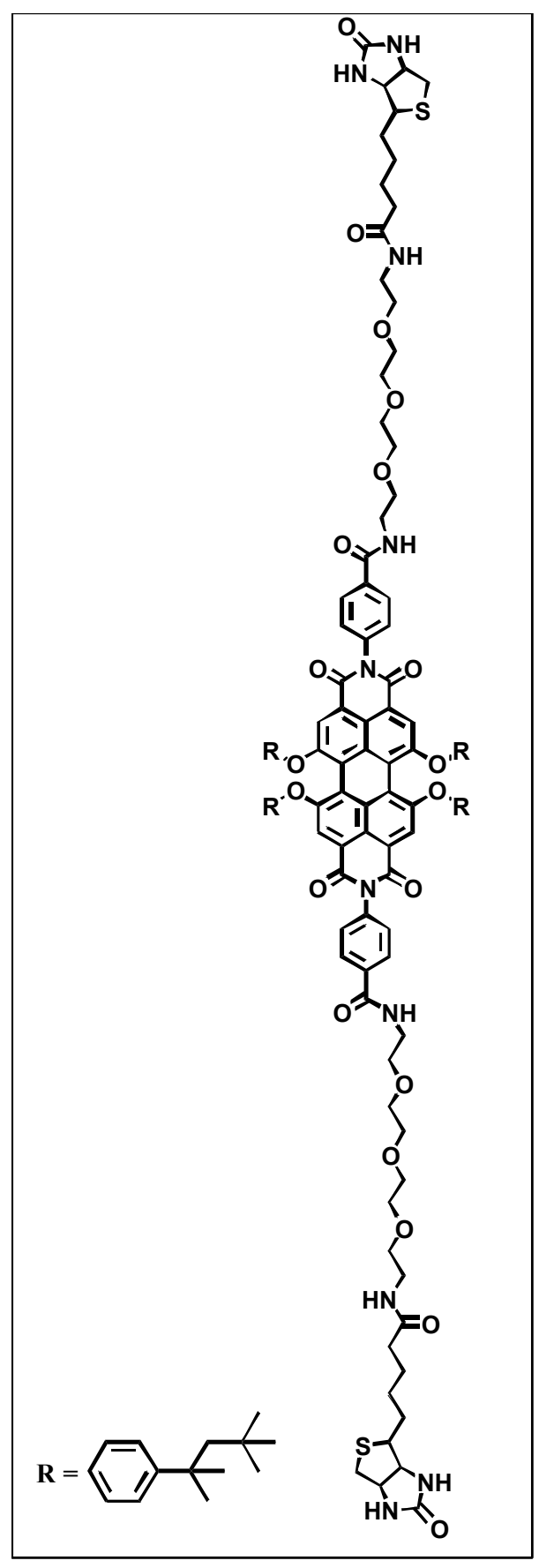

In einem $25 \mathrm{ml}$ Schlenkrohr wurden $50 \mathrm{mg}(0.0345$ mmol) von 3-60, $116 \mathrm{mg}(0.276 \mathrm{mmol})$ eines Biotinderivates, das eine PEO-Kette und Aminfunktion trägt, in trockenem DMF gelöst. Man fügte $40 \mathrm{mg}(0.207 \mathrm{mmol}) \mathrm{EDC}$ und $16.8 \mathrm{mg}$ (0.138 mmol) DMAP in DMF (trocken) hinzu. Nach einer Reaktionszeit von 5 Tage bei Raumtemperatur und unter Inertgasbedingungen wurde eine DC-Kontrolle durchgeführt. Danach wurde die Reaktion abgebrochen. Man fällte das Produkt 3-61 in n-Pentan aus. Der erhaltene Niederschlag wurde filtriert und unter Ölpumpenvakuum getrocknet.

Ausbeute: $52.6 \mathrm{mg} \quad(0.023 \mathrm{mmol})$ dunkeler Farbstoff, $68 \%$

\section{Maldi-Tof-Massenspektrum:}

$\mathrm{m} / \mathrm{z}\left(\mathrm{u} \mathrm{e} \mathrm{e}_{0}^{-1}\right)=2286\left(100 \%, \mathrm{M}^{+}+\mathrm{K}^{+}\right)$

(berechnet für $\mathrm{C}_{130} \mathrm{H}_{162} \mathrm{~N}_{10} \mathrm{O}_{20} \mathrm{~S}_{2}=2248.86 \mathrm{~g} / \mathrm{mol}$ )

Schmelzpunkt: $>300{ }^{\circ} \mathrm{C}$

\section{${ }^{1} \mathrm{H}-\mathrm{NMR}-$ Spektrum,(250 MHz, $\left.\mathrm{C}_{2} \mathrm{D}_{2} \mathrm{Cl}_{4}, 298 \mathrm{~K}\right)$ :}

$\delta(\mathrm{ppm})=8.06(\mathrm{~s}, 4 \mathrm{H}) ; 7.89\left(\mathrm{~d},{ }^{3} \mathrm{~J}=6.62 \mathrm{~Hz}, 4 \mathrm{H}\right) ; 7.27\left(\mathrm{~d},{ }^{3} \mathrm{~J}=8.22 \mathrm{~Hz}, 4 \mathrm{H}\right) ; 7.42\left(\mathrm{~d},{ }^{3} \mathrm{~J}\right.$ $=7.9,8 \mathrm{H}) ; 6.83\left(\mathrm{~d},{ }^{3} \mathrm{~J}=7.9 \mathrm{~Hz}, 8 \mathrm{H}\right) ; 4.38-4.29(\mathrm{~m}, 2 \mathrm{H}) ; 4.21-4.13(\mathrm{~m}, 2 \mathrm{H}) ; 3.55-3.46$ 
$\left.(\mathrm{m}, 24 \mathrm{H}) ; 3.44\left(\mathrm{~d},{ }^{3} \mathrm{~J}=7.9 \mathrm{~Hz}, 2 \mathrm{H}\right)\right)$ 3.35-3.28 (m, $\left.4 \mathrm{H}\right), 3.12\left(\mathrm{~d},{ }^{3} \mathrm{~J}=8.22 \mathrm{~Hz}, 4 \mathrm{H}\right)$;

2.82-2.31 (m, breit, $4 \mathrm{H}) 2.07\left(\mathrm{t},{ }^{3} \mathrm{~J}=7.24,4 \mathrm{H}\right)$ 1.96-1.7 (m, $\left.12 \mathrm{H}\right) ; 1.61(\mathrm{~s}, 8 \mathrm{H}) ; 1.25(\mathrm{~s}$, $24 \mathrm{H}) ; 0.66(\mathrm{~s}, 36 \mathrm{H})$

${ }^{13}$ C-NMR-Spektrum (125 MHz, $d^{6}$-DMSO, 398 K):

$\delta(\mathrm{ppm})=165.5(\mathrm{C}=\mathrm{O}) ; 162.02(\mathrm{C}=\mathrm{O}) ; 155.17 ; 152.03 ; 145.96 ; 137.51 ; 134.37 ; 132.06$;

$128.39 ; 127.33 ; 127.15 ; 122.61 ; 119.04 ; 118.7 ; 118.19 ; 69.39 ; 69.26 ; 69.2 ; 68.77 ; 68.52$

$58.19 ; 56.07 ; 54.75 ; 38.29 ; 38.18 ; 37.6 ; 31.48 ; 31.06 ; 30.7 ; 27.6 ; 26.24 ; 24.57$

Elementaranaylse $\left(\mathrm{C}_{130} \mathrm{H}_{162} \mathrm{~N}_{10} \mathrm{O}_{20} \mathrm{~S}_{2}\right)$ :

Berechnet: C $69.43 \%$, H $7.26 \%$ N $6.23 \%$

Gefunden: C $68.51 \%$, H $7.41 \%$ N $6.07 \%$

N-(4-bromphenyl)-N'-(4-carboxyphenyl)-1,6,7,12-tetra[4-(1,1,3,3-tetramethylbutyl)phenoxy]-3,4,9,10-perylentetracarboxdiimid (4-8)

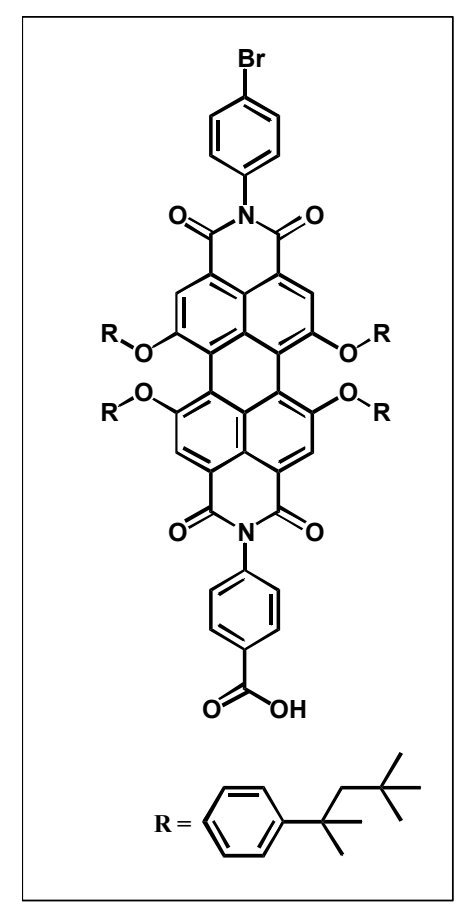

$1 \mathrm{~g}$ von (1.886 mmol) 1,6,7,12-Tetrachlor-3,4,9,10perylentetracarbonsäuredianhydrid (3-18) und $0.811 \mathrm{~g}$ (4.716 mmol) 4-Bromanilin und 0.911 g 4-Amin-benzoesäure-tert.butylester (4.716 mmol) werden in $40 \mathrm{ml}$ Propionsäure umgesetzt. Die Phenoxylierung und Abspaltung der tertButylschutzgruppe werden unter den gleichen Bedingungen wie bei 3-60. Die Abtrennung der gewünschten Verbindung 4-8 vom statistischen Reaktionsprodukt erfolgt säulenchromatographisch mit Dichlormethan als Eluent.

Ausbeute: $900 \mathrm{mg}(0.607 \mathrm{mmol})$ als violetter Feststoff $32 \%$ 
Kapitel 6: Experimenteller Teil

Schmelzpunkt: $>300^{\circ} \mathrm{C}$

FD-Massenspektrum (8 kV):

$\mathrm{m} / \mathrm{z}\left(\mathrm{u} \mathrm{e}_{0}^{-1}\right)=1483.4\left(100 \%, \mathrm{M}^{+}\right)$

(berechnet für $\mathrm{C}_{93} \mathrm{H}_{97} \mathrm{BrN}_{2} \mathrm{O}_{10}=1482,68$ )

${ }^{1}$ H-NMR-Spektrum,(250 MHz, $\left.\mathrm{CD}_{2} \mathrm{Cl}_{2}, 298 \mathrm{~K}\right)$ :

$\delta(\mathrm{ppm})=8.23\left(\mathrm{~d},{ }^{3} \mathrm{~J}=8.52 \mathrm{~Hz} 2 \mathrm{H}\right) ; 8.12(\mathrm{~s}, 4 \mathrm{H}) ; 7.66\left(\mathrm{~d},{ }^{3} \mathrm{~J}=8.85 \mathrm{~Hz}, 2 \mathrm{H}\right) ; 7.41\left(\mathrm{~d},{ }^{3} \mathrm{~J}\right.$ $=8.52,2 \mathrm{H}) 7.32\left(\mathrm{~d},{ }^{3} \mathrm{~J}=8.82 \mathrm{~Hz}, 8 \mathrm{H}\right) ; 7.16\left(\mathrm{~d},{ }^{3} \mathrm{~J}=8.52 \mathrm{~Hz}, 2 \mathrm{H}\right) ; 6.91\left(\mathrm{~d},{ }^{3} \mathrm{~J}=8.82 \mathrm{~Hz}\right.$, $8 \mathrm{H}) ; 1.72(\mathrm{~s}, 8 \mathrm{H}) ; 1.34(\mathrm{~s}, 24 \mathrm{H}) ; 0.73(\mathrm{~s}, 36 \mathrm{H})$

${ }^{13}$ C-NMR-Spektrum, Spinechoexperiment (125 MHz, $d^{8}$-THF, 298 K):

$\delta(\mathrm{ppm})=167.78(\mathrm{q}) ; 162.98(\mathrm{q}) ; 156.83$ (q); $153.96(\mathrm{q}) ; 147.10$ (q); $139.98(\mathrm{q}) ; 135.90$ $(\mathrm{q}) ; 133.73(\mathrm{q}) ; 132.54(\mathrm{t}) ; 131.69(\mathrm{t}) ; 130.71(\mathrm{t}) ; 129.48(\mathrm{t}) ; 128.42(\mathrm{t}) ; 123.94(\mathrm{q}) ;$ 123.81 (q); 122.84 (q); 120.84 (q); 120.74 (q); 120.37 (q); 120.07 (t); 119.85 (t); 57.58 (q); $38.84(\mathrm{q}) ; 32.84(\mathrm{q}) ; 32.06(\mathrm{t})$.

\section{Elementaranalyse $\left(\mathrm{C}_{93} \mathrm{H}_{97} \mathrm{BrN}_{2} \mathrm{O}_{10}\right)$ :}

Berechnet: C $75.34 \%$, H $6.59 \%$, N $1.89 \%$

Gefunden: C $74.51 \%$, H $7.14 \%$, N $2.05 \%$ 


\section{Verbindung 4-9}

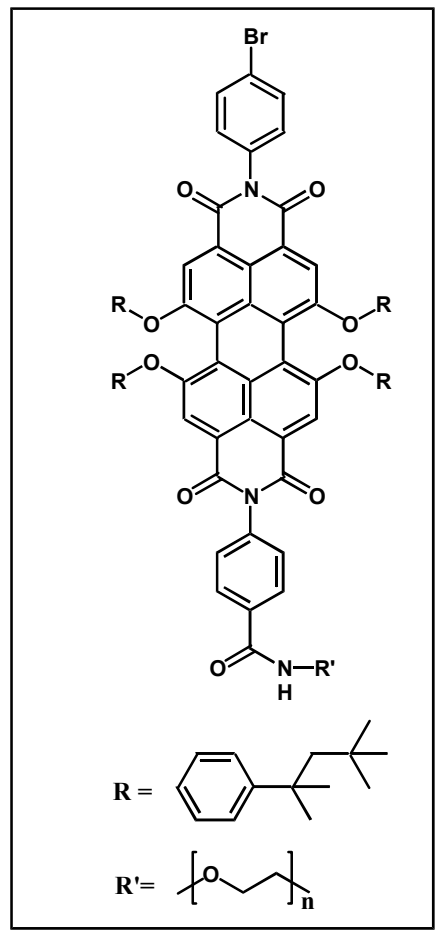

$25 \mathrm{mg}(0.0168 \mathrm{mmol})$ 4-8, $63 \mathrm{mg} \mathrm{H} \mathrm{H}_{2} \mathrm{~N}-\mathrm{PEG}-5000,13 \mathrm{mg}$ (0.068 mmol) EDC und $6.2 \mathrm{mg}(0.05 \mathrm{mmol})$ DMAP wurden in $4 \mathrm{ml}$ DMF gelöst. Man lässt die Reaktionslösung 5 Tage bei Raumtemperatur unter Lichtausschluss und Argon rühren. Danach wurde das Reaktionsgemisch eingeengt und in Wasser gelöst. Dabei löste sich der nicht reagierte Farbstoff nicht und wurde durch Filtrieren entfernt. Die wässrige Lösung wurde eingeengt und mit Dialyse aufgereinigt.

Ausbeute: $71 \mathrm{mg}$ als violetter Feststoff, $64.9 \%$

Maldi-Tof-Massenspektrum: $\mathrm{m} / \mathrm{z}_{\left(\mathrm{u} \mathrm{e}_{0}^{-1}\right)}=6700 \mathrm{~g} \mathrm{~mol}^{-1}$ (Molekulargewichtsverteilung)

Schmelzpunkt: $>300^{\circ} \mathrm{C}$

\section{${ }^{1} \mathrm{H}-\mathrm{NMR}-$ Spektrum,(250 MHz, $\left.\mathrm{CD}_{2} \mathrm{Cl}_{2}, 298 \mathrm{~K}\right)$ :}

$\delta(\mathrm{ppm})=8.41(\mathrm{~s}, 4 \mathrm{H}) ; 8.28\left(\mathrm{~d},{ }^{3} \mathrm{~J}=8.52 \mathrm{~Hz} 2 \mathrm{H}\right) ; 7.94\left(\mathrm{~d},{ }^{3} \mathrm{~J}=8.85 \mathrm{~Hz}, 2 \mathrm{H}\right) ; 7.7\left(\mathrm{~d},{ }^{3} \mathrm{~J}=\right.$ $8.52 \mathrm{~Hz}, 8 \mathrm{H}) ; 7.62\left(\mathrm{~d},{ }^{3} \mathrm{~J}=8.2 \mathrm{~Hz}, 2 \mathrm{H}\right) ; 7.52\left(\mathrm{~d},{ }^{3} \mathrm{~J}=8.52 \mathrm{~Hz}, 2 \mathrm{H}\right) ; 7.27\left(\mathrm{~d},{ }^{3} \mathrm{~J}=8.52 \mathrm{~Hz}\right.$, $8 \mathrm{H}) ; 3.95-3.84$ (m, broad); $2.08(\mathrm{~s}, 8 \mathrm{H}) ; 1.67$ (s, $24 \mathrm{H}) ; 1.07$ (s, $36 \mathrm{H})$

\section{${ }^{13} \mathrm{C}-\mathrm{NMR}-$ Spektrum, Spinechoexperiment (75 $\left.\mathrm{MHz}, \mathrm{CD}_{2} \mathrm{Cl}_{2}, 298 \mathrm{~K}\right)$ :}

$\delta(\mathrm{ppm})=166.82(\mathrm{q}) ; 163.71(\mathrm{q}) ; 156.84(\mathrm{q}) ; 153.31(\mathrm{q}) ; 147.4(\mathrm{q}) ; 138.75(\mathrm{q}) ; 135.74(\mathrm{q})$ $135.24(\mathrm{q}) ; 133.59(\mathrm{q}) ; 132.98(\mathrm{t}) ; 131.1(\mathrm{t}) ; 129.5(\mathrm{q}) ; 128.56(\mathrm{t}) ; 128.34(\mathrm{t}) ; 123.1(\mathrm{q}) ;$ 
$121.07(\mathrm{q}) ; 120.22(\mathrm{t}) ; 120.02(\mathrm{t}) ; 71.08(\mathrm{q}) ; 57.46(\mathrm{q}) ; 38.82(\mathrm{q}) ; 32.82(\mathrm{q}) ; 32.13(\mathrm{t})$; $31.92(\mathrm{t})$

\section{Verbindung 4-10}

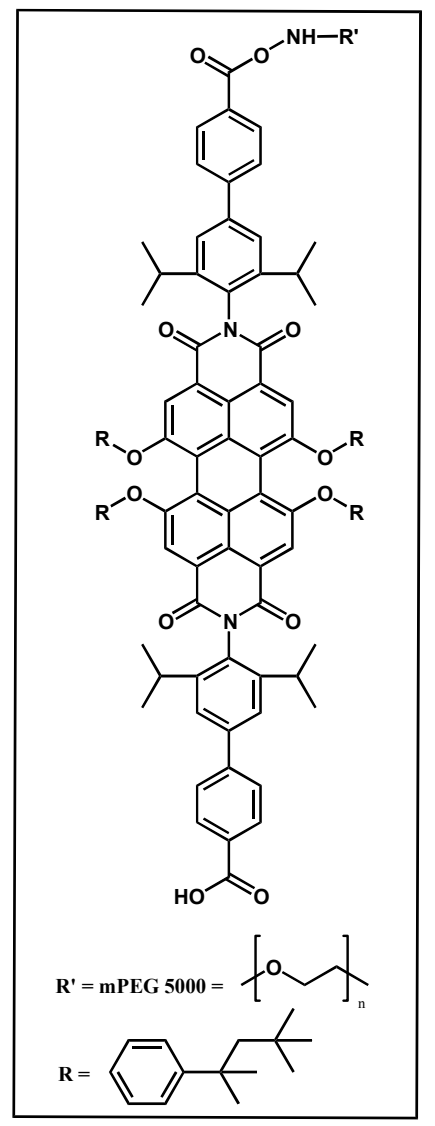

Analog zu 4-9 wurden $40 \mathrm{mg}$ (0.0226 mmol) 3-23, $100 \mathrm{mg}$ $\mathrm{H}_{2} \mathrm{~N}-\mathrm{PEG}-5000,17.3 \mathrm{mg}(0.09 \mathrm{mmol}) \mathrm{EDC}$ und $8 \mathrm{mg}(0.0678$ mmol) DMAP wurden vereint und in $3 \mathrm{ml}$ DMF gelöst. Man lässt die Reaktionslösung 5 Tage bei Raumtemperatur unter Lichtausschluss und Argon rühren. Das Reaktionsgemisch wurde danach eingeengt und in Wasser gelöst. Dabei löste sich der nicht reagierte Farbstoff nicht und wurde durch Abfiltrieren entfernt. Die wässrige Lösung wurde eingeengt und mit Dialyse aufgereinigt.

Ausbeute: $110 \mathrm{mg}$ als dunkelroter Feststoff, $71.5 \%$

MALDI-TOF-Massenspektrum: $\mathrm{m} / \mathrm{z}\left(\mathrm{u} \mathrm{e}_{0}^{-1}\right)=6400-7200 \mathrm{~g}$ $\mathrm{mol}^{-1}$

Schmelzpunkt: $>300^{\circ} \mathrm{C}$

\section{${ }^{1}$ H-NMR-Spektrum,(250 MHz, $d^{8}$-THF, 298 K):}

$\delta(\mathrm{ppm})=8.47(\mathrm{~s}, 4 \mathrm{H}) ; 8.34\left(\mathrm{~d},{ }^{3} \mathrm{~J}=8.52 \mathrm{~Hz}, 2 \mathrm{H}\right) ; 8.26\left(\mathrm{~d},{ }^{3} \mathrm{~J}=8.22 \mathrm{~Hz}, 2 \mathrm{H}\right) ; 8.10(\mathrm{~d}$, $\left.{ }^{3} \mathrm{~J}=8.52 \mathrm{~Hz}, 2 \mathrm{H}\right) ; 8.03\left(\mathrm{~d},{ }^{3} \mathrm{~J}=8.22 \mathrm{~Hz}, 2 \mathrm{H}\right) ; 7.83(\mathrm{~s}, 4 \mathrm{H}) ; 7.7\left(\mathrm{~d},{ }^{3} \mathrm{~J}=8.85 \mathrm{~Hz}, 8 \mathrm{H}\right)$; $7.28\left(\mathrm{~d},{ }^{3} \mathrm{~J}=8.85 \mathrm{~Hz}, 8 \mathrm{H}\right) ; 3.89-3.77$ (m, breit); 3.17 (septettt, $\left.{ }^{3} \mathrm{~J}=6.62 \mathrm{~Hz}, 4 \mathrm{H}\right) ; 2.06$ (s, $8 \mathrm{H}) ; 1.67(\mathrm{~s}, 24 \mathrm{H}) ; 1.46\left(\mathrm{~d},{ }^{3} \mathrm{~J}=6.62 \mathrm{~Hz}, 24 \mathrm{H}\right) ; 1.05(\mathrm{~s}, 36 \mathrm{H})$ 
${ }^{13}$ C-NMR-Spektrum, Spinechoexperiment (75 MHz, $d^{8}$-THF, 298 K):

$\delta(p p m)=167.46(q) ; 164.7(q) ; 158.21(q) ; 154.96(q) ; 148.42(q) ; 146.26(q) ; 141.77(q) ;$ $134.05(\mathrm{q}) ; 132.32(\mathrm{q}) ; 130.85(\mathrm{t}) ; 130.77(\mathrm{q}) ; 128.71(\mathrm{t}) ; 127.81(\mathrm{t}) ; 123.92(\mathrm{q}) ; 123.54$ $(\mathrm{t}) ; 121.02(\mathrm{q}) ; 120.88(\mathrm{q}) ; 120.39(\mathrm{t}) ; 119.91(\mathrm{t}) ; 72.59$ (q); $58.72(\mathrm{q}) ; 40.14(\mathrm{q}) ; 34.04(\mathrm{q})$ $33.27(\mathrm{t}) ; 33.03(\mathrm{t}) ; 31.15(\mathrm{t}) ; 25.23(\mathrm{t})$

\section{N-(2,6-Diisopropylphenyl)-14-(4-methoxycarbonylphenyl)-1,6-di(4-tert-}

\section{butylphenoxy-11(CO),12-benzoylterrylen-3,4-dicarboximid (4-12)}

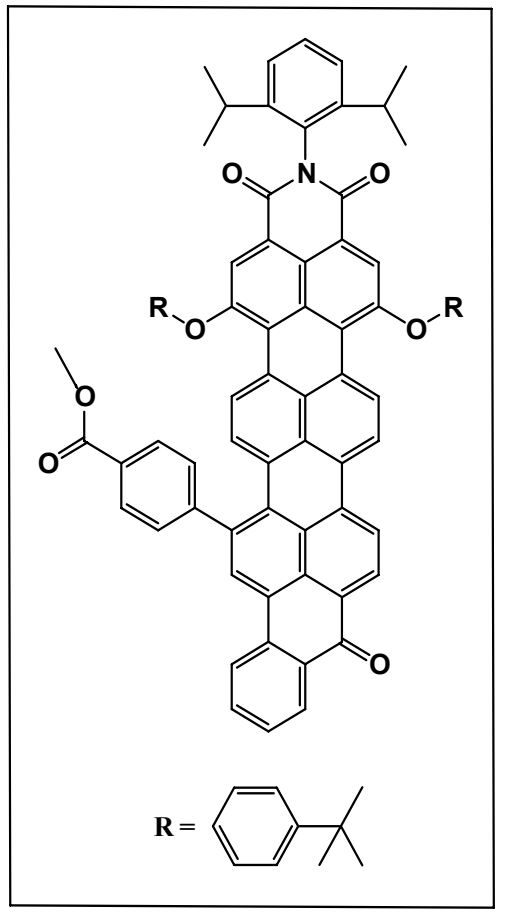

$104 \mathrm{mg}$ (0.096 mmol) N-(2,6-Diisopropylphenyl)14-brom-1,6-di(4-tert-butylphenoxy-11(CO),12-benzoylterrylen-3,4-dicarboximid ${ }^{4-5} 4-11$ und $44 \mathrm{mg}$ (0.24 mmol) 4-Methoxycarbonylphenylboronsäure wurden in $30 \mathrm{ml}$ Toluol und $5 \mathrm{ml}$ Methanol gelöst. Anschließend fügte man $5 \mathrm{ml}$ einer $2 \mathrm{M}$ Kaliumcarbonatlösung und $7 \mathrm{mg}$ (0.006 mmol) Tetrakis(triphenylphosphin) Palladium (0) $\left(\mathrm{Pd}\left(\mathrm{PPh}_{3}\right)_{4}\right.$ hinzu. Nachdem die Reaktionslösung mehrmals entgast und mit Argon gefüllt wurde, erhitzte man auf $75^{\circ} \mathrm{C}$ und ließ das Reaktionsgemisch unter Lichtausschluss und Rückfluss 15 Stunden rühren. Das Reaktionsgemisch wurde auf Raumtemperatur abgekühlt. In einem Scheidetrichter wurde die wässrige Phase von der organischen Phase abgetrennt. Die organische Phase wurde mehrmals mit Wasser geschüttelt und wieder von der wässrigen Phase abgetrennt, über Magnesiumsulfat getrocknet und unter Vakuum eingeengt. Das Produkt wurde mittels Säulechromatographie mit Dichlormethan/Hexan (2:1) vom Rückstand gewonnen.

Ausbeute: $42 \mathrm{mg}$ als dunkelroter Feststoff, $38 \%$ 


\section{FD-Massenspektrum (8 kv):}

$\mathrm{m} / \mathrm{z}\left(\mathrm{u} \mathrm{e}_{0}^{-1}\right)=1139.4 .0\left(100 \%, \mathrm{M}^{+}\right)$

(berechnet für $\mathrm{C}_{79} \mathrm{H}_{63} \mathrm{NO}_{7}=1138,35$ )

Schmelzpunkt: $>300^{\circ} \mathrm{C}$

\section{${ }^{1}$ H-NMR-Spektrum,(250 MHz, $d^{8}$-THF, 298 K):}

$\delta(\mathrm{ppm})=9.21\left(\mathrm{~d},{ }^{3} \mathrm{~J}=9.15 \mathrm{~Hz}, 1 \mathrm{H}\right) ; 8.79\left(\mathrm{~d},{ }^{3} \mathrm{~J}=8.85 \mathrm{~Hz}, 1 \mathrm{H}\right) ; 8.54\left(\mathrm{~d},{ }^{3} \mathrm{~J}=8.2 \mathrm{~Hz}, 1\right.$ $\mathrm{H}) ; 8.44(\mathrm{~s}, 1 \mathrm{H}) ; 8.39\left(\mathrm{~d},{ }^{3} \mathrm{~J}=8.3 \mathrm{~Hz}, 1 \mathrm{H}\right) ; 8.27(\mathrm{~s}, 1 \mathrm{H}) ; 8.21(\mathrm{~m}, 3 \mathrm{H}) ; 8.05\left(\mathrm{~d},{ }^{3} \mathrm{~J}=\right.$ $8.22 \mathrm{~Hz}, 2 \mathrm{H}) ; 7.93(\mathrm{~s}, 1 \mathrm{H}) ; 7.52-7.43$ (m, broad, $6 \mathrm{H}) ; 7.4\left(\mathrm{~d},{ }^{3} \mathrm{~J}=8.85 \mathrm{~Hz}, 2 \mathrm{H}\right) ; 7.32$ $(\mathrm{m}, 2 \mathrm{H}) ; 7.26\left(\mathrm{~d},{ }^{3} \mathrm{~J}=7.25 \mathrm{~Hz}, 2 \mathrm{H}\right) ; 7.17\left(\mathrm{~d},{ }^{3} \mathrm{~J}=8.85 \mathrm{~Hz}, 2 \mathrm{H}\right) ; 7.02\left(\mathrm{~d},{ }^{3} \mathrm{~J}=8.52 \mathrm{~Hz}\right.$, $2 \mathrm{H}) ; 4.21(\mathrm{~s}, 3 \mathrm{H}) ; 3.06$ (septettt, $\left.{ }^{3} \mathrm{~J}=6.78 \mathrm{~Hz}, 2 \mathrm{H}\right) ; 1.36(\mathrm{~s}, 9 \mathrm{H}) ; 1.333$ (s, $\left.9 \mathrm{H}\right) ; 1.21$ (d, $\left.{ }^{3} \mathrm{~J}=6.32 \mathrm{~Hz}, 12 \mathrm{H}\right)$

\section{${ }^{13}$ C-NMR-Spektrum, Spinechoexperiment (75 MHz, $d^{8}$-THF, 323 K):}

$\delta(\mathrm{ppm})=185.19 ; 164.8 ; 162.13 ; 158.12 ; 157.52 ; 154.91 ; 154.51 ; 153.34 ; 152.57 ; 149.57 ;$ $146.25 ; 145.11 ; 141.7 ; 140.4 ; 139.16 ; 138.16 ; 136.69 ; 135.73 ; 135.15 ; 134.48 ; 134.08 ;$ $133.88 ; 133.69 ; 133.41 ; 132.88 ; 132.75 ; 132.54 ; 132.01 ; 131.88 ; 131.74 ; 131.46 ; 131.34$ $131.28 ; 131.08 ; 130.87 ; 130.74 ; 130.61 ; 130.14 ; 129.74 ; 129.67 ; 129.6 ; 129.48 ; 129.41 ;$ $129.07 ; 128.87 ; 128.6 ; 128.34 ; 128.13 ; 128.02: 127.93 ; 127.8 ; 127.74 ; 127.2 ; 126.93$; $126.8 ; 126.33 ; 125.04 ; 120.38 ; 119.91 ; 39.96 ; 38.95 ; 33.8 ; 31.72 ; 24.81$ 
N-(2,6-Diisopropylphenyl)-14-(4-carboxyphenyl)-1,6-di(4-tert-butylphenoxy-

11(CO),12-benzoylterrylen-3,4-dicarboximid (4-13)

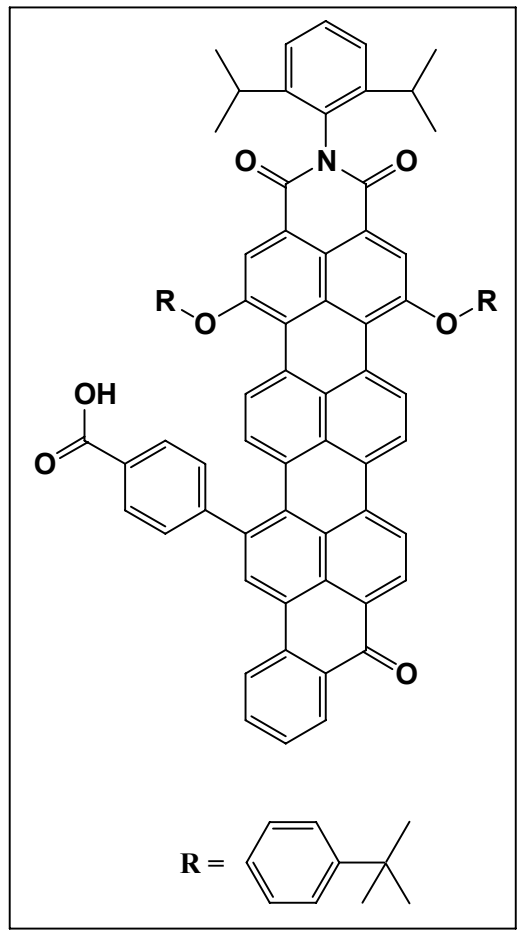

$30 \mathrm{mg}$ (0.0263 mmol) 4-12 wurden in $15 \mathrm{ml}$ THF gelöst. Man fügte $14.7 \mathrm{mg}(0.262 \mathrm{mmol}) \mathrm{KOH}$ gelöst in $1.5 \mathrm{ml}$ dest. Wasser hinzu. Anschließend wurde der Kolben mehrmals entgast und mit Argon gefüllt. Die Reaktionslösung wurde für 24 Stunden bei $80^{\circ} \mathrm{C}$ gerührt. Nach Abkühlung der Reaktionslösung auf Raumtemperatur wurde das Produkt in $300 \mathrm{ml}(2 \mathrm{~N}) \mathrm{HCl}$ ausgefällt. Anschließend wurde das Produkt filtriert und unter Vakuum getrocknet.

Ausbeute: $18 \mathrm{mg}(0.016 \mathrm{mmol})$ blauer Feststoff $61 \%$

FD-Massenspektrum (8 kv):

$\mathrm{m} / \mathrm{z}\left(\mathrm{u} \mathrm{e}_{0}^{-1}\right)=1124.6\left(100 \%, \mathrm{M}^{+}\right)$

(berechnet für $\mathrm{C}_{78} \mathrm{H}_{61} \mathrm{NO}_{7}=1124,32$ )

Schmelzpunkt: $>300^{\circ} \mathrm{C}$

\section{${ }^{1}$ H-NMR-Spektrum,(250 MHz, $d^{8}$-THF, 298 K):}

$\delta(\mathrm{ppm})=9.29\left(\mathrm{~d},{ }^{3} \mathrm{~J}=9.15 \mathrm{~Hz}, 1 \mathrm{H}\right) ; 8.86\left(\mathrm{~d},{ }^{3} \mathrm{~J}=8.85 \mathrm{~Hz}, 1 \mathrm{H}\right) ; 8.59\left(\mathrm{~d},{ }^{3} \mathrm{~J}=8.2 \mathrm{~Hz}, 1\right.$ $\mathrm{H}) ; 8.48(\mathrm{~s}, 1 \mathrm{H}) ; 8.43\left(\mathrm{~d},{ }^{3} \mathrm{~J}=8.3 \mathrm{~Hz}, 1 \mathrm{H}\right) ; 8.3(\mathrm{~s}, 1 \mathrm{H}) ; 8.26(\mathrm{~m}, 3 \mathrm{H}) ; 8.09\left(\mathrm{~d},{ }^{3} \mathrm{~J}=8.22\right.$ $\mathrm{Hz}, 2 \mathrm{H}) ; 7.99$ (s, $1 \mathrm{H}) ; 7.58-7.49$ (m, broad, $6 \mathrm{H}) ; 7.46$ (d, $\left.{ }^{3} \mathrm{~J}=8.85 \mathrm{~Hz}, 2 \mathrm{H}\right) ; 7.39$ (m, 2 $\mathrm{H}) ; 7.3\left(\mathrm{~d},{ }^{3} \mathrm{~J}=7.25 \mathrm{~Hz}, 2 \mathrm{H}\right) ; 7.22\left(\mathrm{~d},{ }^{3} \mathrm{~J}=8.85 \mathrm{~Hz}, 2 \mathrm{H}\right) ; 7.02\left(\mathrm{~d},{ }^{3} \mathrm{~J}=8.52 \mathrm{~Hz}, 2 \mathrm{H}\right)$; $2.85\left(\right.$ septettt, $\left.{ }^{3} \mathrm{~J}=6.78 \mathrm{~Hz}, 2 \mathrm{H}\right) ; 1.35(\mathrm{~s}, 9 \mathrm{H}) ; 1.32(\mathrm{~s}, 9 \mathrm{H}) ; 1.16\left(\mathrm{~d},{ }^{3} \mathrm{~J}=6.32 \mathrm{~Hz}, 12 \mathrm{H}\right)$ 
${ }^{13}$ C-NMR-Spektrum, Spinechoexperiment (75 MHz, $d^{8}$-THF, 323 K):

$\delta(\mathrm{ppm})=185.12 ; 164.76 ; 162.07 ; 158.11 ; 157.49 ; 154.9 ; 154.5 ; 153.31 ; 152.56 ; 149.54 ;$

$146.22 ; 145.09 ; 141.71 ; 140.38 ; 139.13 ; 138.15 ; 136.67 ; 135.73 ; 135.16 ; 134.41 ; 134.08$ $133.82 ; 133.66 ; 133.41 ; 132.91 ; 132.75 ; 132.54 ; 132.02 ; 131.86 ; 131.74 ; 131.45 ; 131.34$ $131.27 ; 131.06 ; 130.9 ; 130.73 ; 130.6 ; 130.14 ; 129.71 ; 129.64 ; 129.57 ; 129.46 ; 129.38$; $129.07 ; 128.87 ; 128.61 ; 128.36 ; 128.13 ; 128.01: 127.92 ; 127.81 ; 127.71 ; 127.2 ; 126.93$; $126.77 ; 126.31 ; 125.01 ; 120.32 ; 119.84 ; 38.79 ; 33.81 ; 31.72 ; 24.83$

\section{Verbindung 4-14}

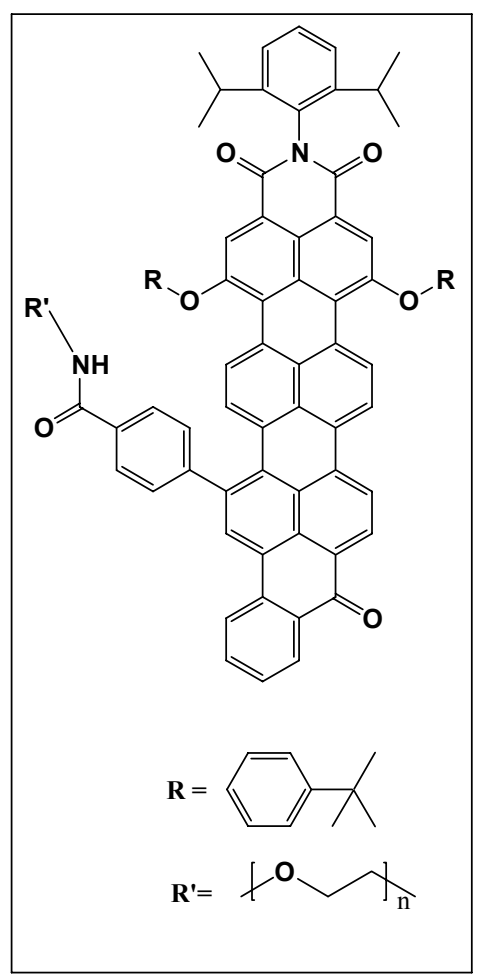

Analog zu der Synthese von 4-9 wurden $9.27 \mathrm{mg}$ (0.0082 mmol) 4-13, 29 mg $\mathrm{H}_{2} \mathrm{~N}-\mathrm{PEG}-5000,7 \mathrm{mg}$ (0.036 mmol) EDC und $3 \mathrm{mg}(0.024 \mathrm{mmol})$ DMAP vereint und in $3 \mathrm{ml}$ DMF gelöst. Man lässt die Reaktionslösung 5 Tage bei Raumtemperatur unter Lichtausschluss und Argon rühren. Das Reaktionsgemisch wurde danach eingeengt und in Wasser gelöst. Dabei löste sich der nicht reagierte Farbstoff nicht und wurde deshalb durch Abfiltrieren entfernt. Die wässrige Lösung wurde eingeengt und mit Dialyse aufgereinigt.

Ausbeute: $38 \mathrm{mg}$ als blauer Feststoff, $75.9 \%$

MALDI-TOF-Massenspektrum: $\mathrm{m} / \mathrm{z}\left(\mathrm{u} \mathrm{e}_{0}^{-1}\right)=6200-6800 \mathrm{~g} \mathrm{~mol}^{-1}$ 


\section{${ }^{1} \mathrm{H}-\mathrm{NMR}-$ Spektrum,(700 MHz, $\left.\mathrm{C}_{2} \mathrm{D}_{2} \mathrm{Cl4}, 403 \mathrm{~K}\right)$ :}

$\delta(\mathrm{ppm})=9.56\left(\mathrm{~d},{ }^{3} \mathrm{~J}=9.15 \mathrm{~Hz}, 1 \mathrm{H}\right) ; 9.02\left(\mathrm{~d},{ }^{3} \mathrm{~J}=8.85 \mathrm{~Hz}, 1 \mathrm{H}\right) ; 8.65\left(\mathrm{~d},{ }^{3} \mathrm{~J}=8.2 \mathrm{~Hz}, 1\right.$

$\mathrm{H}) ; 8.53(\mathrm{~s}, 1 \mathrm{H}) ; 8.4\left(\mathrm{~d},{ }^{3} \mathrm{~J}=8.3 \mathrm{~Hz}, 1 \mathrm{H}\right) ; 8.32(\mathrm{~s}, 1 \mathrm{H}) ; 8.27(\mathrm{~m}, 3 \mathrm{H}) ; 8.16\left(\mathrm{~d},{ }^{3} \mathrm{~J}=8.22\right.$ $\mathrm{Hz}, 2 \mathrm{H}) ; 8.02$ (s, $1 \mathrm{H}) ; 7.91-7.56$ (m, broad, $6 \mathrm{H}) ; 7.45\left(\mathrm{~d},{ }^{3} \mathrm{~J}=8.85 \mathrm{~Hz}, 2 \mathrm{H}\right) ; 7.38$ (m, 2 $\mathrm{H}) ; 7.22\left(\mathrm{~d},{ }^{3} \mathrm{~J}=7.25 \mathrm{~Hz}, 2 \mathrm{H}\right) ; 7.15\left(\mathrm{~d},{ }^{3} \mathrm{~J}=8.85 \mathrm{~Hz}, 2 \mathrm{H}\right) ; 7.01\left(\mathrm{~d},{ }^{3} \mathrm{~J}=8.52 \mathrm{~Hz}, 2 \mathrm{H}\right)$; 3.69-3.52 (m, broad); 3.11 (septettt, $\left.{ }^{3} \mathrm{~J}=6.78 \mathrm{~Hz}, 2 \mathrm{H}\right) ; 1.33(\mathrm{~s}, 9 \mathrm{H}) ; 1.28(\mathrm{~s}, 9 \mathrm{H}) ; 1.11$ $\left(\mathrm{d},{ }^{3} \mathrm{~J}=6.32 \mathrm{~Hz}, 12 \mathrm{H}\right)$.

\section{${ }^{13} \mathrm{C}-\mathrm{NMR}-S p e k t r u m$, Spinechoexperiment (175 MHz, $\left.\mathrm{C}_{2} \mathrm{D}_{2} \mathrm{Cl} 4,403 \mathrm{~K}\right)$ :}

$\delta(\mathrm{ppm})=185.02 ; 164.69 ; 161.91 ; 158.03 ; 157.43 ; 154.91 ; 154.39 ; 153.31 ; 152.49 ;$ $149.42 ; 146.17 ; 145.03 ; 141.77 ; 140.32 ; 139.07 ; 138.11 ; 136.56 ; 135.64 ; 135.08 ; 134.39$; $133.94 ; 133.78 ; 133.55 ; 133.32 ; 132.78 ; 132.66 ; 132.54 ; 131.92 ; 131.77 ; 131.63 ; 131.35$; $131.28 ; 131.21 ; 131.06 ; 130.79 ; 130.7 ; 130.58 ; 130.07 ; 129.62 ; 129.56 ; 129.49 ; 129.42$ $129.34 ; 129.01 ; 128.83 ; 128.52 ; 128.27 ; 128.11 ; 128.02: 127.87 ; 127.75 ; 127.68 ; 127.12$; $126.85 ; 126.72 ; 126.24 ; 125.02 ; 120.29 ; 119.8 ; 70.97 ; 39.89 ; 38.86 ; 33.69 ; 31.63 ; 24.68$

\section{Allgemeine Vorschrift zur Synthese vom Aktivester}

Zur Kopplung der Oligonucleotide an Perylendiimid oder 1,3,5-Tri(4-carboxyphenyl)benzol wurde über die Reaktion von einem Aktivester mit dem Aminoligonucleotid durchgeführt. Zur Aktivierung der Carboxyfunktionen wird die zu aktivierende Verbindung mit N-Hydroxysuccinimid (3 Äquivalente pro Carboxyfunktion) und Dicyclohexylcarbodiimid (DCC, 3 Äquivalente pro Carboxyfunktion) als Katalysator in DMF umgesetzt. Nach einer Reaktionsdauer von 1-2 Tagen bei Raumtemperatur und einer DC-Kontrolle wurde die Reaktion abgebrochen und das Produkt unter Vakuum getrocknet. Aufgrund der Empfindlichkeit des Aktivesters zur Luftfeuchtigkeit wurde auf 
weitere Aufreinigungsschritte verzichtet und das Produkt direkt zur Kopplung mit dem Aminoligonucleotid verwendet.

\section{Die Synthese der Oligonucleotidkonjugate}

Als Beispiel wird die Synthese von Perylendiimid-bis(oligonucleotid)-konjugat 3-25 (PODN1, ODN1-PDI-ODN1) beschrieben. Die Synthese aller Oligonucleotidkonjugate, falls keine anderen Angaben gegeben wurden, erfolgte analog zu dieser Vorschrift.

In einem Eppendorfröhrchen wurden $0.1 \mathrm{mg}$ von 3-24 (51 nmol) in $25 \mu 1 \mathrm{DMF}$ (trocken) gelöst und bei $37^{\circ} \mathrm{C}$ unter Verwendung eines Thermomixers gerührt. $5.2 \mathrm{mg}$ (510 nmol, 5 Äquivalent pro Carboxyfunktion) vom Aminoligonucleotid (ODN1) wurden in $175 \mu 1$ von einer $0.1 \mathrm{M}$ Natriumtetraborat-Lösung gelöst und 5 Minuten bei $37{ }^{\circ} \mathrm{C}$ gerührt. Man fügte die Farbstofflösung ( $25 \mu 1)$ hinzu und lässt das Reaktionsgemisch über Nacht bei 37 ${ }^{\circ} \mathrm{C}$ rühren. Am nächsten Tag wurde eine relativ klare und farbige Lösung beobachtet. Das Reaktionsgemisch wurde unter Ölpumpenvakuum getrocknet und mit Hilfe von Polyacrylamidgelelektrophorese aufgereinigt.

\section{Synthese der asymmetrischen Perylendiimid-Oligonucleotid-Konjugate}

Im Prinzip wurde die gleiche Vorschrift wie bei der Synthese der symmetrischen Konjugate verwendet. Nur die Temperatur wurde auf $45{ }^{\circ} \mathrm{C}$ erhöht. Diese hohe Temperatur war erforderlich, um sekundäre Strukturen, die sich zwischen den zwei unterschiedlichen Oligonucleotidsequenzen (für das asymmetrische Konjugat) ausbilden können, zu vermeiden. Die Konzentration der Oligonucleotide betrug jeweils 4 Äquivalente im Vergleich zu der eingesetzten Menge von Perylendiimid.

\section{Synthese des Trisoligonucleotides:}

Hierfür wurde $0.15 \mathrm{mg}(0.2 \mu \mathrm{mol})$ vom 1,3,5-Tri(4-carboxyphenyl)-benzol in $30 \mu \mathrm{DMF}$ gelöst. 18,4 mg (18 Äq.) vom Oligonucleotid ODN1 wurden in $170 \mu$ l einer $0.1 \mathrm{M}$ Natriumtetraborat-Pufferlösung 10 Minuten bei $37{ }^{\circ} \mathrm{C}$ gerührt. Die Oligonucleotid- 
Kapitel 6: Experimenteller Teil

Pufferlösung wurde $\mathrm{zu}$ der in DMF gelösten 1,3,5-Tri(4-carboxyphenyl)-benzol hinzugefügt. Das Reaktionsgemisch wurde auf dem Thermomixer bei $45^{\circ} \mathrm{C}$ gerührt. Die hohe Oligonucleotidkonzentration war erforderlich, um die Ausbeute am Trisoligonucleotid im Verhältnis zu dem monosubstituierten und disubstituierten Produkt zu erhöhen. Aufgrund dieser hohen Oligonucleotidmenge wurde die Reaktion bei einer Temperatur von $45{ }^{\circ} \mathrm{C}$ durchgeführt, um die Löslichkeit des Oligonucleotides zu fördern und sekundäre Strukturen zu vermeiden. Nach einer Reaktionsdauer von 15 Stunden wurde das Reaktionsgemisch vom Thermomixer entfernt und unter Vakuum getrocknet. Die Aufreinigung des Trisoligonucleotides wurde mittels PAGE bei einer Gelkonzentration von $8 \%$ und unter Spannung von $450 \mathrm{~V}$ durchgeführt. Die Extraktion der Trisoligonucleotidbande erfolgte analog zu den Perylendiimid-Konjugaten. 


\section{Anhang}

\section{Quantifizierung von Oligonucleotid- oder Konjugatlösungen:}

Die Berechnung der Konzentration von einer Oligonuclleotid- oder Konjugatlösung mit einer Sequenz $5 `$ ABCD....K wird mit Hilfe folgender Gleichung und der unteren Tabelle ermittelt:

$\varepsilon_{260}(A p B p C p D p . . . K p L)=\left[2\left(\varepsilon_{A p B}+\varepsilon_{B p C}+\varepsilon_{C p D}+\ldots . .+\varepsilon_{K p L}\right)-\varepsilon_{A}-\varepsilon_{B}-\right.$ $\left.\varepsilon_{C}-\varepsilon_{D} \ldots-\varepsilon_{K}\right]$

wobei man beachten muss, dass die terminalen $5^{`}$ und $3^{`}$ Basen im zweiten Teil der oberen Gleichung nicht berücksichtigt werden, während jedes Dimer (z. B. ApB = dCpdC) im ersten Teil miteinbezogen wird.

\begin{tabular}{|c|c|c|c|}
\hline Base & $\varepsilon_{260}$ & Base & $\varepsilon_{260}$ \\
\hline $\mathrm{pdA}$ & 15.4 & $\mathrm{dCpdG}$ & 9.0 \\
\hline $\mathrm{pdC}$ & 7.4 & $\mathrm{dCpT}$ & 7.6 \\
\hline $\mathrm{pdG}$ & 11.5 & $\mathrm{dGpdA}$ & 12.6 \\
\hline $\mathrm{pT}$ & 8.7 & $\mathrm{dGpdC}$ & 8.8 \\
\hline $\mathrm{dApdA}$ & 13.7 & $\mathrm{dGpdG}$ & 10.8 \\
\hline $\mathrm{dApdC}$ & 10.6 & $\mathrm{dGpT}$ & 10.0 \\
\hline $\mathrm{dApdG}$ & 12.5 & $\mathrm{TpdA}$ & 11.7 \\
\hline $\mathrm{dApT}$ & 11.4 & $\mathrm{TpdC}$ & 8.1 \\
\hline $\mathrm{dCpdA}$ & 10.6 & $\mathrm{TpdG}$ & 9.5 \\
\hline $\mathrm{dCpdC}$ & 7.3 & $\mathrm{TpT}$ & 8.4 \\
\hline
\end{tabular}

\section{Berechnung der Fluoreszenzquantenausbeuten}

Die Berechnung der Fluoreszenzquantenausbeuten erfolgte gegen eine Referenzsubstanz, deren Fluoreszenzquantenausbeute bereits aus der Literatur bekannt ist. In dieser Arbeit wurde Kristalviolet als Referenz verwendet. Für die Berechnung der Fluoreszenzquantenausbeuten wurde die nachfolgend aufgeführte Gleichung verwendet: 


$$
\Phi_{F, \operatorname{Pr} o b e}=\Phi_{F, \operatorname{Re} f e r e n z} x\left(\frac{O D_{\mathrm{Re} f e r e n z}}{O D_{\mathrm{Pr} o b e}}\right) x\left(\frac{A_{\mathrm{Pr} o b e}}{A_{\mathrm{Re} f e r e n z}}\right) x\left(\frac{n_{\mathrm{Re} f e r e n z}^{2}}{n_{\mathrm{Pr} o b e}^{2}}\right)
$$

$\phi_{\mathrm{F}, \text { Referenz }}=$ aus der Literatur bekannte Fluoreszenzquantenausbeute der Referenz OD $=$ Optische Dichte der Probe oder der Referenz bei der Anregungswellenlänge am Punkt des spektralen Überlapps. Hierbei wurde immer eine OD von ungefähr 0.07 gewählt.

$\mathrm{A}=$ Fläche unter dem Fluoreszenzspektrum

$\mathrm{n}=$ Brechungsindex des verwendeten Lösungsmittels

\subsection{Bibliographie}

[1] F. M. Ausubel, R. Brent, R. E. Kingston, D. O. Moore, J. G. Seidman, J. A. Smith short Protocols in Molecular Biology, Wiley, New Work 1999.

[2] D. Tietz Nucleic Acid Electrophoresis, Springer, Berlin 1998.

[3] F. Lottspeich, H. Zorbas Bioanalytik, Spektrum akademischer Verlag Heidelberg . Berlin 1998.

[4] T. Weil Dissertation, Johannes Gutenberg-Universität Mainz 2002.

[5] C. Kohl Dissertation, Johannes Gutenberg-Universität Mainz 2003. 


\section{Publikationsliste:}

"Synthesis and Self-Assembly of Perylenediimide-Oligonucleotides conjugates" M. A. Abdalla, J. Bayer, J. O. Rädler und K. Müllen Angew. Chem. Int. Ed. 2004, 43, 3967-3970

"Nanoparticles and DNA Probes based on DNA-Fluorophore Conjugates"

M. A. Abdalla, J. Bayer, J. O. Rädler und K. Müllen

Nucleos. Nucleot. Nucl. 2003, 22 (5-8), 1399-1401

"Water-soluble Rylene dyes as high performance colorants for the visualization of cells" T. Weil, M. A. Abdalla, J. Hengstler und K. Müllen

Biomacromolecules 2005, 1, 68-79

"Bisbiotinylated Perylenediimide as building block for multilayered nanostructures"

M. A. Abdalla, F. Xu, W. Knoll und K. Müllen

Manuscript in preparation for submission to Journal of Materials Chemistry

"Solution phase synthesis of dissymmetrical perylenediimide-bis-oligonucleotide conjugates"

M. A. Abdalla, J. Bayer, J. O. Rädler und K. Müllen

Manuscript in preparation for submission to J.Am. Chem. Soc.

"Synthesis and selfassembly of a novel Trisoligonucleotid-conjugate"

M. A. Abdalla, J. Bayer, J. O. Rädler und K. Müllen

Manuscript in preparation for submission to Biomacromolecules 


\section{Lebenslauf}

Zur Person: Moustafa A. Abdalla, geboren am 01.04.1972 in

Bani-Suef/Ägypten,verheiratet, Staatsangehörigkeit: ägyptisch

\section{Schulischer Werdegang}

10/77 - 05/86 Grundschule Bani-Suef

10/86 - 06/89 Nour-Eldin Abdel-Aziz Gymnasium, Bani-Suef

$6 / 89$

Prüfung zur Hochschulzugangsberechtigung (Abitur)

\section{Studium}

10/89-06/93 Chemiestudium an der Universität Kairo in Bani-Suef/Ägypten, Abschluss als B.Sc. Chemiker (Gesamtnote: $74.2 \%$ )

10/93 - 10/95 Premaster mit Schwerpunkt: organische Chemie

03/94-02/98 Chemiker bei Shamsi Group für Textilveredlung/ 10th of Ramadan City, Ägypten

04/98-09/00 Master of Science in Textile Engineering, TU Dresden, Dissertationsthema: „Synthese von Reaktivdispersionsfarbstoffen und ihre Anwendungen zum Färben von Polyamidfasern“, Gesamtnote: 1

12/99-02/00 Wissenschaftlicher Mitarbeiter am Institut für Makromolekulare und Textilchemie der technischen Universität Dresden 
01/01-01/04 Promotion im Arbeitskreis von Prof. Dr. K. Müllen am Max-PlanckInstitut für Polymerforschung in Mainz; Thema: „Synthese und Selbstorganisation von Perylendiimid-Olignucleotid-Konjugaten“"

Seit 05/ 2004 Chemiker bei DyStar Textilfarben GmbH/Frankfurt am Main, zur Zeit bei DyStar Orient in Kairo/Ägypten 